
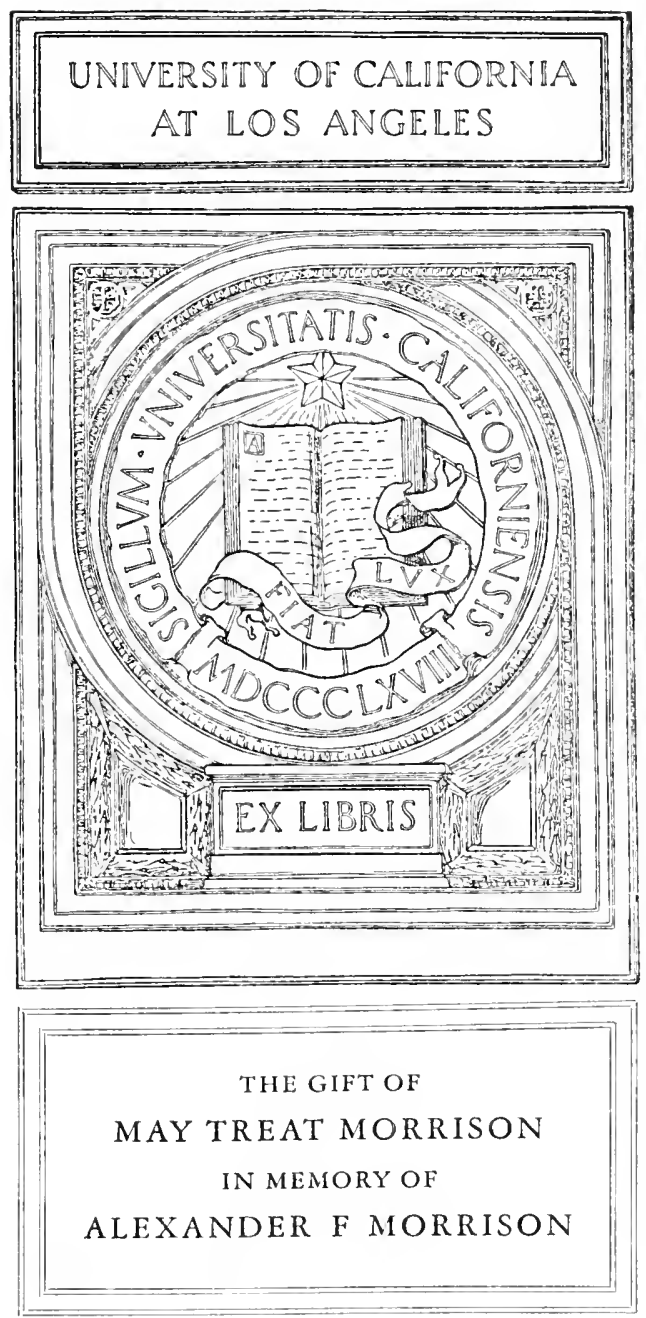
. 



\section{FORTY YEARS}

IN THE

MEDICAL PROFESSION 


$$
\text { . }
$$




\title{
FORTY YEARS
}

IN THE

\section{MEDICAL PROFESSION}

$$
\text { I } 858-\mathbf{I} 898
$$

\author{
$\mathrm{BI}$ \\ JOHN JANVIER BLACK, M.D. \\ MEMBER OF THE COLLEGE OF PHYS!CIANS OF PHILADELPHIA; MEMBER OF THE \\ DELAWARE STATE MiEDICAL SOCIETY, ETC.
}

"A man is as old as his arteries"

PHILADELPHIA

J. B. LIPPINCOTT COMPANY

1,00 
COPYRIGHT, I900,

BY

JUHN JANYIER BLACK.

PRINTED EY J. B. LIPFINCOTT COMFANY, PHILADELPHIA, U. 8. A. 


\section{PREFACE}

I HAVE given forty years of faithful and conscientious work to an exacting and laborious profession, and here are the notings of some of the results. I trust they may enable my readers now and again to while away a leisure hour. Call them what you will: call them, if you choose, the mere flotsam and jetsam which have rolled in upon the waves of

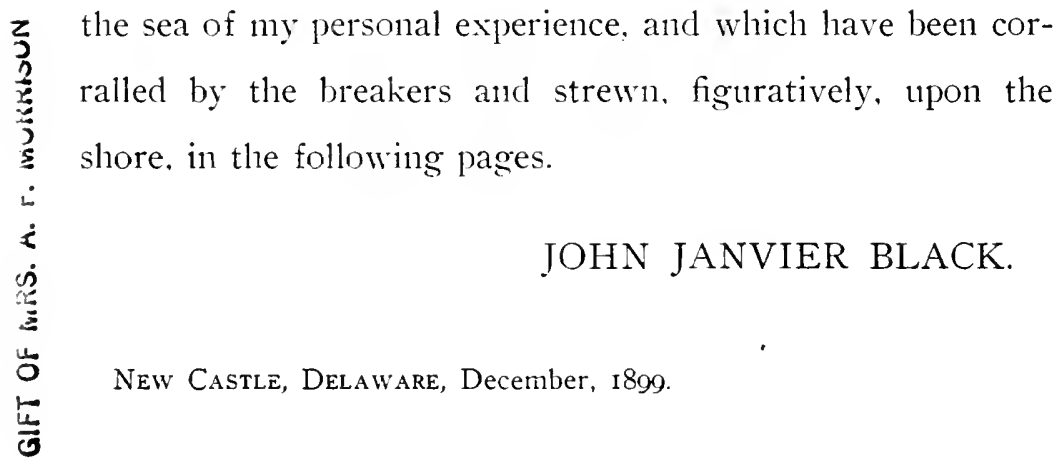





\section{CONTENTS}

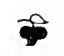

CH A P T R I.

Voyage to San Francisco-The Isthmus of Panama-The Western Coast of Mexico-Arrival at San Francisco-United States Marine Hospital, San Francisco-Diseases among the SailorsThe First Japanese Embassy to the United States-R. H. Dana, Jr.-San Francisco in the Early Days-The Medical Profession -Duels-The Climate-San Francisco in 1894-John Chinaman . . . . . . . . . . . . . . . . . I

\section{H A P T E R I I.}

University of Pennsylvania, Medical Department, I860-The Buildings and Conveniences for Faculty and Students-The FacultyThe Lectures-The Quiz Classes and Students-University Characters-Outside Teaching-The Course . . . . . . . . . . 3

\section{H A P T E R I I I.}

The Jefferson Medical College, Philadelphia-The Faculty-Joseph Pancoast and James Syme-S. D. Gross-The Tone of the Profession in Philadelphia-Clinics-Hip-Joint Cases-Clinical Lecturers in Philadelphia-The Atlees and other Great Men-Professional Methods-Trained Nurses-The Philadelphia Hospital, Blockley, in the Early Sixties-Typhus Fever . . . . . . . 48

\section{CH A P T E I V.}

Started for Liverpool in a Sail-Ship-Tornado-Narrow Escape and Return to New York-Petter Success by Steamer-Paris in 1866 -The Hospitals-The Doctors-Velpeatr, Jobert de Lamballe, Nélaton, Ricord, Sichel, Charcot, Trousseau, Liebreich, Pasteur, I. Marion Sims-Napoleon III. and why he failed-Tone of the Profession in Paris-London-Sir William Ferguson, Sir Thomas Watson, Sir James Paget, and Others-Edinburgh-Simpson and Syme-Ether and Chloroform-Berlin-Von Langenbeck-Frerichs-Vienna-Clinical Schools and Lectures-Billroth, Skoda, Oppolzer, Türk, and Others ............. 67 


\section{CONTENTS}

\section{CHA PTER V.}

Returned from Europe and Settled in New Castle, Delaware-Its PAGE Peculiar Freedom from Certain Diseases-The Medical Profession in Delaware-Country Doctors-A. Conan Doyle-Ian Maclaren-Bacteriology Forty Years Ago-Pathogenic and Other Germs-Toxines-Immunity-Inflammation-Operations Forty Years Ago and their Results-Asepsis-Antisepsis-Origin of Life-Sir Joseph Lister-Obstetrics and Antisepsis-Hospital Gangrene-A Strange Coincidence-Surgery away from the Centres-Disinfection-Necessity of-Gonorrhœa-Bladder Troubles-Syphilis-Eye Troubles-Gynæcology-Proctor Knott-Appendicitis-Radical Cure of Hernia-Intubation and Tracheotomy-Fractures and Dislocations-Instruments-Röntgen Rays

\section{CH A P T E R VI.}

Post-Mortems, etc., Forty Years Ago-Treatment of Pneumonia Then and Now-Heart-Troubles-Digitalis, etc.-Auscultation and Percussion--Vivisection-Improvements in Pharmacy-Dangers in Drugs-Sugar-Coated and Compressed Literature-The BloodThe Trolley-The Bicycle-Preventive Medicine-DiagnosisWall Diseases-Nitrification-Malthusian Theory-DiphtheriaCroup-Sir Morrell Mackenzie-Tetanus-Immunity as to the Sting of the Honey-Bee . . . . . . . . . . . . I26

\section{CHA P TER VII.}

Nervous Discases Forty Years Ago-Somnambulism-HypnotismMotor Disorders - Lunacy - Delirium Tremens - Epilepsy Chorea-Diseases of the Cord and its Membranes-TetanusHydrophobia-Hysteria-Neurasthenia-Dr. D. D. Richardson's Views on the Treatment and the Care of the Insane-The FeebleMinded-Notes by Dr. Martin W. Barr-The Deaf and DumbColonel William Bolling_-_John Brainwood-Thomas Hopkins Gallaudet-Edward Miner Gallatidet-Hon. Amos Kendall-Dr. Crouter-Pect-Rogers-Gillett-Noyes-Fay-Manual Method and Speech-Swedish Movements-The Bath-Electricity-The Masseur and the Masseuse-Hypnotic Suggestion-The Dangerous Classes-The Degenerates-How shall the Problem be solved?

\section{CHA P T E R VIII.}

Ptomaines-Definition of, ctc-Composition of, etc--Vegetable Alkaloids-Changed Food Supply-Canning, etc.-Poisonous Gases in the System-The Different Ptomaines-A Growing EvilFatigute and Ptomaine Poisoning-Chronic Ptomaine Poisoning 


\section{CONTENTS}

-Ice-Cream and Cream-Puff Poisoning-Personal Experience in Ptomaine Poisoning-Auto-intoxication in Disease-The Reflexes from Ptomaine Poisoning and Anto-intoxication-Pathogenic Poisons-The Death Struggle and Auto-intoxication . . . I88

\section{H A P T E R IX.}

Diet now on a Scientific Basis-Study the Individual-Idiosyncrasies -Teach Diet in the Schools-Diet in Youth and Old Age-Carlsbad and its Doctors-Dict and the Poor-Division of FoodsAnimal and Vegetable Foods-Tissue-Builders and Force-Producers-Uses of Food-Oxidation and Health-Water-Rations for Individuals-Children and Proteids-Atwater and Woods on Composition of Foods-All about Eggs-Fish compared with Beef, etc.-White Potatoes, Spinach, Asparagus, etc.-Lead Poisoning-Coffee and Tea-Chocolate and Cocoa-Dietary Studies among the Plain People-The Germans and German ThriftStudy of a Family as to its Diet, Cost of, etc.-Diets for Corpulency and Leanness-Systems of Diet-Banting and OthersDifferent Kinds of Rreads-Toast, etc.-Kissingen and Vichy Remedy for Fatness-Food consumed per Person per Year in Different Conntries--Time required for the Digestion of Various Foods-Sterilizing and Pasteurizing Milk-Infant-Feeding-Artificial Infant Foods-Diet for the Old-Ward McAllister-Infantile Scurvy-Concerning Milk-Tests for Milk-Regulating the Milk Trade-Graded Milk .

\section{CHAPTER I.}

Origin of Alcohol, Whiskey, Brandy, Port Wine, Sherry, Champagne, Burgundy, Claret, Rhine Wine, Porter, Ale, Beer-Per Cent. of Alcohol in Each-Effect of Alcohol on the System-Effect of Alcohol on Bodily Temperature-Alcohol as Food-System consumes more in Disease than in Health-Strength of WinesColors of Wines-National Drinks-Methods of artificially aging Whiskey, etc.-Rum. Gin, Cordials, Malt Liquors-Method of making, etc.-Malt Extracts-Wines-Grapes, Varieties of, etc. -The Wine-Taster-Peculiarities of Wines-Sherry, Madeira, Port-Ward MeAllister-Burgundy, Sauternes, Hock, Johannisberg-Champagne "a Drink for the Gods," as well as an Invention of the Devil-Vin Brut, Vin Sec, Vin Très Sec, Sparkling Moselle-German and Italian Wines-American Wines-California Wines-Care in prescribing Alcoholics-Value of Fruit and Nuts as Articles of Diet-Value of Fruit as Food from an Economic Stand-Point-The Lesion in Rheumatism-Is Fruit Healthy Diet?-The Divisions of Fruits-Special Fruit CuresThe Ripening of Fruit-The Most Digestible ,Fruits-Fruit 


\section{CONTENTS}

Syrups and Fruit Juices-Canned or Tinned Fruits and Vegetables-Fruits in Colonial Times-Fruit in Florida, California, and Australia-Medicinal Properties of Fruits and Nuts-Why Leaves change Color-The Apple-Varieties of Apples-Varieties of Peaches-Varieties of Pears-Grapes-Apricots-The PlumEast India Fruits-The Mangosteen-The Durian, Pine-Apple, Banana, Plantain, Orange, Shaddock, Olives, Lemons, Mulberry, Melons-Partridge-Berry and Salicylic Acid-The Haw-BerryGooseberries, Currants, Cranberries, Cherries, the Quince, Blackberries, Raspberries, Strawberries-Decay of Fruit-Mushrooms, Morels, and Truffles-Nuts-Chestnuts, Peanuts, Almonds, Filberts, Pecans, Shellbark or Shagbark, Brazil Nuts, Chilean Nuts, Betel Nut, Pistachio Nut, Kola Nut, Guarana, Butternut, Walnuts-Eucalyptus Globulus . . . . . . . . . . . . .

\section{CHA P TER XI.}

George B. Wood and S. D. Gross on Tubercle-Koch's Discovery of the Bacillus Tuberculosis-Present Definition of TuberclePhysical Attributes of Tubercle-Tubercle Bacillus in Man and the Lower Animals-Pulmonary Tuberculosis in Man-The Physician and Tuberculosis-Early Diagnosis Important-The Bacillus and Diagnosis-Case of Chronic Interstitial Pneumonia and Tuberculocidin-Tuberculins and their Therapeutic Principles and Uses-Toxines and Antitoxins-Koch's Tuberculins A, O, and R-Maragliano's Serum-Virchow's Objections to Koch's Tuberculin A-Mulford's Serum-The Economics of Tuberculin -Tuberculous Cattle in Europe and America-Necessity for Action-Prevention and Treatment of Tuberculosis-Surgical Tuberculosis-Treatment of Hrmoptysis-Murphy's Method of treating Pulmonary Tuberculosis-Secondary Infection-Cures -What Factors hold Tuberculosis Latent-Climate and Environment-Pulmonary Hemorrhage and Altitude-The Indians as an Object-Lesson-Relieving Crowded Centres-Sanitaria and Sanatoria and Treatment-Common Colds-Consumption in HotelsSolitary Life Best-Altitude-The Heart and Altitude-Diabetics and Altitude-The Climate of the United States East and West-Sanatoria and Climate in Europe-Serum Treatment in the Adirondacks-Inhalations as Remedies . . . . . . . . . . . .

\section{CHA PTER XII.}

Rheumatism an Infectious Disease-The Bacillus of RhenmatismThyroid Extract in Rhemmatism-Uric Acid in RhemmatismNuclein-The White Blood-Corpuscles-Diagnosis-Treatment -Rhenmatic Gout-Multiple Arthritis Deformans-Gout-Arteriosclerosis - Metabolism-Anabolism-Katabolism-Theories 


\section{CONTENTS}

of Gout-Origin of Uric Acid-Causes of Gout-Gout of the Intestines-Treatment of Gout-Water-Lithia-Diet in Gout - Intermitting Heart-Alcohol in Gout-Cider Cure for GoutVegetables in Gout-Contracted Kidney-Medicines in GoutPiperazine and Pichi in Gout-Thyroid Extract causing Gout -Menstrual Gout-Carlsbad-An American Carlsbad-Diabetes Mellitus-Ghucose-Starches-Dextrose-Glycogenic MatterTuberculosis and Diabetes-Pancreatic Lesions-Carl von Noorden-The Liver and Glycogen-Fat-Hyperglycemia-Causes of Diabetes Mellitus-Mayer's Theory-McCaskay's SuggestionsRelationship between Diabetes and Obesity and Gout and Diabetes-Gluten-Diagnosis-Tests for Sugar-Pregnancy and Diabetes Mellitus-Alcohol-Recoveries-Diabetes and Gonty Kidney - How to watch a Diabetic-Diabetic Coma-Diabetics Vulnerable-Diabetics and Tuberculosis-Thyroid Treatment-Prognosis-Diet and Treatment-Jambul and Piperazine-Substitutes for Cane Sugar-Wines and Spirits-Waters-Fruits-NutsAllowable Articles of Diet-Terrapin-Rest Treatment-Gluten Flours and other Diabetic Flours and Foods-Analysis of Macaroni, Flours, etc.-The Soja Bean-Aleuronat Flour-Adulterations .................. . . 418 


\title{
FORTY YEARS
}

IN THE

\section{MEDICAL PROFESSION}

\author{
CHA P T E R I.
}

Voyage to San Francisco-The Isthmus of Panama-The Western Coast of Mexico-Arrival at San Francisco-United States Marine Hospital, San Francisco-Diseases among the Sailors-The First Japanese Embassy to the United States-R. H. Dana, Jr.-San Francisco in the Early Days-The Medical Profession-Duels-The Climate-San Francisco in I894-John Chinaman.

THE unexpected frequently shapes a man's destiny. In my case this was not so, for my paternal grandfather and my father were both well-known practitioners of medicine in Delaware. For this reason it was decreed by my family that I, willing or unwilling, should also become a physician.

I take the date of my entry into the profession as June 5, I 858, on which day I sailed for San Francisco. California, on the steamer Moses Taylor, from New York. The ship was a side-wheel, wooden vessel, with two walking-beam engines, of fair speed, but a notorious roller, and very uncomfortable in a rough sea. She was of about two thousand tons burthen, and as she carried nine hundred passengers, besides her crew, it is evident how overcrowded and uncomfortable we must have been, especially so as during a part of the voyage we were exposed to the intense heat of the tropics. The voyage was uneventful as far as Aspinwall. 


\section{FORTY YEARS IN THE MEDICAL PROFESSION}

There we were landed and were held until the ship could be unloaded and the passengers transferred across the Isthmus of Panama. At this time yellow fever was raging in Aspinwall, but none of our people became infected. At Panama we were embarked upon a larger steamer, the John L. Stephens, for San Francisco, stopping at Acapulco and Manzanillo, Mexico. We received additional passengers at Panama, making our number on the Stephens fifteen hundred in addition to her crew. The heat in the tropics was very severe, ice on the ship was twenty-five cents a pound, yellow fever was raging in Acapulco, and, worse than all, small-pox broke out among the passengers on our ship. After a time we arrived safely at San Francisco, and I only speak of these matters as apropos to my induction into the profession. My paternal cousin, Dr. Richard Tybout Maxwell, who had studied medicine with my father, graduated at the University of Pennsylvania, and entered the United States navy as assistant surgeon, had remained in the navy a number of years, and like many other army and navy officers, had resigned as full surgeon and entered upon private practice in San Francisco. Dr. Maxwell took me as his private student and established me as dresser in the United States Marine Hospital, San Francisco, of which he was surgeon in charge. I was just fresh from Princeton College, and to me the change was both abrupt and novel, as may well appear.

In those days the marine hospital service was not organized, and had no such masterly corps of surgeons and scientific men, with a Wyman at their head, as exists to-day. The surgeons in charge were generally local practitioners, appointed by the Secretary of the Treasury, and did not reside in the institution. At the San Francisco Hospital, a fine large building, at the time one of the few fine ones in the city, had just been finished by the government with a capacity of about three hundred beds. This building is now used as a sailors' home, and has been so much shaken by earthquakes as scarcely to appear safe as an abode for human 
beings. The government has now established a new hospital in a new building, out on the Presidio reservation, near the ocean, where the sick and unfortunate sailors have all the advantages of the well-regulated marine hospital service of the present day.

To go back to the old hospital: The organization was composed of the surgeon in charge, Richard Tybout Maxwell; assistant surgeon, John Ioung Lind; steward, Meredith A. Sullivan; apothecary, Frank T. Maynard; orderly, William Lindop: student of medicine, John Janvier Black; together with a corps of nurses and cooks such as could be held together, taken generally from convalescent patients, and held as long as possible, the almost daily gold excitement alluring all adventurers to the new fields, and those who escaped these sirens generally, sooner or later, fell victims to the sailor's love of rum and its attendant excitement, and in their maudlin state were shanghaied aboard some departing vessel, and only recognized their helpless state when they awakened from their debauch and found themselves far out on blue water, bound most likely on a six months' voyage.

A case recurs to me here worth relating as showing in glaring colors the ups and downs of a sailor's life. One morning an English sailor, a magnificent specimen of the physical man, was brought in suffering from a gunshot wound of the right shoulder. James Whitford, I well remember, was his name. He had been employed as a runner of a sailors' boarding-louse, kept by a man by the name of Sheridan. Whitford stated that Sheridan had shipped the men on the English clipper Beau Monde for a long voyage. To carry out the thrifty designs of such men in San Francisco in those days, he had commissioned IVhitford to go the next night and kidnap the same men from the Beau Monde he had shipped in the morning, with the intention of getting another advance from some other confiding captain. and so on ad infinitum.

The officers of the Beau Monde were looking for just 
such trouble, and as Whitford's head appeared above the rail the first officer shot him in the right shoulder, as before stated, and down he dropped into the bay, but was rescued by his companions and brought to the hospital.

Whitford's case went on, and was a most interesting one surgically, one that probably would not happen now in the days of antiseptic methods. Sepsis supervened. Among other troubles, I remember, an abscess of the liver developed, which opened through the diaphragm into the lung, and the pus, tinged with the bile, all came by expectoration through the mouth. A large abscess developed at the right hip, the head of the femur was dislocated and absorbed, and the head of the bone made a new socket on the dorsum of the ilium. After probably a year the man recovered, with a shortened limb, a physical wreck. I never saw in any human being such an exhibition of brute courage and strength as this man possessed, and his vindictive nature was proved by the sequel.

After he left the hospital he went back to Sheridan's sailors' boarding-house as bouncer and bar-keeper. Not long after he had taken his new position he deliberately shot the proprietor dead, saying, as he shot, it was his sweet revenge for the ruin Sheridan had brought on him in the Beau Monde affair. After a trial in the courts, Whitford was judicially executed by hanging, and I have always regretted I was not at hand to hold a post-mortem over the remains. I have often thought that many a fair romance has been builded on a series of circumstances less weird than those surrounding the life of this unfortunate sailor. Man-of-war discipline was maintained in the hospital, which, under the conditions, was not difficult; sailors are accustomed to obey, and give little trouble usually. Now and then a sea lawyer bobs up among them; throttle him, and the rest is easy. The government provicled amply for their wants in all respects, and gave them more comforts and a better home than they ever obtained elsewhere. Although at the present time they are much better protected from sharpers the world over than they were in the days I am writing of, they are at best an 
unfortunate class of people, never having but one hand with which to help themselves, the other going to the owner, as they express it. The ends of their short lives generally find them struggling with the angry billows, and, whether on sea or on land, little it matters to them. The clinical material in this hospital was plenty, diverse, and interesting. The material was collected, as it were, from the world over. The venereal wards were especially prolific in acute and chronic cases. Secondary and tertiary syphilis and strictures of the urethra were very common. It is in this class of diseases that poor sailors suffer so horribly. They ship often through ignorance, but generally nolens volens, utterly regardless of their condition, and they either die at sea after terrible suffering or are landed at the end of the voyage, hopeless wrecks and cruel sufferers. Skin diseases, both specific and nonspecific, were common, and the clinical material in parasitic diseases was especially abundant and interesting. Jiggers, the tropical penetrating fleas, the guinea-worms (Filaria medinensis), and the different tape-worms were very common. Scurvy was a frequent disease among those admitted. It was common at that day on our own merchant ships, out on long voyages, and also on the French and German ships. Few if any cases came from the English ships. All sailors arriving in those days from long voyages were in probably a slightly scorbutic conclition, but not out of health sufficiently to apply for relief in a hospital. It would be better if all sailors were taken in charge by some friendly hand at the end of long voyages, for if not, they usually go on a debauch and reship, and are in no wise built up after the long privations of the previous royage. This is one great reason of their broken health and short lives as a class.

I never saw scurvy among the officers of the ships. This showed the cause in a great measure. All the men got, as a rule, was salt meat and hardtack, now and then a little duff, and morning and evening some weak cheap tea with molasses. Six months of such diet is enough to sicken any man. Add to this a dreary royage. quarters often cold and never 


\section{FORTY YEARS IN THE MEDICAL PROFESSION}

dry, never a cheery word from any one, nor a morsel of food but what is almost distasteful, from frequent repetition of the same stuff, and you have all-sufficient causes for scurvy. The symptoms then were the same as now,- - the spongy and bleeding gums, the loose teeth, the iron hardness of the muscles, especially the calves of the legs, the petechial hemorrhages, the foul breath, and the great and general weakness of the individual. The tendency to hemorrhage was frequent and persistent, and the blood dark and thin. Of course, at that day no thought was given to it as now as a disease of infection and possibly of microbic origin. The circulation in the sailors' cases was weak and the heart often irregular. We found the first great remedy to be recumbent rest. I once saw a fine physical specimen of a man brought in with others of a crew infected with scurvy. $\mathrm{He}$ got up to walk across the ward, and fell dead. Post-mortem showed no lesion of organs to account for death. Exhaustion was the cause. Had he been kept on his back for a few days, he would in all probability have recovered. This case has ever after been a lesson to me to conserve the strength of a weak patient, the need of watchful care to those extremely ill. Fresh vegetables, oranges, lemons, and the like, giving their salts as citrates and such in the digestive tract, fresh meats, and the salts of potash direct in the shape of potash bitartrate were the usual remedies used, with the best success.

We had patients from every clime, and here was a good place to study racial characteristics. An interesting group was that from the Japanese Embassy, which came over after old Commodore Perry had opened up the ports of Japan to the outside world. They came to San Francisco on their way to Washington in the old sidewheel frigate Powhatan, under the care of distinguished officers of our own government. Many of the servants were ill after their arrival in San Francisco with acute pulmonary troubles. All these fell to $u$ in the hospital, and we appropriated a large ward to their use. We could 
FORTY YEARS IN THE MEDICAL PROFESSION

not do much with them at that day. They were just coming out of their seclusion of centuries, and were very suspicious of outsiders, and particularly of doctors and medicines. Several died, and were buried by their own peculiar ceremonies. The cadavers were continually guarded until burial, and never a coffin was lowered into the grave until the lid had been lifted as a last precaution. The redoubtable Japanese Tommy was with this commission, a bright, restless little mortal, and a frequent visitor to the hospital; but no time to be sick had Tommy. Those with us were inveterate gamblers, great smokers, and, as they grew to better health, quite jovial, yet always suspicious, reserved, and sly. Of course they gambled. They were all men of one sword. They gambled among each other, not with our men. At last one or two of the Japs had about won everything all the others of the party possessed. Then their cumning came in. They sold nearly everything they had, even their swords, to the hospital employees. When their resources from this mancuvre were gone they had come to their wits' end. They came to the hospital authorities to interfere to have their property returned, for if they went back to Japan swordless, each swordless man must then and there commit harikari. The ruse was successful, but had the embassy remained I have no doubt the same process would have been gone over again ad infinitum. These people brought their own food, and ate none of ours. They lived on rice, tea, and what looked like a persimmon pickled in brine, and eaten with their rice. In a medical way we learned little of them or from them. To-day what advances these people show!

I remember another very interesting visitor to the hospital,-Richard Henry Dana, Jr., author of " Two Years Before the Mast," that greatest of sea-tales, and for the writing of which every man who has been a sailor or who has had to do with sailors should doff his hat at the mention of Dana's name. That book started the crusade which has done so much to right the sailor's wrongs and to ameliorate his former deplorable condition. Dana was on his way around the 


\section{FORTY YEARS IN THE MEDICAL PROFESSION}

world, and this was his first visit to the Pacific coast since he left, at the end of his memorable voyage of " two years before the mast." He made a rigid inspection of the hospital and all that pertained to it. He knew how to inspect: he went to the nooks and the corners, to the beds, the clothing, the drainage, the food supply, the tables, the dishes, especially the cups, the spoons, before and after they had been washed. The grounds received his careful attention; in fact, the whole plant and its contents, patients and all, were thoroughly looked over. He was a pleasant, genial gentleman. I had a pleasant time with him on several occasions, and said good-by for the last time as he passed over the rail of the clipper ship Mastiff, cu route for China, on his way around the world. The Mastiff was loaded with Chinamen, living and dead, on their way back to the Flowery Kingdom. In their proverbial recklessness with fire, they fired the ship three days out from San Francisco. All had to take to the boats. In a day or two they were rescued by an English ship bound for China, and were there landed safely at the end of her voyage, or rather at Honolulu, where she stopped en route. This was great good luck, as in those days seldom a ship sighted another on that voyage.

The first major operation in surgery I saw was an amputation at the hip-joint upon a poor fellow brought in for crushed limb, caused by an accident in a steamboat's engine. The limb was fearfully mangled, and the femoral vessels being exposed made their ligation easy, as a preliminary to the disarticulation. I was given the responsible position of holding the limb, and thus my initiation as a saw-bone was a formidable one. Dr. Maxwell did the operation very dexterously, making, rather from necessity, lateral flaps of skin and muscle. The poor fellow died in a few hours, of exhaustion. I remember it was discussed at the time whether or not the operation was proper under the circumstances. The man rallied sufficiently and lived long enough to compel action, and the operation was decided to be justifiable. I have since been placed in a similar position, and operated 
with like result, but believe I was justified. There have been few recoveries from primary amputations at the hip for accident or gunshot wound, but a surgeon may be called upon to give the patient the glimmering chance even in such desperate emergencies.

In those days San Francisco was a new mushroom IVestern town, cut off almost entirely from the outside world, the mails only coming twice each month by the Pacific Mail steaners via Panama. The town then was mostly built along the Bay of San Francisco on made ground; the streets were either sand ways or planked with wood, with a population of less than forty thousand souls.

There were many refined and cultivated people living there, quite a number of United States army and navy people, among them young men who afterwards became famous, Halleck, McPherson, Ogden, Sawtelle, Mackall, Keys, Murray, Alden, and others. There were also many refined English, French, Germans, old native Californians, and Mexicans. The tone of the medical profession was not highly elevated. There were bickerings and jealousies among the members, composed as it was of men of nearly all nations and gathered from all parts of the world. The business was profitable to those in full practice, but living expenses were great. The fees were from three to five dollars each visit, with surgical and other special services in proportion. Among the more prominent men were R. T. Maxwell, H. H. Toland, Thomas Bennett, F. A. Holman, Benjamin Coit, John Hastings, E. S. Cooper, L. C. Lane, R. Beverly Cole, Charles Bertody, H. M. Gray, Augustus J. Bowie, Isaac Rowell, J. M. McNulty, Robert K. Nuttall, William Hammond, and A. B. Stout.

I give these names here as a contribution to the history of the profession in a town now become the metropolis of the Pacific coast, and really one of the medical centres of the VVestern world. Maxwell was a retired, or rather a resigned, naval surgeon, who took up civil practice in San Francisco in 1854 . He was an able man, a good all-round 


\section{FORTY YEARS IN THE MEDICAL PROFESSION}

medical man. He was a fine operator, and especially excelled in genito-urinary surgery. In obstetrics he had a deservedly large practice. He had decided artistic talent, painted well in oil, and was a fine musician and linguist. He died in 1883 . Toland had a very large practice, was quite a surgeon, and made a large fortune. He founded the Toland Medical College in San Francisco, now connected with the University of California, and died some years ago. Thomas Bennett was an Englishman, a man of fine presence, well educated, and a good all-round doctor. He is deceased several years. F. A. Holman was a fine man and a very good surgeon. Coit and Hastings were general practitioners, the latter the author of a "Dissector's Manual." E. S. Cooper was a remarkable man, of decided talent, and very ambitious. He was very aggressive, and started out as a surgeon exclusively. In $185^{8}$ he founded the first medical school on the Pacific coast, the Cooper Medical College. From this beginning has grown, greatly owing to the munificence of Dr. L. C. Lane, Dr. Cooper's relative, the present Cooper Medical College and Lane Hospital. Dr. Lane is a very prominent surgeon, and has been such for many years on the Pacific coast, as the successor of Dr. Cooper, who died comparatively a young man many years ago. Dr. Cole is still prominent, particularly as a gynxecologist. Bertody, Gray, Bowie, and Rowell have passed away. Rowell, I think, was Professor of Chemistry in the Cooper school in the early days. He was Broderick's surgeon in the famous duel between him and Judge Terry, when Broderick received his death wound. I remember, the ball struck him in the upper part of the chest, embedded itself in the soft parts, and was extracted the second day. Sepsis, with its usual train of symptoms, followed, and in a few days Broderick passed away.

Duels were common there in those days, but this one, owing to the prominence of the parties,--one a United States Senator and the other a judge of the State Supreme Court,created much comment, the cause being disagreement on national politics. 
McNulty was a very fine man, who is still living in Southern California. Nuttall is long since deceased. Hammond was an old army surgeon, a num of decided talent, had a fine practice, and I think is still living, retired, out of the city. Stout is, or was recently, living, a very old man. He was a very able man, and one of the best surgeons on the coast.

In the early days San Francisco was a healthy town, and surgical cases dicl well, owing to the cool and dry climate, sandy nature of the soil, natural drainage, and salt water surroundings. Paludal malaria was almost unknown, and zymotic diseases were quite rare. Pulmonary troubles and catarrhal troubles generally were common, and renal disease was very prevalent, this being due to the climatic conditions; the average temperature being about $60^{\circ} \mathrm{F}$., the skin did little work, and threw the onus on the kidneys. Frec living of the people was an additional factor as to renal troubles. Gumshot wounds were frequent, but machinery accidents rare, as there was so little manufacturing done in the city. Of the forty thousand people, ten per cent. were probably Chinese. Towards the ocean there was little beyond Vallejo Street, and in the opposite direction South Park was the built-up limit. To the west there was little beyond Taylor Street, and the docks were confined between Vallejo and Harrison Streets. The churches and schools and other public buildings, compared with those of to-day, were crude, but served their purpose well, and were a happy leaven in the seething cauldron of wickedness at that day rampant. The climate then is the climate of to-day: for the strong and vigorous, perfection; where to merely breathe and exist is perfect bliss; where it is never hot: where it is never cold; where the woman never puts away her seal-skin nor the man his top coat; where, if it is too hot in the sun it is too cool in the shade; where it is pleasanter in winter than it is in summer; where for six months in the year a windmill is as sure a source of power as a steam-engine: where it is apt to rain any day at any minute for six months in the year, and during the other six months no clond mars the horizon; where the 


\section{FORTY YEARS IN THE MEDICAL PROFESSION}

north wind holds sway and the sea fog moistens the verdure almost nightly, a potent aid to the irrigation constantly needed by all growing plants and forest growth.

After an absence of thirty-four years I visited San Francisco for the second time, in the spring of 1894 . Instead of the discomforts of a sea voyage in an overcrowded ship through the tropics, I crossed the continent in a Pullman car, surrounded by all the luxuries of modern travel. Surprised and enchanted at the growth of the country from the Atlantic seaboard on through the West, we entered California in the Sierra Nevadas, my last recollection of which was racing a storm for shelter more than thirty years before. On through forty miles of snow-sheds, we cross the great mountains, and in two hours or little more from the time we could jump into snow-banks over our heads we could alight from the cars and pick oranges from the trees. Passing down the beautiful Sacramento Valley, through the lovely town where the palm and the olive grow side by side in the open air, on to Oakland, crossing at Benicia in the largest ferry-boat in the world, we come face to face with the modern metropolis of the Pacific. When I had last been in Oakland, it was a mere hamlet; I found it now a beautiful and prosperous city of one hundred thousand people. Crossing on another magnificent ferry-boat, I landed at Market Street, San Francisco. What a change from the passiveness of years before! Here are extensive buildings for the railroads and ferries, and the rendezvous of probably the first and best system of cable roads in the world. It is wonderful how they move up and down the very steep hills; some of them a horse can scarcely crawl up, and until one becomes accustomed to it there is great soreness of the muscles of the abdomen and back caused by holding on and exercising muscles not accustomed to action in such a degree as holding on in the cable car causes. A course of massage for vigorous exercise of these muscles as a preliminary to San Francisco cable-car riding would he a proper proceeding. Two cars generally run together, - a motor car, open, and a trailer car, closed. The open car is 


\section{FORTY YEARS IN THE MEDICAL PROFESSION}

enticing, but the newcomer should sit in the sun when practicable, and protect the throat, or very annoying colds are sure to follow. There is no better way to get a view of the city than by going over the hills by the numerous cable lines. These lines are already, in a measure, being competed with by electric lines. Some say the hills generally are too abrupt for electric roads. I doubt it. The possibilities of electricity have been by no means reached as a source of motive power in such matters.

There are now in the city probably three hundred and fifty thousand people,-ten per cent. still Chinese. There are over one hundred and twenty-five miles of paved streets, fifty banks or more, eighty public schools, over three hundred churches, twenty-four parks, about twenty theatres, and thirty hospitals. The annual rain-fall is abont twenty-five inches. The mean temperature is about $56.5^{\circ} \mathrm{F}$; average maximum temperature, $62.4^{\circ}$; minimum temperature, $50.7^{\circ}$; highest temperature on record, $\mathrm{IOO}^{\circ}$; lowest, $29^{\circ}$; clear or partly cloudy days each year, $28_{3}$; cloudy days, 82 ; number of days on which rain falls each year, average, 70. These statistics show an average of twenty years, and are interesting in a medical point of view.

The hotels are among the very finest in the world, and living in them is comparatively cheap. The Palace Hotelif it has a rival in the world, it is the Waldorf-Astoria, in New York-is a grand monument to the enterprise of Ralston and Sharon. Its location, the intersection of Market and Montgomery Streets, is the liveliest place in the city, and the din and confusion there cause one to imagine himself in the very busiest centres of New York or London. Houserents are not high and the necessaries of life are not dear, a contrast to years ago, when I have paid fifty cents for two apples. I believe one can to-day live cheaper and live well in San Francisco than in any other large town in the country. Servants' wages alone are high. At the best hotels you can live on the American plan at a very low rate. Those who know how to live well. I think, prefer the European plan, and have 


\section{FORTY YEARS IN THE MEDICAL PROFESSION}

a few choice dishes, well cooked and well served. You may get a thoroughly good breakfast table d'hote for fifty cents and dinner for one dollar. The Palace serves a good table d'hote dinner with wine for one dollar and twenty-five cents. At the restaurants one may imagine himself in Paris. One may breakfast à la fourchette for almost any sum up to one clollar and twenty-five cents, all with wine. The fifty-cent dinner at the French restaurants is really a good one of its kind, with a red or white native ordinary wine. You will get a soup, a fish, an entréc, a joint, with vegetables, a salad, a sweet, cheese, coffee and cognac, service and attendance by Frenchmen; and it is good.

Of the better California wines, if you want them, you can get a half-bottle of Zinfandel, Riesling, Mont Rouge, or Sauterne for fifty cents, a good red or white Burgundy for seventy-five cents, and native champagne for seventy-five cents. I doubt if true fermented champagne, strange as it may appear, is yet made in California. The foreign wines sell for about the same prices as they do the world over, and the Californian is much given to them, to the exclusion of the native wines. Notwithstanding this, with experience in the fining and refining of the soil, California is bound to become a great wine country. Beer still flourishes there to a greater extent than one would suppose in a wine-producing country. It is the drink of the masses. Wine may be aristocratic. I know of no better reason. This wine business in California is of great interest to the medical profession, and I have no hesitation in recommending medical men to look them up in all relations as to their medical use.

My excuse here for saying so much about San Francisco and California is that it is properly a subject for physicians to study. So many of our patients ask our advice as to travel for health and recreation, and we cannot know too much of just such matters as I am writing about and propose to write about in this work to give them intelligent advice and intelligent help. The markets are fine; the meats are good; the game, fish, fruits, and vegetables are not excelled anywhere, 
except that the flavor of all our Eastern fruits and vegetables is superior to that west of the Allegheny Mountains, I think. The oysters are a revelation. I pass by the little coppery native oysters, which sell for forty cents per hundred, while the Eastern oysters sell for about the same price per dozen. They are not successfully propagated in the California waters, but are brought as small ones from the East, transplanted to good beds, and are soon better than, or certainly not inferior to, the best Chesapeake and Delaware oysters. Here we see the good work of the United States Fish Commission. In early days no shad, striped bass, nor catfish were to be seen in California. Now the very finest shad can be gotten every month in the year at reasonable prices. So the striped bass, the catfish, and the carp. The only criticism I heard on the Fish Commission was that they had introduced carp. The fishermen called it a hog, and accused it of destroying the spawn of other more valuable food fish. This may be a libel on the carp, but in my opinion no man need wish to eat it when he can get suckers.

To-day San Francisco keeps up her well-earned reputation for hospitality. Some of the private residences are among the finest in the world, and are the scenes of lavish entertainment. Strange as it may appear, a great many of the finest houses are built of wood, the California red wood; indeed, the great majority of them. There are probably three reasons for this, - expense, healthfulness of the wooden structure, and fear of the effect of earthquakes on the more massive buildings. The San Franciscan will not acknowledge that the latter reason holds true now, but the other two reasons probably do. The dwelling section of San Francisco is a wooden town.

The fire limits for wooden structures are being curtailed every year, yet very slowly. The red wood is not inflammable, it burns very slowly, and fire in it is easily subdued, yet, with the high winds and dry weather, the fire department must be very efficient to serve the people as well as it does in keeping down destructive conflagrations. It is a grand or- 
ganization, and owns a half-million of real estate, many steam fire-engines, cisterns for water where necessary, with many horses and men. Seeing it in service, one notes the perfect discipline of men and horses, and absence of hurry and bluster too often seen in such service, and one learns to confide in it sincerely when it comes out triumphantly from a roaring fire fanned by a howling gale in a district crowded by frame buildings where rain has not fallen for months.

Golden Gate Park is the pride of the city, and great reason have the people to be proud of it. It is a great therapeutic factor, doubtless. One thousand acres have already been improved, reclaimed from the sand hills, where nothing grew at first but the scrub oaks, and where the sand grass and lupine were planted. It proved better ground than it looked. It was only necessary to haul a little earth and a little long manure and use plenty of water in this alkaline soil, and plant; nature did the rest. The soil looks sterile, if not sterilized, and probably adding soil in small quantity starts up nitrification.

All nature expands as though struck by the magician's wand. Here the herbage and the arborage and the flora are superb. No description can do them justice. It is a paradise for the weary, the invalid, the horticulturist, and the botanist. The eucalyptus tree (Eucalyptus globulus), by its rapid growth, has aided the authorities much in rapidly developing the park, but I am quite sure as the other trees grow they will have to remove a great many of them, for by its power of absorbing and evaporating moisture you see the baneful effect of the eucalyptus on all surrounding grass and foliage. To some its balsamic odor is agreeable, and it is undoubtedly health-giving, and I trust as many as possible may be spared. The children's playground and houses are monuments of forethought and of Mr. Sharon's generosity. They have their nursery, their ponies, their donkeys, all free as air, and there are no signs of "Keep off the Grass." The park is never closed; policemen patrol it day and night. The conservatories are well constructed and the contents admirably classi- 


\section{FORTY YEARS IN THE MEDICAL PROFESSION}

fied, with the finest collection of begonias in the world. The museum of natural history has a fine collection, and is well worth a visit, and must prove a great edtcator. The monuments to Halleck, Rer. Thomas Star King, and Key serve as a beginning, and doubtless many more will appear in time. The aviary is a remarkable exhibition, and only possible in such a climate. It is of wire netting, 300 by 150 by 32 feet. It contains one hundred and fifty species of birds, two thousand of them. It is most interesting, and a great educator for all. There is a large wind shelter on Strawberry Hill within the park, where those who drive may stop for the grand view it affords, with shelter from the driving northwesters, so common to the summer months. The music-stand, the suspension bridge, the deer glen, the buffalo pasture, and Roman bridge all go to complete one of the grandest public pleasuregrounds of the world. Sutro Heights and the Cliff House are resorts much frequented, and although not yet strictly public, they afford additional opportunity for recreation and amusement.

The Presidio, the old Spanish military post, contains over fifteen hundred acres, and is the present government military post. It is situated in the northwest suburbs, and slopes to the harbor, and is an additional grand breathing space for the people. It overlooks the bay and the other government military posts, Fort Point, Point San José, with Alcatraz and Angel Islands. The Presidio has fine grounds well laid out, with shacle and ornamental trees and flowers. It is one of the most desirable of all our army posts for officers and men.

The cemeteries, when compared with those of early days, show well the strides the city has made, and are situated near and around Lone Mountain, which is surmounted by a cross visible from all points. I think this cross was a gift from the late George W. Childs, of Philadelphia. Here are Laurel Hill, Calvary, the Masonic Cemetery, the Odd Fellows' Cemetery, and the Chinese Cemetery. In those lovely spots are the remains of many of those who made San Francisco and 
California what they are, and the mausoleum architecture displayed is worthy of the grandeur of ancient Rome. Here repose the remains of Latham, banker, senator, and governor; of Larkin, pioneer among pioneers; of Maxwell, Toland, and Cooper, eminent in medicine; McAllister, father and son, learned in the law; Hearst, capitalist and senator; Broderick, pioneer and senator; Babcock, the merchant; Folsom, the soldier; Sharon and Flood, each of whom had gathered riches beyond the dreams of avarice. The remains of these and other great men have been gathered here on the borders of these lovely avenues, and under the shade of the laurel and the oak may their dust forever mingle with the soil of the State they loved so much and served so well!

Coming cityward from the park, we pass, on Jackson and Pacific Streets, the beautiful Pacific Heights, the coming part of the town for residences; where the air is pure, loaded with salt and ozone from the ocean; where the view is lovely, embracing mountain and sea and landscape combined. Here are costly residences now, the kitchens and workrooms on the main avenue, while the dining-rooms, libraries, and other desirable apartments are in the rear, where, from the rapid descent of the land, the view is unobscured. Down on the water front we see the wharves and docks and the great improvements resulting from the bulkheading, over which the bitter fight was made many years ago. The torreclo has been conquered; he will not cross a crack in his work, and the built-up pile made by starting with a small four by four and building up with one-inch stuff, and coating with various compositions, has sounded his death knell.

There is only one thing galling to the American as he looks over the scene,-the general absence of the old clipper ships of the early days and the display of foreign flags on most of the great ships now in the docks and at anchor. The Chinese quarter of the present, growing from the nucleus of years ago, has extended, and taken in parts of the city where formerly were desirable places of residence, particularly on Stockton Street beyond Washington Street. Much of Sac- 
ramento, Du Pont, Pacific, Jackson, and Vashington Streets is now Chinatown. In a step we go from Christendom to Heathendom, practically from a typical American town to the middle of the Flowery Kingdom. John walks in the middle of the street for the same reason he wears his cue, because he did so at home. He eats smoked ducks because he did so at home; for the same reason he gambles and smokes opium. If he is free from any of our own vices and many more, we fail to see it: if he has any virtue unknown to the average Chinaman at home, it is not apparent. He is here, in fact, a heathen among heathen, and, like the leopard, can never change his spots. The Argonauts, the Forty-Niners, keep up the old society, have built a fine hall, and have an abundant capital to insure the endurance of the organization, which extends from father to son, and doubtless the sons will be found ever ready and willing to uphold the honor and dignity of the land so thoroughly guarded by their forefathers. Many of the newspapers of the early times still hold sway, reinforced by many others, both able and influential. The Bulletin, a creation from the brain of the martyred King, fertilized by his blood lost in the days of lawlessness and passion, still sheds a brilliant lustre from its pages. The Call yet lives, having grown from a pigmy to a giant. The Examiner and the Chronicle, creations of later days, join the others in upholding the honor and the dignity of the Golden City, whose growth no one can estimate who knew it in its infant days, and whose future we can only imagine, considering its past. IVe can measure its coming greatness by no human scale, but can only conceive of a mighty town like Atlantis risen from the sea; a creation of the magician's wand, a realization of an Aladdin's tale. 


\section{H A P T E R I I.}

University of Pennsylvania, Medical Department, I860-The Buildings and Conveniences for Faculty and Students-The Faculty-The Lectures--The Quiz Classes and Students-University Characters-Outside Teaching-The Course.

In October, I860, I matriculated in the Medical Department of the University of Pennsylvania. At that time the buildings were situated on Ninth Street just above Chestnut, where the present United States Post-Office now stands. There were two buildings. The one nearest Chestnut Street was occupied by the Medical Department, and a short distance from it, towards Market Street, was a similar building, occupied by the Department of Arts. A high iron railing enclosed the whole along Ninth Street, and there was no general outlet to the rear of the buildings. The basement was occupied by the rooms for the Dispensary, Clinics, store-rooms, vat-rooms for cadavers, etc. There were three general lecture-rooms, one used by the Professors of Practice, Materia Medica, and Physiology, one entirely by the Professor of Chemistry, and the other by the Professors of Surgery, Obstetrics, and Anatomy. There were private rooms for the professors adjoining the lecture-rooms, with a small ward for surgical cases. The upper floor of all was occupied by the dissecting-room, next to Ninth Street, and the opposite room was devoted to the classes in bandaging and practical surgery. As to comforts for either students, or even the professors and their assistants, in the way of bath-rooms, toiletrooms, or general wash-rooms, there were none worthy of the name. Yet they were in general keeping with such as were furnished students in the better schools and universities of the day. The lecture-rooms were badly lighted by day and by night, and the ventilation was worse. Princeton College 


\section{FORTY YEARS IN THE MEDICAL PROFESSION}

was no better in the way of such comforts. At that time there was not a decent water-closet comnected with the college, and not a bath-room in the whole collection of college buildings in Princeton. More, there was no way in which a student could get a drop of hot water except by heating it on the stove in his own room, and in the North College, just completed, that was not possible, as it was heated by hot air, with no thought of a bath-room attachment.

What would college men think nowadlays, if they had to do their bathing in individual bath-tubs in their own rooms, as we did who were college men forty years ago? In this, as in other such matters, we behold the evolution of a civilization, and almost shudder at our very recent release from what may appear now as a near approach to almost savage existence. At the University the benches were hard and uninviting, and the rooms were, as a rule, crowded. Every one took matters as they came, and good-humoredly, and as the country was just on the eve of the great convulsion of the Civil War, catısing great unrest in all matters of government and finance, no one had as yet dreamed of the great strides and advancements in store in the comparatively near future for the grand old University and her medical school. The heach of the faculty at this time, next to Professor Jackson, both in age and years of service, was Dr. Hugh L. Hodge. He was nearly blind, and excited the sympathy of every one in his lectures in his efforts to make clear his demonstration. Hodge, like all the members of his family, was a great man and undoubtedly one of the foremost obstetricians of his day in any country. Dr. John H. Packard generally assisted him at his lectures, and was in every way more than friend to the old gentleman. In those days gynecology had made little advancement as a distinct branch of surgery, and an obstetrician rarely took up a knife for anything; and should a case for Cæsarean section present itself in his practice, he called in the general surgeon for the work. Indeed, not to have done so would have been looked upon rather as a breach of professional etiquette. Dr. Hodge had a great reputation as a 


\section{FORTY YEARS IN THE MEDICAL PROFESSION}

gynæcologist as gynæcology was understood in those days. He referred most of the evils of the female organization to irritable uterus, and was very successful in the treatment of displacements of that organ with the pessary bearing his name to-day and still so well known to the profession.

I remember some years since to have been called in by a very aged lady to consult concerning some irritation involving the vagina and adjacent parts. Upon examination I found a mass of granulations, and embedded in it some hard metallic-like substance. I questioned the patient, of course, to try to find out the cause of the trouble. She told me Dr. Hodge had treated her for some time more than twenty years before, and she thought he had introduced some instrument. The case was then plain, and I removed the encrusted instrument by cutting it into segments, and her trouble soon subsided.

While on the subject of pessaries, one case comes to my mind showing the quick resourcefulness of that great surgeon, the late Richard J. Levis. A professional friend came to Levis in great trouble, saying he had introduced a glass globe as a pessary, and the globe had from some cause been broken into bits; and how to get it out without mangling his patient he did not know. Levis took in the situation at once, procured some plaster and water, filled the vagina with the mixture of proper consistence, allowed sufficient time for the setting, then removed the cast, glass and all, without doing any injury whatever to the grateful patient.

The walls of the vagina are very prone to throw ont grantulations and bury within them any substance which may by its presence offend them. Here is a case illustrating this point and of practical application: Some years since I applied a Goddard pessary to a woman for a complete procidentia uteri, and made her entirely comfortable, as these instruments often do. Unexpectedly I did not see her for some years, when she applied to me to examine the conclition of her trouble. Of course these instruments should be removed and thoroughly cleansed, and if necessary renewed at shorter or longer intervals. In this case I found the external bars in position, but 
the cup and part of the stem buried in granulations, which held the uterus in perfect position. My first thought was to cut away the offending growth and release the instrument, but on second thought I cut away the stems and then took away about two-thirds of the ring, leaving the other third in the mass, holding the uterus to the vaginal wall. Here was a perfect correction of her trouble. I examined the case, at long intervals, several times. The corrected condition remained perfect until she died.

To return to Professor Hodge. He published a work on diseases of women, according to his views of the matter, and a colossal and standard work on obstetrics. In this labor he was greatly assisted by his son, the late eminent surgeon and cultivated gentleman. H. Lenox Hodge, and, as he himself has said, without the help of his son, on account of his own lack of eyesight, the book would never have been written.

William Pepper, Sr., father of the late distinguished Professor William Pepper, Jr., was Professor of the Practice of Medicine, having recently been elected to the chair made vacant by the resignation of Dr. George B. Wood. Dr. Pepper was a compactly built, rather small man. He was quick in his movements and very sprightly and earnest as a lecturer. He was a clear thinker, and his lectures were models of their kind, for in those days the course only lasted about five months, and to condense the immense amount of matter to be gone over successfully in that short time required both skill and ability. Dr. Pepper had a great aversion to the use of tobacco, and very properly attributed many ailments and exaggerations of ailments to its abuse. In summing up the causes of the disease he happened to be lecturing upon, we always looked for, as he cast his eyes over the class with a knowing nod, "And, gentlemen, the use of tobacco-_" While Dr. Pepper was a most interesting and successful lecturer, it was in his clinic he excelled. He was a masterly diagnostician, and it was a real treat to hear and see him go through a case before the class. He had a thoroughly educated ear and a wonderful sense of touch, each trained by 
faithful study and practice under Louis. He labored under great disadvantages, from failing health, almost from the time he connected himself with the University. He made a brave and manly fight to the end, and when he died the University lost a devoted teacher and the profession in America one of the ablest of the many very bright men who at that period adorned it. William Pepper, Jr., who has recently died prematurely, was a worthy son of a worthy sire. As a young man in hospital life in Philadelphia I knew him well, as I did his brother George, another bright man, who died just on the threshold of a brilliant career as an obstetrician. William Pepper, Jr., was a man of fair physique, pleasing address, and polished manners. He had naturally a wonderful gift of language and facility of expression, in both of which he expanded as he grew in years and practice. No doubt he had exceptional opportunities in his chosen profession at the start, but no man ever took greater advantages of his opportunities or used them more successfully. Not only was he successful beyond measure in all that pertained to his life as a physician and as Professor of Medicine in the University of Pennsylvania, but he did wonderful work in building up and developing all of the great schools connected with the University, and the grandeur of his work in this direction is well worthy of a lasting remembrance. Indeed, the great institution of to-day may, with no slight to other men, be said to be at once his work, his monument, and almost his tomb, for doubtless he died of old age at fifty-five, from overwork and over-zeal, both as a physician and as a citizen of Philadelphia, the city of his birth, the town he loved so well and did so much to honor and adorn.

The venerable Samuel Jackson was the Professor of Physiology and Institutes of Medicine. Jackson was a remarkable man, and probably might be called the medical philosopher of his day among the medical men of America. He was a lovely old gentleman, short and stout. and at this time unable to walk without assistance. I cannot say much for his didactic course on physiology, for his lack of arrangement 
and common method rendered it impossible to absorb methodic knowledge from his non-methodic methods. Many of his lectures were rare treats, and the most interesting were when he started on some subject entirely germane to his course, and then accidentally branched out on some intercurrent fact that came up by accident. He was fond of bringing up facts, clinical facts, from his large experience in practice, and often charmed his listeners, through the whole hour devoted to his lecture, by a dissertation on the philosophy of dreams, or the localization of cerebral functions, or some equally interesting subject. The old gentleman was fortunately easy in his examinations for degrees. I remember the subject of my own thesis. The first question he asked was, what was the subject of my essay? After I had told him he launched forth and gave a most exhaustive and able discourse on the subject, making me feel, I remember at the time, that I had known very little before. This took some time; then he asked me one or two trifling questions, said, in a very complimentary way, he should like rery much to read what I had written, that he did not feel very well that morning, and politely said good-by.

Dr. Francis Gurney Smith succeeded Dr. Jackson in the chair of Physiology. He was a rather large, fine-looking man, of fine manners and address, and a captivating lecturer, one of the very best among the faculty. The course then was a very simple one,-about three didactic lectures a week, with absolutely no laboratory or experimental work on the part of either teacher or student. Dr. Smith usually wound up his course each winter with a special lecture on "Life and Death." It was beautifully written and well delivered, and did much to leave a good impression of his abilities among the students. Dr. Smith died a comparatively young man, in the midst of his work and well-earned fame. The diagnosis of his last illness had a pathetic sadness about it, and shows well the protean forms of renal disease, and how relentlessly and stealthily it often creeps upon us. He liad not deemed himself much out of health, and had taken for some 


\section{FORTY YEARS IN THE MEDICAL PROFESSION}

reason a specimen of his own urine to compare with a known diseased specimen, to exhibit before some students. He had shown albumin as he had expected to find it in the diseased specimen, both by Heller's test and by heat. When he went to show the different reaction in his own healthy urine, he was horrified to find the albumin appearing there. The realization appeared to crush him, and ever after until his decease he appeared far from well.

Robert E. Rogers was Professor of Chemistry. He was a fine lecturer, but probably not so brilliant a man as his brother, who had preceded him in the same chair. He had a good apparatus at the University, and was, as a rule, very successful in his experiments before the class. He was the Dean of the Faculty, and thus saw much of the students, and was always personally popular with them. Several years after this Dr. Rogers, who was much given to experimentation with mechanical matters, lost his arm in a washing- or wringing-machine in the West Philadelphia Military Hospital. This was a fearful blow to him, which, together with domestic affliction, greatly marred his later life. For reasons best known to himself, he left the University and accepted the proffered Professorship of Chemistry in the Jefferson school, which position he filled satisfactorily for a number of years before his death.

Henry H. Smith, a tall, commanding, very handsome man, was Professor of Surgery. Dr. Smith had been a private pupil of the late Professor William E. Horner, the great anatomist of his day, and afterwards married his daughter. He was a good operator, but there was neither the brilliancy nor the blood in the surgical amphitheatre of the University of that day, such as one saw in the Jefferson arena during the palmy days of Pancoast and Gross. Dr. Smith was a careful and good teacher, and in his clinics one saw practice as it comes to us every day, and from which, after all, the pupil absorbs his very best lessons.

Joseph Carson was the Professor of Materia Medica and Pharmacy. He was a lovable, pleasant gentleman, and well 


\section{FORTY YEARS IN THE MEDICAL PROFESSION}

grounded for the work in his special branch. To many students materia medica was a dry subject; this was much owing to insufficiency in their preliminary training in chemistry and botany. Dr. Carson had prepared a syllabus of the subject, or rather a synopsis, which was a help to his students. He was fond of a joke, but, strange to say, he could never successfully get off one; he wanted to laugh himself, and laughed too soon. The joke nearly always stuck in his throat, and left him disconcerted and embarrassed. One of his choicest was his mercury joke,-hydrargyri chloridum mite and hydrargyri chloridum corrosivum, "but, gentlemen, I assure you there is a mitc difference between the two substances."

Joseph Leidy was Professor of Anatomy. Leidy was a famous man. In all that pertains to nature, whoever was second, Leidy was surely first. His reputation was worldwide, and when he died the whole world lost one of her brightest and greatest men. Probably in 110 place of all places of honor he held, did he appear to less advantage than as a didactic lecturer to students on anatomy. Anyhow, the didactic lecture has had its day. At the present time it is no way to teach medicine, and is fast losing ground, as it should, and soon I trust we shall hear it no more in the halls of medical science. As a student I learned much more in the quiz than I ever learned from didactic teaching. It has been ever so, and will be ever so. Let us empty the cerebral bloodvessels of didactic instruction; let us eliminate its toxines and come to rational proper methorls of teaching. There was little spice in his talk, and he invariably impressed me as one who was lecturing as a means by which to live, and not as one who lived to lecture. He was no surgeon, and applied anatomy had no place in his teachings, yet the acknowledged greatness of the man inspired his listeners, for whatever word Joseph Leidy uttered in a scientific atmosphere could but inspire his hearers. He generally told of his experience in practice, and limited it to one case. He had opened an office soon after graduating, when a woman came in with her child with a grain of corn in its ear. "Well, gentlemen," he would ask, 
"did I hurry? Was there an anatomical reason for hurry? No; remember, gentlemen, the corn could not get into the child's brain, as the mother feared, but I feared it might drop out without my assistance before I got my dollar." Here was applied anatomy for you, anyhow, but Leidy never gave us much more. This mere sketch does little justice to so remarkable a man. Dr. William Hunt's memoir of Leidy is full and most interesting, and should be read by all who can admire the genius and brilliancy of this unassuming, quiet, modest gentleman, who died when the world needed more than ever his great talents and indefatigable industry.

William Hunt was Demonstrator of Anatomy. No better man ever lived than William Hunt. Bright, genial, painstaking, and industrious, he made a good demonstrator of anatomy and successfully filled the position for a number of years. He was a good practical anatomist, and his lectures on surgical anatony were among the best delivered in Philadelphia in his day. He was made surgeon at the Pennsylvania Hospital in the early part of his career, and held the place up to the time of his death. The vast material available at this hospital was a great opportunity for any man in surgery, and Hunt made good use of it. He was conservative and non-aggressive, but he had wonderfully good judgment, and probably no one was better equipped than Hunt for passing upon the propriety or non-propriety of an operation. His nature was most kindly, and he was always ready with a joke or a good story applicable to the environment. Among his stories, two of the best were McMullen's nose and the stone case. As I remember the stone case, when he was first made surgeon at the Pennsylvania Hospital he found a little boy had been admitted to his ward who had stone in the bladder. This was a great find, as stone cases were considered in those days among the most desirable for a show clinic. Hunt had arranged to operate on the coming Saturday. About the time the patient was ready for the ether previous to being taken into the amphitheatre, the father appeared and asked for an interview with the surgeon. "Now, doctor, you are a young- 
looking man. Did you ever in your life do an operation of this kind?" Hunt saicl he was completely taken aback, but soon recovered himself and promptly answered, " No; but I consider myself entirely qualified to do the operation, and promise to do all in my power to help your boy." The father answered, "Well, doctor, I think I will take him to an older man." And then and there he made preparation to remove the lad from the institution, and did so. Hunt went before the class and unreservedly told the whole story as it had happened, adding, in his droll manner, "Gentlemen, I would not tell a lie, no, not even for a stone case." Personally I was greatly attached to Dr. Hunt; he was one of my preceptors and a good and kind friend in my early life; and it is a melancholy pleasure to me to drop a tear upon his tomb and place a fragrant flower upon his grave.

D. Hayes Agnew succeeded Dr. Hunt as Demonstrator of Anatomy at the University. Every one knows who Dr. Agnew was, - one of the grandest of men and one of the greatest of surgeons. As a practical anatomist he had no superior, and as a teacher of anatomy he was wonderfully apt and successful. Being both anatomist and surgeon, he made his lectures inviting on what students have generally considered dry matter, by bringing in regional and applied anatomy, and his school in the rickety old building on what is now Ludlow Street, back of where the old University stood, is well remembered by many men still living who were fortunate enough to get the benefit of his teachings. Agnew took a great interest in young men, and was as kind and affable to the tyro as to the veteran in the profession, and he carried this kindly manner and affability into his professional life as a consultant, and greatly to these kindly traits, strengthened, of course, by his surpassing ability as a surgeon, did he owe the fact of his enormous consultation practice, extending to a majority of such cases, perhaps, happening at the height of his busy life, in the States of Pennsylvania, New Jersey, and Delaware. No thought or look ever escaped him which could be construed as an effort to deteriorate a professional brother 
in a case with him. He always left his co-consultant with the feeling that he was his equal, and every man who had him once wanted him again. All great surgeons do not act as Agnew did, either towards students or towards those who call them in as advisers, and such men sooner or later suffer both in lack of clients and admirers. Agnew was a constant and unceasing worker, from the time he came from his vocation as a country practitioner, all through the days of his obscurity in his dingy dissecting garrets in the city, up to almost the very hour of his death. His literary work will long remain a monument to his memory, both in his great volumes on surgery and in his other books and monographs. He took little recreation, and was little versed in the ways and frivolities of the world. He was in religion a zealous Presbyterian, and in the church he found his amusement and relaxation from his weary toil, rather than in social pleasures. I doubt if he even went to the theatre, possibly had never even seen a circus. He, indeed, knew nothing but work. Thousands got the benefit of his self-denial, and when he clied the world lost one of its grandest, greatest, and best of men.

There were several quiz classes at the University during the later days of its Ninth Street existence which did good work for the students, and were particularly of advantage, for a majority rushed through in the two years' course then allowable rather than take the three years' term. Many men doubtless made their final examinations successful only by aid of the quiz, and, besides, the quiz masters were nearer the students than the professors, and gave them a feeling of confidence, a feeling that they had some friend to turn to in their hour of trial. Morris, Bolling, and Darby had a large quiz in rooms at Ninth and Chestnut Streets, which afterwards became Morris, Bolling, and Hodge, and later, Bolling, Hutchinson, and Hodge. Levick, Hunt, and Penrose had a large and most successful quiz down Jayne Street below Ninth, opposite the entrance to the Medical Department, and back of Balty Sower's well-known saloon. The late Dr. Bishop, a genial good man, and the late eminent Joseph Janvier Wood- 
ward, who did such good work in the medical history of the late Civil War, had also a large quiz class. The present eminent University professors, Tyson and Wood, with the late Professor Pepper, had a very successful class, and another was Black, Boardman, and Woods.

Janitor Price was a genial man, who took charge of the matriculating books and gave advice to the students from a distance in the little office to the right of the general entrance, and was afterwards sticceeded by William Salvador, who was promoted from the charge of the surgical ward connected with the surgical clinic. Salvador is still connected with the University.

Old John Brown, good old Jolnn Brown, was a kindly old man in charge of the rooms and belongings of the Professor of Surgery, and janitor of the bandaging-room. The notoriety attaching to John was the long time he had been connected with the University Medical School. At that time, I863, he had been there, I think, about fifty years, having served Professors Smith, Gibson, and probably far into the time of Physick.

Of all the minor characters about the University, Nash, the janitor of the dissecting-rooms, was probably the most unique and the longest to be remembered. Imagine a very tall, lanky man, with arms too long for his body, with a halt in his gait which compelled him to drag his limb, giving him a compound gait, a gait between that of a Jackey just ashore from a long cruise, and constantly hitching up his trousers, and that of a man learning to walk with an artificial limb above the knee. Nash had all these movements in his walk: he jerked up behind, described an outward semicircle, and then planted his foot with a flop at each step. He was pockmarked, had a small, restless gray eye, a voice with a squeak and a wheeze which appeared to come from his boots. $\mathrm{He}$ had an intimate accuaintance with all the dealers in subjects within many miles of Philadelphia, was well up in preparing them for dissection, always abused the hospital doctors as being the cause, through their post-mortems, of the non-suc- 


\section{FORTY YEARS IN THE MEDICAL PROFESSION}

cess of his arterial injections,-and, as a rule, these never were successful with him,-got up skeletons for sale to the students, mixing his cuneiforms and pisiforms in a way, as Hunt once said, sure to cause trouble when the great reckoning to all men should come, was fond of rum, cursed like an army corporal, swore by Dr. Leidy, and looked like the devil, as imagined by man. Peace to his ashes.

There was another character about the University at that time, a student from North Carolina or one of the Southern States, who to me is rather a memory than a reality, and whose name I have forgotten. He was a true wit and a wily, mischievous wag, up to all kinds of pranks, and, withal, a good student and a jolly good fellow. He left his name embalmed in the University as the author of the Turpentine song. Through the works and suggestions of that eminent professor, George B. Wood, the oil of turpentine was looked upon as a sovereign remedy in many ailments of mankind, and the luckless being in those days with typhoid fever who escaped a turpentine julep every few hours might be looked upon as a freak in nature. I wish I had a copy of the song. I don't know that it is in existence. It referred to some unfortunate imaginary girl in a paroxysm of hysteria. All I remember is the refrain,-

"Turpentine, Turpentine,

We poured cold water down her spine;

We gave her oil of turpentine;

Turpentine, Turpentine."

With emphasis and high inflection on the "tine" in the last line.

The little lecture-room on Ludlow Street back of St. Stephen's Church was a favorite lecture-room for many men who had been, and are now, prominent in medicine in Philadelphia. Dr. R. A. F. Penrose, Emeritus Professor of Obstetrics and Diseases of Women and Children in the University, delivered his well-attended and popular courses of lectures there as an adjunct course to the regular University course. These lectures continued each winter until Dr. Pen- 


\section{FORTY YEARS IN THE MEDICAL PROFESSION}

rose was elected to succeed Dr. Hodge. Penrose was doubtless the best teacher of his day of the art of obstetrics. None who ever heard him will ever forget his old friend Mrs. O'Flaherty and the lifelike demonstrations he gave with her as subject. Mrs. OFlaherty under Penrose's faithful care and assistance probably had more children than any other woman who ever lived, and every conceivable operation that could be performed upon a lying-in woman did Mrs. O'Flaherty undergo time and again. She served her day and generation well, and many of her sex owe her a debt of gratitude for the help she gave in the education of many of the great obstetricians of the present time. The obstetrical hat was another inseparable part of the equipment of Penrose's school. Now and again an advanced student was given a case to attend in the poor district. On these occasions the wearing of the obstetrical hat was compulsory, for no woman would respect any doctor in those days under such conditions who did not wear a high hat. Dr. Penrose still lives, retired, enjoying a well-earned rest, respected and admired by the thousands he has served so well both as teacher and physician.

In the same little lecture-room Dr. S. Weir Mitchell now and again gave a lecture on some subject, generally connected with physiology in an experimental way, and it is only necessary to say that Mitchell gave a lecture, to say that it was bright, educating, and entertaining. At that time he was carrying on his great work on snake-poisons, and these matters were the subjects of some of his lectures. Fortunately for the world, this brilliant man still lives, physician, novelist, and poet, his work ever enduring, his talents ever increasing. May he continue to live many years, and pass the evening of his life as becomes the accomplished and cultivated gentleman that he is. Before leaving the University it may be well to take a surrey of the course of lectures delivered there, and the work done by the students previous to applying for their degree, and compare it somewhat with the work now done in the same institution by men before they take their degree. I think this will show the great changes that have taken place 


\section{FORTY YEARS IN THE MEDICAL PROFESSION}

in medical education and the great advantages men of the present day have over those of forty years ago. Compare these changes with the advances in practice, and they only show that one has necessarily kept pace with the other. Compare the changes and advances in both medical education and medical practice with the changes and advances in all matters pertaining to human change and human progress, and it only shows the great advancement of all things towards a higher civilization,- - the evolution of man towards the perfect type. The completion of a two years' course allowed a student to present himself for graduation, and very few were they who did not accept the opportunity, it having been taken for granted that they had been studying medicine in all for three years.

The following may be taken as a typical day of routine at the school: Nine o'clock A.M., quiz class; ten A.M., lecture by the professor of chemistry; eleven A.M., lecture by the professor of anatomy; twelve M., lecture by the professor of practice; one P.M., lecture by the professor of surgery; three P.M., lecture by the professor of materia medica; four P.M., lecture by the professor of obstetrics; seven P.M., lecture by the demonstrator of anatomy; eight to ten P.M., dissecting or practical surgery. There were also dispensary clinics held several hours each week in the University Dispensary Department which students were invited to attend. Wednesdays and Saturdays were clinic days at the University and at the hospitals, - ten A.M. to twelve M. at the hospitals, and from twelve M. to two P.M. at the University, one hour each of medicine and surgery, respectively. These duties, together with a few outside lectures on anatomy and obstetrics, comprised the whole course, and well it did, for the students were pressed almost beyond endurance if they worked and were conscientions. The fault was with the system, the cramming system, and the comrse too short even for that. There was no practical work in chemistry, none in histology; pathology was taken little thought of, and I don't remember even once looking through a microscope as a part of my course at the 
FORTY YEARS IN THE MEDICAL PROFESSION

University; all of this notwithstanding the work then recently done by Virchow in pathological anatomy and the whisperings of the cell doctrine, the ommis cellula e cellula of this wonderful man.

Turn to the course of studies for the degree of Medicine to-day and see the change. It is apparent at once what makes this change possible, - the compulsory course of four years, and this is scarcely sufficient. The classes are divided into sections, and the mere didactic lectures in the general course are fast becoming the least essential part of the curriculum. The dissecting and practical surgery classes are carried on about as in the olden times. The dissecting done by students even at this day is sufficient to give them a practical insight into the rudiments of the work only. To become a good practical anatomist, a man must pass many midnight hours over the cadaver after he has passed from the halls of his alma mater.

To-day the student takes up in their order, with a fair amount of time devoted to each, and with special instructors, practical chemistry, practical biology, general pathology, normal histology, practical pharmacy, practical physiology, demonstrations in morbid anatomy, autopsies, bedside teaching, with practical work in dermatology, obstetrics, and such like work. A man coming out who has faithfully followed his work and taken proper advantage of such a course should at least be in condition to commence to learn to be a doctor. 


\section{H A P T E R I I I.}

The Jefferson Medical College, Philadelphia-The Faculty-Joseph Pancoast and James Syme-S. D. Gross-The Tone of the Profession in Philadelphia-Clinics-Hip-Joint Cases-Clinical Lecturers in Philadelphia-The Atlees and other Great Men-Professional MethodsTrained Nurses-The Philadelphia Hospital, Blockley, in the Early Sixties-Typhus Fever.

Four decades ago the Jefferson Medical College in Philadelphia had a larger class than the University, and a faculty not surpassed in ability by any in the country. Such great men as Charles D. Meigs, Franklin Bache, John K. Mitchell, Robley Dunglison, Thomas D. Mutter, and others had about closed their long services to the institution, and had been succeeded by Samuel D. Gross, Ellerslie Wallace, J. Aitken Meigs, and S. Henry Dickson. The two great and shining stars of this faculty were Joseph Pancoast and Samuel D. Gross. The former, professor of anatomy, and the latter of surgery. Pancoast was a thorough practical anatomist, his knowledge gained from hard unceasing practical work. As a practical surgeon he was undoubtedly one of the greatest that ever lived. At that day he had an enormous and lucrative practice, and did most of the consultation work in the States of Pennsylvania, New Jersey, and Delaware, just as Agnew dicl at a later day. Pancoast was a large, thick-set man, with a good deal of manner, a kindly manner, which at times appeared forced. His hand, that organ which did so much for him and for humanity, was large, heavy, and thick, with immense blunt fingers; any other than a hand you would look upon as facile and dexterous almost beyond belief. The facility with which he cut for stone was a revelation. He was fond of the bilateral operation in proper cases, and he was unapproachable in this method. He could do a robust 
operation, as a lip-joint, and pass with graceful ease to a case of cataract and remove the lens with all the skill and confidence of a Bowman. It was in practical work as a surgeon that Pancoast excelled. It was wonderful how he could use those great blunt fingers. They appeared to take on any shape he chose to give them; they could turn and twist and reach anywhere. He had a telescopic eye, the artistic touch of a Levis, the precision and confidence of an Agnew, with all the grace and rapidity of a Morton. He had all these gifts and even more. He did little on the literary side of the profession. He was an impressive-looking man, and had a very impressive manner in clinic. His audience was always $\mathfrak{c n}$ rapport with the man, and his patients looked upon him as next to divine. Should I be asked to name the two greatest operating surgeons of that day, I think, without deteriorating others, I should name Joseph Pancoast, of Philadelphia, and James Syme, of Edinburgh. Should I be asked to name the one greatest, I should name Joseph Pancoast, of Philadelphia.

The mention of Pancoast's name naturally brings up the name of his great colleague Gross. Samuel David Gross was the Professor of Surgery, and was an emperor among men. He would have been a great man in any calling, and nothing I can say here can add to his fame, for I doubt if any name in the profession has had more written about it in laudation than the name of Samuel D. Gross. I knew him well, was his resident at Blockley, have seen him under many conditions and under many circumstances, and under all these conditions and under all these circumstances he was the same great man. Gross's methods were in advance of the methods of the day in many matters. Before an amputation he always made us raise the limb and drain the superficial veins by rubbing, and then would apply a bandage, much the method used by Esmarch at a later day, and only lacking the elastic bandage, the ordinary tourniquet taking the place of Esmarch's elastic one. I think he paid more attention to cleanliness in his dressings than most of the surgeons at that time, and insisted on a nearer aseptic condition than others, far as it was removed 
from the asepsis demanded to-day. He also paid more attention to drainage of wounds than did most of his colleagues. As a diagnostician he was very correct, and his vast store of experience served him well in this direction. As a writer and author he was one of the greatest the profession has ever produced, and his great work on general surgery will ever stand as a monument to his memory. In personal appearance Gross was an imposing-looking man, and from pictures handed down to us I should imagine there was a strong resemblance in him to the great John Hunter, his great admiration, and whose biographer he was. In pathology Gross was far ahead of most of his contemporaries. All were fearfully lacking as compared with our modern workers, but Gross was a leader, a close student of pathology, as well as a writer and teacher.

Robley Dunglison was a remarkable man and filled the chair of Physiology with ability. As an author he is well known, and in his great work, Dunglison's Medical Dictionary, has left a legacy to the profession which makes it greatly his debtor. J. Aitken Meigs, his successor, long since deceased, was a painstaking man, and had a world-wide reputation for his special work.

Dr. Ellerslie Wallace served acceptably in the chair of Obstetrics, and often in his lectures gave vivid pictures of the accidents that may come to us in obstetric practice.

John Barclay Biddle, about 1865 , was made Professor of Materia Medica and Therapeutics, served the school successfully for a number of years, and was noted as an author of text-books of much merit.

I have always been an admirer of the high tone of the profession of medicine in Philadelphia. I have travelled a good deal over the world, I have observed the profession critically in many places, and in no country, in no city, in no town, have I ever found more true gentlemanly courtesy between doctors, more true genuine ability in the ranks of the profession, or a higher tone in all matters germane to the great calling we have the honor to follow. 


\section{FORTY YEARS IN THE MEDICAL PROFESSION}

The great hospital clinics of the decade between 1860 and I870 were held at the Pennsylvania Hospital, at the Philadelphia Hospital, Blockley, and at the University and Jefferson schools. At the University Henry H. Smith held the surgical clinic, and William Pepper, Sr., the medical clinic. At the Jefferson, Gross and Pancoast held the surgical clinic, of course, and Dickson the medical. At the Pennsylvania Hospital there were many bright men and good teachers. There were Pancoast, George W. Norris, William Hunt, Thomas G. Morton, and Agnew as surgeons; W. W. Gerhard, J. Forsyth Meigs, Da Costa, Levick, and others in medicine. At Blockley there were Samuel D. Gross, Agnew, Levis, Maury, Lodge, Kenderdine, and others in surgery; Da Costa, Tutt, Zeigler, and others in medicine; and R. A. F. Penrose and Duer in obstetrics.

The great operations for show clinics of that day were stone in the bladder, the tying of the larger blood-vessels, amputation at the hip-joint, and tumors. I remember well three amputations at the hip-joint by the three great surgeons, Joseph Pancoast, Samuel D. Gross, and D. Hayes Agnew. Pancoast's was the first case, that of a middle-aged woman for a sarcomatous growth of the thigh. It took place in the amphitheatre of the Jefferson clinic. There was a large audience present of physicians and students, and S. D. Gross assisted at the operation. The whole scene was dramatic. Both Gross and Pancoast had something to say. Pancoast's address was quite pathetic: he spoke of the poor woman, the gravity of the operation and its uncertain ending for the patient, said she had seen her clergyman, had had the last rites of her church, and trusted herself to her surgeon and to her God. After the ether had been administered, which was done after the preliminary examination and explanation of the case had been gone through with, the abdominal tourniquet was applied by Pancoast himself. He spoke of its uses, and said, "Gentlemen, there will be no hemorrhage." He then took his place, with nothing but a large scalpel in his hand. Gross stood by him, and Manry had 
charge of the limb. "Now, gentlemen, are we all ready? Maury, you are a good fellow. I depend on you; when I say lift, you lift; when I say lower, you lower; when I say right, move the limb to the right; and left, move to the left." He commenced by making first an anterior skin-flap, then a similar posterior one, then a circular of the muscles, completing the operation by dislodging the head of the femur, without once stopping or laying down the knife. There was no bleeding, and the securing of the vessels and the dressings completed the brilliant operation. The patient made a good and rapid recovery.

Not long after Pancoast's operation, Gross had a similar one in the same amphitheatre. This case was a man with a sarcoma of the thigh of rapid growth. It was near the opening of the session, and was made a grand occasion to give éclat to the school. Pancoast was there, grand and imposing. He said. "Gentlemen, Professor Gross is the hero of this occasion, but while he is arranging his preliminaries I will do a little operation to put in the time." He then removed a tumor from the parotid region in a man, and did it gracefully, rapidly, and successfully. Then came Gross's turn. His case was that of a man of middle age. with good antecedents. Pancoast was near, and his regular assistant, Maury. Gross ordered the limb raised at right angles with the body. Then he massaged the limb to drain it of its blood, then had it bandaged as high as possible, not to interfere with his work. He then, with Pancoast's assistance, applied the abdominal tourniquet. He next took up a large scalpel and made, first, an anterior skin-flap, then a posterior one; next he dropped the scalpel and took up a catling of medium size, made short anterior and posterior flaps of the muscles, and completed the operation by disarticulating the head of the bone with the same knife. There was no hemorrhage. These two cases show the great success of the abdominal tourniquet, with no after ill effect. The vessels were soon tied off, the flaps stitched, with the additional support of a long needle, probably five inches long, run through, then across several inches, 


\section{FORTY YEARS IN THE MEDICAL PROFESSION}

and through again. The dressings and bandages completed the operation, most beautifully and thoroughly done.

I saw something of the after-treatment of this case with Maury. There were no soiled towels or dressings lying around, I assure you, when the old gentleman was expected. The man made a good recovery.

The next case was Agnew's, at the clinic of the Pennsylvania Hospital. I think Pancoast was in Europe then, but Gross and many of the other surgeons of the city were on hand. This case was an elderly man who had been to some extent a drinker. His vessels were somewhat hardened, which made the case a little unpromising. It atso was a case of sarcoma, and was no doubt an operable one. The day before, Agnew had laid out the line of his incisions for the flaps by tracing them with a dampened stick of silver nitrate on the skin. He had the limb raised at right angles to the body and massaged, to empty the vessels, and applied a bandage. This was particularly well here, for there were some varicose veins below the knee. Next he applied the abdominal tourniquet, as was done in the other cases. When everything was ready, he took a large scalpel in his hand. Agnew was ambidextrons, and it made no difference to him which he used. He made his skin-flaps anteriorly and posteriorly, following the lines already laid out. These finished, he opened the sheath of the femoral vessels and tied both artery and vein; then with a catling he completed the operation by making short anterior and posterior flaps of the muscles, and lastly disarticulated the bone. There was no hemorrhage. The operation was completed by tying off the vessels remaining, stitching the flaps, and applying the dressings. The man did well until about the tenth day, when he died of secondary hemorrhage, a result not altogether unlooked for, and from no fault of the operator either during the operation or during the after-treatment. The operation was beautifully done, exhibiting that care and attention to detail for which Agnew was always noted. Two out of three cases successful was a wonderful record in those days before asepsis and antisepsis 


\section{FORTY YEARS IN THE MEDICAL PROFESSION}

were thought of. They were, of course, secondary cases,that is to say, not cases requiring amputation for primary injury. Such cases are very different, and most of them have clied from shock during or soon after the operation. There is one thought comes to me before I dismiss Agnew's case: Did opening up the sheath of the femoral vessels and tying the vessels before completing the operation tend towards producing the secondary hemorrhage? Had the man's bloodvessels been sound, he probably would have recovered, but I believe it better to control the hemorrhage by other means than by preliminary ligation.

I had one primary case with my friend, the late Dr. George Troup Maxwell, of Florida,-a little boy, from a railroad crush. He rallied enough and lived long enough to demand action, but died shortly after the successful operation. I have no statistics at hand, but I think there was one case survived out of a great many in the Crimean War. In the late war of the Rebellion, during the first part of it, a number died after or during the operation. So much was said at the time about these operations that I think an order was issued forbidding them on the field, at least. Dr. Edward Shippen, late of Philadelphia, later on in the war did one primary operation at the hip, and the man recovered, notwithstanding he was banged around in an army ambulance for hours, if not for days, immediately succeeding the operation. To-day, thirty and more years since the time we have been speaking of, with all the improvements in instruments, in technique, with our knowledge of asepsis and antisepsis, and other advantages, amputations at the hip in secondary cases should be, and are, cases in which we may, in a majority of instances, look forward to success, and in primary cases the chances ought to be decidedly more hopeful and operation in more of these cases justifiable, provided always, the loss of blood has not been too great and shock has sufficiently subsided. Wyeth's method is now the accepted method in this greatest of operations, and with the control of hemorrhage, and the rigid practice of asepsis, the mortality must materially decrease. 
FORTY YEARS IN THE MEDICAL PROFESSION

Alfred Stillé succeeded Dr. Pepper as Professor of Practice at the University. He is a most accomplished and scholarly man, and for many years delivered a finished and able course of lectures, both didactic and clinical. He still lives, enjoying a well-earned ease in his old age, greatly respected both as a citizen and as a physician.

Among the clinical lecturers of distinction in Philadelphia at this time was W. W. Gerhard. In diagnosis of diseases of the chest he probably excelled any man in America, and as an author was well known for his writings on this special subject. He was very irritable during his clinical talks, and treated his class much as any old dominie might have treated his boys in school-rooms of the olden time. Edward Peace was surgeon to the Pennsylvania Hospital, and did some skilful work, among other cases being one of ligation of the subclavian within the scaleni. Being a man of means, he retired at an early age from active work. The brilliant John Rhea Barton retired early under the same conditions, which early giving up of professional work caused Gross to speak of him as one of the ablest and most brilliant of surgeons, yet at the same time one of the worst.

Paul Beck Goddard did little teaching in his later days, but he was one of the ablest and most scholarly of all the members of the profession in the country. It was said at one time of Goddard, that he could fill, with honor to himself and with special benefit to the class, any one or all of the seven professorships which then comprised the course of our medical schools. That is to say, he could fill the chairs of Anatomy, Surgery, Practice of Medicine, Obstetrics, Physiology, Chemistry, and Materia Medica, and, I may add, be Demonstrator of Anatomy too.

Addinell Hewson was surgeon at the Pennsylvania Hospital, was a good clinical teacher, and an accomplished surgeon and gentleman. George W. Norris was a surgeon of great attainments, was the great authority on fractures of his day, and lectured regularly at the hospital. The Pennsylvania Hospital had an immense amount of clinical material in 
fractures, and it was a treat to have Norris take up this subject for a clinic.

I have already spoken of WVilliam Hunt. His friend and companion Thomas G. Morton still lives, having served as surgeon of this hospital for more than thirty years. A wonderful service in years, and what an experience to a man! what a mine to work! Morton has not failed to work it. He is to-day one of the great surgeons of the world, whose brilliancy, rapidity, and dash are excelled by none. Oh, for a record of such a life work! such a record as Ian Maclaren or a Conan Doyle would write,-the joys, the sorrows, the struggles for life, the triumphs and the disappointments, the sunlight, the gloom, the pathos, the joy, coming and going. day and night! We all get weary of the heavy work, the heavy scientific literature of the profession. To come home weary, possibly irritated, possibly grieved, to sit down to such a character as Doctor MacLure, is positive rest for mind and body wearied by unceasing toil; and what a rest would it be to peruse at such times a record of over thirtyfour years of a surgeon's experience in a great hospital, told by some gifted man!

John Forsyth Meigs was a regular lecturer at the Pennsylvania, a son of the great obstetrician Charles D. Meigs. John Meigs, as he was always spoken of, was a very busy man; in fact, much of the time overworked, from his immense family practice. He was a great authority on children's diseases, as his well-known work on that subject attests. Ellwood Wilson was his friend and frequent consultant in private practice, with an enormous obstetric practice, and was a man of great skill, had abundant success, and, like Meigs, worked nearly to the day he died.

William H. Pancoast was a bright, pleasant man, a son of the great surgeon, who at times lectured acceptably and afterwards succeeded to his father's chair of Anatomy in the Jefferson school: afterwards resigning this chair and going to the Medico-Chirurgical College, where he was actively employed until he died. 
Edward Hartshorne and Henry Hartshorne were proninent in the profession in Philadelphia at this time, the one a surgeon and the other a well-known lecturer and author. D. Francis Condie was also known favorably in diseases of children. on which subject he wrote a very elaborate work and edited Sir Thomas Watson's "Practice of Physic."

Among the greatest of the great names in surgery of the early period of forty years ago is that of Waslington L. Atlee, a worthy follower of his great prototype, Ephraim McDowell. Atlee was one of the great pioneers in ovariotomy when he was struggling to give the operation a substantial basis on which to stand as a justifiable proceeding. I have heard the operation denounced from the amphitheatre of one of the great medical schools as next to murder, and the man who performed the operation as little less than murderer and little more than fiend. Atlee continued on in his heroic struggle, exhibiting all the attributes of a great and fearless man, working to the very day of his death. His death was pathetic, but worthy of the great man he was. $\mathrm{He}$ knew he had malignant disease of the stomach, and when scarcely able to support himself he left his home. went to the house of a patient at a distance, and returning to his home exhausted, he died.

"Like one who wraps the drapery of his couch about him And lies down to pleasant dreams."

Equally eminent in surgery and gynacology was his distinguished brother, John Light Atlee, of Lancaster. One cannot mention the name of either of these two great men without thinking of the other. The Atlees were a family of doctors, and they have all been distinguished men. WValter Franklin Atlee, of Philadelphia, child of Lancaster's great son, still lives, a worthy successor of his father and uncle. As a general surgeon he has been eminently successful, and as a gynæcologist, in the days when it required all the force, all the strength, and all the powers of a man to be a gynæecologist, he was the peer of any of them. Until time shall be no 
more, no woman should pass the grave of an Atlee and fail to drop a tear upon his tomb.

Forty years ago in Philadelphia there were few specialists. In the eye, Dr. Isaac Hays and Dr. Littell did little or no other work. They were both very eminent men of their day, and Dr. Hays was a very scholarly man and cultivated gentleman, and edited until his death, the, at that day, great American medical journal, the American Journal of the Medical Sciences, or, as it was always better known, "Hays's Journal." All the general surgeons like Pancoast, Gross, Agnew, Morton, Hunt, Levis, and others, did eye-work. Ezra Dyer came to Philadelphia, fresh from Von Grafe's clinic in Berlin, and soon established a large practice. $\mathrm{He}$ was followed by George Strawbridge, a most accomplished oculist and eye surgeon, still doing good work. Dr. Charles H. Burnett left the Philadelphia schools, went to Europe, and returned to Philadelphia, where he has since worked successfully, and is to-day one of the world's great authorities on the human ear.

In medicine, few of the contemporaries of the elder Pepper and Stillé survive. Da Costa is probably the nestor, a great didactic and clinical teacher, a most accurate diagnostician of world-wide fame. May he live many years to enlighten the profession he has served so well and done so much to adorn. James Tyson, the Professor of Clinical Medicine at the University of Pennsylvania, is a wonderfully active man in the profession, both as teacher and practitioner, and so is Horatio C. Wood, the Professor of Materia Medica. All of these men have done great and creditable literary work, and upon their shoulders in Philadelphia, together with D. F. Woods, Woodbury, I. Minis Hays, Henry, Stengle, Taylor, Hare, Starr, Cleeman, Ingham, Daland, Anders, Chapman, Gittings, Wistar, James C. Wilson, Arthur V. Meigs, and Musser, distinguished authors and teachers, Wallace, Stryker, Hickman, Cadwalader, Cheston, and others equally well known, have fallen the mantles of Chapman, Mitchell, the Peppers, and other renowned men. These mantles they will 


\section{FORTY YEARS IN THE MEDICAL PROFESSION}

worthily wear until the cycle revolves again, and others, now unknown, shall fill their places; and so the cycle will revolve until time shall be no more.

John Ashhurst and J. William White now stand, by reason of age and ability, with Morton and Keen and Brinton at the head of the list of surgeons. Ashhurst and White are professors of surgery at the University, and Keen and Brinton at the Jefferson school, and each maintains the ancient prestige of these two great colleges. There are many bright and able surgeons, younger men, in the city, most prominent among whom are Henry R. Wharton, teacher and author; Allis, Packard, Mears, Roberts, Simes, Martin, S. Ashhurst, Hearn, Deaver, T. S. K. Morton, Porter, Barton, La Place, Willard, Dulles, Harte, Le Conte, and McCleilan, distinguished author and teacher.

Among gynæecologists are Baldy, author, teacher, finished diagnostician, and operator; C. B. Penrose, at the head of his specialty at the University; Girvin, Duer, Price, Montgomery, Shoemaker, Hirst, Professor of Obstetrics at the University; Davis, of the Jefferson school; Noble, Baer, Woods, Kruser, Ashton, and others well known.

On the eye, ear, and throat are Harlan, Norris, Oliver, Gould, a most accomplished man; de Schweinitz, Cohen, Randall, Stout, Risley, McClure, and many, many more. Not long ago you could count the eye men on the fingers of one hand; now they are very numerous, and still increasing, and so is the good they are doing, for in eye troubles great advances have been and are being made. Philadelphia lost two of her brightest and brainiest men when Osler and Kelly went to Baltimore, where they are now doing great work, and with Halsted, Welch, and others are rapidly establishing at Johns Hopkins one of the great medical centres of the world.

In forty years the knowledge of the pathology of and treatment of diseases of the skin in America has made great progress. It was only taught casually in the schools until recent times, and little attention was given to cases, even in clinics; in fact, I don't think teacher or pupil knew much 
about them. During and after the war of the Rebellion skin troubles increased greatly in America, and are now, as we all know, quite common. Dr. L. A. Duhring took up the subject as a specialty early in his professional life, and now has a world-wide reputation. Dr. Arthur Van Harlingen and Dr. John V. Shoemaker are known experts in this specialty, whilst Dr. Henry IV. Stelwagon is particularly well known as both author and teacher. In nervous diseases there are Mitchell, father and son, Sinkler, Mills, Chapin, Dercum, Martin W. Barr, Horatio Wood, J. Madison Taylor, and others. It was at first not my intention to speak of the living in these articles, but among so many distinguished names it is impossible to forbear mentioning a few.

In the decade between I860 and I870 the hospitals in Philadelphia were sufficient for the needs of the people, and were well conducted. The Pennsylvania was the great surgical institution, and probably had the best medical wards. Blockley was a great obstetrical and venereal school, besides having a profusion of general practice. The Episcopal was a fine hospital, and so was St. Joseph's. Wills Eye Hospital was devoted especially to diseases of the eye. During the war the government established a number of large hospitals in Philadelphia for sick and wounded soldiers, and they did great and good work. These were the West Philadelphia, the South Street, Nicetown, Fifth and Buttonwood, Broad and Cherry, Turner's Lane, Chestnut Hill, and the United States Army Officers' Hospital, at Camac's Woods, now Eleventh and Berks Streets. Everybody took an interest in these organizations, and among the surgeons in charge the names of Camac, Hopkinson, Le Conté, S. W. Gross, and John Neill, one of Philadelphia's most noted anatomists and surgeons, are well remembered. William Camac, M.D., did a great work in this service. He, at his own expense, converted the old family homestead at Camac's Woods into a delightful home and hospital for sick and wounded officers, and through the many dark days of the war worked and watched, relieving the suffering of the many unfortmnates there committed to his care. 
In October, I864, I was elected one of the resident physicians of the Philadelphia Hospital, Blockley. I had been in the medical corps of the United States army since I862, and was glad to avail nyself of the great resources of Blockley for clinical experience. This hospital was the refuge for the indigent sick and indigents generally of Philadelphia City and County. There were about three thousand patients within the walls, six hundred being on the insane side, an entirely separate department. The institution was governed by the Board of Guardians of the Poor, and had a complete organization, which was more or less political, but at that time was composed of very good men and free from the scandals that had some time previously clustered around it. The practice there was interesting, and I soon learned one fact,- that the habitués of almshouses and prisons, as a rule, being accustomed to over-stimulation in all of its phases, withstand knock-out doses with great impunity, and the dosage common among these classes is no safe criterion for dosage in private practice. The under employees were taken from the inmates, as a rule, and whilst many of them were good servants, they were, as a class, moral imbeciles, and I doubt if the employment of such in such institutions is economical either to the municipality or to the State. Now, since the introduction of the trained nurse into the profession, a wonderful change for the better has come to such places as Blockley, and one who was there in the olden time, and seeing the order, attention to detail, and perfect discipline of the corps of wellbred, well-trained women ministering to the unfortunate sick there to-day, cannot help but note the contrast and appland the modern methods and modern ideas.

The clinical material of every class of disease available at Blockley was enormous. There were the old men's wards, the old women's wards, the children's asylum with its wards for the sick, the men's and women's medical wards, the male and female surgical wards, the male and female venereal wards, the obstetrical wards, and the Department for the Insane. There were generally two visiting surgeons on duty, 
one taking the surgical and the other the venereal wards. One medical man was generally on duty at a time, and continued for three months; and so in the obstetrical wards. Dr. S. W. Butler had charge of the Insane Department, with Dr. Sparks as assistant. The services of these gentlemen were continuous. Outside of the Department for the Insane there were eight resident physicians, so arranged that four new men came on in the spring and four in the autumn. In the venereal wards I served as resident to Professor Gross. He took great interest in this branch of the profession, and was a dualist subject to conditions, as syphilographers were divided in those days. His distinguished colleague in the hospital, Agnew, was a unicist, but I thought at the time was weakening a little in his belief. Dr. Gross was a strict disciplinarian in his wards and clinics, was rather fond of a joke at the expense of his patients, and when the old gentleman commenced to whistle in a whisper and kick an unoffending towel across the ward, somebody might expect to hear from him in an emphatic way. He was always most dignified and courteous in his clinics, a gentleman of the old school par excellence, and was fond of making his residents assume responsibilities, as for example, when about to amputate a leg, he would often give the tourniquet a toss to one side and call upon one of us to hold the femoral artery with the thumb. At such times he did rapid work, but if some rebellious vessel caused delay in its ligation the luckless resident at the femoral had his own troubles, I assure you. As a recompense and compliment, after the operation had been successfully brought to a close, the old gentleman, drawing himself to his full height, would turn to the class and say, "Gentlemen, with competent and intelligent assistants, a surgeon can do almost anything." In the surgical wards I served with Agnew. Oh, Agnew was a lovely man! No wonder students admired him and so many of them came to him for advice in their professional work. I have seen him under all conditions,-in his work in the dissecting-room, at his home, in his hospital work, in his clinic. I never saw him ruffled or excited, I never saw 


\section{FORTY YEARS IN THE MEDICAL PROFESSION}

him rude to the most menial of those about him, and I never saw him cross with a patient. He was very attentive to his wards and to his hospital duties, and of course his work was done as few but he could do it. He was kind and considerate to his residents, and took pains to teach them and give them a chance. He has more than once said to me, when cases involving considerable were in the wards, "Now, you take this case; you can do it, and doing it will help you at some later day in your work."

I went through the obstetrical wards with Dr. R. A. F. Penrose as chief. Penrose was thoroughly up in his specialty, and this was before the days of his professorship at the University. He was most considerate and kind to his residents, and took great pains to teach them. I know I was under great personal obligations to him, and when I left his wards I had done over and over again many of the important operations, such as application of the forceps, etc., which served me well when thrown on my own resources in after life. Edward L. Duer, the accomplished accoucheur and gynæcologist of Philadelphia, was one of the visiting obstetricians, and so was Frank F. Maury, but he resigned and took the first vacancy in the surgical wards. Maury was a bright man of delicate physique, was assistant to Professor Gross for a long time, and could do anything in operative surgery he had ever seen Gross do. He obtained a good practice in general surgery, but was particularly well known as a specialist in venereal diseases. His health failed, and he died a comparatively young man.

Richard J. Levis had the surgical wards during the summer term, and therefore had no class for clinics. He was a mastery in surgery, and was a master mechanic, and his lecture on Surgical Emergencies should be read by every one. If Levis was caught in an emergency without an instrument he could do more than any man I ever knew to supply the defect then and there. As an operator he covered all the domain of surgery, from a hip-joint case to the most delicate operation on the eye. He did little literary work, and the 


\section{FORTY YEARS IN THE MEDICAL PROFESSION}

result of his labors was mostly buried with him when he died.

Da Costa had charge of the medical wards, and gave his clinics twice a week. He brought to bear in his work at Blockley the same great ability he has always exercised, and did great work for both students and patients. Dr. Alfred Stillé was also a visiting pliysician, and was scrupulously careful and exact in his work. Dr. Ziegler had the medical wards in summer, and of course held no clinic. Dr. Charles Pendleton Tutt, a most industrious and painstaking physician, was another of the visiting physicians. He had ward classes of students in the spring, and whilst devoting himself assiduously to this work took typhus fever, from the contagion in his own wards. I remember sadly his terrible illness. Dr. Francis Gurney Smith was his physician, and the present Professor Tyson, of the University, Dr. D. F. Woods, and myself took care of him. He died at his home in Philadelphia, opposite the United States Mint, near Broad and Chestnut Streets. I mention this case here to show the changes that have taken place since that time, I865, I think it was. Here was a case of that most loathsome and contagious disease, typhus fever, in the very midst of the best part of the city. There was no restriction as to those coming and going from the house. We who were in attendance even did not take any, or, if any, very few of the precautions we would take to-day. The funeral was not private, any one going who was inclined. I do not remember that any one took the fever from this case. This exemption was surely due to the kindness of an overruling Providence rather than to any human agency.

Now, as to typhus fever, this plague of Athens. In the winter of $1864-65$ we had a serions epidemic of it inside the walls of Blockley. In those days, in those old out-wards, the homes of the indigent, it was like poverty, "always with us," and likely to break out whenever the host was available. When I think of how we treated such cases, as to environment, etc., I wonder we did not all die. Indeed, I wonder we were not all executed by judicial hanging, for I reckon we 
FORTY YEARS IN THE MEDICAL PROFESSION

should have been hanged anyhow, but the good old hymn very truly says,-

"God works in a mysterious way,

His wonders to perform."

In those days we thought a sick man should be kept well housed and warm, no difference what the trouble. Many and many a time I have gone personally into the alcoves or dens in the out-wards, which the old paupers loved to think of as their own home, and dragged out the inmates, covered with the typhus rash, with a temperature high enough to almost burn one; and then the sickening, mousy odor! They were sent at once to the general medical wards and treated there; think of it! Dr. IVilliam H. Ford, my dear friend, who since that time has done so much noble, able, and disinterested work, which rork only stopped the day death overtook him, was one of the resident physicians. As President of the Board of Health of Philadelphia for many years, by his unceasing care and vigilance he has made all such diseases as typhus fever impossible of spreading in epidemic form in the great city, and this work has all been done within a few years. During this epidenic in Blockley I remember one of the great surgeons amputating a colored woman's arm above the elbow. I had care of the after-treatment. On the third day she developed typhus fever; she was kept in her bed in the ward, treated there. and died there. She was taken to the deadroom after death. I posted her, using only ordinary precautions. The only extraordinary precaution we used was that no subject dead of a contagious disease went to the anatomical rooms of the medical schools. The fever went on through the winter; none of the physicians took it until Dr. Tutt in the spring, but many patients and a number of nurses succumbed. After the warm weather came and the buildings were opened up, and the gentle breezes and heavy gales of spring went through the wards, the typhus contagion (we are not sure to-day of its exact nature, although it is probably zymotic) went ont at the windows, and this is how the great epidenic of $186+-65$ left Blockley. Let it return $110 \mathrm{w}$, we 
have all grown in knowledge and prudence, and we would welcome it as the unpatriotic old Whig, Tom Corwin, wished the Mexicans to welcome our troops going to Mexico in the war of I $847,-$ " We would welcome it with bloody hands to hospitable graves.'”

Among the resident physicians was John S. Parry, an original thinker and one of the brightest of men. He has left the profession a classic in his work on "Extra-Uterine Pregnancy," good authority to-day, twenty-two years after his early death, which took place in Florida in 1876 , of consumption. Among the other residents were Dr. William H. Wallace, now a prominent practitioner in Philadelphia; William H. Helm, now of Sing Sing, New York; William McClure, the well-known oculist; C. E. Smith, of St. Paul; R. Stansbury Sutton, the well-known gynæcologist of Allegheny City; Dr. H. IV. McCoy, of Indiana; Dr. Robert Miller, of Kentucky; and Dr. Sparks, of Philadelphia. At that day the organization of the hospital, as far as using the vast amount of clinical material at hand was concerned, was very incomplete; the residents were kept busy, but the pathology was not worked up in any way approaching completeness, and it was sad to see the waste of so much grand material which could have been made so useful. Even in those days, in advancing the science of medicine and in educating those in the profession, both old and young, this lack of organization for work was apparent in the profession in general in Philadelphia. It was rare that a proper interest could be gotten up in the general meetings of the College of Physicians or of the Pathological Society; even if a lecture by some bright man should be announced on some interesting subject, those interested quaked with fear lest no appreciative audience might be present to encourage the lecturer. Professor Gross was one of the most regular attendants and workers at these meetings, especially at the Pathological Society. He was greatly interested in pathology, had written on it, and more than any teacher of his day impressed its importance upon his hearers. 


\section{CHA P T ER I T.}

Started for Liverpool in a Sail-Ship-Tornado-Narrow Escape and Return to New York-Better Success by Steamer-Paris in I866The Hospitals-The Doctors-Velpeau, Jobert de Lamballe, Nélaton, Ricord, Sichel, Charcot, Trousseau, Liebreich, Pasteur, J. Marion Sims-Napoleon III. and why he failed-Tone of the Profession in Paris-London-Sir William Ferguson, Sir Thomas Watson, Sir James Paget, and Others-Edinburgh-Simpson and Syme-Ether and Chloroform - Berlin - Von Langenbeck - Frerichs - Vienna Clinical Schools and Lectures-Billroth, Skoda, Oppolzer, Türk, and Others.

In I866, not being in robist health, having been engaged in private practice in Philadelphia, I went to Europe for the dual purpose of recuperating and studying some of the foreign methods then in vogue in medicine.

I determined to try a voyage longer that the usual steamer run of a few days, so took the American clipper ship Emerald Isle, Captain Eves. I remember embarking at the Battery and being rowed by one of the harbor boatmen in a small boat to the ship, anchored away down towards the Narrows, in the upper bay. There was an easterly storm blowing then, which increased hourly, and held us at our anchor unable to proceed for a week. We had all sorts of adventures, being fouled by other vessels carried from their moorings. At last the wind backed around to the west, and on a Sunday morning the captain came down in a tug, and we were soon under way. I remember the third mate, a rattling little Irishman, made the remark that we were going to sea under a bad omen,- - the wind had gone around the wrong way, had backed around. and would soon come back to the storm quarter again and give us hell, as he expressed it, in a way more emphatic than elegant. Mr. Kelly was right, the storm did return, and we had a week of terrible blows and hurricanes, at the height of which our ship sprung a leak, was thrown on her beam ends, leaked badly, with four and a half feet of water in her hold, 


\section{FORTY YEARS IN THE MEDICAL PROFESSION}

all her pumps choked with grain from the cargo, and nearly every sail blown from the bolt-ropes. A sad plight to be in, surely. It was not my first experience at sea, but it was my worst experience.

Nowhere can a man feel more utterly hopeless and dejected than under such conditions, waiting every moment for his ship to sink under him. Even here the doctor comes in, as he so often does in forlorn hopes. The steward was an old packet rat, a middle-aged man, who had been to sea all his life. During the height of the gale he was very, very seasick, and, to use a sailor's expression, had thrown up everything but his boots, cursing and swearing at a terrible rate all the time. In the midst of one of his worst paroxysms I heard the captain call out to him, "Steward, let up there! we are in rough times; you don't know where you may be this time to-morrow. I will send the doctor to you." I heard him yell back, "Captain, I don't care a $d-n ! d-n$ the storm! d-n the ship! d-n the doctor! I ain't afeared to die. I don't want to live." This shows the horrors of sea-sickness, and that there are times in one's life when even doctors are scorned.

After several days the gale abated, and the pumps were cleared, enabling us to keep down the water. I will never forget the lovely morning when the sun came out, giving us summer temperature, with only a gentle tropical breeze. The ship lay there with scarcely a sail intact, listed very far to starboard, and every one utterly exhausted. The captain talked the matter over with me and the first officer, and we agreed that every man possible should have six hours sleep. The first officer remarked, rather cheerfully, that if the wind came out " norwest" we would never get back to New York, and the ship could never go to the other side in her present condition. The captain said we were two hundred and forty miles from Sandy Hook, and he would endeavor to get her back there as soon as possible. After a rest to the crew, every one was put to shifting the bags of corn between decks to the port sirle. which had the effect of easing the ship up a little 


\section{FORTY YEARS IN THE MEDICAL PROFESSION}

towards an even keel. After some new sails had been bent, we started back, took a pilot next day, and soon a tug appeared and took us to about the same anchorage in New York Bay we had left a week before. I returned the life-preserver Captain Eves had kindly strapped on me, and with a light heart said good-by to him and his crew.

As his ship would probably be delayed a month before sailing, I secured passage in the Arago, Captain Gadsden, a first-class wooden side-wheel steamship. I had a lovely voyage, meeting several old friends, there being only eighty firstclass passengers and none others. The ocean during the whole trip of fourteen days to Havre (you modern traveller. think of fourteen days to Europe!) was as calm as a river. and at no time on the royage was there an hour we would not have been safe in a battean alongside the ship. This proved the old sailor's advice correct,- when you are ready to go to sea, go; don't wait for weather: you can never tell what is coning.

We got our first glimpse of England in Falmouth harbor, where we arrived early in the morning, and crossing the channel, passing close by the celebrated Eddystone LightHouse, we arrived at Havre in due time, and entering the locks were hoisted up into that wonderful artificial basin, the harbor of Havre, large enough to hold five hundred ships the size of the Arago. Through Normandy, with a short visit to Rouen, inspecting the great Cathedral and the scene of the burning of Joan d'Arc, we were soon in gay and lovely Paris. After looking around for a few days, paying visits to friends and delivering letters, I soon took up the object of my visit and began to look up matters pertaining to medicine.

These were the days of the second empire, and Loutis Napoleon was at the very acme of his power. All this had its effect upon medicine, and only those in favor of the ruling power could expect positions of emolument and distinction.

The most striking character I met in Paris, and the one who impressed me most among medical men was Velpeau, Alfred Armand Louis Marie Velpeau. I suppose one reason 
of this was that in my day students probably heard most frequently the name of Velpeau, of all foreign doctors, for he was great and eminent in two great specialties, surgery and obstetrics; in fact, he was a great all-round man in the profession. He was of obscure origin; in other words, entirely a self-made man. I first saw him in the wards of La Charité, busy, going around among the beds early in the morning, with a number of students with him. He was rather a tall, spare man as I remember him, in ordinary dress, the top of his head adorned with a green velvet skull-cap, which he always wore during his hospital work. He had a note-book and pencil in his hand, in which he took copious notes as he proceeded on his rounds. The old gentleman was generally good-natured, often joking, yet a strict disciplinarian. $\mathrm{He}$ was at this time seventy-one years of age. When he was thirty-five he was surgeon at Pitié, and worked until he died, August 4, I867.

Jobert de Lamballe was another interesting character and great surgeon, with an especial reputation in plastic operations. He was a very rapid operator. It is said of him that when everything was ready for a shoulder-joint operation in his clinic, he would pick up a knife, count, with deliberation, un, deux, trois, and the disarticulation was accomplished in three movements of the knife. He was an irritable old fellow, always ready for a fight, as were most of the Paris doctors, and it was not uncommon for one great surgeon, when lecturing before a class, to speak of some other great surgeon as "the little butcher around the corner." I saw little of Jobert de Lamballe, as he had about given up work, and died in a year or two after this time.

Auguste Nélaton was probably the most popular surgeon as a practitioner at this period in Paris. He was an elegantlooking man and a most accomplished gentleman. A Parisian by birth, he was a pupil of the great Dupuytren. $\mathrm{He}$ wrote little, but was for a long time Professor of Clinical Surgery. Later he was made a senator of France, and was a member of the Academy. All of these honors were showered 


\section{FORTY YEARS IN THE MEDICAL PROFESSION}

upon him out of the gratitude of Napoleon III., whose friend and surgeon he was. Nélaton was a very able and capable genito-urinary surgeon, and a man of great mechanical ingenuity and resources, as his celebrated Garibaldi porcelainpointed probe attests. Speaking of the friendship of Napoleon III. for Nélaton brings up a matter in which these great men were actors, and which I have always believed was a great factor in the downfall of the unhappy emperor, and had very great possible effect on the modern history of Europe. The matter I speak of came to me very directly from professional sources. Napoleon III. had suffered for a long time from organic stricture of the urethra and its attendant tronbles. Nélaton was his surgeon, and when he was about fiftyfive years of age Nélaton was compelled, after having done many minor operations, to make a very complete and radical operation and form practically a new urethra. Any one familiar with such operations, and with the conditions before and after such operations, knows too well the sufferings attendant upon such an existence. Probably for ten years previous to his downfall Napoleon III. was a terrible sufferer, and doubtless could give little thought to the details of statesmanship or government. Those around him became corrupt, the whole administration of the government became corrupted, and when he, with the puny will and sickly judgment of one weighed down with all the cruel sufferings such as he sustained, led poor France into the Franco-Prussian War, then, and not until then, did the truth dawn upon him of the absolute hollow rottenness of his govermment and, as a natural result to all this, the thorough inefficiency of his army. The sorrowful surrender at Sedan marked the downfall of this unfortunate man, and his death at Chiselhurst, England, in January, I873, whilst undergoing the operation of crushing for stone in the bladder, under the direction of, and by the skilful hands of, Sir Henry Thompson, only confirms the view I have here given of his case, and shows that his horrible vesical sufferings pursued him, beaten, humiliated, and exhausted. to the very brink of his grave. Nélaton died in 


\section{FORTY YEARS IN THE MEDICAL PROFESSION}

Paris, in September, 1873, only a few months after his great benefactor.

Malgaigne, one of the greatest of French surgeons, died about this time. He is best remembered to-day as the introducer of Malgaigne's hooks for holding together the divided fragments in fracture of the patella, an instrument which has not met with great favor by the profession, but in the present days of antisepsis is less dangerous than formerly.

Civiale was a great authority also in Paris at this date, I866. He worked persistently and intelligently, opposed by Velpeau, Nélaton, and other great surgeons, on his hobby of crushing stone in the bladder, instead of cutting for it. He perfected his lithotrites and other instruments, and has his justification to-day; and were he alive he would see his operation an unqualified success, without limitation as to years or sex, and, with the improvements of Bigelow, the American surgeon, and others, see still greater triumphs in the immediate evacuation of the débris.

Cloquet was a well-known surgeon, and perhaps the best anatomist of his day in Paris.

Philippe Ricord was the great authority on venereal diseases, and although born in Baltimore, Maryland, was a true Parisian. He served at the Hôpital du Midi and was wonderfully active, a great experimenter, not sparing even himself. He was now well on to seventy years of age, still active, with an enormous clientele, as the great authority of his day on his specialty.

On the eye, Liebreich was the man I saw most of, and probably had the greatest reputation at the time, although I think Sichel, whom I never saw to know, had been for years the great oculist of the city. I saw Liebreich operate a good deal, and he was very expert. He appeared to seek and do a great number of operations for strabismus, and always sutured the conjunctiva with very fine silk. I thought the after-effects were bad, and I imagine he did not keep it up. With aseptic precautions sutures might do better. Liebreich was a tall, spare man. of very dark complexion and very black 
hair; he looked like a Spaniard. He probably came from over the Rhine, or very near it. He was not a Frenchman, and I think was compelled to leave Paris in a hurry when the Franco-German War came on. I think he went to London, but I am not sure.

As every one knows, Paris is full of hospitals, and presents the greatest advantages for clinical study. As I remember them, La Charité and the Hôtel Dien were the great and interesting ones. They were internally very old and ramshackle in their appearance. They were kept scrupulously clean. but there appeared to be plenty of harbor for rats, mice. roaches, and other vermin. Their organization was superb for that day, and their great advantages were not allowed to go to waste, whether clinical, pathological, or histological. I remember Fournier and Logier as great hospital workers, and they rarely visited the institutions without spending some time in the dead-house.

Trousseau died in 1867 , and to the day of his death was the great physician of Paris of his time. He made a great specialty of diphtheria, and worked up tracheotomy as no other man had done before him. He was a tremendous worker, was Professor of Therapeutics, and worked up paracentesis thoracis in chronic plenritic effusion, besides all troubles connected with the windpipe. Claude Bernard was the great physiologist of this time, and was an indefatigable and original worker and experimenter: indeed, no man approached him in his special lines. He died in 1878 , when experimental physiology lost her great and shining light. Dr. Campbell was the great obstetrician of Paris, and Dr. Beylard, who came from Philadelphia, was the favorite physician of the American colony, and was a great and good friend to me during my residence in the city.

One of the most interesting times Paris has ever seen in her medical history was upon the advent of the great surgeon, J. Marion Sims, within her borders in r86I. No man doubts to-day that Sims was a great man; no man doubts that he was one of the great men of the world: and no man, 


\section{FORTY YEARS IN THE MEDICAL PROFESSION}

if he be true to himself, doubts that Sims was one of the chief founders of the art of gynæcology, and almost personally and absolutely the founder of plastic gynæecological operations. I doubt if the tone of the profession in Paris was ever good. The whole business always has been constantly riddled with professional jealousies and hopelessly divided into cliques of the most ultra and inharmonious natures.

The causes of this state of affairs are easily to be seen when one makes a study of the conditions. The divisions into cliques is the first cause, and these cliques are intensely jealous of each other, and let pass no occasion to abuse each other, even in the public lecture-halls. Next, the individuals abuse each other, and they carry these personal quarrels with them in their daily rounds, and retail them to their patients, and thus the patients, becoming imbued with the scandals, retail them to their friends; hence society in Paris is full of the medical scandals of the day. They gloat over them, and of course the scandals gather as they go, and it is a common thing to hear details of Dr. So-and-so's great and successful operation, and of Dr. Somebody-else's lamentable failure under like conditions. When Sims entered Paris the tongues began to wag. His fame had preceded him, especially as to his success in vesico-vaginal fistula. There were cases in Paris, in fact, all over France, where Nélaton had pronounced cure impossible, where Velpeau had seconded Nélaton in a like opinion, and, more than that, where Jobert de Lamballe, the great plastic surgeon of the French, had failed ingloriously. Sims took up these cases, and in the presence of the great lights, Velpeau, Nélaton, and others, operated on them and cured them. It was a great trimmph for Sims, a great set-back for the boasted priority of French surgery. Although they had to recognize Sims and his great successes, they continued to belittle him and abuse him.

I remember one night attending a large private dinner of gentlemen, composed chiefly of those who were permanent resiclents of Paris, belonging to the so-called American colony. As is usual on such occasions, the rows among the 


\section{FORTY YEARS IN THE MEDICAL PROFESSION}

French doctors came in as part of the conversation. Sims came up among others. The guests appeared to be mostly in favor of the Parisians; few said anything in favor of Sims, but now and again one would quote something. Velpeau had said slighting him, or something Nélaton had said. I remember one man particularly, who said that a few days before he had casually met Ricord coming out of a hotel, that Ricord had stopped him, asking, "And do you know our friend the new American Dr. Seems? Who is this Dr. Seens, anyhow?" The only real friend and defender Sims appeared to have among the local guests was one gentleman who defended him lustily, and Mr. Pepper, who sat next to me, told me that some time before Dr. Sims had performed an ovariotomy on his wife, to which operation she had succumbed, and, he added, he loved her dearly, too.

In those days Paris was a superb place of residence for a foreigner, so clean, so thoroughly policed, and very inexpensive. You could live as a prince and be thoroughly comfortable, and be equally as comfortable, only less luxurious, on a few francs a day. So long as I remained there I never saw any trouble, such as brawls or street rows, and the only really drunken man I ever met was the man who undertook to drive me to the station on my final leave-taking for London. I sent for a cab, and when it came I got in with my luggage, not noticing the driver more than to tell him where to go. Soon I found myself in a trench on the Boulevard. Fortunately, I was on top, the driver and horse under me. In a few moments I was quietly lifted out, and soon after me the driver. helplessly drunk, as I saw, the cab and horse being reserved for a proper lifting apparatus, which soon arrived. No crowd was permitted to gather; there was no noise, no confusion. In a few moments an officer gently tapped me on the arm, pointed me to a fresh cab, where I found my luggage all safe, and was soon on my way to the station again. Thus I celebrated my departure from enchanting Paris, and with fond anticipations of my visit to merry England. I was soon on my way to the channel. 


\section{FORTY YEARS IN THE MEDICAL PROFESSION}

At this time in England, I866, London was supposed to have the best physicians in all Europe, and to Paris was given the pre-eminence for surgeons. When we come to review the list of surgeons in England and Scotland and Ireland, such a review does not appear to strengthen this claim: Sir William Ferguson, of London, was the peer of any man of his day, and in some of his special plastic operations was probably unequalled; Sir James Paget, the great authority on surgical pathology; Bowman, undoubtedly the most skilful operator on the eye of his time; Annandale. Heath, Hewitt, all great surgeons; and last, but not least, Mr. Lister, then of Edinburgh, afterwards Sir Joseph Lister, and now Lord Lister, of London, the great apostle of antisepsis, whose wife did so much to help him in his work, a daughter of the great James Syme, and who lately died, leaving her famous husband bereft and inconsolable; Toynbee and Wilde, the great aurists of their day: Syme, the wizard of Edinburgh; Sir James Y. Simpson. his great antagonist, unapproached in his day as an obstetrician, gynæcologist, and surgical specialist, and inventor, too: Lizars: Matthews Duncan, student of Simpson; Sir Spencer Wells, and other noted names by the dozen, show the English people to have been no laggards at that day in the world's race for surgical honors.

Sir Thomas Watson, the nestor of the London physicians, honored by royalty and plebeian alike, lived almost a full century, and gave to the profession a monumental work in his "Practice of Physic," which for lucidity of thought, beauty of expression, and as a specimen of finished literary style and pure Anglo-Saxon English, has been rarely approached and surely never excelled by any work in medical literature. Coming after IVatson, the names of Jenner, Gull, Garrod, Todd, Thomas King Chambers, Fothergill, Clark, and scores of others attest her claim as a centre of medicine and medical science. At this date, the names of Tyndall, in England, and Pasteur, in France, were comparatively little known, and Koch was probally a child in kilts. Since that time these men have grown to be giants, and the great Pasteur has 


\section{FORTY YEARS IN THE MEDICAL PROFESSION}

passed away to join the silent majority. Whilst Tyndall is great, whilst Koch is great, Louis Pasteur was the greatest. to my mind, among all scientists of his class who has yet lived. Think of what this man has done and what a pioneer he was! No one had blazed the way for Pasteur in his great experiments, and no one has approached him in the good done to mankind, for, even without Pasteur's work, I doubt if to-day we would have been advanced to the point we are in antisepsis and asepsis. No wonder France is proud of Pasteur, and has done great honor to his memory. He saved her industries and almost her very existence in his combat with and investigations into the silkworm disease. He found the moth with the concentric rings to be the cause of the trouble; destroy these moths, destroy their eggs, said Pasteur, and the silk industry was saved to France. He did equal service in his investigations into the fermentation of wines, destroying the germs by high temperature. So with the anthrax pest, so with the diseases of the vines, did he wrestle and conquer. But above all these, oh, that great boon to those unfortunates who have suffered from the bite of the rabid animal! Oh, the pangs, the horrors, the terrible forebodings these poor unfortunate people suffered before this work of Pasteur with the virus of rabies! His methods, his careful workings, his results, almost approach inspiration. At this work, after these results, even there are scoffers, those who say there is no such disease as hydrophobia in a human being. Away with such! I have seen it: I have seen it in man approaching old age; in man in the vigor and strength of youth: yes, I have seen it in a little child, who never gave a thought to his condition after the first pain of the bite subsided, and who never even knew he had a nerve or felt a nervous twang: in his short life. Yes, there is such a disease as hydrophobia; it has been proved bacteriologically from the human being to the lower animal, and that ends the discussion.

The utility of Pasteur's treatment is now generally acknowledged; even the Germans acknowledge it, and have established centres for carrying it out. Hydrophobia is the 
disease in man communicated to him by a rabid animal. Rabies is the same disease in the lower animal, or supposed to be. Both are infectious, although the micro-organisms of neither have as yet been isolated. In the treatment of hydrophobia Pasteur has stepped in advance of the bacteriologist, for in the other diseases treated with the products of the biologic activity of their germ causation, the micro-organism has been separated and identified before the therapeutic agent has been separated and used. Pasteur's treatment of hydrophobia is just the opposite. I have little doubt but that the micro-organism of rabies will soon be found, and establish the Pasteur treatment of hydrophobia rationally and acceptably to the most exacting of scientists.

A most interesting matter in connection with hydrophobia is the so-called rabies mephitica, hydrophobia from the bite of the common skunk, the mephitis mephitica, a very common little animal which generally makes its presence known. Its habitat is from Hudson's Bay to Mexico. The more southern ones have more white coloring and are smaller than the northern ones. I suppose it is also known in Europe, as the French call it l'enfant du diable, or the devil's own. The fluid having the skunk odor is in no way connected with the urine, as is generally supposed, but is secreted by two glands, one each side of the anus, called anal glands. Voluntary muscles control the fluid secreted by a number of smalleglands around the reservoir for holding the fluid. The tail has nothing to do with the squirting or dashing of the fluid. The fluid is for defence and offence. This is the so-called mephitic battery, and when it opens on you, look out! Until the fluid of this battery is all discharged he rarely, if ever. bites. and this fact will be found of importance farther on. The fluid contained by the gland is not of large amount, and the animal is harmless in this respect until more is secreted, which takes some time. The animal can squirt the fluid from six to eight feet when he discharges his battery. The fluid is phosphorescent at night, and at a distance when discharged looks like a puff of white smoke or a puff of steam in daytime. 
If too freely inhaled by man, it causes nausea and cramps. In minute doses it is said to be antispasmodic.

These matters are all thoroughly treated of by the late Dr. Elliott Crues, U. S. A., in his work on the "Fur-Bearing Animals of North America," and I beg to acknowledge my indebtedness to this work, and to the articles by the Rev. Horace C. Hovey and Dr. John G. Janeway, U. S. A., published in Dr. Crues's book. Mr. Hovey claims that rabies from skunk-bite is a different species of rabies from rabies canina and other forms of rabies. He proposes the name Rabies Mephitica. He claims that rabies mephitica is caused by a special virus generated by sktunks : that possibly there may be a causative connection between the inactivity of the anal glands and the generation of a malignant virus in the glands of the mouth. As I take it, he believes the skunk-bite is always followed by rabies mephitica; that the skunk only bites when his mephitic battery is exhausted, and his bite then always produces hydrophobia. Old hunters in the Rockies, he says, all believe the bite of the skunk is alicays fatal, producing hydrophobia. I would suppose the mephitic battery of the skunk with hydrophobia would always be empty, from the convulsive nature of the disease. The muscles controlling the battery are voluntary in health, but with rabies would be affected by either clonic or tonic spasm.

Hovey claims the spasms of rabies canina are tonic, and of rabies mephitica are clonic; that morphia acts in rabies mephitica, and does not act in very large doses in rabies canina. Hovey asks, "Do skunks take and give rabies, or are they among the animals that spontaneously generate a poison in the glands of the mouth and communicate it by salivary inoculation?"

Surgeon M. M. Spearer, U. S. A., gives an account of four cases of skunk-bite. He thinks there is a marked difference between the symptoms and those of hydrophobia. The four cases were all fatal. He says the skunk virus is as peculiar to it as that of the rattlesnake is to it, and is not an occasional outbreak of disease like the astus veneris of the wolf, or the 


\section{FORTY YEARS IN THE MEDICAL PROFESSION}

rabies canina. The instinct of the dog shows this. He is as cautious when attacking skunks as when he attacks venomous snakes, and is seldom bitten. Hovey says the skunk is of the North American mustelidx, and if this is true the mustelidæ, as well as the felidxe and canida, can communicate rabies, or a new disease communicated by the mustelidre has been discovered, which generically resembles rabies canina, whilst differing from it specifically. Hovey thinks we might go so far as to scek a solution of the whole dread mystery of hydrophobia in the theory that this awful malady originates with the allied genera of mephitis (skunks), putorius (minks), and mustela (weasels), being from them transferred to the cat and the dog and other families of animals. Harvey suggests that the defensive fluid of the skunk might be found to be the natural antidote to the salivary virus. Well, as to this, nature, we know, generates her poisons, why not her antidotes? These suggestions of Hovey's were made twenty-five years ago, and since that time Pasteur has taught us enough, at least, to make all victims of the bites of rabid animals hope$\mathrm{ful}$, when before all were given over to despair and almost hopeless horror. Surgeon John G. Janeway in his article does not agree with Hovey in the main, but does agree in part. He does not believe, with Hovey, that mephitic inoculation is sure death. He has known men and dogs frequently bitten, and they did not go mad. I may add here, men and dogs are frequently bitten by mad dogs and cats, and yet do not go mad. The reason is, they, although bitten, were not inoculated, owing to some circumstance, as clothing or something of that kind absorbing the virus before the fang of the biting animal has entered the flesh. It is said the skunk most frequently bites man on the face, hand, ear, or other exposed parts, and Janeway admits that the bite of the skunk oftener than any other animal produces hydrophobia, and gives this as a reason. Janeway says the rabid skunk at once exhausts his battery, and has little or no odor, then they bite, as Hovey says.

In hydrophobia the virus affects the eighth pair of cranial 80 
nerves and their branches, especially the œesophageal branch, the result being the well-known difficulty in swallowing. The motor nerve of the larynx is also affected, causing sighing, catching of the breath, and difficulty in expelling the frotly mucus accumulated in the throat. Hovey and Janeway agree that these troubles are more serious in rabies canina than in rabies mephitica, that the periods of incubation of the two are about the same, and that man has never been known to inoculate man. All authorities and all experience, I believe, agree on this point. Janeway concludes by declaring that rabies or hydrophobia produced by the skunk is the same rabies or hyclrophobia produced by the dog or cat or similar animals. My own experience agrees with that of Janeway, that dogs and men bitten by skunks do not always die from the bite, either of hydrophobia, rabies, or other trouble of the kind; but I am free to confess there is something peculiar and interesting in this study of the bite of the skunk and its effects. These oddities, or apparent oddities, in nature are interesting and most alluring, and all these peculiarities connected with the mustelidx in contradistinction to the same matters connected with the felidxe and canidxe are worthy of the closest study and most watchful scrutiny. God bless the memory of Louis Pasteur!

Probably the most unique character in the profession in the British Isles, if not in all Europe, at this date was Sir James Young Simpson, of Edinburglı, a Scotchman by birtl. He was a person with a leonine head, yet was one of the gentlest of men. He and Syme were always squabbling, but Syme was the more aggressive, and was very intolerant as to Simpson, whom he considered a mere obstetrician, and not entitled to any opinion of his own on any matter pertaining to surgery, and more than once made the public statement that nothing of importance or of good in surgery could ever emanate fron the brain of an obstetrician. Simpson was a most wonderful man, as gynæecologist, obstetrician, surgeon, and scientist, and, above all, as the discoverer of the anæsthetic properties of chloroform and the introducer of 


\section{FORTY YEARS IN THE MEDICAL PROFESSION}

anæsthesia into obstetrical practice, and as one of the introducers and perfecters of acupressure, at one time much used for securing blood-vessels, but now generally barred by the introduction of aseptic methods with animal ligatures. In regard to the use of anæsthesia in labor, he had quite a controversy with the late Professor Charles D. Meigs, of Philadelphia, who opposed it bitterly, claiming that labor was a physiological process, and we had no right to dull its pangs by artificial methods. Simpson held to his views, and to-day such methods are in general use.

I am fully persuaded, so far as my own experience goes, that whilst the use of anæesthetics in labor, when properly guarded, is perfectly safe as to general conditions, and causes woman to remember her great trial only as a pleasant dream, yet at the same time it frequently interferes with prompt uterine contractions, and renders the patient more liable to postpartum hemorrhage.

When I first entered the profession in the United States Marine Hospital in San Francisco I saw nothing but chloroform used as an anæsthetic. In the clinics of the University of Pennsylvania, during the service of Professor Henry H. Smith, a mixture of chloroform and ether was used, and sometimes the A. C. E. mixture. Agnew preferred ether, and Gross was very partial to chloroform, and if using ether and there was any delay, he would generally order us to pour on a little chloroform to reinforce the ether. I have never seen a death from or during anæsthesia. The nearest fatal case I ever saw was from ether, in a gumshot wound case in the United States army during the Civil War. As Agnew said, there are a certain number of cases who die under ether, and one of these cases may come to any one of us at any time, and we cannot help it. The consensus of opinion among surgeons now is to use ether, because it has been shown that fewer deaths on an average occur from its use than from chloroform. As ether rather tencls to increase blood-pressure when used as an anæsthetic, and chloroform tends to lower it, it possibly makes 
chloroform the safer remedy in obstetrical cases, especially where there are convulsions, and because pain is a vasomotor stimulant. In such cases as contracted kidney, accompanied by hypertrophy of the left ventricle of the heart, where we often have such excessive blood-pressure, also in chronic bronchial troubles, as in old short-neck wheezers, as we may call them, chloroform may be safer. Children have, as a rule, high blood-pressure, and as chloroform is dangerous, as a rule, by paralyzing the vasomotor system, therefore we may generally give it to children with great safety. These are our present lights on the subject. However, science and scientific experimenters never stand still. There is one thing always to remember about chloroform, it is more obnoxious to the kidneys, as a rule, than ether, and has a well-marked devitalizing effect on all nerve-tissue of whatever grade. Again, remember, after anæsthesia, especially prolonged anxsthesia, and especially in neurotic women, we often have a train of bad symptoms following, that may take months of careful treatment to rectify, and it is well always to watch for and remember such symptoms in all cases after surgical operations.

There are two proper ways to give an anzsthetic: either use an Allis inhaler, or merely pour the fluid on several folds of gauze; this method cannot be excelled.

Again, remember, after the use of ether and chloroform particularly, we may have pneumonia, heart troubles, and other circulatory irregularities come on. These cases occur most frequently after pelvic operations and after operations on the tongue and parts adjacent thereto. During my professional life I have seen a few of these cases. They may amount to lobar pneumonia or to broncho-pneumonia, and either may be slight or grave. Examine your patient carefully if after anæsthesia he presents any circulatory trouble. Before operations on the parts connected with the mouth too much care cannot be taken to render the mouth, nose, and all near parts as near as possible absolutely aseptic, and keep them so, for secondary infection may readily occur, and we 


\section{FORTY YEARS IN THE MEDICAL PROFESSION}

may have the micrococcus lanceolatus and the streptococcus present at once. It is important in all cases to have the towels, inhalers, or whatever may be used in anæsthesia thoroughly aseptic. There is another condition sometimes coming on after anæsthesia, especially after operations on nervous women. It may come at once or be deferred for some hours, or even days. The patient suddenly becomes greatly depressed, with great oppression of the breathing, with all the symptoms of heart-failure. There are no signs of pneumonia or other inflammatory troubles, only inability to get a satisfactory breath, which requires prompt attention in the way of heart and other stimulants. The trouble is undoubtedly of neurotic origin, and may be mistaken for pulmonary embolism, which, of course, might possibly occur under such conditions. The same troubles in a lesser degree sometimes come on during or after alcoholic intoxication.

At the suggestion of Dr. Norcross, of Philadelphia, oxygen has lately been administered with chloroform with reported good effect. Dr. Thomas S. K. Morton has lately experimented largely with the simultaneous administration of ether. and oxygen, by an ingenious apparatus. Also the petroleum ether mixture of Schleich is just conining into notice, and may prove a boon to suffering humanity, but its containing chloroform has so far been an objection. Simpson, Morton, Wells, and Jackson are dead, but the great work they did in life lives and grows after them.

During my visit to Europe I travelled generally through Germany, and remained long enough, particularly in Berlin, to get a good insight into medical matters and the medical schools. Germany was then brimful of glory and brimful of sorrow, for she had just emerged from a successful war, which terminated in their great victory at Sadowa, or Königgratz, as the battle is most frequently called, over the Austrians. Soldiers were everywhere, and I remember well the grand appearance they made on review and during their drills, and with what contempt they treated those not in accord with them, as when in Hanover the elegant palace and 
grounds of the poor blind King IVilliam were utterly given over to the soldiers, with the grand apartments of the first floor given to the cavalry lorses as stables.

The great surgeon of Prussia at that day was Bernhard von Langenbeck, then in his prime at fifty-six years of age. He was not an imposing-looking man; he had rather a weak face, a sort of so-called jimber-jaw face, but he was a great man, and lacked neither great courage nor great learning. He was the greatest surgical pathologist of Europe, and was the successor of the great Dieffenbach, in the University of Berlin. He had been doing great work in the war, great military surgeon that he was, and he looked almost worn out with his labors. Von Grafe, the oculist, was the idol of Berlin in all circles, and in his short life probably did more than any man who had lived up to that time to advance everything pertaining to eye troubles, not least of which, by any means, were his researches as to the nature and treatment of glaucoma. Frerichs was one of the leading physicians connected with the Berlin schools, and is now, years after his death, well remembered for his exhaustive treatise on the liver and its diseases. Berlin was full of able doctors, but they had hardly got well into line in their work, everything having been disorganized by the war.

Vienna was the great medical centre of Europe at this time outside of London and Paris, and was undoubtedly the Mecca for a great majority of students coming from countries foreign to Europe. As a clinical school it had no equal then, and has surely no equal to-day, material of all kinds being plenty, both living and dead. I believe there are phlegmatic Germans in Viemna who will hire out to a doctor and allow him to cut off their legs for experimental purposes, provided they be paid well for their suffering. Among the great surgeons in Viemna at this date were Schuh, Dumreicher, and Pitha. Among the obstetricians were Professor Karl Braun, celebrated the world over, Professor Spaeth, and Professor Chiari, both great masters and teachers. Among the oculists were Arlt, Jaeger, and Stellwag. Among the physicians was Skoda, 
without doubt the greatest diagnostician of his day, but I never looked with much favor upon his treatment, for really I do not believe Skoda gave much thought to treatment and had little faith in the efficacy of remedies. He was an enthusiast in diagnosis, but not practical in therapeutics. Oppolzer and Türk were great all-round physicians, and gave great celebrity to the Vienna schools, especially the former.

I cannot close this brief reference to the Vienna medical men without mentioning the most celebrated pathological anatomist of his day, Karl Rokitansky. He was rector of the University of Vienna, was worshipped by the faculty of Vienna, and was justly honored by scientists the world over.

My visit to Germany ended, I commenced my homeward journey, and left Europe with all its wonders in science, in arts, and in culture, thankful for what I had seen and more than thankful for what I had learned. More than that, I left it more than ever satisfied with my own country, with my own people, and that my lot had been cast as a citizen of the United States of America. 


\section{CHA P T E R V.}

Returned from Europe and Settled in New Castle, Delaware-Its Peculiar Freedom from Certain Diseases-The Medical Profession in Delaware-Country Doctors-A. Conan Doyle-Ian MaclarenBacteriology Forty Years Ago-Pathogenic and Other GermsToxines-Immunity-Inflammation-Operations Forty Years Ago and their Results-Asepsis-Antisepsis-Origin of Life-Sir Joseph Lister-Obstetrics and Antisepsis-Hospital Gangrene-A Strange Coincidence-Surgery away from the Centres-Disinfection-Necessity of-Gonorrhce-Bladder Troubles-Syphilis-Eye TroublesGynæcology-Proctor Knott-Appendicitis-Radical Cure of Hernia -Intubation and Tracheotomy-Fractures and Dislocations-Instruments-Röntgen Rays.

AFTER having returned from Europe, for reasons personal to myself, and which I have no cause to regret, I settled in the little city of New Castle, Delaware, a town of about five thousand inhabitants. I only speak of this because I have found a very peculiar condition existing here, in the territory covered by this town, as to its condition of healthfulness. The situation is on the Delaware River about thirty miles below Philadelphia, and is on a point or peninsula jutting out into the river, with a fall towards the river sufficient for natural drainage. The rise and fall of the tide twice in twenty-four hours is about six feet, and the tidal rate is about four miles per hour. Whilst the town originally was built on a slight bluff, above and below the town are lowlands, protected by substantial banks and drained by tidal sluices. These sluices and banks have always been well cared for, and have given good clean meadow-land. The point I wish to note is this,- - and I note it from observation of over thirty years and from statistics gathered from my records of daily practice, which I have scrupulously kept,- the very rare occurrence, comparatively, on this little point of land on which the little city of New Castle is situated, of infectious, contagious, zymotic, or microbic diseases. For over thirty years, 
with very little let-up, I have been a very busy man in the practice of medicine. In that time I have done probably as much work as a man should do, and among my patients in this town ( $\mathrm{I}$ omit all cases in my consultation work at home or abroad) I have not averaged five cases each year of croupous pneumonia. I mean by croupous pneumonia the infectious inflammatory disease, where the diplococcus pneumonix is probably present, coming on with the chill, the bounding pulse, the flushed cheek, high temperature, the crepitant râle, the bloody sputa, the rapid breathing, and so on, as the case proceeds. I have never seen epidemic croupous pneumonia here. Epidemic croupous pneumonia I look upon as a contagious disease, and the mortality is generally high. Nonspecific broncho-pneumonia and capillary bronchitis, especially among the young, and which are possibly non-microbic and non-contagious, are probably as common here as in other places near by. Now for the apparent reason. The peninsula on which New Castle is situated juts out into the river, with lowlands above and below it. The banks are all thoroughly washed twice each twenty-four hours by the tides of the Delaware River, and by this rise and fall of the tides a system of capillary drainage is produced, which acts on the whole town site, stagnation is prevented, and the hosts for the developing of the obnoxious microbes are in a large degree wanting. Other zymotic diseases are rare here, and have been rare, taking thirty years past. Even malarial fevers have never abounded except during the time when the blanket of malaria was over the whole country some years ago, when even the hills of New England were not exempt. I have never seen scarlet fever seriously epidemic here, except upon one occasion in over thirty years, and a serious epidemic of diphtheria has prevailed only once, and that when in October, I878, the great tidal wave swept the shores of the Delaware and carried away the river-banks above and below the town. These remained down until the following June, when they were restored. Then the dead fish and decaying matter in general furnished a most convenient host for the plants, and diphthe- 
ria came upon us in vigorous form. This exemption from zymotic disease extends only a short distance in the country, below, above, and back of the town, and as we travel west and southwest, and pass the water-shed of the Delaware and approach the Chesapeake, we find, especially, croupous pneumonia, frequently epidemic and often fatal.

Among professions in Delaware the medical profession has always held a high position, and its members have always been prominent in all matters pertaining to good citizenship. The Delaware State Medical Society was founded in I 788 , and to this day its organization has been held intact, and its place among like societies in the United States has always been recognized as among the foremost and most zealous. In times gone by the names of many men of prominence have been enrolled in the medical profession, and their descendants to-day are prominent in all parts of the country. Among some of those prominent as practitioners in Delaware in early times, I may mention the names of Tilton, Sykes, Naudain, Clayton, McCalmont, McLane, Lofland, Morris, Vaughn, Couper, Thompson, S. H. Black, Askew, Mitchell, Merritt, Porter, Bush, C. H. Black, Saulsbury, Jump, Hamilton, Whiteley, Kane, Colesberry, Barr, Lowber, and Clark. Most of these men were what we are accustomed to call country practitioners. By country practitioners I mean men practising away from and not within easy reach of the medical centres. This applied in their day more than it does now, for communication is so perfect and rapid in nearly all parts of the country that it is possible for nearly all to keep readily in touch with all centres of trade and business. I know and have known many of these so-called country doctors, and among them are many strong and vigorous men in both mind and body. They are always factors in their neighborhood. Being strong men, they often drift away from pure professional work, and become too much routine practitioners. This is often not their own fault, for, being available men, they are often drafted into politics and into political places by their fellow-citizens, and thus in many cases the public. whilst 


\section{FORTY YEARS IN THE MEDICAL PROFESSION}

gaining a good official, loses a competent and faithful physician. It would be much better if physicians working in isolated locations would take up some by-study which would help them in their profession, such as botany, comparative anatomy, scientific farming, or horticulture, which combine so much of nature study, rather than drift off into politics, or into the mere routine work of pill-giving and empirical drugging.

I know well a great many country doctors, and I know many of them to be good all-round men, fair general practitioners of medicine, good diagnosticians, some very good obstetricians, and some very good every-day surgeons; I know men who have done general amputating; I know men who have done all of the operations in obstetrics, including Cæararean section; and I know of ovariotomy having been done by the country doctor, and successfully, too. These men, like our city friends, have their own troubles; they have their professional jealousies, their little tilts with one another, their troubles with and from the neighborhood gossips and from ungrateful patients, but they as a class are equal to all emergencies, and can hold their own with the best of God's creatures.

A little story of A. Conan Doyle's holds up to nature most admirably the feelings and the engendered jealousies and rivalries often seen when anything comes between the head doctor of a small town and the full sway he has been accustomed to hold for a long time before. I cannot recall the name of the story, but it is true to nature and abounds in skilful knowledge of human nature. A new doctor comes to town and puts out a sign. We will call him Dr. A. Smith. The old doctor of the place is a man of really great merit, and is somewhat worried over the outset of the new one. $\mathrm{He}$ waits for the new one to call, and the new one waits for the old one to call. They do not meet, but the old doctor soon finds out the new doctor is a woman. She proves to be a woman of talent and especially well prepared from hospital experience to do general surgery and eye work, and soon 
makes a local reputation from some fortunate cases. The old doctor has still never met her, but feels that he is losing his pre-eminence to the new woman. The opportunity comes for the new woman, who is really a fine character. The old doctor meets with a runaway accident and serious injury, is carried into a near-by house, and the first doctor found and called in is Dr. A. Smith. Of course the first meeting is somewhat embarrassing, but Dr. A. Smith goes to work and at once shows to our old friend she is no novice, but a really skilful and accomplished surgeon. Well, Doyle elaborates the story very artfully. The case goes through very favorably, the doctor recovers, and the two become inseparable companions. Every one reading the story at this point makes up his mind they will marry. Doyle brings it out differently. Dr. A. Smith soon leaves the small town, goes to a large city, and becomes a great specialist. Every physician should read this little story, and see how " one touch of nature makes the whole world kin."

Ian Maclaren says he has often been asked the question, Was there ever any doctor so self-forgetful, and so utterly Christian, as William MacLure, the hero of his "Doctor of the Old School"? To which he replied, as he said, on his conscience, not one man, but many, in Scotland and in the South Country. Should I be asked the same question, I should answer, on my conscience, yes. I have known more than one IVilliam MacLure in the medical profession. No set of worthy men ever had a greater compliment paid them than had the country doctors when Ian Maclaren took one of them as the hero of his lovely and pathetic story of "A Doctor of the Old School."

That medicine to-day is a progressive science and not the empiricism of the olden times is shown very plainly when we review the course of surgery in the last forty years. Even during this short time surgery has advanced from a mere empirical art to true scientific methods. The surgeon is no longer a mere mechanic, but must be truly a scientific man in all that the name implies. The great advances have been all 


\section{FORTY YEARS IN THE MEDICAL PROFESSION}

along the line, in diagnosis, in manual procedure, in technique, in his armamentarium, and, above all, in the magnificent results of the cases treated.

Forty years ago, bacteriology played little or no part in surgical diagnosis. We knew little of the saprophytic or of the pathogenic bacteria. We knew little of the habitat of germs, or of the parasitic nature of many of the pathogenic germs, or that some could live in both dead and living animal matter and some in dead tissue alone. We knew little of the nature of germs, of their life history and of their requirements for existence. We knew little or nothing of the temperature required for their growth and development, or of the effect of sunshine on their prosperity, all very practical points. Now we know much about them. We knew nothing of how bacteria were propagated, nor that the spores were much more difficult to destroy than the parent, another important point in practice. Every living thing generates its own poison, and, it follows, so do bacteria. The growth of the colony is limited by the poison it generates, and hence we have toxines. Some of these toxines are fermentative, or ptomaines so called, which are cadaveric alkaloids and very poisonous to animal life, as most of us in the course of a lifetime know from bitter experience. Ice-cream poison cases, cream-puff poison cases, fish poison cases, are the most prominent. Others of these toxines are called toxalbumins, and are more or less synonymous with the ptomaines as to results. Bacteriology has advanced to such a point as to have become a great life-study and work within itself, and the different germs can be grown like potatoes, and their life history can be studied with absolute exactness and detail from laboratory cultures, and again by inoculation into the lower animal life; and Koch's law requires this culture growth and reproduction of the original through inoculation into the lower animal.

By this study of the life history of germs we find how they infest the body, how they enter, whether by skin or mucous membrane, or otherwise, or by the mouth only, as the comma bacillus of cholera. We have also learned how they are elimi- 


\section{FORTY YEARS IN THE MEDICAL PROFESSION}

nated or excreted from the body, and also the symptoms they produce, and the resistance the animal body offers to them, being the difference between health and disease, for none of us know how many thousands of millions are bustling about us and lurking in our throats and other parts of our bodies, the fortunate escaping all ill effects, the unfortunate succumbing to many of the ills "flesh is heir to." After all, we are all exposed; it all depends upon the soil the germs light on; those that fall on, to them, good soil carry misery and death in their train, whilst those that fall on stony ground perish, and individual life goes on with unconcern; immune, we say, the subject is.

Now, this question of immunity is a burning question, and the production of artificial immunity is in the direction of the great strides being made to-day in bacteriology, and sufficient has been done in diphtheria, not mentioning hydrophobia, anthrax, tetanus, and other diseases, to have already written one of the most brilliant pages in the history of medicine. Here again practically every living thing generates its own poison, for the great Pasteur took the opposite course to antitoxins when he recommended the starting of a deadly epidemic by inoculation of a few individual specimens with a toxine or disease to rid Australia of her rabbit pest. The great advance made in bacteriology was in the staining of the germs to be examined, and has made possible the great advances made in examining by the microscope many of the pathogenic germs. Take, as an example. Ziehl's solution for coloring tubercle bacilli, following the ustual technique. The bacilli that most concern the surgeon are those mostly concerned in suppuration of some kind,--the staphylococci, comprising pyogenes aureus and pyogenes albus; the streptococci, the gonococcus, the bacillus coli communis, or the bacterium coli commune. The bacillus pyocyaneus is found in the greenish pus-the pus we see, or rather formerly saw, for we aim not to have pus now about wounds-coming from wounds profusely when granulations are just commencing, causing renewed vitality in the condition, creamy, laudable pus. The Klebs- 
FORTY YEARS IN THE MEDICAL PROFESSION

Loeffler bacillus, the germ of diphtheria, also concerns the surgeon. The bacillus tuberculosis is a most important germ which the surgeon now has to know of and deal with, which only a few years ago he did not dream of as a cause of the troubles he was endeavoring to relieve. Especially is this the case in bone surgery. Also the germs of anthrax, hydrophobia, glanders, tetanus, and others concern him.

Forty years ago, in any medical school, upon the advent of a new professor, his standing in the profession and his ability to fill the position was generally measured by his views on inflammation. Even at this day there was little solid knowledge, but it was usually looked upon as a fire to be quenched, as it were, by water; for water, and little of it, was about the diet presented under the antiphlogistic system, and this was freely purged away, although it was about this time that Dr. Tod began his advocacy of opposition to the extreme antiphlogistic school, urged on, perhaps, by the well-known views and practice of Robert Graves, the great Dublin physician; and probably both were in a measure followers of Cullen, who was among the first to discountenance the abuse of venesection.

In looking over an old book on surgery published nearly fifty years ago, I read, " The operator must bear in mind the great principles of all sound practice,-viz., the treatment of inflammation. Is the wound to heal by first intention or by granulation? Is the object of the operation to be attained by exciting inflammation, or will its development destroy the result? Is the action to proceed simply to the effusion of lymph, or to suppuration?" One man is quoted as always purging his patients during the after-treatment of capital operation to prevent inflammation. Many years ago Professor S. D. Gross wrote to me in regard to a case that had not gone on well, using at the end of his letter these words: "God knows surgery is not a sinecure, but a most corroding, soul-disturbing profession." Were he alive to-day, with the use of modern methods, his case would have gone on well, and he would not have needed to pen such pessimistic senti- 
ments; although, in the main, they still hold true, for surgery doubtless is, with all the help given it by modern methods and modern ideas, " not a sinecure, but a most corroding, soul-disturbing profession."

Thirty-five years ago Gross's idea of inflammation was that in considering it, it was necessary, first, to consider the nature of the capillaries in which the morbid action is mainly carried; secondly, the character of the blood which is so singularly changed in inflammation; thirdly, the part played by the nervous system; and fourthly, the condition of the tissues at the seat of disease. This definition conveys the advanced ideas of that time, and really throws no light on the subject; and to show this is why I refer to it. He speaks of changes wrought in the blood, etc., its color, arrangement of globules, buffy coat, etc., the white and red corpuscles stopping the capillaries and producing stagnation, and so on to the products of inflammation. He also thought the nerves played an important part in inflammation. There was no hint yet in those days of zymosis, although the germ theory of disease had been talked about. He did not think inflammation was necessarily attended by suppuration, as Miller, the Edimburgh surgeon, did. Gross thought inflammation, as a rule, should be treated by the lancet, low diet, mercury, blisters, and all the antiphlogistic remedies; yet he said there was a period in almost every attack of severe disease when the patient would need brandy, wine, quinine, and nutritious food.

I have quoted Gross at length as one of the great authorities of the time I refer to, in order to contrast his ideas with those of to-day, where what we know of inflammation is not mere guesswork and empiricism, but approaches the exact results of scientific work. The surgeon to-day, as of old, recognizes inflammation by pain, redness, swelling, heat, and impaired function; and by the results of microscopical examination he gets definite information as to its cause, etc. It may be said that he recognizes bacteria, or rather, more broadly, microbes, as the cause of all inflammation, be the original cause what it may, whether accident, disease, or 


\section{FORTY YEARS IN THE MEDICAL PROFESSION}

injury. There may be exceptions here, as in such a disease as gout, but in this day of wonderful discovery we are not even sure of that. Here, then, is absolute tangible evidence as to the cause of inflammation, the great bugbear of forty years ago, when all definitions were mere guesswork, for the reason that scarcely anything was known of the true cause of the condition. Oh, how the great men of that day floundered in the mire of ignorance! Yet the new professor just called to his chair was usually gauged as to his ability by his lecture on inflammation. The improvenents in microscopes and their collaterals, together with the improved methods and technique, have done everything for the surgeon, and when we come to add to this the practical application of knowledge thus attained by such men as Pasteur, Cohnheim, Senn, Park, Tyndall, and Lister, we commence to see the why and the wherefore of the great march of surgery, from the ranks of an empirical art to the broader domain of a great science.

When I was a hospital resident the surgeon came in from the street, took off his gloves, probably his coat, then his shirt-cuffs, rolled up his sleeves, and was ready for work. If he washed his hands as a preliminary, it was for his own comfort, not from any thought of saving his patient from any contamination; nor did he give a thought to what case he had come from, as to whether or not he might carry trouble to the operatee. The assistants came from any ward they happened at the time to be in, and prepared themselves about as the chief had done before them, and took about the same precautions, and these precautions aimed chiefly at their own convenience. In the well-appointed hospital utensils were of course kept scrupulously clean and neat, but there was no attempt at sterilization or thought of germs. The instruments were spread on a tray, fresh from their receptacles, looking clean, from the washing and wiping after their last use. The dressings were simple,-lint, bandages, and probably a jar of cerate, and adhesive plaster. If the case was a ward case, the parts to be involved in the operation were gen- 
erally shaved and washed the day before. If the case was a recent accident just in, and shock had passed off, the patient was at once taken to the operating-room, placed on the table. and etherized, and then and there his clothing. at least the part involved, was removed, the parts were shaved and washed with soap and warm water, and he was ready for the surgeon.

The operation completed, the dressing was simple. For an amputation of the leg below the knee, for instance, sutures. adhesive straps, a Maltese cross of sheet lint, covered with simple cerate over the stump, and retained by a simple roller of cotton cloth. Drainage was seldom or never used. This was usually removed within the first forty-eight hours, and the case treated as occasion required to the end. Suppuration was always very free; pus cavities often formed; erysipelas. secondary hemorrhage, or gangrene might come at any time. depending much on the condition of the patient or of his environment.

In the Philadelphia hospitals, especially in the Pennsylvania Hospital, the great accident hospital of that day, erysipelas, with all its attendant surgical horrors, was common in the winter months, especially in the months of February and March. The cause of this is apparent: the house closed against inclement weather confined the germs and checked them from floating out on the air currents, as they did when doors and windows were open. Now this has all been changed by methods so simple and so perfect as to make us stand amazed that no one had ever perfected it before. I say perfected, for many before the days of Lister appeared to have inklings of the germ theory of disease and of their ill effects in wounds of all kinds, whether surgical or accidental. For asepsis and antisepsis, the credit of their development and the first rules of application is universally accorded to Sir Joseph Lister, now Lord Lister, and no great title was ever better earned or more worthily bestowed. Other great scientific experimenters are almost equally worthy, among them the great Pasteur. Tynclall. Schwam. Koch. Theodor Billroth. 
and others, all uncrowned kings among men, worthy, living or dead, of the homage of all mankind.

Up to within recent years we were all at sea in regard to the origin of life, of the ultimate element, and the scientific man, the theologian, the materialist, the Deist, and the infidel all had their theories, and some men thought to be among the ablest among those living, had full faith in spontaneous generation. This theory at last was completely nullified by the grand work, especially of Pasteur and Tyndall, and that within thirty years. As to the origin of life, according to Virchow, science can only recognize one cause, previous life. " Omnis cellula e cellulâ," "Omne vivum ex vivo," are his declarations. Spontaneous generation has no claims for him. Creation does not satisfy him. His iclea of the origin of life is life itself; beyond this he cannot lift the veil. Without saying so, whatever is beyond he leaves to the discussions of theology and theologians.

The recognition of the germ theory of disease, of the lower orders of life as the cause of disease, of the parasitic nature of all fermentative or zymotic diseases really brought about the recognition of antisepsis in surgery, and the recognition of antisepsis brought about the recognition of the necessity for the aseptic condition-of ascpsis. Lister's first practical work was in the nature of antisepsis. He taught the necessity of having everything made clean about operator, assistants, the patient, the instruments, the dressings, and the environment, and, in addition, he impregnated the atmosphere, the operator, the patient, the assistants, and everything concerned with germicidal sprays. I will never forget my first experience. It was at the Pennsylvania Hospital. Dr. Thomas G. Morton, with Agnew and Hunt, was making an ovariotomy. The steam-atomizer was started early in the preparations with a carbolic acid solution, and when all was finished I do not know that I could say who had been in most danger, patient, operator, or lookers-on. It was a most unpleasant experience in every way, but the patient developed no septic symptoms, nor did anybody suffer more than temporary inconvenience. 
Is time passed on it was soon found that all these formalities were not necessary, that it was not air contact, but material contact with wounds that was most to be dreaded; in other words, render everything-operator, patient, assistants, dressings, brushes, and the general environment-aseptic before doing the operation. Instead of germicidal poisons for instruments, dressings, etc., we rely on steam, boiling water, and formaldehyde solutions, and for patient, operator, and assistants, scrubbing, scrubbing, scrubbing, with water, soap, ether, and formaldehyde solutions, until all living parts to come in contact with living parts are thoronghly and absolutely aseptic. I have amputated a thigh, using only two per cent. formaldehyde solution, and had best results and $n o$ pus. There are some glaring defects yet that I am sure we must remedy before we get perfect asepsis. It has been found that in conghing and sneezing over an agar plate, and then examining after a proper interval, colonies of bacteria were developed. Here is a source of infection from the surgeon or assistants. To remedy this all must wear gauze masks, and the coming surgeon will acor them. The coming surgeon will also wear gloves of some kind, of a kind that will least blunt his sense of touch. These will be especially necessary in military surgery and where asepsis cannot be rigidly practised. Think of the changes wrought by these methods. They can only be appreciated by those who had experience in large hospitals or in military life, or in obstetrical practice previous to twenty-five years ago.

Before asepsis had been so thoroughly impressed on obstetricians puerperal fever often raged in communities for months, and the mortality often became fearful. In large cities like Philadelphia and New York it was very often epidemic, and sporadic cases were always occurring, and made the life of the obstetrician one of dread and horror, and the safety of all lying-in women was in great jeopardy. Whilst many medical men recognized its contagiousness, and declined other cases whilst attending it, others denied its contagionsness and, we now well know, spread it far and wide as 
they passed from case to case. To-day traumatic erysipelas, if there is another kind, is comparatively nnknown, and the results in compound fractures are simply miraculous, and operations never dreamed of thirty years ago are now performed with impunity and great success. Antiseptics have also invaded the domain of the skin specialist. but it is in military surgery where asepsis and antisepsis are bound to show their great efficiency, in the prevention of much cruel suffering and in the saving of thousands of lives. Those of us who had experience in our late Civil War, and those who saw the slaughter wrought by gangrene, secondary hemorrhage, and allied horrors, now entirely preventable by antiseptic methods, surely can appreciate the great work done by Lister and his followers, and can never cease to thank God for giving such instrumentalities to man for the alleviating of human suffering and the lessening of human anguish. The great distress in war in those days was not at the front in the excitement of battle, nor during the excitement of the primary operations on the field during and after the battles. The horrors came generally a few days afterwards, in the rear, when sloughing, gangrene, and secondary hemorrhage became rife and made life a burden not only to the poor patients, but to the surgeons and all those engaged in helping them.

The remedies used for gangrene and its allied troubles were numerous, and were limited in number only by the names in the pharmacopœia. Bromine was the great remedy. The dead parts were cut away and the bromine applied with a glass rod to the sound tissue, which it destroyed by oxidation. and thus had germicidal action. Proper aseptic precautions were not thoroughly taken, and little headway, as a rule, was marle against the disease, and reamputations, of course, were generally followed by gangrene in the new stump. I used Monsel's salt, the powdered subsulphate of iron, very freely, and thought I got better results than from bromine.

When I think of these cases of hospital gangrene, secondary hemorrhage, and the like, the most affecting scene I ever 
witnessed always comes up before me, and there is a very strange coincidence comnected with it. A young officer, an only son, a thoroughly fine and noble fellow from one of the New England regiments, was fatally wounder in the spine during one of the engagements in Grant's Wilderness campaign. He was brought to the rear, and I had charge of him in one of the hospitals. I became interested in him. As he lingered on, his mother and sister, very nice people, came from their home to see him and do what they conld to help) him. He lasted only a short time, in great suffering. On a beautiful, warm, moonlight evening he was rapidly sinking, his distressed mother and sister hovering over him, when suddenly, without any collusion, a near-by band slowly and softly struck up the dirge very familiar in those days, which runs about as follows:

"Soon with angels ['ll be marching.

With bright laurels on my brow;

I have for my country fallen,

Who will care for mother now ?"

Just as the last notes died away,- - "Who will care for mother now?"-his soul passed to the great beyond, and his terrible sufferings ceased forever. Of all the sad and pathetic scenes I have witnessed, this was the saddest and most pathetic. Such is war, which now again after many years is coming towards us with rapid strides, and again just such sad and pathetic scenes may be witnessed in the land. There is one consolation, suffering will be much less among the sick and wounded, there will be little or no gangrene and secondary hemorrhage, and every soldier will be, or should be. provided with dressings with which to bind up his own or his comrade's wounds temporarily, until the surgeon shall get him and bring to bear his skill, aided by modern methods and modern ideas. Thus the great world moves on.

Since the introduction of antisepsis and asepsis the preparing the environment of the patient has become equally as important as preparing the body of the patient. This is easy 
to accomplish in the well-constructed modern hospital, where everything has been made to conform to this end. In a private house this is much more difficult, often impossible, and even when attempted the whole scheme may be spoiled by some thoughtless member of the family invading the apartment with untidy dress, or fresh from some deadly infection. For this reason I do not hesitate to advise patients who are to undergo operations of almost any kind to seek a well-regulated hospital, where they may obtain the best surgical advice and take quarters suited to their purse, either in the wards or in private apartments, where they may obtain comforts equal to our best hotels, and where at a moment's notice good surgical service may be present for any emergency.

I have done a good deal of surgery during my professional career, but in practice away from the centres it is hard and exacting work. Since the advent of the trained nurse it has improved somewhat, but when a man does a capital operation he is apt to be disturbed at any moment and very often, day or night, during the first day or two, for if even a drop of blood appears on the dressing the doctor is summoned at once, and to a man weary already from overwork this anxiety becomes almost unbearable. Under all circumstances, I believe it better for the patient and for the doctor to send all but emergency surgical cases to a well-regulated hospital. Hospital work is an absolute necessity for a successful surgical career. This is the very opposite to the advice I should have given thirty years ago. Then the average hospital was a pest-house to be avoided in all cases where operative interference was required. So much for the evolution of science in germ destruction.

Disinfection is now carried on to include the whole town under the supervision of boards of health, and the technique is applied to houses and their surroundings, to the sick-room, utensils, receptacles for sputa especially, and for the alvine eracuations. Indeed, the disinfecting organization should doubtless always follow the doctor. Under modern methods and care the vile spitting labit is being much curtailed, for, 


\section{FORTY YEARS IN THE MEDICAL PROFESSION}

besides its filthiness, it is a great factor doubtless in spreading disease. The whole tendency to disinfect is spreading, but not any too rapidly. All places of resort should be regularly made as nearly aseptic as possible; so should all public conveyances, especially the sleeping-apartments of cars and boats. churches, hotels, schools, especially water-closets and such apartments, for undoubtedly the most loathsome diseases may be induced by contact in such places. School-books and library books should be regularly disinfected, and there is no doubt in the world that more care should be exercised by barbers as to absolute cleanliness, and all their tools should be sterilized each time before use. All such rules apply with equal force to dentists, and, of course, to physicians too, whether caring for man or beast. There is one thing that should be carefully. avoided,-never use a catheter, speculum, or instrument of any kind in a cavity lined by mucous membrane without first thoroughly sterilizing it. This is readily done by boiling glass and metal instruments, and if made of rubber, soak them from ten to fifteen minutes in one to one thousand bichloride solution or in a two per cent. formaldelyde solution and then thoroughly wash with water that has been boiled at least twenty minutes. The surgeon's hands also, of course, should be sterilized, as should the lubricant used, and also the organs of the patient and their surroundings. These rules should apply to both males and females. There is a formalin sterilizer for instruments and all dressings now on the market which is simple, cheap, and effective. The formalin is put up in solid tablets, and a simple lamp furnishes the heat. You will thus aroid cystitis and other horrors in your patients. Physicians should protest to patients against many of the habits characteristic of human beings, such as rubbing the eyes with the unprotected fingers, for no man knows when he touches a door-knob, for instance, but that some one before lim may have left the gonococcus or some vile germ as a parting legacy to closing the door, and a gonorrhoal ophthalmia may follow to an innocent rictim. The possibility of such accidents by some such means should be instilled into 
all, and many a sorry victim may be saved from all the horrors of syphilitic and other infections. The hands of every man, woman, and child should be sterilized daily. Cleanliness should be taught to all and practised by all. "Cleanliness is next to godliness," and self-preservation, the first law of nature, is the coming great factor in the carrying out of this proverb. The scales are falling from the eyes of man; science is pointing the way; he begins to see that, living in filth, he, like all living beings, generates his own poison, and that the philosophy of rational existence is wash, wash, wash. scrub, scrub, scrub. Instilling such methods into his patients, the physician becomes what he should be, a public teacher, and thus becomes more and more than he even now is, a public benefactor.

As I look forward to the coming branch of the profession which shall bestow on mankind its greatest benefits, to that branch which shall shed its most brilliant lustre upon the world at large, I see always looming up before me, before all others, the one great light,- - the forermners of which are antisepsis, asepsis, general technique, and absolute cleanliness, -the coming grand practical work, preventive medicine. As to antisepsis and asepsis in obstetrics, they are of great importance, or rather, I will say, absolute care and cleanliness on the part of physician, patient, nurse, and all the help around the woman and the entire inorganic environment should be scrupulously clean, and kept scrupulously clean, during the labor, and the whole lying-in, not forgetting the child, both for its own sake and for the mother's. If we have sufficient warning of the case, the apartment should be prepared as for a surgical operation, and all articles to be used during labor should be kept in this room, first having been sterilized by heat, wet or dry. When labor begins the patient should be absolutely cleansed and dressed by the nurse, having first cleansed herself, and no other umprepared person should approach the patient during her labor. When the doctor arrives he should wash up thoroughly, and doubtless should wear a clean sterilized linen overall gown and rubber gloves, 
and own an inculator to be absolutely ch régle. If the case goes normally, the doctor and nurse need no assistance. Cleanliness is the rule to the end. If operations are necessary. they must be done absolutely uncler antiseptic precautions. In catheterization especially, he careful to be cleanly. The nurse may use one good vaginal douche of corrosive chloride of mercury one to five thousand, to be followed at once by one of water at the first cleaning up, and after that, if any are used, use only sterilized water. Be sure the syringe is aseptic, or you do more harm than good. I prefer acetanilide or boric acid to iodoform for use, if necessary, on both mother and child. Solution of formaldehyde will probably be the antiseptic most used in these cases in the future. During my professional career I have delivered a great many women, and performed about all of the obstetrical operations, from Caesarean section down, and I think, in fact I know, I can more than count on the fingers of my two hands all of the septic cases I have had. Absolute care as to cleanliness and careful technique has been my rule.

What I have said before applies to cases where we can elect just what we are to do, and do it sccundum artcm. What about the other cases?--the cases where you are called just on the eve of the birth of the child, or, may be, find the child born on your arrival; the woman in unclean apartments, with unclean surroundings of every kind, including the granny and officious neighbors just run in, the woman herself unclean? WVell, just do the best you can. Do all you can to clean yourself and make others clean around you. There is a proverb that " God takes care of little children and drunken men." We may add to this, the average lying-in woman. Do as you may, you cannot get aseptic conditions in the average private house, in the average private lying-in patient, in the average attendants on these cases. All you can clo is to do the very best you are able, and trust in the Lord; and I must say the Lord is very kind to these poor sufferers. One thing favors patients in general obstetrical practice, especially when away from the merlical centres: the 
normal vagina will take care of a few of the average germs, whether pathogenic or benign, and physicians away from centres are much less liable to carry contagion than those constantly exposed in the crowded districts. Always remember one thing: if exposed to a septic case, especially if you have handled a case, particularly an abdominal or a pelvic case, where sepsis has been well established, wash as you may, use germicides as you may, you cannot make your hands aseptic in less than forty-eight hours, and you run the risk of taking the life of any surgical or obstetrical case you approach within that time. Under aseptic methods the public hospital is now just as good and desirable for surgical cases as the same hospital was undesirable and unfit twenty-five years ago. To-day the public lying-in hospital, instead of being a charnel-house, is above all other places the safest and most desirable place for the confinement and treatment of parturient women. Indeed, it is the only possible way to give them aseptic accouchement with absolute aseptic surroundings and conditions. In my judgment it would be well now if every community had its lying-in resort, to which any woman could flee as a safe refuge in her great trials. I have little doubt that the coming woman will have such refuge and generally avail herself of it, with men and women as specialists in obstetrics, which will insure more perfect aseptic conditions than the general practitioner can give.

In abortion or miscarriage, any time before the viability of the fœtus, antiseptic precautions are of great importance, and I think much of the blame given to the use of the intrauterine curette is because we are not sufficiently careful of antisepsis in its use. If you find you cannot check the premature expulsion of the ovum, say before the fourth month, do not hesitate to use an antiseptic tampon, made of any material, -iodoform gauze, bichloride gauze, or of house rags even,soaked with bichloride one to four thousand. Often we have to take the best material we can find. Use a boric acid douche, and pack in the tampon well; give ergot and quinine, and in from twenty-four to thirty-six hours you should find the 
ovum unruptured in the vagina, with no necessity of entering the uterus either with the finger or instrument. Give a hot vaginal boric acid donche if you choose, also intra-uterine, at once, and nature and good care will (h) the rest. It is the ruptured ovum that gives the trouble. This must be gotten rid of promptly, if possible, especially if there be the least odor, and here the curette comes in. The patient should be thoroughly washed externally, and physician and nurse should also thoroughly wash up antiseptically. Use the hollow curette invented by the great Viemna obstetrician, Carl Braun; they come in sets of three,-one spoon, one sharp, and one dull, with a common handle to screw on. Attach your curette to a fountain syringe containing your fluid, and then you can irrigate as you curette. Curette a uterus without these precantions, and you run great risk of infecting your patients. Be rough, tear the lining membrane of the uterus, and thus infection may enter. Be rough, and you even may go through the organ.

There is another trouble which will bear watching,- - viz., laceration of the cervix during labor, either by the fœtus, by instruments, or by the hand of the obstetrician. Here we may have free and even fatal hemorrhage. Of course, the surgical way is to draw out the uterus, which, with the proper instruments, can easily be done in its relaxed condition, and suture and tie the ressel or vessels if necessary, which will not often be necessary. When in a position where you cannot do this, and this often may happen, pack the laceration with lint or absorbent cotton, or any porous material, soaked in liquid subsulphate of iron, and the case must be a very serious one, indeed, if the hemorrhage does not stop at once. The iron itself is an antiseptic, and a good one. Injections of hot water may be tried, and will often be fonnd to succeed. Bear in mind this injunction: whenever you have hemorrhage from the genital tract in a woman, watch it. Always find out the cause and the point where from. There are many causes, as we all know, of such hemorrhage. If it happen to be of malignant origin, delay is fatal. Glandular involvement 
comes on, and your patient is lost. An early diagnosis gives the surgeon his opportunity and the patient her one and only chance. This we are learning every day.

In malignant disease, where possible, operate early, operate radically, avoid hemorrhage, and hence avoid shock. On this line S. IV. Gross and Halsted have been pioneers among us. This rule applies to the little crack on the lip which does not heal. Do not let the glands near it enlarge before you get rid of it. This rule applies to rodent ulcer and to lympho- or other sarcomas. Then do not wait for them to spread by the blood-ressels before you get rid of them.

Genito-urinary surgery, like general surgery, has greatly benefited by modern methods and modern ideas. First, as to gonorrhcea in the male. Forty years ago we knew little or nothing of its pathology. Now we know it is caused by a specific micro-organism, the gonococcus of Neisser. I wish I could say as much for the treatment. Forty years ago we thought ourselves fortunate if our patients were free in six weeks; to-day we are satisfied if we can dismiss them well in about the same time. It might be supposed, knowing the cause, and that cause a microbe confined to a small and easily approachable space, all we had to clo would be to apply a germicide and that would end it. Not so. It is a question whether germicides are ever efficient applied to microbes on mucous membrane; whether to be successful they must not reach beyond. There are some new silver salts coming up now for which great claims are made, but upon what scientific grounds I do not as yet know. In my experience the average case of gonorrhœa does just as well, and very many of them much better, especially as to unfortunate sequelæe, when treated by rest, at least as much as we can get the patient to take, a very restricted diet, as near to sterilized milk as we can get, urethral irrigations of sterilized water, with absolute general cleanliness, the wearing of a suspensory truss and a protecting bag for the penis, with a little absorbent cotton in the end, dampened with a little of a one or two per cent. formalklehycle solution. 
Until we can assure ourselves of a successful application to lestroy the micro-organisms, I am almost sure the foregoing is the safest and best treatment for the average case of gonorrhœa in the male. Always be sure to warn your patient of the danger of infecting his own or other persons eyes by. reckless use of hands, towels, etc., and in treating gleets always combine dilatation of the urethra with your treatment. As to the silver salts, I would prefer protargol. For simple clap, first stage, with the gonococci present, in ject three to five times in twenty-four hours, preferably warm, a penis syringeful of one per cent. solution, holding it sereral minutes. This, like all injections, at first causes smarting and increases the discharge. After four days the gonococci should diminish and also the discharge; then use the injection twice only in twenty-four hours, and when gonococci have disappeared use simple astringent injections. If this happy result is maintained in a number of cases, in more than my experience yet justifies, it would go to place protargol as a germicide to the gonococcus. For posterior turethritis, irrigate with a quarter of one per cent. solution of protargol, preceding it by a boric acid irrigation. with salol by the mouth. For the deep urethritis which causes so much suffering, apply locally a few drops of nitrate of silver solution, one to one thousand.

In the female about the same rules will apply. We know now that here the urethra is most often involved, and that the walls of the vagina are sometimes, but not at all in very many cases. The best treatment is by irrigations of urethra and vagina and uterts when possible, distending the vagina to its utmost limit so the fluid may come in contact with all parts. and by the use of suppositories of cocoa-butter, etc. There is one serious trouble following gonorrhœa in the female which has come to the front in the evolution of bacteriology and gynæcology,-viz., gonorrhœal salpingitis, which may be acute or chronic: so always look out for it, for many a poor virtuous woman suffers from it, as a result of connubial infection, for no one knows the limit of life of the gonococcus of Neisser, and man may carry it as long as he has the least 
remnant of a gleety discharge. As a rule, I think its life limited, and colonies like the colonies of micro-organisms generally, generate their own poison and die. Toxines developed in the urine of the individual may destroy them and be one way of cure, but from the nature of the case, these gleet cases are exceptions, and these exceptions are the sad cases.

In epididymitis, orchitis, and other sequela of gonorrhœa there has been little change to note in the treatment. You may still take your choice, from strapping, puncture, suspension, rest, and a diet as near sterilized milk as possible. In the treatment of strictures of the male urethra antiseptic surgery has helped much, as septic troubles now must rarely follow treatment of such by operation. Thirty years ago the treatment by divulsion was common, and Holt's instrument was in the hands of most genito-urinary surgeons. This method has deservedly fallen into disuse, and dilatation, internal urethrotomy, external urethrotomy with and without a guide, and resection of the stricture and suture of the urethra are now most in vogue.

Operations for exstrophy of the bladder now have a better chance since the introduction of antisepsis, but at best are not, as a rule, satisfactory. Surgeons do not hesitate to attack any part now, and great advances have been made in the treatment of all bladder troubles, and particularly of troubles involving the prostate, and by the able work of White and others castration and division of the vas deferens, and even more radical operations on the prostate itself, promise some relief to sufferers from such afflictions. The relief for stone in the bladder has somewhat changed. Thirty years ago, the lateral operation was almost universally used, the bilateral rarely, the median operation being sometimes used for small stones. Then, greatly through the work of Sir Henry Thompson and Civiale, lithotrity became much used; and after this, by aid of Dr. Bigelow, of Boston, litholapaxy, or removing the stone by aspiration after crushing, became most freguently used. Now the old operation of suprapubic 
lithotomy has been revived, and is often and very successfully done. Much credit is due to Dr. Charles Winslow Dulles, of Philadelphia, for work done in reviving this rery easy and rational way of relieving so serious a trouble. The chief dlanger to be feared after this operation is a fistulous opening, which may decline to heal, and thus give great trouble.

In syphilis there have been many changes during forty years, but whether it is of microbic origin or not is not yet known. We no longer hear of micists and dualists. We know now that chancre is the initial lesion of syphilis, and that the chancroid or soft chancre is not a syphilitic lesion, and is never followed by syphilitic infection. We know Ricord was right when he said chancre was not auto-inoculable as chancre, and that chancroid is auto-inoculable. We know that bubo following chancre is hard, and that following chancroid often suppurates. We know now that we may have a mixed initial lesion, being a chancre and chancroid coming on the same spot. I an uncertain about this, but it may let many a man out on diagnosis, at any rate; and when doubtful, treat it as a chancre anyhow. Forty years ago every effort was made to eradicate the chancre as soon as it appeared, strong caustics being used; and excision was practised at Blockley, and is even now in vogue. It was formerly thought this getting rid of the initial lesion might abort the disease, but I do not think this idea holds now, and the local treatment is chiefly antiscptic. Do not order iodoform for your patient, or you convict him at once wherever he goes among men about town, and no man reeking with the stink of iodoform is fit to associate with his fellow-man. Chancroids are not now, as a rule, canterized, but treated with antiseptic dressings, as carbolic acid, corrosive sublimate, solution of formaldehyde, or the old black wash. For bubo after chancre. constitutional treatment, and for bubo after cliancroid, treat antiseptically, and by injecting carbolic acid and such remedies and dissecting out parts of glands not broken down by suppuration. In the treatment of secondary symptoms we still rely on mercury and the iodides, as of old. Inunctions 


\section{FORTY YEARS IN THE MEDICAL PROFESSION}

and fumigations are still used. The newer form of treatment is by hypodermic medication, and, if your patient will submit to it, is useful, if your case is pressing. When you give iodide of potassium alone, give it in milk; it adds greatly to its tonic and, I think, to its specific effect. If iodide of potassium does not agree, give iodide of sodium; it is just as effectual. Now and again you will find a case unable to touch iodine in any form. This is unfortunate for the patient. Coryzas, skin eruptions, and other troubles make his life miserable whilst taking iodine. Mercury and some of the antisyphilitic vegetable remedies are your only resource.

Decided advance has been made in the treatment of the tertiary stages, especially in syphilis of the nervous system, and wonderful results are obtained by heroic doses of the specific remedies. One thing we know in regard to the acquirement of syphilis: it is often acquired by virtuous people innocently. The secondary as well as the primary lesions are contagious, and the only wonder is that it is not spread much more generally than it is. A knowledge of this fact should make us impress on all the absolute necessity of great care in using public drinking-cups, of the danger of promiscuous kissing, and all such useless modes of greeting mere acquaintances; in fact, let it be generally known that the most loathsome of diseases lurks wherever human beings congregate. When your boy is growing up, teach him to confide in you, and if ever troubles of this kind cause him suspicion, have a course laid out for him to pursue, either to come to you or go to his physician, and thus avoid what probably may be to him absolute ruin, for this comes to many a good boy, who is unfortunate in this respect, and most are victims to the cupidity and ignorance of quacks or the ever-ready drug-store clerk. I have practised medicine too long not to have met scores of sad cases. The best advice I can give to the young man is contained in two short lines:

"Pollute not with a harlot's cheek Those lips made sacred by a mother's kiss." 
In the surgery of the eye great advances have been made since I entered the profession, and date from about the time when Von Graefe gave to the profession his classic on "Glaucoma: Its Nature and Treatment." As to glaucoma, I have seen in consultation a number of cases, especially of acute glaucoma, where a failure to recognize the condition early caused lamentable trouble and loss of vision. Careless or ignorant practitioners are very liable to slip up on glaucoma. and we cannot be too careful to have our wits about us when such game is around. Another point here: where glaucoma is suspected, or your patient is over forty years old, be careful of the use of atropine as a mydriatic. There is an apparent contradiction here, too, among experts, for atropine is said by some to lessen tension of the eyeball, and this is what we need in glaucoma. Horatio IVood says be careful of it, because the dilatation of the pupil causes the iris to press against the spaces of Fontana, and that it may impede or stop the lymph circulation in these spaces, which have been already narrowed by disease. Hydrobromate of homatropine and cocaine are better and safer mydriatics for general use, as their effects pass off in a few hours, while the effect of a thorough application of atropine sulphate lasts a number of days. Eserine las the opposite effect of atropine, and has been a great help to the ophthalmic surgeon since its introduction. This is such an important matter, and so much harm may be done by general practitioners in the use of atropine, that I think the following rules are worthy of study by all: (r) Use it in iritis at any age, old or young, but in young children beware of too strong solutions, or constitutional symptoms of poison may arise. (2) Use it in ulcer of cornea and in keratitis. (3) In refractive work in patients under forty use it, but homatropine is better ; also use it as a mydriatic in persons under forty, but cocaine and homatropine are probably better. (4) Do not use atropine in conjunctivitis. (5) Never use it in glaucoma.

Antisepsis has also done as much to help the oculist in lis results as it has done in general surgery, and it is wonderful 


\section{FORTY YEARS IN THE MEDICAL PROFESSION}

what the eye endures in such applications, but the results justify the means used over and over. Local anæsthesia, since its comparatively recent introduction, has been the great boon to both patient and surgeon in eye cases. Cocaine is chief among these, and it is wonderful to see the effect of the distillation of a few drops of a four per cent. solution into an eye. In most operations it has taken the place of general anæesthesia, and reduced pain and unfavorable results to a minimum. Speaking of local anæsthesia, it has done just as much for general surgery. Cocaine is the base of most of it, but not all. Freezing mixtures which work by rapid evaporation, like ethyl chloride, rhigolene, and such, are very useful in minor operations. Schleich's method, by cocaine and morphia and local distention by the subcutaneous injection combined, is effectual, but has not yet generally commended itself as practical. The late Professor Theophilus Parvin was a strong advocate of this plan. Cocaine is not a remedy to trifle with; it may cause serious trouble from subcutaneous use, and one may soon become a cocaine fiend from frequent application of a solution or powder to mucous membrane. Beware how you recommend it in hay fever and such troubles!

To return to the eye. Great advances have been made in treating errors of refraction and such troubles by glasses, and many are now made comfortable, where formerly their inconvenience was ever present, and many a luckless schoolboy or girl, who thirty years ago would have been hustled into a corner as a dullard, has now become the bright scholar of the school-room and the fond hope of parents.

Ear surgery has made wonderful advances, and under the leadership of C. H. Burnett, of Philadelphia, followed by Randall and others, great relief has been afforded to sufferers. Equally good work has been done in throat work, and all such work has been taken from the domain of general surgery and become special work.

During the last forty years we have seen a new branch of surgery entirely, and since the introduction of antisepsis we 
have seen the most wonderful results. Operations have been done never even dreamed of before, and thousands of lives saved which before this advent would have been doomed to cruel suffering and premature deatl. I refer to gynacology. I. Marion Sims was the great pioneer and master here, and his great work was done for the cure of vesico-vaginal fistula. Dr. T. A. Emmett has also been a shining light in this brancl of surgery, and first performed vaginal cystotomy for the relief and cure of cystitis in the female. McDowell made his first ovariotomy in I809, and no great advance was made beyond this until within the last fifty years. Since then the whole system of gynxcology has been really built up, and now nothing is too hidden or intricate to be delved after, and an exploratory incision through the abdominal walls is thought no more of than would have been the amputation of a finger when McDowell commenced the great work. Gynæcology is among the most alluring of all the specialties in medicine, and where a few years ago there were only a few here and there in the denser centres of population, to-day they number many in the surgical corps of every city in the world, and the merest tyros in the business perform operations which a short time ago would have confounded a McDowell or a Sims. Obstetrics and gynæcology are now combined, and the obstetrician is necessarily a surgeon; very different from what it was when I was a student at the University. Then the professor of obstetrics rarely touched a knife, and, indeed, the professional etiquette of the day compelled him rather to seek the surgeon in surgical cases, as Charles D. Meigs sought William Gibson in his celebrated Cæsarean section case, the case where Meigs delivered the woman twice after craniotony, and Gibson delivered her twice by the Cresarean section. Although no anæsthetic was used, the woman declared the knife made the easiest delivery. Such operations have since been much changed and modified, and the child, uterus, and appendages are all frequently removed at one time, as was first done by Porro. I made the eleventh Porro Cresarean section in this country, in the case of a rachitic dwarf 


\section{FORTY YEARS IN THE MEDICAL PROFESSION}

with a collapsed pelvis, complicated with uterine fibroids. The child weighed eight pounds, and the uterus, tumors, and appendages weighed eight pounds. The woman died several days after from exhaustion, but the boy is now a sturdy youth, large and well developed in every way.

General surgery now attacks the abdomen in various ways, and, wonderful, indeed, what appears to be almost supernatural work is done daily; in fact, none of the cavities are exempt from the surgeon's hand; the skull, the chest, and the abdomen are all within his circle. Brain surgery has as yet not produced the most encouraging results, and operations for epilepsy and such affections are unfortunately as yet far from encouraging. In traumatic conditions wonders are accomplished. In the chest also great and successful work is done daily, and anything may be expected as occasion arises. In the abdomen the surgery of the kidney, and even of the liver, is daily expanding, and great relief is now afforded in cases only recently given over to hopelessness and despair. Intestinal surgery shows the most remarkable results: wounds are closed, long lengths of the intestines are removed and the ends joined by various methods, as by Murphy's buttons and such like, and recovery of organ and function follows as a matter of course. Indeed, only recently the stomach has been removed, the ends of the intestine and œsophagus joined, and the patient recovered and enjoyed her food, thrived and did well, thus upsetting all theories of physicians, surgeons, and especially of the physiologists.

Speaking of Murphy's buttons, some time since a successful operator took one from his vest pocket, remarking that it had been through patients fourteen different times, and I think in one of its journeys consumed forty days in its wanderings before passing out. What will not happen! When Proctor Knott made his celebrated speech in Congress, poking fun and ridicule on the young city of Duluth, it was considered a great hit and worthy of a great humorist. To-day Duluth has grown to be a great town, and more than justifies in its reality and greatness all that Knott said of it in fun and 


\section{FORTY YEARS IN THE MEDICAL PROFESSION}

satire, and more, much more. So it is in medicine; it is a progressive science truly, and in the future nothing that may happen can surprise or embarrass us. Even the exaggeration of the old countryman's story, told in the wayside inns of many years ago, may not startle us. He had some bowel trouble, and sent for the doctor. The cloctor arrived, made his diagnosis, and without further formality sent for a sheep, cut open the man and also the sheep, cut off many feet of the man's bowel, did the same to the sheep, attached the sheep's to the man's, sewed him up and left, remarking that the slieep would make good mutton. The doctor some time after, necting his patient, asked him how he felt. "Oh, first rate, doctor, except the beastly hankering I have after grass."

Appendicitis is the trouble that has excited the most interest among both physicians and laymen in recent years. Of course, it has always existed and has always been treated, and in many cases recorered through medical treatment alone, as they do now, and doubtless many cases died that would now be saved by operation. There are, of course a number of troubles in the region of the right iliac fossa which do not involve the appendix, but if inflammation goes on, everything in the end becomes involved. Many cases that formerly passed as obstruction of the bowels, and died as such, probably involved the appendix and its surroundings. Is the condition generally spoken of as appendicitis more common than formerly? Personally I have little doubt but that it is. The causes may be various. It appears to be rather common in young, vigorous men, those who are given to athletics, cycling, and such exercise, especially suffering. it appears to me, although I have no statistics on the subject. Rheumatism and gout are thought to contribute to the cause of true inflammation of the appendix. What effect toxines may have in producing it. toxines introduced by the food or developing from the food are to be taken into account. I think, as a cause, for the reason that we are consuming food, cold-storage food, canned food, and preserved foods of all kinds in large quantities, all of which might be in shape to produce more or less of 
toxine troubles as affecting the digestive tract, far beyond the possibility of such action which the sound fresh foods of former years could possibly have produced. Probably the most frequent cause of appendicitis is the bacillus coli communis, and these very sources of food we have been speaking of, I think, are surely one of the great causes of the increase of such micro-organisms in the bowels of human beings.

Inflammation of the gall-bladder is another disease on the increase, and is also doubtless most frequently caused by this same bacillus coli communis. Thus we see how our knowledge of the cause of disease advances just in proportion as our knowledge of pathogenic germs grows. Appendicitis and cholecystitis are probably the most frequent causes of peritonitis, and both are now cured by the surgeon. This colon bacillus may often cause embarrassment in diagnosis of troubles within the peritoneal cavity. A healthy man may bolt a lot of under-done beef. The digestive juices are naturally antiseptic, and this undigested mass passes to the colon. What a lovely host for the bacillus! They are soon evolved by the million, a subacute colitis is set up, which may or may not run on and involve the appendix and its surroundings, or the bacilli may pass up and involve the gall-bladder; even a rigor and fever may follow from toxæmia set up, and yet in the end there may be no pus, but the patient will be lucky to escape pus formation with all which that implies. The nervous system will play a part; an urticaria may be set up; urticaria is doubtless a vasomotor neurosis, and ptomaine poisoning to a greater or less degree will be responsible for these symptoms. There may be other factors, but I look on these I have mentioned as some, at least, of the causes rendering appendicitis, a grave trouble, of more frequent occurrence than formerly.

Since the developing of antisepsis there has been a revival of operations for the radical cure of hernia. I remember assisting Dr. Agnew in a number of his operations by his method, and one or two did well for quite a long time; but T never thought he greatly favored the procedure as a very 


\section{FORTY YEARS IN THE MEDICAL PROFESSION}

satisfactory one as to results. S. D. Gross never had any faith in the radical cure; that is to say, he gave it little attention as a practical measure so far as my experience with him went. I have seen the result of some good work recently done by Dr. T. S. K. Morton, and so far it is good and very promising as to later results. Halsted, of Johns Hopkins, and Fowler, of the New York Polyclinic, have also lately done some good work by modifications of Bassini's operation, the anterior displacement of the cord. Fowler's modification is somewhat complicated, but seems to greatly strengthen the original procedure of Bassini. Injections of irritants into the tissues about the rings have been advocated and practised, but not with sufficient success in my experience to recommend it, yet I am fully persuaded that sufficient progress has been made in this direction to cause surgeons to give it very careful attention and study. Time alone can show the results in such work, and I trust, for the sake of suffering humanity,one in five suffering from hernia in some form,- - general relief may come in good time to all by operation.

Tracheotomy has seen quite a revival during recent years, and by the work of Wharton, of Philadelphia, and others the mortality has been reduced in these terrible cases of laryngeal stenosis. Intubation, introduced and made an every-day practical procedure by O'Dwyer, has taken the place in a great measure of tracheotomy, especially in children. The trouble in tracheotomy in these cases is to get parents to consent to the operation before it is too late. Intubation comes in most opportunely in just such cases, for almost any parent is willing. to allow the use of the tubes, and they doubtless are destined to save much agonizing suffering and many lives. Besides the many operations on the eyes and ears, and the general operations of the gynæcologist, which are comparatively recent, I may mention excision of the lower end of the rectum for malignant disease. This extensive operation is now frequently done, and $\mathrm{W}$. W. Keen has been very successful in a number of cases. It is wonderful how long those who recover from the operation live before a return of the original trouble. 


\section{FORTY YEARS IN THE MEDICAL PROFESSION}

I know of one case of Ransley's in good health after more than six years. Of course, before the rectum operation a colostomy is done.

Many operations on the brain are now done and are comparatively new, but, as before mentioned, cases other than traumatic ones are not encouraging. IVyeth's method of amputating at the hip is comparatively new, and an improvement on old methods; and so is Gant's operation for deformity after hip-disease. Electrolysis for aneurism, with the addition of Stewart's method by wire, promises some good results in these desperate cases, as does Massey's method of cataphoric treatment in malignant disease. Litholapaxy is an introduction of recent years, and is a great addition to the armamentarium of the surgeon. Aspiration came to us from France, and is one of those methods so simple and useful, the wonder is we did not always have it. Sutures of tendons and nerves, neurectomy, and radical operations on the ear, breast, bones, and joints are among the advances of recent years; and transfusion of blood and injection of normal serum are in high contrast to Mackintosh's bleeding in the cold stage of ague and his saline solution treatment of cholera. The treatment of spinal deformities by application of direct force is very new, and promises good results in the young. Removal of the entire larynx has become an operation any surgeon may now attempt, for Billroth and J. Solis Cohen have, among others, established the precedent, and even an artificial larynx has been supplied. The surgery of the thyroid has made advances, and Green has been a pioneer in method and practice. I might name many other advances and improvements in operative surgery, but what I have said is sufficient to indicate its methodical and rapid advance as a science and an art.

The hot-air treatment, thermotherapy, is coming into extensive use in surgery, and bids fair to afford relief in selected cases, especially in recent sprains and in many forms of joint trouble, both acnte and chronic. Each case is treated from thirty to sixty minutes, and from one to five heatings are used, depending on the condition present. The temperature em- 
ployed runs from $25 \mathrm{O}^{\circ}$ to $35 \mathrm{O}^{\circ} \mathrm{F}$. or even higher. After the heating a protective dressing is applied and immediate use of joint recommended. Charles Lentz \& Sons, Philadelphia, manufacture an efficient apparatus. Fractures and dislocations are becoming more and more generally and better understood, and the masterly work of Allis and Roberts and Hamilton has added much to the simplicity of treatment and to the attainment of good results. Indeed, the whole tendency is to simpler methods and less cumbersome and less complicated apparatus, and surgeons are every day beginning to see and learn that because a man has a broken limb, he is not necessarily to be strung up and bound on all sides like an Indian papoose and made to suffer torture tenfold beyond what his accident has imposed upon him. Among the great improrements in apparatus have been the discarding of the Physick Dessault and such splints, and their substitution by sand-bags and weights. with adhesive straps for extension. and the throwing away of the horrible perineal band, and substituting position to bring about the counter-extension. The fractures that are common, and which have given me in my experience the most trouble and anxiety, are those of the lower end of the radius, the condyles of the humerus, which I have often seen mistaken for a dislocation, the neck of the femur, the clavicle, the patella, and compound fractures of all kinds. The jaw is frequently fractured, and in all conceivable ways, but the jaw-bone is a wonderful bone, and, as the pugilist says, difficult to knock out, and often when we think, from the necessity of the case, we will have a bungle in the cure, this grand old bone comes up smiling and in good shape and ready for another round. The patella is often troublesome. and wiring is now a favorite procedure, with antiseptic precautions. The clavicle is especially apt to be followed by deformity, and in children is particularly hard to hold with the position of upward, outward, and backward. The simpler the dressing the better, and this applies to all fracture-dressings. In compound fractures antisepsis has done wonders for us in relieving our anxiety and saving thou- 
sands of limbs. In fractures at the lower end of the radius, be sure and get in position at once, the sooner the better after the accident, and you have won half the battle. In fractures of the condyles of the humerus and of fractures involving the elbow-joint, treat, as a rule, by placing the arm in strong flexion and keeping it there.

The Röntgen rays are a great help in diagnosing fractures. and the skiagraph picture generally shows the exact trouble. Whilst it is a boon to the surgeon, it may be also a bane, for doubtless many damage-suits will be brought on what it reveals, whether the result be good or bad, whether the surgeon be fortunate or unfortunate, skilled or ignorant.

In surgical and other instruments since forty years there has been great improvement in quality, in style, and general make-up, besides the introduction of a great many new and valuable inventions. During the decade between 1850 and I860, Charrière was the great maker of Paris, and had a world-wide reputation and clientage, and only second to him was Liier, also of Paris. In New York Tiemann was the noted manufacturer, and in Philadelphia were Schiveley, Gemrig, Lentz, Kolbe, and others. Of all the new instruments, counting from forty years back, there is no doubt in my mind as to which has proved of the greatest use and help not only to the surgeon, but to the patient as well. This instrument is the little hæmostatic forceps, with the scissor handle and the aseptic joint. Take, for example, a case of excision of the mammary gland, and let one follow a rapidly operating surgeon, and with the old-fashioned tenaculum and forceps catch up the bleeding vessels. You stick, you jab, you pinch, and after a while you get them, the surgeon or an assistant stops and ties, and goes on; again you stick and jab and pinch; the surgeon stops and ties again; and so on to the end of the operation. Much time has been consumed, and your patient has lost nuch blood, enough, indeed, possibly to turn the scale against her. With the hæmostat all is changed; the surgeon operates rapidly, as a vessel bleeds, the hæmostat clicks in the hands of an assistant, he drops it, the hem- 
orthage is checked, and the surgeon goes on, and soon completes his work. After this he leisurely ties off and removes the hiemostat, and the whole operation is finished and an infinitesimal amount of blood has been lost. The hæmostat was a gift to the profession from the gynæcologists, I think from the great French surgeon Pean, and they use them in all shapes and in all sizes, and thus save themselves much wear and tear, control their tempers, and rescue many imperilled lives. The Röntgen rays are coming more and more into use as aids to diagnosis, both in medicine and in surgery, and I have by me now a good illustration, where, among the first in this country, and surely the first in the State of Delaware, Dr. William H. Hancker, superintendent of the Delaware State Hospital, at Farnhurst, in the suburbs of New Castle, located a ball in a lad's foot, a patient of mine, that had been buried there for several years. At the present time it is possible to obtain a skiagraph of almost any foreign body or lesion.

There has been a general evolution of electrical devices to the benefit of medicine, which it is not necessary to refer to here. In catheters there has been marked improvement, and to-day the soft-rubber instruments are effective for all purposes, and in great contrast to the wretched metal devices of years ago. Professor Kelley, of Johns Hopkins, catheterizes the uterus and thus assists greatly in the diagnosis of renal troubles. The centrifuge is a great help in microscopic work, and is one of the new and valuable instruments recently perfected. Uterine dilators are of many kinds, metal and rubber, and serve their part as helps to gynæcologists and obstetricians; so do cephalotribes, axis-traction forceps, and different specula; wires of different metals, the animal ligatures and sutures, atomizers, various new styles of tourniquets, and elastic bandages are among the great helps to the modern surgeon worth mentioning in this connection. The endoscope has been in use for some years. We harl it tried in Blockley in $186+$ in the urethra, but not with great practical success. The laryngoscope was then new, and Dr. J. Solis 


\section{FORTY YEARS IN THE MEDICAL PROFESSION}

Cohen first used it in that hospital, and as one of the masters in that work has lived to see its use extend to all parts of the world where civilized man has a foothold. Different forms of suspension apparatus and jackets for spinal deformities have come with recent years, and are now indispensable in the treatment of all such troubles, and success has increased pari passu with their advent. The improvement in rubber goods has given us very perfect stomach-pumps, stomach syphon tubes, and feeding-tubes, and these have caused great advances in the treatment of stomach ailments and in feeding the recalcitrant insane and those who from any cause are unable to swallow.

I will speak of one more instrument, one of the most valuable we possess, and one that has done so much to soothe the pains and keep up the courage of suffering humanity, and that is the little hypodermic syringe. The first one I ever owned I bought of Lïer, in Paris, in I866, and to this day it has served me well. It is first class in every respect, has gold needles, and I have used it continually in all kinds of cases, in all kinds of diseases, and with many and various fluids, and it has never failed me. I have seen numerous patterns, and have several, one without a piston, and easily made aseptic, but none better than my old Parisian friend. During my experience in the United States army of more than two years, from i 862 to I 864 , I never saw one or had seen one, and I do not remember that they were on the list of hospital supplies. I know, in Philadelphia, in I860, the favorite anodyne was an enema of fifty drops of laudanum in a tabespoonful of warm water or thin starch, or a rectal suppository of butter of cocoa, with a sait of morphia or extract of opium or powdered opium, in combination sometimes with belladonna or some such remedy. Where the hypodermic syringe originated I do not know, but I have a suspicion that the hypodermic method of administering remedies was first used by a physician in Wisconsin or Iowa, or one of our northwestern States; and if so, he probably had the first instrument.

The clinical thermometer is another instrument not appre- 
FORTI YEARS IN THE MEDICAL PROFESSION

ciated by those who have entered the profession in recent years as it is by those who can compare its every-day use with the times when we were without its airl. It is a help of the very utmost importance, as every one knows, in the general treatment of cases and in diagnosis. Take a case of suspected appendicitis: here the thermometer is our right-hand weapon in giving us hourly temperatures, and in from twenty-four to forty-eight hours we can almost allay or confirm our suspicions. So in suspected incipient tuberculous troubles, the daily moderate erening use of temperature. should the case present such a chart for a number of days, would go far to put us on our guard for further confirmations. 


\section{CHAPTER VI.}

Post-Mortems, etc., Forty Years Ago-Treatment of Pneumonia Then and Now-Heart-Troubles-Digitalis, etc.-Auscultation and Percussion-Vivisection-Improvements in Pharmacy-Dangers in DrugsSugar-Coated and Compressed Literature-The Blood-The Trolley - The Bicycle-Preventive Medicine-Diagnosis-Wall Diseases-Nitrification-Malthusian Theory-Diphtheria-Croup-Sir Morrell Makenzie-Tetanus-Immunity as to the Sting of the Honey-Bee.

Forty years ago there was little known of bacteriology as a science, and little heed was taken of such matters in medicine. Pathology was in its infancy as compared with the present day, although Wünderlich and Rokitansky were laying the foundation for great advances along all lines. In the post-mortems made in the hospitals in this country at the period of which we are speaking, say previous to 1866 , the eye and the touch were the chief aids brought to bear in examining specimens.

There were few expert microscopists available, and the work done was of the most primitive kind. Learned professors had their own ideas and opinions, and these ideas and opinions were generally derived from some one equally emphatic who had preceded them, probably amplified from time to time as light gradually began to show itself on the medical horizon. Yet most of their ideas and opinions had not fact, scientific or otherwise, for their basis, but an absolutely empirical origin; in other words, true science had not yet dawned upon medical practice and medical thought; and this was not long ago, either, but in full memory of many of the most active men in the profession to-day. The treatment of a case of croupous pneumonia at this period will well illustrate the condition. Auscultation and percussion were well understood, and the physical condition of the lungs would have been carefully noted. Bleeding from the arm had well-nigh yielded as a remedy, but wet cups would probI 26 
ably have been applied and veratrum viride have taken the place of the lancet. The temperature would have been judged by the touch, if any thought had been given to it, and the pulse at the wrist would have been the guide as to the patient's condition, together with the noting of the respiration and the character of the sputa. Antimony would probably have been given in the first stage, with the antiphlogistic diet, but not too much water. In the second stage calomel and opium would have come in, and in the latter part of this stage blisters to the involved lung; and after this some increase of notrishment, and alcohol. probably, to some extent, if the physician in attendance was an advanced thinker. Note the difference to-day: The physical and rational signs would be most carefully noted. the temperature, as indicated by the thermometer, would be scrupulously watched, so the pulse, the respiration, the condition of the skin, the stools, and the sputa, the latter studied microscopically and otherwise. The jacket poultice, or, much better, the dry jacket, would take the place of the wet cups and blisters, and ice-bags might possibly be applied, or cold sponging. Strychnine would be used as occasion required, and digitalis with scrupulous care, watching it when the heart is weak and the lung solid; with alcohol also, and probably the inhalation of oxygen, and possibly subcutaneous injections of cultures of the pneumococcus.

Liquid air, or, rather, liquefied air,-which is the air we breathe deprived of its heat, which heat came originally from the sun,-it is claimed, can now be produced commercially, and this being true, we can get air absolutely free from germs, can cool such apartments as hospital wards and keep them at a temperature when germs of contagion will not propagate, and if we need the stimulating effects of an excess of oxygen free from the contaminations which now are so objectionable to its practical use, we can get it at will.

Now, as to the difference in mortality between the two treatments. Medicine is now a progressive science, and I trust the mortality in croupous pneumonia is decreasing, but it is well to remember it is a self-limited disease, and not be too 


\section{FORTY YEARS IN THE MEDICAL PROFESSION}

active in treatment in all cases. I believe the sheet-anchor in the treatment of this disease to-day to be good, sound, dry champagne. If from any cause the inky dry French wine cannot be obtained, get the dryest American wine you can find. If this cannot be gotten, use the best sherry or other wine you can get hold of, in equal parts of carbonic acid water. The carbonic acid gives zest to the drink, whatever it may be, and appears to me to have some specific action in all diseases of the respiratory tract.

As to digitalis, one of our most useful remedies, I know of no medicine which is oftener used ill advisedly, wrongfully, and ignorantly. To speak of a remedy in heart lesions, or functional heart disturbances of any kind, is a suggestion to many medical men of digitalis, with no thought of scientific or rational basis for its use. Improperly arministered, it may and perhaps does cause or hasten sudden death. Take a case of aortic insufficiency: acting through the motor ganglia of the heart, it stimulates the ventricular contractions, thus overwhelming the heart by the increased back current of blood and causing instantaneous stoppage and death. Thus a man's chin drops, and he is dead whilst talking to you. In aortic stenosis we probably always have compensatory hypertrophy; when this begins to fail, the patient's condition becomes very uncomfortable. Digitalis may befcautiously ventured on here, for it undoubtedly has a tendency to hasten and keep up compensatory hypertrophy, but I am very chary of it in all lesions of the aortic valves. In pure hypertrophy of the heart never use it. It increases blood-pressure fearfully, and puts a fearful strain on the capillaries and even larger vessels of the brain, and the kidneys particularly. Some combine it with nitroglycerin and strophanthus to counteract its force. Although strophanthus itself lengthens diastole, and thus increases arterial pressure, it does not change the caliher of the vessels through the vasomotor system. In mitral stenosis and mitral insufficiency digitalis is useful and gives great comfort in these distressing cases so often accompanied by dropsy and cardiac asthma. In mitral stenosis the 


\section{FORTY YEARS IN THE MEDICAL PROFESSION}

orifice is narrowed, and is therefore too small to let out the column of blood that must come through in a given time, therefore the heart struggles and hurries and wabbles, of course the auricle behind dilates, the right side of the heart becomes congested, and on the left side the blood-pressure is lowered. Here digitalis comes in: it gives force to the ventricular contractions, and thus does away with the bad effect of dilatation; diastole is also lengthened, and the auricle can now have time to empty itself. This action of digitalis is also a tonic to the heart-muscle itself through the coronary arterial circulation, and helps over the venous blood to the red circulation, thus relieving congestion. In mitral insufficiency it is also of the greatest use. Here we want to make contraction short, sharp, and decisive, and to lengthen expansion. After this has been accomplished, in order to check the too great effect of the digitalis in increasing blood-pressure, we may add nitroglycerin, or, as Da Costa does, nitroglycerin, belladonna, and strophanthus.

It has been suggested by Jacobi and other good authorities to be very careful of the use of digitalis in the aged. Here it has an unfavorable action on the arterioles of the heart. interfering with its nutrition, and thereby interfering with the general nutrition of the individual. Combining it with nitroglycerin will in a measure remedy this defect.

My experience leads me to look upon strychmine as the great heart tonic to be used in shock, and it should be used in full doses subcutaneously. It acts by stimulating the vasomotor centres, contracts the capillaries, also stimulates the ragus, and thus checks too rapid action of the heart. The caffeine in coffee is a good heart stimulus: it tends to lessen the number of beats in palpitation and increases their force. It does this, perhaps, by its action through the vagus. Veratrum viride decreases vascular tension, but is a remedy to be watched very closely. So nitroglycerin reduces blood-pressure and is quick and rapid in its action, and is a great boon to sufferers from angina pectoris and other troubles caused in part or altogether by high blood-pressure. Aconite also 


\section{FORTY YEARS IN THE MEDICAL PROFESSION}

acts in the same way, but is a depressant where nitroglycerin is a stimulant to the action of the heart; and this is most important to remember. Nitroglycerin acts like a strong man at a pump pumping fluid through hose; with his brawny arms he rushes the pump, and by this very force he expands also the hose, and thus the pressure is less than it would be should a weaker man have been at the pump, who had not strength enough to expand the hose, which here may represent the blood-vessels.

I find the convallaria majalis, the root of the beautiful little early spring flower, the lily of the valley, an effective heart tonic, and very useful in weak persons who are subject to attacks of palpitation, or where there may be a suspicion of fatty heart. It and strophanthus make a most useful combination. In the very common trouble of intermitting heart of a purely functional nature.-not the irregular heart, which is a very different thing, - a combination of strophanthus and convallaria will add to the tone of the heart where such a remedy is needed, and is far preferable to digitalis, so often illadvisedly used under these conditions. I know little of sparteine or broom-corn from personal experience, but would be inclined to use it in hysterical palpitation. Quebracho bark has been vaunted as a remedy in dyspnœa, but repeated trials have always failed to produce any effect whatever in my hands. The one generally used is the white quebracho, Aspidosperma quebracho. Quebracho gum, the dried juice of Schinopsis Lorent, two drachms, might be more effective by increasing the oxygen in the blood-cells. In aortic regurgitation,--one of the most difficult forms of valvular heart trouble to make out by the ear, I think, but comparatively easy when the additional symptoms of attacks of dyspnœa come on,-cactus is the remedy. It shortens and makes systole more snappy, lets up the blood-pressure, and makes the beats fewer. This is what we want in this most serious trouble. These patients may also drink strong coffee, as the effect of the caffeine will be good, and cocaine is not contraindicated; but look out for general anasthesia. When we give 
opimm, we increase the blond-pressure, and with ergot we do the same and decrease tendency to capillary hemorrhage by its stinntating action on the vasomotor nerves; but some leny this. When we wish to lessen the force and frequency of the pulse and lower arterial tension, we take the nitrites, the bromides, - particularly the strontium bromide.-and the antipyretics, and thus gain the wonderful control we now possess over annoying and distressing trotibles like angina pectoris, which formerly we and our patients had to grin and bear.

Speaking of angina pectoris, my experience leats me to the belief that it is most common among those who live sedentary lives and do much brain-work. I believe it is more common among students, literary and professional men, than other people. and it is especially common among those who apply themselves more or less constantly to desk work, the local pressure here possibly acting as a cause. The Schott treatment of heart disease by carbonic acid baths and muscular movements is creating some stir in Germany, probably more general than professional stir. I have had no experience with it, nor can I altogether imagine its rationale. One thing. remember: in all cases of organic heart tronble, the first and greatest of all remedies is rest of mind and body, and as near perfect rest as it is possible to attain in the given case: and next to rest, the proper climate for the individual, where his environment gives us a choice of a mode of life.

IVell, pardon me, I did not start out to write a treatise on therapentics, but such matters are of the first importance, and we cannot give them too much thought to insure the safety and comfort of those committed to our care.

Whilst auscultation and percussion have been elaborated in different ways both by men famous in these specialties and by the invention and adaptation of new instruments, we are to-day not much more exact in our diagnoses than were Avenbrugger, who inventer percussion as applied to the diagnosis of disease, and Laennec. who invented anscultation. Their work has been carried on by such men as Andral, Louis, 
and Skoda, in Europe, and by Cammann. Gerhard, Da Costa, and others in this country. Laennec's original instrument was a single cylinder, and is the instrument that has been used most in America. Cammann invented the double instrument. I started with this in my student days, and have always used and preferred it. It is now gaining in favor. which gain may be much ascribed to the fact that so accomplished and able a diagnostician as Osler, of Johns Hopkins, recommends and uses it. A recent invention, the phonendoscope, with some of its principles modelled after the telephone, is coming into use, and I can testify from personal experience that it is of great use in differentiating sounds. and making diagnoses in many cases easy. Auscultatory percussion is growing in favor. I have used it myself for many years. It can only conveniently be practised with the binaural stethoscope. After all, we become accustomed to different methods and different instruments, and of course we become prejudiced in favor of those old friends who have served us well for a long time. and are conservative as to adopting new tools. This is the great reason why many really great improvements are slow of finding general favor.

With the introduction of auscultation, percussion, and other and various methods, the diagnosis of disease became the most fascinating part of medical study, and everything else yielded to it. What little attention had been paid to pathology, histology, microscopy, and therapentics especially were neglected. The great aim of the physician was to become an accurate and acute diagnostician. Skoda was the great leader in Europe. Alonzo Clark, Austin Flint, Gerhard, and Da Costa, and later. Musser and Osler, in this country. I remember hearing it said of one of these eminent men, that when asked why he did not write a work on practice, he replied, he could not do it, for the treatment of clisease he considered so unsatisfactory he could not conscientiously advise in such matters in a work on the practice of medicine.

Even so great a man as Marion Sims lad little faith in remedies. I remember of hearing that his medical adviser 
and friend, a few days before his sudden death, suggested that he take some prescription for the heart lesion from which he was suffering. Sims replied, "No, I have little or no faith in remedies." But medicine is a progressive science now, not a mere empirical art, as it once was, and not long ago either, and happily this era of therapeutic nihilism is rapiclly passing away, not from fashion, not as a fad, but it has been driven to the wall by the onward march of progress and reform. We are learning much from chemistry, from physiology, experimental and otherwise, and from nature generally, and great credit is due to men like Horatio Wood, Hare, Welch, Vaughan, and many others for the great work they have done and are doing in practical therapentics and practical physiology.

There is an ill-adrised movement now on foot engineered by many good people with mistaken zeal to pass an act against vivisection. If any wanton cruelty is practised by men engaged in such experimental work, there is ample law now possessed by the Society for the Prevention of Cruelty to Animals. In this work there is no wanton cruelty, but it would be wanton cruelty personified if the knowledge that has been gained from such work and applied for the relief of suffering in man should be cast off among the lost arts and no longer be arailable for the use of physicians. Where would intestinal surgery be, where would be our knowledge of serumtherapy, or where would be all, or nearly all, we know of bacteriology, which as it expands is surely leading to the annihilation of all zymotic diseases which are now the great factors in sapping the lives of the fairest and often the younger and most useful of the human race? The honest vivisectionist works not for any selfish motive: of all men, such experimenters are usually the most unselfish. Many of them live in garrets, and their most elaborate repast is frequently a crust. They have none of the motives urged on by insatiate ambition and pride, such as Willis ascribes to Parrhasius when he makes him say as he looks upon the writhings of his poor old slave, whom he is torturing to death, the better to 
get the expression of hopeless horror with which to adorn his great painting, Prometheus, whom he was about to paint:

"' 'Pity' thee! so I do!

I pity the dumb victim at the altar,

But does the robed priest for his pity falter?

I'd rack thee though I knew

A thousand lives were perishing in thine:

What were ten thousand to a fame like mine?"

Not on these lines does the scientific man work, but his only ambition is to induce nature to give up the secrets she may hold inimical to the health and confort of man, and in this great and noble work, practising constant restraint and selfdenial, he asks no reward beyond honest recognition and a free and untrammelled going out and coming in among men, such as is accorded to the meekest and most lowly among us.

Pharmacy and chemistry as applied to manufacturing have made great strides in the last few years. The active principles of medicines, being of very small bulk, are now dispensed in little tablets of almost infinitesimal size, and are in great contrast to the great powders and pills and boluses of former days. Think of a dose of quinine, and then think of the dose of ground bark your grandfather had to take to get the equivalent of the alkaloid in your small tablet. Pharmacentical preparations now are really artistic and beautiful to look at, and I have no doubt when honestly prepared are far more efficient than those prepared by the old methods. There is one danger, and by no means an insignificant one, and that is the palatable and attractive way preparations are put upon the market containing stimulating remedies, such as opium, cocaine, kola, alcohol, and so on ad infinitum. Physicians cannot be too careful in prescribing such dangerous drugs. Unfortunately the physician controls only a small part of the output of such preparations. The general public takes them self-prescribed, or recommended by the vender, and thus the nodern drug-store becomes an element of danger to the community, second only to the modern saloon. These matters need attention. No proprietary preparation containing opium, 
alcohol, cocaine, or such dangerous drug, should be sold withont the fact of the amount of each in each prescribed dose being plainly printed on the wrapper. Many goor people would stand in horror did they see such information on what they are often buying and taking now as harmless "liver regulators" or innocent "blood-searchers." In fact, in many of them they get a good morning eye-opener, a mid-day cocktail, or a composing niglit-cap in each dose; whether it be composed of opium, chloral, alcohol, cocaine, or what not, it brings the answer, and the poor deluded dupe is soon on the road to some form of intemperance, with all that the name implies. However, quackery and quack doctors have always existed. and probably will continne to thrive until the people are better informed and better educated in all that pertains to the good and comfort of their bodies, the depth of their pockets, and the salvation of their souls.

It is humiliating nowadays to pick up many of our daily newspapers. Many of the most prominent ones have advertisements in them that are utterly immoral, utterly obscene. and utterly unfit to come into the home of any decent man; indeed. some of them are unfit for the abode of strumpets. The pictures of so-called distinguished men, of governors of States, of Congressmen and clergymen, are especial favorites in the picture column. Could anything be more vulgar? Could anything be lower or more common? God save us from such rulers, God protect us from such influences, and purify at least in some small degree the newspaper press of the world! The literature put out by the great manufacturing drug-houses is, some of it, very good, well written, well digested, and gotten up by bright men, and, making due allowance for the exaggeration of zeal for trade, is useful to the profession, notwithstanding it has frequently been railed at and derided as worthless and worse than worthless, and as literature both sugar-coated and compressed, and warranted not to pass the alimentary canal undissolved.

Many men in the profession have little time to rearl. and do not take what time they have; some have no books, and 


\section{FORTY YEARS IN THE MEDICAL PROFESSION}

are unable to buy them; some will not read. These little brochures scattered about promiscuously from time to time by the great drug-houses fill a want among these people and disseminate much useful information.

Among the remedies introduced since I entered medicine, amyl nitrite strikes me as one of the most useful. If it did no more than relieve the pain and anguish of angina pectoris, it would be an invaluable remedy, and we owe much to Brunton, the great English physician, for having found out its merits in this distressing disorder. It also gives instant relief in those cases of hysteria where we find the patient suffering acutely with the bolus hystericus, or with the convulsive form. A few whiffs from a few drops on a handkerchief, a sudden flushing of the face, and the storm is over. In true functional spasmodic asthma it is also effectual and safe, and in the spasmodic pain of dysmenorrhœa and allied troubles.

Nitroglycerin, trinitrin, or officially U. S. P. glonoin, is a new remedy of great usefulness and power. It serves about the same purposes as amyl nitrite, but is more capable of general use, by the mouth and so on. In weak heart, in asthma, and in convulsive troubles it is a wonderful remedy, and can be used whenever we need to lower the blood-pressure. The new antipyretics-the so-called coal-oil derivatives, antipyrin, acetanilide, phenacetin, and such like-have proved great boons to the medical man, and have given him effective weapons with which to control many ills both great and small, and whilst in the hands of the profession they have done great good, done away with Dover's powder, sweats, and all such abominations of the by-gone days, yet, nevertheless, they have been subjected to great abuse by laymen, and doubtless are responsible for many deaths not directly traced to them. Every drug-store, and, for that matter, even many bar-rooms, have them for sale to any one coming in under the guise of Dr. Somebody's headache powders, and guaranteed to be harmless. These preparations, above all others, should not be taken without proper supervision, and their 
promiscuous sale should be stopped. 1 can testify from personal experience to the good effect of antipyrin in strong solution as a hemostatic in nose-bleed. bleeding after tooth extraction, etc.

The introduction of the ductless glands is also recent, and wonders have been accomplished in myxuelema by thyroid feeding. It las also been used in certain forms of insanity, but success to any extent has not followed this use of the thyroid, and the same may be said of its use in syphilitic skin affections; yet I believe I would try it in these troubles if myielding, and also in obesity, with proper diet, if it amounted to a disease. I have seen it clo wonders in leg ulcers. The thymus gland is also used as a remedy, but little success has as yet come from it. The suprarenal capsules are used in Addison's disease, and success enough has been recorded to give us hope in a hitherto hopeless malady. The nose and throat men are also using it as a hamostatic in their operations. The mammary gland has been recommended in the treatment of uterine fibroids, and the parotid gland has been used for the cure of ovarian disease. These applications will doubtless be further elaborated. Indeed, all sorts of glandfeeding appears to be going on, spurred up by the recommendations of the late Brown-Séquard, with the result that a tendency to quack the whole business has come about and thus for a time clone injury to true scientific investigation and application.

Of all the introductions of remedies into the profession since my advent into it, that of serum therapy has been the most far-reaching, and, being based on true scientific principles, is the most astounding. I do not propose to discuss this theme here, but will speak of it more at length farther on. Nitrous oxide gas has been introduced within a few years, and has proved a great boon to those compelled to have teeth extracted, and may be used in minor surgical operations of short duration. My experience leads me to decry its use where we want muscular relaxation, as in the operation for fistula in ano, for the sphincters are rigid, not relaxed under 
nitrous oxide gas, and this rigidity embarrasses us in such operations. Salicylic acid, sodium salicylate, salol, and strontium salicylate have been wonderful acquisitions to one who was compelled to treat rheumatism particularly, and also gout and uricacidæmia generally by the old remedies. Rheumatism had about exhausted the pharmacopœia, and rheumatic fever often meant from three to six weeks' suffering, not to speak of the sequelre. I find strontium salicylate, while less soluble, to agree in some cases better than sodium salicylate, and vice versa. Why I know not, but the same thing occurs with potassium iodide and sodium iodide. In rheumatism I appear to get the best and quickest results from ten-grain doses of the salts, sodium salicylate, or strontium salicylate, given in capsule or mixture. If in mixture, add sufficient liquor ammoniæ acetatis to clear the liquid. Horatio Wood recommends giving salicylic acid in officinal oil of gaultheria in ten- to fifteen-minim doses. In gout this acts well. I am fond of a capsule containing twenty centigrammes of methyl salicylate, $\mathrm{C}_{7}\left(\begin{array}{l}\mathrm{H}_{5} \\ \mathrm{CH}_{3}\end{array}\right) \mathrm{O}_{3}$, and one-(puarter of one milligramme of colchicine. I always like a little colchicum with the salicylates in gout. Two of these may be given at a dose as occasion requires. They are a French preparation.

Carbolic acid has been introduced of late years, and is so useful in many ways, and another contribution from the wonderful coal-tar. Trional and sulphonal are great helps, which we who were in the profession twenty-five or more years ago had to do without. Now with their use we can give a patient comfortable and safe sleep, where before we had only opium and its salts, whose sequelre are so seriously annoying, and chloral, and even this last does not go back far. As between trional and sulphonal, I prefer in every respect trional. If there is great pain, add a grain or two of svapnia or a modicum of codeine. Formaldehyde is a recent addition as an antiseptic, but mostly used under the name of formalin. Horatio Wood says formalin is a forty per cent. aqueous solution of formaldehyde. Merc's formaldehyde is a forty per cent. solution of formal!ehyle also, and therefore the sane as forI. 38 
malin, which is a proprietary preparation, and therefore more expensive. When you order, order merely a simple solution of formaldehyde. One to twenty with water will give you a two per cent. solution, strong enough for surgical work; one to forty a one per cent. solution, strong enough for gargles or mouth-washes, or for applications to abrasions and skin troubles, as a rule. A ten per cent. solution will harden specimens for section for microscopical work. After using formalin or formaldehyde, two per cent. in surgical work, I find it difficult to remove blood-stains at once, but they disappear in a few hours, and everything looks clean. It is doubtless a strong germicide in even one per cent. solutions, but whether or not it will entirely take the place of heat and corrosive sublimate and other aids in surgical work, my experience with it being limited, I cannot venture an opinion. I trust it will, for it will save much trouble and make antisepsis and asepsis easier and more pleasant.

Horatio Wood, in the last edition of his " Therapeutics," speaks of formal-gelatin, brought forward by Dr. C. L. Schleich, as a valuable wound-dressing. It is non-irritant. non-poisonous, and when brought in contact with wounds undergoes decomposition with the liberation of formaldehycle, and the consequent complete destruction of all septic organisms. This, if effective, would be a grand addition to the armamentarium of the surgeon.

As long as I can remember, the great tonic, and the one almost miversally in use, has been a combination of iron, quinine, and strychnine. The formation of a proper portion of hæmoglobin in the red blood-corpuscles was thought to depend on the amount of iron taken up by the corpuscles. There is a disposition among physiological chemists to den! that inorganic iron salts are absorbed. that they do not appear in the urine, and that all go off in the fecal discharges, which they blacken by meeting with sulphur in the alimentary débris. These same chemists claim, of course, that iron organically combined, as in foods, is absorbed sure. Thus claiming, these men have gotten up, and are getting up, preparations of iron 


\section{FORTY YEARS IN THE MEDICAL PROFESSION}

organically combined. Such preparations are dried blood, nucleo-albumins, hepatica-ferruginous preparations, and such. Extended trial has not yet convinced me that inorganic iron does not in some way influence the red blood-corpuscles for good, and I am not yet convinced that the new preparations are any more effectual, if as effectual, as the inorganic salts. Let me say here that continued use of these new preparations of iron and iron and manganese, as the peptonized albuminates and such, organically combined, is beginning to give me great confidence in them in many diseases, particularly of the wasting diseases, and I begin to feel that we have a therapeutic weapon more powerful than any we have even dreamed of before, which is destined to supersede all the inorganic salts of iron and such materials. If this is true, real science is driving out ignorance and mere conjecture.

Tincture of chloride of iron and Basham's mixture are the best forms of giving inorganic iron, to my mind, and the tincture of the chloride given in milk is among the greatest of all organic tonics. Drop the iron in a little water first, then add to milk, and it will not coagulate, and is pleasant to take. Remember one thing: used in any way it is hard on the teeth, should be taken through a tube run far back in the throat, and the mouth should at once be rinsed with an alkaline wash.

Piperazin is a new remedy recently introduced, and one which my slight experience in its use leads me to think is a valuable addition to the Pharmacopœia. I have no faith in its dissolving stone already formed in the bladder, unless it might be brought about by injecting directly, although it soon passes by the kidneys. I am now using it in a case of diabetes, where strictly non-starchy, non-saccharine diet cannot be kept up. Since giving it in five-grain doses three times a day, the specific gravity has fallen to IO28 and 1029, where before, under the same conditions, it ranged at I035 or over. It is supposed to check some of the sugar-forming influences on some of the blood ferments, I believe. I used it with great apparent success in the most exaggerated and persistent case of uric acid gravel I ever encountered. For several years 
a gentleman of forty, at the conmencement of his trouble. had attacks of renal colic every two or three months. He was temperate as to drink, but intemperate as to diet for one afflicted as he was. I have known him to pass seventy small calculi of uric acid in one attack, and altogether I am afraid to say how many he passed, but a very large number. After this had been going on for several years. I put him on piperazin, five grains, three times a day, in water on an empty stomach. He took it steadily for nearly six months, then stopped two months, then took it again occasionally for a week or two at a time, and then stopped it altogether. He only had one attack after he commenced the remedy, and now has not had an attack for over two years, and has not been careful with his diet either. It acted as a diuretic moderately with him, darkened the urine, and reduced somewhat the quantity of urea. No bad or umpleasant symptom of any kind resulted from its use.

These uric acid cases are such peculiar cases; a man is too vigorous, as it were, to be healthy, the very opposite of the feeble anæmic man, as can be so readily shown now by our improved methods of diagnosis in estimating the bloodstrength as to its corpuscles and other constituents, all of which is so readily shown by the improved microscopes, the hæmocytometers, the hæmatokrits, the hæmoglobinometers. and so on, instruments and methods we who entered the profession forty years ago never dreamed of. The hrmoglobin of the blood, of course, may be lessened by the lessening of the number of red corpuscles or of the coloring-matter of the red corpuscles, and an easy test of the amount of hæmoglobin is by the specific-gravity test, a table of which Dr. E. Barker, the pathologist at the Delaware State Hospital at Farnhurst has kindly prepared for me. Mix chloroform and benzole to make a specific gravity of I059, about that of normal blood. Chloroform is heavier than blood, and benzole is lighter. Drop a drop of blood from a pipette into the mixture of chloroform and benzole. If the drop sinks to the bottom, add more chloroform: if it rises to the top, add more benzole until 
the drop remains stationary in the body of the liquid. Now note the specific gravity of the liquid, and this denotes the specific gravity of the drop of blood. Have all instruments clean, and add chloroform and benzole drop by drop, stirring with a glass rod. This test is not reliable in cases of dropsy.

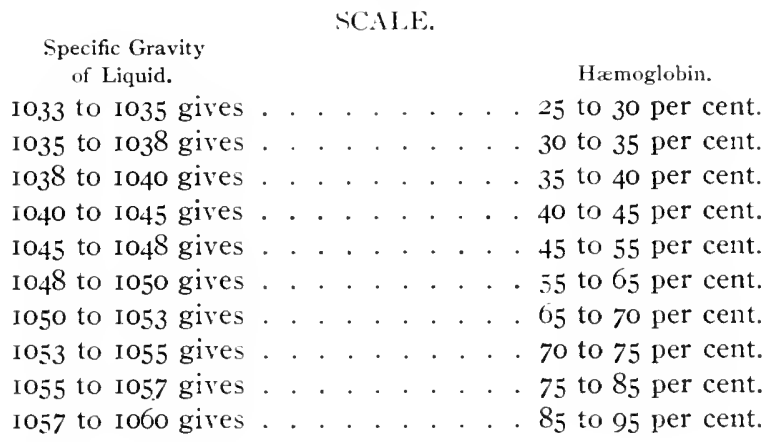

Dr. William H. Hancker, Superintendent of the Delaware State Hospital at Farnhurst, has given me an outline of a method of determining approximately the deficiency in the red blood-corpuscles which is simple and useful. The glass tube of the centrifuge is graduated to Ioo; on turning it, say, two and one-half minutes, the red corpuscles will gravitate to one encl. If it registers 50 , or about one-half of the entire amount, the blood is proximately normal, or between five and six millions of red corpuscles to one cubic centimetre. If it goes below that, the reading can readily be understood. In other words, if the red corpuscles show only to about 25 , it means that the red corpuscles are only about one-half the quantity they ought to be.

The practical application of the Röntgen rays, already spoken of, to medical diagnosis is merely dawning, and time alone can tell of the perfection to which it will be brought. It is not safe to predict that we may not soon be able to see clear through a stone wall. The centrifuge is another little instrument of great use and recent introduction, and adds greatly to our exactness in the examination of all fluids. The aspirator is another great help, from the little hypodermic 
FORTY YEARS IN THE MEDICAL PROFESSION

syringe, which often makes a very good one for diagnostic purposes, to the one large enough to aspirate the larger cavities of the body. We are indebted to the French for this instrument, the invention of Dieulafoy.

The great discoveries in electricity and its application to medicine have been of great help in many ways. I look upon the introduction of the trolley as a wonderful therapentic agent. It is a cheap and, with its steady, even motion, a very pleasant way of getting about. It is a great factor in persuading sedentary people to breathe fresh air, to mingle with the crowd, and to take at least passive exercise. To a man or woman fatigued by a hard day's work, and perhaps weakened and enervated by excessive heat, a fanning up by an hour's ride in the trolley has a wonderfully refreshing effect: the tired, nervous feelings vanish, and sleep comes readily, bringing renewed strength for the work of to-morrow. One thing beware of,- the trolley cold is so often taken in the open car. As a rule, this can always be avoided by wearing a silk handkerchief around the neck whilst in motion, and never getting on the car when perspiring. The electric fans are also of great use for general comfort, and especially so in the hospital or sick-room. Be cautious here, and avoid drafts from these sources also.

The bicycle, too, I look upon as a great therapeutic factor when used rationally under medical supervision. We are bound to see the effects of its use apparent in the coming man and woman. The bank clerk, the stenographer, and such persons now have some resource for recuperation after long hours of incessant labor, and a ride on the wheel sends them home not exhausted, but rehabilitated in mind and body, their organic functions are kept active, and the channels of excretion and secretion are no longer clogged for want of the proper stimulation of healthy exercise. Another great factor in improving the health of communities, and thus reducing the death list, is the improvement in the water supply of cities and towns, and even of individual premises.

The driven wells, in place of the old-fashioned large dug 
wells, are a great improvement in the low countries; surface contamination is thus avoided and pure water is more easily obtained. The extensive filtering-plants now being put in by cities are moves in the right direction, and the results are very encouraging in decreasing the prevalence of zymotic disease where such plants have been in operation. There is yet only one way to have water absolutely safe, and that is to boil it to absolute sterility; but filtering-through sand particularly - mdoubtedly remores many and great dangers.

The intelligent physician, especially in communities removed from centres, should have supervision over all these matters appertaining to the economies of life. Indeed, I think one of the great factors in the usefulness of the physician will be in preventive medicine. In public matters that is now making great stricles, but I refer particularly to the relation to families in private life. All families should be under the supervision of an intelligent all-round medical man. All the environments of the home should be supervised; the enviromments of the individual should be supervised; then the physician will know in time and have some warning of the approach of many illnesses and be able to warn those interested. As it is now, often we are summoned to some fair youth with a report from parents that a bad and persistent cold is the only trouble, when examination reveals a brokendown lung, and a condition of well-advanced pulmonary tuberculosis, and the case almost hopeless as far as remedies are concerned. With competent supervision of a medical man over that family, observation, with the finding of a slight rise in the thermometer every evening, would have called attention to the true trouble months or years before, and this early finding out of the cause gives the only shadow of hope in these sad cases. Such a case illustrates the necessity of such general medical supervision of families, and herein rests one of the great usefulnesses of the physician, and in this sphere he is bound to work more and more as the evolution of a perfect civilization progresses.

The physician, of course, naturally should be an observant 
man above all otlers, and, more than this, he should cultivate habits of the most careful observation. It is very easy to be tripped up in diagnosis by very simple matters, and practice alone makes perfect, but practice does not help unless backed up by acute observation and general knowledge. No obscure case, in fact few cases, should be treated without a thorough examination of the urine. No one but the physician knows how much knowledge of cases we gain here. What woful mistakes are made by a neglect of this procedure, not only in missing the direct cause of the disease in question, but also in showing up collateral troubles and complications to give cases! How depressing to meet a case of renal asthma, for instance, and find it has been treated for every other disease which may possibly cause dyspnœa except the right and proper one! How often do we have patients consult us, who are just a little under the weather and want a little medicine to set them up, and on investigation we find a contracted kidney and all which that implies! How humiliating to be called in consultation for a case of obstruction of the bowels, and a thorough examination reveals a strangulated hernial tumor as the cause; and how terrible it would be should it have passed beyond the time of successful relief!

In my experience, latent syphilis is the cause of a great deal of obscure disease; indeed, syphilis is a protean disease, and how often in its latent form it is overlooked, and in most cases how satisfactory the treatment! In nervous syphilis what wonders we see! I was once called to a fine young fellow under thirty, and found him helpless on the floor with a complete hemiplegia. Under thirty and a paralytic! I at once knew the trouble,-only syphilis, or metallic poisoning. once in a thousand cases, and by all odds syphilis. A history of the case soon revealed syphilis as the origin of his trouble and enabled me to venture a favorable prognosis. In a few months he was about, and in two years was a strong, vigorous man, with directions whenever he was sick, even from a bad cold, to always tell his attending physician he was or had been a syphilitic, and thus get proper treatment at any time. Large 
doses of the iodides saved him. How many such cases are sacrificed to ignorance and pretence!

Many mistakes in diagnosis are made in malarial diseases. Latent malaria, both civic and paludal, are very common diseases, and the therapentic test with the alkaloids of cinchona unmasks very many of them, and the microscope is still more effectual. There are many complications between typhoid fever and other diseases, but in my experience it is well to be very careful and not mistake appendicitis, tuberculous disease of different forms, trichina spiralis, melancholia, renal troubles, and malarial troubles. Remember that diabetics under thirty-five are apt to be tuberculous, so be careful to be on your guard and differentiate here between the diabetes, tuberculosis, and typhoid fever. Are there mingled types of fever, for example, typho-malarial fevers? The prevailing opinion in the profession appears to be against this mingling of fever types. I do not know, surely; probably no one does; I do know that the autumnal fevers prevalent on the Delaware and Chesapeake peninsula act in many cases like true enteric fever, with a true mingling of malarial invasion, and full antiperiodic doses of the alkaloids of cinchona are necessary for their control and successful treatment. The Civil War started this discussion as to fevers, and the present war may do much to further elucidate the subject.

The more I see of our autumnal fevers of the Middle and Southern States, which are usually diagnosed as enteric fever, and which are many of them such as were spoken of during the Civil War as typho-malarial, the more I am convinced there is in these cases something more than the ordinary case of typhoid or enteric fever. There is a malarial complication, or some complication more than malarial, which will at some future day be explained. There is in these cases evidently to $m e$, as it were, some auto-intoxication che to tissue waste, or some such trouble, possibly to one or more of the pathogenic germs occupying the intestinal tract. If no mingling of the fevers, there must be a mingling of the causes of these cases more than the one cause producing true enteric fever, and 
these mingled cases may be due to a mingling of malarial organisms, of typhoid organisms, of unicellular animalcules, together with the bacillus coli communis and its attendant evils; thence follows a mingled fever; why not?

Just now, whilst writing these lines, I understand they have discovered at the Pepper Laboratory of the University of Pennsylvania the plasmodium malarix in the blood of a case of a well-marked enteric fever, where the typhoid rash was thoroughly developed and identified. Of course, in this patient there must have been a malarial explosion within twenty-four hours, to have found Laveran's characteristic organism. I am not surprised at this discovery; it only confirms views I have long held on this subject. From experiments made in new countries, Paget concludes that the typhoid bacillus exists in virgin soil, but it requires educating, - that is, to be transferred through a series of hosts,- - before it produces typhoid fever. The so-called typho-malarial fever, he thinks, is produced by the typhoid bacillus before it has gone through these various hosts. This is quite a pretty theory, but the day of theories in medicine is fast passing away, and giving way to exact science. My friend Dr. Richard Woods has kindly given me the hospital record of the case of mingled fever referred to, as follows:

J. McK., twenty-three years old, single, admitted to University Hospital September 9, I898. Previous history negative: was first at Camp Alger and then transferred to Camp Meade. Previous to admission, headache, lassitude, pain in back, etc.; enlarged spleen; rose-colored spots; bronchitis; iliac tenderness; plasmodium malarix found in the blood. Widal test present. Highest temperature, I04. $6^{\circ} \mathrm{F}$. Had a chill following admission. Quinine given, and no recurrence of the chill. Discharged October Io, I 898 .

The microscope will help out as the Widal sero-diagnosis becomes more generally accessible, and the spirillum in relapsing fever now makes that clear, as does the malarial organism in malarial fever. In regard to the malarial organism, there are probably three different kinds, and the recurrence 
of the chills and fevers is believed to be cansed by a large number of the parasites coming to maturity at once. Thus we have the quotidian type of parasite, the tertian type, and the quartan type, each taking a different length of time to complete its maturity, and then the storm comes. These bodies destroy the red corpuscles and thus produce anæmia, and as they pass on in their life pigment bodies are developed in them, which are picked up by the white blood-corpuscles and destroyed, and probably our specific remedies, as quinine, act through these white blood-corpuscles and thus destroy the organisms. As to their life history and hosts we know very little. Some such organisms have been found in some birds, and the mosquito has been suggested as a host. Some use for the mosquito, anyhow, if true, even if a bad use.

Nothing shows the rapid advances in the study of medical science more than the unfolding of our knowledge in reference to the malarial parasites, and in treating malarial diseases it behooves us to take heed of the results furnished us by the scientists to be at all successful. Osler claims malaria to be the only disease for which we have absolute specifics. IVe will find, as we treat cases, that all the types of the organism do not yield to bark alone, but require additions of other remedies. Dr. Charles Dewey Center, of Illinois, has given us a good résumć of the subject. In I879 Lewis discovered a malarial parasite. Laveran made his discovery in I880. Thayer claims it is not a single and polymorphous organism, but the three forms represent distinct varieties: ( I) There is a variation arising from difference in the parasites; (2) a variation of individual differences; (3) variation of place and season; (4) variation as to what remedies have been used or omitted.

If we recognize the quotidian organism of Golgi, which is not yet admitted by all, there are four forms of the organism, -the quotidian, which gives attacks every twenty-four hours, and may possibly not be a distinct species, but a mixed species of the other three; the tertian, the quartan, and the crescent, or estivo-autumnal. the name denoting its time of appearance, 


\section{FORTY YEARS IN THE MEDICAL PROFESSION}

from cstas, summer, and autummus, autumn. My experience in looking for these parasites shows it of importance to recognize the type from the symptoms, and in all cases it is probably important to use the microscope as soon after the chill or explosion as possible, and not to delay in any case over a few hours. The flagellæe are active in all forms, and are, according to Koch, the spermatozoa. They all inhabit the blood. The crescent lives in the blood chiefly of the bone marrow and the spleen, and this form produces probably relapsing fever, pernicious fever, and the irregular malarial fevers. The practical point to bear in mind is the remedy for each form of malarial fever, depending on the examination of the blood by the microscope at the proper time, thus showing us the organism we have to treat, whether it be the quotidian, the tertian, the quartan, or the crescent or estivo-autumnal. The different alkaloids of bark are probably specifics for the first three types, but if we do not add arsenic to the bark alkaloid we will fail in treating the crescent form. There is where we probably often fail in our treatment of stubborn cases. Of course, when I say bark, I mean Peruvian bark. In spleen cases and in cases where we have the fearful bone-aches, headaches, and nausea, we likely will not succeed with bark alone, but will succeed with arsenic and bark, and with the iodides and iodine and bark, and such remedies.

Especially since our newer and nearer relations to the home of yellow fever, we may often be embarrassed in our diagnosis of fevers. Take a case of a man on our first seeing him with coma, jaundice, and high temperature, probably from a yellow fever district; bacteriology is the only help to save us from embarrassment. The presence of a malarial organism and the absence of the bacillus icteroides would go far to clear up the diagnosis. Whether these organisms coexist in the same individual has probably not yet been determined, but it looks as though the bacillus icterondes had been defined as the cause of yellow fever.

Now for antitoxins or specific remedies in all of these pests. I believe the tertian malarial organism to be the one found 


\section{FORTY YEARS IN THE MEDICAL PROFESSION}

generally in the Middle States and upper Southern and Western States. We do not often see the quartan on the Delaware and Chesapeake peninsula. In the tropics and in the jungles look out for the crescent form with all of its horrors, and remember we may find it well to the north too.

Let me repeat, when we have a case of malarial fever, and find the quotidian, tertian, or quartan organism, we will at once relieve the case by a mercurial purge and one of the alkaloids of bark, followed at proper intervals by bark salts to prevent a recurrence, and then by attention to a proper change of environment and general tonics. Let the estivoautumnal or crescent parasite be present, and you will surely need arsenic added to your bark salts, and probably iodine and the iodides. It is a common belief in our extreme Southern States that if a person run down by malarial fever goes to the mountains he will most probably develop typhoid fever. Can this be so, and what is the relation here? The Western mountain fever is probably an enteric fever.

Another link in the chain in the diagnosis of enteric fever is Ehrlich's reaction, or the diazo reaction, as pointed out to me by Dr. E. Barker, now of the State Hospital at Norristown. Pennsylvania. Tyson gives full directions for this test in his " Practice of Medicine," and says it is symptomatic, not diagnostic, certainly not pathognomonic, as it occurs in many diseases with high fever, among which measles and miliary tuberculosis are conspicuous. If not present, the case is probably not typhoid fever. In typhoid fever it appears from the fifth to the fourteenth day, and disappears later on. There is one important point: it is said sometimes to appear in malarial fever. These are probably cases of typho-malarial fever, as we now know such to exist. The cause of typhoid fever is now generally recognized as the bacillus of Eberth, and it is found in many parts of the body besides the intestines, as in the blood, the mesenteric glands, the spleen, the gall-bladder, and even in the rose-colored spots. It is often found in the fecal discharges, and here, of course, is diagnostic, if the patient has fever. The bacilli have been known to live in water 
three months, in soil six months. They have been known to have lived in a vacuum over two hundred days; in fact, they are most tenacions of life. Sunlight, next to heat, is most destructive to them. What effect electric light rays may have on them I do not know. This effect of light is a practical point; keep the house open to the sun, and air all dark corners. Why houses are ever built with cellars I do not know. I do not think the coming man will be fool enough to dig a hole as a resort and home for all kinds of germs, pathogenic and other kinds, and then build his house over such a pestbreeder.

The bacillus of typhoid fever enters the system of man most frequently through milk and water, but it may enter through any kind of food or drink, or with the dust from rooms or other sources by inhalation. The bacillus of Eberth and the bacillus coli communis have been found together in a room where typhoid fever had existed months before. I believe the Eberth bacillus can be inhaled from sinks and such places containing contaminated dejecta; at least, I have practical reasons for thinking so.

It is possible to spread the bacillus to soil and water-courses by spreading night soil, but I have practised medicine a long time in a community where the night soil from seventy thousand people is spread on the soil of the suburban surroundings, and although I have watched this point closely, I cannot say the people in this neighborhood suffer from typhoid fever to a greater extent than those living on other farm lands. I may remark here that my experience with the application of cold in typhoid fever has been very satisfactory, both by bath and by cold sponging, but in private practice, as cases usually occur to us, the use of the bath is so inconvenient to patient and attendants as almost to prohibit its use and drive us to cold sponging and other means of applying cold, as the coldair current, etc. Thayer has shown that after a Brand bath the leucocytes are doubled, or more than doubled, and that the medicinal antipyretics have the effect of decreasing the leucocytes, and we all know how they depress the heart. Believing 
such testimony, no one can fail to choose the Brand method, or some modified form of it, and limit decidedly the use of medicinal antipyretics, though not absolutely, as undoubtedly small doses of acetanilide are often safe and most useful. Some claim the high temperature is only evidence of the combustion of the materies morbi, the germs. Beware! do not let the high temperature go to the point of roasting the host whilst it cooks his guest.

As to the antiseptic treatment of typhoid fever by intestinal antisepsis, neither my reason nor my experience has led me to give it my unqualified approval. If the pathogenic germs be alone and only in the intestinal tract, we might reach them. In a healthy individual, the normal intestinal fluids being antiseptic and germicidal, there is little or no need of germicides from without. When we see a person ill with typhoid fever for the first time, the pathogenic germ has long before doubtless left the intestinal tract and is swarming in the spleen, the liver, the blood, and other parts. Can these be reached by a small dose of an antiseptic administered per orem? Most probably not. Such practice leads to empiricism and routine practice,-a pellet for this and a pellet for that. God save the intelligent physician from such methods! Notwithstanding this, I usually give an antiseptic in typhoid fever. It may reach some of the pathogenic germs in the intestinal tract, and if salol is used, it splits up into carbolic and salicylic acids, and may even act farther on as a germicide, but I doubt it. I scarcely believe, for instance, such can sterilize the blood. There is one use for intestinal antisepsis in typhoid fever where I advocate it ardently for its local action,- -in the secondary cases, we may call them, where the case has apparently run its course and is going on to recovery, but recovery does not come. In these cases we have probably an example of auto-intoxication, caused by poisonous ptomaines, alkaloids, or what not, generated in the alimentary tract. The proper treatment here is undoubtedly antiseptics locally applied, per orem, and, if necessary, per rectum. These are the posttyphoid fever cases some authors speak of. Watch them 


\section{FORTY IEARS IN THE MEDICAL PROFESSION}

keenly. Constipation from milk diet may be the cause; the causes, especially in young ratients, may be purely nervous. Above all things, watch for the creeping upon your patient of some tuberculous trouble. Occasionally laryngeal troubles come on in the later stages of typhoid fever. They may be inflammatory and run a usual course. Again, they may not be inflammatory at all, but a true paralysis of the laryngeal muscles, particularly of the posterior crico-arytenoid and lateral crico-arytenoid muscles. The muscles paralyzed cannot perform their functions of widening the glottis by relaxing the rocal cords, and thus breathing may be greatly interfered with or stopped altogether. Tracheotomy is usually necessary in these cases, and the tube may possibly need to be worn a long time, or even indefinitely.

I look with some hope for the victims of typhoid fever from inoculation from cultures of the pathogenic germ, Pfeiffer's and Jez's bactericidal serum, accounts of which are just beginning to be whispered towards medical circles. Even the blood-serum of convalescents from the fever is being used. Typhoid fever is mildly contagious, doubtless, and for this reason patients should be isolated as much as possible, and put in absolute aseptic surroundings. Disinfect stools and urine with chlorinated lime one pound, and carbonate of soda two pounds, to the gallon of water. This is Labarraque's solution. or very near it, and years ago I have seen it sell for one dollar for a bottle holding less than one quart. Cover all discharges with this and allow them to stand thus covered for three hours, and they will then be aseptic. If this is not done, flies will surely convey the pathogenic germ. I am sure fever is often spread in this way, especially where many human beings are congregated, as in camps. Keep the defecating and urinating organs of the patients aseptic externally. As a rule, do not give your patient animal broths, they are culture media for the pathogenic germ, and should not be used as food for typhoid patients. Watch your patients keenly, feed them liberally with liquids and semi-solids only; be particular not to starve them; especially give them now and again 
hot coffee or tea, if they crave it; do not spare alcohol when needed; it is not always needed; and above all things do not over-drug your patients.

Such methods as the foregoing have been very successful with me. If symptoms of perforation appear and they be verified, there is only one slight hope-promptly appeal to surgery. Not all cases of typhoid fever have diarrhœa. This. I think, is more apparent in later years, showing the distribution of the pathogenic germ from some cause to be more general in the system and not so thoroughly confined to the intestinal tract. I doubt if three-fourths of the cases have it. but in every case of typhoid fever, where there is no diarrhœa. or even where there may be constipation, you give a mild cathartic and you will have excessive action of the medicine as a diagnostic sign, as a therapeutic test.

In my early professional life I was always taught to avoid purgatives in typhoid fever as I would avoid poison, and I cannot conceive but that the eliminative treatment by purgatives, as adrocated by Dr. Thistle, may be accompanied by great danger. Such treatment cannot get rid of all the germs, for they are not all in the tract swept by the purgative, and the local lesions cannot help but be greatly disturbed by constant irritations set up by the cathartics. I have never seen the result of a post-mortem in one of these cases, nor proved one bacteriologically, where there was no diarrhœa. Diarrhœa is the serious symptom and its sequelæ. and the case is serious, as a rule. as the diarrhœa is serious, and I suppose the diarrhœa is serious as the intestinal lesions are serious.

In my experience I have only seen two undoubtedly thoroughly authenticated cases of typhoid fever occurring in the same individual twice. Both cases were young men. In both the first attacks were very severe. In one there was a complication of phlegmasia alba dolens. The attacks in both were about three years apart; the last attacks were mild in every way, but marked: the effect of the first attacks appeared to me to establish at least some tolerance, but to establish no immunity, at least after three years had intervened. Another 
point in typhoid ferer: the diagnosis may be obscure, because some cases run only a few days and are very light, with no symptoms beyond a furred tongue and general malaise, no diarrhœa, enlarged spleen, or rose spots. The IVidal test will usually differentiate these cases. These may be ambulant cases and scatter the pathogenic germs by their urine and fecal discharges, and thus distribute the disease through camps and such places. Such cases exist, so be on your guard. IVe may have also what Osler calls acute typhoid septicæmia, cases overwhelmed by the pathogenic germs. Here we have intense headaches, furious mania, and even cerebro-spinal convulsions. The Widal test is our resource again here. Beware of the cases in which you have jaundice. Here the pathogenic germ has invaded the gall-bladder and set up a toxamia, local and general. Intestinal hemorrhage and epistaxis are common in these cases, and death is the usual outcome with these complications.

Dr. C. N. B. Camac, of New York City, has given us a classical essay on the involvement of the gall-bladder in $t y-$ phoid ferer. (See Johns Hopkins Bulletins.)

Whilst on this subject let me say something of the use of saline infusion, or normal salt solution. The true normal salt solution approaching nearest to the blood-sertm is seveneighths of one per cent. I have seen some reports of its successful use by merely throwing it into the large bowel in threatened collapse from hemorrhage, etc., in typhoid fever. Anyhow, it is wonderful, even by our old methods. how many cases of hemorrhage from the bowels in this fever recover. This method is worth trying. Dr. Thomas E. Reilly, of New York City, has given us the best paper on the technique and use of saline infusions. He gives ninety-two grains of ordinary table salt to a quart of water as making a solution of six-tenths per cent. For all practical purposes, one teaspoonful to one pint of water will make the normal solution. and $I$ think is the easiest to remember. Now boil and filter the solution. In using the solution have it at a temperature of $100^{\circ} \mathrm{F}$. The ways of getting this into the system are by 
the veins or the arteries subcutaneously, and by injections into the bowels. I should say that even into the peritoneal cavity might be worthy of trial. Whichever way it goes, use absolutely antiseptic precautions, even if used per orem.

In advanced heart disease do not use the method by the blood-ressels. By the subcutaneous method attach an aspirating needle to a Davidson's syringe or to a fountain syringe, or, as Dr. H. A. Kelly suggests, by reversed aspiration; and I see no reason why the old-fashioned antitoxin syringes might not do. Put the fluid into the loose connective tissue of the abdomen, the axilla, under the breasts. You can introduce, Reilly says, from six to ten ounces in one place. $\mathrm{He}$ says no accident in his experience has followed this operation, not even cellulitis. I, myself, have seen sloughing in a rundown hospital case, so be careful to observe the proper technique.

For the intravenous method Reilly uses a glass funnel connected by a piece of rubber tubing three feet long to a canula four inches long by one-eighth of an inch in diameter, curred at its point one inch, to better introduce it into the rein. This should have a stop-cock. Now supine the forearm, cleanse it, bandage it tightly at its middle to distend the veins at the elbow, and incise one inch over the median basilic or cephalic vein. This goes through skin and fascia; with a grooved director tear away fat and tissues over the vein and raise it; pass two catgut ligatures under the vein; now tie the distal one, or, better, wait until the vein has been opened. To open the vein make a clean longitudinal cut three-eighths of one inch long; now introduce the canula one-half inch upward; use the upper ligature to tie the canula in place, and take off the bandage, sure. After the canula is removed tie the vein with the ligature and close wound.

Dr. Dawbarn has injected the fluid into a large artery by an aspiration needle, but this is not considered safe. There are many modifications of intravenous methods, hooking up the vein in any way you are able and using even a medicine dropper, and I do not see why any vein in the system you can 
expose will not answer. There is little or no danger of air entering to cause sudden death; this is now well proved. It takes about five minutes for one quart of solution to run in. The quantity to be used is from a few ounces to sereral quarts. Guides to quantity are, return of pulse or increase of pulse, return of color and consciousness, etc. Rarely use more than one quart to a sitting, but it can be frequently repeated. and the canula can be kept in place for this purpose. There is little danger of using too much after severe hemorrhage. Watch the bladder, as it may distend enormously. Its great use is in loss of blood from various causes. Shock is another great cause for its use; so also is uræmia. especially in uræmic convulsions. Draw ten to twelve ounces of blood from the arm and introduce a quart of salt solution, and in a few hours you can give if necessary as much more. CEdema of lungs is not a contraindication. In suppression of urine it may be used. In diabetic coma it may save life in this almost hopeless condition. In sepsis of all kinds it is doubtless the great remedy. In Asiatic cholera it is useful. In pneumonia it will save life, especially in double pneumonia with dyspnœa, etc. Use it here as soon as pulse flags. It has been used successfully in various other troubles, including purpura hemorrhagica, ulcerative endocarditis, pyelitis, coal-gas poisoning. mushroom poisoning. after venesection, after extensive burns. in acute alcoholism, toxæmia from colon bacillus, painter's colic, carbolic acid poisoning, tetanus, and epilepsy.

Reilly thinks it will do great good in arsenic poisoning. He speaks of it going into the blood at a temperature higher than that of the blood, and it thus increases the antitoxins of the blood and cures, or keeps the patient up until the crisis has passed. In his summary, Reilly recommends its use in all cases of severe hemorrhage. external or internal; in shock of all kinds it fulfils all indications. In all toxæmic conditions, bleed first and then use it. There is nothing like it in uræmia and septic conditions, and in all cases of vegetable or mineral poisonings. In any pathologic state attended with feeble pulse due to lessened blood-pressure, use it, and as a 


\section{FORTY YEARS IN THE MEDICAL PROFESSION}

last resort in all cases of imminent death from any canse of an accidental nature, use it.

The sheet anchor in diagnosis is tact. Do not jump at conclusions too rapidly. The special diagnostician, the older he grows, becomes more non-committal, and leaves a loophole of escape. This makes him no less a diagnostician, but he has learned that diagnosis is not an exact science, but is one growing and expanding every lay, and is one making great and rapid strides to a perfect development, and one that requires all the strength, all the force. and all the senses of a man.

Among the many nice points in diagnosis, my experience leads me to refer to the very frequent occurrence of movable kidney, especially in women, and to differentiate this from other abdominal lesions. Dr. Charles P. Noble, surgeon-inchief of the Kensington Hospital for Women, at Philadelphia, is entitled to great credit for original work in this lesion. Sometimes small-pox and chicken-pox may cause anxiety for a time as to the diagnosis, and people are liable to press for an immediate opinion. So in measles in the negro, as to the possibility of its being of the variola type. Is the trouble an aneurism, a tumor, or an abscess? My experience leads me to advise great care in any trouble where the lines are not definitely marked in this trio. Drunkenness, turæmia. and apoplexy are another trio demanding care, knowledge, good judgment, and tact; and opium and other narcotic poisonings may be added to the list, and also malingering, a very common failing under certain conditions, especially among soldiers, sailors, prisoners, paupers, and hospital bummers.

In general diagnosis, do not forget the microscope, and especially do not forget its use in the urine, the sputa, and the blood, and very frequently in the alvine discharges. When you have a constant, continued, wearing pain, well localized, study it thoroughly; examine all parts, far and near, possible to be involved, and especially do not dismiss it as a form of rheumatism or neuralgia. It is probably not functional, but of organic origin, and some serious formidable trouble is apt to show itself sooner or later. An aneurism, a malignant 
growth, or some serious lesion of the nerve-centres may become the sequel. Diagnosis as it was is a very fascinating art. I say art, for I can scarcely call it a science. Diagnosis as it is, is still a fascinating art, but true science is just beginning to shed its indistinct rays of light on it, sufficient to mystify it and take somewhat from its fascination, for fascination comes from mystery and from conjecture more than from demonstrated fact.

As we go on higher up the mountain to the goal of perfect knowledge, we are giving up, must give up, our reasonings by inductive methods, and diagnosis as it soon will be commences to $u 11$ fold itself as a true science. Even to-day the general practitioner needs continuous recourse to bacteriology; he cannot practise medicine and be just to himself and do justice to his patients without such recourse. A diagnosis cannot be made any more from sight alone, from touch alone, from hearing alone, from the sense of smell alone, or from the sense of taste alone. We must have the help of the bacteriologist, and our diagnosis must be biologic wherever possible, not mere deductions, not mere inductions. In the future, diagnosis is to be a true and progressive science, not a mere art, and in making this advance it is only in keeping with other great advances in the business and scientific world.

I may close this rather desultory talk on diagnosis, and quote two practical mistakes which I know were made many years ago by practitioners of medicine, and which go to show want of thoroughness, want of tact, and, possibly, want of knowledge, all three essentials to the successful physician. A physician was called to see a young unmarried woman (and these are the cases which usually throw the cloctor off his guard) on a lot summer night. He found her in a room surrounded by anxious female neighbors and her own mother. He made a hurried diagnosis of cholera morbus, and prescribed a mustard plaster and a narcotic and retired. When he called in the morning lue was met at the door by an old gramny, who complimented him on his success, and showed him a bouncing boy. The doctor retired without in any way 
covering his retreat, and in a rather short time left the town for other fields of conquest. The other case was a similar one, except that the doctor had tact, got out of the scrape gracefully, and long afterwards the family never knew, when he paid his second visit and found the child born, that on his first visit he had left without an idea of what was coming; in other words, had made a hasty call, a hasty diagnosis, and a humiliating error. To the diagnosis of pregnancy in any stage the greatest embarrassment is apt to come to a physician, and if the subject be a young unmarried woman, among the very greatest of all embarrassments confronts him. Here you will have use for all your skill, all your care, and all your tact and knowledge. In these unfortunate cases it is always prudent to call a medical friend in consultation.

As not altogether out of place here, I will refer to a peculiar condition as a cause of disease which the originator, Dr. E. Vallin, calls "wall disease." He speaks of the presence of saltpetre in the walls of inhabited houses. On the brick walls of houses in Philadelphia, Wilmington, New Castle, and surrounding towns we often see a white deposit, especially on the chimneys. This, I think, has been demonstrated to be sulphate of magnesia, and comes from the magnesia in the clay from which the bricks have been made, in connection with the sulphur compound from the coal burned in the houses. Vallin describes this trouble as a disease of the walls, due to the presence of micro-organisms. He seeks to "cure" the walls, as he puts it, to save those living in the houses. The disease is caused by the penetration into the walls of the bacilli of nitrification, and consequently the houses become damp and unwholesome. This is likely to occur, says the London Lancet, the account of which I take from the Philadelphia Medical Journal, in damp localities and in the presence of nitrogenous organic matter. From a sanitary point of view this disease of the walls should be cured, as we cure or prevent virulent diseases among men and animals. Vallin says, first, thoroughly drain the ground around the walls, and isolate them from the surrounding earth by a trench and by 
the use of asphalt cement or coal-tar. Thus the access of water bearing nitrifying bacteria that are aerobic would be prevented. It is also necessary to mix the mortar used with antiseptic solutions, such as dissolved copper sulphate, etc. Where these precautions had not been taken, and the disease had already broken out, then he advocated the following treatment: First, scrape off and wash away all superficial traces of the saltpetre (and magnesia, too, I should say, if the deposit should be magnesia and not potash). Then inoculate the walls with active cultures of the anti-nitrifying bacilli, the kind which impoverish farm manure by decomposing the nitrates, and by throwing off in the atmosphere a great part of the nitrogen which they contain. These walls should then be covered over with impermeable paint, so as to retard the process of nitrification of the aerobic germs, and on the other hand to stimulate the growth of the anaerobic and anti-nitrifying germs which remove the oxygen from the nitrate, and from the ammonia, when they cannot supply themselves with oxygen from the atmosphere.

This ingenious theory has made quite an impression. The idea of applying the principles of inoculation to the preservation of material used in buildings opens a vast field of possible progress in the domains of sanitary engineering and architecture. I will add that many things of this character are being done, and many discoveries have been and are being made in regard to the nitrification of plants, etc. Take the leguminous plants. It is now known that they are provided by nature with little tubercles on their roots, nitrogen-traps, which generate little micro-organisms through which, or by the aid of which, or both, these plants receive nitrogen from the atmosphere, and thus store it up, not only for their own use, but for the use of other crops to follow on these plants turned under the soil. Where a soil becomes sick as to nitrogen and will not bear the leguminous plants, it is a custom now to supply soil from a field not thus sick and where legumes are growing, and thus revivify the sick soil. The German chemists are now supplying bacteria which they 
call nitrigin for such purposes, and this may become a commercial business. Take a jar, fill it with earth, thoroughly kill all organic life in it, and sterilize it by heat. Plant peas in the jar, and the peas will not grow. Go to a bed in the garden where peas are growing, and take a very little of the earth from the pea-bed and add it to the sterilized earth, and at once the peas start off and grow. Why? Because you bring the micro-organism from the garden soil and add it to the sterilized soil, and at once they increase, as only such organisms can increase, and we have the essentials for the growth of the peas by the addition of this microscopic life. Just as we add a little yeast to the bread, and the proliferation of the yeast-plant acting with the gluten raises the bread. So with all ferments: some are necessary to organic life under certain conditions, and some are fatal to organic life under certain conditions.

All of this is of the utmost importance in medicine. When we can supply to the human organism at will a micro-organism constructive, as it were, and when we can supply to the human subject at will a micro-organism destructive, as it were, then will we be approaching a definiteness and an exactness in medical science which will raise it from the empiricism and uncertainty of the past, and make the physician what he is rapidly nearing, one who can get definite results from definite means, and these definite means being in great measure the application of nature's laws. It being undoubtedly true that every organic thing in nature generates its own organic poison, which really means limits its own life, the converse may be true, that every poison thus generated by an organic body may prove in some way a factor in making life possible in other organic bodies.

All of these things go to show the wonders of life, and how dependent every life is on other life, until we come to man, who holds everything in the organic world subservient to his own existence and to his own comfort, and how this whole scheme of life is beginning to dawn on him. Whilst, for instance, he has always held the ox as one of the great re- 
sources of his food and comfort, he has taken little account of the mere microscopical point, a little thing scarcely defined as to its place in nature, whether where the vegetable ends or the animal begins, the bacillus of diphtheria, which under favorable circumstances has the power literally to drive him from the earth. He is just beginning to see that he has power also over this little unseen enemy; that he can absolutely control its development and can absolutely render its danger to himself nil; and this history of this little germ shows the lines upon which medicine is working, and gives an insight into the great progress now dawning on the medical horizon.

Now, suppose we obtain absolute control over zymotic diseases; suppose we absolutely control all epidemics heretofore so fatal; we have confronting us great questions in political economy. The Malthusian theory confronts us,-that population when unchecked by wars, vice, epidemics, and other depopulating causes, increases in a geometrical ratio, whilst food can only be made to increase in an arithmetical ratio. Well, let us shut our eyes to all coming troubles of this kind, knowing full well that the future will take care of itself, and that Providence will provide a way. If medicine brings about this complicated condition by putting off death to old age, what a compliment to medicine would such a state of affairs be, and what man would be so great a man as the doctor!

Serum Therapy.-Among the recent introductions into medicine, the therapeutic serums have been the most remarkable and promise the most wonderful results. First of all, the diphtheria antitoxin is probably best known, for it has undoubtedly passed the experimental stage, and none of our specific remedies to-day are probably more sure than is the antitoxin of diphtheria in that disease. We have no right now to treat a case and fail to give its use due consideration. There is no doubt but that the illustrious Washington died of diphtheria. On a visit to Mount Vernon, when I was accorded special privileges I examined the house and premises 
FORTY YEARS IN THE MEDICAL PROFESSION

thoroughly. I know not why, but in the good old times the thrifty housewife seldom allowed the best quarters to herself or her family, but the desirable apartments were guest-chambers, which were often full owing to the generous hospitality of the day. The quarters occupied by the general and Mrs. Washington were the smallest and meanest of the establishment. very near the kitchen apartments and near the servants' quarters, just the part of the premises furnishing teeming hosts for all pathogenic germs, and a home and surroundings just as acceptable and lovely to the deadly Klebs-Loeffler bacillus as it was to the great man and his wife,--at once, their home, their monument, and their tomb.

As to its discovery, manufacture, etc., I do not propose to treat of them here, for they are now fully described in all works on Materia Medica. When it first came out, in Europe. I sent to Germany and procured a quantity from Behrings', and before I had had possession of it more than a very few days I was called in consultation by Dr. H. G. M. Kolloch, of Newark, Delaware, to see a child of eighteen months suffering from laryngeal diphtheria which had produced stenosis and serious embarrassment to the breathing. We used one injection of about seren hundred and fifty units. In twenty-four hours there was marked relief, and after that prompt recovery. From that day I had confidence in the diphtheria antitoxin. Those now made in this country by Mulford, of Philadelphia, and by Parke Davis \& Co., of Detroit, are among the best, and the price is getting within reach of all. I have never seen any ill effect beyond now and then a rash, which soon fades away.

The true secret of success, in my experience, is to use it early and nse plenty of it. Do not be afraid of it. Especially in laryngeal cases use large doses. I have seen it do wonders in these cases. Before its introduction I lost a great many of these cases, notwithstanding I performed a number of tracheotomies, with poor success. Although many in the profession held ont a long time against what we called true membranous croup being true diphtheria, few now deny it. 
The opponents now acknowledge ninety-five per cent. to be genuine. and I have 110 (loubt but that the other five per cent. contain the bacillus.

Some years ago, when this matter was being discussed warmly, i had a number of cases in which I had made tracheotomies which bore on the matter and confirmed the views of Sir Morell Mackenzie in a marked degree. I prepared some notes of the cases, and sent them to Sir Morell, and I had several very nice letters from him in the matter, telling me he had used the material for his new book then in press, and the mannscript of which was destroyed by fire while in the printer's hands. I never give less than five hundred units to an infant under twelve months, and repeat it as often as necessary. Children require larger proportionate doses than adults, for they are more susceptible to the disease and carry more of the toxine. In laryngeal cases over two years of age, never start with less than two thousand units, and do not hesitate to repeat in eight to twelve hours, and re-repeat as necessary. These are the cases to be bold in, and are the cases which give us the wonderful results and are making tracheotomy and even intubation less and less necessary. I think it best to immunize all the children in the family if there is a case in the house, and lo not use less than five hundred units, as a rule, for immunization. Begin as soon as you detect the case, and do not wait for microscopic confirmation. If the case goes on over thirty-six hours, you begin to have streptococcus toxine poison.

I have not used the combined treatment of diphtheria antitoxin and streptococcus antitoxin, but such is recommended. Do not let your case go on to secondary infection. As to local treatment, do all you can with it. One to two per cent. solntion of formaldehyde will do wonders in most cases. This local treatment is all very well in adnlts and in children old enough to be reasoned with. In children where you have to fight them and exhanst them by your efforts to use local treatment, drop it when you cone to this point. I an sure they lose more than they gain by their efforts at resistance and by 
fright. Ail the tact and all the skill of a good nurse will not overcome these troubles in many children. Food and nourishment and absolute recumbent rest are most important, and where necessary tracheotomy and intubation are to be entertained. Watch the heart for weakening, particularly, and keep in mind digitalis, trinitrin, strychnine, atropine, and alcohol. Champagne is the best stimulant, or heavy wines in carbonated waters. If your patient be a negro you will usually find the disease of virulent type.

Another point: the antitoxin as now furnished comes much more potent as to quantity than formerly. Mulford puts up five hundred units to one cubic centimetre. At this rate it is easily used in a first-class hypodermic syringe, and there is no necessity for the large quantity of fluid and the large cumbersome syringe which first came out. Of course, in its use, observe on every hand the most perfect antiseptic precautions. In tuberculous troubles, I believe I have used almost all the serums that have come out and one or two of my own ideas, but have no real success to report, and will refer to this matter again, when I cone to speak of tuberculosis in general.

In tetanus I have had experience only with one case,--a boy of fifteen, who had wounded his foot with a rusty nail some days before, and who had marked premonitory symptoms of tetanus when I saw him. In twelve hours I saw him again (having treated the wound medicinally before I left him), and during my absence he had taken chloral and potassium bromide in full doses. Having obtained the antitoxin of tetanus from Dr. Gibier, of the Pasteur Institute, New York City, I used it according to directions. The boy was really better when I commenced the use of the antitoxin, but still had marked symptoms. He gradually improved and got well.

An editorial in the University Medical Magawine, February, I 899, gives a good synopsis of the treatment of tetanus to date by serum. Wasserman, it says, showed that a mixture of tetanus toxine with the brain or spinal cord of a susceptible ani- 
mal could be injected into a guinea-pig subcutaneously without causing tetanus, while the same quantity of toxine without the admixture of brain or cord, invariably caused fatal tetanuts. This gave Rotx and Borrel a pointer, and they treated forty-five guinea-pigs in which tetanus had been produced artificially by in jecting tetanus antitoxin into the brain, thirtyfive of which recovered. Of seventeen treated by subcutaneous injections of antitoxin, in much larger doses than was thrown into the brains of the forty-five cases, only two recovered. Of seventeen animals tetanized and allowed to go without treatment, all died.

It is a serious matter to throw anything into the brain, but these are serious cases. Use two and one-half centimetres of double strength tetanus antitoxin serum. Do everything. antiseptically. Trephine with a small trephine or Archimedean drill. The spot to choose is two and one-half inches above the external angular process of the orbit and one and three-quarters inches from the median line. Introduce the needle two inches into the frontal lobe, and inject drop by drop, allowing ten minutes for the injection. At the same time in ject twenty cubic centimetres of ordinary tetanus antitoxin stbcutaneously.

Heckel and Reynes thus group tetanus: Where incubation is fourteen days or more, temperature below $39^{\circ} \mathrm{C}$, and a little dyspnœa, here serum treatment will cure. In subacute cases running a rapid course, with dyspnca and irregular pulse, intracerebral injections may cure if used promptly. In acute cases beginning in from five to seven days, temperature over $40^{\circ} \mathrm{C}$, with rapid appearance of spasm, oleguria, rapid breathing, and rapid pulse, use serum therapy subcutaneously as soon as trimsus appears. Puerperal tetanus, tetanus neonatorum, and the cephalic tetanus of Rose are not favorable cases for serum treatment. The first essential of treatment is early diagnosis. When trismus appears, the disease has passed far along. It then becomes a question of intracerebral injection of antitoxin. Our great effort should be to find something to make out the form before trismus appears. 
The bacillus of tetanus, in my experience, is common in low countries and in marshy places, and is especially common about horse-stables and on farms on river-sides. It is an aerobic, and hides in the dark. The bacilli and not the toxine is usually the matter inoculated, and it takes some days for the toxine to form in the system as a result of the bacilli inoculation. One thing remember: the bacilli of tetanus have probably more tenacity of life than all other of the diseaseproducing germs, and the tetanns toxine is the most virulent of toxines. Bichloride of mercury solution one to one thousand will not destroy them in an hour or more. They will stand more boiling than all other of the disease germs. Be on your guard; remember this as a practical point in surgical operations and in treating the local wounds in cases of tranmatic tetanus (indeed, even trivial wounds): boil all water used at least one hour, if it comes from a source suspicious as to tetanus bacilli, or you may have tetanus following your operation, and wonder where it came from. Tetanus has also been treated by carbolic acid, known as Baccelli's method. A two per cent. solution is used hypodermically, at intervals of two to three hours, using three grains a day, rapidly increasing to six to eight grains a day. The systen is very tolerant of carbolic acid in tetanus. This is claimed to give better results than the antitoxin treatment. Dr. D. F. Woods, of Philadelphia, has reported a very interesting case cured by the carbolic acid treatment.

I have had little experience with transfusion and infusion, but will mention it later on, in Chapter IX. Lentz \& Sons have a very efficient apparatus for the latter work. My experience leads me to advise great care in injecting fluids into the cellular tissues in large amounts, as, in such a case, where the patient was weak and run down, I have seen very troublesome sloughing follow. The normal saline solution is a simple one: add one teaspoonful of common salt to one pint of water previously boiled one-half hour; boil this ten minutes, strain it thoroughly, and inject it at a temperature of about I OO $^{\circ} \mathrm{F}$. Where we have oedema of the lungs, - a patient I 68 
drowning, as it were, in his own fluids, - be careful of jaborandi and pilocarpine: sudken death may follow from any but its very careful use. Hot baths and sweats are safer. Here intravenous saline injections may come in, especially where there is uremia, say a ruart into the most convenient veins; but be very guarded at every point in this work. Intraperitoneal injection in these cases really might be the safer, and either may be used after shock from extensive lutrus.

Inch has been said and written about the nucleins and the nuclein preparations, and great disappointment so far in my experience has followed their quite extensive use. In one well-marked case of expandling sarcoma of the femur a free use of proto-nuclein, both hypodermically and by the month, did really appear to retard the advance of the lesion. but then we all know such cases often remain dormant for a time after rapid growtl, and then after a time advance again and go on to death, as dicl the case I am speaking of. In lympho-sarcoma, after faithful trial, I have never seen the nucleins or any other treatment retard the growths, and I have had the same experience after trials of the bacillus prodigiosus and erysipelas toxine in malignant disease. I have never had the opportunity of trying the method, but it has been recommended to me from a source worthy of regard, in the case of a hrmophilic bleeding, to apply blood from a liealthy person, and thus check the hemorrhage.

Whilst on this subject, let me refer to the effect of the sting of the honey-bee on human beings. I have made some practical study of this subject, and am prepared to affirm that from frequent stings the individual becomes immune to the poison, in many cases absolutely immune, and this study of the effect of bee-stings has impressed me forcibly as to the possibility of rendering man and other animals immune to all organic poisons of creature origin or vegetable origin, whether pathogenic or otherwise. I know of one bee-keeper, with a wife and several childen, who are all more or less immune to the poison of the sting. In all of them, immunity has come by degrees, after frequent stings. The man assures me he 
can now be stung two hundred times in twenty-four hours and feel no ill effects, locally or constitutionally. From his first stings he suffered acutely. He is always careful to brush off the stings so they will not be held by the little saw-like teeth at the end. The poison is a transparent fluid of sweetish taste and acid reaction, and the antidotes are potassium permanganate and ammonia or other alkalies. The queens and workers have the stings, whilst the males have none. When it is known that very numerous stings have killed horses, and would probably kill a man, the fluid compares in virulence with many of the serpent poisons when we consider the comparative amounts involved in bee-stings and serpent-bites, and these comparative studies become most interesting and useful.

I have never met any one naturally absolutely immune to the sting of the honey-bee, but have seen such cases reported. I have never met a bee-keeper who was not more or less immune after frequent exposures, but I have heard of some few cases where no tolerance ever became established. The possibility of causing immunity in the individual to such troubles as the bites of serpents and such creatures by the use of the poison of the sting of wasps, bees, and such, is beginning to attract attention, and my friend, who can endure two hundred honey-bee stings in twenty-four hours. may have, from the toxines of these stings, sufficient anticlotal and antitoxic properties developed in his system to withstand the bite of the rattler, or even of the cobra. Who knows? Who will make the trial? No one willingly, probably, but some poor jungledweller may yet be the subject to demonstrate the fact. There is another interesting question as to the honey-bee, and maybe to other stinging insects so far as I know. I refer to the action of its sting poison on the poison of rheumatism in man. It has been quite well established, as we know, that rhemmatism has its pathogenic germ, and hence we may infer that this has its antitoxin either in nature or artificially produced. As before stated, the poison of the bee is a clear fluid, with a sweetish acid taste, with an acid reaction, the acid being probably formic acid. Organic toxines usually lose their viru- 
lence in the presence of an organic acid. Possibly here may be the secret. Be it as it may, from my talks with experienced bee-keepers and bee experts, and from my own experiments with the action of the bee-sting upon human beings suffering from rheumatism, I am satisfied there is some antagonism between the bee-poison and the toxine of rhemmatism, and that not only does the bee-poison neutralize in a measure the rhemmatism toxine, but it also for a time at least renders the system immune to a greater or less extent to said poison. I look upon the matter as worthy of fuller investigation both as to rheumatism and to gout.

I gather from the report of the Secretary of Agriculture and from an article in the Philadelphia Medical Journal on "Diseases and Abuses of Animals in the United States," by Dr. D. E. Salmon, the accomplished head of the National Bureau of Animal Industry, most encouraging statements of the serum treatments in the diseases of the lower animals; and these statements go far to confirm and strengthen all such treatments in man now in their very infancy, but which soon, mark my words, are destined to give to the results, when compared with all that has heretofore been done in the science of medicine, a brilliancy and success the most sanguine among us have little dreamed of. The matters referred to, among others, are swine plague and hog cholera. In the Bureau of Animal Industry they have demonstrated these as distinct infectious diseases. They have shown, having found the germs of each, how they leave the bodies of sick animals, and are disseminated, and how they get into the bodies of healthy animals and make them sick. They have experimented with medicines and disinfectants; they have tested the method of killing all diseased animals and burning them. They have tested vaccination, inoculation, and serum treatment. Salmon says the practicable and efficient plan has been found in the serum treatment.

Ten millions of hogs die annually of these infections diseases. Think of such a terrible slaughter by disease, and how easily such a holocaust might fall on man! Such might easily 
FORTY YEARS IN THE MEDICAL PROFESSION

be the case; the material is all about us in nature for just such plagues, and to think that by science everything points to the fact that man can control such an outbreak, whether in man or in the lower animals. Think how Pasteur pointed the way, and how his great helpers are day by day working to the perfect end. In these hog epidemics-or rather epizootics-the serum treatment, used in herds where seventy-five per cent. of them were too sick to eat, caused many in twenty-four hours to eat, and on the third day a great part of the herd would be wonderfully improved. In herds treated, seventy-eight per cent. were saved. In untreated herds, fifteen per cent. only recovered. In a few days, in treated herds, the disease is stopped. All this means the saving of ten millions of hogs a year. How many animals, how many human beings, does it mean annually saved, and what an improvement in the economics of animal industry when these true scientific principles are successfully applied, as they surcly will be, to all zymotic diseases, to all diseases caused by pathogenic germs, not speaking of the possibility of immunizing both man and the lower animals to all such germs, as Jenner did in his small way many years ago! How can we help but become enthusiastic as science unfolds her mysteries! 


\section{CHAPTER VII.}

Nervous: Diseases Forty Years Ago-Sommambulism-Hypnotism-Motor I)isorders-Lmnacy-Delirim Tremens-Epilepsy-ChoreaDiseases of the Cord and its Membranes-Tetanus-HydrophobiaHysteria-Neurasthenia-Dr. D. D. Richardson's Views on the Treatment and the Care of the Insane-The Feeble-Minded-Notes by Dr. Martin W. Barr-The Deaf and Dumb-Colonel IVilliam BollingJohn Brainwood-Thomas Hopkins Gallaudet-Edward Miner Gallandet - Hon. Amos Kendall - Dr. Cronter - Peet - Rogers - GillettNoyes-Fay-Manual Method and Speech-Swedish Movements-The Bath-Electricity-The Masseur and the Massense-Hypnotic Suggestion-The Dangerous Classes-The Degenerates-How shall the Problem be solved?

FORTY years ago the nervous system and its diseases, compared with the present time, were little understood, and it was a great field in medicine, little worked and less tilled. Take the classification of nervous diseases in a popular work on the practice of medicine at that period, and it ran perhaps in this fashion: Diseases of the brain, under which we would get inflammation of the brain and its membranes, acute and chronic, cerebritis, tuberculous troubles; organic diseases of the brain; softening, hypertrophy, tumor, apoplexy; functional diseases of the brain; nervous irritation, vascular irritation, depression; then morbid phenomena, as headache. stupor, sunstroke; then came mental disorders, ecstasy, somnambulism, artificial somnambulism or animal magnetism, or mesmerism, now called hypnotism; then came motor disorders, convulsions, catalepsy. The next division is lunacy, and moler it the different divisions of the day, as monomania, insane impulse, etc.; then comes delirium tremens, and what student in the days of Professor George B. Wood and IVilliam Pepper, Sr., does not remember the horrible inaginings displayed on canvas by a recovered patient as among the recollections of his risions and dreams during his illness. At the 
close of the lecture, with what form and ceremony and much ado did Levick remove the cover and expose them to the expectant gaze of an applauding audience. Then came epilepsy and chorea, then diseases of the cord and its membranes, and then functional diseases of the same, as tetanus-so it was placed in those days-and hydrophobia; then inflammation of the nerves, under which came, chiefly, neuralgia; then a sub-section, paralysis, and lastly hysteria. Such was about George B. Wood's classification.

The causes of the troubles, the pathological conditions, were, comparatively with the present day, little understood, and the treatment was on the general principles then in vogue. Read such descriptions to-day,-and they were good descriptions, too, for their time,--and then compare them with nervous diseases in a standard work on practice at the present time: or, better still, with the grand work of Mills, just out, or even with Rosenthal's work of twenty years ago, and we see at once what a great branch of medicine has arisen based on the nervous system and its diseases, and what great work has been done by such men as Charcot, Rosenthal, Weir Mitchell, Sinkler, Mills, Dercum, Taylor, Dana, Horatio Wood, Seguin, and other equally able and zealous men. A grand system has been built up from a beginning so small as to be almost insignificant, and in proof of this it is only necessary to refer to the great improvements in classification, in our knowledge of the causes of nervous troubles, of their pathology, and of their treatment.

I may mention the knowledge we have gained of the localization of cerebral functions as a great step in advance in general medicine and surgery. The knowledge we have gained of neurasthenia, the American disease, so called, is another great advance and practical help in every-day practice.

It is not my purpose here, nor does it come within the scope of this work, to go into details of any kind in reference to nerrous diseases, but I propose, in showing the contrast hetween the past and the present, to give in detail 
statements made to me slowing such contrasts by three of the ablest men we have in the profession in their several specialties to-day. I will refer first to matters pertaining to the insane. Dr. D. D. Richardson, the well-known alienist and superintenclent of the State Hospital at Norristown, Pennsylvania, has kindly given me the following answers to my inquiries connected with his specialty: "The changes in the treatment of the insane for the past thirty-eight years has consisted in the amplification of the methods dating lack to I 84 . Physicians have arrived at the unanimous conclusion that insanity comes of disease. The courts do not stand wholly on this solid foundation, though I an glad to say there are many of the learned bench who hold with us that insanity is the outcome of sick physiology or pathology. Hippocrates taught that insanity is caused by disease. The mythical notion that the insane were possessed of the devil was not countenanced by this most celebrated physician of ancient times. Gymnastic and calisthenic exercise holds a foremost place in the physical culture of the insane. Herodicus, an ancient physician of Thrace, and one of the medical educators of Hippocrates, insisted upon the application of gymnastics in the prevention and treatment of disease, and the spark has been caught up and kindled the enthusiasm of alienists to such an extent that there is hardly a hospital of any pretensions where physical culture is not advocated and promulgated. The ramifications have led to the dance, the bowling-alley, the billiard-table, foot-ball, base-ball, racing, and jumping. Then, too, it has extended its usefulness to horticulture and to agriculture. Fifty per cent. of the cures at the Norristown Hospital may be attributed, I think, to exercise in-doors and out-of-doors. From I 839 , when Connolly began the non-restraint system, to the present time alienists have favored less and less all forms of restraint. Some hospitals claim to have entirely discarded it, others to have modified it to the minimum. Very much pro and con may be said upon this important subject. My own practice has been to avoirl it if the hest interest of the patient justified 
it. It is due to Connolly's love of his fellow-man to say that his noble efforts have borne good fruit. Blood-letting in the treatment of the insane has seen its day. It was practised too frequently in early times, and now, though seldom used, is used quite often enough. The supporting plan, feeding often and to repletion, meets with better and more satisfactory results. Purgatives do not constitute an essential part of the treatment of the insane, but it is believed to be indispensable that the contents of the alimentary canal should be evacuated daily. This treatment has gained favor in hospitals, and nurses are especially instructed as to the evils of constipation and the necessity of instructing their patients as to the propriety of after-breakfast visits to the water-closet. Opium and its constituents are used less frequently than formerly. Chloral, introduced in I87 I and freely administered, is used with more caution now. Hyoscine is a reliable remedy, and is to be recommended, its tastelessness facilitating its administration. Paraldelyde acts well in many instances. Sulphonal is a safe remedy, producing sleep quite like 'nature's sweet restorer.' Trional is looked upon with favor by many physicians. All of these remedies are regarded with suspicion by some of the profession, and are substituted by feeding night as well as day. The therapentics of insanity have come to be more like the therapy of other diseases. Physicians know now that there is no specific remedy for this "ill that flesh is heir to,' and that the physical condition should receive our first attention. We have learned to regard physical improvement as the sinc qua non which brings, sooner or later, the dawn of 'the perfect day' of mental restoration. Occupation, diversion, encouragement,- - these three words are more deeply engraven upon the minds of the superintendents of the present day. Of recent years considerable attention has been given to electricity and massâge, in the hope that muscular tone might be developed. This practice, supplemented with nutritious, assimilable food, open-air exercise, followed by several hours' rest in bed, has made good showing, and bids fair to continue to bring favorable results. The thermometer 
is in general and more satisfactory use. Analysis of the urine and blood are more and more engaging the attention of alienists. Thorough physical examinations on admission are much more thoroughly prosecuted. Entertainments are frequent and diversified. Schools for training attendants have been organized in many of the hospitals, and thus a more intelligent and competent class of nurses is secured, and the outlook becomes more farorable as we work on hoping and trusting."

What Dr. Richardson has thus hastily written is sufficient to show the advances made and being made in the treatment of those who have lost the use of their reason, and chains and bolts and bars are not even alluded to, so thoroughly have they gone out and their places been taken by custodial care, the patient being always or nearly always under intelligent observation. The feeble-minded are an interesting class to the physician, indeed to all intelligent people, and when we compare the condition of those gathered in our thoroughly supervised institutions devoted to the care of such unfortunates with the poor imbeciles we encounter in private homes and those we see daily on the streets of our cities and towns, or, more unfortunate still, those who shamble along the village walks, the butt of the boys, loved by few and respected by none, it is then and only then we see the grand work such schools are doing, and at once we stand in awe and admiration at the self-sacrifice of their teachers and of those unselfish men and women who have given time and money without stint to help these poor and weary "children of a day."

Dr. Martin IV. Barr, the distinguished physician-in-chief of the Pennsylvania Training School at Elwyn, and the successor of the lamented Dr. Kerlin, one of the great pioneers in the work, has kindly given me a few notes in reference to these people, and I take great pleasure in giving them at length, with the assurance that they will prove most interesting.

"The imbecile is traced through all the ages, all climes. IVe find him as the Fatura of Rome. the Tardivi of Italy, Les 
Enfants Arrières of France, Geistig Zurück-gebliebene of the Germans. The Koran gives this special charge to the faithful: "Give not unto those who are of weak understanding the substance which God has appointed you to preserve for them, but maintain them thereout, and clothe them and speak kindly unto them.'

"The first recorded attempt to educate an idiot was made in the year I 800 by Itard, the famous physician in charge of the National Institution for the deaf and dumb at Paris, upon a boy known as the Savage of Aveyron. In the year i 8 i 8 and for a few years afterwards several idiotic children were instructed in the American Asylum for the Deaf and Dumb at Hartford, and fair results were obtained. In I828 Ferret, of the Bicetre, near Paris, attempted to teach the imbecile, and his success was also fair. In I 83 I Fabret tried the same at the Salpetrière, and in 1833 Voisin founded his private school for idiots in Paris. In I837 Seguin, the pupil of Itard and Esquirol, took under his protection a number of idiots and instructed them at his own expense. Exiled from his native France during the revolution of 1848 , he came to America, where he was instrumental in establishing schools for idiots in various States. In 1848 a private school for imbeciles was opened at Barre, Massachusetts, by Dr. H. B. Wilbur. In I85 I the State of New York appropriated six thousand dollars annually for two years for the purpose of establishing a school for imbeciles, and in $8_{53}$ the school was formally opened. Pennsylvania was the third State to take up the work, and in 1852 a private school for idiots was opened in Germantown by Mr. J. B. Richards, of Massachusetts. This school was incorporated April 7, I853, as the Pennsylvania Training School for Idiotic and Feeble-Minded Children, and in ${ }^{8} 855$ it was removed to its present site at Ehwyn. The Ohio institution at Columbus was established in I 857, the Connecticut School for Imbeciles in 1855 , and the Kentucky School at Frankfort was opened in $\mathrm{I} 860$, followed by the erection of a school in Illinois in 1865 .

"Thus, in $\mathrm{s} 874$, twenty-six years after the recognition of I 78 


\section{FORTY YEARS IN THE MEDICAL PROFESSION}

the fact that an imbecile could be trained, institutions had been established in seven States. At the present time there are twenty-four large institutions in the United States caring for eight thousand four hundred and ninety-four children, besides many small private schools. In the training of the feeble-minded a correct classification is most important. Is IVilbur forcibly put it, we do not propose to create or supply faculties absolutely wanting, nor to bring all grades of idiocy to the same standard of derelopment or discipline, nor to make all capable of sustaining creditably all the relations of $\therefore$ social and moral life; but rather to give to dormant faculties the greatest possible development and to apply these awakened faculties to a useful purpose under the control of an aroused and disciplined will. At the base of all our efforts lies the principle that, as a rule, none of the faculties are absolutely wanting, but dormant, mndeveloped, and inperfect. Broadly considered, the feeble-minded are divided into two classes, - the imbecile, improvable; the idiot, unimprovable; which, modified, stands thus:

"I. The imbecile, trainable in three grades, low, micldle, and high.

"2. The moral imbecile, found in all these grades, trainable only under rigid custodial care.

"3. Idio-imbecile, improvable as regards cleanly living, and trainable in a very limited degree.

"4. The idiot, except in rare cases and by expensive methods, absolutely unimprovable.

"The imbecile, the only trainable class, divides into low, middle, and high grade. The first of these may be brought to give, always under direction, fairly good service for farm or house, if training be begun early, before apathy or indolence becomes a settled habit. He rarely if ever learns to read, and very soon reaches his mental limit. The imbecile of middle grade is capable of making slow progress in primary school work. I might say in about four years, especially if he has had previous training in the kindergarten, he will attain some proficiency in reading, writing, and number work, 
together with such a knowledge of form, color, and practice in free-hand drawing as shall materially aid him in learning a trade. Indeed, mental development for him is best attained through simple handicrafts having their initiative in the kindergarten.

"The high grade shows children but slightly mentally deficient, who progress slowly as far as the ordinary grammarschool grade, frequently developing an aptitude for music, drawing, and the various industries. These are the backward children that the schools complain of, the feebly gifted ones of England, the 'Tardivi' of Italy, les enfants arrières of France. These are they so often not recognized in seminary or college life, until under excessive pressure or excitement of competition comes complete breakdown, idiocy, insanity, or early death. So nearly normal are many of these, that their defect would perhaps be noticed only by the initiated, and the question is often asked, why are these who do so well accounted feeble-minded? The public little knowing that the time and labor has been double that expended for like results with a normal child.

"The moral imbecile, generally of high or middle grade, quick of apprehension, crafty, and cunning, or, if of low grade, sullen and cruel often to brutishness, absolutely destitute of the moral sense,- what might be termed immoral or unmoral,-is too dangerous an element to be permitted in the schools. This, the saddest victim to a fatal inheritance, is he who claims most at the hands of society and who gets the least, because, precocious and often abnormally bright, he is, as a certain jurist once delighted in saying, "The kind we hang.' As intellectual training cloes but add to his armament of ill, for him should be provided, within strongly guarded asylum walls, all the benefits of a manual training school and its outcome in the various trades, which shall at once give vent for his superfluous energy and render him self-supporting; but this should be coupled with all the ameliorations of cheerful living that humanitarianism owes to this scapegoat for the sins of others. Hard labor and life-long sequestration is 
FORTY YEARS IN THE MEDICAL PROFESSION

the only medicine for his ill, a disease too often due to the sins of a normal ancestry.

" The idio-imbecile. who, as the name implies, partakes of the nature of both the idiot and the imbecile, is generally undersized, with very defective speech and a limited vocabulary confined to a few scattered words, never a full sentence; his improvement is but limited. The most we can hope to do is to keep his nervous, restless fingers employed; he can sometimes learn to knit. to weave mats, or do simple bousework, but never to read or write. For him, as for the idlot, but little can be done beyond giving him the custodial care best adapted to his peculiar needs, the genuinc benefit being found in the family relieved of such a burden, as it has been computed that, for every case sequestrated, two if not more members are released to society. The idiot is usually but poorly developed, and in most cases unable to stand or even to sit alone, hardly conscious of his physical needs; he has no language but a cry; he rarely learns to talk; indeed, in all my experience of idiocy, do I recall but two; of these, one, after much effort, was able only to speak his brother's name, and the other acquired three words in three years.

"A word as to methods. These, based upon the theories of physiological education dictated by Pestalozzi, Froebel. and Rousseau, were first successfully practised with mental defectives by Itard and by Seguin, and include all the means that modern thought and experience have gathered. Kindergarten, nature studies, object-lessons, Sloyd, and the many occupations included under the name of manual training all lend a successive and continuous stimulus, the one underlying principle and aim of the schools being to induce observation and comparison as a basis of thinking and doing. Calisthenics and military drill induce plysical development and muscular co-ordination, quick observation, and prompt subordination. These vital principles of physiological education have practical and intellectual application in the exercises in freehand drawing, modelling in clay and wood, in Sloyd, in basket and straw braiding, and in the phonetic and articula- 
tion drills and musical exercises of the class-room, each being the initial of a life-long occupation.

"Believing, as we do, that ' the working hand makes strong the working brain,' there is always something for the child to do, some object to be made, not an abstract thing to be put out of sight when finished, but something of use to himself or to one for whom he cares. Work constantly stimulated through the emotions is his all along the line, from kindergarten, class-room, and Sloyd, to shoe-shop, printing-office, and other useful trades. Should his limit of application be soon reached, and the avenue of happiness and safe living be for him reduced to one simple groove, the more active pursuits of the farm, the garden, laundry, or household service will interest and provide vent for superfluous energy, or by constant stimulus keep him from retrograding or lapsing into apathy. For these varied occupations he is all the better fitted by the previous training of the senses received early in the schools, and if, happily, he should have there learned to read or to draw, to color, to carve, or has acquired any skill in music, he will have many avenues of recreation closed to his less fortunate brother, to whose comfort and pleasure he himself will be the better able to minister.

"In regard to the medical treatment of mentally defective children, the treatment is not essentially different from that of the normal, except, perhaps, they are not so sensitive to drugs, and we generally increase the doses. They need many tonics, and I find that punch, or even plain whiskey, combined with strychnine, quinine, and iron, is about the best. They are peculiarly susceptible to lung and cutaneous diseases. Some ten years ago the medical world was agog with accounts of brains liberated from compressing skulls by the surgeon's knife. The press was filled with sensational articles on the subject of craniectomy, and every alienist caring for feebleminded children was besieged with applications from parents, who, notwithstanding the certain risks attending surgical interference, begged that the operation might be tried upon their children. I have seen a number of cases operated upon, 
and in only one case have I seen the slightest improvement,this an idiot, to whom I have referred before in these notes as having learned three words in three years. IVas this post hoc or propter hoc?

"We must always take into consideration the amount of extra care a child requires after an operation. IVhile abroad I examined with Bourneville the magnificent collection of skulls operated upon at the Musée Anatomo Pathologique of the Bicêtre, and the skulls healing without enlargenent show the hopelessness of the operation. Victor Horsley, Shuttleworth, Beach, and Telford Smith agree with the rest of us in the opinion that it is the brain that moulds the skull, not the skinll the brain."

\section{THE DEAF AND DUMB.}

There is another most interesting class of unfortunates, the deaf and dumb. In i 890 the census of the United States showed that there were over forty-one thousand of such people in the country. Much has been and is being done for their comfort, education, and training. Millions of dollars have been expended in buildings, and now almost every State of the Union has its training-school for the deaf and dumb, and the Gallaudet College for the deaf, at Washington. D. C., which grants diplomas and degrees, after a full college course, is a fitting monument to the country and to the great men who founded it. The first record of efforts to teach the deaf and dumb in this country was by Colonel William Bolling, in Goochland County, Virginia, in the year i8s2. Colonel Bolling had three deaf children, and employed John Braidwood, a Scotchman, a grandson of Thomas Braidwood, who had a school for the deaf and dumb in Scotland. Colonel Bolling did much for Braidwood, but his intemperate habits rendered him worthless for practical work.

The real introducer of successful teaching of the deaf and dumb into the United States was that distinguished man, Thomas Hopkins Gallaudet, and the place Hartford, Connecticut. His first pupil was Alice Cogswell, a daughter of Dr. Mason F. Cogswell, of that city. Dr. Gallaudet hats a 
worthy successor in his son Edward Miner Gallaudet, Ph.D., LL.D., the distinguished head of the Gallaudet College for the deaf, at Washington, D. C., and to whom I am indebted for the data I am using in this writing. Hon. Amos Kendall should not be forgotten in this connection, for it was from his goodness of heart that the first funds and efforts were supplied towards the establishment of this great institution.

In America at present there are many able and eminent men engaged in educational work among the deaf and dumb, and in addition to those already mentioned I may name Dr. Crouter, of the Philadelphia Asylum at Mt. Airy, Peet. Rogers, Gillett, Noyes, and Fay, connected with different institutions. Why are so many children deaf and dumb? That is what concerns us as physicians. Can we as physicians do anything to prevent it? Doubtless in many cases we are at fault, not by doing harm directly, but possibly by neglect and careless indifference. Physicians should watch infants under their care during the first few days after birth, and see that nurses understand something of the anatomy and pathology of the ear. A child may be kept in a draught of cold air, and acute inflammation may arise and do serious harm; or water may be carelessly thrown into the ear by the nurse whilst washing the child, and may pass back to the membrane, remain there, and cause pain and inflammation, and end by serious disaster to the hearing, or. by passing to the brain, to life itself. Inflammation from a catarrhal cold, or from teething, may extend to the ear and cause great trouble. Thus it behooves the physician to be always watchful of such conditions, which may arise at any time and in any case.

As to the methods of teaching the deaf and dumb, the manual method prevailed entirely up to the year I867, and very little speech was taught. Since that time great progress has been made, especially in speech. It seems strange that the deaf and dumb should both hear and talk, but practically, now, they do both, and the lips are helping out the hands in the work. A deaf nutute can now deliver an oration that would do credit to a Demosthenes or to a W'ebster. Speech will not 
take the place of the mantal method, nor will the manual method entirely prevail. The present American method. which is doubtless the best in the world to-day after thirty years of trial, is the combined system, in which the best effects of both methods may be secured. In all the schools of the United States to-day every pupil is given an opportunity to learn to speak, and with these pupils, where substantial success cannot be attained after examination and fair trial, instruction in speech is not continued. As far as I can ascertain, probably less than one-half the deaf and dumb are taught speech so as to use it with practical success.

Many methods have been brought to bear upon, and are used in the treatment of those suffering from general nerrous troubles which not many years ago would have been looked upon as doubtful in erery way, as verging on quackery, or even on the supernatural. The movement cures, as first taught in Sweden, have been made wonderfully effective; all forms of the bath are used; electricity and the masseur and massense are in constant demand and doing acceptable and effective work. Learned professors hold seances frequently, and mesmerism, now dignified by the name of hypnotism. is brought into frequent and useful therapentic use. This is right and as it should be. Whatever this potent influence is. whaterer hypnotic suggestion may be, it should be taken from the hands of the charlatan, the magnetic healer, the mesmeric doctor, and used by legitimate medical men. If you ask for a definition of electricity, now so much and so deservedly and successfully used as a therapentic measure, the answer is, ' a subtle fluid.' Any answer as to what hypnotism is will probably convey nothing more definite. It is spoken of as animal magnetism, as partial cerebral inhibition, sleep produced in one waiting anxiously for suggestions from another, or any condition produced by the same. IVe have it under the name of telepathy, or mind reading, the motility of the neuron to explain it, and here we are again, - the motility of the neuron may be a subtle fluid, and that is about all we know of this force. After all, it and electricity may be one and the same. 
FORTY YEARS IN THE MEDICAL PROFESSION

Hypnotism has been practised in the East for centuries, and has there great influence on the ignorant, and is thus used to sway the minds of men, and not with the higher therapeutic aim. Probably we see its result every day and do not recognize it. The influence of one man over another, or over many men, in personal matters, in religious matters, in political matters, in social and other matters, is undoubtedly hypnotic, a result of hypnotic suggestion. In nervous diseases its action is little short of miraculons, and here it finds often willing subjects. Whether it exerts any permanent influence for good, as in the case of the dipsomaniac or other victims of the passions, I am not personally sufficiently informed to answer. The mistake is to look on it as a panacea. That it reaches some cases not reached by drugs there is no doubt. There may be danger in it. Harmful suggestions may be given, but it probably does not weaken the will. Possibly the best subjects are those with weak wills, and these are the ones whom, as a rule, hypnotism may benefit and who suffer from such troubles as are relieved by hypnotic suggestion.

One of the great problems confronting us is, what to do with the defective classes, or, rather, how shall we stop their increase and reproduction? We well know they are rapidly increasing, and increasing in proportion far more rapidly than the race is increasing. There are many ways to account for this: the increase in luxurious living and general invitations for dissipations, with absolute lack of restraint by the State on the marriage law and the violations of the marriage rite, both by omission and commission. Epileptics are increasing, the insane are increasing, the dangerous classes are increasing; in fact, all degenerates, all moral imbeciles, are increasing at a startling rate. These cases are all cases below the type of normal man, and because of them, and for them, this great branch of medicine has developed and grown up. The magnificent race of Spartans, or Lacedæmonians, of ancient Greece was made in a manner possible by allowing only the fit to survive. Even to-day among us the question of nnsexing the defectives in early life is discussed; not only 
behind closed doors, it is talked of and adrocated openly, yes, has been actually practised, with asserted good effect to the individual and surely to posterity, to the evolution of a perfect race.

Under the defectives come the tuberculous, and particularly to these should apply the supervision of the marriage laws by the State, argue the advocates of such supervision, and there is no doubt of the soundness of their arguments, as we now understand the pathology of this the greatest scourge to mankind. All this matter of heredity comes in under this law of advance or retreat from the normal type. The syphilitic, -and with the syphilitic should go gonorrhœa, the other venereal type, which we now know causes untold suffering and race degeneracy, through the female particularly, and she not the sinner, either,-the alcoholic, the drug-taker, all tend to lower the tone, the type, and the vigor of the race, and come uncler the neurotic class. It is the part of the physician to care for and improve the condition of these unfortumate beings, and by building up this great system of medicine deroted to nervous diseases most nobly has he accomplished his task, and most nobly does he continue to expand, to improve, and to unfold his work.

This is not all that interests mankind in the work of destruction of the race now surely going on, even to the threatening of the extinction of the normal type. Can the increase of the defective classes be restrained? That is, can they be restrained in the reproduction of their kind, and can the normal type be restrained from producing abnormal and not the normal type? These are the problems confronting us, these are the problems confronting the plysician, the alienist, the statesman. We must grasp them; posterity must solve them. 


\section{CHAPTER VIII.}

Ptomaines-Definition of, etc.-Composition of, etc.-Vegetable Alkaloids -Clianged Food Supply-Canning, etc--Poisonous Gases in the System-The Different Ptomaines-A Growing Evil-Fatigue and Ptomaine Poisoning - Chronic Ptomaine Poisoning - Ice-Cream and Cream-Puff Poisoning-Personal Experience in Ptomaine Poisoning -Auto-intoxication in Disease-The Reflexes from Ptomaine Poisoning and Auto-intoxication-Pathogenic Poisons--The Death Struggle an Auto-intoxication.

Among the most interesting matters brought to the attention of the medical profession in recent years is the knowledge of the presence of what are called ptomaines in organic food-products, and much of this work has been done by Vaughan and other scientists in this comntry. Billing's definition of a ptomaine is that it is a strongly basic compound, the result of putrefactive changes in animal tissues closely simulating vegetable alkaloids. It may be liquid, containing no oxygen, and of peculiar cadaveric odor, or solid, crystallizable, containing oxygen, soluble in water but insoluble in alcohol, chloroform, etc. All ptomaines are precipitated by phosphomolybdic acid, but there is as yet no general test distinguishing ptomaines from vegetable alkaloids. They all lave conspicuous reducing power. Here, observe, is a cadareric alkaloid. Now let us give Billing's definition of a vegetable alkaloid. It is an organic basic substance in its behavior with acids, resembling ammonia. They all contain nitrogen, and are the active principles of most poisonous plants. Here, then, are two great sonrces of poison to human beings always present with and surrounding us; given large doses, and the acute attack makes known at once their presence; given small and constantly repeated doses, and chronic poisoning besets us. Just this danger confronts us in these cadaveric alkaloids. It is not the large dose and acute poisoning that is so threatening, but it is the constant small dose, the coup sur coup, the blow upon blow, that is undermining the health of so many 
of the human race at the present day and makes their action so much like the slow poisoning we often see in the consumers of the regetable alkaloids, as those from opium and other plants, like the nicotine from tobacco; they cause the slow poisoning, the weakened, intermitting heart, which allows a slight regurgitation of blood through the imperfectly closed valves, thus preventing complete oxidation in the lungs, and allowing poisonous gases to accumulate in the system.

The great change in handling the food-supply of the more advanced countries, the system of cold storage, the system of canning or, as the English say, of tinning the animal foods, all tend to the increase of ptomaines in such supplies, for although in canning the bacteria are destroyed by heat and the contents once sealed hermetically will remain sound until again exposed to the air, the ptomaines, if present at canning, are not destroyed by the process, and remain to taint those eating them. The nere fact that meats, fish, milk, and such products are kept much longer before consumption than formerly, even though our methods of preservation are so improved and superior. makes us all more exposed to these poisonings. Such discoreries are causing the art and the science of medicine to be rewritten, just as chemistry and electricity have been and are being rewritten.

As to the origin of ptomaines. I am not certain that we know surely about it. They have been isolated and named, many of them, as tyrotoxicon, or cheese poison, found in milk; halichthytoxin, found in fish: mytilotoxine, found in mussels, and others. Some deny that ptomaines are the product of putridity and that the matter in which they exist is necessarily tainted. From what I know of them I am inclined to believe that ptomaines are alkaloids, the result of bacterial action in matter undergoing pritrefactive change. I have seen one definition of them as of one of the temporary forms through which matter passes in changing from bacterial life to dead inorganic matter. This makes them the result of bacterial action whaterer the cause. I have no cloubt but that their increaserl jresence is clue to the changed meth- 
FORTY YEARS IN THE MEDICAL PROFESSION

ods in handling the general food-supply, to filth, to lack of attention to details in large packing and canning establishments, to long distances by which food products reach the consumer, and last, but not least, to the rapid increase of population in the great centres, producing the classes of people likely, owing to their condition and environment, to furnish numerous subjects for these poisons. It is doubtless a growing evil, and one that must be carefully supervised both by the medical profession and by the police power.

Ptomaines lurk particularly in milk, the albumin furnishing a good medium for the growth of the bacteria which give rise to them. Take out the fat and they still thrive, for some of the worst cases of poisoning I have seen have been from buttermilk. Put aside a can with some left-over buttermilk, let it stand twenty-four hours, and then fill with fresh buttermilk, and you will almost surely have ptomaines developed. I have seen severe cases from the tyrotoxicon in cream puffs. Investigation showed me lack of cleanliness and lack of attention to the details of cooking, in all these cases. No maker of such pastries will poison his patrons who is absolutely careful to provide good and reliable materials, and who practises absolute cleanliness, with strict attention to all minor details as regards place and utensils. Ice-cream frequently is the villain causing the trouble. Not the ice-cream from a first-class place, even though it claims to be such, but circus ice-cream, picnic ice-cream, washed-over ice-cream, is always the offender.

As to the chemical nature of ptomaines we know but little, and it follows we as yet know of no antidote. Sone crystallized substances have been found, and various fungi or fungous growths, differing as their hosts differ. In the acute cases I have seen the symptoms have been usually about the same,-nausea, vomiting of frothy fluid in profusion, free purging, with thin soapy stools, anxious countenance, with great pallor, sweating, and pain in the bowels, in fact, a general tendency to collapse. The feeling of fatigue and exhaustion are referred now by some physiological chemists to a 
form of light ptomaine poison, making it rather in its milder forms purely a physiological act, and a regular storm of it is when it passes the danger line. The treatment, of course, is to get rid of the offending matter from the digestive tract in all possible ways, drinking warm water, washing ont the stomach and bovels, and supporting the heart, above all things, while nature is making her desperate fight for supremacy. Collapse and coma may end the scene, but in my experience death is not frequent in these acute cases where the heart, liver, and kidneys are sound, the efforts of nature, with the little assistance we can give, generally proving effective.

What shall I say of the chronic cases? Well, I don't know, but I know enough to warn the profession to be on its guard and to take into consideration chronic ptomaine poisoning as one of the coming, one of the dangerous, one of the threatening ills of mankind. By a strange coincidence, just after I had written the foregoing I myself had a personal experience with ptomaine poisoning. I had been well and very busy. At about eight o'clock in the morning I ate a light breakfast, consisting of a small portion of boiled mackerel, surely not over a tablespoonful, eating it with stale bread, and butter to give the bread a flavor. This, with a cup of coffee, composed my breakfast. At ten o'clock I left my office and was busy out and in my carriage for five hours. When I came home I had a natural movement of the bowels, when a slight nausea came on, with a tendency to taste the fish. I took no luncheon, and rarely do. The nausea increased, and by the time my ustal dinner-hour ( six o'clock) came I was very sick, vomiting and purging, more particularly purging, continuously. I may say, before this conmenced, coincident with the onset of the nausea, I noticed attacks of irregular heart-action and intermitting heart. As I grew worse the intermitting and rapid heart-action increased, and before I commenced to come around I was verr weak generally. For fifteen hours the purging kept up, a passing of thin, soapy, frothy, almost colorless. looking fluid, perfect rice-water discharges. I could 


\section{FORTY YEARS IN THE MEDICAL PROFESSION}

not imagine one passing more in quantity during the same length of time. There was great general uneasiness in the stomach and bowels throughout the attack, but only for a time was the pain very severe, when a true colic came on, which was relieved by vomiting. After the diarrhœa ceased the nausea remained for about thirty-six hours from the commencement of the attack, with a horrible general tight binding headache. The temperature never went over IOO $^{\circ} \mathrm{F}$. Altogether I was inexpressibly miserable, and had I been on a rack of torture I could not have suffered more in joints and muscles than I did. The mackerel was undoubtedly the cause of the trouble, as I had eaten nothing else to cause it during the twenty-four hours preceding. Fortunately no other member of my family partook of the fish, and the uncooked part of it after I was taken ill was made away with before I was able to give a thought to its examination.

Having spoken of ptomaines and their actions brings us to another subject germane to them, and one of very great importance to both physician and patient, and one which has but recently assumed a position of importance, owing to the work and writings of Bonchard, more particularly. I refer to auto-intoxication in disease, or self-poisoning of the individual. This is one of the parts the alkaloids chiefly play in the causation of disease and diseased conditions in man, and are greatly the result of ptomaines in one shape or another. We would probably all die sooner or later from these poisons, generated from complex digestive processes going on chiefly in the small intestines, were it not from the fact that their life is self-limited, being destroyed by the poisons they themselves generate, thus fulfilling that relentless law of nature that every living thing generates its own poison, to which rule man even is no exception.

According to Bonchard self-poisoning in man is only prevented by the action of the liver and kidneys, and the resulting fluids are poisonous as they pass out of the system. The ferments formed outlive their parents, the bacteria. Alienists are now giving much attention to the part anto-intoxication 
plays in mental diseases. The injection into the lower animals of urines of those suffering from different types of insanity gives results characteristic as to the form of insanity. The delirium of fevers is probably much of it owing to autointoxication from pathogenic organisms. Bouchard believes many of these germs are innocuous in the intestinal tract of the animal forming them, but may be harmful when taken up by an animal of another kind. The white blood-corpuscles may destroy them and the liver may check them. Asphyxia is an intoxication.

Uræemia is an interesting condition to all observant physicians. It is a complete intoxication according to Bouchard. Formerly urea was considered the chief or only poisonous agent. Now many other matters are known to be more the cause, as alkaloids, and are found as extracts in evaporated urine. Ammonia, soda, and potash are poisons in urine. There are two substances causing convulsions,--potash and the other an organic substance. If this is correct, how important to avoid potash, in all renal insufficiencies particularly; substitute iodide of sodium for iodide of potassium, and aroid potash in the salines so much used in renal troubles. Putrefaction plays a great part in auto-intoxication, coming from imperfect changes in digesting matters, and also from micro-organisms in the intestinal tube. These are the nitrogenous substances already peptonized, which are excellent culture media for microbes; additional microorganisms go down with each swallow of saliva from the dust of the air, etc. Fermentation does not go on continually in the stomach, because the hydrochloric acid which is always being secreted by the healthy stomach when food is being introduced stops it; going on through the pylorus, this acid is neutralized by the intestinal alkaline fluids, which are only feebly acicl, when acetic fermentation begins. Bile only feebly opposes fermentation in the small intestine, and can have no influence on the active fermentation of the large intestine. Thus the small and large intestines both pass products of putrefaction into the blood. These matters are 
toxic; they enter the blood and act at once. If infectious, they would not act at once, for infection implies time for incubation. We find the alkaloids in the fecal contents of the large intestine, for here putrefaction goes on unchecked by any presence of hydrochloric acid. Fecal matter is toxic in a general way to living cells. The aqueous extract is toxic; the alcohol extract is more so. Here is a great source of auto-intoxication, if such accumulations are allowed to remain beyond the proper time. Let the kidneys be diseased, and here is another prolific source of intoxication. They may be doing badly and the patient do pretty well. If they be diseased so much as no longer to eliminate in twenty-four hours the quantity of poison sound kidneys should eliminate in this time, the consequences must be serious. Sound kidneys can do more than is normally required of them, as in the amount of water they eliminate in diabetes. They may go further; they may eliminate substances that should not come off by them, as peptones and albumin, and the blood is impoverished. Twelve grammes in twenty-four hours is much albumin to lose by the kidneys, especially if we do not recruit it by healthy digestion. The poverty of the blood caused by these intoxications is frequently the cause of retinitis, amaurosis, phlegmons, œedema of the glottis, hemorrhages, and such.

These auto-intoxications of intestinal origin come chiefly from reabsorption from the intestines. Constipated people, as a rule, all suffer from such, and among them vertigo, dizziness, headlaches, disturbances of sight, etc., are common. Many are hypochondriacal. Among the insane are many sufferers; some may have almost constant diarrhœea and yet be sufferers from accumulated masses in the large intestines. Diarrhœeal discharges may pass through a hole bored through the centre of such masses, making quite a lumen. Wash out the bowels fully and often is the remedy, using antiseptic injections. Common salt is among the best and safest. Be careful of carbolic acid in large doses. The danger in its use does not often compensate for its advantages. 
After such treatment fevers will often abate and comfort return to your patients. Many of these people have dilated stomachs. Treat such stomachs by diet, and locally wash them out as you wash out the bowels, and improvement and cure comes. In dilated stomaclis we have all sorts of fermentations, and so intoxications and reflex troubles come, as headache, urticarias, and such. As before said, I believe urticarias and such are vasonotor neuroses coming from auto-intoxication from ptomaine poisonings of more or less chronic character. Bouchard speaks of a form of dilated stomach, accompanied by albuminuria, the albuminuria being caused neither by heart nor kidney trouble. In the treatment of typhoid fever he cautions care in watching for auto-intoxication, and believes in intestinal antisepsis here, using naphthalin, iodoform, and carbolic acid, with lavage of the large bowels. The fever causes the withdrawal of the blood-corpuscles to the spleen, and thus enlarges it. According to this we should have enlarged spleen in all fevers.

This matter of intestinal toxiemia is a most interesting subject, and its development and elucidation by study and observation must work great good to suffering lummanity. It is always to be taken into account in the diagnosis of fevers and of all obscure cases, especially the enteric fevers, the fevers arising from tuberculous disease, from renal troubles, from slow poisonings of different kinds, especially the mineral poisons, and from lithæmia and lithæmic troubles. It is common in children, more especially in bottle-fed children. Here in the retained matters in the intestines, both large and small, we have fermentation and putrefaction going on with the formation of acids, as butyric and lactic; gases are also developed; these pressing on the filaments of the pneumogastric nerve give rise to local troubles and also to reflex troubles involving the brain and general nervous system. The albumin of the milk and other nitrogenous substances eaten gives rise to the development of indol, one of the aromatic series, resulting from the decomposition of albumin; skatol, tyrosin, a product of pancreatic digestion: with phe- 
FORTY YEARS IN THE MEDICAL PROFESSION

nol in the urine. From all these troubles we have many reflex symptoms arising and expressed in bronchial attacks, local and general convulsions, spasm of the glottis, circulatory irregularities, with skin troubles and rashes of different kinds. In such cases do not forget to watch the kidneys, remembering that whatever troubles may arise in them are usually functional. Remember the cause of all these troubles is in the digestive tract. Remove it and the cure is assured.

Pathogenic poisons exist in the sick man, and the death struggle prolonged is an auto-intoxication. In certain diseases there are certain morbid poisons engendered by the normal life of microbes or the diseased life of human cells, whatever these may be. Light is gradually dawning on pathological conditions, and man is thus paving a better way for the rational treatment of his own ills and the prolongation of his own life. 


\section{H A P T E R I X.}

Diet now on a Scientific Basis-Study the Individual-IdiosyncrasiesTeach Diet in the Schools-Diet in Youth and Old Age-Carlsbad and its Doctors-Diet and the Poor-Division of Foods-Animal and Vegetable Foods-Tissue-Builders and Force-Producers-Uses of Food-Oxidation and Health-Water-Rations for Individuals-Children and Proteids-Atwater and Woods on Composition of FoodsAll about Eggs-Fish compared with Beef, etc.-White Potatoes, Spinach, Asparagus, etc.-Lead Poisoning-Coffee and Tea-Chocolate and Cocoa-Dietary Studies among the Plain People-The Germans and German Thrift-Study of a Family as to its Diet, Cost of. etc.-Diets for Corpulency and Leanness-Systems of Diet-Banting and Others-Different Kinds of Breads--Toast, etc.-Kissingen and Vichy Remedy for Fatness-Food consumed per Person per Year in Different Countries-Time required for the Digestion of Various Foods-Sterilizing and Pasteurizing Milk-Infant-Feeding-Artificial Infant Foods-Diet for the Old-Ward McAllister-Infantile Scurvy -Concerning Milk-Tests for Milk-Regulating the Milk TradeGraded Milk.

AT the present day I believe the profession is coming more and more to appreciate the importance of diet. Surely forty years ago, when I entered the profession, little was said about it and less was taught concerning it in the medical schools. All or nearly all at that time believed, empirically believed, in the antiphlogistic system of treatment, and almost erery sick man, or wounded man, or crazy man, for that matter, was put on a diet of as near bread and water as possible, and because women were fortunate enough to have babies, for that they were generally starved for six weeks, much to their own injury and the inconvenience of the luckless offspring. Why were they starved? Oh, to prevent inflammation. What was inflammation? Too much blood. Thanks to Professor IV. Gilman Thompson, Liebig, Sir Henry Thompson, Fothergill, Horatio Wood, and others, the matter of 


\section{FORTY YEARS IN THE MEDICAL PROFESSION}

diet to-day has advanced from mere empiricism, from the mere didactic, thoughtless, even ignorant assertions of the school men, to something approaching an exact science, and, like general therapeutics, is no longer a mere assertion or pill-giving calling, but is a well-studied scientific profession.

Professor Thompson's recent work on Practical Dietetics is a timely and most useful gift to the medical profession, and I wish here to acknowledge the generous use I shall make of the information gained from its pages in this little sketch of modern dietetics I am writing. When we order this thing and that thing to a sick person to eat, do we do it thinkingly or unthinkingly? Surely we should think in carbon and hydrogen, oxygen and nitrogen. Given a patient with contracted kidneys and hypertrophy of the left ventricle, and other ills perchance following in the wake of these, of what use is medicine, of what use are pills and powders and potions, if we allow such a patient to stuff himself with an excess of nitrogenous food?

These are cases of commencing or confirmed arteriosclerosis from which arise aneurisms, apoplectic seizures, and so on. The first symptoms are usually increased steady heart action and an excessive flow of urine of low specific gravity, soon followed by renal contraction. How useless are medicines in these cases if the eating and drinking of the patient are not supervised and rigidly controlled! When we order our pills and potions and powders in such a case, let us think in carbon and hydrogen and oxygen and nitrogen, and see to it we do not increase his blood-pressure by food whilst we are endearoring to control it by drugs. In such a case, if I must abandon one course of treatment and keep only to the other, give me diet, "throw physic to the dogs."

Another practical point in dietetics is, study the individual. It is very true that what will nourish one man will poison another, and, further, what will be proper for a well man may kill a sick man. Some individuals can live on milk alone when they try; with others it is impossible. Many a man can eat mutton and grow fat on it, so he can eat eggs and 
thrive; to others, again, these are poison. Such are mere idiosyncrasies, and it is well to remember them. I believe the principles of diet and nutrition, the effects of alcohol and tobacco and such, should be taught to some extent in the schools, not fanatically, but reasonably. Some general knowledge on this score would add much to the general health of a people and be of assistance to physicians in treating the average man. There is a diet for the young, for the man of middle age, and for the aged person. We commence with milk, the complete food, the balanced ration. IVe go through all of the luxuries of a lifetime, and as we approach toothless old age we come back again to childhood and to childhood's ration, milk, and in extreme old age the nearer we adhere to the simple milk diet the better and happier we are, and the longer and more satisfactorily we live. My observation and experience lead me to believe, as intelligent persons grow to middle age and beyond, they, as a rule, become careful as to diet. Indeed, many become cranky or full-fledged cranks, especially the idle and well-to-do. This is all right so they do not approach melancholia. These people are the ones who often take and who often benefit by the course at Carlsbad and such resorts.

I do not approve always of Carlsbad diet for the given case, and have been familiar with some diagnoses made by resident physicians of Carlsbad that I did not by any means agree with. I once knew of an ardent temperance woman who took her young son, a boy of serenteen, to Carlsbad, thinking the course might relieve him of some dyspeptic trouble, too many sweets in his diet, probably. She called with John at the office of a prominent constiltant, who was very affable and very painstaking, asking many questions, finally coming to diet. "Vell, Shon, vhat do you drink?" "Drink," said John. "Yes, vhat do you drink?" "Water, of course," answered the mother. "Nothing stronger, I assure yout." "Vaser! Vaser!" said the doctor, in wild amazement. "My Got! it vill kill him, madame; it vill kill him." It is safe to say madame did not take the roctor's advice as to John's 


\section{FORTY YEARS IN THE MEDICAL PROFESSION}

beverages, and left Carlsbad with a poor opinion of its doctors.

There is, no doubt, much suffering from improper diet, and bad cooking is responsible for many ills and, doubtless, many deaths. A little observation of the inner life of the poor will cause one to realize in a high degree the utter discomfort and utter misery, even unto death, which come to those untutored and unskilled in providing, in choosing, and in preparing properly for the table even the simplest of foods. Education, supervision, the evolution to a higher plane of living for these people is the only corrective for such pitiable ignorance and carelessness. These people need supervision, they need instruction. The principles of cooking practically taught in schools would help out in this work. Call it paternalism if you choose, but as we grow wiser in government such matters must come up and be taken up before we reach the highest civilization.

Thompson divides foods, say, into solids, semi-solids, and liquids. Next into fibrous, gelatinous, starchy, oleaginous, and albuminous. He speaks of eggs and milk as examples of complete foods which alone will support life; others, again, as starches, will not alone-absolutely alone-support life for a length of time. The sources of food are animal foods and vegetable foods. Animal foods are meats, poultry, fish, shellfish and crustaceans, eggs, milk and its products, animal fats, and gelatin. Vegetable foods are the cereals, vegetables proper, fruits, sugars, and vegetable oils. The simplest chemical classification is Liebig's nitrogenous and non-nitrogenous. The nitrogenous group are tissue-builders or fleshformers. The non-nitrogenous group furnish the body with the fuel and keep up the animal heat, and are the force-producers. The tissue-builders also produce some force and heat. There is some nitrogen in the vegetables, though not a great deal. The outside coverings of the starch granules contain some nitrogen, for example. Nitrogenous foods also are not absolutely nitrogenous, as they contain some fat and glycogen. The uses of food are to serve the body with ma- 
terials for growth and renewal, and with power, much as fuel does for the stean-engine. The consumption of the fuel furnishes the power. The starches and sugars furnish much of the power to man. The original force is in the heat of the sum; this is stored by the plants in the latent form of chemical compounds, as Professor Thompson says. The main source of power is oxidation, chiefly of carbon. Wherever it goes, or any waste product goes, it is not destroyed, it only changes its form; you cannot destroy matter. Take urea: it is matter merely of our food in a changed form, something like ashes from coal. This urea and other débris, if not gotten out of the body, blocks the system and prevents the normal processes of oxidation, which must go on properly to give one good liealth.

Thompson says it is still difficult to trace in the case of all foods their final uses in the body and determine accurately what proportion of each goes to power, what proportion to tissue repair, and what proportion to furnish heat, for tissue metabolism is very complex in its chemistry. The daily allowance of nutritive material allowed by Professor Egleston as given by Thompson for a healthy man is seven hundred grammes, divided into carbohydrates, four hundred grammes; fats, one hundred and fifty grammes; proteid, one hundred and fifty grammes, yielding in all three thousand six hundred and fifty calories, or units of heat, a heat unit being the amount of heat required to warm one gramme of water one degree centigrade.

Water is to be looked upon as food, composing as it does seventy per cent. of the weight of the body, and much of it passes through the body unchanged. Withhold it, and life is impossible. I am sure as a remedy it is not half appreciated. Many persons do not drink water enough, and suffer accordingly, whether sick or well. Others, again, may take too much, and it is the duty of the physician to study each case and set his patient right on so important a matter. Of course, much of the water we take goes in as part of our food, and this fifty to sixty per cent. of water in our solicl foods must 


\section{FORTY YEARS IN THE MEDICAL PROFESSION}

be taken into account. The salts, such as lime and magnesia, abound in the body, and they, with many others, have their uses in tissue formations, etc.

Thompson, quoting from Von Pettenkofer and Voit, shows that during the performance of hard labor the consumption of albumin remains practically the same as during rest, whereas three and one-half times as much fat is consumed, and the amount of carbohydrates is the same, hence for hard laborers give plenty of fat pork, butter, oil, and such. A workingman will take from fifty to seventy-five ounces of solid food in twenty-four hours, and about the same amount of water by weight. The ration should contain one part of nitrogenous food to three and one-half parts of non-nitrogenous food. The average albuminous food gives about sixteen per cent. of nitrogen. Again quoting Thompson, for a man weighing sixty-seven kilogrammes the daily allowance of food ranges from six to nine grains of carbon, and .25 to .36 grain of nitrogen per kilogramme of body weight. Cow's milk and wheat flour approach nearest to a balanced ration of all food as to their nitrogenous and non-nitrogenous proportions. In cow's milk the proportion is one to three, and in wheat flour one to four and one-half.

These are matters of great practical importance, and all physicians should be more or less familiar with them. The destruction of the carbohydrates in the body is very complete when eaten in excess, and they do not produce fat like fatty foods taken in excess. This is an important practical point. The carbohyclrates are more or less fattening when eaten with albumin and fats, because they check the consumption of albumin and fats and leave more of them to be converted into tissue fats. Eaten alone they are not so fattening. For example, the Chinaman, living mostly on rice, is not usually over-fat. Another practical point: when you have children growing rapidly and using their force in the ceaseless activity of the young, see that they get sufficient of proteids in their daily ration. The food value of certain articles of diet is most important to the physician, whether to make up a ration 
for the soldier, for the laborer, the professional man, or women or children, or, more than all, of the sick intrusted to his care. Of albuminous matters used as food, one-third of it is excreted as urea. This is important to remember when the kidneys are diseased and camnot get rid of this urea, although, as before said, some are beginning to deny that urea mexcreted is the great offender it has heretofore been given credit for.

Probably most persons over thirty-five years of age consume too much nitrogenous food, especially those who inherit gout. These gouty, bilious people are usually the strong and healthy, and, as a rule, have ravenous appetites; they live to eat, rather than eat to live. They often incline to be good drinkers of wines, spirits, and malt liquors, but, as a rule, much to their disadvantage, are light water-drinkers. If they drank more water the ill effects of a vicious metabolism, of vicious tissue change in nutrition and secretion, would be carried out of the system more generally in the various secretions and excretions. It is surprising to see how soon one who has been a free meat-eater can come down to almost a 1lon-nitrogenous diet and enjoy life and feel lighter and better and more contented in every way, provided the excess of nitrogen he had been taking was doing him harm. One nunst know something of the chemical composition of foods to lay out such a diet, for it will not do to tell a patient to live on milk and eggs and fish and all manner of vegetables, and to avoid only red meats and the black meat of poultry, etc.

Professor W. O. Atwater and Charles D. Woods, of the Agricultural Department at Washington, have given us some interesting tables of the percentage of protein, fat. etc.. in common every-day food-stuffs, and it is surprising to see how nearly what some consider light diet approaches to heary nitrogenous diet. Roast ribs of beef contain r6.9 per cent. of protein and 26.8 of fat; sirloin steak holds i 8.3 protein and 20.2 of fat; beef liver, 2 I.6 of protein and 5.4 only of fat; corned beef, 15.3 protein and 23.3 of fat; beef tongue, 2 I.5 protein and 23.2 of fat: loin of real. $59 .+$ protein and 10.4 
FORTY YEARS IN THE MEDICAL PROFESSION

fat; loin of lamb, I 7.6 protein and 28.3 fat; leg of mutton, I8.2 protein and is fat; loin of pork, i 6.8 protein and 30.3 fat; salt ham, $\mathbf{5}_{5} .5$ protein and 39. I fat; bacon, Io protein and 67.2 fat; pig's feet, I6. I protein and I 4.8 fat; pork sansage, I 2.8 protein and 45.4 fat. Of course, sausage may contain protein and fat just as the maker chooses to put in each ingredient. Soups: Bouillon, 2 protein and I fat; consommé, 2.5 protein, no fat: mock-turtle, 5.2 protein and 9 fat: chicken soup. 3.6 protein and I fat. Roast chicken, 22.8 protein, I. 8 fat; this is the average of all edible parts; white meat would contain less protein. Tripe, protein I3, fat I6, a good morsel, low in protein but quite high in fat. Sweetbreads, the thymus gland of the calf, protein I5.4, fat I2.I. Brains of the calf are very fatty and not very nutritious, and contain a high percentage of cholesterin. The liver and kidneys of the calf are very palatable and fairly nutritious; the former contains protein I6.6, fat 7.4, and ash I.3, and the latter about 18 protein and 5 fat. All pork, as a rule, is indigestible on account of too much fat in proportion to other matters. Goose, I 3 protein and 49.9 fat; turkey, 20.6 protein and 22.9 fat: quail, 2 I. 8 protein and 8 fat. As a rule. all game is high in protein.

It is interesting to compare fish with the meats and to see how they compare in percentage of protein, particularly with our strong foods, such as roast beef and mutton. The average fish diet is surely not the light diet we unthinkingly are apt to take it to be; nevertheless fish is a safer and lighter diet than red meats and such, even if we take the stronger fish like cod. Fish diet does not load the blood with as much waste as the heavy meats do, requiring the getting of more oxygen by exercise to eliminate them from the system. Thus fish diet does not render the over-fed man dull like heavy meats, nor is there any truth in the common belief that fish diet is the best brain-food from the excess of phosphorus it contains. Black fresh-water bass, $20 .+$ protein and 1.7 fat. These proportions are all from the edible portions alone, and so with the meats we have been speaking of, and thus give 
higher percentages than though all parts were taken in making the percentage. Sea bass, IS.S protein and .5 fat; fresh shad, I 8.6 protein and 9.5 fat; shad roe, 20.9 protein and 3.8 fat; rock, I 8.3 protein and 2.8 fat; blue fish, i9 protein and I.2 fat; salt cod, 2 I.4 protein and .4 fat; sheepshead. 20.3 protein and 6.7 fat; fresh cod, I 5.8 protein and 4 fat; flounder, I3.9 protein and .6 fat; haddock, i6.8 protein and .3 fat; halibut, fresh, 18.3 protein and 5.2 fat; smoked herring are well up in nitrogen, and so are white fish; fresh mackerel, I 8.2 protein and 7.I fat; salt mackerel 22 protein and 22.6 fat; white perch, I9. I protein and 4 fat; pike, I8.6 protein and .5 fat; fresh salmon, 19.9 protein and 7.4 fat; salmon trout. I8.2 protein and I I.4 fat; smelts belong to the salmon family, and have a little less protein and fat than salmon: salt sturgeon and caviare are very high in protein, fresh sturgeon not so high; weak fish, I 7.4 protein and 2.4 fat: clams, 8.6 protein and I fat; lobster, edible portion, I6.4 protein and 1.8 fat; oysters, 6.2 protein and $\mathrm{I} .2$ fat; scallops, I 4.8 protein and .I fat; shrimps are very high in protein; terrapin is high in protein, the dressing makes it higher; crabs, edible portion, protein I6.6, fat 2 . Average cow's milk, protein $3 \cdot 3$, fat 4 , water 87 , carbohydrates 5 , salts .7 ; cream. protein 2.7, fat 26.7 , water 66 , carbohydrates 2.8 , salts I.S; skim-milk, protein 3.4, fat .3, water 90, carbohydrates 5.I, salts .7; condensed milk evaporated in vacuo to about one-fourth its bulk, water 30.5 , protein 8.2 , fat 7.I, carbohydrates 52.3, ash I.9, carbohydrates being increased by the sugar added; human milk, albuminous matters 2.04, fat 3.76 , milk-sugar 6.95, mineral matter .I4, water 87.I I ; buttermilk, water $9 \mathrm{I}$, protein 3 , fat .3 , carbohydrates 4.8 , ash .7; goat's milk is stronger in sugar and fat than cow's milk. Koumiss is a useful food, and very light, and contains after twenty-four hours' fermentation about is alcohol, milk-sugar $\mathrm{I}_{5}$, fat 20 , salts 4 . lactic acid 5, albumin 23, carbonic acid 7 , etc. To make koumiss from cow's milk, take one quart of new milk, one-third compressed yeast-cake or dessertspoonful fluid yeast, one heaped tablespoonful pulver- 
ized sugar; mix and warm this, put in a champagne bottle, and tie cork down. Do not use a thin bottle. Ten hours' standing at a heat of $90^{\circ}$ will make it. A pint patent-stopper beer-bottle is a proper utensil to make a pint in. Keep on ice or in a cold place. Ordinary cheese, 33.5 protein and 24.3 fat.

The following complete analysis of hens' eggs has been compiled at my request by the Director of the Delaware College Agricultural Experiment Station: A hen's egg of medium size weiglıs 50 grammes, the shell 6 grammes, the yolk I6 grammes, the white 28 grammes; total, 50 grammes. Of one hundred parts of the edible portion of the egg, 36.3 parts equal the yolk, 63.7 parts equal the white; total, Ioo parts. The white of the egg consists of water 86 per cent. (protein), albumin I 4 per cent.; total, Ioo per cent. The yolk consists of water 53 per cent. (protein), albumin I6 per cent., fat 30 per cent., salts I per cent.; total, ioo. The Bulletin of the Agricultural Department at Washington makes the edible portion of the whole egg I 4.9 per cent. albumin on the basis of the whole egg; 32 parts in Ioo represent yolk, 56 parts in IOO represent white; of the 32 parts of yolk, I6 per cent., or 5.12 , equal albumin; of the 56 parts of white, I4 per cent., or 7.84 , equal albumin; total, 12.96 albumin. From this it will be seen that the whole egg is fairly high in nitrogen and the yolk has considerable fat. The yolk is fairly low in nitrogen, and the gouty man may eat it moderately, but not the whole egg. For some reason some persons cannot eat eggs at all, and with the sick they often disagree. During intestinal digestion sulphuretted hydrogen and ammonia are evolved, and an intestinal storm ensues. The yolk here produces the disturbance.

If there is any difference in the nutritive value of eggs as to color, the white eggs are the most nutritious. The salts of the whites are chiefly chlorides. The eggs of chickens, turkeys, ducks, guineas, and geese are most used for food. The duck- and goose-eggs have most fat; the eggs of the plover are said to be the most delicate, and are a rare treat. Eggs 
are most completely digested, and hence are very nutritious as to their weight, and make a well-balanced ration with carhohydrates alone. The yolk is rich in fats, containing olein, palmitin, yellow pigment, and lecithin. It also contains grapesugar in very small amount, phosphates, iron compounds, and sulphur.

Notwithstanding the general belief to the contrary, experiment shows five minutes' actual boiling to be the proper time to boil hens' eggs to make them most digestible. A tenminute boiling is better than three minutes. Fifteen minutes makes the yolk very digestible. As to the shape of eggs, those of hens, ducks, geese, crocodiles, and snakes are mostly oral; those of guineas and most sea-fowls are pear-shaped; those of owls and turtles and the like are spherical. Yellow or brown colored eggs are laid by the dark Brahmas, partridge Cochins, black Langshans, Wyandottes, and barred Plymouth Rocks; brown Leghorns, buff Leghorns, white Leghorns, and the white and black Minorcas lay the whiteshelled eggs. The fresher the egg, the more digestible and more palatable it is. The albumin becomes less digestible as time passes. The odor of spoiled eggs comes from the formation of hydrogen sulphide from the sulphur in the yolk. As an egg becomes old it gets lighter in weight. Look through a fresh egg towards the light, and it is homogeneous. If spoiled, it is opaque at the top, owing to the formation of an air-space. In salt and water, two ounces to the pint, a good egg will sink. To coddle an egg, put it in cold water and heat it up to $\mathrm{I} 67^{\circ} \mathrm{F}$., and keep it there until the albumin is cooked to the centre, say five to seven minutes. The white coagulates at $163^{\circ}$, and the yolk at $167^{\circ}$. A coddled egg is never boiled, for then the heat must reach $2 \mathrm{I} 2^{\circ}$. At fifteen cents per dozen, hens' eggs are cheap food. At thirty cents per dozen they are expensive food.

The special cheeses are stronger than ordinary cheeses. Butter contains 3 protein and 92 fat. Of course, in milk and cream there is some little carbohydrates. Sugar is nearly pure carbohylrates with a little water, about three per cent. 
Boiled unpared white potatoes contain 2.7 protein, .2 fat, and 22.3 carbohydrates; white potatoes have considerably more protein when boiled with the skins on than when boiled with their skins off. In boiling with the skins off the Department of Agriculture at Washington finds that there is loss of organic nutrients and mineral salts. The potassium compounds particularly are lost, and these are very necessary for health. The loss is suffered by the abrasion of the soft parts while cooking. Here nearly three per cent. of the carbohydrates and four per cent. of the available flesh-forming nitrogenous matter are lost. Boil them with the skins on, and there is only a little loss of non-albuminoid nitrogenous substances and mineral matter. Let the young and strong preserve the skins in cooking. Let the gouty man discard them and thus reduce his nitrogen. The proper way, after all, to cook all potatoes is to bake them, and thus better break up the starch. Unpared boiled white potatoes also contain 73.7 of water. In these analyses the ash does not appear to vary greatly, and is composed of the potassium, sodium, calcium, and magnesium chlorides, sulphates, and superphosphates. These are important to take into account, and in such diseases as angina pectoris, where the hardening and deterioration of the blood-vessels is to be taken into consideration, we want as much as possible to eliminate lime and such constituents from the diet.

Wheat flour gives protein I0.4, fat I, carbohydrates 75.6, and little ash. Macaroni gives about the same as wheat flour, so it is not a gluten preparation by any means. Barley, protein 9.3 , fat I, carbohydrates 77.6 , about the same as wheat flour. Buckwheat flour has only 6. I protein and 77.2 carbohydrates. Corn-meal has 8.9 protein, 2.2 fat, 75. I carbohydrates, and little ash. Corn hominy, about the same as corn-meal. Oatmeal, protein I 5.6, very high, fat $7 \cdot 3$, also high, and carbohydrates 68 , less than corn and wheat. Boiled rice has only 5 protein. .I fat, 4 I.9 carbohydrates, and 52.7 water, with little ash; it is easily digested, and if not eaten with too much fat is not very fattening. Rye flour is less in 208 


\section{FORTY YEARS IN THE MEDICAL PROFESSION}

protein than wheat flour, but is higher in fat and carbolydrates. Tapioca is nearly pure starch. Dry beans are very strong in protein, carbolnydrates, and fat. Fresh lima beans have much water, and only 7.I protein and 22 carbohydrates, not much stronger than white potatoes. Green peas have much water, and only 3.6 protein and 9.8 carbohydrates. Potato chips have 7.6 protein, 35.5 fat, and 50.6 carbohydrates, a very fattening morsel. Sweet potatoes have protein 3.6, fat I.3, carboliydrates 49. I, ash 2 ; these excel the white potatoes very much in fattening properties. Fresh radishes are nearly all water and refuse; so is rhubarb, but it has oxalic acid, and bears watching. Onions are chiefly water and a small percentage of carbolydrates, mostly sugar, and so are parsnips. Lettuce is mostly water. Okra has 2 protein and 9.5 carbohydrates. Egg-plant is mostly water, but is generally cooked with too much fat. Celery is mostly water with I. I ash, where its virtue lies. Cauliflower has orer go water, cabbage about the same. Artichokes have considerable carbohydrates. Beets have over 90 water and little protein, but considerable carbohydrates in the shape of sugar, depending on the variety of the beet. Graham wheat flour has 8.5 protein, I.8 fat, 55.9 carbohyclrates, I.5 ash, and 32.3 water. The average fruit of the market has water I6.9, protein 6.2, fat I0.5, carbolydrates 64.7 , ash 1.7 .

In looking over this list it is interesting to note how nearly alike they run in nitrogen, how much they vary in fats, and how little they vary in ash. Roast beef is scarcely as strong as sirloin steak in protein, but excels it in fat as usually cut. Boiled beef is much less in protein than roast beef, and loin of lamb is also lower. Pigs' feet are a delicacy, and rather low comparatively in protein. The average pork sausage is not very strong in protein, but has too much fat. Of the soups, consomme is the weakest and mock-turtle the strongest, and therefore the least desirable where nitrogenous diet is objectionable, as in gout and such troubles. The seeker after light diet might take a little goose. avoiding as much as possible the fat, whilst he will find turkey and chicken, if he 


\section{FORTY YEARS IN THE MEDICAL PROFESSION}

eat the dark meats, a little strong in protein. When we come to fish, we find them disappointingly high in protein. Tell your gouty patient to take a fish diet, and he goes unwittingly to salmon. He gets 19.9 protein and 7.4 fat. He might as well eat roast beef, except he gets less of the salts and other strengthening ingredients of the beef. Fresh mackerel are nearly as bad, and salt mackerel worse, except here one eats less in weight. Smoked herring are very high in protein and fat, but I think one takes so little of it, we may indulge in a little of the flesh and roe in order to give an exquisite flavor to a simple breakfast or tea of stale bread and butter. Fresh herring are about like shad in protein and fat. If you are gouty, avoid cod, especially salt cod. May your gouty friend eat of colfish and potatoes? Well, Sunday morning only he may partake sparingly of this New England luxury, provided they have not absorbed too much grease in the cooking. Flounders are among the lowest in protein and fat of all the fish, and may be eaten more freely where we wish to avoid too much nitrogen. Smelts are a delicacy in cold weather; in fact, are one of the few fish whose flavor is not affected by freezing, but alas! they are of the salmon tribe, and are very strong food. Lobsters and crabs are reprobated by some authorities for the gouty, but why I know not, if eaten with plain dressing only, as they are not over 14 to 16 protein and very little fat. Some good authorities give lobster too low in protein. It is surprising how high in protein those elegant fresh-water fish, the white perch, and black fresh-water bass are, the perch giving I9. I protein, but only 4 fat, and the bass 20.4 protein, but only very little fat. That king of edible fish, the shad, has i 8.6 protein and 9.5 fat, quite a strong food, but we must allow shad now and again, though very sparingly. The roe is another luxury, but is very strong in nitrogen, but not so very strong in fat.

How disappointing all this! Everything good is high in nitrogen, and nitrogen is poison to so many of the good and lorave in this world. Where shall we send them for luxuries? 
FORTY IEARS IN THE MEDICAL PROFESSION

Well, thank God for giving us the oyster, and the clan, and milk. The oyster has only 6.2 protein and little fat. The clam has 8.6 protein and I fat. Scallops are stronger, having I 4.8 protein. Now, with milk and oysters and clams, a few scallops now and again, a little consommé,-very little, for a few tablespoonfuls of soup are sufficient as a prelude to a dinner always,-milk ad libitum, even if it must be skimmed or partly skimmed or separated, or alkalized, with rice and white potatoes as vegetables, surely one cannot starve.

White potatoes are, I think, a much-abused vegetable. They contain comparatively only a little protein, and, if well baked, a very little, and only a little over 20 carbohydrates, and lots of water, which harms no one. I look upon them as among the most innocent of the starchy foods, with a tendency to increase the alkalinity of the blood. When baked almost to a crisp, I allow them now and again to diabetics, to keep them in even hmmor, and never see cause to regret it. Do not forget, it all depends on the cooking, though. No one dieting to cut down weight can afford to eat potato chips as usually cooked; remember that.

For the day laborer oatmeal is a generous food, but for the gouty man it is to be shumned. Too much of it is eaten by those leading sedentary lives, especially by those having attained middle age, but when sugared and creamed, ol, what a dose! Oh, my liver!-except for the young, active, and vigorous, or those suffering from wasting diseases, and often I think it too much even for some of them. Think of it: protein 15.6 , fat 7.3 , and carbohydrates 68 , and to this add more fat in cream and more carbohydrates in sugar. As to the non-starchy vegetables, spinach, asparagus, tomatoes, and the like, they are mostly water, with very little protein and little carbohydrates, and fulfil various indications in diet. The only trouble about them is, most of them have considerable oxalic acid, which is not desirable in renal irritations. Peyond this, they undoubtedly serve a good purpose in the economy. As fruits and nuts will be referred to at length 
farther on, I will not stop to consider them now as an article of diet. Green corn boiled is a vegetable much used, and deservedly so. To those who need a food low in proteids it is very acceptable, and to those who suffer from slowness of the bowels it is a great help, the refuse of the corn helping here very much. Green corn fresh runs about thus: water 88.2, protein I.I, fat .4, carbohydrates 9.2, ash I.I; green corn canned has water 75.7 , protein 2.8 , fat 1.3 , carbohydrates I9.3, ash .9; the sugar always put in canned corn increases the carbohydrates; there is also the antiferment, probably salicylic acid.

In all canned vegetables and in much of the other canned stuffs will be found some antiferment, most probably salicylic acid. Whilst probably these antiferments do no great harm directly to the individual consuming such foods, they doubtless do harm in the end to those who eat them continuously, for they slow digestion and in other ways interfere with its normal processes. There is another trouble not to be overlooked by those eating canned products, - the danger of lead poisoning, a condition which entails a horrible state of suffering and broken health. In properly conducted canning establishments no solder should ever be allowed to get into the can, and all solder-joints should be made absolutely on the outside of the seam of the can, and no low-grade tin should be used for cans, for it is nearly all lead and iron, and little tin. Canned products are very miversally used, not only by those at sea, and by travellers who are cut off from fresh supplies, but hotels and boarding-houses and even private families use them almost exclusively as being cheaper and more convenient, in the very midst of summer, and in the heart of the vegetable-producing country. I believe this practice to be in violation of good sanitary methods.

Speaking of lead poison, I believe it to be in one degree or another the cause of a great deal more of suffering and ill health, not to mention its evident tendency to increase the evils of uric aciol troubles, with all that this implies, than is 
usually thought. It is particularly a cause in the water supply, and the increased use being made of it in the trades, such as in packing tobacco and like matters. Rubber also, it is well known, contains lead, and should be used carefully with that in view. I have personally met with some interesting cases where the diagnosis was very obscure, until the water supply was looked into, and then all was plain. IVatch for lead poison in cloubtful and obscure cases: it is easy to get tripped up on it, my medical friends.

In the part of Delaware where I reside the surface water is very pure and free particularly from lime, and hence no insoluble coating is formed on the pipes, as in limestone districts, hence lead pipes for the water supply almost invariably cause poisoning. I have met with a number of cases. Insoluble compounds of lead may produce poisoning as they break up and disintegrate; even when insoluble coatings are formed on lead water-pipe, after a time the pipe corrodes and disintegrates by age, and is dangerous. Fortunately iron, for economical reasons, is taking the place of lead in furnishing the water supply, and thus much lead is being eliminated as a menace to the good health of families and communities. There is one thing yet that should be stopped. In Philadelphia, for example. I notice that when they lay new mains of iron, the connecting pipe leading from the street main to join the pipe leading to the house to be supplied, say one, two, or three feet in length, is made of pure lead. This should not be. As this pipe gets old it disintegrates, and notwithstanding it is covered by an insoluble coating of lime, etc., which the Schuylkill water furnishes, these disintegrated portions become a menace to the health of those using the water. Every State should pass a law forbidding the use of lead water-pipes, at least, under any and all conditions, and the use of lead under all circmmstances where it may become a factor for harm should be placed under most thorough supervision, as should all other substances which may cause similar trouble. 


\section{FORTY YEARS IN THE MEDICAL PROFESSION}

Coffee, so universally used as a beverage and an article of diet, cannot be passed without mention. Haig condemns it for the lithæmic individual, but condemns tea more. Its composition is given as follows: Water, I.I 5 ; fat, I4.48; crude fibre. I9.89; ash, 4.75; caffeine, I.24; albuminoids, I3.98; other nitrogenous matter, 45.09; sugar, gum, and dextrin, I.66. This is the analysis of the coffee-bean; of course the beans vary in quality and strength. In excess it produces restlessness and tremulousness in man, according to Horatio Wood and other authorities, but these troubles are rather spinal than cerebral. In proper loses, not too large, caffeine stimulates the heart; in poisonous doses, overcomes it. It increases arterial pressure independently of the vasomotor centres, according to Horatio Wood, so altogether it may do good in some neurotic conditions, in some heart affections, and where we want diuresis. Where we wish to avoid increased blood-pressure, watch it. If very strong, it retards digestion and puts away sleep from weary eyes. Like all others of its kind, it has many good uses, and may be, and doubtless is, subject to much abuse in excessive use.

Tea may be classed with coffee, and we use it both green and black. For green tea, the leaves are steamed before they are rolled and dried, also green tea contains more astringent matter than black tea. Thompson gives this analysis of Kozai. Green tea: Crude protein, 37.43; fibre, Io.06; ash, 4.92; theine, 3.20; tannin, I0.64; total nitrogen, 5.99. Black tea: Crude protein, 38.90; fibre, I0.07; ash, 4.93; theine, 3.30 ; tannin, 4.89; total nitrogen, 6.22. If theine is identical with caffeine, as it is said to be, then, as far as theine is concerned, tea acts like coffee on the system. There is not much difference apparent, and authorities differ upon which is best to help on the soldier in his marches, bit all agree that one or the other is essential to get the best results. Tea, if taken in excess, retards digestion by precipitating the digestive ferments, just as coffee does. When you make tea do not boil it, do not stew it. In the early days of the advent of 


\section{FORTY YEARS IN THE MEDICAL PROFESSION}

the Japanese to the outer world, from the members of the great Japanese Embassy which left Japan after the Perry expedition I learned to make tea. Put, say, one teaspoonful of tea-leaf for each half-pint of tea you want; pour on this boiling hot water; let it stand tightly covered two minutes, then stir it thoroughly with, say, six to eight revolutions to the right and as many to the left, using spoon or chopsticks; the tea is then at its best, and the sooner you drink it the better. You get little tannin and none of the disagreeable bitter extractive matters of the tea. Boil your tea, you get tannin, bitter extractives, and altogether an indigestible, unwholesome dose. Stew it,- - well, don't throw it to your pigs, they won't eat it or drink it, and the pigs are right.

Again. we have cocoa and chocolate, both prepared from the cacao-beans, which come from the tree, Thcobroma cacao. Theobromine is the alkaloid of cocoa, and is very much in every way like caffeine and theine. The kernels of the cocoabeans are, when ground, called cocoa nibs. Cocoa is made from these, and starch, or sugar, or both, are added in the making. A German analysis is as follows: Theobromine, I.73; total nitrogenons matters, I9.88; fat, 30.5 I; water, $3.8_{3}$; ash, 8.30 ; fibre, etc., 37.48 . In recommending cocoa, remember it is fattening from fat and sugar, and also contains starch usually. Chocolate is made, according to Thompson, from the husked, dried, ground, and fermented cocoaseeds, which are then roasted and made into paste. Sugar is added, at least fifty per cent., and various flavorings. Chocolate is less fatty than cocoa, and altogether not so rich. The husks of the seeds make cocoa-shells, and a decoction of these is often used for a light drink, where we want something near to water.

Before leaving the subject of coffce, tea, and cocoa, let me enter a plea for their close study by the physician as an article of diet so universally used. Whilst they may be abused by the masses generally, they are all strong weapons in the hands of the profession for good. Remember their stimulating 


\section{FORTY YEARS IN THE MEDICAL PROFESSION}

properties, their comforting properties, and the habit so universal with our patients. Remember, in your fever cases, in your cases with wasting disease, you will often find in these products a very useful ally. Remember that because people are ill is by no means a reason they should not drink tea or coffee. Study the case and decide it properly.

The dietary studies made by Atwater and Woods in New York City in I896 show many interesting facts for the physician and statesman. They show in a glaring manner the average want of thrift among the plainer people and the utter ignorance, especially of the women, of the value of one food above another, of the kind of food to purchase, looking to its food value, and of the proper method of preparing it. Our people need general instruction in all of these matters, and it should commence in the schools, and some general system should be devised in communities to teach the average housewife at least the first principles of food values, of the difference between a food that will furnish fat and one that will furnish muscle and endurance, and thus give her some insight how to dispose of her money to the best advantage when she goes to purchase her supplies. Atwater and Woods show the result of such ignorance very plainly as they progress in their studies. Physicians should be able to instruct the families they attend as to their food supply and the nutrients required by different families to keep them in strength and good health. A family where most of the nembers are laboring men and women surely requires a different food supply from the family of men and women living a quiet life of ease and comfort. Practically no thought is taken of this either by families or by physicians. I am sure, as society goes on to the evolution of a higher civilization, it will be the duty and the every-day work of the family physician to take charge of such matters in the families they attend, and thus lead to a more general rational living, and to better, happier, and healthier lives for the individual.

The lower classes of Germans and French at home have 216 
more of thrift, of methodical saving, of home thrift, than have our people. The paternal gorermments they live under and their habits have most to do with this. The German lives close and is not reckless as to rumning into debt as are our people. He is not mean, he is close and careful: most of the food of his family is purchased ready to eat. He, as a rule, keeps no fire to cook by, because it is expensive. When he gets too cold to sit up he goes to bed. He has little home life. His recreation is taken at the beer-garden, and his family goes with him. His native thrift follows him there. He does not guzzle beer, nor pay for it, as our people do, for others to guzzle. If he has children at work, they get up in the morning and eat their breakfast cold, probably bread, sausage, and beer. On their way to work they stop and buy their dimner, - a roll, a slice of meat of some kind, and very little of it; this, with a glass of beer from a near-by shop, completes their dinner. Their supper does not liffer from their breakfast. The cost of living per individual is low, very low. It is their life custom, and they keep it up. Many of the Germans are dyspeptic from this way of living, and, as a rule, too much beer in their ration keeps it up. At the same time this ration is about correct as to its protein, carbolyydrates. and fat, and serves its purpose better than a more elaborate one not so well balanced.

Our people are dyspeptics too, not because they are frugal. but because they, as a rule, violate every law of gastronomic hygiene, and keep at it, because from ignorance and want of proper teaching they know no better. As preventive medicine asserts itself more and more, and becomes more and more a science, the physician will become a teacher and more and more the confidential friend and adviser of his patients, not more during the illness of his patients than during their good health, and thus man will approach nearer and nearer the ideal man science is now more than dreaming of.

To return to Atwater and IVoods. They give the result of a ten days' sturly of the diet of a family, consisting of 
father, a mechanic, mother, and three girls, one eleven years old, one eight years, and one eight months. The family was poor, and the eleven-year-old daughter did the marketing, and, of course, was imposed upon. The cost of the food purchased for ten days was $\$ 10.22$, very high for their means. The rent was \$I 2 per month. The man when at full work made $\$ 50$ per month. Deducting cost of food and rent from this, it only left $\$ 7$ per month for fuel, lights, clothing, and other requirements. By proper expenditure for proper food, $\$$ I 5 to $\$ 20$ should have kept this family, instead of $\$ 30$ per month. The cost of the animal food was fifty-six per cent., and of the vegetable food forty-four per cent. Beef, veal, mutton, and fish composed more than one-half of the cost of animal food. The cost of the vegetable food was enhanced by the use of high-priced self-raising flours and the like, showing want of management in buying. Bananas and oranges were extravagances for them to indulge in, considering their food value, being mostly water. The girl bought peanuts, and thus unconsciously made a good bargain. You get much protein for a small price here, and also much fat and carbohydrates. For this family the food purchased per man per day furnished one-fourth more nutriment than is needed for a man at moderate work. Three per cent. of the total food was thrown away in the table and kitchen waste, and thus one per cent. per man per day of protein was wasted. Deducting this, and there was still an excess of food. The food eaten contained at least 25 grammes of protein and a fuel value of 600 calories per man per day more than was needed by a man at moderate work. When the man was ont of work he and his family would have been well nourished if the food had only contained roo grammes of protein, and had a fuel value of 3000 calories per man per day. The nutritive ration of the food eaten ( $\mathrm{I}: 5.5$ ) was about equal to the dietary standards. In this case Atwater and Woods suggest that the amount of food purchased might have been reduced twenty-five to thirty per cent. and a considerable saving of 
money effected. A more judicious selection of food and greater attention to details of marketing and preparation of the food might have still further reduced the cost. Such carefulness in purchase and preparation would also have reduced the kitchen and table wastes, so that practically no food would have been wasted. The more intelligent selection of food. from both the nutritive and pecuniary stand-points, would preclude the purchase at the prices paid of such foods as chicken, cod, flounder, shad, condensed milk, canned asparagus, prepared flours, radishes, celery, cherry jelly, etc., which this inexperienced little market-girl bought, and would lead to the increased purchase of more economical foods, including peas, beans, wheat flour, rice, and the cheap but nutritious cuts of beef, veal, and mutton. In this way a large proportion of the money spent for food could have been saved with advantage to health and without interfering with the palatability of the food eaten.

All this is interesting and quoted here to show in what a slipshod manner such people live. Surely the physician must be one great factor in bringing about a better system, and should surely study all of these great economic questions. In another case, to show injudicious division and expenditure of an allowance of money, they give a family where it seemed hopeless to attempt to express in terms of protein and fuel value what was needed for their better nutrition. The housekeeping needed absolute revolution. With such carelessness on all sides it is almost useless to suggest improvements in the kinds and amounts of foods to be purchased. The dietary needed more protein, and a much smaller expenditure for butter would allow this family to procure it. They spent about as much for butter, fish, and chicken as for beef and pork, the amount spent for beef and pork being $\$ 3.57$, and for butter, fish, and chickens, $\$ 3.48$. The former furnished I 645 grammes of protein and $41.95^{\circ}$ calories: the latter, 743 grammes of protein and 35.700 calories. This case shows the necessity for judicious buying and selecting to get the 
best results for health and strength, and physicians cannot know too much about it; patients and the people generally surely know too little.

Great advances have been made in feeding the lower animals both for milk and meats by working up and studying and feeding a balanced ration. How much more is it necessary to work up and study and prepare for man a balanced ration! We would get all the required nourishment for man from pork, stale bread, olives, milk, and cheese, but it would not be a good combination for easy digestion, because there are too many articles here of slow digestion. A man doing hard work would enjoy life more and thrive better on pork. beans, and corn-bread than he would on a steady diet of even a balanced ration like corn-bread, milk, oysters, and rice, for the latter would not last long enough in digestion, and leave the organs too long inactive between meals. Oatmeal, bread. and milk would do better, especially should some sugar be added. The balanced ration is the important matter for man. A man who does not eat enough often gets an unbalanced ration and does not thrive; so does the man who eats too much. Pork, butter, and eggs would be an unbalanced ration,--too much fat and too little carbohydrates. A man cannot live on potatoes alone and thrive: it would take a peck of potatoes daily to give him enough protein.

Again, let me give the estimated food necessary for man for twenty-four hours. A work ration: Protein, I25 grammes: fat, 125 grammes; carbohydrates, 450 grammes; calories, 3500 , with salts, 30 grammes. A mere subsistence ration would be as follows: Protein, 75 grammes per day; fat, 40 grammes: carbohydrates, 325 grammes; calories, 2000, with salts, 25 grammes. An ideal ration (Mrs. Richards) would be, for twenty-four hours: Wheat bread, i6 ounces; beef, 8 ounces: oysters, 8 ounces: cocoa, I ounce: cow's milk, 4 ounces; broth, I6 ounces; sugar, I ounce; butter, $1 / 2$ ounce. This for a man doing average work, and would furnish 2575.52 calories. So far as we know, basing onr idleas on chemistry and pluysiology, so far as developed. 
we are right in the view's of diet here taken. IVe have gone upon the theory that the nitrogenous or albuminous principles, after undergoing complete combustion, end in urea, and incomplete combustion, end in uric acid, and are unfit diet for diseases caused by excess of urea and of uric acid, whether the cause be from damaged machinery of the body, or from a peculiar diathesis. These nitrogenous foods, comprising butcher's meats, poultry, fish, shell-fish, eggs, and milk, not forgetting the vegetable albuminoids, as the coverings of the starch granules of grains, etc., are the tissue-builders or fleshformers. Now, although we are so sure of this and so sure we are right, yet there are those, and men of reputation, who deny such conclusions as regards diet for the so-called uric acid conditions, and advocate the exclusion of the carbohydrates rather than the nitrogenous group. All we can say to such criticism is, we believe we are right, yet we will strive to learn more, even to the rewriting. if necessary, uf everchanging uric acid literature; but we shall not despair, for there are those living who deny the virtue of diphtheria antitoxin or the protection from small-pox by vaccination. We have also gone upon the theory that the non-nitrogenous foods, all the vegetables, fruits, cereals, starches, sugars, gums, fats, and oils, being both animal and regetable, and the organic acids, are the maintainers of animal heat and the force-producers. As before mentioned, these are also tissue-builders in a small degree from the regetable albuminoids they contain. We have also recognized as fact, that certain salts also are taken from the fouls eaten, the least from fruits and nuts, next from meats, and most of all from vegetables, these salts being for the most part chloride of sodium. potassium chloride, sodium carbonate, potassium carbonate, potassium sulphate, sodium sulphate, magnesium sulphate, calcium phosphate, sorlium phosphate, potassium phosphate, and others, these going to various uses in the economy, such as regulating the specific gravity of the blood, checking putrefaction of tissues, controlling osmosis, etc.

I'egetarianism.--It has been pretty well established that 
man cannot live in health and comfort and enjoy life on a vegetable diet alone. As before stated, it would take a peck of white potatoes a day to give a man sufficient protein for laborious work. He may get everything from vegetables, but not sufficient for a balanced ration from a reasonable amount of food. Vegetarians are usually fanatics, non-producers, but, as a rule, take great care of their health and do not dissipate, commendable qualities, and if they would only live on a scientific, well-balanced ration, they would, as a rule, live longer, be happier, and be more useful citizens. Those who live only on vegetable food, and on that food which destroys no life to get it, such as eggs and milk, can get a wellbalanced ration, and surely will be better and happier than those who take an omnivorous diet unscientifically chosen in quantity and quality and ravenously eaten. We cannot argue that the ancient Britons subsisted on roots and nuts and the spontaneous productions of the ground, or that certain savage tribes live on vegetables alone. Providence provided and does provide a complete ration for them in some way and at some time, if not regularly, or they would never be the sturdy races they were and are.

Special Diets for Corpulency, and how to get Fat when too Lcan.-All of these special diets, or special systems, or fads, or whatever you may call them, mean starvation in a greater or less degree. Withhold a proper amount of food from the animal, and you cause loss of weight. Excessive weight is a great source of inconvenience,- - a humiliation to some. It is most frequently hereditary and a perfectly natural state for the individual. After all, the philosophy of existence, in one sense at least, is to feel good and well. Obesity may be a disease, but if so, it is usually the fault of bad habits in the individual. If one will live a sober, industrious, and in every way a temperate life, restricting, as one surely must very decirledly, the appetite for sugars, starches, and fats in particular, and for all meats and drinks somewhat, but not beyond the comforts of existence, as most of these special methods do, then one will neither be overburdened with fat nor threat- 
FORTY YEARS IN THE MEDICAL PROFESSION

ened with evils of a more dangerons kind from unscientific regimen.

The Banting system undoubtedly, if followed up, causes loss of bulk, but has its dangers, and surely is most inconvenient and umpleasant to those following it. He allowed about twelve ounces of lean meat per day, about two ounces of bread, and about twelve ounces of fruit and green vegetables. He allowed thirty-five ounces of fluids in twenty-four hours, nothing like as much fluid as a man should part with in the same length of time. As Thompson says, the fats and albuminoids are not well balanced here, and constipation of the bowels must ensue.

The Ebstein system, as given by Thompson, is, that animal food, as well as carbohydrates, particularly sugars and starches, are capable of being turned into fat. The carbohydrates, he says, furnish force for the body, and by their combustion spare the complete oxidation of the albuminates, which are therefore stored in the tissues in a suboxidized form. His theory is that fatty food does not give rise to the storage of fat in the body, and he allows it, and particularly because it causes satiety sooner and makes one eat less. He allows no sugar, potatoes, rice, or other farinaceous food except three ounces and a half of bread daily. He allows the non-starchy vegetables and a moderate amount of any kind of meat. He restricts fluids to about one-half normal. Breakfast, one cup of black tea, no sugar or milk, with two ounces of buttered toast. Dinner, at noon, six ounces of boiled or roasted fat beef, with drip gravy, one or two non-starchy vegetables in moderation, and for dessert a salad and fruit, a little light wine, and tea, no sugar or milk. Supper, tea, no milk or sugar, one soft egg, a moderate allowance of fish, ham, or cold fat meat, one ounce thin buttered bread or toast, and fruit. On this diet one cannot work hard or take active exercise and be thoroughly comfortable, for he only gets fourteen hundred calories potential energy in nutrients.

Here is a table by Atkinson of a comparison of dietaries for corpulence, with ordinary dietaries. from Thompson: 


\begin{tabular}{|c|c|c|c|c|c|}
\hline \multirow{2}{*}{ IUETARIES. } & \multicolumn{5}{|c|}{ Nutrients. } \\
\hline & Protein. & Fat. & $\begin{array}{l}\text { Carbohy- } \\
\text { drates. }\end{array}$ & Total. & $\begin{array}{l}\text { Potential } \\
\text { Energy in } \\
\text { Nutrients. }\end{array}$ \\
\hline & Grammes. & Grammes. & Grammes. & Grammes. & Calories. \\
\hline Banting system . . . . . . . & $17 \mathrm{I}$ & $\delta$ & 75 & 254 & 1085 \\
\hline Ebstein system . . . . . . & 102 & $8_{5}$ & 47 & 234 & 1400 \\
\hline $\begin{array}{l}\text { Playfair's standard for subsist- } \\
\text { ence diet . * . . . } \\
\text { Voit's standard for laboring }\end{array}$ & 57 & 14 & $34 \mathrm{I}$ & 412 & 1760 \\
\hline $\begin{array}{l}\text { man at moderate work . } \\
\text { Playfair's standard for adults }\end{array}$ & II $\delta$ & 56 & 500 & 674 & 3050 \\
\hline $\begin{array}{l}\text { with moderate exercise. } \\
\text { Atkinson's standard for a man }\end{array}$ & 119 & $5 \mathrm{I}$ & 531 & 701 & 3140 \\
\hline $\begin{array}{l}\text { with light exercise. } . \\
\text { Atkinson's standard for a labor- }\end{array}$ & 100 & 100 & 360 & 560 & 2815 \\
\hline $\begin{array}{l}\text { ing man at moderate work . } \\
\text { Poor sewing girl, London, diet }\end{array}$ & 125 & I 25 & 450 & 700 & 3520 \\
\hline $\begin{array}{l}\text { barely sufficient for subsist- } \\
\text { ence . . . . . . . . . . } \\
\text { University professor, Germany, }\end{array}$ & 53 & 33 & 316 & 402 & 1820 \\
\hline $\begin{array}{l}\text { very little exercise . . . } \\
\text { Well-to-do family, Connecticut, }\end{array}$ & 100 & 100 & 240 & 440 & 2325 \\
\hline food actually eaten $\quad . \quad \cdot \quad \cdot$ & 128 & 177 & 466 & 771 & 4080 \\
\hline $\begin{array}{l}\text { Mechanics and factory opera- } \\
\text { tives, Massachusetts, food } \\
\text { purchased . . . . . . . . . }\end{array}$ & 127 & I 86 & $53^{1}$ & 844 & 4430 \\
\hline $\begin{array}{l}\text { Food actually eaten by college } \\
\text { students- }\end{array}$ & & , & & & \\
\hline From Northern Lnited States. & 138 & 184 & 622 & 944 & 4825 \\
\hline From Eastern L'nited States. . & 104 & I 36 & 421 & $66 \mathrm{I}$ & 3415 \\
\hline
\end{tabular}

From this table, the patients under Banting and Ebstein get starvation diet sure. Whilst the student from the Eastern United States gets too much. Atkinson's man at moderate work gets well supported, the poor sewing-girl is ill nourished, mostly on carbohydrates, as we should suppose, and the German professor, how about him? IVell, he does not live high, but gets several glasses of beer, as his carbohydrates show.

The Girtel system is a newer system, and I am indebted to Professor Thompson's book for information in regard to it. 
The feature in Ertel's system is to strengthen the circulation by strengthening the heart, and then the fat, once gotten rid of, does not return. He makes two classes of the obese, and regulates their diet accordingly: First, those in whom fat has accumulated, but in whom the circulation and respiration are not impaired and the person can use muscular effort and walk or run. Second, those in whom, from advanced stasis and hydramia, and with a deficiency of hremoglobin in the blood, anæmic, the amount of oxygen taken up from the lungs is much reduced, and who are short of breath on exertion. For the first class he allows 50 grammes of fat, carbohydrates 200 grammes, with I 50 grammes albumin, or more, if needed. For the second class-fat people, short-winded, and with dropsical tendencies, I suppose, he mostly puts in this class, yet with organs fairly sound-he allows 30 grammes of fat daily, with Ioo grammes carbohydrates, and considerably over I 50 grammes albumin, more, you see, than the first class gets. In this second class he gives little fluid, and not overmuch to the first class. He thus, he says, reduces bloodpressure, venous stasis is lessened, and thus the vessels in the fatty tissue are drained, and nutritive changes occur here, the fat is broken up, carried away, and cremated, as it were. Ertel allows twice the amount of animal food that Ebstein allows, double the amount of carbohydrates, and less than half the fat. He also allows more fat and starch than Banting. He allows twelve ounces light wine, and as much water at dinner, a very fair allowance, with six ounces of bread daily. He allows eggs now and again. For those who are able he prescribes the "terrain cure," mountain climbing, watching the heart, which gets strength as the exercise progresses. For those who cannot climb or use exercise, he prescribes massage, friction, and baths, here still further reducing fats and starches.

The Schweninger system is about like CErtel's, but he allows no drink at meals, but must wait until two hours after meals to drink. He gives little bread, and restricts fluids generally. 
FORTY YEARS IN THE MEDICAL PROFESSION

G.ermain-Sée says much water is necessary in treating corpulency. He allows meats, lean and fat, but no sugar or starches. His drinks are hot, weak tea and an abundance of water. He allows little or no alcohol. Thompson suggests this treatment with plenty of fluids is best for gouty and rheumatic cases where we desire to eliminate the waste from the system. This, at any rate, is some encouragement to the gouty, stout man, who so far has received little consideration in this matter.

S. Weir Mitchell's system for obesity consists chiefly in rest, skim-milk diet, massage, and movements for passive exercise. After a fortnight he begins to allow a little light broth; he is careful to watch the condition of the heart; after six weeks he allows some lean meats. This treatment requires the abandonment of all labor, and is among the best of treatments to amuse whilst at the same time it relieves, and is especially applicable to women society-tired and suffering from over-indulgence in various forms.

There are a number of other treatments, named for the men first recommending them, but they differ only in degree from those already mentioned. The principle in all is the same,semi-starvation;- - and the end aimed at the same,-viz., to cause those undergoing the treatment to oxidize and eliminate the accumulated fat and to prevent its forming again. There are many quack remedies, under various names; all are harmful and even dangerous, with just knavery enough in the recommendations accompanying them, putting those using them on a diet which avoids fat, starches, and sugars, to give them a semblance of doing effective work in reducing flesh. There is at present quite a fad going around, especially among women fond of society, taking upon themselves some cure for obesity. This is all wrong, unless they have intelligent medical supervision, and this intelligent medical supervision should see to it that the heart and kidneys of these patients are thoroughly observed and looked after; withholding fluids in these cases is often attended with serious consequences. Renal calculi may supervene, or gall-stones may form and great suffer- 
ing ensue, all because the elimination of waste has been interfered with. I once knew a gentleman, a royal good fellow, of middle age, who, being stout and, having a lung capacity below the average, did not oxidize his fat fully by throwing it off from his lungs in the shape of carbonic acid and vater. Hearing from some wise man that a dose of Epson salt every morning in a small portion of water would make him thin, he took it faithfully for several months. The consequences were disastrous. This man had a strong appetite; in fact, he ate meat like a bloodhound, starch like an $o x$, and fat like an Esquimaut, and the more salts he took the more he ate. All of his fluids ran off, normal metabolism was interfered with, the composition of the blood was altered, the elimination of waste was interfered with, and of course the result, renal calculi, one after another, stone in the bladder, and prolonged suffering. Nature resents such unwarranted interference with her laws. My own idea in these cases is, above all things, to study the individual, then arrange the diet, exercise, and the habits of life generally. Watch particularly the condition of the heart, the general circulation, and the kidneys. Age is very important to take into consideration, and so is sex and the environment of the patient. The gouty patient needs different advice from one not so afflicted, and so does the patient with dropsical tendencies. Explain to each what their case needs. Explain the difference in the make-up of foods, as to oxygen, hydrogen, carbon, and nitrogen, and the difference between proteids and starches, sugars and the like, and fats, and the tendency of each in diet. Intelligent advice and supervision are what these people want. Notice the superb condition generally of the athletes of the University of Pennsylvania. How is it their condition, their fitness, excel? The answer is evident. It is the intelligent supervision and direction of strong and able men like Dr. J. William White, assisted by such experts in diet and other accessories as Dr. Horatio C. Wood and others, which bring this about. This earnest, intelligent supervision is one of the great factors of success in much that pertains to life. 
Leanness, the opposite of fatness, afflicts some persons, and is often so extreme as to cause humiliation. The remedy is to find out the cause, and remove it if possible. As to diet, reverse the principles applied to obesity. Lean people are generally perversely lean, and will not get fat, even when in perfect health. Plenty of proper meat and drink, avoiding excesses, rational employment, sound sleep, a clear conscience, and proper medical supervision is a good recommendation to such people.

Woman withont a Stomach!-What shall we say of the woman withont a stomach, now living in Switzerland, and possibly of others in Europe and in this country? This case of Dr. Schlatter's in Zürich is remarkable. The entire stomach was removed, and she is enjoying good health and even gets sick at the stomach (?) if, perchance, something does not agree. How paradoxical! From the start this woman was fed on soup, oatmeal. brandy, and wine, and these were digested. A month after the operation she became nauseated and vomited; in the vomit bile was found, which is against medical theory. Here the entire theory of stomach digestion is made to totter. These internal functions must be restudied, and this part of physiology must be rewritten. We know the intestines do a great deal of the work of digestion and assimilation, but we did not know before. nor did we believe, complete digestion and complete assimilation would go on without a stomach. A new motto has been generated. What is woman without a stomach? Much.

Whilst speaking of diet for obesity, it may be well to refer here to the best form of bread, "the staff of life," withont which, in some form, it is almost impossible, for civilized man, at least, to exist. The best form of bread is the bread of wheat, white bread, as distinguished from rye bread or graham bread. The white bread contains the least carbohydrates naturally, even if it has a little more fat. There is a rage now among well-informed people, especially among ladies endeavoring to reduce their avoirdupois, for overtoasted bread, the twice-baked bread, it is familiarly called, 
which really approaches very near to the well-known German "zweiback." This twice-baked bread is quite palatable and quite nutritions, and if eaten in moderate quantity, one may appease the appetite for bread and find it much less fattening than ordinary bread, and very much less likely to cause fermentation during digestion. To prepare this twice-baked bread, cut from the loaf (at least twenty-four hours baked) thin slices, place them in a pan, and subject them to the heat of a quick, hot oven for from twenty to thirty minutes. In making toast, what happens? The toasting destroys all yeast germs and other germs which may be with the bread, and thus the toast is sterile. Surely a great advantage. The starch in the bread, of course, must be converted into sugar before it can be assimilated. The toasting does this in part. Carry the toasting still further, and we convert the starch into dextrin, a gummy substance. Carry the toasting still further, and we get the dark-brown and even black toast, the sugar being caramelized, and the flavor is improved. Steam the toast, and you further dextrinize the starch. Butter it lightly, and you make it more digestible by diffusing it, as it were, and the saliva acts better on it, in first starting starchy digestion, which is continued after swallowing by the amylopsin in the pancreatic juice and diastase in the intestinal juices with some other digestive substances.

Another bread is very digestible: Take light dough, roll it very thin, cut it into strips, roll it into hollow cylinders, and bake very quick and dry. You here have bread cylinders. very digestible, about the same as toast. Crackers are not, as a rule, very digestible, because they are baked as very dry dough, not much water being added, and thus the starch granules are not well broken up, and the cracker is thus more difficult to digest. To be digestible, all starches must be well cooked, with sufficient water to soften the granules and break up the cell-structure. Pretzels are superior to crackers as an article of diet, because the dough is here first boiled well, which breaks up the starch, and then thoroughly baked. There is generally too much salt about them. for the carry- 
ing of which, it is said, they were invented, to make the lounger drink two glasses of beer when otherwise one would have sufficed. This, doubtless, is a libel on Boniface.

I applied to Dr. Neale, the director of the Delaware College Agricultural Experiment Station at Newark, Delaware, for his views on the effect of toasting on bread. He wrote to Professor Atwater, the well-known expert on food analysis. Professor Atwater referred the question to Professor Woods, and I take great pleasure in appending Professor Woods's very satisfactory reply.

"Chas. D. Woods, Director.

"Maine Agricultural Experinent Station, "Orono, MaINE, December I3, I898.

"Director Arthur T. Neale, Agricultural Experiment Station, Newark, Delaware:

"Dear Doctor Neale,- Your letter of December 9 to Professor Atwater has been forwarded to me for reply. I wish I could tell you a great deal more than I can relative to the changes which take place in bread by toasting. While, as you know, there has been a very large amount of work done upon bread, comparatively little of it has brought definite information. As is well known to you, the difference between fresh bread and stale bread is not due to a loss in water, but to a molecular change. In the process of baking there is probably a distillation of water from the surface which is recondensed in the more central parts of the loaf. In cooling, the reverse goes on. It is believed, rather than known, that in fresh bread the greater part of the water is free, while in stale bread part of the water is combined with the starch, or perhaps with gluten, and that these are again separated when the loaf is reheated. In toasting, water is driven off and a greater firmness is acquired. If the slice is thick, and the surface is merely scorched by the action of the heat, as is the case in most restaurant- or hotel-made toast, the interior changes are very much the same as when stale bread is rebaked. On the other hand, when bread is thoroughly toasted, so that crispness extends throughout the slice, there is quite a large loss in water, much of the starch is changed to dextrin, and some of it is even converted into caramel, or substances closely related thereto. The peculiarly pleasant burnt taste is probably due to caramel, the sweeter taste and the apparently greater ease of digestion is probably due to conversion of a considerable part of the starch into dextrin. It is, however, probably true that much of the apparent increased case of digestibility of the toast over the bread from which it was prepared is due to a change in mechanical condition, so that in mastication it does not pack in the way that even stale bread does. I think that the above includes all that is known of the chemistry of toasting, as well as some things which are merely inferred.

"Respectfully, 
The latest treatment for fatness is the altemate drinking of Kissingen and Vichy, the water of the Grande Grille preferred. Dr. William T. Cathell, in the Maryland Medical Journal, recommends that a full glass of Kissingen be taken one-half hour after each meal, and the next day, in the same way, a glass of Vichy: alternating in this way, the artificial waters may be used, or the waters prepared with the various effervescing salts on the market. If the patient loses more than two pounds in weight per week, take a small glass, or omit the mid-day glass. If he loses less than two pounds per week, add the juice of half a lemon to each glass of Kissingen, or a teaspoonful of the aromatic spirit of ammonia to each glass of Vichy. It is not necessary to restrict the diet, but cut down somewhat alcoholics, starch, sugar, and fats, if given to consuming large quantities of them. In other words, avoid overeating and excesses at the table. Sleep on an empty stomach as near as possible, so some of the surplus fat may be burned up as fuel whilst we sleep. Take plenty of out-door exercise, to promote tissue oxidation. If more convenient, the patient may take one glass of Vichy before breakfast, and a glass of Kissingen just before going to bed, and expect good results. There is no doubt that even sipping the waters now and again, to the amount of from three to four glasses per day, alternating between Kissingen and Vichy by days, would prove equally. if not more, effectual. Taking these waters may be kept up from one to six months, or longer if necessary. I may add here that this is not a new system of treating obesity, but is a revival of the Dancel system,-giving sodium bicarbonate with tartaric acid and water in the effervescing state. How do they act? Well, they may act in several ways. By merely inhibiting or controlling the disproportionate activity of fat-cell nutrition, thus placing less fatty pabulum and more blood, brain, muscle, nerve, and gland elements at the disposal of the absorbents, whilst the fat and oil, being of lower organization, are naturally the first to be removed by the corrected physiolngical processes, or they may act as alteratives and restore equilibrium to the nutritive processes by 


\section{FORTY YEARS IN THE MEDICAL PROFESSION}

destroying or neutralizing some morbific fat-forming agency, occult derangement of digestion, or perversion of assimilation that have been causing diminished oxidation of fat and, consequently, its accumulation.

Another supposition: Kissingen and Vichy, the former acid and the latter alkaline, and both containing salts of lime, magnesia, potash, soda, and other minerals, united with carbonic acid and other gases, may, when alternately mingled with the chyme in the stomach and intestines day after day, - their special combination of ingredients,-bring about reduction by some chemico-physiological readjustment of the alkalinity and acidity of the blood and the visceral fluids, or possibly of both humors and solids, and that this readjustment makes the fat-yielding pabulum less plentiful and less rich, less favorable for fat creation, and metabolically explains why increase of fatness ceases and why reabsorption of the surplus contents of the fat-cells begins, and also why this physiological reduction and reconstruction results, and thus reduces the fat of the body to the normal proportion of one to fifteen or twenty. Whether Dr. Cathell is correct here or not, he declares that practically they work wonders, and the individual losses are from fifteen to ninety pounds. My experience in practice confirms somewhat Dr. Cathell's.

In matters of diet, we spoke of studying the individual in ordering a course of diet for a patient. Climate is also an important matter to take into consideration. The Esquiman needs, from his environment, much fat to keep up the heat of his body, but what would the inhabitant of Manila do with blubber as a main article of diet, living constantly as he does under the hot rays of an equatorial sun? Our soldiers in Manila do not want blubber, but experience shows that we must still keep the fat in their ration. According to George Waldron, Ireland eats more white potatoes than any other nation, consuming a daily average of four pounds per person. Germany comes next, and Italy last, consuming only forty-eight pounds per person per year. The United States consumes two hundied pounds per person per year. In 
wheat, France leads the list. using four hunclred and sixtyseven pounds per person per year. Canada comes next. The United States consumes two hundred and forty pounds per person per year. Japan uses only twenty-two pounds per person per year, which is just the amount of rye used by each person in the United States. Norway uses the most oats per person, being one hundred and twelve pounds per person per year. England, including Scotland and Treland, uses only twelve pounds of oats per person per year,-very remarkable, so much of it being used in Scotland, and such an ideal food for the climate. In meats, the United States stands at the head, using one hundred and forty-seven pounds per person per year. Italy uses the least, as her climate might indicatetwenty-four pounds per person per year. The United States also uses more eggs than any other country per person,-one hundred and twenty-three per year. In rice, the United States takes only four pounds per person per year. Great Britain takes nine pounds, and the province of Bombay, India, uses five hundred and forty-seven pounds per person per year. Here we see how climate comes in in diet. In sugar, Great Britain uses the most, - eighty pounds for each inhabitant per year. The United States uses serenty-three pounds, and Spain only seven pounds. In tea. Great Britain leads,-about five and one-half pounds per person per year. Russia uses only nine ounces per person per year, and yet are supposed to be a tea-drinking people. Here we see the condition as shown by diet,-too poor to drink much tea. In coffee, the Netherlands use the most, over twenty-three pounds per person per year, whilst we use nearly ten pounds. Russia uses only three ounces per person per year. In malt liquors, Great Britain takes the lead, thirty gallons to each person per year, actually leading Germany three gallons per individual. We. in the United States, use fifteen gallons per person per year. In the wine-drinking countries comparatively little is used. although it increasing in France, she now using six gallons per person per year. Spain uses only a little over a pint, but in wine consumption Spain leads the world,-thirty-five gal- 


\section{FORTY YEARS IN THE MEDICAL PROFESSION}

lons to each person per year. France, twenty-nine gallons, and Italy, twenty-four gallons. It is interesting to note that the United Kingdom uses less than two quarts per person per year. Her climate demands something stronger. Surprising to say, Germany uses only a little over one gallon of wine per person per year. In the United States the consumption of wine is rapidly increasing, but it is yet only two quarts to each person per year, making the respectable quantity of thirty-eight million gallons. Great Britain and her colonies and Russia are among the great spirit-drinking countries, and climate here is the great factor in determining the quantity consumed.

It has been said that " a piece of charcoal, some atmospheric air, a little water, and some salt contain all the elements of a typical diet, and in ample (juantity," but we cannot live on a piece of charcoal, some atmospheric air, a little water, and some salt served in kind at least, but dress them up in palatable dress, and we take them with avidity and grow fat, showing it is not altogether the elements the food contains that make it available, but how and in what way these elements are contained is the important matter. Another thing it shows: we must know something more than the absolute chemical composition of food-stuffs before we can foretell exactly the effect on the indivdual.

It is now autumn, and a lady, married, with no children, of middle age, of normal weight, and very bright, has just asked me to recommend an average diet for her, not that she is sick, for she is very well, has no vices and no fads; she merely wants to take good care of her present satisfactory health. I suggested the following: For breakfast, she being always ready for it at eight A.M., a baked apple or pear, not very sweet. with, if she prefers, some milk that has been Pasteurized. If preferred, a few grapes or a peach may be eaten, without sauce, an naturcl. A plate of oatmeal, wheaten grits, or corn grits, with Pasteurized milk but no sugar, stale bread with butter, and a cup of coffee and hot milk. If preferred, two hen's eggs boiled from three and one-half to five minutes 
FORTY YEARS IN THE MEDICAL PROFESSION

may be substituted for the oatmeal or grits. Lumcheon, one P.M.: some light soup, with stale bread and butter, some boiled fresh fish, and some plain fruit. Provided she is not to take active exercise for an hour or two, a chop or some minced meat or a bird may take the place of fish. If desired, a well-baked white potato may be added to this meal. Dinner, six P.M.: a soup, not rich, such as consommé or a clear vegetable soup, choice of roast or boiled beef, mutton, or poultry, or its equivalent; baked white potato or sweet potato. and either rice or macaroni, with either cauliflower, spinach, or cabbage, boiled, with a plain sance. A light salad may follow, with a taste of cheese and a taste of hard cracker heated. If any wine is used, take claret and water. For dessert take plain rice-pudding, plain custard, or a little light pastry, some fruit if clesired, with a demi-tassc of coffee. If the custom of her home, then a sociable cup of mild black tea, without cream or milk, one hour after linner, may take the place of the coffee.

Merely as a matter for reference, I will give the time required for the digestion of some of the commoner articles of diet. May I preface this with one admonition? In cooking in general, avoid the frying-pan, as a rule, and rich, variousflavored. wonderfully made sauces. The frying-pan makes easy a cheap and indolent method of preparing food. It has been said that words were made with which to disguise our thoughts. The French, particularly, invented the various sances to disguise natural flavors and to enable them to serve any dish from almost any material, thus serving two purposes. - the satisfying the palate of the guest and establishing an economical method in the kitchen. None of these methods are conducive to the good health and prosperity of the individual. Time required for the digestion, or rather, the chymification of earious articles of food: Boiled beef, $23 / 4$ hours: roast beef. 3 hours; boiled mutton, 3 hours; roasted mutton. 3/4 hours; turkey roasted or boiled, 2 I/4 hours; stewed chicken, $23 / 4$ hours: fried beef, $t$ hours; roasted chicken and duck, + hours: boiled chicken. + hours; roasted fresh pork, 
$5 \% / 4$ hours; soused pig's feet boiled, I hour only, and tripe the same; venison steak broiled, I $1 / 2$ hours; fried brains, $I 3 / 4$ hours; fried beef liver, $2 \mathrm{I} / 2$ hours; calf's liver, $13 / 4$ hours; roasted goose, $2^{\mathrm{T}} / 2$ hours; roasted young pig, $2^{\mathrm{T}} / 2$ hours; roasted lamb, $2 \mathrm{I} / 2$ hours; boiled salmon, I I $/ 2$ hours; boiled salt cod, $2 \frac{1}{2}$ hours; stewed oysters, $3 \frac{1}{2}$ hours; raw oysters, much less; cheese, $3 \frac{1}{2}$ hours; gelatin is digested in from $2 \frac{1}{2}$ to 3 hours, cartilage in $4 \frac{1}{2}$ hours, and tendon, well cooked, in 6 hours; raw eggs, $11 / 2$ hours ; roasted eggs, $21 / 4$ hours; hardboiled eggs, $3^{\mathrm{I}} / 2$ hours; fried eggs, $3 \frac{\mathrm{r} / 2}{2}$ hours; soft-boiled eggs, 2 hours; boiled lean ham is quite easy of digestion; boiled white potatoes, $3 \frac{\mathrm{r} / 2}{2}$ hours; if well baked or roasted, 2 to $2 \mathrm{r} / 2$ hours; boiled cabbage, 4 hours; boiled turnips, 3/2 hours; boiled rice, I hour; boiled beans, $2 \frac{1}{2}$ hours, and the same for boiled parsnips; carrots, boiled, from $3 \frac{1}{4}$ to $3 \frac{1}{2}$ hours; baked wheat bread, $3 \frac{1}{2}$ hours; boiled beets, 4 hours; boiled or baked apple-dumpling, 3 hours; raw apples, from $\mathrm{I} / 2$ to 2 hours, - sweet and mellow digest the soonest; corn-bread, 3/4 hours; hoe-cake, 3 hours; sponge-cake, 3 hours; boiled barley, 2 hours, tapioca the same, and sago about the same. Sugars are very rapidly absorbed from the stomach, and, as a rule, so are fats. Of course, digestion may be retarded by different causes, as by food that does not agree with one, such as unripe fruit, badly cooked food, animal food too tough to be eaten, etc., together with the stones, seeds, and skin of fruits and sucl.

I cannot quit this subject without saying something of milk as food for man, the support of his early infant days and his last resource if toothless old age overtakes him. As a general thing, unless otherwise stated the milk of the cow is referred to in this comnection. Another thing remember: milk is really a complete food, and its indiscriminate use as a beverage by those who already eat a full supply of regulation diet is to be condemned as superfluous. When used properly, by sick or well, under the guidance of proper medical advice, there is nothing to equal it, and no tonic devised by man, as tonics are understood, can in any way approach milk: but as 
a tonic milk cannot be used alone. Natnred man cannot live and thrive on milk alone; something else must accompany it in the ration. Besides, if he lives alone on milk he soon gets tired of the monotony, and for good reason. It takes nine pints of milk at a specific gravity of ozo or over to give him the twenty-three ounces of dry food needed for his daily allowance, and whilst taking this much he gets too much albumin, fats, and water, for he does not need so much. This is all right for the growing infant. It needs more of these, and can live on milk alone for a considerable time, but it should drink some sterilized water in addition, an important matter very often overlooked, otherwise they become dyspeptic and wretched and cross. I say sterilized water, for it is safer, and the water of the milk keeps intact the cell protoplasm if sterilized or distilled water will not accomplish this, or even injures it. Hemorrhagic troubles, uric acid troubles, and troubles of a pigmentous kind are common among young children, and water is useful in carrying off the débris of the system which accumulates rapidly, the red corpuscles of the blood being rapidly destroyed at this age and lithic formations frequent. I think three pints of good milk in wwenty-four hours will support life in a natural man, but it surely is not a working ration. The chemical composition of milk has already been given,-protein, 3.3 ; fat, 4 ; carbohydrates, 5 ; ash, 7 ; and water. The lactose, or milk-sugar, is an important ingredient in milk. It is equal, usually to half the solids of the milk, leaving out the fats. It sours the milk by being converted into lactic acid during the fermentation of the milk, caused by nitrogenous materials in it. Great reforms are still needed in milk inspection, from the environment of the cow, through the cow, and through all of its phases, up to the time it is userl as an article of foor. It is an ideal host for most of the pathogenic and other microbes, and when we come to think of their universal presence, under all circumstances and at all times, we soon see low it is impossible to guard too closely and too jealously all that pertains to this nniversal nourishment of man. I believe that twenty per cent.- surely 


\section{FORTY YEARS IN THE MEDICAL PROFESSION}

not less than fifteen per cent.-of the cows furnishing the milk supply to the people of the Middle States are tuberculous, and some, at least, of these have tuberculosis of the udder. These last, at least, surely furnish milk contaminated by tubercle bacilli, and when I say I believe such milk unsterilized can reproduce tuberculosis in man in its various forms, is it not right and proper, is it not our bounden duty, regardless of expense, regardless of any obstacle whatever, to do all in our power to eradicate such a menace to human health, such a bar to human happiness? Can man be so base. so mean, so low, as to reckon in dollars and cents the price of any means to be used to eradicate this evil, probably the evil of all cuils now confronting him? Oh, the fond friends, from the darling prattling infants to those the brightest and loveliest of matured age, we, all of us, without exception, are mourning, have mourned, and will never cease to mourn, unfortunate victims of this greatest, most unrelenting of all the scourges inflicted upon the human race!

Milk being such a good host for pathogenic germs, I believe it should in some way be sterilized before it is taken for food into the human stomach, and probably, in the end, Pasteurizing is the best method of accomplishing this. It surely leaves the milk in the most palatable condition of any of the methods, and there is only one loop-hole of escape for error, and that is, are the spores thoroughly destroyed by Pasteurizing, as thoroughly destroyed as are the parent germs? Therefore, if you keep Pasteurized milk any time, Pasteurize it once every twenty-four hours, to destroy the spores as they arise. To sterilize milk, bring it to boiling, $2 \mathrm{I} 2^{\circ} \mathrm{F}$. To destroy the spores absolutely and surely, bring it to the boiling point a second time. To keep it, put it in bottles, being sure first to sterilize the bottles by boiling them. Stop them with cotton which has been sterilized by baking in an oven from twenty to thirty minutes. The cotton is better than a solid cork, for it allows escape from within and checks entrance of microbes from without. If you boil the milk twenty minutes, it will really digest better than if you only sterilize it. 
To young infants raw milk is an anti-scorbutic, and Professor Bartholow and others think sterilizing it may take away this property in a measure. According to Leeds, as stated by Thompson, sterilizing milk destroys the amylolitic ferment. checks the coagulating of the casein by remnin, retards the digestion of the casein, and checks somewhat the absorption of the fat, and, if the boiling is prolonged, the lactose is destroyed more or less. It takes more sterilized milk to nourish an infant than it does of milk as from the cow.

To Pastcurize milk, raise it to a temperature of $\mathrm{I}^{\circ} \mathrm{O}^{\circ} \mathrm{F}$., and keep it there twenty minutes. It digests easier than sterilized milk, but does not keep so well unless repasteurized daily. It is more palatable. Before any bottles in any way used about milk are used the second time, they should be thoroughly sterilized by boiling twenty minutes. Bring the boiling along slowly, and the bottles, as a rule, do not break. After one or two boilings, they appear to become tough. Always rinse them with boiling water just before use, putting some borax or boracic acid in the water, and use a bottle-ivasherthat has been just sterilized. For a substitute for mother's milk I can recommend the following: Milk, eight tablespoonfuls; cream, two tablespoonfuls; water that has been boiled, eight tablespoonfuls; pancreatin, three grains; baking-soda, ten grains; mix the milk and cream together, then add the pancreatin and baking-soda to the water, and mix with the cream and milk; then Pasteurize the whole mixture. Very rich Jersey or Alderney milk will do without the addition of cream, using that much more of milk. If baby does not thrive on this, subtract half the amount of milk, and in its place put the same amount of very strong barley-water, ricewater, or oatmeal-water. Be particular and never forget to add to this amount of nourishment as here given (a little over half a pint) an even teaspoonful of refined cane-sugar and a good pinch of table salt. I prefer cane-sugar to sugar of milk to add to baby food.

There is a healthy erolution going on in the economics of milk, from its production to its consumption by the consumer, 
and people are beginning to see what a great benefit such evolution will afford. In the larger centres of population per cent. milk may be obtained, the physician giving his prescription for the per cent. of fat. sugar, casein. etc., needed for an individual case, and a scientific vender filling this prescription by compounding the milk needed artificially, much as the recipe for artificial mother's milk is here given. The world moves. Medicine is a progressive science, and medicine moves as the world moves, althongh it did appear to be a good while starting.

Condensed milk is a useful product, and as it comes from the original package should be sterile, for in closing it the bacteria are destroyed by heat and all outside air is shut off. Thus, with care in detail, we can get an article which sometimes serves a good purpose for the sick. For condensed milk the condensation is ustally to about one-fourth of the original bulk. If condensation is carried still further, more sugar is added. On an average. condensed milk has added to it about forty per cent. of cane-sugar. This prevents fermentation. Dilute condensed milk eight to ten times with sterilized water for a baby at birth, and add some fat in the shape of cream or olive oil. A formula, such as this, will be found about correct: Condensed milk, one teaspoonful ; cream, four teaspoonfuls, or olive oil, two teaspoonfuls; hot water, five tablespoonfuls. If oil is usecl, make up the deficiency by two teaspoonfuls more water. Pasteurize for use. On account of the excess of sugar. condensed milk does not keep long. and is more apt than normal milk to cause fermentative troubles in those using it. Add an excess of fat, and it frequently proves a serviceable food for consumptives.

Dcwonshirc cream is cream skimmed from heated milk, so the albumin is coagulated and comes off with the cream. and may be substituted for col-liver oil, when such disagrees.

Evaporated milk is extra strong milk, the water having been driven off, and as it is for immediate use, it is all naturel, no sugar or anti-ferment having been added; at least, this should be so. 
FORTY IEAKS IN THE MEDICAL PROFESSION

Buttermilk is milk with the fat removed for butter. There is albumin and casein left in it, and water and the milk salts, with lactic acid. A man cannot live long on buttermilk, nor skim-milk, that is, absolutely.

Cottage checse or schmierkäse, or smearcase, is a very inviting help to diet, especially in hot weather, but it is quite high in protein, contains less than half the fat of pure milk, with much lactic acid formed from the sugar as fermentation goes on.

Whey is another product, and with wine is often useful, especially for the sick. It contains water, milk salt, some albumin, and lactose or milk-sugar; it does not keep long, and should be sterilized before use, which may coagulate some of the albumin.

Let me add here that the distribution of the milk-supply should be taken in hand by the police power in all communities, and so should its source, the cow, in all of its environments. A vicious distribution of a milk-supply to any neighborhood may do more harm than a pestilence; indeed, it may start a pestilence. There should be a code of laws to govern this distribution in every town, be it large or small, and this must come sooner or later, as laws must come to eradicate tuberculosis from the lower animal as the evolution of society goes on to perfect government. Infected milk may cause typhoid fever, diphtheria, scarlet fever, tyrotoxicon poisoning, Asiatic cholera, in fact, all zymotic diseases, all fermentative diseases.

A milk called the "IValker-Gordon" milk, from the farm on the golf links of the Philadelphia Cricket Club. Wissahickon Heights, contains, on an average, according to Dr. Samuel S. Kneass, only $354 \frac{1}{6}$ bacteria per cubic centimetre. This shows wonderful care in attention to detail, as well as careful selection of dairy stock and attention to the environment. Where police supervision is fully carried out over the milk-supply to a community, no milk is rejected where the number of bacteria per cubic centimetre does not go over ten thousand. The smallest number does not appear to be many. 
but when we come to think of it, that two germs by simple fusion can produce two of its kind in one hour, and in the next hour four, and in three days a mass not countable,- - say, 4,772,000,000,000,000,-we begin to comprehend what the lower order of life really is, and the great step between it and the evolution of man. To check this formation of germs many antiseptics or antizymotics are used by dealers, and it makes us pause and reflect whether or not it is not better to use them surrounded by proper guards than run the risk of this auto-infection of the milk-supply. To the reckless and careless and vicious antisepsis may be a protection, but the enlightened citizen will use sterilization in its various forms. Benzoic acid and salicylic acid uncombined with bases are much used as antiseptics for milk, but borax and boric acid are cheaper and more tasteless. These destroy the vegetative activity of the various fungi and bacteria, and thus check fermentation and decay. The dealer may extract five per cent. of the cream and add ten per cent. of water, and escape detection, unless by experts.

In the milk-supply of London the average number of bacteria per cubic centimetre is 500,000, a bad showing surely. Such figures startle us, and point with no uncertain hand the direction to take to institute reforms that shall more than in any other direction reduce the amount of zymotic disease, and thereby check, in a large degree, the mortality among the human race from this its greatest factor. We know that normal milk in the udder of the cow is absolutely sterile, and consequently we know just where the trouble begins. The abnormal cow may, of course, produce abnormal milk from the udder,- as the tuberculous cow. The most important germs found in milk are the bacillus coli communis, composing ninety per cent. of all in many cases, and this is indicative of fecal contamination, and shows dirty stables and bad environment of the cow. Liquefying organisms are also found, and show one of two things, - dirty cans and utensils or a needless exposure to a bad atmosphere in the stable or dairy-house. I believe one source of evil is housing the 
cows too elaborately and too closely. The finer Herd-book herds, on which vast sums of money have been spent in selection and on their environment, are the sickly herds in the end, are the herds in which we most likely find tuberculosis and such troubles, and I am sure much or all of this vulnerability to zymotic troubles connes from unnatural environment. In palace stables, making allowance for all difference in climate and the environment of the plains, we see the difference and the cause.

When we come to analyze the statistics of tuberculosis in the East and in the IVest, the showing is altogether in favor of the Western cow, and the same thing holds good of the Indian,-lhouse him abruptly, and you kill him. Never milk a cow in its stable. Milk in the open air, or in an open shed, and let no person with any zymotic disease go near her.

Another germ is found in milk, often abundantly, - the bacillus fluorescens. This is that which oftenest lurks in impure drinking water, and when found in milk it has probably been reduced by water, and by infected water, too. The Experiment Station Record gives as the solid impurities in milk the following parts per million: In whole milk, 2.6 parts; ordinary skim-milk, 2. I parts; separator skim, .3 part; cream, I.5 parts. The impurities were largely particles of litter and fodder, pieces of straining cloth, etc. In many samples were found woollen and colored cotton fibres from clothes of attendants. Separator skim-milk is the cleanest. Altogether this is rather a cleanly showing. In London more pathogenic germs were found than in the United States, including the oildium albicans, the exciting cause of thrush; this is well for physicians to know, for it is very common in bottle-fed babies everywhere. Sulphuric ether (as I pointed out thirty years ago), locally applied, is a sovereign remedy.

Food adulterations, including milk, are encouraged by intense competition, with low prices and small profits, and it often becomes a question with a dealer whether he shall give up his integrity or give up his business. This is a phase in the evolution of bartering. and will in the end give way to 


\section{FORTY YEARS IN THE MEDICAL PROFESSION}

better methods as the development of the better laws of trade unfolds.

Great advances have been made in the general treatment and nourishment of infants in the last forty years. When I was a resident at the Philadelphia Hospital, Blockley, I had the opportunity of seeing something of the practical workings of the day in a foundling hospital, but before I had time to more than get a knowledge of the horrors of the system, much less attempt to apply remedies, my term had expired. At that day most of the formollings of Philadelphia came to this hospital, and there were quite a number of these poor little waifs. In winter or in summer they nearly all died, starved to death, as it were, from too much and ill-advised feeding, paradoxical as that may appear. Indeed, if one lived beyond infancy it was a curiosity. One or two in several years did so survive, and one named after President Lincoln was always looked upon with curiosity as a survivor of the holocaust of infants at Blockley. I am sorry to say Lincoln did badly as he grew up towards matured manhood, and the last I heard of him he was a bad man among bad men of Chesapeake oyster-men. Can you "make a silk purse of a sow's ear"? But, " revenons à nos moutons." There was no system in caring for these bereft babies. A good, well-meaning woman was at the head of it, and the doctors looked in if anybody was ill, or if they took sufficient interest to go oftener. Pauper inmates from among the women were the nurses. Imagine such a thing as asepsis, the use of antisepsis, or any attention to detail with such a gang! You could not trust them with forty drops of spirits, nor with one particle of a narcotic. The baby-food was milk, generally diluted with water, cold or hot, as best suited the convenience of the attenclant. There was no special care of the milk, no special care of the bottles, and the same might serve for half a dozen children, and, as a rule, were fitted with. as I remember, the long hose nipples, an abomination, an invention of the devil. The babies did not remain long, and the end was a death certificate of "Inanition" and a grave in " Potter's Field." 
I remember about this time Liebig put forth the formula for his food for infants. I had it made, and tried it on these little ones. Of course, I had no success. The children were too young, as a rule, and I commenced too far away from bed-rock,-sterilization, asepsis, and antisepsis, not only of the food, but of the child, the whole environment from $\mathrm{A}$ to Izzard. To properly care for a bottle-fed baby, to give attention in a proper manner to every detail (and in this attention to detail lies the whole secret), is full and exhaustive work for any strong, healthy, and vigorous woman. Think of this, when we oftener see, yes, much oftener, one poor, frail creature caring for, in some fashion, with absolutely unsanitary environment, not only one bottle-fed baby, but several children besides; and yet this is not half she does: she washes and irons for the family, does the cooking and scrubbing. makes the clothes, and does the mending of the children at least, and entertains company in the evening in her best gown. Poor little bottle-fed babies! your lot is a hard one; no wonder you continue to die beyond the normal rate that should prevail among you. Never mind, the good time is coming, and zymotic disease shall less and less prevail among men. Science is leading mankind as a beacon to a safer and better harbor.

The physician, in looking after an infant under four months old, should first consider the mother, as to the quality of her milk, her family history, her present condition of health, etc. An examination of her milk chemically is of prime necessity. especially if the baby does not thrive. She should nurse the baby altogether as near as possible until it has reached the age of one year at least. Whatever baby takes, starchy and other foods, should be withlheld until from four to six months have passed since its birth, and no flesh should be given until the teeth have come to chew and disintegrate it. Broths may be used before meats, and sometimes water extracts of carbohydrates may be necessary before four months of age. As in older people, when looking up the baby study the individual. Nothing is truer than that every case of infant-feeding is 
a study, whether it is living on the mother or artificially. Everything comes in in this examination,-family history, its general health, its form, the treatment it is apt to reccive in feeding, bathing, and general care, and its clothing. This first six months of life is all-important to the baby, and has much to do, very much, indeed, as to whether it may reach vigorous maturity, and become a useful citizen of the commonwealth. If the baby cries, it is either hungry, cold, too hot, or in pain; a little food, a blanket, the removal of superfluous covering, or attention to the diet will usually work wonders in the crying baby. Remember, in the improperly fed infant nutritional diseases, scorbutus, marasmus, rickets, and others, are apt to show themselves at an early age, and if the infant should grow up to adult age, only misery and wretchedness are in store for it and its kin. Remember the size of the baby's stomach, and if possible regulate the diet so it will not be necessary to vomit the surplus, and thus add to the dangers of germ contamination. A child may starve, like a man, even when stuffed, should it not get the properly balanced ration. This is as essential to watch, even in children well grown, as it is in man. See that they get a properly balanced diet, and here is one of the great needs of the supervision of a family by a competent physician, now so little thought of. After a while the doctor will be called to stop the child before he gets sick from a mess of sweets, to see he gets no such trash. Now, often, the well-grown child eats the mess of sweets, and the doctor is called to cure him of the effects of his indiscretion, much like "locking the stable door after the horse has been stolen."

Most of the practice of medicine has now to do with women and children, and no one will feel the good effect of the constant care of the coming actors in preventive medicine so much as these same women and children, and ages hence the race will show the good effect in a strongly developed and perfected manhood. If the baby has to be weaned, and weaned prematurely, then comes the great trial. What shall the food be? Well, this will depend much on the age and the 
surroundings. If under six montlis, it must, as a rule, be liquid, and the nearer to mother's milk the better, and if this be departed from a little animal broth is the best help to milk. Fresh milk must be a good part of the diet. We know not exactly why, but if we omit it, scorbutic troubles quickly show themselves, and the physician must be quick to recognize them. Remember, condensed milk will not take the place of fresh cow's milk for artificial feeding of infants. Watch it. The baby will thrive for a time, but for a time only. It lacks freshness, and this lack of freshness predisposes to nonthriving in the baby. That is as much as we know. Watch the gain or loss of weight in the baby, and you learn much as to its proper advancement.

As to infant foods of various kinds, some are good, after the baby is old enough to take them; some are vile and bad. From idiosyncrasies one baby may thrive on one and starve on another, and so it ever will be with man. An artificial food for infants, and all invalids for that matter, should have the following properties at least: It should have some fresh cow's milk with it in feeding, most of the time at least, to give it freshness, that which keeps away scurvy. In the preparing of it at the laboratory perfect sterilization of everything should be practised. It should have some chemical approximation to mother's milk, and should also physiologically approach it. If it does not agree with the child at once, do not persist in it; change to another; sometimes the coadministration of digestive ferments and digestive enzymes may help these foods. It will try the patience of any man as he has to deal with the diet of infants deprived of their proper food. After all, as science advances, various modifications of milk must be our chief reliance. Science aids us much at present, but mere empiricism is still a part of our dependence. The coming artificial food will be one not for all babies, but will probably be graded to age and must be one approaching more or less the composition and effect of mother's milk. Commercialism must not have a part in the coming baby foof. Honest men, satisfied with a moderate profit, must make it. 


\section{FORTY YEARS IN THE MEDICAL PROFESSION}

When baby is sick, let the physician investigate the source of the food-supply, whether from the mother or from artificial sources, and he will probably find out the cause, even if he has to take in the whole routine of the milk-supply in the community, and the entire culinary details of the household.

We have spoken of the diet for childhood, and of diet for the active, strong, and vigorous youth, and for vigorous middle age. When one reaches fifty years of age, having escaped the pitfall of dissipation, and enters upon this stage of life sound in mind and body, it behooves to pay great attention to what one eats and what one drinks. These remarks apply more particularly to the idle and well-to-do, and to those who do brain-work more than manual labor. For those working with their hands the all-important part is a properly balanced ration and proper preparation. Persons who reach fifty, of the well-to-do class particularly, eat too much and eat too often, and take insufficient exercise, and thus grow fat and corpulent, not working off the excess as they did in the earlier and more active periods of life. Especially is this the case with men who retire to enjoy a well-earned competency, and which so often ends in disaster to their health, giving us an object-lesson that it is better to wear out than to rust out. No one should go from an active, busy life and drop into a lazy, useless one. It is never too late to take up some occupation. no difference what, so it gives some rational employment to body and mind. Some study and practical work in nature is the best,-agriculture, horticulture, and such, and what comes out of them and with them, as botany, etc. At fifty, remember old age is approaching, and the average man is sick ten days in the year, only being sick fonr days at twenty. At fifty the blood loses some of its richness and loses in quantity: The bloof-vessels enlarge and are not so elastic, and the dangers of atheroma are upon us, cansing liability to apoplexy, etc., the natural way for old people to die. The heart weakens somewhat, probably a provision of nature to reduce the blood-pressure and thus relieve the pressure on the blond- 
ressels, now becoming weak like the tubes in an old steanboiler. At sixty a general shrinkage begins, or is well under way, and continues on progressively into extreme old age. accompanied by the loss of teeth, a weakened digestion. cansing distention of the stomach and bowels, thus pressing up against the diaphragm and interfering with comfortable and satisfactory respiration. Thus metabolism is interfered with and tissue changes go on. Katabolism, retrugrade metamorphosis, is active. anabolism-the building up of tissues. the building up of living tissue, the forming of protoplasm, without which there is no life, from nutrient material, in other words, assimilation-becomes less active, and the body hence thrives less and less as age increases.

Men and women at fifty should begin to cut down their nitrogen particularly in their diet. At this age one shonld dine not more than twice a week: twice a week we may live to eat, five times a week we shonld eat to live. If we take wine. one wine should suffice. If champagne, it should be very dry. No one should take sweet champagne after fifty. I am speaking of the well-to-do and in good health, and not of invalids. The clarets and light Burgundies would be better. Port, Madeira, and sherry are most dangerous of all, in the order here given. Remember, after fifty, avoid alcolol as much as possible, and shade off your tobacco if you use it to excess. As we come to sixty years, it is still more of importance to be careful in diet and to take the proper ration. Arteriosclerosis and its consequences are what we wish to aroid. Milk or its equivalent becomes more and more an important and proper article of diet. If the appetite is ver! strong, curb it. Do not eat richly and drink generously and then complain you cannot breathe properly, are uncomfortable. The reason is you cannot digest properly what you have taken; your diaphragm is pressed against your natural breathing space, and you are in a condition of semi-suffocation, and are laying rapidly the foundation for a miserable old age or early death. The gonty should take particular care not to orereat. Semi-staration for these people at times is pro- 
FORTY YEARS IN THE MEDICAL PROFESSION

longation of comfort in living. After that is gone what is there in life?

To those growing old lavage of the bowels is of great importance and a great comfort. Water in proper amount for drinking is of great importance, not too much nor too little. The skin does not throw off as much, but more is required to carry off nitrogenous waste. After fifty the mid-day luncheon should be dispensed with, or reduced to a mere bite, and twice a day is enough for a hearty meal. As I said before, twice a weak is often enough to dine; let the other dinners be merely frugal repasts. The elaborate mid-day luncheon as usually set for families or partaken of at the restaurant is an abomination for those over fifty. I am speaking now of those who breakfast in the morning and dine in the evening. For those who dine in the middle of the day the tea should be only a formal one.

The late Ward McAllister, a good authority on dining, wanted a walk of ten miles and no luncheon as a preliminary to a good dinner, and yet I do not think he took much thought of the chemical composition of his dinners, but catered to his tastes chiefly. I never met Ward McAllister, but in my early days I knew most of the other members of the family well. They were strong, staunch people. The father, the judge, was a polished and accomplished gentleman, and the mother a woman of lovely character and great accomplishments. The sons adorned the professions of law, of arms, and the church, and were polished men, all. Cutler was a Yale man. was good company, quite a wit, could sing a good song, tell a good story, and make a good salad. Peace to his ashes. They are all dead, barring the possible exception of the sister, Mrs. Francis, of New York City. Read Ward McAllister's book, and, having read it and come to moralizing, you may gain great good. You may see the dangers to the younger, at least, among the smart set, of being carried away by dissipation in eating and drinking. Should they escape the shoals here, you may see the dangers they run after fifty of gout, of the horrors of dyspepsia, and of the possibility of death from 


\section{FORTY YEARS IN THE MEDICAL PROFESSION}

old age at sixty or under. Should they escape all these troubles. or any of them, at the age given, you may no longer wonder that some men and some women are born with great capacity for eating and drinking. But after all, it is only carrying out and giving an object-lesson of Darwin's famous law, that it is only the "fit who survive," and no longer will we wonder at the stories told of the famous days of ancient Rome, of her feasts, of her fair women and more famous men, and, whilst not forgetting the Roman senators, I am sure we will modestly vote, in all that pertains to an accomplished and polished host, Mr. Ward McAllister the " noblest Roman of them all."

From a combination of causes, but, after all, on account of the general increase of intelligence among the people at large, and their more general intermingling, there is a tendency at the present time to fads in food and diet in general far beyond what there formerly was. It will be well for physicians to guard their patients against the pursuit of these fads too zealously, for after a time it does harm to the individual. People congregated in the sanatoria and sanitaria of the day are prone to discuss such matters in connection with their general infirmities, and to carry the same habits out into the world with them and thus generate the custom. People should depend more on their medical advisers, remembering that " he who is his own lawyer generally has a fool for a client," and I will add to this by declaring as my opinion that the amateur doctor is usually a knave or a fool, or worse.

The effect of a fanatical pursuit of matters pertaining to one's diet, that is to say, of the diet of one who does and should in a measure diet, is to produce a real fear of food, which in the end may produce a genuine disease, a genuine neurosis. It is not well to think too much over what one eats. We must observe the general principles of diet according to our condition of health, as I have endeavored to impress upon my readers all along, but after these hygienic food principles have been observed, the appetite and the food furnished us may be more or less trusted, indeed must be trusted, to retain 
our proper appreciation of food. The child teaches us many things, and he teaches us something in diet. The stomach of the child is delicate, as is the stomach of advancing age, yet one reason why the child can eat and digest certain things which the older person cannot is because the child never gives it a thought after swallowing, whilst the older person, especially the one who has fads about eating, will have it disagree with him because he thinks about it and expects it to disagree and give him discomfort. The lesson to be learned from all this is, do not become fanatical in matters of diet, do not make them a matter of too general discussion, and rely more upon your physician than you do upon your friend who has visited all the great health resorts of Europe and America, and who, to use a slang expression, "knows it all." Above all things, take no advice from newspapers, quacks, or amateur doctors.

Infantile Scurry.-Adult scurvy is an acquired afebrile disease, caused probably from the want of fresh vegetables and fruits, and from too much salt, from bad water and bad surroundings in general. There is even a possibility of its being an infectious disease, caused by some pathogenic germ as yet undiscovered. The salt used in preserving the animal foods of soldiers and sailors and others may be a factor in causation by extracting the native salts of meats along with the water, and by its well-known antiseptic action changing in some way the meat-fibres. The chief symptoms are debility, rapid heart action, iron hardness of the muscles. especially of the gastrocnemii, hemorrhages cleep-seated and superficial. spongy and bleeding gums, loose teeth, and the "greeneryyallery" look of Gilbert's young man in "Patience."

An entirely different trouble is infantile scurvy, scuroy' rickets, Barloce's diseasc, periosteal cacheria. This is a most interesting disease, but recently recognized, and especially increased, it is supposed, since the advent of the various proprietary infant-foods now so common. Professor Roberts Bartholow has given the best account of this trouble, and by so doing has again made good his reputation as an original 
investigator. Infantile scurvy was really quite well described by the late Dr. John S. Parry, one of the brightest men of his day, who died prematurely of tuberculosis in I 876; but Parry wrote only of infantile rickets, and unknowingly gave us a good account of the disease we are considering. It is usually confined to the first six years of life, but has been seen as late as nine years and as early as four weeks. It comes more frequently to those children who have a tendency from birth to lack of normal bone-structure. and to those early deprived of maternal nourishment and fed on artificial infant-foods and sterilized milk. Pasteurized milk is less apt to be a factor in its production, but remember, it has caused it. It has even been seen in children fed absolutely from their own mother, yet these cases are very rare. It is probably a combination of scurvy and rickets, or rather, probably children predisposed to rickets are more predisposed to scuryy. The symptoms are numerous, but the distinctive symptoms are pain on motion, which is very acute, simulating rhemmatism, or even paralysis, and the characteristic spongy gums, there often being ulcerative stomatitis, but rarely, if ever, gangrene of the mouth.

When connected with the Philadelphia Hospital, Blockley, years ago. I probably saw cases of infantile scurvy and made a study of these infantile mouth diseases. Among the symptoms are increase of blood-pressure, causing polyuria and restlessness of the individual: there is often periostitis about the joints, particularly of the tibial, and a general hyperesthesia of the whole body. The pains are supposed to be caused by hemorrhages beneath the periostemm, and hemorrhage causes much of the gum trouble. There may be hemorrhages under the skin in various places, there may be "black eye" caused by hemorrhage into the orbit, and there may be hemorrhage from the nose, bladkler, and bowels. Ansmia and marasmus may accompany infantile scurvy, without being the cause, or in some cases the child may appear to be thriving, and yet the leg-pains, the general hyperzesthesia, and the condition of the gums make the diagnosis plain or give us sufficient hints to get at the trouble. As a rule. the child has a 
dusky, sickly look, and there are frequent swellings of the joints and soft parts. Fever is seldom present, but has been recorded as high as $105^{\circ} \mathrm{F}$. There are other important points in the diagnosis as distinguishing it from summer complaint, so common in the Middle and Northern States and much less common in the South and the West. Neither vomiting nor constipation nor diarrhœa are constant symptoms, but I think, most assuredly, cholera infantum as we see it predisposes to infantile scurvy, and, as a rule, only bottle-fed babies have cholera infantum, and, as a rule, only bottle-fed babies have infantile scurvy. The report of Drs. J. P. Crozer Griffith, Charles G. Jennings, and John Lovett Morse to the American Pediatric Society, as published in the Philadelphia Medical Joumal, shows that about an equal number of males and females have the disease. A majority of the cases developed from the seventh to the fourteenth month, and a large majority of the cases were among the well-to-do. I should draw from this that it was due chiefly to artificial feeding, for the best mothers for nursing are not, as a rule, among the higher classes.

Now, as to the causes of the trouble. Whilst we must frankly admit that infantile scurvy has been seen in the child who has never been fed otherwise than from its mother's breast, this milk coming up to the average standard of human milk, and whilst we must equally frankly admit that a satisfactory explanation of the etiology of infantile scurvy has not yet been given, yet I confess, to me the most important etiologic factor is the use of the common every-day babyfoods sold in the shops. Next comes the use of sterilized foods, more particularly milk. There is evidently something in the cooking of foods, of destroying all life in them, which has something to do with causing this disease, showing that nutrition in general may be affected in human beings by lack of at least some of the natural elements of food in a raw and natural state when these natural elements are driven out by cooking or sterilizing. Probably sixty per cent. of the cases have been caused by proprietary infant-foods, leaving forty 
per cent. to other causes. It may be well to state here that from the reports family history has not been an important factor in the disease. In a large majority of the reports received by the physicians before mentioned, those making the reports thought the nature of the food used caused the trouble. In 406 cases the food used when the scurvy developed was as follows: Breast milk alone. Io cases; raw milk and amylacere, I case; sterilized milk with amylacer, I case; total, I2. Raw milk alone, + ; with breast milk and amylacex, I: total, 5. Milk alone, nothing said about heating, 8; peptonized, 4; with amylacere, 4; total, I6. Sterilized milk alone, 68; together with proprietary foods, $2 \mathrm{I}$; with amylacer, 8 ; peptonized, Io; total, io7. Pasteurized milk alone, I6: with proprietary foods, 2; with amylacex, I ; peptonized, I ; total, 20. Peptonized milk, 3; sterilized, 8; Pasteurized, I ; with proprietary foods. I; with amylacere, I; total, I 4. Amylaceous food (not proprietary) alone, 6; with breast milk, 3 ; with milk, 5 ; with sterilized milk, 8; with Pateurized milk, I ; with peptonized milk, I; total, 24 (nine of these were oatmeal). Table food, nothing else mentioned, I I ; with condensed milk, I ; total, I2. Mellin's food, nothing further stated, 42; Mellin's food and condensed milk, 22; with sterilized milk, I6; with Pasteurized milk, 2; with other proprietary food, I; total, 83 . Malted milk, nothing further stated, 44; with cream and malted milk, I; with amylacere, I; with other proprietary food, 2 ; total, 48 . Condensed milk alone, 32 ; with milk, I; with cream, I; with other proprietary foods, 3 ; with table-food, I; total, 38 . Reed and Carnrick's soluble food, I3. Imperial Granum, 6. Liebig's food alone, I; with condensed milk, I; total, 2. Lactated food alone, 3: with condensed milk, I; total, 4 . Nestlé's food alone, I; with sterilized peptonized milk, I ; total, 2.

In a number of reports proprietary foods were given with no name, making sixty per cent. of the cases fed on proprietary foods. The farther away the diet of the child is from mother's milk, the more likely is it to develop scurvy. 
Whether it is an infectious disease or not we cannot yet say, but in the end some pathogenic germ may show up explaining all of the symptoms and thus giving us a rational cause for the trouble. The mortality is not great. Twentynine reported cases out of three hundred and seventy-nine died; two of these, at least, died of other diseases, leaving only twenty-seven deaths due to scurvy. The autopsies showed the following lesions: Hemorrhagic spots on the pericardium and on the liver surface, subperiosteal hemorrhages of long bones, subpleural hemorrhages, separation of the lower epiphysis from the shaft of the femur, bronchopnenmonia, hemorrhage into the muscles of the thigh, swelling of knee and both ankles, exudative nephritis, the right leg from the knee to the ankle stuffed with a puffy mass replacing the normal tissue, separation of both bones one inch above the ankle, blood-serum in the pleural cavity, perforating ulcer of the stomach, tuberculosis of the peritoneum.

It may be proper to state here that Dr. Augustus Caillé, of New York, presented a minority report, being on the committee with Drs. Griffith, Jennings, and Morse. Dr. Caillé believes infantile scurvy to be a chronic ptomaine poisoning due to the absorption of toxines. It follows the prolonged use of improper foods, and abnormal intestinal fermentation is a predisposing factor. Sterilizing, Pastemrizing, or cooking of milk-food is not per se responsible for the scurvy condition. A change of food and the administration of fruit-juice and treatment of any underlying cause is the rational therapeutic procedure in scurvy. Here Dr. Caillé gives a definite cause, which differs from others, among them Dr. David Bovaird, of New York City, who has given us a good article on this disease in the Philadelphia Medical Jommal for August 20, I898, and from which I have now and then quoted in this article. Dr. Bovaird concludes as follows: "Sterilized milk evidently does cause infantile scurvy." He says the evidence presented in his article is not conclusive, but it renders it highly probalble that persistent sterilization of the food by boiling may produce scurvy. It must even be admitted that 
scurvy may be developed in nurslings. The admission of this proposition carries with it a frank confession of inability to accept as adequate any theory of the cansation of scurvy thus far advanced. Practically the only theory that has of late commanded any general support is that which attributed the production of scurvy to the absence of some vital principle from the food, the life of the food being destroyed by some process of preparation. If, now, we admit the possibility of infantile scurvy developing in nurslings, we must abandon even this hazy attempt at the elucidation of the problem, and frankly confess that a satisfactory explanation of the etiology of infantile scurvy is still to be sought.

Personally I think something may be gained in getting at the etiology of this disease through thorough and systematic examinations of the urine. Dr. Churchill, of Chicago, among others, has given us some information useful as to the renal secretion of children in general, and this may serve as a comparison in clinical studies in such diseases as we are discussing. According to Churchill's observations, infants pass highly concentrated urine, small in amount, with a high percentage of urea and, of course, high specific gravity. The amount of urea per kilogram of weight might be an important point. It grew less towards the seventh year, when the average was only 0.296 . At three years the average was from 0.468 to 0.655 . Different diets may give different results, and surely will, and may lead ns to detect the trouble through the amount of nitrogenous and other waste of the system, and thus check it before serious harm comes to the individual.

Treatment.-If the child is weak and debilitated see that it has proper support by stimulants and by the administration of the salts of potash. The best 1 know of and which has served me best is the bitartrate of potash, cream of tartar. Give this diluted with a large amonnt of water, both to get the potash and the water, which is of great importance. Whatever the child has been feeding on, change that diet. Stop proprietary and prepared amylaceous foods. Give raw 
cow's milk, keenly watching its source. If this should not agree, Pasteurize it only, do not sterilize it; give beef-juice from fresh beef and no other, that is to say, no prepared beefjuices, as they may be as bad as proprietary amylaceous foods. Orange-juice from fresh oranges is best because it takes up) the basic salts during digestion and thus serves its good purpose of supplying potash and such salts. Fresh, ripe, soft peaches are a food par excelluce for these little sufferers.

I had a little patient which was brought to me in very hot weather, supposed to be a sufferer from cholera infantum. Much to the horror of his friends, I ordered him all the soft, ripe peaches he could eat. He took six and eight every twenty-four hours, and the improvement that child made was a revelation. If you cannot get oranges or peaches, get apples, pears, strawberries, plums, and any fruits in market. There are always some kinds. Always choose the softest and juiciest.

Just here remember one thing, the possibility of developing such a trouble as infantile scurvy in your typhoid fever and other tedious cases from a prolonged use of sterilized milk and such food-stuffs. I say keep it in mind, if your patient from some hidden cause ceases to advance properly towards convalescence. Remember, above all things, all the food ordered must have the element of freshness. Canned peaches will not do; canned beef-juice will not do. In canning we sterilize first, we destroy all bacteria, and all the elements of freshness are taken from the food, thence such food is scurvy breeding. So it is with the preserved fruit-juices: they are not fresh, hence are neither food nor medicine for infantile scurvy. Keep these principles in mind, and you will soon cure all of your patients. Heed them not, and you will probably lose both your patients and your professional reputation.

In "Pædiatrics" Dr. Cotton suggests the following as the essentials of a good baby-food: ( 1) Does this food contain all the constituents in abont the same proportions as they are found in mother's milk? (2) Can this food be administered in a form suitable to the physiological requirements of the in- 
fant's digestion? (3) Can it be given in quantities adapted to the capacity of the infant's stomach? (4) Does it possess the antiscorbutic property, or has that been clestroyed by cooking? (5) Is the food wholly or partly of animal origin? (6) Is it free from pathogenic micro-organisms?

Concrming Milk.-Experience teaches me the great importance of physicians knowing much about milk, that great staple article of diet for all, and especially for the very young and for the very old. A physician should be able to advise honsekeepers and nurses on all points concerning its composition already spoken of, of the different grades, of the roguery of dealers as practised, of the tests to detect such deceit, of the proper methods of keeping and marketing the article; in fact, all about it. The details I am about to give will be found best set forth in "Farmers' Bulletin," No. 42, United States Department of Agriculture, by R. A. Pearson, B.S., Assistant Chief, Dairy Division, Bureau of Animal Industry. Ten years ago the value of the milch cows in the United States was three hundred and serenty millions of dollars. This shows the importance of the industry. There is a cow in this country to every four of its inhabitants, but much of the product goes abroad as cheese and butter and condensed milk. Americans do not appreciate the product of the cow as much as they do in most parts of Europe where they use more milk per capita than we do here. One reason doubtless is, we use more meat here. The average consumption of milk in the United States is one half-pint per day to each inhabitant. Milk to the ordinary observer appears to be a perfect solution, and is bought and sold by liquid measure. Under the microscope it is seen to consist of a clear, transparent fluid containing many minute globules of various sizes. The fluid part, called the milk serum, consists of water and all of the other constituents except fat, and all of these constituents except the fat are in solution. The globules are little bodies of pure fat in the serum and not dissolved. They are semisolicls and form with the serum an emulsion, and therefore milk as we see it is a true emulsion. The solid constituents of 
the serum are sugar and casein mostly. Albumin and mineral matter are present in small quantity, and there is also a little fibrin. There is more sugar in milk than any other solid, and this when separated is the well-known sugar of milk. It is not so sweet as cane-sugar. When milk sours it is the sugar that undergoes the greatest change. The casein and albumin of milk are its nitrogenous constituents, and are comparable to the white of egg. Acid or rennet causes casein to coagulate, forming curd, and as such this forms onefourth of cheese. The mineral matter is the ash when burned, and consists chiefly of phosphates and chlorides of soda, potash, and lime. Milk may be compared to a thin syrup with many fatty and light particles floating in it. Milk is sticky, and this retards the too rapid rise of the cream or fat. The fat globules are very, very small. A single drop contains many millions, - the number is too large to be appreciated. The globules average one-ten-thousandth of an inch in diameter. The Jersey and Guernsey cows have the largest fat globules, and thus their cream rises more readily and their skim-milk is poor. The larger the globule, the sooner and easier it rises. These are very important facts for physicians to know. One hundred pounds of good milk contain 87 pounds of water, 4 pounds of fat, 5 pounds of milk-sugar, $3 \cdot 3$ pounds of casein and albumin, and .7 pound of salts. The solids vary in milk from Io to $\mathrm{I} \&$ parts in Ioo. Here is the important part which distinguishes good from poor milk.
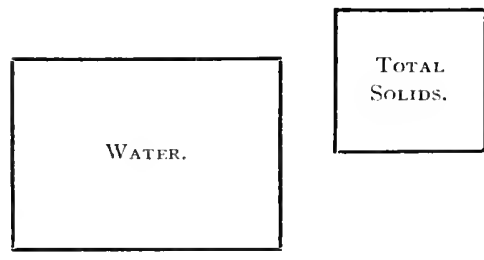

Showing relative parts of milk.

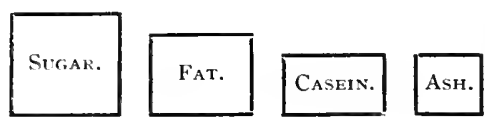

Most of the States have a standard for milk. The laws usually require from three to three and one-half per cent. of fat and from nine to nine and one-half per cent. of "solids not fat." When we speak of "solids not fat," the trade 
knows this to mean all solids not fat. The average law then requires at least twelve to thirteen pounds of solids to every one hundred pounds of milk. It is wrong to think fat the only good in milk. Skim-milk has great value; the casein and albumin of skim-milk are very cheap forms of nitrogenous food. There is one thing true, though, - the more fat in milk, the more "solids not fat" there are. Jersey and Guernsey cows produce the best milk for cream, but not for use as milk. Durham and Ayrshire cows are better cows for milk for use as milk. The Holstein cors give the largest quantity of milk: some of them give good milk, whilst the mills of others is blue and poor. The feed of the cow influences some, but the breed more. The feed influences quantity more than quality.

Remember that the colostrum, the first milk given by a cow after calving, contains much albuminoids and is laxative, and is not fit for human food. Nature designs it for the calf alone. The albumin and casein in colostrum may form fifteen per cent. of the milk. The sugar percentage is low, the fat normal. In a week after calving the cow produces natural milk. The dairyman in his greed does not usually wait this long, but he should be made by law to wait at least seren days.

The percentage of fat in milk varies from day to day in the same cow, and any variation in her food does not account for it. and this and other such causes make it appear better to use for children's food the milk from a healthy herd rather than from one healthy cow. The longer a cow milks from her calving, the more solids there are in her milk, and the less easily the cream rises. A cow can be milked ten months in each year, and should go dry two months.

The term " extend the milk" is used in the trade to denote adulterating the milk by different methods. Milk is a cheap article of food at a fair price, and cheap milk cannot, as a rule, be good milk. When the dealer has delivered you good milk, remember it is easily contaminated after you have received it. If clust settles on it, or flies or other insects have access to it, or if placed in a badly ventilated cellar, or in a refriger- 
FORTY YEARS IN THE MEDICAL PROFESSION

ator with other foods, or in a place too warm, it goes to the bad in a few hours. To have milk in proper condition for food it should be kept in an apartment absolutely to itself, and at a temperature of as near $50^{\circ} \mathrm{F}$. as possible. Remember well this injunction: there is only one class of vessels fit to keep milk in, and these are glass or porcelain vessels. Use no tin, no iron, no patent wares, no earthenware: use only glass or porcelain. I wonder the trade does not supply glass or porcelain milk-pans and such like useful articles.

In cities, if you have trouble with the milk furnished your patients, investigate the milk-man and the servants, and see if any possible connivance may be going on between them or between rival dealers. Thunder-storms, impurities, warm temperature, and other conditions may change milk, but these are indirect causes only; bacteria are the great causes. There are various bacteria in milk, and various fermentations which go on in it. Milk becomes blue, bitter, slimy, ropy, according to the species of bacteria, etc., present. Any mills with sediment is suspicious. Where you have dirt you have microorganisms. Those who attend to cows and milk in all of its phases should be clean, morally and physically, and healthy. It is of equal importance that the cows should be healthy. Discard all milk of an unnatural appearance or odor. Bacterial action may cause odors, as well as garlic and such pungent vegetables. Watch for the adulteration of milk. Water may be used, part of the cream may be extracted, or it may be blended, good with bad, and very bad. Impure water used in adulteration may bring pathogenic germs to the milk; do not forget this. Even rinsing the cans in impure water may distribute pathogenic germs on the milk route. All milk-cans and bottles should be absolutely sterilized before each time of use. Prohibit as physicians the use of artificial preservatives in milk. Salicylic acid, boric acid, borax, and formaldehyde are used. They all slow digestion even in small doses, and formaldehyde interferes with the digestion of albuminoids. All of these remedies should be used as remedies under care of physicians, not in trade by ignorant venders of food-stuffs. 


\section{FORTY YEARS IN THE MEDICAL PROFESSION}

Do not have milk delivered early in hot weather and left exposed to the stm, as is often done. It should! be cold when delivered, and at a temperature of $50^{\circ} \mathrm{F}$. will keep sweet and pure for thirty-six to forty hours. Let every household keep a floating dairy thermometer, and see that the milk is kept at about $5 \mathrm{O}^{\circ}$, and it will give no trouble by souring and spoiling prematurely. To raise cream on milk, put it in a cold place as soon as received. When you need cream, raise the temperature of the milk to $\mathrm{IOO}^{\circ}$, and then lower it quickly by placing the dish in cold water. To do this the milk must be in good condition, or it will sour before the cream rises. The cream rises quicker in jars than in pans.

As to the use of glass milk-jars for delivering milk. There is much to be said on both sides here. It would be an ideal method if we could depend on the average milk-dealer to absolutely sterilize each jar each time before delivering milk in it. This you cannot do. The jar may have been in the room of a typhoid fever patient, or even of a small-pox patient, and you may be the next customer to get your milk in it loaded with these unwelcome pathogenic germs. I confess I rather oppose these milk-bottles for general use, but there are milksupply people whom I would trust to distribute milk in them, and these are the people I would patronize, and be willing to pay them an extra price for their product. This is the only way I know of to get pure milk, or milk any way near pure. Each bottle should be sealed, not hermetically, when received. and no bottle with a broken seal should be accepted.

Detecting Impure Milk.-Here is a matter of the greatest importance to physicians, and how many know about it as they should know? Pure milk is the product of healthy, wellfed cows, properly handled and cared for by individuals morally and physically clean and healthy. Good milk should have a slightly yellowish-white color, a slight odor, if any, and should have a distinctly pure taste, as Pearson says. When it has stood quietly for several hours, cream should rise naturally, and if the separation is thorough the cream should be from one-fifth to one-eighth of the bulk. No sediment should 
appear at the bottom. When poured from a tumbler it should cling to the glass some, and not run off clear like water. Skim-milk is thin and bluish in color. The yellow shade of milk is due to the fat, but color is not a safe test, as some cows give rich milk of a lighter color than milk from cows which give poor milk; and milk may be artificially colored.

To test Milk.-First get a fair sample. To do this it will not be fair to take all from the top or bottom of the can: mix it thoroughly by pouring from one vessel to another several times. No lumps must appear on the surface. If small lumps of butter are floating on top a fair sample cannot be taken. Of course, if you want a thorough test, employ a chemist and have a complete analysis. There are ordinary tests, sufficient for the practical purposes of physicians.

The Creamometer Test.-Creamometers, as well as lactometers and all ordinary testing apparatus, may be purchased at any well-conducted dairy-supply house. The creamometer is a long, graduated glass tube with the zero mark near the top. It gives a fair test, but not always exact, as age of milk and method of handling it may make some difference. Fill the tube to the zero mark with milk and allow it to stand in a cool place for twenty-four hours. Warm the milk to $\mathrm{IOO}^{\circ} \mathrm{F}$. and set the tube in cold water to bury the cream, or fill the tube with half milk and half warm water, which raises the temperature and reduces the viscosity: now only half as much crean will appear as you are to give the milk credit for, on account of the water used, so double the per cent. shown and you get the true per cent. If the milk does not vary from day to day in the amount of cream, it shows you are getting milk of regular quality. In this test you also have good opportunity to look for sediment. Always use the tube quietly.

The Lactometcr.-Milk is heavier than water. Its specific gravity varies from 1029 to 1033 , and a departure from this standard, as to skimming or watering, can be measured by this instrument, which every physician should own and every household should have at hand. The Quevenne lactometer is nne of the best, and has a thermometer combined. It can be 
purchased at any good dairy-supply house. with full directions for use. These instruments can only show specific grality. If cream has been removed which is lighter than whole milk, the specific gravity is increased, and if water has been added, the specific gravity is of course lower. Now, if we get a high specific gravity, we suspect skimming, and if a low specific gravity watering.

There is also another test, which combines mathematical formule in its carrying out, - the Babcock fat test. This is a reliable test for the fat of milk, and is much used by creameries and other houses nsing milk and crean commercially. The milk is centrifuged, if I may be allowed to coin the word. Only about a tablespoonful is required, and fifteen minutes suffices for the test. The instrument can be purchased of dealers for a few dollars, with full directions, and is simple and easy in its operation.

The Acid Test.-Professor Farrington's acid test is simple. and should be recommended by physicians to those engaged in the care of children. Acid commences to form in milk soon after it comes from the cow. This test will show if it is too near the souring-point for use for delicate stomachs. Tablets containing a definite amount of alkali, caustic, potash, or soda, say, are dissolved in water and added to a definite amount of milk. The tablets contain a little phenolphthalein, which is colorless in acid solution and pink in alkaline solution. A solution of these tablets is slowly added to the milk, and the mixture is stirred until it becomes pink. It is known now that enough alkali has been added to neutralize the acid in the measured amount of milk, and the amount of solution required indicates the acidity of the milk. Fresh milk has little acid, and turns pink on addition of a small amount of alkali, while milk nearly sour requires more alkali to turn it pink. These Farrington tablets can be found in the shops, with full directions for use, and every house should have them on liand. They are made of definite strength. Should a solution of two tablets turn one ounce of milk pink. that milk sluould keep from twenty-four to thirty-six hours with proper care. If 
the milk remain white after the addition, it will soon turn sour.

Test for Colostrum.-If milk coagulates on boiling, it shows the probable presence of colostrum, because colostrum is highly albuminous, and here it is the albumin which has coagulated. The cow furnishing this milk has been milked too soon after calving. The calf, not the baby, should get this milk. It will probably give the baby diarrhœea, among other troubles. We have no reliable test for micro-organisms but the microscope, and this should be brought to bear when necessity points in that direction. Percentage milk I have spoken of before whilst speaking of diet in general, and I trust its use may grow rapidly, for it is capable of being put to great therapeutic advantage under many and various conditions.

I append Pearson's rules, to follow in choosing your milkman and milk-supply. He should show a quarterly certificate from a veterinarian of good standing, - a licensed veterinarian, by all means, - stating that after a careful examination of his cows-if he is a producer as well as a vender; if only a vender, then from the herds supplying him with milk-they were all found to be healthy; that if there were any doubtful cows, they had been removed; that the quality of the feed and water, the sanitary conditions of the stables and surroundings, and the health of the employees were approved. If you believe your milk-man is honest, let him know it. If not honest, get another at once.

Pearson recommends consumers to visit the dairy farms and general sources of supply of their milk, as apt to do good. On a well-conducted dairy farm he would expect the visitor to see a roomy, clean, dry, light, and well-ventilated stable or cow-house. To produce good milk, cows must be comfortable, and these conditions not only add to their comfort, but are absolutely necessary to keep them in the best health. Let me add here, do not make them too comfortable; do not change their natural enviromment too radically. Give cows palatial stables, Axminster carpets, and modern heating ap- 
pliances, and you will develop tuberculosis in eighty per cent. of them in a twelvemonth. The cows must be healthy, well fed, and contented. An abundance of pure water twice a day I would add here after each milking, when the system has been drained. Feed should be of good quality. The grain and coarse fodder should be free from dirt, decay, or musty condition. I spirit of kindness towards the stock and gentheness of the animals themselves is necessary, as well as provision for washing and sterilizing all utensils which come in contact with milk.

Provision for straining, aërating, and cooling the milk in a clean atmosphere, free from stable and other odors, is absolutely essential. This treatment should take place immediately after the milk is drawn from each cow. Facilities for storing the milk and keeping it cold must be at hand. Especially great cleanliness in regard to everything connected with the dairy should be observed. The atmosphere of the stable should be pure and free from dust when milling is being done. Employees should carefully wipe the udders and wash their hands before milking, and should be in clean clothes. Whitewash is a good disinfectant, and should be seen in many more stables; and land plaster (sulphate of lime) should be sprinkled about to absorb moisture and odors. The cow should stand on clean litter only. If the milk is handled through a store, the building should be kept scrupulously clean, with no dust or dirt in the milk-room. There should be provision for keeping the milk cold when stored, and apparatus for sterilizing utensils after washing.

Pearson suggests, as improvements in the business, that graded milk be sold, graded as to its fat test particularly. Let the people learn there is as much difference in milk as there is between the better and coarser cuts of beef. This is all right. Let us think of milk not as milk in the abstract, but as to its composition, and that when we buy it we pay for what we get, knowing what we get, knowing there are ligh-priced and low-priced milks. Such methorls are followed in France and Germany. Doctors should know all about such things, not 
only as to milk, but all about marketing in general as to the cuts of beef, mutton, and veal, how to judge poultry and game and fish and vegetables and fruits; in fact, all domestic supplies; and he should know how to prepare them for cooking and how to cook them, too. The milk-supply should be rigidly inspected in all communities, and derelictions should be punished by radical laws enforced without fear or favor. Such laws are necessary to the well-being of society, and are not by any means sumptuary, and do not interfere, when properly looked at, with the liberty of the individual. Even if they do, the liberty of the individual should not stand in the way of anything which brings death and destruction to communities.

Pearson suggests that milk-carts carry graded milk, putting different grades in different cans, plainly marked with their grade, and with separate taps on the outside of the cart leading to each can. Purchasers would then see what they were buying, and know exactly what they were paying for it. He suggests the following grades. The grades of milk should be numbered with the whole numbers nearest to the percentage of fat contents. Thus a separator skim-milk with but a trace of fat would be o; skim-milk, with from one-half to one and one-half per cent. fat, would be $\mathrm{I}$; and so on. Whole milk would be of three grades, 3,4 , and 5, and extra rich and fortified milk, to which cream has been added, would be 9 or Io. Cream would run from i 3 to 5 o. No more grades of milk or cream need be carried than is the custom now, but each should be marked with its appropriate number. While the idea of the percentage of fat thus indicated might not be clear to all, it would soon be understood that the higher numbers meant the richer milk. If this practice were observed, it would be difficult for drivers to tell their customers one thing and the milk inspector another abont the quality of the contents of the same can. The signs should be so attached to the wagon-side or can that they could not easily be changed. If bottles are used, the number representing the quality should be attached to each one. 


\section{CHAPTER X.}

Origin of Alcohol, Whiskey, Brandy, Port Wine, Sherry, Champagne, Burgundy, Claret, Rhine Wine, Porter, Ale, Beer-Per Cent. of Alcohol in Each-Effect of Alcohol on the System-Effect of Alcohol on Bodily Temperature-Alcohol as Food-System consumes more in Disease than in Health-Strength of Wines-Colors of Wines-National Drinks-Methods of artificially aging Whiskey, etc.-Rum, Gin, Cordials, Malt Liquors-Method of making, etc-Malt ExtractsWines-Grapes, Varieties of, etc.-The Wine-Taster-Peculiarities of Wines-Sherry, Madeira, Port-Ward McAllister-Burgundy, Sauternes, Hock, Johannisberg-Champagne "a Drink for the Gods," as well as an Invention of the Devil-Vin Brut, Vin Sec, Vin Très Sec, Sparkling Moselle-German and Italian Wines-American WinesCalifornia Wines-Care in prescribing Alcoholics-Value of Fruit and Nuts as Articles of Diet - Value of Fruit as Food from an Economic Stand-Point - The Lesion in Rheumatism-Is Fruit Healthy Diet?-The Divisions of Fruits - Special Fruit Cures - The Ripening of Fruit - The Most Digestible Fruits -Fruit Syrups and Fruit Juices-Canned or Tinned Fruits and Vegetables-Fruits in Colonial Times-Fruit in Florida, California, and Australia-Medicinal Properties of Fruits and Nuts-Why Leaves change Color-The Apple-Varieties of Apples-Varieties of Peaches - Varieties of Pears-Grapes-Apricots-The Plum-East India Fruits -The Mangosteen-The Duriat, Pine-Apple, Banana, Plantain, Orange, Shaddock, Olives, Lemons, Mulberry, Melons-Partridge-Berry and Salicylic Acid-The Haw-Berry-Gooseberries, Currants, Cranberries. Cherries, the Quince, Blackberries, Raspberries, StrawberriesDecay of Fruit-Mushroons, Morels, and Truffles-Nuts-Chestnuts, Peanuts, Almonds, Filberts, Pecans, Shellbark or Shagbark, Brazil Nuts, Chilean Nuts, Betel Nut, Pistachio Nut, Kola Nut, Guarana, Butternut, Walnuts-Eucalyptus Globulus.

IT is not to my purpose here to speak particularly of alcohol. Absolute alcohol is used only for chemical purposes. as a rule. The Pharmacopœia recognizes alcohol containing ninety-four per cent. by rolume of absolute alcohol, and having the specific gravity of 0.820 . Deodorized alcohol contains 95. I per cent. alcoliol by volume, with a specific gravity of 0.8 r6. Dilute alcohol, U.S.P., contains 48.6 per cent. by rohme of absolute alcohol, with a specific gravity of 0.936 . Alcohol 


\section{FORTY YEARS IN THE MEDICAL PROFESSION}

comes from sugar by fermentation, as is well known, or from the destructive distillation of organic bodies. Chemically it is an ethyl hydrate, $\mathrm{C}_{2} \mathrm{H}_{5} \mathrm{O} . \mathrm{H}$.

Whiskey is distilled from fermented grains, and brandy is distilled from fermented grape-juices, and each undiluted should hold from forty-eight to fifty-six per cent. of absolute alcohol. As sold in the markets, whiskey and brandy carry from thirty-five to forty-five per cent. of alcohol. Port wine carries from eighteen to twenty per cent. alcohol; Madeira, about the same; sherry, about sixteen per cent.; champagne, ten to eleven per cent.; Burgundy, ten per cent.; claret, six to eight per cent.; Rhine wines the same; porter, five to six per cent., and beers and ales, from three to six per cent.

According to IVood, alcohol increases the frequency of the pulse and increases blood-pressure. It is a cardiac stimulant. and in overdoses is a heart depressant. There is one thing well to remember: there is an apparent contradiction in the effect of alcohol on bodily temperature. When a man takes just sufficient to slightly increase his heart action, there is a very slight rise in temperature. After a full dose there is a slight fall of temperature, and when a man is fully intoxicated, his temperature may fall as much as $3^{\circ} \mathrm{F}$. The explanation here is simple: the full dose drives the blood to the surface where it is cooled, and the temperature of the whole body falls. It then follows, actually, that a man may take a drink to warm him up, and may take a drink to cool him off, and science supports him in both.

A drink of spirits makes the breathing freer and fuller. An overdose weakens respiration, and this is often seen in the case of drunken men, exclaiming they cannot breathe properly. There is here a tendency to centric respiratory paralysis from alcohol poisoning. I have always been taught to believe from my own experience that alcohol was not directly a food, but that a man conld live longer with it than without it, because he did not die so rapidly; that is to say, with a certain amount of alcohol daily, (lestructive change of his tissues did not go on so rapidly as when that certain amount of alcohol 
Was withheld; but the recent experiments in detail by Professor Atwater and others appear to give to alcohol direct food value, but this is not yet fully settled.

Horatio Wood sums up as follows: For a person in health, alcohol must be considered as one of the most wasteful, uncertain, and often deleterious of known substances which are considered foods. In disease, however, where its stimulating and narcotic purposes favor its usefulness, its capability of heing rapidly burnt up without undergoing any primary assimilation, and of thus yielding force to an exhausted system, may well make it an invaluable assistant to the physician. The human system will burn up much more alcohol in disease than when in health. What I will have to say of alcohol will be altogether as to its therapentic use in the various forms of spirits, wines, and malt liquors. These in moderate amounts improve digestion, whilst in large amounts they retard or stop it altogether for the time being.

Being articles of the materia medica, there is no reason why physicians should not know as much of wines and liquors as they do of the other matters therein contained, but such is apparently not the case. The practitioner should at least know that brandy should be not less than six years old before it is fit for medicinal use, and whiskey should be five years old. He should know that port, sherry, Madeira, and champagne are the stronger wines, and that the Burgundies, clarets, and hocks are the weaker. He should know that the important ingredients of wine are the alcohol, the sugar, the flavor and aroma, and the relative quantity of these in each kind. He should know the relative colors at least: that port las usually a color of its own, the port-wine color, approaching purple, although there are some white ports; that sherries vary in color from very pale to dark red, and so do the Madeiras; that clarets and red Burgundies vary in red or claret colors, and that Burgundies are many of them white, but true clarets never: that the hock wines are usually strawcolor or white: that clampagnes vary from almost white to pink, the color being, as a rule. at the fancy of the maker; 
and that whiskeys, brandies, ales, and beers vary as to the demands of trade for this or that color, whiskey and brandy being colorless when first distilled, but are colored by the addition of caramel or burnt sugar. Gin, as a rule, is white, and the Irish and Scotch whiskeys are either colorless or of light or dark straw-color. The cordials are usually colored to suit the fancy of the manufacturers. Whiskeys, brandies, cordials, and all artificially colored liquors should be left as nature intended them,--entirely free from artificial coloring or artificial flavoring. Such will never be; coloring for the eye, flavoring for the palate, and blending for both will always be carried on so long as "water shall run and grass shall grow." It is said that the Esquimo has no alcoholic drink, for the climate is too cold for fermentation, and he cannot make it there; but I have no doubt that his more southern brothers have long ere this supplied him, even though alcohol may lessen his powers to resist cold.

Going south, we find all nations have their favorite tipple, and far sonth we find only those drinks which are fermented in a hurry and drunk in a hurry, for they will not keep over thirty-six hours, as the Mexican pulque. Brandy is, we all know, distilled from wines, while wines are fermented grapejuice. Brandy in the market is of various colors, owing to the amount of coloring-matter put in it,- - some very dark, the pure being colorless. The best brandy I ever tasted was made in California and sent to me from the vaults of General $\mathrm{H}$. M. Naglee. It was selected stock from the time the grapes blossomed until it was barrelled in the vaults. It had no color whatever, no artificial flavoring, but had the rich aroma of the grape, and no headache in it. This is the kind of spirits we should dispense for our sick, but we cannot always get it. To make brandy we must add color and the true brandy flavor, in addition to the natural ethers, sold in any quantity, to give it the bon gout.

Whiskey.-Probably whiskey is the safest of the spirits to use in the United States for the sick, as it at least ought to be the purest, and it should be the cheapest. Age regulates its 
price, and the fusel-oils in it decrease by age, so old whiskey is the best and safest, provided it has been kept in wood. There are artificial ways of aging whiskey, as rumning it down a woollen string from the ligher stories of a building to the lower stories, each rumning down evaporating it and losing its fusel-oils, equivalent to one year passed in the barrel. This is roguery and not true aging. The price of whiskey, as a rule, is too high to the retail purchaser, but the trade controls it and the good people must bear it. Rye whiskey is probably the best in this country, although whiskey is made from wheat, barley, corn, and other grains. The flavor comes from the process of kiln-drying of the grain or grains of which it is made. The Scotch and Irish whiskeys get their flavor from the peat used in drying the grains. The mashes used in making whiskeys are the sweet and the sour, and corn and rye are often mixed in given parts with malt. This makes sour mash if scalded with the refuse liquor used before, this containing the ferment to start the alcoholic fermentation. Sweet mash is made by adding water only and yeast to start the fermentation.

Rum comes to us from Jamaica, Santa Cruz, and New England chiefly. Molasses is fermented, and then from this the rum is distilled. Santa Cruz, with the lime fruit, makes the best punch, but it does not compare with a punch made from the pure California brandy. Let me digress here. We often hear the doctor say he is giving the patient milk punch when he is giving him whiskey and milk. There is no such thing as milk punch made from whiskey and milk. Milk punch is made from brandy and milk. Milk toddy is made from whiskey and milk.

Gin is usually colorless and has some diuretic properties, owing to the juniper and other aromatics in it, which also give it its peculiar flavor. Gin is distilled from almost any fermented grain, but the grains are not previously kiln-dried. Then, to get a nentral spirit, there is a second distillation, and to this the flavoring of the aromatics is added. Gin is a strong liquor. The English call it Hollands, and Old Tom 


\section{FORTY YEARS IN THE MEDICAL PROFESSION}

gin, a favorite brand, is sweeter than ordinary gin. Individually, I do not cotton to gin, and I do not advise any one else to cotton to it. I never indulged in it but on three occasions, as I remember,-once at college, when it made me quite ill; the next time when I took a cocktail with the captain of a clipper-ship just starting on a long voyage, and we were shipwrecked within a week: and the last time with a friend, on the birth of his long-wished-for son, and on my next visit the son was dead. These last two cocktails were taken before breakfast, that heathenish time to consume spirits, although it has been the custom of my lifelong environment. Thanks, I don't take gin, even though Lord Byron gave it renown in poetry as the poor man's substitute for riches; nor do I drink before breakfast, nor before noon, and never did but twice in my life.

There are other spirits, but not in general use, and it is not worth while to take space to enumerate them. Cordials are not often of use to the sick, but if needed. the best are chartreuse, hot and peppery, and probably the best. Maraschino is toothsome, but too sweet. Curaçoa is of orange-peel flavor and quite useful for flavoring unpleasant medicines, but there should be no use for it now, for we should no more give unpleasant potions; there is no necessity for it. There are some West India cordials, as parfait l'amour and others, but they have no place in medicine. As to cordials, they are merely sweetened and artificially flavored spirits.

Bcor.--The English, as a rule, speak of all malt liquors as beer. All malt liquors are fattening, and there are few better mild tonics than lager beer, and given in connection with organic iron and manganese, you have a combined tonic par excellence. The same remarks may apply to all malt liquors and malt preparations. Lager beer is made from infused malt, which is barley dampened and allowed to germinate and then kiln-dried, and the whole flavored with hops. The temperature to which the malt is brought in the kiln determines the color of the product. If the temperature runs below $\mathrm{I}_{4} \mathrm{O}^{\circ} \mathrm{F}$., you get pale beer; increasing the temperature gives 
FORTY YEARS IN THE MEDIC.LL PROFESSION

you dark beer, or ale, up to porter, which is almost black. Of course, by the malting process the starch of the grain is converted into dextrin, and so on up to sugar. The brewer, to make beer, first infuses the malt, then boils it with hops, which give flavor and bitterness and keeping quality, and lastly cools it rapidly and adds yeast to start fermentation. In three or four days the fermentation is completed, the alcohol of the beer is dereloped (if lager beer, about three per cent.), and carbonic acid is given off. The product is then allowed to clarify of its own accord, or beech-wood or isinglass is used, which carry down by physical laws all the particles which render the fluid turbid. Lager beer should be stored in dark. cool vaults for from four to eight months, or even longer, to give it the best form. As now produced, it is said to be put on the market at a much earlier stage of its life, both to the detriment of the beer and of the consumer. Ale is made from light-colored malt usually, more hops are used to give it a more bitter taste, and all of the sugar goes to alcohol, giving it an average of six per cent. alcohol. Porter is strong, dark ale really, the malt used being dried at a greater heat. Brown stont is stronger still, both porter and brown stout containing more of the carbohydrates extracted from the grains from which they are made than either ale or beer. In alcohol they are about equal to ale. Malt liquors fresh from the wood are better and more healthy than the same products bottled, because in bottling malt liquors, especially for exportation from the countries in which they are made, antiferments, in the shape of salicylic or boric acid and such, are apt to have been added, all of which slow digestion. For the same reason many of them are reinforced, and thus contain more than their normal proportion of alcohol. So it will be seen that it is usually better, provided the Boniface keeps his pumps and environment clean, to "rush the growler" when we want pure beer, than to purchase it bottled.

Now, as to the malt extracts, so called, of which the shops are full, and many of which are not even good porter. To make true malt extract. you rapidly eraporate an infusion of 
malt to the consistency of thick honey at a temperature not above $130^{\circ} \mathrm{F}$. It should contain all of the diastase in the malt. It should be sweet in taste and of acid reaction, and should mix easily with water. Some of these malts are really only glucose, and some, as stated above, not more than beers. To be right it should not contain the least alcohol. If it does, the fermentation has gone too far. If it contains glucose or alcohol, it is a food. It is of no good unless it contains only diastase, as far as aiding digestion is concerned; that is to say, its claimed merits depend on diastase and not on glucose, alcohol, and such. Acids of the stomach destroy the diastase, and therefore it must be taken before meals, before the stimulus of the food draws out the gastric juices. Of whatever use it is, it is to aid in digestion of starches, and it can only do this when it meets with alkaline or neutral surroundings, and this is not often, for starchy indigestion always brings its acidity. As a rule, then, the malt extracts of the shops are trash, and worse than trash. Have your patients spend their money for good beer, ale, or porter, and get some return for it.

Wincs.-The grape is renowned in song and story; in history, both sacred and profane, it holds a leading part, and Bacchus, its mythological god, is the father of all the ills it has brought to the world and the hero of all who worship at his shrine. What a power for good and what a weapon for evil environ its luscious juices! Botanically, it is of the genus vitis, the type of the order vitacere. In the wild state the flowers of some specimens are imperfect but very fragrant, but in cultivated specimens they are always perfect and have the delightful odor of the mignonette.

The horticulturist now divides grapes into the European and American varieties. The European varieties will not grow in open air in America east of the Rocky Mountains, and they have been so long cultivated in Europe for flavor and size, that the vine has become delicate and the prey of insects and fungi, and to rehabilitate it. it has become necessary to grow the European varieties on true American stocks 


\section{FORTY YEARS IN THE MEDICAL PROFESSION}

to restore them to vigor. This same fact is often shown in nature, not only in fruits and regetables and such, but in animals as well. In American grapes the seeds are held together by the pulp. which slips from the skin easily. In foreign grapes the seeds are easily extracted and the skin adheres to the pulp, and all are eaten together. The grape is subject to many enemies, both in this country and in Europe, of which I know practically something, for I have a vineyard of $m y$ own which has often demonstrated to me the truth of the saying. "There is many a slip between the cup and the lip." The phylloxera-Phyllowera i'astatrix-is the great European enemy, and also in California, whilst in the East the rots fungi and anthracnose are the serious troubles. Lou cannot raise grapes now without spraying with copper solutions and arsenites, and what effect these sprayings are going to have on the yeast fungus which nature develops on the stems of grapes to set up the wine fermentations is for the future to decide. If we are to get these ferments from yeast, the flavor of the product must suffer.

Wine is the fermented juice of the grape. The finer wines are probably still made in Europe, where the experience of ages gives them every advantage, but America is now producing the ordinary wines of good flavor and purity, and these are far better, and within the reach of all pecuniarily, than the cloubtful and expensive foreign wines, unless you can get these out of the line of general trade, from special sources, and at enormous prices, as, for instance, champagne of a certain year and certain vintage at one hundred dollars per dozen. which is frequently paid by those having the taste and the means with which to gratify it.

Forty years ago I drank clarets and the other lighter wines in California. Invariably they had an earthy taste, as thongh filtered through earth. They hat not the least idea then what particular soil and what particular location gave certain flavors to the grape and thence to the wine, a fact which they are rapidly learning now. To illustrate this point. I once visited the celebrated Schloss Johannisberger, less than fifty 
acres in extent, on the Rhine, where that fragrant, aromatic, and much-sought-after wine is made from the grapes grown on the hill, and is equalled by no other wine of its kind except, perhaps, a fine old Tokay. The gentleman with me, an attaclie of the place, showed me much as to the intricacies of getting true Johannisberg. They knew the soil, every foot of it. He showed a place on the hill-side, say thirty feet square. In this square were arranged a number of small plots, and every one of these small plots produced a grape which gave a wine of a different flavor. The best gave a wine worth its weight in gold,- - the genuine Schloss Johannisberger,and only a Metternich. or the friends of the house of Metternich, ever tasted it, and so on down, until the poorest qualities went to the general trade: but. he added, "No one ever gets a bottle even of the poorest Johannisberger from the general trade. If he thinks he does, he has been defrauded."

The United States Pharmacopœia now divides all wines into two classes, the white and the red, and leaves off special names, by reason of our native wines coming more into prominence. The light wines are those which contain the smaller per cent. of alcohol, as clarets and hocks, and do not keep after they have been exposed to the air. These have about eight per cent. of alcohol. The heavy, or fortified, or reinforced, or brandied wines are another division, and keep indefinitely when exposed to the air. Sherry and Madeira are examples of these, and they contain from seventeen to eighteen per cent. of alcohol. We have sweet wines and dry wines. A sweet wine is sweet, and a dry wine has very little sugar. We speak of a sweet or a dry sherry. We speak of champagne as dry, extra dry, as sec, or très sec, and of Vin Brut, a wine fermented absolutely naturally, without artificial interference; no sugar is added, and the natural sugar of the grape has nearly all gone to alcohol. True dryness is a result of age, the sugar being slowly converted into alcohol, but the wine man is full of tricks; in fact, wine is subject to trickery from the grape to the consumer. To hurry up dryness, an artificial acetous fermentation is started and the sugar is nearly all 
consumed by this in a comparatively short time, say six months, whilst the natural process may take years. Thus is champagne dry because it is sour from the development of vinegar, and is not dry because the sugar has been naturally converted into alcohol as it should be to be good wine. Take this wine, let it become exhausted by losing all of its free carbonic acid, and it will still turn litmus blue to red, showing its acidity is not altogether due to the carbon dioxide.

There are various terms applied to wines by the connoissenr which it is well to be familiar with. There is the aroma or bouquet; there is the body, that which makes us feel as though we were swallowing something better than water, and the nearer wine approaches, in swallowing it, to water, the less hody it has. Then wine has color, fruitiness, astringency; strength, due to its alcohol; its acidity and its sparkle, due to its carbon dioxide mainly. If it were not for the sparkle, there would be much less consumption of many palatable drinks than there is at present. What would beer be without its sparkle, or champagne? Try exhausted beer or exhausted champagne, and you will see.

Wine properly used has a good effect on the system. Its abuse entails untold evils. Liebig said, "Wine is unsurpassed by any product, natural or artificial, as a restorer of the vital forces when they have been exhausted; it animates and revives the saddened spirits, it serves as a corrective and antidote in all irregularities of the animal economy, which it preserves from the passing ills to which inorganic nature subjects it." In wine there is a union of alcohol with an acid liquid; the acid holds the alcohol in check. especially the effect of the alcohol on the nerves; the tamnin and coloring matters favor rather than retard digestion, and the bonquet serves to soothe and quiet restlessness. IVine has a density nearly equal to water; it is absorbed much less rapidly than spirits, and thus its effects come less rapidly and last longer than the effects of spirits. Hence, as remedies, when you want rapid action, use spirits, not wine. Wine enters the $\therefore$ stem with no change except being mixed with the digestive 
juices, and absorbs none of the digestive ferments in its own digestion, and hence its usefulness in dyspeptic troubles.

The expert wine-taster is an important man, and few can individually be of more use in the world. Their powers of discrimination by taste and smell are beyond belief, and such men are absolutely necessary to protect both dealer and consumer, for chemistry has become such a science as to make possible the imitation of all beverages without the presence of any of their natural constituents. It is responsible for nearly all of the frauds which deceive both the eye and the palate and overturn the digestive processes. The wine-taster is the bulwark here which separates honesty from fraud. Red and white wines differ materially in their composition and effect upon the system, and it is important for physicians to know this, and it is growing more important from year to year, for America is becoming more and more a wine-producing country, and it follows that we are becoming more and more a wine-drinking people, and less a spirit-drinking people. Statistics show this undoubtedly.

As a rule, red wine is fermented in contact with the stems, seeds, and skins of the grapes, and the white wines are fermented separately from these. Guyot says the difference in color is an accident. The real difference consists in the special and often opposite hygienic qualities of these two kinds of wine. If white wine is fermented from white grapes in conjunction with their seeds, stems, and skins, we may get a white wine having the hygienic qualities of red wine, not otherwise. White wines made without using the stems, seeds, or skins of the grapes are diffusible stimulants to the nervous system. If they are light, they act rapidly on the physical organization, of which they intensify all the functions; they escape rapidly through the skin and mucous membranes, and above all through the kidneys. Red wines are more tonic and persistent stimulants of the nerves, the muscles, and digestive organs: their organic action is slower and longer, they are not eliminated so rapidly from the sys- 
tem, and their general action is astringent, persistent, and concentrated.

Now, here are the well-defined differences between red and white wines, and physicians can profit greatly by heeding them in prescribing. Among foreign wines we will first take up sherry, which is a Spanish wine, named for the town of Jerez de la Frontera, in Andalusia. It is a heavy wine and improves by age; the older the sherry the better it is, provided it is brut, - that is to say, if nature, not art, has been allowed to work it ont. As it ages it gets dryer, because the sugar is converted into alcohol, and if old enough it becomes inky dry for the same reason. Its color varies from dark red to almost white. By the makers the flavor, which is a peculiar ether flavor, the sherry flavor, is formed by the soleras or stock wines. This stock is kept up and used to flavor wines in bulk. Solera wine is no more palatable than sulphuric ether, but gives the flavor to all sherries as it is added in larger or smaller quantities. Sherries are all reinforced or fortified by brandy, and physicians should know this. The Amontillado sherries have the ether flavor most strongly marked. The presence of aldelyde causes this flaror. The Manzanilla sherries are so named from their flavor resembling the Manzanilla or chamomile flower. These are the white or nearly white sherries. The sherries we get in the shops, or from dealers, often are known by the names of the commercial houses which deal in them, as the Gordon sherries, etc. Sherry is often too alcoholic and has the effect of spirits, and it is not, as a rule, a good wine for the sick, except used as wine whey, and I do not recommend this, as a rule. except when we are, as often happens, at our wits' end for something palatable to the patient. There is one place it comes in, and that is as a substitute for champagne when that wine is ton, expensive for the sick one. or good champagne cannot he obtained. Mix it in definite proportions with the common solawater of the shops, the carlonic acid water, made by charging water with carbon dioxicle up to fifteen atmospheres at least. 
and served to customers in glass siphons which preserve it well charged until all of the contents have been used. Such a mixture will often be found of the greatest benefit, and should be much more used among the sick than it is.

Madeira, so far as medicine is concerned, is a passed wine, but it is, as Ward McAllister called it, the king of wines. A physician should be a connoisseur in wines, or at least know, of all men, something about them and their merits and their history when they are discussed, as they often are, so cheerily, at a pleasant dinner. In times past I have tasted some of the good ones, and the flavor of a Butler I6, or of a Thorndyke Sercial, or a Charleston Blandy of I $_{2} 8$, lingers still close to my palate, and I wish I could enjoy them still, and that my throat was as long as a gun-barrel and I could taste them all the way down. I cannot do it, eren if I could find such in existence, for the old stocks must have nearly passed away, and the long lapse of the Madeira grapes from disease has made impossible the replenishing of the old stocks, and the new wines are as yet unfit to drink, and if they were, probably modern methods will make impossible the old wines of the honest old days. Madeira is the most gouty of wines, and many among us cannot touch it. even if we get it, and it is 11ot, as the French would say in regard to Madeira, "chacun a son gout," but rather. " each one as to his gout."

Ward McAllister said Madeira was a national wine, and only matured well in our Southern States. It raises man's vitality and leaves no headache. McAllister said age always improved a good Madeira but never a poor one. There are stock Madeiras in this country to-day over one hundred years old, but if always in glass, I do not see how they have inproved much, unless they have been recorked every seven years and allowed access to air for a time. McAllister's best way of keeping Madeira was in the garret, with a corn-cob for a stopper. Light and air do not injure its flavor. $\mathrm{He}$ always said that the thin pipe-stem wine-glass was the only glass from which to drink Madeira. 


\section{FORTY YEARS IN THE MEDICAL, PROFESSION}

The old stock Madeiras were, most of them, named from the ships which brought them over, and the famous ones were the Marsh and Benson I 8og, the Coles, the Stuyvesant, the Clark, the Eliza. In Philadelphia the Butler i6 was famous. In Boston, the Kirby, the Amory I 800 and I $8 \mathrm{I}$, and the Otis. In Baltimore, the Marshall, the Meredith or Great Unknown, the Holmes Demijohn, the Mob, the Colt. In Charleston, the Rutledge, the Hurricane, the Earthquake, the Maid, the Tradd Street. In Savannaln, the All-Saints I79I, the Catharine Banks, the Louisa Cecilia is 8 \&, the Rapic $\mathrm{I} 8 \mathrm{I} 7$, and the IVidow. I will add the Blandys as among the noted and better stock wines of their day. One of the Blandy brothers was the head of a well-known Delaware family, some of whom reside here now.

Cheese and nuts bring out the flavor of sherry, port, and Madeira, and this is why they come in so well and cause a cheery lingering over the wine. This all may appear to he fudge and gossip as introduced here, but I assure you it is history and worthy of being preserved. In the old days many of the gentlemen imported their pipes of Madeira, even from the days of the early settlements on the James River in colonial times, where the old planters exchanged their grain for supplies for their families and plantations, and the pipe of Madeira was a frequent article in the exchange. Again, should any professional friend at any time have one of the old boys "with a toe" for his patient, and on one of his visits find him suffering and cast down and even emplatic in his remarks condemnatory of gout. I advise him to give the old gentleman these lines to read. not whereby to do penance. but to bring to his mind possibly visions of the good old days now past and gone, and to help assure him and to reassure him that there had been other sufferers, too, who had passed through it all. and that again, even to him, dark as the present may look, lo bon tomps riendra.

Port wine is a very gouty wine, in which fermentation has leen arrested by adling a certain amount of alcohol. It im- 


\section{FORTY YEARS IN THE MEDICAL PROFESSION}

proves greatly by age and in the bottle, it only being necessary to watch the corks and recork it about, as a rule, every five or six years. It is an astringent wine, and is used in diarrhœeas when wine is indicated. It is often used for making the famous " mulled wine," which is a good tonic taken with a cracker. The sweet wines are of little use in medicine: in fact, should rarely be ordered. The Tokays. Malagas, lachrymze Christi, etc., contain more sugar and less alcohol. Age renders them dryer as the sugar goes to alcohol. but even this does not recommend them, even for sick women, who, as a rule, defy all the rules of hygiene in their love of sweets, especially the cordials, Malagas, and sweet champagnes. There is one thing to remember about all wines: a sound wine may be acid, but this acidity is owing to the natural acid of the wine, tartaric acid. A spoiled wine, or turned wine, is sour because it contains acetic acid or vinegar. which has developed because the fermentation has gone too far, and it has soured just as cider or perry sours after a short keeping.

What is the difference between a claret and a Burgundy? Clarets are not known in France as clarets, but are known as Bordeanx wines, and common wine is vin ordinaire, which may apply to any of the cheap every-day wines. The Burgundies are stronger wines than the Bordeaux or clarets, and are therefore more gonty, and are both red and white, but the true and best Burgundies are red. True Burgundy, as the French understand it, is made from the grapes raised in the department of Burgundy called Cote d'Or, the golden side. which is only thirty-six miles long and reaches from Chalon-sur-Saône to Dijon. Chambertin we rarely see in America, or Corton, or Clos de Vougeot, or others of the true Burgundies. Burgundies do not travel as well nor keep as well as the clarets, and hence clarets are much more frequently seen here. The best white Burgundy of the Côte d'Or is the Montrachet. The most common of the white Burgundies we see in America are the Chablis wines. They 


\section{FORTY YEARS IN THE MEDICAL PROFESSION}

are good, have good flavor, and are resirable for the sick where a Burgundy is needed, yet they are not absolutely true Burgundies, are not wines made from the Côte d'Or grapes.

The Bordeanx or claret wines are naned Bordeanx from the city of Bordean, the capital of the department of Gironde. France. The city of Bordeaux is the centre of this wine tradle. The vineyard name of the district is the Bordelais. The name claret is taken from the French clairct, which means a clarified wine, and, as before mentioned, is not used in France as a name for wine. The Bordeaux wines are mild, not very astringent, pure and fragrant, provided you get fairly good ones. There are anong them high-class wines, fine wines, and ordinary wines. As a rule, a sea royage improves them, whilst it deteriorates Burgundies. The high-grade clarets should always be warmed to the temperature of the room, in order to bring out their bouquet and flavor. They gain in bouquet by keeping in bottle. if properly corked. The Medoc wines, named from a province of the Bordeaus country, are among the best of clarets. The Château Margaux, the Châtean Laffitte, and the Château Latour are rarely seen here in their true form. but good Medoc wines may be found. Medoc wines are natural wines, are not reinforced wines, and are therefore mild clarets. We do not know now what we get when we buy foreign clarets, as there is so much roguery at Bordeanx, and the remedy is to use those made in our own country, unless we get the better French wines from some favored source. Among the best of the red wines of Bordeaux is the Haut Brion.

The Santernes are white and are sweeter than the clarets, but have goorl flavor and pure aroma. The poor grades are sour. Barsac is among the best of then, if Barsac is a Sauterne. A bottle of the renownerl and famous Chateau Yquem would be a curiosity in America, or would have been some time since. The great fortumes accumulated in this country can now buy the best of the world's luxuries, and the highpriced luxuries will follow the accumulated money. Château 


\section{FORTY YEARS IN THE MEDICAL PROFESSION}

la Tour Blanche is another famous brand. The best of the sweet wines are the Muscatelles, Malvoisie, and the Maccabéo. They are sweet, full of aroma, and full of vim. They go principally to Russia, where they doubtless turn to vinegar in the stomachs of the unfortunate subjects of the great Czar.

The Rhine or German wines are usually of the lighter character, both white and red, but the white far predominate. They are low in alcohol, but yet keep well, as a rule. They have much free acid and tartar salts, and are considered allowable in patients who are afflicted with calcareous troubles. Hock wines are so named from the district of Hockheim, from whence they come, near the banks of the Main. Johannisberg is the prince of the Rhine wines, and I have already spoken of it. If any one wishes the best, let him get Johannisberg. The Riesling grape is one of the great Rhine grapes, and we will see more about it when we come to speak of the California wines. It is most interesting to visit the Rhine region, the Rheingau, and to ponder and study the surroundings, where the work of ages has been carried on with the grape as the chief factor. Steinberg is a brand next in flavor to Johannisberg, and in some seasons is better. That is really the case with all brands of wine. The grape of the brand makes good wine this year and poor wine next year. Ask a judge of wine about a brand, and he will first ask you to tell him the year of the vintage of the particular specimen. That makes a mighty difference. Other brands of Rhine wines are Rupertsberger, Deidsheimer, Dürkheimer, Liebfrauenmilch, the Fenerberger, Laubenheimer, Bodenheimer, Niersteiner, and many others.

The Moselle wines are light in alcohol, have much fragrance and an aromatic flavor, resembling elder-flower, which is said to be artificial. The Moselle wines make good sparkling wine. Sparkling Moselle I have drunk frequently on the Rhine, but rarely see it here. Some German hocks are also fermented and made to sparkle: in fact. a sparkling wine may be made of almost any still wine by the arts of the wine- 
maker. The Italian and Hungarian wines do not come to us in any quantity except they come in wines from France. for much of the wine of Italy and Hungary goes to France for blending purposes. The wines of Italy are chiefly red, at least those from Northem Italy are, and they are, as a rule, rough and badly made, the skins, stems, and seeds being macerated too long. Some of the Hungarian light wines are of fine flavor, have good aroma and smooth taste, and are growing in favor in the United States. The white Italian wines come from middle and southern Italy, and Tuscany; as a rule, they are also rough and badly made.

Champagne.-Professor S. D. Gross always spoke of champagne as a "drink for the gorls." and it was his custom, when he came home weary and tired out from hard work, to open a pint bottle of Mumm's Extra Dry, and sit down and enjoy it. Whilst champagne is undoubtedly a " drink for the gods," for the gouty individual or for the diabetic it is an invention of the devil. For the delicate or for the weary valetudinarian it is a generous and acceptable tonic, and as old age comes over us, provided there is no contraindication, it is here that alcohol in some form is so acceptable, and champagne becomes a remedy par e.tecllence. Owing to the carbonic acid it contains, it is a rapid stimulant, and is rapidly and completely absorbed, and this quality makes it of great use in so many of the acute diseases where we need rapid action and where the digestive processes need just the spurring up that the carbonic acid and alcohol give. In acute croupous pneumonia confine me to one remedy, and I believe I would choose champagne.

There are true champagnes. "Vin Brut," as the French call it, wine made without any artificial additions whatever, and fermented absolutely in the bottle. Then there are the ordinary champagnes. when the maker hurries up the acetous fermentation. by which all of the sugar is quickly converted into alcohol. This is done by adding from four to eight per cent. of sugar. Fonr per cent. makes the wine 
sooner, and it is ready to sell sooner, but if it be a dry wine it is dry because of the acetic acid in it, and not because the sugar has gone to alcohol naturally. Here, then, is the distinction between "Vin Brut" and a sec or dry wine, or extra dry. We get probably little "Vin Brut" in the United States, but we get plenty of dry and extra dry. Good sec (dry) or extra dry (très sec) can be bought for from twenty-five to thirtysix dollars per dozen in this country, whilst true Brut, if of a fashionable vintage, will sell for one hundred dollars per dozen, or more, and is usually imported by the consumer. The only wine I know of, sold by the general trade in this country as "Vin Brut," is the wine of Ruinart Pére et Fils, Rheims, France. Roosevelt \& Schuyler are sole agents for the United States and Canada. It is a good, sound, decidedly dry wine, but I do not see how it can be a true Brut wine at the price, although it is a high-priced wine as champagne is sold in the United States. I am in error as to Ruinart being the only reported Brut wine sold here. Moet et Chandon, one of the very best French makers, offer a Brut wine as Brut Imperial, together with their White Seal. Their green seal pink wine has always been one of their best. Piper-Heidsieck also offer a Brut extra. The genuine Heidsieck wines are among the best, but this brand is most frequently counterfeited of all wines, probably, coming to America. Pommery and Greno, sec, is another of the good brands, and so are the Veuve Cliquot, but these are usually too heavy and sweet for the sick. The wines of the house of G. H. Mumm \& Co. are among the best and most reliable of champagnes in the general market in this country, and are particularly well bottled and corked, and this is of great importance when you have wine on hand any length of time. Mumm's Extra Dry is a very fair wine and safe for therapentic use.

After these wines come champagnes of many kinds and sorts, until you reach the vile stuff with sugar and any alcoholic mixture for a base, with carbon dioxide forced into it sola-water style. I will not speak of our domestic cham288 
pagnes until I come to speak of our domestic wines in general. Artificial champagnes, as a rule, besides being vile mixtures, are heady; that is to say, the carbonic acid goes rapidly to the head and produces an umpleasant fulness, different from that produced by alcohol. God help the man who drinks too much at one time of the best champagne! It is a sickening dose, but if the stuff is artificial, do not mention the great misery which overcomes him. Sparkling Moselle is a fairly good light wine, and if it can be obtained it can be recommended for the sick when such a wine is needed.

The making of good champagne is a tedious and expensive process, and consists of vatting, curing, bottling, racking, disgorging, and handling. The bottles must be of the best, and even then fifteen per cent. are broken in the process. I remember having seen men testing bottles by the eye and by the hands, in the famous cellars of Moet et Chandon, Epernay, France. The only wonder to me was, they did not all fly to pieces in the mere testing. The slightest bubble in the glass condemned the bottle. All champagne bottles are made in clay moulds, and have no mould-marks on them. These bottles must stand a pressure of one hundred pounds to the square inch, thus reaching near the point of an explosive, although not a high one. This is in the first fermentation. The bottles must really stand a pressure of twenty atmospheres, or three hundred pounds to the square inch. Champagne is a blended wine. The cuvée, literally a vat, is the mixture or blend of the wine from which the champagne is to be made. The cuvée is the most important part of the work of making champagne, and requires great experience and tact. It is necessary to ascertain the exact proportion of alcohol, sugar, and acid, or the mousse or sparkle will be too violent, or not violent enough. The blend of the wine gives the color, lightness, its sweetness or dryness, and the strength, in a great measure.

Now the corking is done by machinery, and it is an interesting process. Formerly, string and wire both were used 
to hold the corks; now much wine is tied by wire alone. After the bottles have been filled, they are tied with one string, and are then kept at a temperature of about $80^{\circ} \mathrm{F}$. for several months. During this time the albumin and natural sediment of the wine goes to the lower side, the bottles having been kept on their sides. At the end of several months the carbon dioxide has formed, and probably ten per cent. of the bottles have exploded, yet the wine is not always lost, but is caught in gutters and used sooner or later.

After fermentation has gone on for months the bottles are put into racks and turned every day for several months. This brings the sediment down to the neck, the racks holding the bottles cork down. After this, the bottles are stood up perpendicularly on their corks. All champagne bottles have their bottoms pushed up into a cone, as is well known. This is not, as is generally supposed, to reduce the contents in quantity, but is necessary for the strength of the bottle. After fermentation has been completed the sediment must be gotten rid of, technically called disgorgement. A man does this very expertly, and loses very little of the wine. He wears a wire mask, as do all who enter the champagne vaults during the cure of the wine. If the wine is to be helped, and is not absolutely natural, or brut, as soon as the disgorger has finished, another man puts in the proper amount of syrup, and thus arranges for the dryness or sweetness of the wine. The syrup is cold process syrup only, and made with grape sugar, and may have some flavoring added, but this is really not proper. If too much wine has been lost in disgorging, more is added, and the waste goes off into some such by-product as vinegar. Nothing is wasted.

After the wine has been corked and wired it is put away for probably a year in the cellars, and is then ready for labelling and packing. I think there is a difference of opinion as to the improvement or non-improvement of champagne by age. If it can be kept absolutely quiet and air-tight, and with a proper environment, it may improve by age, certainly, at 


\section{FORTY YEARS IN THE MEDICAL PROFESSION}

least, until all of the sugar has been converted into alcohol, the wine then becoming as dry as it can ever be. The life of the cork must measure the life of the wine, and this is probably not over five or six years on an average.

France makes most of the champagne for the world, and the true champagne district cannot supply grapes sufficient for one-tenth, probably, of what France exports. Fortunately, there are other places which furnish grapes for good champagne, and this wine is utilized. Champagne is supposed to have been invented by monks, and resulted from the bottling of new wine and its exploding the bottles whilst undergoing fermentation. The true clampagne country of France is the department of the Marne, east of Paris, and which one passes through in going from Paris to Strasbourg, on the way going through Epernay, Rheims, and Nancy. The German army went by this route on their way to Paris after Sedan. The surface soil is shallow, the subsoil calcareous and chalky. The subsoil analysis is, carbonate of lime, 8o; carbonate of magnesia, 2 ; silica, I 8 . Surface soil analysis: alkaline salts, .985; carbonate of lime, 28.862 ; magnesia, I.4OI ; oxide of iron, 4.545; phosphoric acid, . I 47 ; alumina, .849; soluble silica, .095; organic matter, 3.750; insoluble residue, 59.366 .

Dealers in wine will tell you that brands of wine, especially of champagne, like brands of cigars, are likely to deteriorate after the brand has been well established, and recommends the newer brands as often the best. This may be the case, but I think the character of wines is most frequently determined by the year of the vintage, as the grapes differ so much in different years, one year making good wine, and another year making very inferior wine.

Amcrican Wincs. - Within fifty years wine-making has become quite an industry in the United States, and to-day California, Missouri, New Jersey, Ohio, and Virginia furnish a great deal of very good wine, especially of wines of the lighter kinds. These wines are doubtless purer, and often better, 


\section{FORTY YEARS IN THE MEDICAL PROFESSION}

than the foreign wines, for they are so cheap that it does not pay to take the trouble or expense either to change them or to counterfeit them. In 1894 the producer, for his lighter wines in California, could barely command six cents per gallon in his vaults, scarcely the price of good cider as we find it in the general market. California is our great wine-producing State. In I 898 she exported fifteen millions of gallons of wine, and there the business is in its infancy, and doubtless, as years go by, there will be a wonderful development, and a great rival will arise to France and Germany and all of the other great wine-producing countries of the world.

It is the duty of our physicians to know all about our native wines and spirits, for, as a rule, they are within the reach of all in price, and equal to any we can buy in efficiency, and there is every reason why we should use them therapeutically almost exclusively. When we ferment the grape the sugar of the grapes is transformed, on an average, into alcohol, 48.4 per cent.; carbon dioxide, 46.6 per cent.; glycerin, 3.3 per cent. The malic acid is converted into succinic acid, .5 per cent., and the yeast ingredients $\mathbf{I} .2$ per cent., making in all Ioo per cent. The germs come from the atmosphere, where they exist always in the lower strata. On tops of mountains, perhaps, natural fermentation would not start owing to the absence of yeast germs, but here we could start it by adding old must or yeast. Natural fermentation is best. Here is an important point: if the fermentative germs do not exist on mountain-tops, it is reasonable to suppose the pathogenic germs do not exist there. Indeed, I have my doubts if tubercle bacilli flourish at an elevation of over five thousand feet above sea-level. The same may be the case on the high seas and in deep canons and such places. In California wines mature much more rapidly than they do in Europe. In the future, we may expect wines from the Pacific coast of a high character, especially of the Medoc type, and Burgundies, true Sauternes, and those of the cognac type. I have never yet seen a real good sherry among them; there is too much sugar 
in their sherries, and the same may be said of those of the Madeira type. Some of the port wines are fair, and are particularly to be recommended for therapentic use. California sherries and ports are usually sold in the shops, not by any particular name, but by the vintage, which really means nothing, as choice old port I885, pure port I880, extra port I 870 , and so on; and the same with the sherries and those of the Madeira class.

The California wine business has fallen into the hands of trade entirely, and the wine, after it leaves the cellars of the producers, is subject to all the arts and manipulations of a not over-scrupulous set of dealers, and those who drink it must take the best they can get.

This is really the case with all wines, even down to spurious and artificial wines. The California hocks, Rhine wines, and Sauternes, as we find them in the trade, take the names of the true hocks, Rhine wines, and Santernes, as Haut Santerne, Choice Old Liebfrau Milch, Rudesheimer, Hockheimer, and such. Of these wines, I like the true California Rieslings the best. The sweet wines of California are sold as Choice Old Muscatel, Choice Angelica, and such, and are among the best of these wines obtainable, if they come from a good source. California Burgundy we find in our markets as Burgundy i885, Burgundy is8o, and so on. The clarets come under a number of names. The Zinfandels, to my mind, are much the better. The Zinfandel grape has a peculiar flavor of its own, which pervades the claret and grows on one rapidly. Of course, to get the best results in flavor, etc., the wine is blended with the red and white Zinfandel and other wines, Zinfandel predominating largely, until the desired result is obtained. These California clarets are stronger in every way than the foreign clarets, and approach near to the Burgundies, and need water added to them when used as ordinary table wine. The Cabernet Sauvignon makes a highclass Bordeaux wine alone, and the Burgundy Pinot grape does the same, but these are among the few on the Pacific 


\section{FORTY YEARS IN THE MEDICAL PROFESSION}

coast that do not need blending. We find in the shops clarets under the names of Medoc, Cabernet, St. Julien, Larose, Pontet Canet, Santa Monica, and others. The Zinfandel grape has been very extensively planted in California; it is hardy and flourishes everywhere, and for this reason, among others, it is the greatest claret grape, and properly blended, as Zinfandels we get the best of the California clarets, although the Medoc class might possibly be better could we get them from first hands. The Zinfandel has a bouquet of its own, is of light astringency, and has a light color.

There is no manner of doubt, as we purchase mediumpriced clarets in the general market, that the California and other American clarets are far better than the adulterated stuff we usually get from abroad. I do not hesitate to advise their use generally. Some very good clarets are made in New Jersey near the coast, and among the best of American clarets I have ever tasted are those made in Virginia,--near Charlottesville, I think. Physicians in seeking for good sound wines of this class should not overlook these Virginia clarets. Should we need a sweet wine, the Virginia Scuppernongs are worth testing. Of the hock varieties of California, I prefer the Rieslings. The Riesling is the noble grape par excollence of the Rhine, and predominates in the famous Johannisberg vineyard. I believe a true Johannisberg will be made in California much better than we can buy of European origin in our market, if you can buy any at all. If you wish one of the best wines of the Rhine wine type to-day, buy the California Riesling in preference to the average foreign wine.

This brings us through the list of American light wines and other wines, except the sparkling wines,-champagne, the true "Vin de luxe." Let me add here, that Californians accuse the dealers who buy their wines of shipping them in bulk to Europe and bringing them back here with European ligh-sounding labels on them, and selling them to us as genuine European wines. The way for us to stop this is to drink our own wines, as we should do, whenerer possible. As to 
American champagne, I cannot say much for it. After looking into the matter quite thoroughly, I have come to the conclusion that there is very little true champagne-that is, champagne fermented in the bottle-made in America. We have plenty of soda-water champagne, and some of this is quite pleasant, and serves a good part in taking the place of the more expensive European wines. It is easy to make artificial champagne from the natural dry wines. An Italian, Carpené by name. has invented a simple and cheap apparatus. The result of Carpenés apparatus is a fairly good sparkling wine, at a very moderate cost.

Old Nicholas Longworth, of Cincinnati, years ago made a sparkling Catawba, which was probably fermented in the bottle. Arpad Haraszthy some years ago made a good champagne in California, which he called the "Dry Eclipse." I believe this wine was fermented in the bottle. Haraszthy's "Eclipse Champagne" is yet on the market, but I think he is probably dead some time since. It is yet one of the best of our domestic sparkling wines, but whether it is bottle fermented now or not I do not know. "Golden Age" is one of the better domestic brands, and so is Urbana and the Great Vestern of the Pleasant Valley Wine Company. Cook's Imperial Extra Dry is a fruity wine, and pleasant. As a rule, our domestic champagnes lack body and are too sweet. They sell by the case at from twelve to fifteen dollars per dozen for quarts, and for pints they cost a trifle more. No good reliable house can or will sell a domestic champagne fit for one to drink much below these prices. The stuffs in the market under these prices are slops, and worse than slops.

American brandies are chiefly made in California. They are, as a rule, cheaper and much better than the ordinary French brandies. If some one in the business in California would supply physicians and their patients with a natural brandy,-a brandy distilled from good pure wine, and bottled without adding artificial flavoring or any coloring matter whatever,-he would do a great good to suffering humanity, 


\section{FORTY YEARS IN THE MEDICAL PROFESSION}

and undoubtedly be rewarded by large financial returns. The resultant liquor would be better than all the whiskeys, rums, and other spirits on the market for its special purposes.

Unfermented grape-juices are now much used by sodawater men and temperance people, so called. Grape-juice, fresh, may be very nice and quite palatable. To prepare it, it is boiled more or less, and bottled and sealed. Much of it, to keep it, has some antiferment added, and this is done particularly when it is retailed in small quantities; and under these conditions it is unwholesome and adds another turn to the screws that Satan will give the soda-water men when he gets hold of them for all the vile stuffs they have cunningly devised for credulous humanity.

Adulterated wines and spirits of various flavors are used and wholesale adulteration is carried on, and no law appears to check it. You can buy any wine, brandy, or whiskey in a general market, or receipts for making them, and no genuine juice of the grape or grains will in any way enter into their composition. Such concoctions are called "rot-guts," but they do not appear to kill more rapidly than the better and truer stuffs. Those who take them are generally the poor among the dissipated, who have not the means to overeat and over-drink which those have who are more prosperous financially. The drunkard with unlimited means often goes sooner and more rapidly than the tramp and "bum" with no means whatever. As adulterants, ginger and peppers are used, cocculus indicus, quassia, aromatic seeds, wormwood, ammonia, nux vomica, gentian, juniper, chamomile, almonds, orange-peel, licorice, honey and other sweets, and astringents. In wines there is great roguery. According to Thompson, a fair imitation of Château Latour can be made with almonds and other nuts, and a Châtean Lafitte with violets and nuts; and to other grades cherry-juice is added. Artificial pigments, alum, tannin, fusel-oils, cider, pear-juice, and lime salts are often added to wines. Logwood is frequently added to make clarets and Burgundies. It is the fusel-oil in liquors 
that usually causes headache, foul mouth, and dyspeptic symptoms following their use: and if carried on too long the hobnail liver comes with all its succeeding lorrors. There is no longer taste for even Chambertin or Château Ýquem.

Wines are made from almost any fruit or regetable containing sugar, - as from rhubarl, the tomato, the fig, the strawberry, the blackberry, the raspberry, and the currant. That made from the latter is among the best. If such an excess of sugar were not usually added, these wines might be useful in sickness. As usually seen, they are a sorry dose for sick or well.

Cider and perry - the first from the juice of the apple, and the other from that of the pear-are common drinks. They contain a small amount of alcohol, malic acid, some extractives, sugar when new, and some salts. When first fermented they are very palatable, but soon get sour and go to vinegar. Cider in France is used as a gout cure. For the life of me, I cannot see why or how it can add to the alkalinity of the blood, except by forming salts in the system with the bases it meets, and even then not enough to have any practical effect. I have known one or two gentlemen who lived in France to declare it did them great good. Those of our patients who need cider had better always drink fresh cider. All bottled cider, as a rule, is cider in which fermentation has been limited by the addition of antiferments, and is neither palatable nor proper to drink.

It is wonderful the number of articles made from the wine residues, and many of them are of every-day therapentic use. Those products that furnish the greater number of articles are the pomace, the lees, and the tartar. Tartaric acid is obtained from the pomace by a complex process. Spirit is made from the pomace by distilling it. Frankfort black is made from the pomace. Oil and tannic acid are extracted from the seeds, and vinegar is made from the pomace; but true wine vinegar-the best vinegar-is made from true wine gone on to the acetous fermentation. Enocyanin, a coloring matter, 
is made from the skins, and is much used in wine-making for coloring purposes. Verdigris is made from the pomace and copper. Grape pomace is also used for food for stock and for fertilizing purposes, I suppose from the salts of potash, nitrogen, and phosphoric acid formed in it. The lees contains alcohol and tartrates, and is valuable as to the quantities of these contained. The common raw tartar, or argol, is a very valuable by-product of the grape, and is precipitated on the lower side of the barrels. This tartar salt is usually in composition as potash or lime salt. There are two kinds of raw tartar, the white and the red. Raw tartar is a great commercial product, and it is therefore, like many other articles, much adulterated, sand being used, and also steam-boiler crusts. Physicians should know about such matters. Tartaric acid is made from the raw tartar by an interesting process. It is first changed to calcium tartrate, then by sulphuric acid all the tartrate of lime is made into sulphate of lime and tartaric acid, the calcium sulphate precipitating. The tartaric acid is then crystallized out. Tartar emetic is a double tartrate of potash and antimony. The acid tartrate of potash, cream of tartar, a bitartrate, is a very important by-product from the grape. The neutral tartrate of potash is also a well-known substance. There is another salt, a very valuable one, and one deservedly used in medicine, the double tartrate of soda and potash, called the Rochelle salt. This has a mild, not unpleasant, salty taste, and we all should know that it is one of the good things coming from the grape as a by-product in the art of wine-making.

From the official reports of the British Board of Trade we can compare the consumption of alcoholic drinks in England, Germany, France, and the United States. In France the consumption of wine increased from 2 I. 3 gallons per capita in I885 to 29.5 gallons per capita in I896. In Germany the consumption of wine is 1.06 gallons per capita per year. In England it is four-tenths of a gallon per capita per year, and in the United States it is twenty-two-hundredths of a gallon per capita per year. All these show a slight increase from 
former years. All wine consumed in England is imported. In the United States, seventy-eight per cent. of the wine used is made at home. This is an important showing. Germany consumes 25.5 gallons of beer per capita per year, and in this there is a tendency to increase. England consumes 30.7 gallons of malt liquors per capita per year, and the United States consumes fifteen gallons per capita per year. The French, among whon wine is the national drink, consume five gallons of beer per capita per year, and beer-drinking is increasing in France. Belgium consumes forty-three gallons of beer per capita per year, and Bavaria fifty gallons per capita per year, and Bavaria makes the best beer in the world. Of spirits, Germany consumes I.94 gallons per capita per year. France consumes I. $_{5}$ gallons per capita per year. England consumes r.or gallons, and the United States .83 of one gallon per capita per year. In Holland and Belgitum the consumption is two gallons per capita per year. England collects as taxes from spirits, wines, and malt liquors $\$ 449,820,000$. Our country collects $\$ 444$, I 6, I23. The French government at large only collects from these sources $\$ \mathrm{IO} 2,400,000$ per year, but there are other taxes by cities and towns, just as we have in the United States, and are not included in the general government tax. Germany only collects directly $\$ 57,969,040$. The average German at home or abroad rebels when you tax his beer, for it is the main-spring of his pleasure, not only of his palate, but of his whole social life. The old lady said to her son, who had left his American home to reside temporarily in Germany, "Henry, I hope you go to church on Sundays." "Yes, mother," said Henry. "Henry," said the good mother, "I trust you visit the pastor now and again at his home." "That is not necessary, mother, I always meet and chat with him at the beer-garden on Sunday after service."

I think there is one thing we may truthfully say: the consumption of spirits as a beverage is gradually declining in this country, and that mania a potu is more and more becoming a rare disease. Such is my individual experience, 


\section{FORTY YEARS IN THE MEDICAL PROFESSION}

and it has been and still is considerable, having been connected during much of my professional life with various eleemosynary and criminal institutions where such cases abound, and I have seen it in men and women of all colors and nationalities. The increased consumption of beer and wines accounts for much of the decrease of consumption of spirits, and it looks to me as though the coming man would gradually cease to use spirits as a beverage, a condition greatly to be wished for truly. I think man begins to realize the fact that the consumption of spirits as a beverage is the greatest bane to his health and happiness that lies in his path of life. Instinct tells him this, just as instinct teaches the lower animals to aroid certain plants as poisonous. The ancients invented spirits (probably the Arabians), and I mean by spirits the brandies, whiskeys, rums, gins, and such, not the much less harmful malt liquors nor the mirth-provoking mellow wine. The ancients used these spirits as medicine alone. May we who live after them, and may those who live after us, gradually come to use them in no other way; and as medicine may we of the medical profession learn to guide and guard their use.

I add here an important table taken from an article in the University Medical Magasinc for October, I898, by Dr. B. Franklin Stahl. The table is by Roberts, and shows the retarding effects of wines and spirits on digestion, both peptic and salivary digestion. Let me first quote from Stahl's conclusions, using his quotations from Chambers, Osler, and others.

"Wines and beers, a glass or two taken with a meal, will help gastric digestion. When consumed in quantities, as not infrequently used, a pint of claret or a large amount of beer, they retard digestion more or less. As to time of administration, they should be given with food, or a part in certain instances taken just before food. Osler says the man who drinks before noon is lost. As a beverage, I say, a man should postpone his libations until the dimner hour. Chambers says the laborer, whose limbs are stiff with his day's toil, 
and the brain-worker, who still more acutely feels the wear and tear of bread-winning, are not wasting the money they earn with which they buy a fair ration of beer or wine for their evening meal.

"The malt liquors are indicated as fattening agents, to stimulate digestion, and as mild tonics and stimulants. The spirituous liquors are required in acute illness, and are beneficial in old age. The wines are most useful in convalescence and in those cases where we are unable to give the stronger liquors, because of their mucceptability to the stomach. Furthermore, they have a fixed place in our dietetics. They are to be avoided in atheromatous conditions of the blood-ressels, and particularly in angina pectoris from the free salts they contain, and this is why spirits is the drink of old age when the blood-ressels have deteriorated. Finally, considering some special conditions where selection must be made, it may be said that in anæmia, in conditions included under the term malnutrition, and in convalescence, you will do well to order a good claret, Burgundy, or Sauterne. The lighter wines of good quality are best for daily consumption for brain-workers who lead sedentary lives, and who need a digestive and stimulant.

"You will hasten recovery in many by ordering a light luncheon, accompanied with wine, between meals. Gout is regarded by many as the child of port wine. Next in order as causative of gout comes champagne, especially the sweet wines. A gouty person should drink only the dryest of the dry champagnes. Then come sherry, Madeira, Burgundy, and malt liquors. Cider is almost as potent in its causation of gout as are the wines. Some differ from this assertion, as I have explained. Claret is almost the only safe wine in gout. I will say that water is safer and better than any of the alcoholics. In diarrhœa and dysentery you will find brandy of service, especially in the old. Claret is also valuable here; in Germany and France it is frequently used to the exclusion of water. Very little water the French and Germans drink, anyhow. In diabetes, claret is safest, but Bur- 


\section{FORTY YEARS IN THE MEDICAL PROFESSION}

gundy, hock, or dry sherry and some whiskey will be found to agree. I would say, drop the sherry of all kinds, and confine the whiskey to those specimens not colored with caramel. In fever, if self-limiting and of moderate severity, alcoholic stimulants are not indicated until convalescence has been established, when they may be given with advantage. You may regard it as an indication for alcohol when the fever is very high from the outset, and the heart appears embarrassed, as shown by a weak or absent second sound. Chronic alcoholism, in nearly all instances, may be successfully treated without liquor. When it is required, it should be given in the form of spirits, and in large doses. In liver disease alcohol is usually contraindicated. If demanded, claret or brandy, well diluted with aërated water, should be chosen. Insomnia is often relieved by mulled wine or by whiskey and hot water. Beer is also of service in this connection. I need hardly say there is danger of the formation of the habit under these circumstances, nor need I renind you that whiskey is best for the old. In consumption the malt liquors are of service early, and the spirituous liquors later in the disease. Remembering that here, more than in almost any other disease, the digestion is of the greatest importance, you will be governed entirely by the effect produced on the digestion. In chronic rhemmatism and renal disease they may only be given when the demand is greater than the contraindication, and all the while the effect must be noted. Well-diluted spirits are best here. In scurvy, malt liquors are especially serviceable, yet some do better on claret or spirits and water.

"Now, while certain suggestions can be made quite positively and on well-founded reasons, there must remain many instances where your individual judgment must come into play. Whenever you prescribe an alcoholic, whether to man or to woman, whether to the young or to the old, remember well and ponder well on the terrible weapon you are using both for good and evil. I beg of you not to use it therapeutically in a reckless manner, and I pray God to especially guide you in prescribing it to the young and susceptible." 
FORTY YEARS IN THE MEDICAL PROFESSION

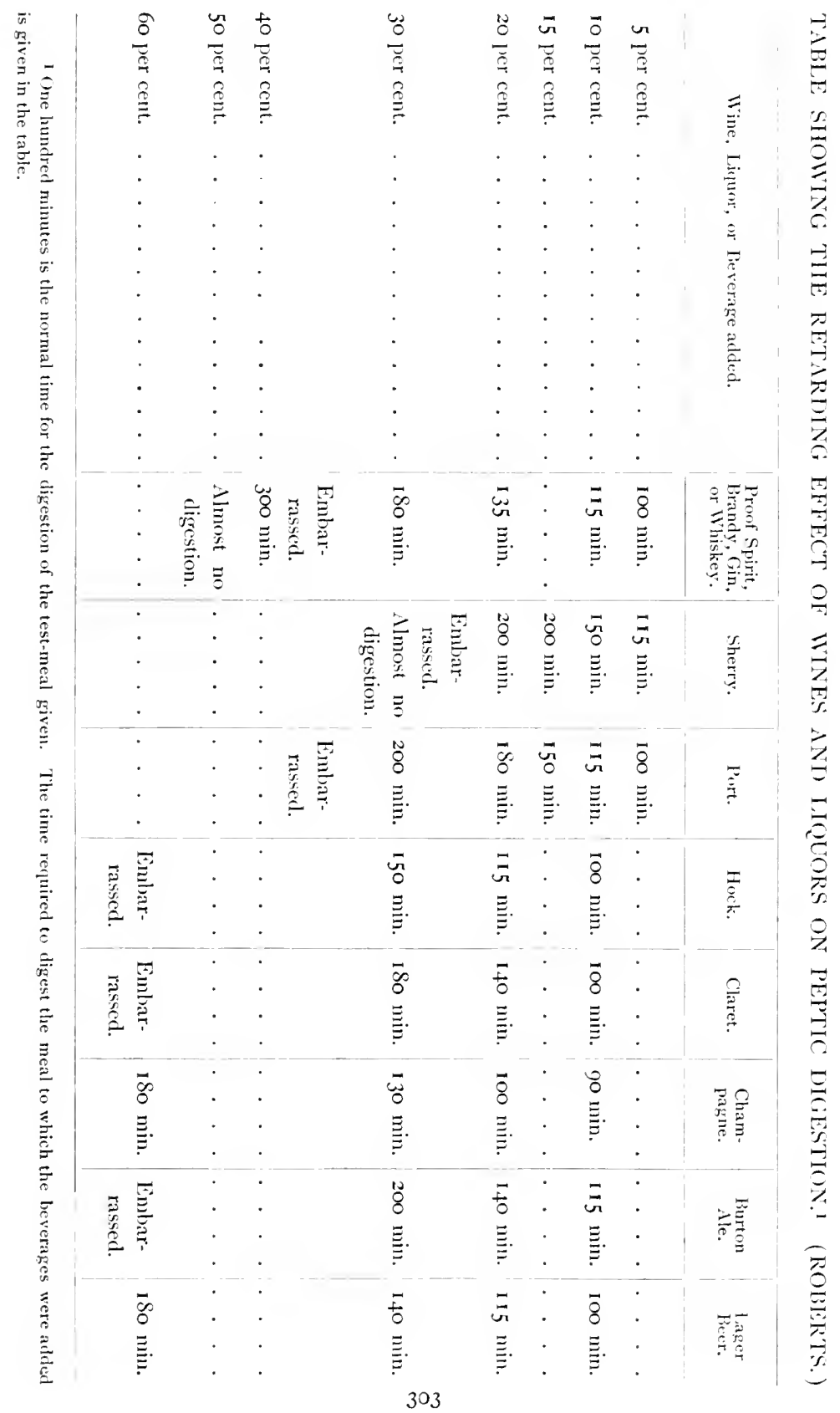


TABLE SHOWING THE EFFECT OF SHERRY AND HOCK UPON SALIVARY DIGESTION.1 (ROBERTS.)

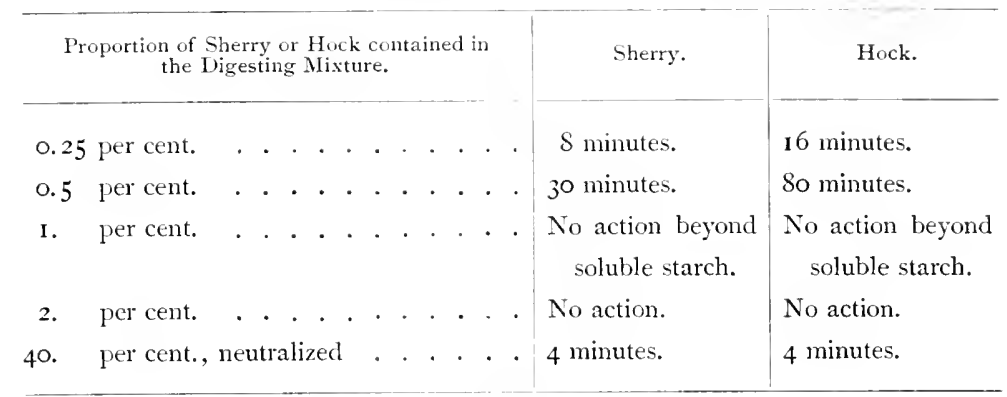

1 Time normally required equals four minutes.

TABLE SHOWING THE EFFECT OF ALCOHOL, BRANDY, AND WHISKEY ON SALIVARY DIGESTION.2 (ROBERTS.)

\begin{tabular}{|c|c|c|c|}
\hline $\begin{array}{l}\text { Proportion of Proof Spirit, } \\
\text { Brandy, or Whiskey } \\
\text { in the Digesting Misture. }\end{array}$ & Proof Spirit. & French Brandy. & Scotch Whiskey. \\
\hline 5 per cent. . . . . & 4 minutes. & 4 minutes. & 4 minutes. \\
\hline ro per cent. . . . . . & 4 minutes. & Very slow action. & 30 minutes. \\
\hline 20 per cent. & 4 minutes. & No action. & Very slow action. \\
\hline 40 per cent. . & $S$ minutes. & No action. & No action. \\
\hline 60 per cent. & I 4 minutes. & No action. & No action. \\
\hline 70 per cent. . . & 20 minutes. & No action. & No action. \\
\hline 90 per cent. . . . . & Very slow action. & No action. & No action. \\
\hline
\end{tabular}

2 Time normally required, four minutes.

Fruits and Nuts as Articles of Dict.-There are few things of more importance for the physician to know and understand than the composition of foods, their effects upon the system, and the philosophy of the physiology of metabolism, including katabolism and anabolism. There is great defect in the teachings of the day in our medical schools in regard to these matters, and whilst they have advanced considerably in recent years, there is yet great room for betterment and improvement. 


\section{FORTY IEARS IN THE MEDICAL PROFESSION}

A glance at the accompanying tables will show the value of fruit as food from the economic stand-point.

\section{VARIOUS SUHSTANCES.}

\begin{tabular}{|c|c|c|c|c|c|}
\hline & & $\begin{array}{c}\text { Waste } \\
\text { from roo } \\
\text { pounds as } \\
\text { purchased. }\end{array}$ & $\begin{array}{l}\text { Edille Iry } \\
\text { Matter in yoo } \\
\text { pounds as } \\
\text { purchased. }\end{array}$ & $\begin{array}{l}\text { Cost of one } \\
\text { pound of } \\
\text { Edille Iry } \\
\text { Nlatter. }\end{array}$ & $\begin{array}{l}\text { Fuel value } \\
\text { of one } \\
\text { pound as } \\
\text { purchased. }\end{array}$ \\
\hline Potatoes . . . . & . . . & $\begin{array}{l}\text { Pounds. } \\
\text { I5. }\end{array}$ & $\begin{array}{c}\text { Pounds. } \\
17.9\end{array}$ & 2.8 & 325 \\
\hline Wheat flour . . . . & . . . & . . . & 87.5 & $3 \cdot 5$ & 1640 \\
\hline Corn-meal (bolted) . . & . . & . . . & $87 . \mathrm{I}$ & 2.3 & 1655 \\
\hline Oatmeal .... & . . . & . . . & $92 . S$ & 6.7 & I 860 \\
\hline Milk . . . . . . & . . & . . . & 13. & 17.7 & 325 \\
\hline Fresh codfish .... & . . . & 29.9 & I1. 6 & $34 \cdot 5$ & 205 \\
\hline Hind-quarter of fat beef & . . & 14.1 & $35 \cdot 9$ & $33 \cdot 3$ & II 35 \\
\hline Fowl . . . . . . & $\cdot \cdot$ & 30. & $24 \cdot 4$ & 61.5 & $68 \mathrm{o}$ \\
\hline Oysters . . . . . . & . . & . . . & II. 7 & 150. & 235 \\
\hline
\end{tabular}

FRUITS.

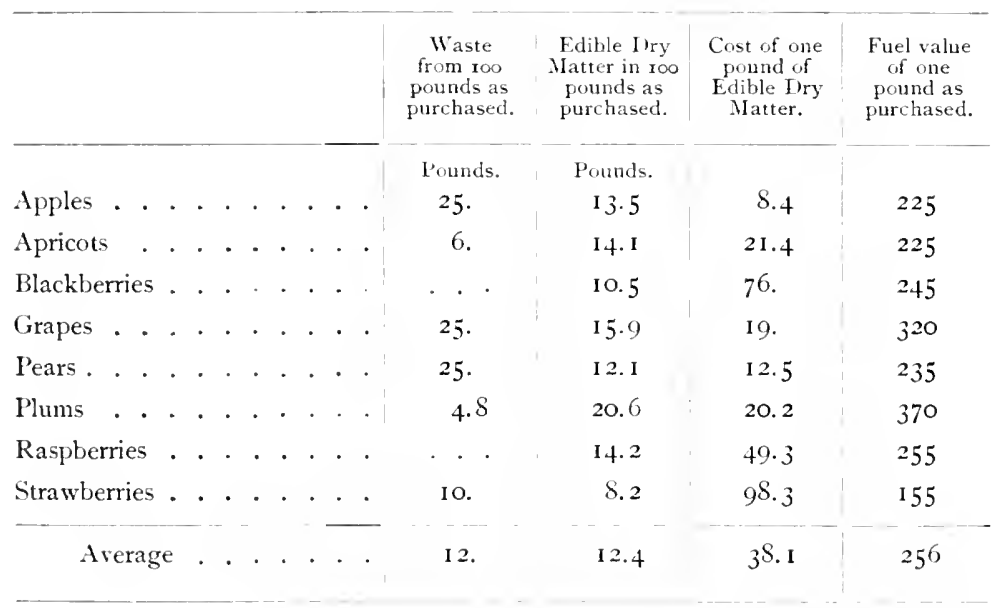


VEGETABLES.

\begin{tabular}{|c|c|c|c|c|c|c|c|}
\hline & & & & $\begin{array}{l}\text { Waste } \\
\text { from roo } \\
\text { pounds as } \\
\text { purchased. }\end{array}$ & $\begin{array}{l}\text { Edible Dry } \\
\text { Matter in roo } \\
\text { pounds as } \\
\text { purchased. }\end{array}$ & $\begin{array}{l}\text { Cost of one } \\
\text { pound of } \\
\text { Edible Dry } \\
\text { Matter. }\end{array}$ & $\begin{array}{c}\text { Fuel value } \\
\text { of one } \\
\text { pound as } \\
\text { purchased. }\end{array}$ \\
\hline Beets. . & . . & . . . & $\cdot \cdot \cdot \cdot$ & $\begin{array}{c}\text { Pounds. } \\
20 .\end{array}$ & $\begin{array}{c}\text { Pounds. } \\
\text { IO. }\end{array}$ & 6.6 & 170 \\
\hline Cabbage &. & . . . & . . . . & I 5. & 8.2 & I 8.3 & 140 \\
\hline Carrots . & . . & . . . & . . . & 20. & 9.5 & 9. & 170 \\
\hline Lettuce . & . . & . . & . . . & I 8. & 4.9 & 102. & 85 \\
\hline Onions . & . . & . . . & . . . & Io. & II. 4 & I 9. & 210 \\
\hline Parsnips & . . & . . . & . . . . & 20. & I6. I & 9. & 285 \\
\hline Green peas & s . & . . . & . . . . . & 50. & II. & 72.8 & 200 \\
\hline Pumpkin & $\cdot$ & . . & . . . . & 50. & $3 \cdot 4$ & 30. & 60 \\
\hline Rutabaga $t$ & turnif & ps . . & . . . . . & 30. & 6.4 & 7.8 & I 35 \\
\hline Squash . & . . & . . . & . . . . & 50. & 6.7 & $37 \cdot 3$ & I 25 \\
\hline Tomatoes & $\cdot$ & . . & . . . . & $\cdot \cdot$ & 5.6 & 22.3 & 105 \\
\hline Avera & age & . . & . . . . & 25.7 & 8.5 & 30.3 & I 53 \\
\hline
\end{tabular}

These are Professor W. H. Jordan's tables, and are valuable from the stand-point of the chemist and of the economist. The tables show that fruits cost about ten times as much as flour, corn-meal, and such articles, taking into consideration their food values; therefore there must be found other considerations than that of food value for prescribing and eating fruits. Fruits have long been a great part of the diet of the older races, and of the semi-civilized and savage tribes. The latter, especially those of the tropics and temperate latitudes, live on fruits, fish, and starchy vegetables, and these people are usually healthy, strong, and vigorous, and were more so until their more civilized and enlightened brothers introduced among them the various seductive poisons of a higher civilization. As a rule, with fruit we take much bulk that is not nutritious, and this very bulk is useful because it prevents us eating too much of the stronger articles of diet. Given fruit as the first course at breakfast, and we will not be so apt to orerload our stomachs with buckwheat cakes and sausages, and the fruit taken will in many ways help us 
to get comfortably rid of the greater burden, the sugars and acids of the fruit course being the factors here. The aroma of the fruits is pleasing to the senses, and thus aids secretion in various forms, especially of the digestive juices.

Taking this view of the matter, fruit is better taken with the meal, and before the meal rather than after the meal. During the meal especially we crave condiments or something to cater to our taste and bring out a proper secretion of the digestive juices and ferments, and to accomplish this we eat cramberry with our turkey, currant jelly with our roast mutton, capers with our boiled mutton, roast apple with our goose, and apple-sauce with our roast pork. A good scientific reason for eating these fruits is that the fats of the meats with which they are eaten are, as a rule, neutral fats; that is to say, they have not sufficient acid in them to cause the alkaline bile and pancreatic fluid to emulsify these fats, and the fruit acids here make up the deficiency in nature. What a teacher nature is, anyhow!

Fruits contain much water, and the general make-up is finished with sugars, starches, the gelatinous substance called pectin, acids, and cellulose, the cellular tissue, composed of carbon, hydrogen, and oxygen. When fresh they are markedly antiscorbutic and appetizing. Pectin is a carbohydrate, and the quince contains a large amount of it, making it especially good for jelly. The acids of fruits are the citric, the tartaric, especially in the grape, and the malic, which exists largely in the apple particularly. The organic acids are in union with alkalies, and these form salts, and these salts are split up in the system and leave the alkalies free, which usually combine and form carbonates or phosphates with acids found in the body.

Again, this is a fact of great importance both practically and scientifically. Why do we give lemon-juice and expect benefit, in rheumatic fever for instance, when the blood is so acid already that the profuse perspirations change litmus blue to red almost by their fumes before contact? We can answer, in giving lemon-juice in such cases, or any other fruit-juice, 
we do not give it as an acid to increase the already over-acid condition of the blood. We give it, paradoxical as it may appear, as an alkali to increase the alkalinity of the blood, bringing this about by the citric acid of the lemon being combined with salts, and these salts splitting up and reappearing as carbonates and phosphates, and these reducing the acidity of the blood, and thus aiding the return to health of the rheumatic condition. Even if the citric acid of the lemon is free, it meets salts in the system, and does the same good in a more direct way. This matter is all important.

Dr. Hoy has launched a tirade against fruit as an article of diet, simply because it is an acid diet, as he claims, and destroys the alkalinity of the blood. Hoy claims that fruits are mostly sugar and water, and this mixture ferments easily and destroys digestion. He claims that digestion, especially digestion below the stomach, is accomplished in alkaline surroundings and in alkaline media, and the acid in fruits eaten destroys this alkalinity and thus interferes with digestion, and therefore that fruit is improper diet in most instances. I think we have shown that it does no such thing, and that the fruit acirls, both combined and free, are, by the time they reach the point of intestinal digestion, in a condition not of acidity to render the surroundings acid, but are neutral or alkaline, and in this way help digestion, as they undoubtedly do even if they do not contain a special digestive ferment, like the pine-apple, called bromelin, which has the property of converting albuminoids into peptones. The juice of the papaw has the same power, even in a greater degree than the pine-apple, and doubtless many more fruits have juices with this power, if, indeer, all fresh fruit-juice does not have it to some degree greater or less. The prune and the fig and such fruits he condemns as causing by their coarse skins and seeds bowel irritations. More likely nature has provided just such fruits for these special purposes for man, and instead of condemning them it is our duty to learn all about them and use them in the proper cases. The fig, the date, the prune, and such fruits are, indeed, most useful fruits. 
Hoy says again, in his opposition to fruits as food for man, that the intestinal juices fo not act on starch, albuminoids, and fats, but act on the maltose made from the starch by the saliva and pancreatic juice, and on all forms of sugar, which may have been taken with the food. They convert these into glucose. The media in which this conversion occurs must be alkaline. Acid destroys this action, therefore acid in fruit eaten stops it. Yes, it would if it was present as free acid, but it is not present as free acid, but is combined with bases in the form of salts, and has an alkaline effect. Again, the small intestines transfer the digested matters in them into the blood. By their epithelial cells they change peptone into serum albumin and globulin, and as these they enter the blood, and here the media must be alkaline, and therefore fruit-eating is against this process. I say again, fruit rather helps along the alkaline surroundings, does not either check them or stop them, and is therefore beneficial. There is one condition where it is wrong to eat much fruit, especially wrong, such a fruit as apples, for example. If such be eaten after a hearty dinner, where much starchy matter like rice and potatoes has been eaten, acid indigestion will surely follow, because the fermentation has been hurried by the combination of the fruit-juice and the excess of starch. A little soda or potash will soon correct this temporary trouble. That "fruit is gold in the morning, silver at noon, and lead at night" is not altogether true, but will serve somewhat as a guide in our eating it.

Hoy gires the following as refinitions of fruits and regetables. "All succulent fruits produced by annual plants, as well as the stalks, roots, leaves, and tubers of any plant used by man as food, are vegetables. All succulent fruits produced by peremnial or biennial plants, and used as food, are fruits. The ripened edible seeds of leguminous and graminacenus plants are vegetable food, as are also nuts, which are the dry, oleaginous, or starchy fruits of perennial plants, in which the epicarp is liquefied." He speaks of fruit as acid and of regetables as not acid. Many regetables contain acid, as the 


\section{FORTY YEARS IN THE MEDICAL PROFESSION}

spinach with its oxalic acid, the cabbage with a little of the same, and the rhubarb with a great deal. The tomato has acid, much of it at times, but by its continued evolution from the realm of the vegetable to that of the fruit, it may be well to pause in classifying it, so rapid is its transformation to the fruit list approaching. Fruits contain, some of them, a little fat and waxy matter, as the olive, but, as a rule, sugars and starches predominate, with a very little nitrogen in the shape of vegetable albumin. Their aroma and flavor are given by various essential oils and compound ethers inherent in them and generated in the ripening of the fruit. The mangosteen of Borneo and the durian of Java are said to hold these above all others and to be the most luscious of all fruits. From the latitude in which they are raised, they are evidently sweet fruits. The cultivation of sour fruits, whether in a temperate or a hot climate, reduces the acid in them and improves their aroma and flavor. There is one thing always to remember in eating fruit of any and all kinds,-- they are invariably an inviting host for all pathogenic and other germs, and should never be eaten until the outer skin has been removed or until they have been thoroughly washed and cleansed. The boys' green-apple bellyache comes as often from the pathogenic germs that go down with his apples as from any indigestible properties pertaining to the fruit he has eaten.

A good anecdote is told of the great Pasteur, who above all other men probably knew of the risks we run from taking in pathogenic germs with our food. Pasteur was dining, and among other things cherries were served with the fruit. Pasteur was very careful to thoroughly wash his cherries before eating them, and delivered quite a lecture on pathogenic germs and their dangers, to those about the table, among whom were several children. The dinner finished, Pasteur, wanting water, in the absent-mincled way often attributed to great men, quaffed off the water in which he had washed his cherries, and the children chaffed him in great glee. Here were two object-lessons in nature study, one on absent-mindedness, and one on pathogenic germs. 
Fruits are usually classified as stone fruits, pomes, or the fleshy fruits, like the apple or pear, berries, capsules, or covered fruits, and the pepos, or melon family. Some, like the banana and the date, will support life for a long time on account of the great amount of sugar in them; others, like the pear and the apple, are helps in the general diet; and others again have less nutritive value than these, but have their uses as appetizers and digesters, as the papaw and the pine-apple. Thompson sums up the uses of fruits in the animal economy as follows:

To furnish nutriment.

To convey water to the system and relieve thirst.

To introduce various salts and organic acids, which improve the quality of the blood and react favorably upon the secretions.

As antiscorbutics.

As diuretics, and to lessen the acidity of the urine. They do this owing to the decomposition of various alkaline salts in the blood or tissues, which are reformed into alkaline carbonates, and as such are excreted. For this reason fruit is good for gout and the gouty diathesis, because it prevents the accumulation of acid urates.

As laxatives and cathartics.

To stimulate the appetite, improve digestion, and give variety in the diet.

As special cures for certain diseases, like the grape-cure, although their specific action is very doubtful.

The apple, lime, lemon, and orange have much potash, lime, and magnesia in their composition, and are the antiscorbutic fruits par cxcollonce. Peaches may be added to these. The most nutritious fruits are the sweet and starchy fruits, and are the banana, the fig, the date, the plum, and the grape. The most watery of fruits are the melons, the citrus fruits, as oranges, limes, lemons, and shaddocks, together with grapes.

The ripening of fruit is an interesting process. The absorption of oxygen by the fruit has much to do with it. The 


\section{FORTY YEARS IN THE MEDICAL PROFESSION}

contained acids and the tannin are altered by this as time goes on and the astringency and acidity of the fruit decrease, the starch going into levulose or glucose, and the gelatinous pectin is formed. Now, with these the volatile ethers and oils appear, and the fruit is ripe, or fit to eat, and this holds and this ripe condition increases until the fermentations of decay start up and the fruit returns again to its original elements, just as do all other organic bodies.

Thompson gives the most digestible fruits as grapes, oranges, lemons, cooked apples, figs, peaches, strawberries, and raspberries. I look upon strawberries and raspberries as rather gouty, from the less tendency of their acids to combine with bases during digestion, and thus leaving more free acid than other fruits to disturb the alkalinity of the blood. Not so digestible as the other fruits in the list given are melons, prunes, plums, rav apples, pears, apricots, bananas, and fresh currants. Of course, in all this much depends upon the condition of the fruit as to ripeness, etc., and the idiosyncrasy of the individual. The most useful fruits for invalids are oranges, lemons, baked apples and pears, stewed prunes, grapes, and the meal made from the banana, but not the fresh banana; it is too sweet and too starchy.

Frtit-juices I have spoken of, and of fruit-syrups, which are much used, and are made either from the fresh fruit or from the prepared fruit-juices; both are equally good when the materials are in proper condition. Lemonade, orangeade, raspberryade, raspberry vinegar, and such compounds are much used, and should be made from the juices of the fresh fruit, when obtainable, especially lemonade. Circus lemonade is made from citric and tartaric acid and colored with probably some aniline dye to make it pretty. Such a drink has no call for either the sick or the well. For the sick, lemonade and orangeade made from the effervescing waters are among the best and most invigorating, and such drinks slould not be overlooked.

Dried fruits are fruits from which the water has been expelled either by the sum or by artificial heat, and are preserved 
by their own sugar or glucose. Most of these are bleached by sulphur fumes. Whilst this may do no great harm to them as articles of food, it surely can do no good, and is a trick of the trade that should be stopped.

Proscres we are all familiar with. They are, as a rule, indigestible, containing a large excess of sugar, and are more and more being superseded by canned, tinned, or bottled fruits. Here the fruits are heated to destroy the bacteria present in them and then are hermetically sealed, and will keep in this condition just so long as no fresh air enters to bring new bacteria among them to set up fermentation. Remember one point: after a tin can has been opened, immediately empty it and keep the contents until used in a china or glass bowl. If left in the can the contents soon become poisonous and unfit for food.

The very finest and best of the fruits, and, in fact, all other articles of food preserved in this way, are those done up in glass. They are probably more expensive, but are in every way safer, for there are many reasons why metal cans and metal soldering, together with the acids of the contents, may react on the consumers and produce metallic poisoning, especially lead poisoning. The competition in trade causes many of the canners to use low-grade tin, the tern plate. which is little more than iron with a coating of lead: indeed, in this quality of metal there is little or no tin, and if the cans are recklessly soldered so the solder may enter and mingle with the contents, then doubly unfortunate are those who consume it. Remember, as to all preserved, canned, or otherwise treated fruits, they lack the elements of freshness, and for some unexplained reason they are not nearly so useful as antiscorbutics as are the fresh fruits or vegetables.

To show the importance of fruit to the American people as a part of their diet, let me give a short review, the facts for which I obtain from government publications and my own experience. The early colonists found here many wild fruits, herries, grapes, and nuts. From these selections were made, and these were cultivated and improved, and foreign slips and 


\section{FORTY YEARS IN THE MEDICAL PROFESSION}

cuttings were planted and grafted. In I82 I about three millions of pounds of dried fruits were imported. Apples were the first fruit we exported successfully. John Bartram, of Philadelphia, the well-known originator of Bartram's Garden in that city, a part of which is the Eastwick property at Gray's Ferry, and I think is now a public park, grew on these grounds the well-known Newtown pippin apple, which he successfully exported to England by sailing vessels, the trip consuming, on an average for the eastern voyage, forty days. In I82I we imported over two millions of pounds of raisins. In I894 California alone exported one hundred and three millions of pounds.

It is not generally known that the dried currant as imported is not a true currant, but is a small seedless raisin from Greece. They can be grown and cured in California, but the business is not very profitable. Plums are growing to be a large item of fruits in this country, and prunes are already a very large item, and are rapidly driving out the foreign product. In I 896 California produced over fifty-five million pounds. Figs are now being raised and cured in this country in quite large quantities. In Mississippi and in Louisiana quite a number are packed, and in California the original old Black Mission fig, grown there as such for over one hundred years, is being replaced by trees of the Smyrna and Italy varieties, and the fig industry is prospering. California produces now over a million dollars' worth per year. Dates are not as yet grown commercially in this country, nor are tamarinds.

The citrus fruits are grown very largely in Florida, California, and Arizona, and some in Louisiana. Previous to the serions damage to the trees in Florida in 1894 and 1895 , the Americans controlled the market in the United States. In I894 Florida grew five million boxes, and in I900 they hope to again have a large crop, barring accidents from frost. The Florida oranges, considering the care and attention given to them in selection and cultivation, are cloubtless the finest of any in the world. The California oranges are chiefly of 


\section{FORTY YEARS IN THE MEDICAL PROFESSION}

the Bahia variety, or, as otherwise called, the Washington navels and Riverside navels. California can ship now four million boxes of oranges annually. This is indeed a wonderful State. I have been on the summit of the Sierra Nevada Mountains and could have jumped into a snowbank that would have buried me many times over my head. In two hours by rail you could land and pick oranges and lemons from the trees and see the palms flourishing in the open air.

Australia is a great fruit country. The pine-apple, the grape, and the banana are grown in Queensland. The grape, the orange, the apple, and the peach are grown to perfection in New South Wales and South Australia. IVestern Australia is a great grape country. In Tasmania they raise among the finest apples and pears of the world, and ship them to Europe in cold storage successfully. The strawberries, raspberries, currants, and gooseberries of Tasmania are also noted. My friend, Dr. H. Benjafield, of Hobart, Tasmania, is one of the great Australian authorities on fruit, and is an accomplished gentleman. If we reflect, we see that when the trees of Australia are in bloom, our trees here are about maturing their crop, and vice vorsa, they being about as far south of the equator as we are north of it. When their fruit arrives in Europe or in the United States most of our crop of the year has been consumed. In the Australian countries fruit is so abundlant that, in the season, pine-apples can be purchased at three cents apiece, United States money, grapes for from five to six cents per pound, Mandarin oranges for one cent per dozen, and bananas for from two to four cents per dozen.

In Australia the consumption of fruits by all classes of people is enormous, and thoroughly explodes the idea that fruit causes general intestinal disturbances and is unhealthy. The death-rate in these countries is very low. There are luncheon shops in all of the towns of Australia, Tasmania, and New South Wales where fruit is given, all one can eat, with a cup of tea, coffec, or milk, for from ten to twelve 


\section{FORTY YEARS IN THE MEDICAL PROFESSION}

cents. These shops are used by all classes for the mid-day meal, and the people patronizing them are usually strong and healthy. In summer the weather is very hot, and fruit ices are used to a large extent. There are many of what are called tea-rooms, for women exclusively; the attendants are women, who in their black dresses, white aprons, and white caps have a neat and attractive look. In these rooms six cents is paid for a cup of tea or coffee, with bread and butter and all the fruit they can eat. I mention these matters here because I think physicians should encourage such arrangements for both men and women in this country, for the Australian people are a strong, vigorous, sober, intelligent, and progressive race, and this strength and vigor comes, very much of it, from their environment and from the great quantities of fruits and meats they so notably consume. In giving fruit with bread and butter and cereals, use the sweeter and subacid fruits to the exclusion of the very acid or sour fruits. The very acid fruits may affect digestion of the starch in the bread and cereals, as they may not be sufficiently combined with bases, but contain too much free acid. When the system appears to crave acids, eat sour fruit, do not drink vinegar and such.

As to the peculiar medicinal properties of some nuts and fruits, almonds are credited with giving brain-power, juicy fruits give the higher brain- and nerve-power, apples give the brain rest, prunes are nerve sedatives. There are fruit-cures, and several centuries ago medical men became enthusiastic over their medicinal virtues, and grapes and strawberries to the amount of many pounds a day were recommended to be eaten. Here certainly was an opportunity for nettle-rash to get in its work, and for the vasomotor system to become embarrassed.

The grape-cure, not only for the indigestions, but for various other ailments, is carried on at the present time to a considerable extent. Many persons flock every season to the Rhine vineyards, or to Italy and the soutl of France, to take the grape-cure for from six weeks to two months, and 


\section{FORTY YEARS IN THE MEDICAL PROFESSION}

are expected for that lengtl of time to eat from five to ten pounds of grapes daily. Grapes are fattening, and hence are good for the tuberculous and dyspeptics, and they are also of service to the neurasthenics. The grapes must be thoroughly ripe and of the best quality. Sour grapes are said to have the opposite effect. " The fathers have eaten sour grapes, and the children's teeth are set on edge."

The various pathogenic and other germs of the alimentary canal are said not to thrive at all in fruit-juices, and this is given as the secret of the success of the various fruit-cures. There is another way to look at it. Those who take these cures are generally high livers, are from anong the Carlsbad people, and the fruit-cure to them is semistarvation, and senistarvation to them is just what they need for restoration to health. A course at Carlsbad is about one and the same thing with grape-cure.

The physician should never tire of nature study, and before I pass to special fruits let me give some views of Dr. Bolling IV. Barton, of Johns Hopkins, on "Why the leaves turn color and fall."

Dr. Barton says the leares of most of our trees fall in the autumn because it would be poor economy on the part of the tree to retain them. They would catch the snows and ices of winter and thus break the limbs of the trees by this extra accumulated weight. The evergreens hold their leaves in winter; such are tough and leathery or reduced to needles like the pines. Most trees shed their leaves by an act of amputation, or sloughing, and cover the scar with a layer of cork, which stops bleeding and excludes germs. In the fall they assume the splendid colors of autumn foliage. This change in color has, so far as is known, no special biological significance; it is a mere incident in the later life and leath of the leaves. Color in flowers makes of them organs of allurement to insects, birds, etc., which visit them for their honey, and in return render service in pollination. Color in fruit makes it conspicuous, and secures free transportation by sundry animals, which thus scatter the seed. The hues of au- 


\section{FORTY YEARS IN THE MEDICAL PROFESSION}

tumn foliage mean little more in the lives of the plants than does the color of precipitates in the test-tubes of the chemist.

To understand these color changes in the dying leaf we must know something of the purpose and functions of healthy active leaves. This function is not, as is often said, to give shade, whether to the plant itself or to man or beast. If they shade the roots and so economize water, this is only by the way, and not the important rôlc they play in the life of the plant. The plant gets its food from the earth and the air. These are the raw materials, salts of the soil dissolved in water, and oxygen and carbonic acid gas free in the atmosphere. These simple substances are received in the leaves and spread out with the green substances of the leaf-cells to the action of the sun's rays, and are thus converted into the complex organic products upon which the plant depends for its growth and upon which animals can live. The leaf-green or chlorophyll is the substance upon which all this complicated chemistry depends, and has therefore been spoken of as the most important of all known compounds, for life, as we know it, could not exist without it. Without light and a certain high temperature the chlorophyll would avail nothing.

Leaves may be likened not inaptly to a factory operating only in summer time, when the sun is bright and the air warm. Then it is that a number of definite products are manufactured and transported back through leaf-stalk and stem to parts where they may be immediately needed for growth, else to be stored for future use. As autumn comes on the nights grow chill and conditions become unfavorable; preparations are set on foot to stop work and to destroy the factory. At this period the factory is more or less filled with manufactured goods and of waste or accidental products, the more important ones of which are to be removed and saved before the factory goes. The most expensive of all these is the chlorophyll. This, with starch, sugars, etc., is to be carried into the body of the plant. But they are not transmissible in their present form; they must be changed into soluble if not simpler substances, and so removed to the storage-places. In 
this breaking up of the clilorophyll especially, new products arise, such as microscopic oil-drops and certain fine granular bodies. These refract the light and are the cause of the color in the leaves, together with other coloring-matters dissolved in the cell sap. In a word, we may say that the color of atltumn foliage is due to waste products at the time the leaves are being emptied of valuable material preparatory to being cast off as dead tissue. The better the crop of leaves, the more brilliant fall colorings we may expect. Frost is not necessary to start it, only chilly nights. The changes may occur in July even, if wounds or disease come to the tree. In the northern part of the United States and in Canada the colorings are brighter than in the Middle States or farther south. The reason is, the maple abounds in the North and has brilliant coloring, and, moreover, in the North they are not subject to droughts so much as farther south, and consequently the cool autumn catches the leaves with richer contents, more color-forming material.

\section{SPECIAL FRUITS.}

The Apple.-Chemically the apple is composed of vegetable fibre, albumin, sugar, gum, chlorophyll, malic acid, gallic acid, lime, and much water. It also contains more prosphorus than any of the other fruits or vegetables. This is useful in forming the nervous matter of the brain and spinal cord and the general nervous system. What I have said of fruits in general will apply to apples and all fruits to follow, and I wish merely to call attention to the best of the species for all purposes, and especially for purposes of diet for the sick. A physician should know which apple, which pear, which grape, etc., is the best, their season, and all about them. The apple grows in most of the States of the Union, and is generally distributed over the world. Some varieties, of course, are better in some districts than others, and some are known only in certain localities. Of the hundreds of varieties of fruits, I only propose to mention and rescribe those which have merits sufficient to warrant them a place. 
SUMMER APPLES.

Summer Quccn.-This is the best of our early summer apples for eating out of hand or for cooking. It is striped with red on a yellow ground, and is of medium size, somewhat acid, spicy and rich flavor.

Srucct Bough.-Next comes the Sweet Bough, a greenishyellow apple, sweet and pleasant for eating, but does not cook well.

Rcd Astrachan.-Large, striped, red apple, very beautiful, and one of the best of the summer apples to eat raw or to cook. It came to us from Russia.

Ycllow Transparcnt.-Also a Russian apple, of a lightyellow color, and one of the best of its season.

Summor Pcrmain.-One of the very best and handsomest of the late summer apples. This is a beautiful red apple and very choice in every way.

There are other summer apples, but they are not much used anyhow, especially now, as we can keep over the winter varieties so late by cold storage, and those I have given are the best.

\section{FALL APPLES.}

Maidcn's Blush.-This is the handsomest and among the best of the early fall apples. It is yellow, with a distinct blush, and very good for eating and cooking and for decoration; it is very handsome.

Fallaz'ater or Tulpchockcn.-This is a large, yellowishgreen apple, and very good for eating or cooking.

The King Applc.-This is a large red apple, and in every way a very desirable one.

- Smith's Cidcr.-We see a great many of these apples in market in the early autumn. It is a red apple, very good to cook, not very good to eat raw.

Grimes's Golden Pippin.-Yellow with russet dots. A desirable fall apple in every way.

Ycllow Bcll-Flower-Bcllc Flcur.--Beyond a doubt, when you can get this apple, raised in Pennsylvania, New Jersey, 


\section{FORTY YEARS IN THE MEDICAL PROFESSION}

Delaware, or Maryland, it is of all apples facile princeps of its own season, from October to Cliristmas. There are many in the market coming from the $\| 1$ est, but they do not compare in flavor with those raised in the States mentioned. The surface is pale yellow, with a beautiful blush in the better specimens. The apple is juicy and crisp, with a spicy aroma and flavor altogether its own.

\section{IVINTER APPLES.}

Balditin.-This is a red apple, and probably the most common apple in the market in early winter. It is one of the best of the all-round apples, being tasty and pleasant, both to eat out of hand and to cook.

Ben Davis.-Of late this is the apple we see most of in the winter market, especially late in winter and in the spring. It is a beautiful recl apple, but there its good traits end. It is mealy, soft, and tasteless, and has not one redeeming merit to recommend it, except its looks and keeping qualities. The latter especially is unfortunate, for the sooner it rots the better for lovers of good fruit. For the grower it is unfortunately a profitable apple.

Spiticnberg.-This is a solid, not very attractive-looking red apple, known among the market men as "Spitz;" but taste it, and you will say there is a spiciness, a flavor, that attracts you; and eat another, and you will say, "Surely, this is the best apple by odds I have ever eaten." It is the best apple I have cover catch. No other apple compares with it, not even the Newtown pippin or Bell-Flower. It is very scarce in the market. New York is the chief source of supply. There the trees are not doing well, and this makes the apple scarce and high. Never mind that; buy it at any price if you want a delicious fruit to eat out of hand or to cook.

Necutoun Pippin-Albcmarle Pippin.-This is a grand apple, and the best specimens grow in the Shenandoah Valley, in Virginia, and its neighborhood, and in our market it is the most expensive apple, bringing nearly double the price of other apples. Her Majesty the Queen of England is said 


\section{FORTY YEARS IN THE MEDICAL PROFESSION}

to import a supply of them yearly, although, as a rule, the Englishman will take none but red apples. The Newtown pippin is a large, yellowish-green apple when ripe. The stalk is short and deep-set, and surrounded by light-russet rays. As a rule, to get the finer specimens now, we must spray the trees with fungicides, as we must all apple-trees at the present day.

When buying apples of any kind, always look for smooth, regular-shaped specimens. The irregular knotty ones have been prey to insects. Those with black and other dark spots have been prey to fungi, and, as a rule, are what are called scabby, and have been raised by careless growers and are not first class.

Romc Bcauty is an apple from Ohio we see frequently in the market. It is of medium size, verging on dark red in color, and is in every way desirable.

Cart Housc and its seedling Nero are lovely apples; indeed, are among the most desirable for all purposes. There are two species of Cart House,-the yellow and the white flesh. The skins of both are deep red, and every specimen will without an exception show one or more little warty excrescences. The yellow-fleshed variety is by far the best, and we in Delaware never take any other when we have the choice.

Stayman's Winc-Sap (its parent, the Old Wine-Sap).Always buy Stayman's. This species originated with Dr. Stayman, of Kansas. It is large, of a bright-red color, keeps well, and is in all respects a desirable apple.

Lady Applc.-This is a most beautiful little apple for decorating purposes, and has a lovely aroma and spicy, attractive flavor. It is of a yellowish waxen color, with deep crimson cheeks where it greets the rising sun. This is the proper apple to treat as the French do for table and other decorations. Just before the coloring sets on the apple they apply with an adhesive material a cut of any figure they wish to show on the apple, - a bird, a fish, or any mythological or other figure. This remains until the apple is gathered, and 
if still adhering. it is removed and the figure shows on the apple. In Paris apples so treated bring from one to two francs each.

The Morien is a very beautiful apple and of very high flavor. It is a seedling of the Lady apple but somewhat larger, and originated on "Morven," one of my fruit-farms at New Castle, Delaware.

Northern Spy.-This is a large red apple, with much green in its tinges, and is one of the first-class fruits found in our winter market.

There are several native Delaware and Eastern Shore of Maryland apples whose cultivation is increasing. If you ever come across them, buy them and you will not regret it. They are: Late Delaware Winter, which resembles Lawver, a red apple; Jackson, a red apple resembling the old Grindstone, of which it is supposed to be a seedling; Lankford, a red apple with green tinges; and the Lily of Kent.

Smokchouse is a red apple, a very good one, but scarce after November.

Roxbury Russet.-This is an apple of beautiful russet color, of medium size, and shading off in places to a light green in many specimens. It keeps late, and is a most toothsome apple in the spring, probably the best obtainable after February. Golden Russet and English Russet do not differ greatly from Roxbury Russet. Grindstone is a good apple at this season also.

Suadr-A greenish yellow. If you can buy Swaar you will make no nistake, especially in the early winter.

York Imperial.-A light-crimson apple, shaded with dark; subacid and very desirable.

Stark.-You will often find Stark in the market. It is a greenish yellow. I cannot recommend it highly.

Now and again you must allow an apple to your diabetic patients, and you want them as free from sugar as possible. The best for such a purpose are Red Astrachan, Summer Permain, Smith's Cider, Bell-Flower, King, Rome Beauty, Spitzenberg (this is the apple par crccllonce for the diabetic), 


\section{FORTY YEARS IN THE MEDICAL PROFESSION}

Northern Spy, Stark, York Imperial. Apples in the spring have more sugar, and should then be avoided by the diabetic. The foregoing list comprises the best obtainable, and is sufficient to supply apples of the best varieties all through the apple year. Oregon and some of the far Western States are beginning to ship us apples. They come in boxes like ordinary orange-boxes in shape and holding about a half-bushel of fruit. They are handsome, but are by no means equal. in flavor to the apples east of the Rockies.

PEACHEs. - The chemical composition of the edible parts of the peach is as follows: Water, 93.7 ; protein, .5; fat, .2; carbohydrate, 5.3; ash, .3. Fuel value per pound, I I 5. I give here a list of the peaches found in our markets during the season, and as nearly as possible in the order of their ripening, beginning with the earliest, which usually come from Georgia, beginning the latter part of June, and ending with those coming from California as late as the Christmas holidays.

Alcxandcr.-This is about the earliest peach, but we rarely see it except when it is grown near home, as it is too delicate to carry far. It is a white peach, of good flavor, and usually a freestone.

Amsden.-This closely resembles Alexander in every way.

Early Rivers.-Freestone. This is the best of the early peaches, and comes ten days after Alexander. It is a handsome white peach.

Troth.-This is a beautiful little white-flesh peach with deep blush. It is a dry, sweet, mealy peach, and is a freestone. Some years peaclies cling to the stone more than they do other years. Of course, there are some peaches always clingstone.

Monntain Rose.-Freestone, white flesh, one of the best peaches, and much like the old Early York, whose place it has taken.

St. John.-The best large, early, yellow peach, with a red cheek.

Foster.-A very good orange-red peach with yellow flesh. 


\section{FORTY YEARS IN THE MEDICAL PROFESSION}

Crawford's Early.-This is much like Foster, but it is not holding its own as a variety; it is freestone.

Old Miron.-This is the queen of peaches as to flavor. No other peach equals a perfect Old Mixon in flavor, I care not where it is grown; and those grown on the Delaware and Chesapeake Peninsula are the most luscious of all the peaches of the world. It is a freestone. The skin is of a yellowish white with a deep-red cheek; the flesh is white, red at the stone, and both tender and rich.

Moore's Favorite.-Almost exactly like Old Mixon.

Recues's Favorite. - A very large and handsome peach with yellow flesh, among the very handsomest and best of the yellow peaches; freestone.

Stump.-A superb peach with white flesh and a bright-red cheek, and is free from the stone.

Thurber.-A good peach, supposed to be a seedling of the Chinese cling, but it is a freestone.

Old Mixon Cling.-Like its sister, the freestone Old Mixon, it exceeds in flavor all other cling peaches, but is a very rare peach in the market.

Mary's Choicc.-Resembles Crawford's Early, but is superior to it in every way as found to-day; freestone.

Susquchanna.-A rare peach in the market, but it is a magnificent one of yellow flesh and red cheek, and is usually very large; freestone.

Elberta.-A truly grand peach, and the show peach of Georgia. It is a seedling of the Chinese cling. Yellow flesh, with beautiful deep-red cheek, and is elliptical in shape and freestone. Its only fault is, some specimens have some bitterness of flavor.

Georgia Bell.-A very fine peach, something like Elberta, but is white fleshed and comes from Georgia.

Dr. R. P. Harris told me the finest peach ever in the United States was the "Robinson Crusoe," a seedling grown in Dr. Cox's yard at Ninth and Spruce Streets, Philadelphia. Dr. Cox's son brought the stone from Juan Fernandez and planted it. 
Crawford's Late.-A superb peach; yellow flesh, red cheek; very large, handsome, and luscious; subacid flavor; freestone.

Lcmon Cling.-Elegant, large, and handsome cling peach.

Ward's Latc.-A freestone, white-flesh peach, with a beautiful red cheek and delicious flavor. It is scarce in market.

Chair's Choicc. - A very good late yellow-flesh peach, with red cheek; freestone.

Fox's Secdling.-One of the best of the late white freestone peaches, with red cheek. It is rather oval in shape, with an unguiform projection at its apex end.

Smock and Bccr's Smock.-Late, yellow flesh, very dry and mealy peaches, much used in canning and preserving. For those who like a dry, mealy peach they are very fine.

Doctor Black.-A very late, very large, lemon flesh color, luscious freestone peach. The finest peach of its time of ripening, coming after the other desirable peaches have gone. Very few are on the market, but Mr. Charles Wright, of Seaford, Delaware, is propagating the tree commercially.

Geary.-A very late freestone, yellow peach, which has the peach flavor somewhat, but never ripens. This is our latest peach.

Whitc Heath Cling.-This is a grand peach, is very scarce, and is the proper peach to brandy.

Salcuay.-Not very good in the East, as a rule, but is the best peach we get from California, and can be bought on the fruit-stands usually up to Christmas. It is mealy as we get it, and, like all California peaches we get in the East, is insipid. The other peaches coming from California are, chiefly, Early and Late Crawfords.

In order that one may know when to go to the markets for certain peaches, I give a table of the time of ripening of the better varieties of the Delaware and Chesapeake fruits. A week to ten days later will give the time for finding the New Jersey, Western Maryland, and Pennsylvania peaches, and four to six weeks earlier will find the same varieties from Georgia and the South and Southwest: Alexander, July I 
FORTY YEARS IN THE MEDICAL PROFESSION

to 7 ; Amsden, July I to 7; Early Rivers, July 20 to 25; Troth, August I 5 to 20; Nonntain Kose, August 23; Foster. August I 5 to IS; Crawford's Early, August I 5 to 20; Reeves, August 20; Moore's Favorite, August 23; Old Mixon. Angust 25; Ward's Late Free, September I to 2; Susquehanna, August 3I; Mary's Choice, Angust 20; Stmmp, September I ; Crawford's Late, August 30; Fox's Seedling, September 5 to 7 ; Smock and Beer's Smock, September I5; Salway, yellow, freestone, September 25; White Heath Cling, for brandied peaches, October I to I5; Doctor Black, October Io to I5; Bilyeu, October I to I 2.

If a diabetic should eat peaches at all, and he surely may now and again, the proper ones for him are the subacid varieties, the best of which are Foster, Early and Late Crawford, Reeres, Susquehamna, Smock, Salway, Elberta, Doctor Black, and Bilyeu. I look upon the peach particularly, but all fruits more or less, as very important articles of diet. The acids of the peach are very prone to break up the compounds of the waste substances, particularly of nitrogenous waste, and thus they are enabled to pass off through the kidneys, and an excess of water drunk helps this passing off. These tissuewastes may be largely in the form of uric acid, and thus peaches particularly may help sufferers from rheumatism, gout, and allied disorders, by breaking up these compounds and placing them in a condition to be eliminated from the system, and thus relieving the toxamia, for toxæmia it really is.

PEARs. - These I give in the order of their ripening. The summer pears are usually perishable, but the late pears hold, many of them, up to Christmas, and by the use of cold storage can be held indefinitely, and are found in onr markets up to warm weather in the spring. I may say here that pears are grown on the natural grafted or budded pear-tree,-that is, pear on pear,-but many are grown on quince stock. This dwarfs the tree, and hence we have standard pears and dwarf pears. The dwarf trees are shorter lived, but undoubtedly produce the best specimens of fruit in every way. Some varie- 


\section{FORTY YEARS IN THE MEDICAL PROFESSION}

ties dwarf better than others. Some pear-trees require to be double worked to get good results; that is to say, you graft one variety on a stock, and then next year to this you graft a variety that grows well only on this last stock. There are half-standard trees, that is to say, trees that have been planted as dwarfs,- - pears on quince-roots,- -and these planted deep enough to throw out roots from the pear stock as well as from the quince. These trees live longer than pure dwarf trees. Early pears ripen better in a cool room or shaded spot, after they have been picked. Late pears should be left on the trees as long as possible, then kept as nearly as possible in a temperature of $40^{\circ} \mathrm{F}$, and then moved to a warmer apartment as we wish to ripen them. Wilder and Koonce are two early pears, whose status is not yet exactly known. Manning's Elizabeth is the best of our early summer pears for eating out of hand, and is due in mid-summer. Its flesh is melting, sweet, and perfumed, with plenty of juice. It is rather a small red pear, with some russet on the crown half.

Lawson.-One of the most beatiful pears grown, but not of high quality to eat. It comes in July. It very much resembles the German pear, Forelle, the most highly colored of all pears when properly grown. The only place I have ever seen the Forelle in market in this country was in Baltimore. These pears, the Lawson and Forelle, are very valuable for decorative purposes, and for the sick-room are equal to the rose, violet, or carnation; and what is more comforting to the sick than fruit and flowers and the subdued tones of sweet music, and what a touching object-lesson has Dumas given us in "La Dame aux Camélias"!

Bartlctt.-Among the grandest of pears in every point of view. The best come from Pennsylvania, New York, Delaware, and Maryland, the handsomest from California, but these lack flavor. When will people learn to buy fruit for eating purposes, not by its color, but by its taste? A dealer in choice fruits some time ago asked me if I had any highly colored pears to send him; he said it made no difference about flavor, he wanted high color, to make it sell. Califor- 
nia sends the clearest, cleanest, highest colored fruits, because her clinate is so dry and free from fungi, which do so much to harmlessly discolor fruit. It all lacks flavor here, for it is pulled too green. In California it is better, but not equal to Eastern fruit.

Clapp's Favorite is a handsome pear, but apt to be found unsound at the core.

Doyennó d'Été is a small summer pear, as its name indicates; of good flavor.

Buffum is a very nice russet pear coming in the early autumn.

Duchesse d'Angoulcme.-One of the largest and grandest of pears, and when properly ripened is superb for eating. It has a thick skin and not always high color, but these do not hurt it. No one should eat the skin of any fruit: the rind carries germs, pathogenic and otherwise, in abundance. If you cannot pare the fruit, at least wash it thoroughly.

Anjou.-One of the rery best of pears, and comes to us late in the season; and from California it comes late into the winter and spring. The Anjou is one of the great pears, and you will make no mistake in buying them when able.

Clairgcau.-A beautiful pear, but not often found in our market, except from California: nor is Flemish Beauty.

Howell.-This is a lorely pear, much like the Bartlett. It is the whitest in flesh of all pears, and this makes it a beautiful pear to seal in glass.

Seckel.- We all know Seckel, that lovely little pear which comes to us in the early autumn, and is only excelled in flaror by one pear, and that pear is Dana's Hovey. This looks something like Seckel, with some cinnamon russet on it. It is melting, buttery, juicy, with a honeyed sweetness and exquisite aroma. It is undoubtedly the highest flavored of all pears. Seckel is second to it. Dana's Hovey comes very late. We ought to find it in the market in November. December, and January. I think it is more easily obtained in Washington and Boston than in other places.

Laaronce.-I want to recommend the Lawrence pear. It 
FORTY YEARS IN THE MEDICAL PROFESSION

is a lovely pear, and few are better for eating or packing. Its merits are not generally known. It is not a showy pear, and seldom has any color except yellow and green. You might sell to the passing crowd one barrel of the beautifully colored California Bartletts while you were selling a handful of Lawrence. The handful of Lawrence, however, is worth the barrel of Bartletts for eating purposes.

Bosc.-A long, slim, russet pear, so good a pear that some pronounce it not excelled by any pear that grows.

Sheldon.-A large, yellow, russet pear, nearly of the average apple shape. If the Sheldon pear should be offered you, buy it; you will seldom get a better one.

Kieffor.-The modern wonder among pears. It is a hybrid, and supposed to come from the union of the Japanese sand pear and the Bartlett, and was found growing in a garden in the city of Philadelphia. It is a most wonderful pear to produce fruit, and will keep to mid-winter or later, if properly cared for, without cold storage, and, if well ripened, has a fair flavor and a beautiful blush for decorative purposes. It is a great winter pear, and many barrels are yearly sent to Europe. Next to the Bartlett and Howell, it is the best pear to can. It is white and clear, but if too much sugar is added it takes on a pink tinge. This does not hurt it at all, but dealers object to it as off color. It is probably the most profitable pear to raise in the East; at least my own experience tells me so, as I have hundreds of trees on my fruit farms. The proper way to handle it is to allow it to remain on the tree as long as possible, then gather it and lay in longrows under the trees in the orchard, and only remove to the house when freezing weather threatens. Keep them at about $40^{\circ} \mathrm{F}$. until you want to ripen them up, when a warmer temperature soon makes them fit to eat or to can. They are better canned when ripe and not too green. To ship them to Europe they usually reduce the temperature by a month's cold storage before starting them.

The pears that come to us from California are the Clairgeau, the Easter, the Bartlett, the IVinter Nelis, the Anjou, 
FORTY YEARS IN THE MEDICAL PROFESSION

and the Doyenné du Corniche. They are all fairly good, but the best is Winter Nelis, so far as I am able to judge. As to pears in general, they are among the best and most luscions of our fruits, and to pick out the best is a difficult undertaking. In nny opinion, the three highest flavored pears are the Dana's Hovey, the Seckel, and the Bosc, in the order here given. For an invalid, such as a diabetic, the Kieffer is the best for him, and may be allowed now and again. The chemical composition of the pear is as follows: Water, 83.9 ; protein, .6; fat, .8; carbohydrates, I4.2; ash, .5. Fuel value per pound, 3ro. Recollect this is an analysis of the edible portion only. Pears are stronger food than peaches, but not so strong as apples.

Grapes.-The chemical composition of grapes is as follows: Edible portion, water, 78.8 ; protein, 1.3 ; fat, 1.7 ; carbohydrates, I7.7; ash, .5. Fuel value per pound, 425. Probably a little stronger than apples. The best grapes grown in the East, for eating purposes, are as follows:

Moore's Early.-This is the best of the early grapes. It is a large black grape with a blue bloom.

Worden.-A fine grape, and as an eating grape is superior to Concord, and has a thin skin and a large berry.

Concord.-A large purplish-black grape. It comprises a large portion of the grapes we see on sale in the market. It has not a very high flavor, but is useful for all purposes that grapes are put to.

Dclaware.-A small red grape, and probably the best flavored of all the grapes we buy of the American type.

Catawba.-Next to the Delaware in flavor is the Catawba. It is a larger grape, and is a very common one in the market. Martha.-A white grape, and one of very high flavor.

Lady is about as good as Martha, and is white.

Niagara is the white grape we see most of in the general market. It is a very good grape, with a little of the foxy flavor.

Empire State is a grape much like the Niagara, but possibly not quite so good. 
Pocklington is another white grape, and probably has a better flavor than either Niagara or Empire State.

Clinton is the great wine grape for domestic wine, and Salem is another, but the juice of any of them makes a fair wine. For unfermented grape-juice, the Concord is most used, because it is plentiful and cheap.

The before-mentioned grapes are all of the American variety and are distinguished from the European varieties by the fact that the skins are thick, the pulp holds the seeds interworen with it, and the pulp comes out of the skins holding the seeds, and when eaten we usually swallow seeds and pulp and discard only the skin. In the European varieties of grapes the seeds are merely set in the pulp unattached, and can be picked out like the kernels of a nut, and we eat skin and pulp, discarding only the seeds. Most of the California grapes we get in the market are of the European variety, and far excel any we can raise in the open air east of the Rocky Mountains.

Tokay.-This is the beautiful large red grape we see so many of in baskets holding from five to eight pounds. It is an elegant grape, of delicious flavor and aroma, and is more eaten here than any of the Pacific coast grapes.

Muscat.-This is by far the highest flavored of the California grapes we get in the East. It is a white grape, with the true Muscat flavor and aroma, and is a revelation to grape-eaters. The Muscatelle is a smaller grape of the same flavor as the Muscat.

Emporor.-This is a red grape from California, but not so often seen as the before-mentioned varieties.

Morocco.-This is a black, round grape, and, like all the grapes from the Pacific coast, is attractive and pleasant.

Fordcl is a white grape which has been mentioned to me, but I am not familiar with it.

Cornichon is a black grape, large, egg-shaped, and quite plenty in the market, especially late in the season. It has good flavor, but is the most unsatisfactory of the California grapes, as it is of the American type, where the pulp and 
FORTY YEARS IN THE MEDICAL PROFESSION

seeds intermingle or tangle up; the skin is thick, and unpleasant if eaten.

Raisins.-The California raisins are probably now the best in the world. The climate is most suitable, and the grapes from which they are made are in every way satisfactory.

Colcman Grape.-This is the great black grape, with stems half an inch in diameter, which we see in the fancy fruitstores, the bunches weighing pounds, and selling for fabulous prices. These grapes are imported from England, where they are grown under glass as one of the luxuries.

The English and French fruits, including peaches, plums, apricots, and such, grown under glass or protected in some way, are magnificent; they are perishable, and of course we never see them here; even there they are only luxuries those in affuent circumstances can enjoy. IVe grow here under glass very fine grapes of the European type which are of exquisite flavor and full aroma. Among the best are Black Hamburg, a very large black grape: Sweet Vater, a white grape of good flavor; and the Muscat, always fragrant and always acceptable to sick or well. The white Almeria grapes come to us from Spain, on the borders of the Mediterranean, and, although rather insipid, fill a void when no other grape is in the market.

Apricots.-The apricot is a delicious fruit, coming as it does very early in the season, between cherries and peaches, and from California we get them quite early in the spring. The California apricots hold the Eastern market because so few are raised here owing to the attacks of the curculio and worms at the collar of the tree. These are matters now which we know all about, and the remedies are at hand, and it is the fault of the grower in omitting attention to details if he does not succeed in raising apricots as well in the East as they do in California. The Russian varieties do best with us, probably, and the best of these is Harris Hardy, with a flavor exceeding any of those brought from the Pacific coast. Others we grow in the East are Early Golden, Acme, Moorpark, and Roman. Gibbs is an extra early, ripening in June, 
and Budd is a late one of good quality. Apricots are raised on peach stocks, on almond stocks, on apricot stocks, and on Myrobolan plum stocks. Among the best of the California apricots are the New Castle, Russian, Moorpark, Blenheim, and Royal. There are many other varieties. The apricot is naturally more nearly allied to the plum than to the peach, having the broad leaf and the smooth stone of the plum, but having down on its skin like the peach.

Nectarines.-On the other hand, the nectarine is a peach, with a smooth glossy skin like the plum. The nectarine is inferior in every way to the peach and to the apricot as a fruit. It has more of the noyau flavor than has the peach. Among the good varieties are the Downton, Boston, New White, Old White, Lord Napier, Elruge, and Golden.

Plums.-The plum is a popular fruit, and we may look for a great increase in its cultivation in the East and a great increase in the fruit in the markets. They have been arranged in two divisions,-Division I., red, purple, blue; Division II., green, white, yellow. There are varieties of plums without end. J. W. Kerr, of Denton, Caroline County, Maryland, is one of the great American authorities on plums. $\mathrm{He}$ is a large nurseryman and propagator of these and other trees, and a large plum-grower for market. In his American group, native plums, he gives over one hundred and twentyfive varieties, among the names being American Eagle, California, Etta Holt, Kieth, Louisa Smith, Stella, Winnebago, Yellow Sweet, Sloe. We will begin to find a constantly increasing supply of native plums in our markets, and they are bound to become an important part of the fruit supply for the masses. The Nigra group is for the far-off cold Northwest, and we will probably see few of them here, but they will give those people a hardy fruit for their inhospitable climate. The Miner group of plums are grown in the East and are late in ripening. The Vayland group are hardy, and grow in all parts of the country except the extreme Northwest. The Wild Goose group is the profitable group for the country south of New York in the East, and Wisconsin in the West, 
and are the ones we are most apt to encounter in the markets of New York, Philadelphia, Baltimore, and Washington. Among the best varieties are Choptank, Clifford, Freeman, Kroh, Ohio, Osage, Smiley, Sophie Whitaker, Red Cling, Wild Goose, Wooten. The Chickasaw group of native plums is for the country south of Mason and Dixon's line. Among the best are Munson, Newnan, Piram, and Yellow Transparent.

Besides the before-mentioned groups of native plums, we have the IVatsoni group, the Marianna group, the Maritima group, the Prunus besseyi (the sand cherry), the mongrels, and others, not yet classified. Truly, a great class of fruits, and one destined to do great good as it goes on in its evolution to perfect types.

The next type of plums is the Triflora group, or the Japan plums. Much of this fruit comes to us now from California, and the beautiful large plums we see in the fruit-stores are mostly from this source. Delaware and Maryland are growing them now in perfection, and our supply of the future will be much of it from these States. The Abundance is the variety we see most of,--large, oblong, mottled, lemon-yellow, sometimes much red, cling. Another is Berckman's, a cling, and another, Burbank, which rots badly. Hale is a good one, greenish yellow, with streaks and shadings of red, cling. Kelsey, greenish yellow with red, or all red. Kerr, very early, cling, conical, bright yellow. Red June, very early and good. White Kelsey, large, conical, greenish white. Yosebe, earliest of all Japan plums, small, red, fireestone. Chabot, one of the best, red on yellow ground, cling.

I give here the chemical analysis of the average apricots, nectarines, plums, and prunes. Plums, edible portion: Water, 78.4; protein, I ; carbohydrates, 20.I ; ash, .5. Fresl prunes, edible portion: W'ater, So.2; protein, .8; carbolydrates, I8.5; ash, .5. Dried prunes, edible portion: Water, 26.4; protein, 2.4; fat, .8; carbohydrates, 68.9; ash, I.5. Nectarines, edible portion: Wrater, 82.9 ; protein, .6; carbohydrates, I 5.9; ash, .6. Apricots, edible portion: Water, $8_{5}$; protein, I.I; 
carbohydrates, I3.4; ash, .5. Fuel value per pound of plums, 390 ; of fresh prunes, 360 ; of dried prunes, I 360 ; of nectarines, 305 ; of apricots, 270 .

Many of the old plums under the old names may still be found in market, and among the best are the Lombard, the red gage, Smith's Orleans, Washington, green gage, Imperial gage, Damson, and others.

Frcsh Pruncs.-If we get fresh prunes here in the East, they probably come from California. Prunes are plums, that is the long and the short of it. A fresh prune is a plum of a variety which, when dried in a peculiar way, makes the dried prunes, or prunes of our market. The names of the chief varieties of the French prune plums are the St. Catharine and the Brignolles, with a number of others. The chief California varieties are the Brignolles, Bulgarian, Datte de Hongrie, German Golden, Hungarian, Silver, St. Catherine, St. Martin's, Tragedy, Wangenheim, Giant, and Imperiale Epineuse. The fruit is picked after the dew is dried off. California has an advantage here over France,- the climate is so dry. The fruit is then ripened in shallow baskets. When ripe it is shut up in spent ovens for twenty-four hours. It is then removed and the ovens reheated. Then the prunes are replaced in the ovens. In twenty-four hours they are again removed, turned over, and laid on the leaves in the bottoms of the baskets. A third time the ovens are heated and the prunes are returned, and in twenty-four hours are taken out and allowed to cool. They are again heated from one to three times more, and then they are packed and ready for market. Nearly all of the prune output of California is sun-dried, and no artificial heat is required. There is a plum there called the Hungarian prune, yellow egg, much of which is cured by heat in evaporators. There is a large prune product in Oregon, Washington, and Idaho, nearly all of which is cured by artificial heat in evaporators.

The prunellos are plums, sometimes called prunelles. They are dried and packed in regular masses like dates, and come in boxes or mats. They are quite acid, and not very easily 
FORTY YEARS IN THE MEDICAL PROFESSION

digested. Remember, always, in luying plums of any kind fresh, to see that they are just ripe and not over-ripe. After fermentations of decay have started in them they become very hospitable hosts for many germs, pathogenic and otherwise, and are apt to produce what the boys call "green-apple bellyache," or something worse.

Date Plum.- Some species of this tree produce ebony, and are valuable trees. They are of the genus Diospyros, belonging to the natural order Ebenaces. The chief species from which the fruit comes is the Diospyros kaki, or Chinese date plum. Our common persimmon is of this genus, the Diospyros virginiana, and is quite a good fruit after it has been well frosted and developed its sugar. We are all familiar with dates, how they come in mats. They have a good flavor, and are a useful fruit for many purposes. The Diospyros kaki gives us the Japanese persimmon. We see them in market now, fresh from California and near by. Few of them thrive in the open air in the East above the Carolinas. Fine ones come from Florida. The Tane Nashi is a yellow seedless one, and thrives in the open air on the lower part of the Delaware and Chesapeake peninsula.

The chemical composition of dates and persimmons is as follows: Edible portion, water, 20.8; protein, 2.2; fat, 5.I ; carbohydrates, 70.4; 'ash, I.5. Fuel value per pound, I $_{5} 65$.

Tamarinds come to us chiefly from the WVest Indies. The tamarind-tree also grows in the East Indies. I never thought much of tamarinds. They are said to be laxative and cooling. The tree furnishing the fruit is the Tamarindus indica. The fruit is a pod from two to six inches long, containing seeds or beans, with a pulp something like our common locust bean. The pulp, put up with sugar, gives us tamarinds as we get it.

The mango, of the species Mangifcra, we get green, as a pickle, or put up with sugar as a preserve; neither is of much account. The mangosteen we never see in the United States, but will probably see them frequently when we run over to Manila to shake hands with our fellow-citizens of the 
Philippines. When those islands become States of the Union, we may get them from there in cold storage. When we do get them, and get them in prime condition, they will be of about the shape and size of an orange, and have a broad, peltate, lobed stigma. The rind is like that of the pomegranate; it is also something like the pomegranate in structure. It is at first green, and changes to dark brown. It is said to be the most luscious of fruits, the pulp and juice a mingling of the strawberry and grape. It is absolutely healthy, and can be eaten with safety in the tropics in great quantities by sick or well.

The Durian.-Here is another East Indian fruit. The expansionists probably had eaten it, and know what they are going for. It is a most delicious fruit, which undoubtedly those of our people who oppose expansion to the East have not yet tasted. The name of the tree bearing the fruit is the Durio. of the family Stcrculiacea, the only known species of its genus, Durio zibcthinus. The fruit is round or oval and nearly a foot long. It has a hard rind, with prickles. It has five cells, each with several seeds. The pulp is of a light yellow, with a delicious flavor, and an odor not at all inviting. The seeds are cooked and eaten like nuts.

The papaw is the fruit of the Carica papaya. It is something like a fig, and is eaten like it. The taste grows on one. It is coming into use as a digester of albuminoids. I have the trees growing, having raised them from the seed. They grow wild in Delaware, especially around mill-ponds, but are difficult to transplant. In the southwestern part of the United States they grow wild luxuriantly.

Pomegranate.-The many-seeded fruit, botanically. The tree bearing this fruit is Punica granatum. There are two kinds, the sweet and the sour, of a yellow color tinged with red. The pulp is the edible portion. It is hardy, even in the Middle States, if trained on the southern side of walls or other protector. I have eaten them in California and Mexico, where they thrive admirably. They are a poor fruit where we have so many better ones, but may be grateful in hot 
weather to one craving acid. The bark contains much tannin, and is used medicinally where an astringent is needed.

Figs.-The fruit of the Ficus carica. Chemical analysis: Water, 79. I: protein, I.5; carbohydrates, I8.8; ash, .6. Fuel value per pound, 380 . Figs thrive in the open air, on the lower part of the Delaware and Chesapeake Peninsula, and from there south and on the Pacific coast. The fresh fig is very sweet, to some insipid, and to others very grateful. Great quantities of them can be eaten at once when just ripe, as they are very digestible. They are cured by artificial heat, and in California in the open air. They have a reputation as an aperient; this is probably on account of the peristalsis produced by the physical action of the seeds.

Guava.-From the fruit of the Psidim guaiaia. The fruit is bright yellow, and very fragrant; indeed, so fragrant is it that the taste appears insipid after the delightful odor. It comes to us chiefly from the West Indies and Florida. The jelly made from it is delightful.

Alligator Pear (Pcrsea Gratissima).-This fruit is a native of the West Indies and of tropical America. The leaves and the bark have some reputation as an antiperiodic. I have eaten them on the western coast of Mexico, where they are highly esteemed as a breakfiast course.

Alligator Apple.-Fruit of the IVest Indian tree, Anona palustris. I give it here merely to distinguish it from the alligator pear. It is user medicinally as an astringent chiefly in Mexico. It is known as the Custard Apple.

The Coconnut.-Fruit of the Cocos nucifera, one of the best known of the palm-trees. and which always greets us as we approach the shore of any of the tropical islands. It flourishes only near the sea, but will grow inland in hot countries, but is unfruitful there. The blossoms are very beautiful. The clusters of blossoms are produced every six weeks during the wet season, and each cluster produces a number of nuts. In planting nuts, the three black spots, or monkey eyes, are set upward, and from one of these eyes the sten emerges. In the tropics the trees live one hundred 


\section{FORTY YEARS IN THE MEDICAL PROFESSION}

years; in greenhouses, from ten to twelve years only. In the tropics the wood is known as porcupine wood. Here the large leaves are used for clothing and to build huts. They are also used for writing on and for fans, fences, nets, sieves, combs, etc. Of the husks, scrubbing-brushes, ropes, and such utensils are made. The juice extracted from the flowers makes a drink. Fermented, it makes palm wine; distilled, it yields arrack, like that obtained from rice. The nuts when green contain quite a quantity of fluid. This is much used as a cooling drink, and the gelatinous mass lining the shells is eaten alone or flavored to suit the taste. If too much of the juice is taken, it irritates the urinary organs. It contains sugar, water, gum, oils, and soluble and insoluble salts. What we know as cocoa-nut is the albumin, etc., deposited on the inside of the shell. It is dried and prepared as we see it in the market, and used for various purposes by both the sick and the well. The chemical analysis is as follows: Water, 3.5; protein, 6.3; fat, 57.4; carbohydrates, 31.5; ash, I.3. Fuel value per pound, 3125. Quite a strong combination, truly. There is much oil extracted from the cocoa-nut, which makes the finest soaps, candles, and such, and for body lubrication it is unsurpassed. The cocoa-nut is a digester of albumoses, and an active one, from a proteolytic ferment which it contains.

Banana.-A plant of the genus Musa. The banana is Musa saficntum, the plantain is Musa paradisiaca. We buy in our markets bananas for plantains, and we buy plantains for bananas. For food there is not much difference. They come yellow and red. The red are usually larger. The chenical analysis of each is about as follows: Water, 74.I ; protein, I.2; fat, .8; carbohydrates, 22.9; ash, I. Fuel value per pound, 480 . Compare this with boiled white potatoes, and see how nearly they approach. The potato has most of its carbohydrates in starch, and the banana in sugar and starch. The sweet potato has both sugar and starch. Boiled white potato: Water, 73.7; protein, 2.7; fat, .2; carbohycrates, 22.3; ash, I.I. Boiled sweet potato: 
Water, 69.3: protein, I.8; fat. .7; carbohydrates, 27.1 ; ash, I.I. Fuel value per pound: White potatoes, 475 ; sweet potatoes, 565 . Here we read the values as foorl of the three great staples,-the banana, the white potato, and the sweet potato. The banana grows from the slip; that is to say, they cut the plant off at the ground and transplant it. I have seen them brought from the IVest India Islands and planted in Florida in this way, and they thrive in the southern part. The fruit is very green when cut to ship to our Northern cities, and suffers in flavor compared to that cut and ripened in the tropics. Formerly much was lost in shipping, but now fast steamers bring it in three or four days from Jamaica, Cuba, and the nearer islands, and we are getting the fruit in good shape compared with the earlier days. Fifty years ago a banana was almost a curiosity in Philadelphia; now it is a staple article of diet, and a very wholesome one. In the tropics the banana is the eating variety, and the plantain usually the variety they cook in various ways. They are fried, baked, and marle into pies and puddings. Bananas are dressed with wine, with sugar and cream, and with wine and orange and other juices. I think the devil is the author of some of these mixtures, by which he hopes to inveigle some foolish mortals he has set his keen eyes upon. The natives cut bananas into strips and dry them, and mash this up and eat it. We are getting now into our markets a bananameal. This, I think, will prove a good thing for both sick and well. It may be eaten in any way after cooking, as we eat porridge of any kind; with milk or cream and a little sugar added, it is most palatable and invigorating. In eating the banana out of hand, it slsould be very ripe, and it is not very ripe until the skin lras softened and turned well black. Fermentation has not commenced on the inside when the skin is quite dark.

The Pine-Apple.-This is another of the tropical fruits rapid transit is putting in our markets in prime condition. In the parlance of trade they are called "Pines." It takes its name from its resemblance to the pine-cone. Botanically it 


\section{FORTY YEARS IN THE MEDICAL PROFESSION}

is Anauassa satica. It belongs to the family Bromcliacca. From this its active principle, bromelin, takes its name. We formerly looked upon pine-apple as a most unwholesome fruit in every way, as a breeder of all sorts of diseases, especially of cholera. How little we knew then of the origin of such troubles, and the merits and demerits of things to be eaten! If prepared properly, pine-apple is a most digestible fruit, and is a digester itself of albuminoids, from the ferment bromelin it contains, as before spoken of. The wrong way to eat pine-apple is to shred it and throw away the core and the skin, for in the core and fibre and skin resides the bromelin. The proper way to eat pine-apple is to shred it and then squeeze all the juice out of the fibre and core and skin, spread it over the pine-apple, and eat it thus, plain or sweetened, and after eating - not before eating-other things. The proper time to eat pine-apple is after dinner, or after a "dejeuner à la fourchette." Then the bromelin assists the digestion of all the albuminoids consumed at the meal. So powerful is this bromelin that if persons eat the skin, the core, or the fibre, particularly, the tender skin and mucous membrane of the lips and tongue and inside of the mouth goes through a process of digestion in spots, and pine-apple sore mouth is developed. Here is a scientific explanation of what every one knows comes now and again from eating pine-apple. The best preventive is to cleanse the mouth and lips with water, or better, mint water, or some of the essential-oil waters, after having eaten this fruit. I frequently prescribe, with very good results, pine-apple juice for the dyspepsia arising from the indigestion of the nitrogenous foods. This juice, to be effective, should be made from the fresh fruit, using the skin, core, fibre, and all, and then straining it. A wineglassful or more may be taken after eating. If you cannot get the fresh juice, you may use the juice of the shops, with more or less effect, but the fresh juice is the best, as it is of all fruits for all purposes. The best and finest pine-apples I ever saw were grown on the island of Toboga, in Panama Bay. The chemical analysis of the pine-apple, edible por- 
tion, is as follows: Water, 89.3: protein, .4; fat, .3; carbohydrates, 9.7; ash, .3. Fuel value per pound, 200.

Tine Orange.-The queen of the citrus fruits, Citrus aturantium and other varieties. The other citrus fruits are the lime, the lemon, the citron, the berganot, and the shaddock. The orange needs a favorable soil and climate. In Europe the orange grows as far nortl as $42^{\circ}$. It will not do it in our country east of the Rocky Mountains. They grow the best in the world in Florida; they are also grown in Louisiana and Mississippi, and a few in Texas, Georgia, and Alabama. In Arizona they grow to perfection, and in California they are a staple crop, being chiefly of the seelless navel, so called; they are a Bahia orange. Our Consul there found that they grew wild in the surrounding jungles. He sent a few cuttings to the Agricultural Department at Washington, and Mr. Saunders succeeded in growing a few of them, and gave a few to Mrs. Luther C. Tibbetts, of California, who took them to her husband, Luther C. Tibbetts, at Riverside, California. He succeeded with them, and to him is due the honor of introducing the navel orange from Bahia, Brazil, into California.

The orange is a native of India, and grows wild along the sonthern slopes of the Himalaya Mountains among the tributaries of the Ganges. They were brought to the United States from Europe. The seedling orange-tree is known to exist orer six hundred years old. The seedling trees live much better and longer than the grafted trees; in fact. grafting is a levitalizing process as far as the orange goes, if it does not apply to all grafted trees. The grafted orange-trees give us better fruit and commence to bear earlier, but their limit of useful life is about twenty-five years. The chemical analysis of the orange is as follows: Water, 88.3; protein, .8; fat, .6; carbohyclrates, 9.7; ash, .6. Fuel value per pound, 220 .

Really the best oranges I ever tasted I bought in Acapulco, on the western coast of Mexico. They were a very small yellow orange, grown on the momtain-slopes, and were prob- 


\section{FORTY YEARS IN THE MEDICAL PROFESSION}

ably seedlings, as the Mexicans did not give much care to improving the natural character of their fruits. The sweet orange is the Citrus aurantium, as before stated. The bitter orange is the Citrus vulgaris. We have no use for it except for its bitter peel now and then, and to send it to the Scotchman with which to flavor his Dundee jam or marmalade. We all know of the uses of orange-blossoms for their lovely perfume, for the adornment of the bride where they are classic, and for the making of orange-flower water. In the orange countries we see the blossoms on the tree and the fruit of the last season still hanging, truly an enchanting scene, and the melting odors from the bloom render the surroundings ravisscmont. The best oranges we get, as I have said before, come from Florida. The Indian Rivers are the best of these. They also send us some very fine navels. The special oranges are the Mandarins and the Tangerines, the Chinese types, those little oranges which slip from their skins like walnuts from their hulls, and in doing so do not soil your kid glove; they have a flavor and odor of their own, and to some they are very palatable. There is another little curiosity of the Citrus type, the cute little Comquot, or Chinese orange. They are a condensation of lusciousness and full of aroma. You eat them skin and all, and to the sick and weary invalid they are often a revelation, and help his lagging digestion. They come to us from Floricla. Jamaica sends us good oranges, and manifest destiny, it appears, will soon literally smother us with such luxuries from our new colonial possessions.

Shaddock.-The fruit of the Citrus decumana, the word decumana referring to its size,-immense. It is supposed to be the "forbidden fruit," and was introduced into the West Indies from China by an English sea-captain, Shaddock by name. It comes to us now from the West Indies and Florida chiefly as grape fruit. The quality of the fruit is inferior: it is at once sour, bitter, and umpleasant, but has become popular to eat before breakfast as a peristaltic persuader, and is also used at ladies' luncheons, but is here dressed with sugar and sherry and other wines, to make it palatable. The devil, 
I am sure, had something to do with the invention of this last concoction, and women are still using it to tempt their own sex, if not to tempt man.

Orives.-The fruit of the Olea curopar, or common olive. The lilac and the ash, among our well-known trees, come under the same order as the olive. They furnish us with olive oil and the fruit. The oil we are all familiar with, or, rather, we suppose we are, but much of what we get in the shops for pure olive oil is expressed from cotton seed and peanuts, both of which, by the way, when properly handled, make fair table oils. True olive oil, as we find it in Italy, would not suit our tastes in America at all. It is dark and heavy, with strong taste and odor peculiarly its owrn. It is remarkable how one gets accustomed to it and comes to like it. It is like leaving France and her sweet saltless butter and going to England and eating her salted butter. At first the difference is marked, but we soon become accustomed to it. The oil is gotten from the fruit by expression, and as fine as I ever tasted was at the home of my late friend. Tiburcio Parrott, in the Napa Valley, California. He paid great attention to the getting of a good quality of oil, and California and her olive interests lost a good and progressive helper when he died. For eating, the olive goes through a preparation peculiarly its own, to get it rid of its bitterness and unpleasant flavor. The fruit is gathered green, but full grown, varying in size from a filbert to a pigeon's egg, and is then put into strong lye, and after a while in water, which is renewed often for several days. They are then bottled and a liquor poured over them one-half water and one-half saturated brine, with a number of aromatics added, this brine being first boiled. We find ripe olives, with the stones removed, treated in the same way. They are far the best for eating. I think, and add zest to the post-prandial wine and nuts. The olive farcie is a toothsome but rich morsel. They are the piece de resistance of olives, and are made by extracting the stone and stuffing with anchory, etc.

Lenons.-The fruit of the Citrus limomium, and one I 
FORTY YEARS IN THE MEDICAL PROFESSION

almost overlooked, yet one of the most important and grateful medicinally. Its juice, its rind, and its oil are equally useful. It came originally from India with the orange. The lemon- and orange-trees are much alike and grown under the same conditions of soil and climate. Lemon-juice contains two per cent. of citric acid, with mucilage and a bitter extractive. There is one peculiarity about the oil, as about most of the essential oils, - it does not keep long, but becomes to all intents and purposes turpentine and utterly unfit for its special uses. We should insist always on having such oils fresh or properly preserved from this change. Mixing with alcohol is the proper way to preserve them.

The Mulberry.-The red mulberry, Morus rubra, is a common one, and one of the best, having a pleasant, very sweet flavor. Being very perishable, it is only found in the market a short time. The same may be said of the white and the black mulberry. They are closely related to the fig family of fruits. The white mulberry, the Morus alba multicaulis, is the favorite tree for the silkworms to feed upon, and doubtless most of us remember the stories of our grandfathers of the excitement produced by the silkworm craze years ago. Downing's Ever-Bearing is probably the best producer of the best berries, and goes on producing day after day during a long season. Few ever appear in the market. They are a healthy fruit.

The Cantaloupe.-The best and most delicate fruit of the melon tribe, and so named from the Villa Canteluppi, near Rome, where the fruit abounds. It comes from the $\mathrm{Cu}$ curbitacca, or gourd family, and is botanically the Cucumis mclo. It grows almost anywhere in America. The best come from Delaware, Maryland, New Jersey, and Colorado. The skin is roughened with a cork-like net-work, and the better the specimen the more developed is this net-work. The small round or oval, dark greenish-yellow specimens are the best, although some of the large elliptic-shaped ones are of good flavor. There is a mean-looking melon of small size, with the net-work well developed, with dark-green coloring, 


\section{FORTY YEARS IN THE MEDICAL PROFESSION}

and a snout at one extremity, ustally of a lighter color, on the order of a wart. This melon usually comes from Gloncester and Salem Comnties, in New Jersey. It is without doubt the best and most luscious of all specimens yet introduced, possibly barring the new melon, Rocky Ford, from Colorado. Look at it only, and you would pass it by as for the pigs; taste it, and you will never cease to praise it. Jenny Lind is its name. The market men eall them "Ginnys." Just as I am writing this I received the following note with seeds from my friend, Dr. Robert P. Harris, of Philadelphia:

"I send you a new citron melon from Greece. There were four kinds of seeds, and their testing in Florida showed that these were the best, produced the largest citrons and the most distinctive. Fruit yellow fleshed, ten by thirteen inches, semitranslucent, superior to known varieties. Try them. They are in the shape of a truncated cone, as to form of melon." I will try them, and the "Harris," I have no doubt, will excel. A few days after I received the seeds Dr. Harris died, and all good work lost a devoted follower.

The IVAternelon.-The delight of our fellow-citizens of African descent and the pride of the small boy. Botanically, the Citrullus vulgaris. It grows almost anywhere and under almost any conditions. Thousands come to our markets yearly, starting in June or earlier from Florida, and ending with those from New Jersey up to the appearance of the Frost King in September. They are of various colors externally, the Southern melons being generally striped with light and dark green lengthwise, with the forbidding name of rattlesnake. Thoroughly chilled with ice, they are a luscious delicacy on hot days, are very healthy, somewhat dinretic, and altogether clesirable for the well, and often for the sick. The seeds are without doubt valuable in some cases as a diuretic.

The chemical composition of the cantaloupe is as follows: Edible portion, water, 89.5; protein, .6; carbohydrates, 9.3; ash, .6. Fuel value per pound, 185 . That of the watermelon is as follows: Edible portion, water, 92.9; protein. .3; fat, 


\section{FORTY YEARS IN THE MEDICAL PROFESSION}

. I; carbohydrates, 6.5; ash, .2. Fuel value per pound, I 3 O. There is a citron melon, a true watermelon. It is spherical and marked with stripes and shades of green. It is hard and tough, and is used only for preserves. It makes a handsome, clean preserve, and so does the rind of the edible watermelon. Its chemical composition, dried and sugared, is as follows: Vater, 25.6; protein, .4; fat, .6 ; carbohydrates, 72.5; ash, .9. Fuel value per pound, I380. The carbohydrates here are doubtless mostly sugar.

PARtridge Berry.- - Here we have a very interesting berry for the physician, often called the teaberry, the flavor of which is familiar to every child in his candy-stick. Botanically it is Gaultheria procumbens, and I believe is the same as the Mitchclla repens of Gray, which is also called checkerberry, winter clover, and wintergreen. It is a beautiful little red berry, of a sprightly pungent, aromatic taste, in market throughout the winter. Its flowers are very fragrant. It is an evergreen trailing plant, creeping around the roots of trees in moist places in the woods and swamps. The fruit is often grateful to invalids, and especially is useful in lithremic cases. This berry is one of the sources of oil of wintergreen, and much of it is prepared in New Jersey according to the United States Dispensatory. Professor Proctor has also obtained it from the sweet birch. It is supposed to exist in the roots of Polygala pancifolia and in the roots and stems of Spirca ulmaria, Spirca lobata, and Gaulthcria hispidula. This is all of great importance to the physician on account of the free use now made of salicylic acid and its salts, especially in the treatment of rheumatism and gout. The question here arises, Is there any advantage arising from the use of it, as it exists in nature in these plants, over that produced synthetically by chemical process? This is done by the method of Kolbe, by treating a solution of carbolic acid in caustic soda with carbon dioxide at a moderate heat. Horatio IVood lays down the chemical difference very clearly. Tht1s, oil of wintergreen contains ninety per cent. of methyl salicylate, a substitution compound in which one atom of the hydrogen of sali- 
cylic acid has been replaced by a molecule of methyl. $\mathrm{CH}_{33}$. The formula of salicylic acid is $\mathrm{C}_{7} \mathrm{H}_{6} \mathrm{O}_{3}$. The formula of methyl salicylate is $\mathrm{C}_{7}\left(\begin{array}{l}\mathrm{H}_{5} \\ \mathrm{CH}_{3}\end{array}\right) \mathrm{O}_{3}$. When oil of wintergreen is taken into the animal system, one atom of carbon and two atoms of hydrogen in the methyl are removed by oxidation and $\mathrm{C}_{7}\left(\begin{array}{l}\mathrm{H}_{5} \\ \mathrm{CH}_{3}\end{array}\right) \mathrm{O}_{3}$ becomes $\mathrm{C}_{7} \mathrm{H}_{4} \mathrm{O}_{3} . \quad \mathrm{C}_{7}\left(\begin{array}{l}\mathrm{II}_{5} \\ \mathrm{CH}_{3}\end{array}\right) \mathrm{O}_{3}$ has an atomic weight of ${ }_{15} 2$, while the atomic weight of $\mathrm{C}_{7} \mathrm{H}_{45} \mathrm{O}_{3}$ is I 38 . The administration of one hundred and fifty-two grains of methyl salicylate ought to be equivalent to the administration of one hundred and thirty-eight grains of salicylic acil. Now, as one hundred and sixty-nine grains of oil of gaultheria contain one hundred and fifty-two grains of methyl salicylate, they should be equivalent to one hundred and thirty-eight grains of salicylic acid. Now, the important question comes up, Does the use of the natural salicylic acid in these different vegetable sources, as from the partridge berry, birch, and such, have any advantage over the use of the synthetic compound made artificially by using carbolic acid, caustic soda, and carbonic acid? Stokvis has investigated the subject closely, according to Horatio Wood, and concludes that there is a marked quantitative difference, the natural acid being distinctly less poisonous than the synthetic product. This he believes to be due to the superior osmotic action of the natural acid. There is a general impression abroad that the artificial product is much more irritating to the kidneys than the natural, and therefore it is, I think, better to use the oil of wintergreen as our source of salicylic acid than to use the artificial salicylate or its salts, as the sodium salicylate; although I am not inclined to believe one much more injurious than the other, especially if we use the salt and not the pure acid, which I believe is now rarely done. I am particularly well pleased with the combination of colchicine and methyl salicylate in acute gout. I have given this particular notice to the partridge berry to show what great importance in medicine may attach to an insignificant little fruit, and to impress upon my readers the importance of accu- 
rate investigation into such now universally used remedies as salicylic acid and its salts, and methyl salicylate as it exists in nature.

Pigeon Berry or Poke Berry.-The beautiful lake-colored berry of the common poke, Phytolacca dccandra, should receive mention here, if merely to warn persons that it is not free from danger if used as food, and has some of the properties ascribed to it as a cure for rheumatism. Pigeons are very fond of the berries, and when eating them abundantly their flesh may be poisonous, as pheasants may be from eating the laurel. Poke-root is emetic. Another poke is the Indian poke growing wild around us. This is the American hellebore, and produces the well-known remedy, formerly used more than at present, Foratrum siride. White hellebore is the European hellebore, the Voratrum album.

HAw.-The hawberry, or at least one of them, of a darkblue color when ripe, is a very toothsome one, but the species which bears it is a very rare one; indeed, I am in doubt as to its identity and whether it comes under the hawthorns or the stone fruits. The buckthorns, as a rule, have purgative qualities, and we get the valuable cascara sagrada from the California buckthorn, the Rhammus purshizana.

Wine Berry.-A new berry of the raspberry order, and said to be different from any other berry. It is juicy, and its flavor is sweet, and may be used for eating, wine, preserving, or canning.

LOGAN BERry.-Another new berry among the fruit men. It grows or trails on the ground like the dewberry. Its fruit is often over an inch long, dark red in color, with the shape of a blackberry and the color of a red raspberry, with a combination of the flavor of both.

Gooseberries.- The gooseberry is a very common fruit, and with cultivation and proper ripening it is very toothsome, especially the large English varieties introduced here. These are at the same time very delicate, from the tendency of the berries to mildew (erysiphe mors uac). It comes botanically uncler the type Ribes grossularia. There are many species in 


\section{FORTY YEARS IN THE MEDICAL PROFESSION}

America. They nake among the hest of jans, and analyze as follows: Refuse, 3.5; water, 85.7; protein. 5: carbohydrates, 9.8, which includes $1 .+$ per cent. acill: ash, .t.

The Currant.-There are two species of the Ribes tribe. The Ribes rubrum, the red currant, is the one we generally see in this country, and the best varieties are the Red Dutch and Fay. The fruit is quite acid, yet a few of them are pleasant to eat, and are healthy. There are also some white varieties, or, rather, some light-colored varieties. The black currant is the one most used in England, and has a heary odor and flavor of its own. The red currant makes a sprightly jelly for mutton, venison, and wild ducks, giving zest to the flesh and acidifying, as it were, their fats, which are more or less neutral, and do not emulsify properly with the bile and pancreatic juice until acidulated somewhat. The black currant, Ribes nigrum, is quite astringent, and is a favorite ingredient in throat lozenges and such remedies. The Englishman loves its jelly. The currant analyzes about as follows in the dried state: Water, 27.9; protein, I.2: fat, 3: carbohydrates, 65.7; ash, 2.2. Fuel value per pound, I37o.

The Cranberry.-The cranberry we all know of from the delicious sauce it makes and which serves the same purpose in digestion as currant jelly and other sauces. It comes with many varieties from the Iraccinimm macrocarpon and other shrubs which grow wild in boggy places in the temperate zone throughout the world. In the bogs the organic decay around it gives it its organic acid: cultivation improves the berry greatly, and the finest I ever saw were sent me by a friend from his bogs on Cape Cod. Cranberries ship best over the seas packed in water; they analyze as follows: Water, 88.5; protein. .5; fat, .7 ; carbohydrates, ro. r ; ash, .2. Fruel value per pound, 225.

The Cherry.-This fruit especially delights the small boy, and gives him many a barl turn, not so much because the fruit is innately bad as that the small boy is innately reckless in his eating of it. Here is the analysis of the ellible portions: Vater, 86. I: protein, I.I: fat, .8: carbohyclrates, I I.4; 
ash, .6. Fuel value per pound, 265. Not a bad showing for health. The bad reputation of the cherry as an article of food is doubtless caused by the habit of eating it out of condition as to ripeness, and as to its fermenting or rotting state, and because it is a most hospitable host to pathogenic and other germs. Before it is eaten it should be thoroughly washed and cleansed. Botanically it is the Prunus cerasus, or Prumus vulgaris, and is said to be of Asiatic origin. The wild cherrytree is the Prumus virginiana, or the Cerasus virginiana. There is much prussic acid in the cherry-wood, particularly in the bark of the wild cherry, which is taken advantage of for medicinal purposes. Our finest cherries for eating come undoubtedly from California, where the soil and climate suit them exactly. They come to us of the black and white varieties, the finer specimens being the Governor Wood, Black Tartarian, Cleveland Bigarreaı, Reine Hortense, Llewelling, Napoleon Bigarreau, and others. These are all magnificent fruits, and give us good healthy luxuries of the fruit kind. In the country east of the Rockies, including our own near-by neighborhoods, these grand cherries of the French and other types do not do so well as young trees. They appear to be weak, and yield to sun scald and other destructive diseases. I have planted a number of them, and very few live, while, on the other hand, on the same fruitfarm there are trees vigorous and hardy of the best of the old heart cherries approaching a century old. I cannot help but think there is some inherent weakness in our young trees brought about by improper propagation and by the devitalizing processes of grafting and budding. We grow fine sour cherries where we cannot grow the sweet ones, the best of the sour cherries being the Early Richmond and May Duke.

The Quince.-This fruit is useful only for preserves and for its many medicinal qualities. Its seeds produce an emollient much used by oculists as quince-seed mucilage. In treating it, the fruit requires parboiling to set the albumin as a preliminary to sugaring it. The best varieties are the Orange, the Champion, the Meech, and the Rea. 


\section{FORTY YEARS IN THE MEDICAL PROFESSION}

The BlackBerry.-This comes under the genus Rubus. The wild blackberry is the Rubus villosus. It is cultivated, and the evolution to the higher types has been rapid. It is used medicinally for its astringency, the fruit, the leaves, and the roots. The best varieties we find in the market are the cultivated Wilsons, Wilson, Jr., and the Early Harvest. The common wild blackberry has a fine flavor, more delicate than the cultivated. All the berries, both wild and cultivated, are much used for jams, wine, and brandy, each being more or less astringent. The analysis is as follows: Water, 89.9, protein, .9; fat, 2.1 ; carbohydrates, 7.5; ash, .6. Fuel value per pound, 245 .

Dewberry.-This is about the same berry in analysis as the blackberry, but it is perlaps a little sweeter and larger in the wild state, and trails along the ground, whilst the blackberry-canes grow upright. The Lucretia is the chief variety in the market. They are both known among countrymen as brambles. Botanically the dewberry is the Rubus trivialis, or Rubus canadensis.

The RAspberrY.- This comes under the same genus as the blackberry, the Rubus. The raspberry is the Rubus idaus. The red wild raspberry is the Rubus strigosus, and the black wild raspberry is the Rubus occidentalis. The fine specimens we see in the cultivated reds and black caps doubtless come from these as the result of selection and cultivation. They are too familiar to all to need any description, and I need only say that the flavor of the raspberry is among the most delicate and delicious of all berries. They analyze as follows: Water, 85.8; protein, I ; carbohydrates, I 2.6 ; ash, .6. Fuel value per pound, 255. The best red varieties are Miller, Marlboro, Brandywine, Turner, Cuthbert, or Queen of the Market, a very large and beautiful berry, but apt to be soft if carried far. Shaffer's Colossal is the largest; Hansell is the earliest. Of the black caps, the best are probably Souhegan and Gregg. You will occasionally see a yellow or amber raspberry in the market; they are sports. The Golden Queen is a fine one, and is a sport of 


\section{FORTY YEARS IN THE MEDICAL PROFESSION}

the Cuthbert. It is a luscious berry, and an odd one for decorative purposes. Raspberry vinegar, raspberry syrup, raspberry wine, and raspberry jam are products of the raspberry.

The Strawberry.-The strawberry is a luscious and in every way an interesting berry. Let me say, as a matter of precaution in regard to the strawberry, the raspberry, the blackberry, and all such berries, care should be exercised as to eating large quantities of them, and particularly of raspberries and blackberries. Children and elderly people should be particularly cautioned, as the large bowels are liable to become packed with the seeds and cause inconvenience and trouble. They also cause urticaria in many, probably from some idiosyncrasy of the individual, or from something they may accidentally meet in the bowel, and set up a ptomaine poisoning on a limited scale, evincing itself by the indigestion and the rash accompanying it. Let us return to the strawberry. Its chemical composition is as follows: Water, 90.9; protein, I; fat, .7; carbohydrates, 6.8; ash, .6. Fuel value per pound, I75. The various species belong to the genus Fragaria, and are of the rose family. The fruit as we eat it is not really the true fruit of the vine. The pistils are placed upon a convex receptacle, and this, when the ovaries are ripe, is much enlarged, and this is the fruit as we eat it or call it. The true fruit is the little ripened ovaries which look like seeds scattered all over what we eat as the fruit. Under cultivation the stamens of some varieties abort, and the blossom is thus not self-fertile; that plant is diocious, and in raising the berries practically, it is necessary with these diœcious plants to set a fertile or some monœecious kind about every third or fourth row. This makes the plant an interesting study, as the Indian-corn plant is an interesting study. Here the silk is the pistils, and these must be impregnated by the pollen of the antlers at the top of the stalk, or no grains of corn will be produced. Here the stamens and pistils are in different flowers or different parts of the same plant. The best varieties of strawberries are named below, and to appreciate the great consumption of the berries it is only necessary to watch the line of 


\section{FORTY YEARS IN THE MEDICAL PROFESSION}

travel on the railroads leading from the Delaware and Chesapeake Peninsula or from South Jersey. Thousands of carloads pass every season for the markets of the great cities. The Michel is the first of the early berries, and is an all-round good berry. It has a perfect blossom. The Ideal is one of $\mathrm{J}$. W. Kerr's new berries, with a perfect blossom. Oriole is another, with imperfect blossoms. The Sharpless is an old, very large, and well-tried variety. The Bubach No. 5 is, I believe, the largest and, taking everything into consideration, the finest berry yet introduced. It is imperfect as to blossom. The Gandy is the best berry we see late in the market, and has a perfect blossom. The Kentucky is the firmest late berry, and has a pistillate bloom. Warfield No. 2 is a good berry, pistillate. Wilson Albany is one of the very oldest varieties and a very firm berry, and carries a long distance well; staminate. The Haverland is a fine berry of the lady-finger order; pistillate. The Lady Thompson, staminate, is a good berry from North Carolina early in the season, but not good raised in the Middle States. These early berries, some coming from Florida in January, must be firm to have carrying capacity. Warfield No. 2, I think, comes from Florida in January and February. The Crescent is probably the most productive berry for the grower; it is small, a good berry, but not attractive; it is pistillate. The Hovey is the oldest of the large varieties, very dark red, and very large and luscious. It is rare now. Lovett, a good berry from New Jersey. Van Deman, named for Professor Van Deman, late United States Pomologist; staminate. The best new strawberries in our markets are the Bismarck, Tennessee Prolific, and Johnson's Early. All these have perfect bloom. The largest and finest strawberries I ever saw were in California forty years ago. They were a light cream-color, nearly white, and immensely large, with a delicious flavor. I have never seen berries like them in any other country. Whether they were sports or originals I do not know. California is a great State for all fruits, and I believe you can purchase strawberries in the San Francisco markets every month in the year. 
How and why Fruits decay.-Dr. G. C. Caldwell, of the Cornell Experiment Station, has given us some good points on this head. The changes which take place in the ripening of fruit are in some respects similar to the changes of rotting. In ripening, the abundant starch of the green fruit is changed to cane-sugar; later a great part of the cane-sugar becomes glucose. These changes may go on whilst the fruit is still on the tree, or in the storage-room after it has been picked. This change of cane-sugar to glucose does not help the fruit in flavor, for glucose is less sweet than cane-sugar. The riper fruit gets, short of decay, the sweeter it gets, not because the cane-sugar changes to glucose, but because so much of the starch, which is tasteless, becomes sugar and some of the acids of the fruit are decomposed. As fruit goes on to rot, what cane-sugar there is goes to glucose, and then this glucose is decomposed. The proteids and the tannin also are decomposed, and new chemical compounds are produced which cause the brown color and the unpleasant taste of the decay which has now set in. Different species of fungi cause this rotting of the fruit, and the three important ones are Pencillium glaucum, Botrytis vulgaris, and Oilium fructigenum. This last-mentioned one exists even on the fruit-trees, and attacks both the ripe and the green fruit, and is even found on the blossoms. It goes in at the stem of the fruit, into the twig and the leaves, and kills both, producing the twig blight and leaf blight so common. Flies and wasps and other insects carry this fungus from tree to tree. The more wasps and flies there are about, the more decayed fruit there is. These fungi of decay produce a poison which kills the cells of the leaves and of the twigs and of the fruit. Now, as to spraying for these fungi with copper and arsenic, even if we spray late, when the fruit is grown, there is little trace of the poisons on the fruit, and they are safe to eat. I have several years since experimented with fungicides sprayed on apples in winter storage in Delaware, and at the time I thought the results were good. The great increase in these fungi over the times of fifty years ago, together with the 


\section{FORTY YEARS IN THE MEDICAL PROFESSION}

higher temperatures of our cellars where our fruit is often stored, are the great reasons why our fruit does not keep now like it did in the cellars of our grandfathers. General cold storage is coming in to remedy all this and to decrease, I trust, the development of the fungi of decays.

\section{MUSHROOMS.}

The Edible and the Poisonous Fungi.-Mushrooms are so universally used for food that it is of the greatest importance that not only physicians but laymen should know at least sufficient about them to avoid those growing wild which are poisonous, and to distinguish those which are edible. Bulletin No. I5, Department of Agriculture, by Dr. W. G. Farlow, gives the best résumé of the subject I am acquainted with, and to him I am indebted for assistance. Mushrooms are toadstools, and therefore the names do not distinguish them. The best known and edible of the toadstools are what we know as mushrooms, so called in the markets. There are many other toadstools not known in market as mushrooms, which are edible, and many more of them are not poisonous, even if not very palatable. How do you tell the edible from the poisonous fungi? We do not exactly know scientifically, but we know in regard to many of them empirically, because some one has eaten this one and lived to tell the story, and another person has eaten that one and died from the effects. The number tried empirically is small in comparison to the whole number of species of toadstools. As to this great number of unknowns, we might say that this one is not poisonous because it resembles that one we know to be harmless, and this one is poisonous because it resembles one we know to be poisonous. This reasoning may not always be practically safe. Mushrooms and toadstools (I use the word mushroom to apply to the edible fungi, or, rather, the ones we are familiar with in market or on our tables, and the word toadstool to apply to those not generally used as food, whether edible or not edible) belong to the group of fungi known as Hymcnomycetes. They grow in the ground or on the bark of trees. 
There is first a ball, which gradually enlarges and shoots up into a stem bearing at the top the umbrella, or pileus. This gradually expands, in some species largely, and in others keeps more of a ball shape. The mushroom or toadstool comes from fine threads. These threads are the spawn, or the mycelia, the spores of fungi. Each thread is called a hypha.

The word mushroom is almost universally used to express an upstart of any kind, whether in real life or otherwise. This would seem to indicate that we all think of the mushroom as springing up in a night. This is not the case. The button developing from the mycelia takes often a long time, even weeks, months, or years, before it comes from the mycelia or spawn in the ground to the top. True, the mycelia, or spawn, are the whole plant, and the mushrooms are the fruit only, the reproductive bodies like the apples of the apple-tree. The spores, the mycelia, the spawn, reside in the mushrooms or fruit of the fungus. The buttons, in the parlance of trade, are these young non-expanded mushrooms, and mushrooms are the expanded buttons. In Europe buttons are most used. In this country we use mostly the expanded fruit. In the toadstool family the under side of the umbrella, or the pileus, bears the spores or seeds. In some species these are like the spokes of a wheel, and radiate to the circumference from the top of the stalk. In others they are packed in and together like tubes in a boiler, in others like teeth, whilst in still others the surface is only set in wrinkles. The wheel-spoke or gill group are called Agaricini, or the agarics; the tube group are the Polyporei, the teeth group the Hydnei, and the wrinkle the Thelephorei.

There are some toadstools with no stalk at all, yet even some of these mere balls are edible, but no one but an expert should even think of eating them. Nearly all of the edible mushrooms belong to the agarics and the polyporei. No one when beginning, and not yet an expert, should gather buttons for food, for it is then so difficult to distinguish the species. Of course, this does not apply to cultivated mushrooms, for 


\section{FORTY YEARS IN THE MEDICAL PROFESSION}

the species is known and raised only for food. Again, do not eat old decayed mushrooms, as even the edible ones when old may develop poisons.

The common mushroom, Agaricus campestris, is really the only species cultivated and sold in our markets during winter. In summer it grows wild, is most plentiful in June, July, August, and September, and is found more frequently in old pasture-fields than in other places. As a rule, it does not grow in the woods. The stalk and umbrella are white or cream-color, and the gills are pink, going on to dark brown or purplish brown as the mushroom gets older. This pink or brown color is due to the spores on the gills. The stalk is cylindrical and solid, and near the umbrella is a membranous ring, and below this there is no membrane or scales. Remember this. They grow singly or in clusters of several. Before the umbrella opens the gills are covered by the veil; when the mushroom expands, the veil ruptures and the red gills are exposed. What is left of the veil clings around the stalk and forms, a little below the umbrella, the ring before spoken of. Some fragments of the veil also remain attached to the margin of the umbrella, giving it a slightly fringed appearance. When looking for this mushroom see that the gills are pink or dark brown and not white, that the stalk is round and solid and has the ring below the umbrella, and that it has no bulb at the ground end and no scales or bag of a membranous material. It never grows on old logs or trees.

The two poisonous toadstools in danger of being mistaken for the common mushroom are the Amanita phalloides, the deadly agaric, and the Amanita muscaria, the fly agaric. The former is the worst, and the latter is the most common. The fly agaric is quite common; it grows on roadsides, on the borders of fields, but not often in pastures, and not usually with the common mushroom. It grows very often among pine-trees and under evergreens. It grows singly and is often very large. Its gills are white, not pink. Its stem is hollow, not solid like the common mushroom stem, there is always a 


\section{FORTY YEARS IN THE MEDICAL PROFESSION}

bulb at the ground end, and scales on it. The color of the umbrella is brilliant yellow to orange, and a deep red, especially orange. The surface of the umbrella is polished with a number of warty scales, which cannot be rubbed off. There is a large membranous collar hanging down from the upper part of the stem. This is the mushroom most frequently causing poison, but surely $n 0$ one having the least experience in gathering mushrooms could mistake it for the common edible mushroom. Pick it up, and it is light, and the stem has no strength, and bends like a piece of cooked macaroni. The common mushroom has a firm, solid stem. This fly agaric strongly resembles the Amanita rubescens, one of the most delicious of mushrooms, with a flesh of red tinge. None but an expert should gather this; they may pick the poisonous fly agaric for it.

There is another delicious mushroom not common in the North, but often found in the South,--the Amanita casarea, or royal agaric. Here the gills, ring, and stalk are yellow, not white, no scales on the stalk, but a bag-like membrane through which the stalk runs. The deadly agaric has the umbrella without warts, the gills white, the stalk hollow, with a large ring and a bulb at the ground end, with a bag-like upper margin, and a hollow stalk long and slender. No one can mistake this hollow stalk in any mushroom for the solid stalk of the edible common mushroom after once he has felt and compared them. There are no scales or warts on the common mushroom; then the color of the gills, the general appearance, its standing with head erect, whilst the hollowstem ones have a mean, leaning, cast-down look, showing them the villains they are. The common mushroom often has the umbrella four inches broad; the stalk is stout, round, and smooth below the ring, and not usually as long as the umbrella is broad. The common mushroom has an odor of its own, a woody odor, a raw odor, and so has the deadly agaric. The fly agaric has little or no odor. All these three - the fly agaric, the deadly agaric, and the common mushroom-have a taste not unpleasant in the raw state, and un- 


\section{FORTY YEARS IN THE MEDICAL PROFESSION}

fortunately, when cooked each has good flavor and not distinctive.

The Horse Mushroom, Agaricus aracnsis, looks like the common mushroom, the Agaricus campestris, but is larger, and is often taken for and eaten for the common mushroom. It is edible and safe. It grows along hedges and in cultivated fields. The umbrella is shining white and the stem is a little hollow. The gills are at first white, a very suspicious quality, but they brown up as it gets older. The ring is double, not single, as in the common mushrooms.

There is another common mushroom, an edible one, the Hypholoma appendiculatum. It grows in clusters around stumps in grass fields. The color is transparent white, with a purple or a brownish tinge when wet. The umbrella is thin and bell-shaped, and the edges roll up somewhat. The gills are a purple-brown; it has no ring, and the stalk is hollow.

The Horsetail Fungus, the maned agaric, Coprimus comatus, is edible, and grows along the roadside in grass in dense clusters. The umbrella in this species remains closed, not open, and when commencing to decay it rolls outward, and the fungus liquefies in a dark fluid. This is the way it decays. The umbrella is white, with fringy scales. The gills are broad, close to the stalk, and, like the common mushroom, turn from pink to dark. The stalk is long and hollow, and has a ring which can be moved up and down. A few appear in early summer, but it is most plentiful in the fall. Two other specimens of Coprinus are found, and mostly around walls and houses,-Coprinus atramentarius. The stalk is short and stout, and it is edible. The color is ashy and dark, and it has no scales, but is furrowed. Coprintus micaccons is a small one and is edible, with the umbrella light brown or darker. These species are quite common and grow around houses, but I do not think they are so palatable as to entail the certain risk the amateur runs in eating such.

I think ninety-nine-one-hundredths of the wild mushrooms we eat are the Agaricus campestris, the common mushroom, 
and any one can tell them after a very little practice. Before eating any other kind I want them passed upon by an expert who has very frequent practice. Our most poisonous species of toadstools have a wrapper, as it were, around the base of the stalk, called a volva; if in addition they have white gills and spores and a bulbous base, with scales, they should not be eaten.

The Parasol Fungus, Lcpiota proccra, is large and tall, and grows in grass; it is not poisonous, but is tough and not desirable. It is white or brown. The umbrella is scaly, and the ring is free on the stalk.

The Chanterelle, the Cantharcllus cibarius, grows in the woods in summer. It is yellow and has a crumpled margin. The upper surface is depressed and the gills run down over the stalk. It is not good enough to risk eating it, if gathered by the average hunter.

The Fairy Fungus, Marasmius oreades, grows in the grassy lawns in rings, which are called fairy rings. It is tough and not good, though edible. The stalk is tubular, and the umbrella or pileus is thin. It is of a drab color; the spores are white. To determine the color of the spores of a mushroom press it on a piece of white paper and allow it to remain a while, and the color of the spore will be shown.

Fungi with Milky Juice.-These are of the genus Lactarius. The milk is usually white, but may be red or blue. In some species it is very acrid. They are safe, but not good. There is one specimen said to be good,- - the Lactarius delicosus. It is a mountain fungus. The milk is red and afterwards turns to green. The fungus is red. The Russulce are mostly small and grow in swamps and woods. The gills are yellowish. Some are edible, and some are poisonous. The Oyster Fungus, Plcurotus ostreatus, has no central stalk, but grows to trees attached by a short stalk at the side. They grow in clusters attached to a tree, like oysters attached to rocks. They are yellowish in color, and the clusters are often a foot or more wide. The gills are long. It is edible, but not very palatable, and not worth any risk. The Polyporei, or 
FORTY YEARS IN THE MEDICAL PROFESSION

tube-bearing fungi, as distinguished from the fungi with gills, have central stalks and some only lateral, like the oyster fungi. Most of the species are not palatable if edible. The edible species belong to the genus Bolctus. They are soft and fleshy, and grow on the ground in woods and fields. Some are edible and some are poisonous. They are not worth risking as an article of diet. Boletus subluteus is edible, but not very palatable, not worth eating.

The Steinpilz of the Germans is very large. The stalk is stout. The tubes are two inches long; they are white, and then become yellow. It is edible, but not worth eating. This is the true $C e ́ p c$. In the boleti, if the mouths of the tubes are red, do not eat it. The boleti, as a rule, are rather dangerous.

The Beefsteak Fungus, Fistulina licpatica, grows on stumps, particularly on oak and chestnut stumps. When young the upper side is of a peach-color, growing to a deep red with age. The tubes are flesh-color and are on the under side. The surface looks like a cooked tongue or like a beefsteak. It is safe to eat.

Teeth-bearing fungi, $H y d n c i$, hedgehog fungi, are some of them edible, but not palatable. Their color is white to brown and red and yellow. The two most common are Hydnum imbricatum and Hydnum repandum. They are found in swamps. The coral-shaped fungi of the family, Thelephorei, are not poisonous. I do not think them worth eating, but some experts say many of them are good.

Morels and Truffles. - The morels are among the best of fungi to eat. Botanically they are not close to the toadstools. They may be called the tripe-like fungus, and the honey-comb runs into the covering. Hunt for them in the spring and early summer in woodland that has been burned over. The stalk is white and granular. Truffles, the great delicacy of Europe of the fungi, are not found in the United States, at least not the prized ones. They are like small potatoes, and are hunted by trained dogs and pigs, and dug out of the ground. If found with us, it will probably be on calcareous soil, among hills covered with oak-trees. 


\section{FORTY YEARS IN THE MEDICAL PROFESSION}

Puff-Balls.-Gasteromycetes, or puff-balls, as a rule, have no stalk; they lie on the ground. The powder comes with age and is chiefly composed of mycelia or spores. The largest is the Lycoperdon gigantenm, and grows to a circumference of forty inches. The flesh is white or yellowish and firm, and edible before it becomes powder. Another puff-ball, edible, as most of them are before the powder forms, is Lycoperdon cyathiforme. There is one species of puff-balls poisonous, and it grows around houses, the Scleroderma vulgare. The exterior is yellow and warty, and the inside is purple or black, with white. None of these puff-balls are sufficiently attractive as food, unless one is starving, to cause one to run a risk of eating Scleroderma vulgare for Lycoperdon cyathiforme. Dr. Farlow well says, "When you are in doubt, never eat a fungus." This is the only rule needed. Truly they are only a luxury anyhow, not a staple food. There is no danger in eating cultivated ones, for then there can be no mistake: no poisonous ones are cultivated. The cultivated common mushroom, the Agaricus campestris, is as finely flavored when cultivated as when grown in its wild state.

The tests to distinguish poisonous from non-poisonous mushrooms or toadstools in common vogue, as of cooking a silver spoon with them, the blackening of the spoon being a sign of poison, are utterly unreliable. Cooking in milk or vinegar may do more harm than good if the fungi be poisonous. There are two classes of poisonous fungi, the irritant and the narcotic. The narcotic are the most dangerous. The irritant may work their own cure by causing vomiting soon after they have been eaten. The narcotic may cause serious symptoms after ten or twelve hours through the nerve-centres. The irritant fungi, as a rule, have a pungent, disagreeable taste, the narcotic a rather pleasant taste. Muscarin is the chief poisonous active principle of the Amanita muscaria. Muscarin is a colorless alkaloid, which forms salts with acids. Muscarin is not poisonous to flies, but this mushroom contains another poison which is volatile and kills flies. Muscarin can be made synthetically by treating cholin with nitric 
acid. Poisoning by the fly mushroom comes on in from a half-hour to two hours, up to ten hours. First come colic, vomiting, and diarrhoa, then contracted pupils and salivation; then the patient becomes drunk, as from alcohol, the vision is disturbed, and convulsions may supervene; stupor comes on with apoplectic symptoms, and either symptoms of collapse and death follow or the patient gradually recovers from his stupor and recovery takes place. The fatal result is often postponed until the second or third day.

As to treatment, evacuate the stomach by emetics or apomorphine hypodermically; if free vomiting does not take place, use the stomach-pump and give croton oil to evacuate the bowels. Atropia is the antidote to muscarin; give it hypodermically. Combat tendency to heart failure with digitalis, strychnine, etc. Atropia is only a physiological antidote; there is no known chemical antidote to muscarin. The poison in the Amanita phalloides, the death cup, is phallin. Phallin is a toxalbumin, and boiling fortunately makes it less dangerous. Phallin kills, not by causing collapse, but by destroying the red blood-corpuscles, setting free the hrmoglobin. Poisoning sets in after from twelve to fifteen hours. The patient acts like one in collapse of cholera, but death comes not from heart paralysis, as in poisoning from the fly amanita, but from the blood breaking down, causing exhaustion. Evacuate the stomach and treat on general principles. Be sure and use injections of normal salt solution into the veins or the tissues. There is no known antidote to phallin. It is supposed to arrest the heart's action in diastole. The proper treatment is to evacuate the stomach by proper methods, even washing it out with oceans of aseptic warm water. Digitalis is probably antagonistic to muscarin. Give twenty drops of tincture of digitalis hypodermically, and then digitalis, whiskey, ammonia, and such remedies as the case may require. In digitalis poisoning the heart is usually arrested in systole.

Farlow's rules for beginners gathering mushrooms are as follows : 
FORTY YEARS IN THE MEDICAL PROFESSION

I. Avoid fungi in the button state, and in the decayed state if the decay is only slight.

2. Avoid all fungi which have stalks with a swollen base surrounded by a sac-like or scaly envelope, especially if the gills are white.

3. Avoid fungi having a milky juice, unless the milk is reddish.

4. Avoid fungi in which the umbrella or pileus is thin in proportion to the gills, and in which the gills are nearly all of equal length, especially if the umbrella is bright colored.

5. Avoid all tube-bearing fungi in which the flesh changes color when cut or broken or where the mouths of the tubes are reddish, and in the case of other tube-bearing fungi experiment with great caution.

6. Fungi which have a sort of spider-web or flocculent ring around the upper part of the stalk should in general be avoided.

Rules I, 2, and 5 may for the beginner be regarded as absolute, with the exception to Rule 2 of Amanita cesarea, the gills of which are yellow.

Rules 3, 4, and 6 have more numerous exceptions, but these rules should be followed in all cases unless the collector is content to experiment first with very small quantities, and learn the practical result. As to mushrooms, they have been supposed to be highly nitrogenous and hence strong food. I have seen this recently denied, and they were put down as wishy-washy diet. They give up much water on cooking.

The following analysis shows just what they are as food. Fresh mushrooms: Water, 9I.II; non-nitrogenous substances, 2.57; fat, .I3; grape-sugar mannite, I.05; other non-nitrogenous substances, 3.7I; woody fibre, .67; ash, .76. Fresh truffles: Water, 72.08; non-nitrogenous substances, 8.9I ; fat, .62; other non-nitrogenous substances, 7.54; woody fibre, 7.92; ash, 2.2 I. Fresh common morel: Water, 90; non-nitrogenous matter, 3.48; fat, .24; grapesugar mannite, .72; other non-nitrogenous substances, 3.95; 


\section{FORTY YEARS IN THE MEDICAL PROFESSION}

woody fibre, .67; ash, .94. This is not a strong showing, and does not make them the highly nitrogenous diet we have been taught that they are. Remember, though, in cooking most of the bulk goes off in water, and what remains is quite concentrated.

There is something unexplained attaching to mushrooms. In Italy the common mushroom, Agaricus campestris, is not only rejected as an edible variety, but it is feared as poisonous. The climate, soil, and environment must make a difference surely. The mushroom for spontaneous reproduction probably depends on animals, especially the horse and the horned cattle. The mycelia are taken in with the grass they eat, then passed through during digestion, and come forth in the manure of the animal. Animal droppings are the proper material in which to sprinkle the mycelia when artificial cultivation is to be carried on. They grow in caves, in casks, or in benches placed in flower forcing-houses or in cellars. Some grow them in the cellars of dwelling-houses, where the heating apparatus of the house is utilized to give proper heat for developing the mushrooms from the spores. This is a very dangerous custom, as many pathogenic germs may be cultivated at the same time, and that much-dreaded germ of tetanus or lockjaw, the bacillus tetani, is especially at home in stable droppings. Mushroom spawn or spores come in socalled bricks, from their shape and resemblance to common bricks, and can be purchased from the general seed dealers. This is really the proper way to get mushrooms. Raise or buy the cultivated ones. You always then get the common mushroom, a perfectly safe one, and the best of all, taking all things into consideration, and you do not depend on the Toms, Dicks, and Harrys who gather the wild ones and hawk them from door to door, and who know nothing whatever about discriminate selection.

\section{NUTS.}

Nuts in the United States are not a staple article of diet, and the chief ones eaten and containing nourishment are the cocoa-nut, the almond, the chestnut, the English and black 


\section{FORTY YEARS IN THE MEDICAL PROFESSION}

walnuts, peanuts, shellbarks, and pecans. There are many of good flavor which are appetizing and attractive, and as one lingers over a good dry sherry they give a softness and a mellowness to the wine and bring out its good qualities, as it enlivens and brightens the post-prandial conversation.

In Europe, especially in France and Italy, nuts enter largely into the diet of the poorer classes. In the United States, Indian corn is so plentiful and so cheap, and is so much in every way the better food, there is no need of even the poorest of our people taking to nuts as food. Of late years wheat has become so reduced in price as to make it available for food to all of our people, and the poorer classes are now even turning up their noses at Indian corn.

In France the laboring classes eat freely of chestnuts. They remove the outside shell and blanch them by throwing them into boiling hot water; then rubbing off the inside skin, they place a cloth wet with hot water in an earthen pot, and nearly fill it with chestnuts. These they cover with another wet cloth, and put the pot on the fire and steam them. They usually eat them with salt, like roasted potatoes, or with milk. Thus eaten, they are a palatable and useful article of diet. We must remember that none of the European chestnuts are as palatable as our American sweet chestnuts. They are much larger, but have much less sugar. Raw, they usually are not palatable. In Europe they eat their chestnuts boiled and roasted, and in soups and as dressings for meats and poultry. In the mountainous regions they make a bread out of chestnut-meal, which is palatable, and they use the nuts for food for animals. For such purposes they do not shell them. In Europe they are cheap, selling for about one cent per pound at retail. Chestnuts may be served as a purée, with chops, boiled tongue, and such dishes, instead of mashed potatoes, and if made from the American chestnuts it will be found delightful. The marron glacé is a luscious confection, and is made from the meal and sugar properly flavored.

Chestnut soup: Hull and blanch a pound of chestnuts, the best obtainable; put them in cold water, then dry them, and 


\section{FORTY YEARS IN THE MEDICAL PROFESSION}

cover them with one quart of good stock; stew them for three-quarters of an hour, then rub them to a paste and pass them through a fine wire sieve; boil this and add milk sufficient to make three pints of soup, and season to the taste with salt and pepper.

The chestnut botanically is the Castanca vesca or Castanca vulgaris. It has an oblong, lanceolate leaf, serrated markedly. The blossoms are peculiar looking, and come quite late in the spring or early summer. There are sterile clusters in long catkins, and fertile blossoms, two or three together, in a round prickly involucre at the base of the catkins. There is no corolla. The calyx is on the summit of the ovary, and encloses the stamens and stigmas. The nut is familiar to all. The chestnut-tree lives to a great age, and attains an enormous size. They analyze thus (the fresh edible portion): Water, 44.9; protein, 8; fat, Io.8; carbohydrates, 54; ash, I.S. Fuel value per pound, I4So. Dried: Water, 5.8 ; protein, I0.6; fat, IO; carbohydrates, 70.9; ash, 2.7. Fuel value per pound, I940. Here is a food value nearly equal to wheat flour or corn-meal, and also showing that the chestnut is not fit food for the diabetic.

The chief enemies to the chestnut are the larve of the chestnut weevils, the larger ones from the Balanimus caryatrypes and the smaller ones from the Balaninus rectus. The grubs, of a light cream-color, are often found in the nuts. When the trees are in bloom the beetle appears, just about the time the staminate catkins drop. They have long, slender snouts, and bore through the rough sticky burs and through the shells of the nuts within the burs. The female lays her eggs in the nut, and the hole heals. The eggs hatch, and the larve work within the nut and mature with the chestnuts. The worm, now grown, eats through the shell and ruins the nut. It goes to the ground, where it changes to a pupa, and the next season appears as a beetle again, and again goes through his transformation. The remedies for the worms are not satisfactory. Spraying does not reach them. The best we can do is to kill those in the gathered nuts by 


\section{FORTY YEARS IN THE MEDICAL PROFESSION}

smoke or hot water and other methods, so as to prevent the larva from entering the ground and changing into its pupa state, and becoming a beetle again.

I ask no concessions for this digression into this little nature study. Physicians should know all about such things, and such studies are a relief to one exhausted with the overwork of practical medicine. Physicians, lawyers, clergymen, school-teachers, and others should all take up some form of nature study. They would be happier and better in every way. It should in many ways be taught in the schools, and I am glad to say efforts in its behalf in that direction are succeeding.

Our chestnuts in this country are the native sweet seedling chestnuts, the native grafted chestnuts, the European chestnuts, and the Japan chestnuts. Leaf fungi, the Marsonia ochroleuca and the Cryptosporium epiphyllum, attack the European and the natives, and rarely the Japan. Spraying with the Bordeaux mixture used for grapes, etc., being lime and copper sulphate in water, is effectual in controlling it.

Professor G. Harold Powell, entomologist and horticulturist of the Delaware College Agricultural Experiment Station at Newark, Delaware, is one of our best authorities on the chestnut, as is J. W. Killen, of Felton, Delaware, one of our best practical authorities. Powell holds that the Japan flora better suits the United States than the flora of the chestnuts from Western Europe, and thinks the Japans will improve greatly by selection, etc., in our country, and also by the infusion into them of our native stock.

To my own taste our native chestnut and our native chinquapin, Castanea pumila, are by far the best of all in flavor, whether raw or cooked. Next come the European varieties native in the United States, as the Ridgely, Paragon, Numbo, and the du Pont. Next come the Japans grafted, which are dwarfish in their nature and very early and prolific bearers. The best of them are Kerr, Martin, Biddle, Doctor Black (for an early one), Kent, Killen, Hale, and Parry. Last I place the European seedlings, generally known as Italian chestnuts 
with us. I have a number of trees a quarter of a century old, which bear large crops. The weevil is hard on them. Most of my trees fortunately bear good large nuts, but in buying these seedling trees, of course it is a lottery as to what quality of nut you get. The leaves of the chestnut have antispasmodic properties, and the fluid extract is a remedy in pertussis and such troubles.

Peanut.-The peanut is a legume, the Arachis hypogea. The French call it the pistache de terre. It comes to us either from Africa or Brazil. Its chemical composition is: Edible portion, water, 9.2 ; protein, 25.8 ; fat, 38.6 ; carbolydrates, 24.4 ; ash, 2. Fuel value per pound, 2560. Here is a very strong food, high in protein and fat particularly, and too strong in carbohydrates for diabetics. It is the poor man's nut for food beyond all others. They are too strong in fat for many stomachs, but a little fruit or subacid jams eaten after them will help out in their digestion by assisting to emulsify the peanut oil. Vast quantities of these nuts are raised in the United States, and they are of very great commercial importance, furnishing a staple article of diet in the nuts, and much oil useful for many purposes, even making a very good salad oil, and with our cotton-seed oil often sold for the best olive oil.

Almonds-Amygdalus.-The plum, peach, cherry, and nectarine are of the same genus. The peach is the Amygdalus persica. There are the bitter and sweet almonds. The bitter almond has less oil than the sweet, but contains more hydrocyanic acid. The leaves of both contain much hydrocyanic acid. The sweet almond is a toothsome nut, but indigestible, as a rule. Sweet almond oil is much used, and valuable in its way. The chemical analysis of sweet almonds is as follows: Water, 6; protein, 23.5; fat, 53; carbohydrates, I4.3; ash, 3.I. A gouty and fat-forming food, it should be used only moderately, to bring out the flavor of sherry, Madeira, or port.

Filberts or Hazel Nuts.-Genus, Corylus. Two species are native of the United States. They flower very early in 


\section{FORTY YEARS IN THE MEDICAL PROFESSION}

the spring and are attractive. They are bushes rather than trees. The Corylus colurna grows to a tree in Asia, and yields a fine oil. The chemical analysis is as follows: Water, 7.I; protein, I7.4; fat, 62.6; carbohydrates, I0.4; ash, 2.5. Like almonds, they are low in carbohydrates and high in fat. Diabetics may eat them moderately, as they may eat almonds.

Pecans. - The Carya olivaformis, or hicoria pecan, is a species of hickory. This nut is very common in the South, and especially in the Southwestern United States. It thrives in the Middle States, especially on the Delaware and Chesapeake Peninsula. It has been proposed to graft it on the English walnut to hurry its growth and to improve the nuts. It will take on all of the hickories. Dr. John Le Conte, of Philadelphia, well known for his scientific attainments, brought, in 1853 , a unique pecan from Texas. He named it Hicoria tcrana. It has been cultivated in Georgia. The tree only attains a height of from ten to twelve feet. The ordinary pecan-tree grows to a height of one hundred feet. Pecans are becoming very plentiful, as large orchards of them are being planted commercially in different parts of the country. They analyze not much differently from the filbert or shellbark, or the common hickories. The membrane covering the kernel is bitter, and should be avoided in eating them. They are high in oil. The kernel will burn and make a good light. Pounded up or ground, shells and all, they make good hog-feed. Corsa thinks the mast fed to cows would give a good flavor to butter if the shell were excluded.

Shellbark or Shagrark.-William P. Corsa gives this as Hicoria laciniosa (Sargent) or Carya sulcata (Nuttall). This is undoubtedly the best flavored of all the nuts that grow. The best are so soft of shell that they may be cracked with the teeth, although I am free to admit that an inorganic nut-cracker or hammer of some kind would be safer so far as the teeth are concerned. The nut is oily, fairly high in protein, and sufficiently low in carbohydrates for the diabetic to eat. There are many other species of the hickory-nut, all of which have been noted by Corsa in his work on Nuts and 


\section{FORTY YEARS IN THE MEDICAL PROFESSION}

Nut Culture in the United States. There are the Mocker Nut, Hicoria alba, known as the bull nut, etc.: the Pignut, Hicoria glabra, or Bitter Hickory; the Nutmeg Hickory, Hicoria myristicafornis; the Bitter Nut, Hicoria minima; the Water Hickory, Hicoria aquatica.

Creail Nut, Brazil Nut-Bcrtholletia Excelsa.-It belongs to the order Lectythidacca. The natives call it Juvia. It is too tender as to frost for the United States, even for Southern Florida, commercially. This nut is a curiosity. They are, as we see them in the stores, in the form of a triangular prism; a number of these are contained in a round case or box. fitted in, the case being often as large as a child's head. Crack the case, and out fall the nuts. The meat is in one piece, like an almond, and of the triangular shape of the hull. When fresh they have a fine flavor. As they grow old they become rancid. In this country we do not often get good fresh Brazil nuts. The oil from the nuts makes good lamp oil.

Chilean Nut.-A most beantiful tree, and is growing successfully in California, Guevina arcllana. The fruit has an agreeable nut-like taste, but in its raw state is poisonous, like the Brabejum.

Queensland Nut-Macadamia Temifolia.-Corsa reports this fruit like a drupe, round and smooth, with a shell like a walnut; it is like the filbert, but superior in flavor.

Betel Nut-Arcca Catechu.-This is only one of the areca nuts. The fruit is the size of a hen's egg, and the seed or nut is the size of a nutmeg. The people of India chew it as the Americans chew tobacco, calling it betel. This is made by mixing it with the leares of the piper betel and lime. The nut is used mostly with us by reducing it to charcoal and then making a tooth-powder from it. This charcoal is so hard it polishes the enamel of the teeth. From four to six drachms of the nut is said to be effectual in tapeworm. One of the various catechus comes from the Areca catcchu, official U.S.P.

Pistachio Nut-Pistach-Pistacia Vira.-The tree is diocious. The muts are borne on the female tree in clusters, 
and are covered with a light-green husk. The tree is a native of Syria, but has been introduced into the United States and grows successfully in the South and in California. It is used for flavoring medicines and confectionery, and also for coloring them light green. The French use it to flavor sausages and such foods.

Kola Nut-Sterculia Acuminata, Cola Acuminata.-This nut is a native of Africa. It commences to bear when four years old. The tree, like the orange, has the flowers and fruit on it at the same time. The ripe nut is a brownish yellow capsule, inclosing both red and white seed, varying in number from five to twenty. They are collected and assorted with care. The sound seeds are placed in dark baskets lined with leaves, and are thus transported. If not well cared for, they are liable to ferment. According to Dr. Neish, the nut is rich in caffeine and theobromine. Kola nuts contain more caffeine than coffee, and in them it is free and uncombined and easy to obtain pure. It lessens mental and bodily fatigue, and is safer than beer as a beverage. The natives of Africa esteem it highly as a help in fatigue. It may be harmless, but surely all such remedies need care and watching in prescribing, and kola and coca are among those needing most to be watched.

Guarana.-The fruit and leaves of the Paullinia sorbilis; these also furnish caffeine, and also are astringent.

Butternut-Juglans Cinerea-White Walnut.-This nut is very generally distributed in the United States. In Delaware it is common along the banks of the White Clay Creek. The soft half-grown nuts make a very good pickle. The quality of the nut is put down as good. Personally, I do not like it. It is difficult to remove from the shell, and is strong in oil.

Black Walnut-Juglans Nigra.-Every one knows this nut, it is so widely distributed. It is more planted for its timber than for its nuts. It bears a strong oily nut, but has a flavor of its own. Its analysis is as follows: Water, 2.5; protein, 24.9; fat, 54.7; carbohydrates, I6.3; ash, I.7. 


\section{FORTY YEARS IN THE MEDICAL PROFESSION}

It is quite a strong food, very oily, with a little too much carbohydrates for diabetics to eat of freely. A few will do them no harm. My friend, Dr. Robert P. Harris, of Pliladelphia, recently deceased, has called my attention to the effect of washing with soap and water a black walnut just taken from its green hull. It makes it of a beautiful light cream-color, and renders it quite attractive for market.

California Walnut-Juglans Californica.-This is a California black walnut. Its fruit is smaller than the Eastern walnut. It makes a good stock for the Persian walnut. $J_{u \text { - }}$ glans rupestris is another black walnut common to Texas.

English Walnut, Madeira Nut, Persian Walnut, Grenoble Walnut-Juglans Regia.-This tree is a native of Asia. It is widely distributed. It grows in Delaware to perfection, and I have never seen it cut down by frost. It bears abundantly. The anguillula does not affect it here. In the city of New Castle there are trees probably a century old, which bear bushels of the best nuts annually. The houses screen them and doubtless prevent sun scald. In exposed places this can be prevented by screens. I have fine thrifty trees growing on my fruit farms in Delaware and Maryland over twenty-five years old. As yet they have borne few nuts. In my experience the tree does not commence to bear in orchard culture in the Middle States under sixteen to twenty years of age. The chemical analysis is as follows: Water, 2.5; protein, I7.I; fat, 60; carbohydrates, I9.I; ash, I.4. They are quite rich in fat, and almost too strong in carbohydrates for diabetics to eat freely. There are many varieties, with no great difference between them, some having softer shells than others. The finest seedling I have seen was from a tree in Merchantville, New Jersey, and sent to me by the late Dr. Robert P. Harris.

JAPAN WALNuT-Juglans Sicboldiana, Juglans Cordiformis, Juglans Mandshurica.-The Mandshurica is much like our butternut, but has a very much harder shell. The meat is a little on the butternut flavor. The Sieboldiana does not differ much from the Mandshurica; probably the shell is a 


\section{FORTY YEARS IN THE MEDICAL PROFESSION}

little more like the English walnut shell, but very much harder; indeed, it is very hard and dense. Cordiformis is smaller than the other two, and has a somewhat softer shell. The trees all look alike. The nut may be a valuable addition to our list, but as a shade-tree I regard the Japan walnut as a very great addition and a great boon. The trees have beautiful foliage, beautiful blossoms at the tips of the branches, bear their fruit in clusters, and grow more rapidly than the Carolina poplar; in fact, they are hardier, and will produce good effect and good shade quicker than any other tree I know of. The Persian walnut is also a beautiful lawn tree, and grows fairly rapidly. The Eucalyptus globulus grows as fast as the Japan walnut, but is not hardy generally in the United States, and absorbs so much water that it robs other trees and plants near it.

Souari Nut.- This is a new nut just introduced into this country from the Indian River country of Venezuela. This nut consists of a single nut in a very hard shell, like the Brazil nut, except that the Brazil nut is multiple in its larger shell, not single. The outer shell of the souari nut is very hard, and is clam-shaped and of a snuff-color. It has a creamy taste, but is inferior to the Brazil nut in flavor. It has something of a raw mushroom odor and flavor. It may be eaten plain, or with pepper and salt, or with cheese, or may be roasted or boiled. 


\section{CHAPTER XI.}

George B. Wood and S. D. Gross on Tubercle-Koch's Discovery of the Bacillus Tuberculosis-Present Definition of Tubercle-Plysical Attributes of Tubercle-Tubercle Bacillus in Man and the Lower AnimalsPtilmonary Tuberculosis in Man-The Plysician and TuberculosisEarly Diagnosis Important-The Bacillus and Diagnosis-Case of Chronic Interstitial Pnetumonia and Tuberculocidin-Tuberculins and their Therapettic Principles and Uses-Toxines and AntitoxinsKocl's Tuberculins A, O, and R-Maragliano's Serum-Virchow's Objections to Koch's Tuberculin A-Mulford's Serum-The Economics of Tuberculin-Tuberctlots Cattle in Etrope and America-Necessity for Action-Prevention and Treatment of Tuberctulosis-Surgical Tuberculosis-Treatment of Hremoptysis-Murphy's Method of treating Pulmonary Tuberculosis - Secondary Infection - Cures - What Factors hold Tuberculosis Latent - Climate and Environment - Pulmonary Hemorrhage and Altitude - The Indians as an Object-Lesson - Relieving Crowded Centres-Sanitaria and Sanatoria and TreatmentCommon Colds-Consumption in Hotels-Solitary Life Best-Altitude -The Heart and Altitude-Diabetics and Altitude-The Climate of the United States East and West-Sanatoria and Climate in EuropeSerum Treatment in the Adirondacks-Inhalations as Remedies.

VITHOUT discussing its cause at the opening of this chapter. we may well say that tuberculosis is the greatest of all factors in hurrying mankind to death; not only mankind, but the lower animals as well, descending to as yet unknown depths in the scale of life, and carrying destruction to an extent that we are only just beginning to realize and understand. Forty years ago Professor George B. IVood was a close observer and a high authority on medical subjects. His distinction between tubercle and cancer was that tubercle tended to health, and cancer tended to death. His definition of tubercle was: A solid extravasated matter, which, in certain states of the system, is deposited in various parts of the body, and from its shape, ordinarily assumed, is called tubercle. The state of the system leading to this deposit was 
called in those days, as it is to-day, the tuberculous diathesis. He recognized the gray and translucent and the yellow and opaque tubercles, that they underwent softening, acted as foreign bodies, and sometimes the cavities left by them healed, or the whole mass became protected by organized fibrin and isolated from doing harm. He recognized heredity as a cause of tuberculosis. To his idea, tubercles were not a product of inflammation, but were a cause themselves of inflammation. At this time they were cutting quite close to the cause of tubercle, or rather tuberculosis, by microscopic investigation, and the one thing lacking was the advent of some genius to add staining of the specimens to the resources of the microscopist.

Compound corpuscles were noticed by Virchow as early as $185 \mathrm{I}$. Pus was not inherent in tuberculous masses, but, when present, came from the surrounding inflamed tissues. As tubercle softened, fatty matter was generated, and a fatty degeneration took place. The true tuberculous liquid was sometimes absorbed, and left in the place of the tubercle only a calcareous mass. That is a physical fact true to-day.

To sum up, here is Wood's definition of tubercle, and the accepted definition among a great majority of pathologists of that day: A formless fibrinous matter is first extravasated, having a low and feeble vitality; that, as the result of an imperfect attempt at organization, coagulation takes place with the production of granules and peculiar corpuscles, and that the tubercle thus formed grows by accretion of similar matter to its surface, and then, as a result of the law of its constitution, undergoes a series of changes, ending in its complete disintegration. Light at this time was just commencing to dawn upon the profession as to the zymotic nature of so many diseases. Two theories as to contagion were then in vogue, and advanced thinkers were becoming less and less conservative. The first theory of contagion was fermentative, the ferments entering the blood and causing chemical changes that result in a further production of similar contagious matter. Thus the reproduction of the morbific agent 
is explained. The contagions existing in the system are exhausted by these fermentations, and thus second attacks of such diseases are prevented.

The second explanation of contagion is on the germ theory, "invisible organic agents, animal or vegetable, which, fully developed or in the state of germs, enter the blood-vessels and there live and propagate to the no little disturbance of the system, which is at length excited into desperate efforts and throws off the intruders and their whole brood, or perishes in the attempt." This doctrine was not exactly accepted by Wood and his contemporaries, but they were beginning to see visions of the true causes of disease.

In 1864 Professor S. D. Gross made no distinction between tuberculosis and scrofula. To him phthisis and scrofula were the same. A tubercle in the lung was the same disease as a tubercle in a bone or in a lymphatic gland, having the same origin, running the same course, and producing the same results. He intimated that he considered syphilis as the great parent of tubercle and its parasitic existence. The old gentleman had a way about him of looking ahead, and getting about as near the truth without the use of modern helps as any of his contemporaries. He denied that tubercle was an unorganizable product like colloid and melanosis. Gross was one of the best pathologists of his day. The blood-vessels demonstrated to be in it clearly show there is something within it to be nourished and protected. Tubercle is an organic substance, he repeats, because it often begins to soften at its centre. He looked upon tubercle as a morbid deposit provoked by anything causing the system to run down, from heredity to syphilis. Local inflammation of the part sets the seat of the tuberculous deposit. Gross denied the contagiousness of scrofula or tuberculosis.

Less than twenty years ago these views of forty years ago which I have quoted were held and defended by the average pathologists and thinking men of the medical profession, and it was only as far back as 188 I that Robert Koch gave to the scientific world his famous and far-reaching discovery of the 


\section{FORTY YEARS IN THE MEDICAL PROFESSION}

Bacillus tubcrculosis, and demonstrated it beyond peradventure to be the cause of all forms of tuberculosis, thus clearing up many questions which had been clouded by the mists of ages, and giving to suffering man a scientific basis upon which to work and, I trust, to effectually eliminate the greatest enemy to his future existence and continued happiness. Since Koch's discovery we know enough to define tuberculosis as an infectious disease, the cause of the infection to be the bacillus tuberculosis. We know now the cause of the tubercles to be the setting up of a specific inflammation by the tubercle bacilli, and the cause of general tuberculosis to be the same microorganism. We know the end of these inflammations may be caseation or hardening, and these may end in ulceration, chronic ulcerative consumption, or calcareous degeneration, which is a method of cure, the calcareous masses being expectorated or remain in the lungs, surrounded by a ring of hyperplastic connective tissue. As to the tubercle bacillus, this is not the place to discuss it, for it is as well known to bacteriologists, as the cattle are to farmers.

There is one question yet probably not clearly settled. Is the bacillus tuberculosis of man identically the same as the tubercle bacillus of the lower animals? As to the onset of pulmonary tuberculosis particularly, I propose to give the result merely of my own personal experience. If the practice of medicine was properly appreciated by the world, and was not, even at this enlightened era of its existence, looked upon by the average man as a mere business of pill-giving, empirically at that, the family physician in his watching over his clients, if he were an intelligent and careful man, would probably see, on account of his training, some youthful member of the family, not sick, yet not well. A close scrutiny of the individual, having gone over the family history, which he would know anyhow, for that would be a part of his business, would show that probably after three o'clock P.M. almost daily the bodily temperature of his ward would be one or two degrees above normal, and the cheeks would flush slightly; and further investigation would show at this time that there 


\section{FORTY YEARS IN THE MEDICAL PROFESSION}

was a slight fulness at the top of the sternum and a tendency to hack a little; all these symptons passing off with a slight moisture of the skin and a little debilitated feeling towards midnight. To the practised ear some change in the physical signs in the lungs would be found, if in a space never so small, and possibly, by proper examination, the dreaded microorganism of consumption would be found in the sputum. The diagnosis thus early assured, what innumerable chances of recovery that patient would have over those coming for help late with the disease well established. Should no trouble be found in the lungs, it would be the duty of the physician to institute a thorough examination of every part and organ of the body where tubercle might invade, and weigh all the symptoms.

See the other side of the picture: a happy family, with no medical supervision, with a bad family history as to tuberculosis, if you choose; a favorite son or daughter just budding into maturity, all these symptoms appearing as enumerated: the high evening temperature,-oh, only the crimson cheek of health; the congh,-only a little cold; the progressive weakness-nothing, the appetite is so good, only a little rest required; and so the case goes on,-cough, sweats, expectoration, hemorrhage perhaps, and then the doctor called in haste. An examination shows the helplessness of all human aid, and another is added to the death-rate of consumption, already appalling, and much of this owing to faulty methods in the organization of society. The only remedy for this state of affairs is for society to recognize the necessity of constant medical supervision over each and all of its members. To-day it clings to the old couplet philosophy:

When the devil was sick, the devil a monk would be;

When the devil was well, the devil a monk was he.

Moral: The devil does not know when he is sick, but should have an expert at hand to tell him. The chances of cure in consumption, or of checking its progress, all depend upon an early diagnosis. I think this is a law, surely; that it is the 
experience of every thoughtful practitioner of medicine, I doubt not.

The finding of the bacillus tuberculosis in the sputa confirms the diagnosis of pulmonary consumption. Does the failure to find it declare the case not to be one of pulmonary consumption? I must confess that in my experience it excludes it. I have had some most interesting cases, and where the bacillus was not found they all came out right. I had one most remarkable case: this man had all the rational signs of consumption; for a year his cough disturbed the neighborhood, his expectoration was profuse, his emaciation extreme, and with his coughing spells he vomited his food. He had evening rise of temperature, and it was never normal, and hectic and night sweats were marked. In this condition he came to me. He had numerous moist bronchial râles with puerile respiration, except in the lower lobe of the left lung, which was flat. The apices, with the exception of the respiration, were normal. His family history was not first class. There was no fluid in the pleural cavities; there was dyspnœa, the chest was retracted, its circumference was diminished, and its movements were restricted; there was even amphoric resonance over the diseased lung. The man was the picture of a case in the last stages of consumption, with secondary infection of the system; and such was my fear, although there were some hopeful signs, as sound apices, etc., left to comfort me. I am never willing to give an opinion, even in such a case, until after one or more examinations of the sputa. I felt sure those of this man were reeking with the micro-organism. Repeated examinations by one of the ablest bacteriologists in this country, Professor F. D. Chester, of the Delaware College Agricultural Experiment Station and the Delaware State Bacteriological Station at Newark, Delaware, failed to find a single specimen. I began to have hope that the man would get well, but it seemed like hoping against hope. With bacteriological examinations frequently, the man went on for months without much improvement, although everything apparently possible was done for him. 
After these repeated investigations for the bacillus tuberculosis, with negative results, I made the diagnosis of chronic interstitial pneumonia, with a possible chance of improvement, but not of cure. I then commenced the use of tuberculocidin, which came from Germany, and which I obtained through the courtesy of Dr. Arthur T. Neale, Director of the Delaware Experiment Station. The result was wonderful. The other treatment was kept up. Normal vesicular murmur gradually appeared in the diseased lung, and the man, from having given up, began to regain his spirits. In six months he was apparently well, went into business, and now for several years has been an active, successful citizen, and keeps up with the boys, too. The tuberculocidin, I believe, had some effect. There was reaction after each injection at first, and he had a great number, extending over months. It must have had some effect on the fibrous structure, and allowed the restoration of the alveolar structure of the lung.

Klebs prepared tuberculocidin by separating it from the original tuberculin by chemical reagents. It is supposed to contain germicidal agents specific to the pathogenic organism, which germicidal agents are produced by the pathogenic organism in the culture medit:m. The books give chronic interstitial pneumonia as a lingering, but incurable disease. Since this case, I have had no case in which to repeat the treatment. Should I get a similar one, I should use tuberculocidin, or one of the tuberculins. If my diagnosis was correct, and I think it was, this case surely got well. As to the tuberculins and kindred products, I have used them all or most of them, or seen the result of their use in conjunction with medical friends. I do not like to give up hope for the hopeless in this direction, but oh, what a cruel fate was that which dashed the hopes first held out to these poor sufferers by Koch's first efforts! I hope still, even if it is against the laws of true science as we see them to-day, to look for hope and relief in this direction. I brush aside all such doubts, and still I hope, and hope, and hope, and trust, and trust, and trust, and to-day I almost believe succor will at last come 
from some such source, for do we not know that in nature every living thing generates its own poison, why not this king of little microbes?

Professor Samtiel O. L. Potter, of San Francisco, the wellknown author, has given us clear views as to the different tuberculins and what they are. He says, in strict usage the term serum therapy would include only the employment of blood-serum from an animal other than the patient, the serum carrying an antitoxin specific to the disease from which the patient may be suffering. As generally used, it embraces also the use of toxines and modified toxines, produced in media other than the blood-serum. The therapeutic principle is the same in all,-the employment of an agent produced by the life action of a pathogenic organism for the purpose of effecting an artificial immunity against the clisease to which the said organism is specific. If we use a toxine, the organic cells of the patient's body are supposed to be excited to produce an antitoxin in the patient's own blood-serum. If we use an antitoxin, the organic cells of another animal are relied upon for the manufacture of the antitoxin, the patient being saved from the strain of doing it. In treatment by modified toxines, an effort is made, first, to partially destroy the toxine by oxidation, thereby attenuating its power and so lessening its excitant action without wholly destroying said action. Secondly, to separate the toxic material by chemical precipitation from a supposed curative ingredient, retaining the latter for therapeutic use. In each method the existence of an antitoxin is inferred. In the last, this is supposed to be developed in the culture medium, together with the toxine, by the action of the pathogenic organism, while in the others it is presumed to be produced by the organic cells of an individual animal organism excited by the toxine to such production.

As to Kocl's tuberculins, the original was a purely toxine treatment, by which he sought to produce an artificial immunity against the disease in the patient by exciting the natural reaction of his own organic cells to produce a specific antitoxin in his blood. This is Koch's tuberculin A, and is made 
FORTY YEARS IN THE MEDICAL PROFESSION

from tubercle bacilli by extraction with a one-tenth normal soda solution. I take this to be Koch's original tuberculin.

Tuberculin $O$ he obtains by oxidizing cultures of tubercle bacilli by drying them, pounding them in a mortar, and then forcing them through hydrogen monoxide, $\mathrm{H}_{2} \mathrm{O}$, in a centrifuge.

We have recently heard much of tuberculin $\mathrm{R}$. This is what is left after tuberculin $O$ has been taken off as the upper layer. In making tuberculin $\mathrm{O}$, what is left is treated again with $\mathrm{H}_{2} \mathrm{O}$, and thus again and again subjected to the action of oxygen, until no residue is left, the conversion into oxidized tuberculin constantly going on. If pursued too far, the resulting tuberculin would be inert. This oxidation attenuates the tuberculin as Pasteur attenuated his hydrophobia virus, by drying and pounding the spinal cords of rabbits. The more the attenuation, the less the reaction. Now, as to all tuberculins and such remedies, the attenuation is produced by oxidation, either by Koch's and Pasteur's plans, as given, or by heat.

Maragliano's serum is an antitoxin, and is made by subjecting the blood-serum of another animal to the action of toxine, and thus forcing the animal to manufacture the antitoxin at its own expense, and saving the individual upon which it is used that strain upon his organization. The ass is nearer immune to the tubercle bacillus than most animals, and I think Mulford's tubercle antitoxin comes through the ass. Having seen exactly what these toxines and antitoxins are, it is easier to analyze them and see what we might expect of them as to curing tuberculosis. Virchow's objections to Koch's tuberculin A were that the severe reaction-that is, the elevation of temperature-attending its use was often dangerous. The actual results of using it were the softening and disintegration of passive tuberculous deposits, and thus from these disseminating the bacilli in abundance and lighting up new foci of infection wherever these lodged. It is easy to be seen that, if used at all, it should be used only in the very first stages, and if secondary infection had come, it might be quite 


\section{FORTY YEARS IN THE MEDICAL PROFESSION}

dangerous. Koch claims these dangers are eliminated by oxidation of the tuberculin, and thus its attenuation, and that tuberculin $\mathrm{R}$ can be used with impunity.

Let us hope on until hope has been realized. Neither Horatio Wood nor Joseph McFarland are hopeful. Wood says, as all can see, when the tubercle bacillus grows in the human lung, the toxine which it forms slowly kills the tissues and produces ulceration. At the same time it finds its way into the blood and produces hectic fever and other symptoms we so often see. Now, if Koch's tuberculin (tuberculin A, I suppose he refers to) is injected into the individual in small quantities, no reaction is seen, but when this is aided by the toxine which has been produced by the system (remember, tuberculin $\mathrm{A}$ is a toxine), and which is already in the blood, the two toxines together-the injected and that already in the blood -will produce reaction and hectic fever. At the same time, the injected toxine will reinforce that in the blood, and the two will bring about rapid ulceration of the lung and discharge of the tubercle. Even if this ended in the discharge of every tubercle bacillus, it would not cure the patient. It does not help the primary weakness of the patient, his inability to resist the onset of the tubercle bacilli; it does not even prevent the reinfection of the loosened tubercle. Indeed, the very loosening of the tubercle bacillus favors its entrance into the lymphatics and the blood-vessels, and its consequent dissemination throughout the body.

Virchow soon found out that a general tuberculosis often followed immediately upon the treatment of a local tuberculosis by injection of tuberculin A. This is all undoubtedly true, as we see it to-day, but let us "hope on, hope ever." We have made great progress: we have the cause of the disease; we know it is an infectious disease; we know the natural history of the cause; we know that we can in a great measure limit the production of that cause by proper methods, by proper laws, and by proper hygienic rules. The protection of the individual will compel the enforcement of such methods, of such rules, and of such laws. 
FORTY YEARS IN THE MEDICAL PROFESSION

The bacillus itself is a parasite, and lives on the animal body. The problem before us is to destroy it and its toxine developed by it in the animal body, and yet not destroy that animal body. Let us work and hope, and hope and work. I trust we shall yet triumph. When it comes, and may God hasten the day, the serum treatment will not be a toxine serum, as the tuberculins, but an antitoxin serum, like diphtheria antitoxin. Some animal will be rendered immune to the toxine, and its serum will be the antitoxin to the tubercle bacillus toxine, and if also to the bacillus itself, then we will have it. McFarland, Maragliano, and Panquin are working on these lines, as well as many others.

I will merely mention here that epidemic influenza, commonly called " grip," a word which has been engrafted on our language from the French, has its bacillus, the bacillus of Pfeiffer. It comes in the form of rods, single or in chains, and stains well in methylene-blue.

As a preliminary to consumption, we spoke of the rise of temperature, etc., in the evening as one of the first symptoms. When watching this symptom, always think of the possibility of syphilitic fever; it acts almost in the same way and needs far different treatment. In consumption, mark the dry hack when the patient first lies down. Gravitation from the apex of the lungs when standing, and the return when first lying down, causes this. It is a mere physical symptom. Keep up examinations for tubercle bacilli; they are not always found at once. Watch the apices of the lungs, especially the left, for dulness and changed râles; have the patient frequently weighed, and watch for loss of weight. Always examine the urine for sugar and other irregularities; your patient, if under forty, may be diabetic and need attention to diet. Examine the blood for anæmia, and remember there are latent cases, and these may have other foci than the lungs. If possible, have infecting foci, as enlarged lymphatics, etc., removed. In my experience, hemorrhagic cases of consumption are more chronic than non-hemorrhagic cases. The local depletion retards the toxæmia and the secondary infection. 
Dyspnœea is a sad complication, and laryngeal complications are among the most distressing. Pain is chiefly pleuritic, and can usually be alleviated.

Acute miliary consumption is a sad complication; here we have the shad-roe lung, as Dr. William Pepper, Sr., called it. Look well here for foci of general infection in all parts of the body, and you will probably find one or more; and watch for bacilli in the supta, the blood, even in the freces and in the eye. Do not mistake it for typhoid fever, for malarial fever, or for asthma. Be careful you do not mistake any case of tuberculosis for malarial fever. This onght not to happen now, with a proper use of bacteriology. Tuberculosis of any kind may follow typhoid fever; here the system is in good shape for the successful reception and attack of the bacillus. Keep your wits about you; remember the family history, the environment of your patient; watch the rational signs carefully, one and all, and take in all of the physical signs, with the aid of auscultation, percussion, and bacteriology, not forgetting the heart and large arteries. Do not let the brassy cough of an aortic aneurism pressing on the recurrent laryngeal deceive you as to its origin, or whooping-cough or malignant troubles about the chest throw you off the track; and remember that malignant and septic troubles, other than those of tuberculous origin, may affect the organs of the chest, as well as of other parts of the body. Senn says he believes many cases of supposed carcinoma are nothing more than cases of some form of tuberculosis. Senn is a great surgeon, and good authority. Do not forget to hold this matter in mind. If such mistakes have been made in the past, they should not be made in the future. It is well to remember that the insane, the feeble-minded, and weaklings generally are especially prone to tuberculosis.

As to the use of tuberculin for diagnostic purposes in man, it is scarcely proper to use tuberculin A in case the patient has tuberculosis. As to tuberculin $\mathrm{R}$, if one wishes, he may use it as an additional help to diagnosis. I do not think it would do harm. Tuberculin $\mathrm{A}$ is used a very great deal 388 
among cattle, and the reaction here after its introduction never fails to take place if the animal is tuberculous.

In the work done in the matter of tuberculosis among cattle by Dr. Neale and his coworkers of the Delaware Agricultural Station, I had an opportunity of investigating whether or not there was any antagonism between the bacillus of tubercle and the bacillus of anthrax. I had hoped there might be, and at first there was evidence of some antagonism, but it did not bear closer investigation, and the results of the work were negative. To lessen tuberculosis among human beings, it is our duty, first, to lessen the number of tubercle bacilli abroad in the world. To do this, we must get rid of the great causes producing them. In the second place, it is necessary to endeavor to raise up the human race to a point of health where susceptibility will decrease and place them under conditions where they will not be so prone to the attacks of the bacilli. I believe syphilis to be one of the greatest factors in rendering the human race vulnerable to the tubercle bacillus, and this factor reaches from generation to generation, "the sins of the fathers" being visited upon the children.

Our greatest hope to-day, in dealing with human tuberculosis, is in its prevention. Personally, I believe the State should go to extremes in this matter, and at the same time the unfortunate owner of infected and infecting animals should receive some compensation. There is no manner of doubt that the milk of a tuberculous cow, especially if she have tuberculosis of the udder, will infect man with tuberculosis. I believe the milk will infect if the udder is sound. I believe the meat of an infected animal, if eaten by man, will produce tuberculosis in man unless it has been sterilized by heat or in some other way. Then what? IVhy should man allow such a menace to his health? Why not eradicate it as far as possible? Why dilly-dally? We are doing better, but are not yet radical enough. Whilst statesmen and politicians and poor, weak humanity falter, the brightest and best among us are the constant rictims of a cruel and cowardly 


\section{FORTY YEARS IN THE MEDICAL PROFESSION}

hesitancy. In France and Germany the inspection of beef animals is the most advanced. All animals are rigidly inspected after they have been killed. If tuberculous, certain parts are allowed to be sold and are marked as tuberculous, and full directions are given how to cook it to make it safe for human food. Go to our cattle-yards and you can pick out the tuberculous cattle, and most of them are cows. They are often-not always-thin of flesh, and they cough. "Coughers" is the name the dealers give them. Another name is "Boulogneys."

Not to take up time and space. I will give a few statistics showing the fearful presence of tubercle among our food animals. In Copenhagen, out of 132,294 bullocks and cows slaughtered for food, 23,305 showed evidence of tubercle. Out of 8292 pigs, I 272 were tuberculous. Even 369 calves out of 185,765 showed evidences. Only one sheep out of 337 ,OI 4 showed evidence. Here is a practical point and an object-lesson. In Berlin, out of I42,874 cattle slaughtered, $2 \mathrm{I}, 603$ showed evidence. Of 5 I 8,073 hogs, there were 7055 showing evidence of the tubercle. Of IO\&, 348 calves, I2 5 were tuberculous. Of 355,949 sheep, only I5 were condemned. In Edinburgh a number of cows were killed on account of the appearance of pleuropneumonia there. Forty per cent. of these were tuberculous. Here is an object-lesson in city-kept cows with generally bad environment.

The tubercle bacillus is of general distribution. It is in all expectorations of the tuberculous; it is on their persons and hands; it is in the houses, in cars, in boats, in the dust of houses, and in the dust of the streets, and the more it is blown about and distributed the worse it is. They love to be dried and remoistened; they revel in such treatment. In our houses brooms should be abolished; heavy hangings and heavy carpets should be much curtailed; also upholstered furniture. Carpet-sweepers and moist cloths should take the place of brooms and dusters. The aseptic house will come after a while, and cars and all such places of congregation and resort will be, in a measure, aseptic. Man will be more 
careful in his herding. Individual bedsteads will take the place of the present abomination,_-particularly of the United States, - the double bedstead. No two persons should occupy one bed as a rule of domestic life, and, if possible, every individual would be the better of a separate room or apartment. All these reforms accomplished, we will then approach the condition where the aseptic indivicual is possible.

In my own State, Delaware, from what I can learn from having been active in starting the work of investigation, and from information gathered from my friends and coworkers, I am sure twenty per cent. is a small estimate of the number of our milch cows tuberculous. In New Jersey there are probably as many, and in Pennsylvania, from the investigations of Professor Leonard Pearson, there are probably more; but active interference there has of late reduced the percentage. All herds should be tested with tuberculin; it is sure, and Dr. James Law, the expert of Cornell, says, from a large series of experiments, it does no injury whatever to the sound cow. It is the gilt-edged herds that need watching most. Choice breeding and selection, the environments of the palace stables, and want of out-door life are active causes in breeding the bacilli and rendering such cows fit subjects for their attack. So, again, are the cows kept with bad environment in towns and cities. It is equally important that no attendant on dairy cows should be tuberculous, and every effort should be made, by spraying water around the stables, to keep down all dust whilst men or animals might be subject to its influences, for by dust the bacilli are most frequently spread around. The natural life of the cow is in the free and open country. West of the Mississippi River horned and other animals are the most robust. They liave a more natural environment, and the bacillus tuberculosis does not thrive so well in the pure dry air of that region.

Again let me say, I look upon this question of tubercle bacilli, in our meat and milk supply particularly, as a burning one. This source throttled, and the mortality of tuberculous diseases would diminish greatly, and instead of being our 


\section{FORTY YEARS IN THE MEDICAL PROFESSION}

greatest foe, would become a minor evil. To-day it is through milk that a great many of our so-called summer diseases among children are tuberculous. As it is, we must sterilize or Pasteurize these foods, watching that we do not go too far in removing all their freshness and causing scorbutic troubles. Men who appreciate the horrors of the situation must take these matters up and educate the people, who for their self-preservation must act; surely they will act. To bring about proper legislation will take money, for I do not believe in taking the private property of the individual, even for the public good, without some proper compensation. Pursuing this matter, by the light thrown out on the way by science and scientific men, we will in the end see mankind immeasurably benefited, and the human race saved from the horrors and sufferings now so relentlessly imposed upon it by many or all of the so-called zymotic diseases.

Here let me say, Lupus a'ulgaris is a very interesting affection, and its tuberculous origin, owing to the work of Henry W. Stelwagon, Duhring, and others, is now well known. The great point is to distinguish it from syphilitic lupus and from rodent ulcer, and to cure it. It comes to little children from being fondled often by tuberculous parents or nurses. I would not hesitate to use tuberculin $\mathrm{R}$ here, and study its action, watching it closely. Everything should be done to prevent autoinfection and the infection of others. It is my rule always to impress this on my tuberculous patients. The spitting habit, always vulgar anyhow, should especially be avoided. Persons are beginning to appreciate this, and the authorities are becoming active. Houses cannot be kept too clean, and especially dishes, knives and forks, spoons, and such used by the invalid. The temporary spit-cup should be used, or cloths or porous paper, and these frequently burned up. All clothing or bedclothing used by the invalid-better, the clothing of all in the house-should be frequently boiled one hour, or roasted at a high heat in ovens, or disinfected by formaklehyde fumes, and all apartments should be frequently fumigated with formaldehyde. If there is hereditary tendency 


\section{FORTY YEARS IN THE MEDICAL PROFESSION}

in one or more of your families, watch them closely from infancy to forty years of age. Especially watch mothers and nursing babies. Do not allow a tuberculous woman to nurse a child, or even care for a child, nor, above all, to sleep in the same apartment with it.

The very serious question comes up, Shall we isolate consumptives? "Blood is thicker than water." We cannot do it until by isolation we can promise cure or hope of cure. Then we can talk of isolation absolute, not before.

As to the medical treatment of tuberculosis, find, first, the focus or foci of infection. Call in the surgeon, if any of these can be removed. Pulmonary tuberculosis is the common trouble, of course. If the digestion is good, use the stomach for the strongest nourishment in every possible form, both direct and indirect nourishment, and this is all it is necessary to. say. I differ from most physicians. If the patient is a user of tobacco, let him continue it to the full extent of his enjoyment. It is as good a germicide as creosote and all such stuff that is given, and has just as good a chance of reaching the pathogenic germ or its toxine, and the smoke inhaled is worth all the other inhalations so universally used, and gives the otium cum dignitate without the accompanying opium cum digitale. Of course, if your patient's circulation is weakened by the tobacco, curtail it; for we want no points of stasis as a starting-point for new foci of infection.

Through the lungs is one of the most arailable channels to reach the bacilli, for, as external causes of infection go, they reach the general system as frequently through the lungs as they do through the ingestion of tuberculous substances. In children I believe the bacilli enter with the milk and enthrone themselves in the delicate intestinal epithelium as the most, to them, available method of reaching the system. The stronger intestinal epithelium of the adult is not so available as the resting-place of the pathogenic germ, and here the lung becomes the most available, and thus we reach more of them through the lungs. Never give nauseating expectorants to your consumptive patients, nor opium if it upsets them. Chlo- 
ral and such remedies are far better. Upset the digestion, and you do great injury, irreparable injury, indeed. Give cod-liver oil, if it can be taken with advantage, and emulsions only if the crude oil cannot be assimilated. Alcohol is a sheet-anchor in checking retrograde tissue change, and has doubtless some germicidal action. Man is the only fool who takes alcohol as a beverage. Counterirritations, as a rule, I have abandoned, and have relegated them, with the moxa and the actual cautery, to the realm of the barbarous ages, where they belong and always did belong.

We have learned much about tuberculosis of the bones, and these the surgeon deals with. There is only one point here, and a very practical one, and we should study it, each from his own experience. Does the cure of a tuberculous ailment not of a serious character change the focus of distribution of the pathogenic germs, and thus more speedily infect vital organs like the lungs? The same question we may put to ourselves in gynacological tuberculosis. There is one thing the gynæcologists have taught us: we can cure tuberculous peritonitis by laparotomy as a preliminary treatment. In the treatment of pulmonary hemorrhage it is a mistake to use ergot, a remedy so much and so erroneously used. It only increases the trouble by its action on the vasomotor system. The proper remedies are trinitrin and such remedies as decrease the blood-pressure. The older physicians used bloodletting to produce the same effect. It was effective, but the result was obtained by the long way around. I have had no experience with the method, but I cannot help referring to Dr. Murphy's proposed method of treating pulmonary tuberculosis.

Murphy claims that nature cures consumption by a deposit of connective tissue around the focus of infection. Anything favoring this will cure the disease. He illustrates by a tuberculous knee-joint. Set it at rest, and new tissue forms and the cure comes. Rest is necessary. We have ninety square metres of respiratory surface in the lungs; we can live with half of that surface, or much less for mere existence without 


\section{FORTY YEARS IN THE MEDICAL PROFESSION}

exertion. The lung has great capacity to repair itself should there be solution of its continuity. IVe coffer-dam the diseased spot, and nature makes the cure. There are three ways to clo this. First, remove a rib, or ribs, and allow the chest to contract over the diseased region. Secondly, open the chest and inject some non-poisonous substance into the pleural cavity, a substance that will remain a long time unabsorbed. This method is similar to allowing the chest wall to collapse by the removal of the ribs. He recommends nitrogen gas for this purpose. The gas remains for months unabsorbed, and the cure goes on. There may be slight dyspnœa after the injection, but this soon passes off. The operation is simple, with little pain or discomfort. Murphy thinks the dangers of compressing the lung too suddenly and of the gas entering the veins are possible, but not probable. I see the instrument-makers already have out the whole apparatus for the purpose as devised by Dr. Murphy. Murphy's third method is much like his first: open the chest and allow the wall to sink over the seat of the disease.

The philosophy of cure in consumption is to check the ravages of the catse, the tubercle bacillus. If checking the ulceration caused by the toxine generated by the pathogenic germ will cure consumption, Dr. Murphy is on the right track. If his method leaves the author of this ulceration and toxæmia to go free, and to come time after time and repeat his work, Dr. Murphy's methods will not cure consumption. The difficulty in consumption is, the disease is usually local, and does not produce immunity after infection. Again, we have the secondary or mixed infection to contend with as the case advances, and, so far as we know of remedies at present, this makes the case hopeless. Murplyy is right, the formation of fibrous tissue around the foci of infection is the only cure, so far as we know, but this is the spontaneous method, nature's method. The logical plan, then, is to spur on nature to effect the cure, and to curtail the evolution of the tubercle bacilli, the great first cause. The number of spontaneous cures of consumption is greater than we dream of, and the 


\section{FORTY YEARS IN THE MEDICAL PROFESSION}

number of cases of surgical and other cases of tuberculosis recovering is very large. More than half of the human race are tuberculous, and more than half of these die of tuberculosis in one form or another, and in those who do not die of it it generally becomes latent or is cured, and they die from some other cause.

The question presenting itself to us now is, What is the great factor in holding tuberculosis latent, or in curing it? So far as we know, it is climate and environment; and could all the unfortunate victims of tuberculosis avail themselves of such resources we would see a great diminution in the number of victims. As we go north and west, in our own country particularly, we find such atmospheric conditions and such altitudes as conduce to the comfort and well-being of the tuberculous, because, by the altitudes and state of the atmosphere, the almost constant presence of sunlight in daytime, the conditions are sterilized, immunized, and strengthened. The almost entire absence of humidity, the low temperature, the altitude, the pure air, cause increased respiration, and hence the number of red corpuscles in the blood is increased, and the oxygenizing power of the blood is of course enlarged. In these high altitudes persons going there at first suffer from embarrassed respiration to a greater or less degree. This is caused by the diminution of the atmospheric pressure causing increased action of the heart. These symptoms usually subside in a few days, and a tolerance of the environment is established. Epistaxis may come on, from vasomotor activity. You will say hemorrhage from the lungs will probably come on, and may be an element of danger. As a rule, persons with unsound lungs will not suffer from pulmonary hemorrhage in high altitudes; they may suffer more than those with sound lungs from embarrassed respiration, on account of encroachments of disease upon their normal lung space, but they will not be apt to bleed from the lungs, for the reason that the excessive vasomotor activity will drive the blood out of the deep viscera, such as the lungs, and thus deplete them and render them less liable to bleed. Thus, then, 


\section{FORTY YEARS IN THE MEDICAL PROFESSION}

we have the two explanations: the nose bleeds because vasomotor activity renders it, a superficial organ, plethoric, and the lungs, the deeper organs, depleted.

Reasoning from what we have said in regard to the bloodcells, etc., why would not blood be a remedy to check the onward course of tuberculosis? I have tried it faithfully in a number of cases, the patients going to the slaughter-houses and drinking it hot from the animals. I have seen refined, delicate women drink it thus without the least repugnance. I never saw it do any real good, after considerable observation. The patients were always enthusiastic, and expressed and argued themselves better, but each went to the common melancholy end of the great majority of consumptives. I have travelled extensively through our Western country, both recently and in the early days. There is a prevailing impression in all of the high altitudes that the tubercle bacillus, from a lack of moisture, will not live, or at least will not thrive, at an altitude of over five thousand feet, and some say even four thousand feet. I believe there is much truth in this as far as the open air is concerned. Now, at five thousand feet build a town, or at ten thousand feet, the altitude of Leadville, Colorado, erect your modern houses, furnish them with modern furnishings, and heat them up to the modern standard of $75^{\circ} \mathrm{F}$. Here you have builded a palace and an elysium for the king of pathogenic germs, and from this we can draw our moral of the treatment of consumption: High altitude, dry air, sunlight, little or no artificial heat, and, whenever possible, in the open air, and in a tent rather than in a house, at any time.

The Indian is an object-lesson. Turn him out wild, and he is vigorous, hale, and hearty, if only he can be held aloof from the selfish designs of the white man. Bring him into civilization, give him houses and lands and all modern comforts, what is the result? The deadly tubercle bacillus finds in him a victim after his own heart, and the poor Indian soon yields to his relentless charges. A few years ago the United States army had recruited for it some companies of Indians. 
Great care was taken to choose only the best of a very large number offering. The result was melancholy. As soon as they were brought under army discipline in barracks they began to fail, and consumption made such inroads upon them that the authorities were compelled to abandon the effort for Indian soldiers. I saw the last company in barracks at Fort Douglass, Utah, in I894. They were a fine-looking set of men, but nearly all of them showed incipient signs of consumption, and in a few days all were discharged and returned to their natural environment. Fortunate men, that they could so easily regain conditions where nature might restore them, or at least check their rapid march to the grave.

Thousands living in the parts of the world where consumption runs rife, unrestrained by any natural influences, must bear and suffer unless they have pecuniary means with which to seek more congenial climates. Can this large class be helped at home? Can we do anything for them as they pass on through all of the stages to the last, the secondary infections? Can the antistreptococci, the normal, immunized, or other serums avail them here? Can pneumotherapy, can pneumatic differentiation, help them over the thorny path? If people could only be scattered, scattered in their residences, scattered in their towns; and this can only be done by scattering the towns. Have no slums. The dwellers of cities, owing to the increased facilities for near-by travel offered both by steam and electricity, are scattering more and more into suburban homes, thus relieving the crowded centres. This will surely have a good effect on the tuberculous and on those with tuberculous tendencies. Take the world over, I do not care whether it be in the dry high altitudes or on the moist and level plains of the seaboard, the cases of tuberculosis, the deaths from tuberculosis, vary as the density of the population varies, - the denser the population the greater the number of victims. In the city of New York, with 8I,828 dwellings, there were during the last five years deaths from tuberculosis in 18,77 I houses. In the fourth ward, in 248 houses, there were 54 I cases of tuberculosis in three years. 
In many houses the continued recurrence of tuberculosis is reported. Here is a good object-lesson and its sad story, from which we may gather inspiration for reform, which leads us to infer that to check tuberculosis entirely we must discard towns except for business, discard houses and their surroundings for tents, destroy all infected animals, give up our modern luxuries in travel, and go back to primitive times, in order to drive out the modern monster, the bane of our civilization. Society will not do this, but modern methods and modern ideas, guided by the ever-spreading and expanding light of science, will take hold of this scourge and will in the end conquer it, so far as nature allows her methods to be interfered with by man.

As to climatic treatment, we can make the ideal climate at or near our homes, provided our homes are not in favored regions; this we can do by placing our patients in sanitaria and sanatoria now rapidly coming into rogue for the purpose. There are many in this country, and many in Europe. Insurance societies in Germany are establishing them for the treatment of their clients, and such societies, I think, will come sooner or later in this country, and thus solve a problem for the man of limited means. For the opulent we have many already. They are only a make-shift. When possible, the patient should move, bag and baggage, to the proper climate, and make it his home. Years ago, consumptives went to mild winter climates only. The only reason was to avoid taking cold. This did good, saving the onset of cold through the extremities by chilling the nerve extremities, causing congestions reaching to the lungs themselves, and establishing new foci of infection. This was all, the surroundings were reeking with the pathogenic germs, and were in every way undesirable.

When the great Northwest began to expand, forty years or more ago, experience showed that consumptives, if in the preliminary stages, did well there. St. Paul, Minnesota, became quite a resort. Experience was right, although we then knew nothing of the cause of the disease. St. Paul had a dry, 


\section{FORTY YEARS IN THE MEDICAL PROFESSION}

bright, sumny atmosphere and many other desirable qualities as a residence for the tuberculous. The altitude was not suffcient, and the thermometer went too low at times, and the mid-winter thaw was against it. For sanitarium treatment in place of special climate and altitude treatment, we may make the case conform to the surroundings, and it need not be necessary to take into consideration the age, condition of the heart, the stage of the disease, etc., all of which must be thoroughly looked into before we order our patients away for climatic or altitude treatment.

Now, as to the sanatorium treatment of tuberculosis. First, as to the two words as they are used, sanatorium and sanitarium. The former is really the proper word, and both are of rather recent coinage, rendered necessary, like other new words, by the world's progress. They are both derived from the Latin verb sanare, to heal, whence we have sanitas, health, and samus, sound,--sound health. Sanatory is derived from sanator, one who heals. Sanitary is derived from sanitas, health. Sanitary refers to a condition. Sanatory refers more to action towards the condition. I should incline to speak of a large resort for invalids, without special methods of treatment, or where treatment and pleasure were combined, as a "sanitarium." A private hospital, or an institution not exactly a hospital, but at the same time devoted altogether to the care and treatment of invalids, whether general or special, I would call a "sanatorium." The Century Dictionary gives sanatorium as the proper word, and the word sanitarium as an improper use of the word sanatorium. I rather incline to the definitions I have given.

Treated at home, consumptives, or patients having any form of tuberculosis, should, first of all, live as near as possible out of doors, and dress for the weather. They should exercise absolute personal cleanliness, and care for the expectorations, etc., so as to burn them up. They should have a room to themselves, if in the house, and exercise all means to prevent infection of friends or premises. This is the gist of home sanatorium treatment. 


\section{FORTY YEARS IN THE MEDICAL PROFESSION}

General hospital treatment is now becoming more and more an open-air treatment, even if the patients are bedridden. This helps the patient, and lessens the liability of infection to others and to the premises.

The popular sanatorium rest-cure is about the same in all, and is about as follows: Selecting the spot in the proper location, at a proper elevation, and with the proper atmosphere, sunlight, and surroundings, the sanatorium is established. First, there must be absolute cleanliness of buildings and surroundings, and the patients must be examined before admission, to see that the case is a proper one, so far as the heart, etc., are concerned, for the environment. The altitude should not be less than four thousand five hundred feet. Disinfection must be thorough and continuous, to protect both the sick and the well who are compelled to live in the sanatorium to care for them. 'The expectoration of patients must be burned, every drop of it. Rooms and floors must be washed daily. All dust must be burned, and all utensils must be boiled, particularly napkins and towels, after each using. For the "restcure," a gallery is built opening to the south. Here absolute rest is taken all day in chairs and beds. After three or four months of this treatment, short walks are indulged in around the grounds, where are arranged seats and sun-boxes. The head and eyes must be protected from the sun. The surrounding air, if the sanatorium is properly located, is perfectly dry, and on this account the doors and windows of the sleepingrooms are always open, the patient avoiding drafts as much as possible. If the least chilly, the patient must always summon an attendant with hot-water bags and wraps. If the temperature of the patient runs above normal, a cold-air bath in the sun is used to check it, much as we use cold water for typhoid and other fevers. Food, rest, open air, and sunlight are the remedies used, without much medicine. This method, closely followed, is affecting cures in from six months to three years, or even longer.

These methods are particularly applicable to the weak and delicate cases and those too far advanced or too much 


\section{FORTY YEARS IN THE MEDICAL PROFESSION}

complicated with secondary infection for rough-and-tumble life.

There are some favored spots in the world where the inhabitants never take cold, and instances are given which show that colds are surely infectious diseases, the infection being carried by human beings; that it runs a definite course; and that one attack for a certain length of time confers immunity, thus showing a pathogenic germ to be the cause. In my own case I have an object-lesson. I have made a number of seavoyages; nearly every time I have come ashore and mingled with the busy world; in about from forty-eight to seventytwo hours I have taken a cold, which has run the usual course of colds. It is said of Nansen and his men that during their three years' residence in the Arctic regions not one of them ever took a cold, yet they were constantly exposed to cold, wet, and fatigue. So, of the members of an expedition for three years in Franz Josef Land, none ever took a cold. As soon as these people returned to the civilization of the Temperate Zone they took colds. Men living in Spitzbergen, away from the centres, keep well. As soon as they go to the coast settlements they take cold. On the island of St. Kilda, away beyond the western Hebrides, about one hundred people reside. The coast is inhospitable, and only for about four months in the year can vessels approach it. The people are always well, and never have colds during the eight months of non-intercourse with the outside world. So soon as a vessel arrives, then, in a few days, every man woman and child on the island has a cold.

These are wonderful object-lessons, and cause us to think deeply. We will probably utilize such places, but we must do it with certain restrictions as to intercourse with the outer world, and bar the luxuries of our advanced civilization, and thus bar out the pathogenic germs of consumption, pneumonia, influenza, and all zymotic diseases. Thus by prevention, through fresh air and sunshine, we can really do much more for our patients than by saturating them with creosote, guaiacol, and such remedies, which have 


\section{FORTY YEARS IN THE MEDICAL PROFESSION}

a vannted germicidal power, yet appear to be in little or no way specific remedies.

The sanatoria are all very well, and some of the rigid rules, as to antisepsis, of these institutions should be carried to our homes, our hotels, our steamships, our sleeping-cars, our places of amusement. and particularly our churches and our schools. Our boarding-schools and colleges should come under rigid inspection, and sanitary schools in aseptic regions will in the future be a proper safeguard for boys and girls who may be delicate, with bad family histories.

As to the general resorts for consumptives, carried on commercially in the western part of our country, such as large hotels and the so-called sanitaria and boarding-houses, my adrice to invalids is to give them a wide berth. I have travelled through a great deal of that country, and been in a number of them, and among the saddest of sights is to see a large roomful of consumptives comparing notes, coughing and spitting during the whole time. the atmosphere and furnishings and the company themselves reeking with tubercle bacilli, and deluded with the idea that they are doing what is best for them to do to regain health, which never under such conditions can be regained, but all going faster, under the circumstances, to their sad and inevitable end, and, worse than all, laying the foundation for just such horrors in those around them not yet infected. Those who go away for health want to avoid the crowd; they need to live as nearly alone as possible, and they want to be well enough and strong enough to take active exercise, to live in the open air almost entirely. Ranch life is the ideal life, and the nearer companionship is reduced to the horse and the blanket, the better chance will the patient have of cure. The "one Jungers," as the natives call them, patients with a cavity, or honey-combed or solid apex, can enjoy this life and improve greatly and prolong life indefinitely if only secondary infection has not set in. After that lias come, the unfortunate consumptive should not, as a rule, leare home, especially if diarrhœa and other weakening troubles accompany it. 


\section{FORTY YEARS IN THE MEDICAL PROFESSION}

As to altitude, it is best to ascend gradually. Do not go to ten thousand feet at once. Probably four thousand to six thousand feet is best. Individual peculiarities may assert themselves, and compel changes from time to time. If the case is one of fibroid consumption, be very careful of too high elevation, as well as in cases of laryngeal tuberculosis. As to this last, the great desideratum is to be within reach of a good physician, and to get a place absolutely free from dust; and increase the altitude slowly, at least. Always examine the heart of your consumptive patients before you send them away, and note any deviation from the normal. Do not send your cases with hypertrophy of the heart suddenly to high altitudes, and cases of weak dilated heart, never. Diabetics do not do well in high altitudes; the heart is very irritable, and the blood-pressure increases the urine outflow.

So far as I can determine, the United States and Mexico have the best climates in the world for the tuberculous, and the best of these are in Colorado, Arizona, New Mexico, and old Mexico. In our Adirondack region many find a congenial home, but I think the good care and treatment they receive there has as much or more to do with it than the climate. The elevation is only about two thousand feet, and there is, as a rule, too much moisture. This applies to all of our country in the East of two thousand feet elevation or less. The North Carolina, South Carolina, and Georgia climates are fair, and have some places with good accommodations at about two thousand feet, but there is too much moisture, and too many invalids are crowded together to make such places desirable, unless one can have a cottage of his own. Florida is too moist, and the temperature varies considerably. Here the crowds of sick and delicate people are an objection, if in hotel life. I do not like southern California, especially on the coast, yet it is a delightful place to spend a winter; but it is too hospitable a home for the pathogenic germ. Minnesota, Nebraska, and Dakota have an elevation of about one thousand feet, and are in places fairly dry and pleasant. In Colorado the climate is very dry, and at times very cold, and is, as a 
rule, most desirable for those able to take exercise and live out of doors. Much the same may be said of parts of Wyoming and Montana, and parts of New Mexico and Arizona. Here we can get elevations of from four thousand to as high as fourteen thousand feet, if we choose to go to the top of Pike's Peak in Colorado. The ideal climate, I think, is the warm and dry climate of southern New Mexico and southern Arizona, with an elevation anywhere from three thousand to five thousand feet. At the Las Vegas Hot Springs, New Mexico, there is a sanitarium well cared for, where both sick and well can spend a pleasant winter or make a pleasant home. This is not far from Santa Fé and Albuquerque, and in a very pleasant part of the country. Silver City, New Mexico, is in a good location, one of the best, indeed, and the surrounding country gives opportunities for persons who can rough it. The town itself is not overrun with invalids. In Arizona, Phœnix is a desirable place, and, taking it as a centre, one may choose widely and establish a home in some available locality. Those who go to such places should go with a view of taking up a permanent residence and establishing a home. If they get well, it will not be safe to leave for five years, at least, and in that time they make new friends and the old homes change, often so much as to make the return a sad one, and the disease may light up again in the moist climate.

There is one thing to remember in choosing a climate for the tuberculous, - the individual is the important factor. Study and observe well the individual. The idiosyncrasies of one person may make a place in every way improper, which would suit another exactly. Remember what those persons seek who migrate searching for health: as far as the tuberculous are concerned, they seek a place, first, where the pathogenic germ does not thrive; secondly, where they may best maintain the natural immunity inherent in all; and thirdly, where they may best establish and hold an artificial immunity to the germ. The surroundings are important, and very important matters are occupation and amusement, and 
proper food and clothing. I have advised many patients to change their residences on account of tuberculosis, and I have watched many who have changed who were not under my personal care. Those going to Europe for travel, and then locating on the Mediterranean and in other genial climates, have, as a rule, not done well. The life generally is tiresome, and not suited to an invalid unless a home is established.

There are many sanatoria (especially in Germany), as at Göibersdorf, Falkenstein, Hohenhonnef, Nordach, and Reiboldsgrüne. These may suit the Germans. We have them just as good at home, and in a much better climate. Besides, I do not believe in crowding the tuberculous either in houses, in districts, or in communities. We want to separate them. If crowded, asepsis as to the individual, his belongings, his food, his surroundings, in fact in all conceivable ways, must be perfect, for both his own protection and for the protection of others. Those persons I have sent away who have done best are young men and women of moderate means, who, after their location, were compelled to take up some employment for a livelihood. Those who went into the country, or roughed it on ranches and in such employments, did best. A number have located in Denver, Colorado. They generally, at my advice, took employment where they could get plenty of outside air. They made friends, they have done well in a business way, they have established homes, some have families, and most of them are prospering in mind, body, and estate. The secret was, the necessities of existence drove them to work, they became interested and separated from their fears and evil forebodings as to their condition of health, and the result was in every way good. On the other hand, I have known a number who had everything in this world, in a pecuniary way, to make them happy. They went for long visits, and generally in the winters; of course, they put up at the best hotels, crowded as they were with brothers and sisters in suffering. The result was always bad, and, as a rule, they would have been better and safer, and perhaps lived longer, in their own comfortable homes in the East. 
Another class, young men of means, in the incipient stages of pulmonary tuberculosis, start to travel, and spend a season in the Riviera. They live luxuriously at the hotels and clubs, and a society life in general. Of course, they deteriorate; they come home and go IVest for a home; they settle, perhaps in the city or town, where they meet the best society and lave the best time. They live at the club usually, and live an idle, listless life. They suffer from cnmui, of course, and nothing can shake them up to activity of any kind. The result is bad, and the remorseless disease completes its work in about the average time of the average case. Had such men gone IVest and at once started out on the trails, away from the civilization of the towns, taken up ranch life of some sort, and lived with their horses and blankets, their chances of recovery, or of lives greatly prolonged, would have been excellent. In such cases lies the moral of the whole treatment of tuberculosis by climatic conditions. It depends as much upon the individual and his actions as it does upon the climate and the environment in general.

Before I close, let me return once more to the captivating and hope-inspiring subject of serotherapy in tuberculosis, and give the experience of Dr. J. Edward Stubbert, of the Loomis Sanatorium for Consumptives, at Liberty, Sullivan County, New York. The matter is from his report for the six months ending May I, I898. The altitude at Liberty is two thousand three hundred feet. Patients do better there in winter than in summer, although the year round they do well. The atmosphere is dry and the sunlight is abundant. The cold northwest winds do the patients good and not harm. They walk through snow two feet deep, and improve by such work. He allows all patients whose evening temperature does not go above $100^{\circ} \mathrm{F}$. to walk moderately, and if the temperature does not go over $99^{\circ}$, no restriction whatever in regard to exercise is placed over them, even up to or exceeding walking ten miles or more a day. IVe try, he says, to improve the general nutrition of the patients, in order to enable them to overcome a specific poison. As to medicines, he uses creosote, 
oil of cinnamon, ichthyol, and guaiacol valerianate. Ichthyol in keratin-coated pills is best, especially if there are intestinal complications. I suppose Dr. Stubbert looks upon it as exercising a local germicidal action here, as, no doubt, this is the great field for creosote and all such remedies. Hot air inhalations were used in about thirty-five per cent. of the cases, with encouraging results.

Now, as to the serum. I agree with Dr. Stubbert in the following statement, when he says, "I am not ready to pin my faith to serotherapy in tuberculosis, but in view of the fact that, so far as bad results are concerned, it has proved negative, and that a comparatively fair number of cases have apparently improved under its administration, I believe it to be the duty of the profession to continue clinical investigations along this line." He says the cases treated in New York City in private practice by Dr. Loomis and himself as yet give rise to no positive conclusions. Loomis's experience in hospital patients in New York City gave entirely negative results as to improvement. Stubbert says the good effects appear to be reduction of temperature, decrease of tubercle bacilli, and probable immunity conferred upon patients after returning to their homes. He says he has discarded its use in the sanatorium except in incipient cases. The serum he used in his cases reported was the United States government serum of de Schweinitz. Now, I take it this serum is a tuberculin, the tuberculin A of Koch, without attenuation by oxidation. Therefore it is a toxine, and not an antitoxin. Let me give here his recapitulation of the number of cases treated :

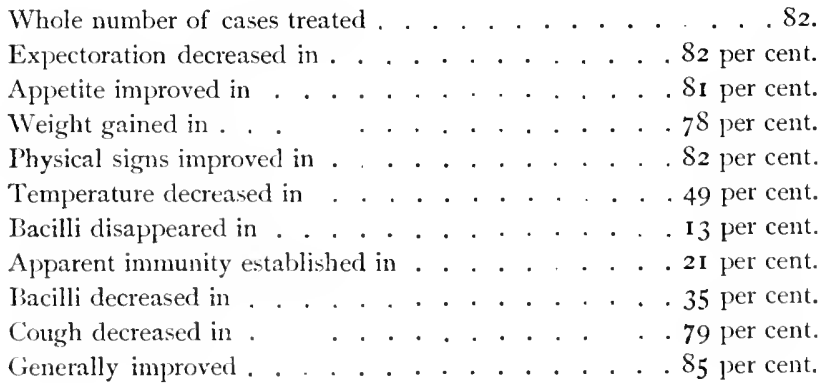




\section{FORTY YEARS IN THE MEDICAL PROFESSION}

This surely is not a discouraging showing, coming from a reliable source. The use of tuberculin is contraindicated in cases showing much softening or carities, in incipient cases with marked hereditary taint, in those in whom vital capacity is much below normal, in those showing rapid heart action, and in most cases of mixed infection. In any casc, it is not dangerous to inject the scrum; occasionally a slight reaction occurs in the first few treatments. It does not interfere with digestion; where the bacilli have disappeared they have done so while the sputa were still present. No report of any relapse of patients cured has been given, although they may have returned to their former environment.

The most encouraging report from Dr. Stubbert was in regard to his use of the Pasteur antistreptococcic serum in six cases of mixed infection, showing, of course, the presence of streptococci in the serum. The idea was to neutralize the secondary infection, and give thus a clear field for the action of the antitubercle serum. The injection used was about ten cubic centimetres each time. In the first case expectoration ceased almost immediately for a number of days and then returned in diminished quantity. On examination, the streptococci were found to be far less numerous and smaller in size. The next case had had bronchitis for four years. Then tuberculosis developed. This disappeared under antitubercle serum, but bronchitis remained. The sputa were muco-purulent and contained streptococci. After one injection of antistreptococci serum cough and expectoration increased materially. After a few weeks the patient began to improve, and the expectoration became very markedly less purulent. This patient still lives. The next case had a dry cavity at one apex. The streptococci disappeared after four injections of antistreptococci serum. and the sputa, after a considerable time, still contained tubercle bacilli. In the fifth case, the antistreptococci serum had no effect. The sixth case was one of tuberculous meningitis. Eight injections of antistreptococci serum had no effect. If the cause of failure of antitubercle serum is in many cases mixed infection, then see 


\section{FORTY YEARS IN THE MEDICAL PROFESSION}

how important the report of the action of antistreptococci serum in these cases becomes, and how encouraging to go on with its use, and how very encouraging to these cases which we have always had to look upon as so hopeless heretofore. The antistreptococci serum acts very much more slowly in these cases of chronic infection than it does in cases of acute infection.

It will be remembered by the reader, that when, a few pages back, I spoke of the work clone in order to test the relationship of the bacillus of tuberculosis and the bacillus of anthrax by Dr. Neale and his assistants at the Delaware College Agricultural Experiment Station at Newark, I was compelled to record my great disappointment at the negative character of the results of the experiments. I have now by me the Quarterly Bulletin of the Pasteur Institute of New York City for December, I897. In it I find an article by its Director, Dr. Paul Gibier, " Do Laboratory Researches allow us to hope for the Early Discovery of a Specific Remedy for Tuberculosis?" Gibier was working on microbic symbiosis in general, with the object of investigating whether, by some kind of vital competition between the bacillus tuberculosis and the various other bacteria, it would be possible to cause the latter to develop a soluble ferment giving the cells of the animal organism the power of digesting the bacillus. He inoculated successfully a number of guinea-pigs with the tubercle bacilli. He kept four animals as tests: that is to say, he allowed them to go without any treatment after they had developed tuberculosis. The others he inoculated with a liquid obtained by filtering through clay the cultures of a number of bacteria which had thrived in company-symbiositic bacteria they might be called-with the tubercle bacillus. Injections were made every other day, the quantity of fluid being gradually increased to two cubic centimetres. The test pigs died in two and one-half months, three months, and three and one-half months. Those treated with the filtered liquids of the cultures of tubercle bacilli and streptococci, tubercle bacilli and staphylococci, tubercle bacilli and subtiles and others, were 
not helped as to their tuberculosis, and died before the test pigs. He took two of the tuberculous pigs and treated them with a liquid of a culture of tubercle bacilli and anthrax. After receiving five or six injections, the ulcerations at the points of their tubercle injections began to heal, and their inguinal glands, before enlarged, began to decrease in size. One of the two tubercle and anthrax pigs died accidentally. The other continued to receive the combined tubercle and anthrax injections, at first every two or three days, then twice a week, and then once a week, for two months. At the end of the two months, the ulcers had healed and the glands had gone down to natural size. It was well, and at the end of two years, when it was killed accidentally, it had thrived and doubled its size. Other experiments in the same line by Gibier did not turn out so encouragingly, but he rightly argues, "Experiment in this line is worth while, and in the end we will by some such means be able to arrest the development of the tubercle bacillus," and thus cure tuberculosis in man and the lower animals. God speed the day.

Another method of attacking the pathogenic germ is by inhalation, and an account of some experiments given by Murrell in the Philaddplia Medical Journal for February 18 , I899, shows how men are working on all sides to overcome this arch enemy of animal existences. He took twenty patients suffering from pulmonary tuberculosis in various stages, none of whom were confined to bed. He arranged for them to inhale once or twice a day, and some of them continuously night and day, air impregnated with either oil of cinnamon or oil of peppermint. The details were well carried out, and the results were uniformly unfarorable. In the bacteriological examinations neither of the oils showed any deleterious influence on the growth of the tubercle bacillus. Experiments were made with formaldehyde in forty per cent. aqueous solutions, the patients inhaling a spray containing one part of this solution in sixteen of water; at the same time, bacteriologic examinations were undertaken with a six per cent. solution of formaldehycle, and the results proved most 
satisfactory as regards its action on the bacillus tuberculosis. No contaminations occurred in any of the tubes. All the controls grew well except in one agar-agar tube sealed with paraffin in a jar, which failed by an accident. No tube kept under the influence of formaldehyde vapor for forty hours, ninety-six hours, or ten days showed any growth whatever. Subcultures were made from several tubes of the solid media, and from all the tubes of the fluid media. All of these failed except one of glycerin and beef-broth exposed for forty-eight hours, which, reinoculated on blood-serum, began to grow feebly after three weeks. A repetition of these experiments gave the same result.

All this shows that even a weak solution of formaldehyde shows a marked inhibitory influence on the growth of the tubercle bacillus, and prolonged for forty-eight hours entirely prevents their growth and future development. The clinical results are quite up to the bacteriologic experience. The six per cent. solution was usually employed, increased or diminished according to the idiosyncrasy of the patient. The drug was inhaled once or twice a day, compressed air by a simple mechanical arrangement being made to bubble through the solution. Coughing in some cases was annoying during the inhalation. Out of twenty cases treated, six were inconclusive, because not persisted in, or other treatment was used with the inhalation. The other fourteen cases did well, only the inhalation treatment being used. Twelve were decidedly benefited, and two were slightly improved. These cases were in all stages of the disease.

Murrell recommends, as the best method of treating pulmonary tuberculosis, to obtain bacilli from the expectoration, cultivate them, pass over them various volatile substances until one is found which will arrest their growth, and then administer it by inhalation.

I have not said much of drugs in connection with tuberculosis, but the new South American remedy, kalaguta, must not be passed over, for it really, on so good an authority as the Loomis Sanatorium physicians, shows great antiseptic prop- 


\section{FORTY YEARS IN THE MEDICAL PROFESSION}

erties, in doses of three grains three times a day. Attention was first attracted to it in South America by the effect the eating of the leaves had on tuberculous cattle. It apparently cured them. The remedy produces no ill effects. The analysis is given as follows: Water, 8.5 I ; extract of ether, 3.or ; albuminoids, 22.19; ashes, 16.79; cellular and extract matter not ozote, 49.43. The Loomis report gave five per cent. apparently cured, sixty-two per cent. improved, fourteen per cent. stationary, nineteen per cent. worse. In septic cases ichthyol is highly recommended from the same source, and good authority it is, too. It is almost a specific in changing purulent sputum in doses of from twenty to thirty grains a day. The Sanatorium also, in its last report, gives more hope from antitubercle serum than do most other clinicians at the present time.

One word more. We have considered tuberculosis of the lungs, bones, joints, glands, and other parts, but have not spoken of the circulatory system. Tuberculosis is a protean disease, the more we study it. In cases of heart disease, especially in the young and delicate, whether of the myocardium, the pericardium, or the endocardium, before you relegate the case to the domain of rheumatism or to the class of cases regarded as idiopathic from cold or wet, consider them well. Cardio-vascular disease surely predisposes to tuberculosis of some form. Either the tuberculous trouble or the cardiac trouble may be primary. The tubercle bacilli and its toxines and other pathogenic germs may produce the heart trouble. The toxines are active in producing the sclerotic forms. The bacilli produce nutritive changes in the tissues. Tuberculous lesions of the valves of the heart are often found; so it is well to remember the possibility of this in all cases. Tuberculous pericarditis is probably far more common than is usually supposed, and doubtless the cause of the condition is far more commonly overlooked than diagnosed. There is another trouble which is very frequently of tuberculous origin,- - acute pleurisy. Remember this in diagnosis, in treatment, and, above all, in prognosis. 
Before I close this chapter let me add a note on a practical point in hay-fever. Having been a lifelong sufferer myself from a form of hay-fever,-the June cold, commonly called the rose cold,-I naturally take interest in any matter pertaining thereto. We know it comes in other forms besides the June cold, the chief other forms being the autumnal catarrh, coming on about August 20, or when the rag-weed or bitter weed (Ambrosia artcmisiafolia) blooms, and the perennial form which pesters its victims during the whole part of the year when all vegetation is not dormant. I believe all of these forms have a common cause, and that cause is bacterial. Plant pollen is given as a cause. Vibrios in the nasal chambers have been given as a cause, and vibrios are bacteria. Some claim it is a neurosis pure and simple. I know all sufferers from hay-fever are neurotic at the time they are under the morbific influences, and during this time there is occlusion of the nostrils and tender spots on the nasal mucous membrane: but there is really no essential diseased condition of the nasal mucous membrane as a cause, and the neurotic condition is an effect rather than a cause. As I said before, I believe the cause is from pathogenic germs, and these enter with the dust of the air and cause the trouble. There is an individual sensitiveness to their action, just as some individuals are sensitive at times or always to other pathogenic germs. I believe the pollen of plants do their part, but more as a host for the pathogenic germs, and by their natural irritating qualities, than in any other way.

Now, as to the practical point. In investigating some matters in connection with electric lighting, I met a young man who had been a sorry sufferer from hay-fever since he was four years of age. His residence is Wilmington, Delaware. From August 20 to the first heavy frosts of each year he has been unfit for any work, from asthma and other troubles. Three years ago he went to Oakland, Maryland, high up in the Allegheny Mountains, and worked in an electric-light plant, which merely generated the current, but had no storagebattery plant. He received no benefit there, either from ex- 
posure in the works or from the climatic conditions. Since last spring he has worked in the plant at IVilmington, Delaware. much of the time in the storage-battery room. This year he has been absolntely well in every way thronghout the hay-fever season, and he attributes his freedom from trouble to something he breathes when in the storage-battery room.

I examined this young man during the time he should have been suffering. I found him well and strong, twenty-three years of age, weight one hundred and thirty-five pounds, five feet six inches high, with a good fanily history, and not a hay-fever subject by inheritance. There were a few dry and moist râles over the chest. such as we might find in any one who might have been at times more or less asthmatic. $\mathrm{He}$ told me he was cured. I asked him by what means? He said by inhaling the fumes in the storage-battery room. "I am especially benefited," he said. "when we are overcharging to bring up low cells and when the booster is on." The question now was to find what these fumes were. I found upon questioning the very intelligent gentlemen connected with the plant that their idea was that the fumes were hydrogen peroxide, hydrogen dioxide. Here was an explanation consistent with my belief of the cause of the disease, the cause being bacterial and hydrogen dioxide a destroyer of bacteria; and probably this patient was benefited in the storage-battery room just as whooping-congh patients are benefited in the gas-houses where illuminating gas, carburetted hydrogen, is made, the carbolic acid fumes here acting as a germicide to the now pretty well established cause of pertussis.

In order to more fully investigate what these fumes of the storage-battery room might be, I consulted my friend, Professor C. L. Penny. Professor of Chemistry in the Delaware College Agricultitral Experiment Station, Newark, Delaware. In giving me notes of his examination, Professor Penny alludes to the young gentleman, the victim of the hay-fever, as saying that the curative agent in his case was hydrogen dioxide, and that it had to him an unpleasant odor, yet hydro- 


\section{FORTY YEARS IN THE MEDICAL PROFESSION}

gen dioxide has no odor. "If the hydrogen dioxide is the curative agent, it must be largely as carried into the air by the spray from the bubbling of the battery, and in that case with some of the dilute sulphuric acid. Whether it would be abundant enough and far-reaching enough, carried in that way, to do any good, I do not know. In view of everything, it would seem to me that ozone is the one probable explanation of the case. Ozone has long been known to be evolved from electrolytic action, such as that of battery-charging. Where such enormous electrolysis is going on as in the Wilmington power-house, and in so small a confined space as the battery-room, the air must be very highly charged with ozone. The electrolysis of less than an ounce of acidulated water, with a weak battery current, will emit an odor very perceptible in a room for some feet around. Now, the amount of action must be multiplied by many thousands to make it comparable with that in the power-house at Wilmington. Then I do not see anything improbable in supposing that there is, at certain hours, enough of ozone in the air of the battery-room to have an unquestionable effect on floating organic matter, or miasms, and prove disastrous to them. We do not know certainly of any other volatile emanation from electrolysis than ozone, common oxygen, and hydrogen. So far as I know, no one suspects any other such emanation; hence I would say, with the information available, that if a curative effect in the battery-room, peculiar to that place and not noticed elsewhere, is unquestionable, and if, as I understand to be the case, the curative effect is noticed only or chiefly when the liquid in the batteries is boiling, with evolution of gas, then I would not hesitate to attribute the curative effect to ozone as the only body certainly known to be present and capable of such effect."

I know one case is little upon which to base inference in clinical medicine, but this case opens up an interesting subject, and may point the means to relief and cure in many cases now only relieved by changes in climate and residence, so inconvenient to all and so impossible to the many. 
FORTY YEARS IN THE MEDICAL PROFESSION

Dr. Douglass, of New York, recommends for all forms of hay-fever the dried suprarenal glands. I have no doubt he argues for this remedy on account of its well-known property of depleting the nasal mucous membrane. It thus restores the over-distended condition of the nasal erectile tissue. $\mathrm{He}$ uses it both locally and as a spray, and by tablets internally every two hours until until some prostration is manifest. 


\section{CHA PTER XII.}

Rheumatism an Infectious Disease-The Bacillus of RheumatismThyroid Extract in Rheumatism-Uric Acid in Rheumatism-Nuclein - The White Blood-Corpuscles - Diagnosis - Treatment - Rheumatic Gout-Multiple Arthritis Deformans-Gout-Arteriosclerosis-Metabolism-Anabolism-Katabolism-Theories of Gout-Origin of Uric Acid-Causes of Gout-Gout of the Intestines-Treatment of GoutWater-Lithia-Diet in Gout-Intermitting Heart-Alcohol in GoutCider Cure for Gout-Vegetables in Gout-Contracted Kidney-Medicines in Gout-Piperazine and Pichi in Gout-Thyroid Extract causing Gout-Menstrual Gout-Carlsbad-An American Carlsbad-Diabetes Mellitus-Glucose-Starches-Dextrose-Glycogenic Matter-Tuberculosis and Diabetes-Pancreatic Lesions-Carl von Noorden-The Liver and Glycogen-Fat-Hyperglycæmia-Causes of Diabetes MellitusMayer's Theory-McCaskay's Suggestions-Relationship between Diabetes and Obesity and Gout and Diabetes-Gluten-Diagnosis-Tests for Sugar-Pregnancy and Diabetes Mellitus-Alcohol-RecoveriesDiabetes and Gouty Kidney-How to watch a Diabetic-Diabetic Cona-Diabetics Vulnerable-Diabetics and Tuberculosis-Thyroid Treatment-Prognosis-Diet and Treatment-Jambul and Piperazine - Substitutes for Cane-Sugar-Wines and Spirits-Waters-FruitsNuts-Allowable Articles of Diet-Terrapin-Rest Treatment-Gluten Flours and other Diabetic Flours and Foods-Analysis of Macaroni, Flours, etc.-The Soja Bean-Aleuronat Flour-Adulterations.

Forty years ago Dr. George B. Wood defined rheumatism, meaning rheumatic fever, to be a constitutional affection, attended with a peculiar irritation or inflammation, to which all parts of the system are liable. The general definition to-day is, an infectious disease, with fever and arthritis, more or less general. Some yet believe it to be due to a disturbed metabolism, the nitrogenous products being converted into lactic and uric acids and alloxuric products, instead of being carried off as urea. Hence we get the highly acid perspiration and high fever. Probably a few yet class it among the neuroses, like the neuralgias. Every day the number grows who class it with the specific infections, as they do typhoid fever, dysen- 
tery, erysipelas, and pneumonia. Personally, I believe here is where it belongs.

A French bacteriologist claims to have isolated the pathogenic germ, an anaerobic bacillus resembling the bacillus of anthrax. It is said to elaborate negative chemotaxic substances, and also products which produce necrosis in animal tissues, thus accounting for the heart lesions so often seen in rheumatic fever. Salicylic acid is said to affect adversely this bacillus, and the germ is not usually found in the blood. This might explain why the giving of thyroid extract produces rheumatism, as has been the experience with some, because it acts not specifically as thyroid extract, but only by the pathogenic germs it introduces into the system.

Whatever may be the cause, it looks at present very plausible to me that it is caused by a specific pathogenic germ which is destroyed by the exhibition of salicylic acid, acting as a germicide. How germs may act in producing the disease is for the future to determine. They may check the breaking up of the many compound waste substances in the system, which when broken up pass off harmlessly through the kidneys and other organs. These tissue wastes may be in the form of uric acid and allied substances. Again, as claimed by Bouchard, rheumatism may be a toxemia resulting from the decomposition of food-stuffs in the stomach endowed with conditions favoring such decomposition, such decomposition favoring the generation of the peculiar germs: not only in the stomach, but throughout the whole intestinal tract may these conditions be present.

What part uric acid may play in causing rheunatism is an interesting question. If rhemmatism is an infectious disease of bacterial origin, uric acid can only play a secondary part in the causation. It is either produced by or increased by this bacterial action, or its elimination from the system is checked by it. The same may be true of lactic acid. As to the source of uric acid, Vaughan says nuclein is broken up, alloxuric bodies are formed, and uric acid, the most highly oxidized of these substances, is the chief representative in the 
urine of the nuclear metabolism resulting, as here indicated, in the body. Here we come back to the cell, "omnis cellula e cellulâ," and in their life and death we look for the origin not only of life, but of death. Every cell at some period of its life has a nucleus. The nucleus of a cell is the part concerned in the transmission of its life to another cell. Nuclein is the material of which the nuclei are composed. In health, the nucleus of the red blood-corpuscle perfects it to carry the oxygen and disappears. From Kossel's experiments we know that nucleated cells contain, in addition to nucleinic acid, germicidal basic substances, protecting them against bacterial invasion. Here we approacls the claims of those who insist that we have in nuclein a germicide. Inject it into the system, and we increase the number of white blood-corpuscles, these being the natural scavengers of the body, which check or prevent entirely the multiplication of the pathogenic germs in the body. These polynuclear white blood-corpuscles do not eat up, as it were, the germs, but destroy them by some chemical action peculiar to themselves. What germicidal properties blood-serum may have, inherent or acquired, come through the polynuclear white blood-corpuscles. Increase these and you fortify the body against the attacks of all pathogenic germs.

I mention these somewhat intricate facts and suppositions to show that in some part of it we may sooner or later locate such diseases, not only as rheumatism, but gout too, and all may arise from a vicious metabolism in all the name implies, and the cause of this vicious metabolism may be a bacteriological one and a controllable one. This theory is more plausible because of Vaughan's adherence to the theory of Horbaczewski as to the formation of uric acid in the economy. Ve have long been taught that uric acid is the result of the imperfect oxidation of urea, or rather uric acid should have gone to urea had its completed oxidation gone on. Horbaczewski showed that the amount of uric acid and other xanthin strbstances formed in the body is a measure of nuclein metabolism, the more there is in the body, the more nucleated cells 
we know are undergoing disintegration. In such a disease as rheumatic fever there must be enormous disintegration of nucleated cells, and here the excess of uric acid may be a result and not a cause of the disease. Compare rheumatism with the so-called gonorrhœal rheumatism, and we can reconcile ourselves more and more to ordinary rheumatism being a germ disease. Gonorrhœal rheumatism is undoubtedly caused by the gonococcus, this protean germ even attacking the heart, as in mycotic endocarditis, and thus showing its similarity to rheumatic fever.

So far as my experience goes, rheumatic fever is a much more rare disease than it was formerly, say forty years ago. Like all zymotic diseases, - if it is a zymotic disease,-it is becoming, indeed, quite a rare disease. The reason for this undoubtedly is the great improvement in drainage and the general improved environment of homes, whether in town or country. People are much better clothed and much better shod than they were some years ago, and the means of travel are so much more comfortable and expeditious, and hence less conducive to colds and illness coming from them. When the germ theory as to rheumatism is settled, and affirmatively, there will be little trouble in the diagnosis. To-day our methods of distinguishing the disease are about as they were years ago. It is a disease rather of the poor than of the rich, although this applies rather more to the chronic forms than to the acute. The prognosis is much improved, on account of the improved and more successful methods of treatment, and heart, brain, and spinal complications are more rare. Keep your wits about you, and you will rarely mistake it for another disease in its ordinary forms, but be very careful when you come to its concealed forms.

Years ago the cure for rheumatic fever was given as six weeks in bed. To-day most of the cases we can control by salicylic acid and its salts within seventy-two hours. We may use them in any form, by the mouth, by the skin as in ointments, and by the rectum. Healthy surroundings should by all means be given the patient; indeed, surroundings as 


\section{FORTY YEARS IN THE MEDICAL PROFESSION}

near aseptic as possible, and he should never be allowed to have cotton or linen come next his skin. There is nothing new in diet, except it is more liberal than that of our fathers. I oppose all animal broths, such as beef-tea and the like, in most of the zymotic diseases, because they make good culture media and model hosts for pathogenic germs, and for this reason I oppose them in rheumatism in any form, for, if it is a germ disease, the digestive tract is a place to grow them par crccllence. Should the treatment by salicylates not be tolerated, we have salol and such drugs, really much the same, as salol breaks up into salicylic acid and carbolic acid in the intestines. These not agreeing, or failing, use intestinal antisepsis of different kinds, both direct and indirect, using freely of alkalies, with opiates to subdue the pain. Make all affected joints as nearly inmmovable as possible. This method gives great comfort. Subacute and chronic forms now and again will yield to salicylates and germicides generally. It is most important in these cases to make their surroundings comfortable and give them wool next to the skin and plenty of it. Intestinal lavage does good here, keeping in mind the sreatly increased possibilities of auto-intoxication.

These rules apply to cases of muscular rheumatism also, particularly the intercostal and lumbar types. See that your cases of chronic rheumatism are well fed with proper food, especially of milk and bread and fish and eggs, and do not forget massage and electricity; they increase oxidation, and thus carry off the waste products. Cod-liver oil is good food. These are generally alkaline foods, and, reasoning from the general acid condition of the blood in all rheumatic cases, should be proper food. If such patients waste away and lose flesh, give them, freely even, of starchy food. Starches are really diluted fats, and fat in diet checks the waste of albumin in the tissues and subserves the strength.

Arthritis Deformans, Rhcumatoid Arthritis, or Rhcumatic Gout.-I have seen this much more frequently in women than in men, and most of the women have borne children. This makes me think there may be something in the neurotrophic 
theory of the disease first put forth by Dr. John K. Mitchell, the elder. Behind all this there may be a pathogenic germ working in some mysterious way, a veritable polyp. Codliver oil and strychnine are the best remedies I know of, with wool clothing, good food, and an environment as nearly aseptic as possible.

Multiple Arthritis Deformans.-I see these much more frequently in women. They are supposed not to be true gout. I am sure most women who have them, under favorable conditions of life, live to be old. I am sure heredity plays a great part in their production, and they appear to me to nearly approach some forms of gout or rheumatic gout. If they ulcerate, suppurative arthritis is apt to follow. The chronic progressive form may affect nearly every joint of the body, and the patient be helpless and in a condition not differing much from ultra cases of rheumatic gout. Whether or not uric acid is present in the blood in these diseases, as it is in gout, or absent, as it is in rheumatism, I do not know. In the treatment of acute articular rheumatism, and in all forms where pain is the prominent symptom, I believe the hot-air treatment will prove to be of great value.

\section{GOUT.}

It has been truly said, "A man is as old as his arteries," and the great factor of all in causing their loss of elasticity and the lessening of their caliber, thus producing a true arteriosclerosis, is undoubtedly syphilis; the next factor is the abuse of alcohol, and the next is gout, followed by other less important causes, such as luxurious living, with a want of exercise, the play of the emotions, and the zymotic diseases. Coming on after this hardening of the arteries, we have enlargement of the left ventricle of the heart. a compensatory enlargement, for the arteries are really peripheral assistants to the heart. and when they lose their elasticity the central heart must beat more lustily to drive the column of blood through the system, and hence we get increase of bloodpressure, followed, if not by renal changes, which really often 
coexist with these troubles in the form of contracted kidney, then by oliguresia, the condition of the heart and arteries rendering them incompetent to pump the full blood-stream through the kidneys, and hence, even with sound kidneys, we have albuminuria. Given renal casts, we may know the kidneys are yielding. Such as these are the exaggerated cases of arteriosclerosis, and with them a man has reached old age, whether he be forty years old or ninety. If forty or under, to bring on the condition he has violated some one or more of nature's inexorable laws. If he has reached old age, his condition is a normal one, his sands of life have about run out, and the rupturing of his hardened arteries brings him a timely and natural passing to the regions of the silent majority. Such a case is apparent to the trained diagnostician, but arteriosclerosis reaches to much more refined and to finer lesions of the economy than these. So much so, indeed, that it has been said more than once that a majority of mankind really die of arteriosclerosis, either of the grosser or finer kinds. Such being the case, and gout being one of its great factors, we should study and investigate most thoroughly such an arbiter of human happiness and human existence.

Before taking up the studly of the causation of gout, it will be well to pass in review some matters pertaining to food and its action on the economy, including such processes as metabolism and its congeners, katabolism and anabolism. I think I have before given the definitions of metabolism, katabolism, and anabolism, but it will do no harm to repeat them, for, if we do not know them, we surely cannot appreciate or understand the supposed causes of gout. Metabolism signifies change as applied to tissues, tissue change in nutrition and secretion. Katabolism is the process of forming products of secretion-which, according to Virchow, are metabolic products-by protoplasm. This is retrograde metamorphosis. Anabolism is a building-up process, forming living protoplasm from dead nutrient material. This is assimilation.

Professor W. O. Atwater has given us, in speaking of the uses of food in the body, a very good idea of metabolism, and 


\section{FORTY YEARS IN THE MEDICAL PROFESSION}

I will make use of it in speaking of these matters. He thinks Liebig's assertion, that chemical changes in the vegetable world are synthetic and in the animal analytic, is true; but there are many exceptions in both. Atwater thinks the physical processes in the plant are chiefly the transformation of kinetic or motor energy into potential energy. Those in the animal are just the opposite,- the transformation of potential into kinetic or motor. Now, this is normal metabolism. Normal metabolism is of two kinds, the metabolism of matter and the metabolism of energy. These two processes conform, the former to the conservation of matter, and the latter to the conservation of energy. This brings these complex processes into line with the two fundamental laws of the conservation of matter and the conservation of energy, and thus the doctrine of nutrition is set on a firm basis. Atwater says the terms "flesh formers" and "fuel values" are plainer terms than protein, fats, and carbohydrates.

Food has two chief uses, - to form the tissues and to act as fuel. In tissue-building we have the metabolism of matter. In fuel we get the heat and muscular power, and thus deal with the metabolism of energy. The proteins, as we have before stated when considering diet, are the tissue-builders chiefly, but also serve in a measure as fuel, the fats and the carbohydrates being the chief fuel factors. As fuel, the nutrients replace each other as to their potential energy. In food we must have sufficient of protein to form tissue and sufficient energy from the fuel foods to give heat and strength. In the body fat we lave stored fuel. The fuel value of fat is double that of protein and carbohydrates. Fat in the food is stored in the body as fat. This is important. The fuel part of the proteins and the carbohydrates must be transformed into the body fat. The fuel value of food is its fat-forming value. To get at the amount of matter metabolized we take into account the food and the drink taken and the oxygen inhaled by the lungs. Much of this goes to form blood, muscle, body fat, bone, etc. What is left is outgo, and consists of the residue after having made the blcod, the bone, the muscle. the 


\section{FORTY YEARS IN THE MEDICAL PROFESSION}

fat, etc., the worn-out materials of the body which undergo chemical changes and go off as gases through the lungs and skin; the excreted urine, being composed of both liquid and solids, the fecal matters, and the other excretions from the digestive tract. All these processes going on normally in the healthy individual constitute normal or healthy metabolism, and such an individual will not suffer from gout. So far as we know, the gouty individual is gouty because the different metabolic processes going on in his system are abnormal, and the victim of gout is the victim of abnormal metabolism.

What causes this abnormal metabolism is the problem to solve. Does it come through the food primarily, owing to its unbalanced condition as a ration for the individual,- - that is to say, owing, for instance, to an excess of nitrogen, now so generally claimed,--or could it possibly be an infection, a zymotic infection, the food eaten making the digestive tract an acceptable host to the pathogenic germ, this germ being the author of the abnormal metabolism in devious and remote ways, and hence in the end causing the excessive formation of uric acid or its defective elimination, acknowledging for the time that the pathological factor in gout is uric acid? I am not inclined to acknowledge anything as proven irrevocably as the pathological factor in gout, and, such being the case, I see no objection to theorizing, or guessing, if you prefer to call it so. To-day, I think the chances of gout being an infectious disease caused by a pathogenic germ or germs are just as great as that uric acid in the blood or system causes it, or if uric acid in the blood or system does cause it, there is good reason to believe that a pathogenic germ or germs may be a direct or indirect cause of the excess of uric acid. It may be askerl here what part do intestinal microbes play in ligestion? Their ferments may be factors in digestion, as are the enzymes and unorganized ferments. Bacteria may be necessary to the physiological decomposition of albuminoids in the digestive process, and hence by their absence or greater or less number may influence their digestion and the formation of uric acid. 
Again, taking this infectious view of the origin of gout, we know bile is the great intestinal antiseptic and the natural peristaltic persuader. Practically, we find in gouty attacks and in lithemic conditions a more or less deficiency of bile, and hence a clear intestinal field for the workings of intestinal microbes, as we might suppose them to work, if a pathological factor in gout. In gouty persons there is this condition, it appears to me from clinical experience only, generally existing, accompanied by constipation and all the conditions going to make up what we might call an hepatic insufficiency, which insufficiency might rest on the liver anatomically or upon some defect inherent in it as a producer of bile up to the proper standard for its work in the animal economy.

Haig claims that calomel drives the uric acid out of the blood and into the tissues, and that this causes an attack of gout, for he looks to uric acid as the one cause of gout. On the other hand, the calomel should stimulate the liver to send out an excess of bile and render the surroundings antimicrobic and check the gouty attack sooner or later. The two suppositions are not so opposite to each other as one might think on first examination, and may be easily reconciled. Haig believes all colds to be caused by an excess of uric acid in the blood, uricacidremia plus a microbe. I trust that some day he may find out all gout to be uric acid plus a microbe, or a microbe plus uric acid.

Haig writes entertainingly and delightfully, his style is charming, resembling that of Sir Thomas Watson more than any writer I know of. His work on uric acid in the causation of disease reads like a romance. Sometimes I think his enthusiasm runs away with his judgment: again he resembles a book-keeper who forces his balances to meet the conditions present. I say this without any feeling of disrespect. I admire his enthusiasm and his perseverance, and only good can in the end come from his honest intentions and zealous industry. Haig believes gout to be rheumatism, and rheumatism to be gout, age only varying the clinical aspect, and the cause of all to be uric acid. Indeed, the presence of uric acid in man 
is a protean factor in disease, and the cause not only of rheumatism and gout, but of many and various ailments and conditions harassing mankind, the latter diseases being caused by the effect of the uric acid on arterial tension. Haig appears to have absolute faith in his ability to handle uric acid as a pathological factor in man. He claims to be able to produce. artificially an arthritis in man. Salicylates, he says, clear the blood of uric acid by removing it from the body, whilst acids, sulphates, opium, mercury, the iodides, iron, lead, and lithia remove it by holding it in the joints, liver, spleen, and other tissues. By giving an alkali, he claims he will produce headache, mental depression, slow pulse, etc., by increasing the excretion of uric acid. By giving an acid he claims to cure the headache by decreasing the excretion of uric acid, and, as it is not excreted, it must go somewhere. and it goes into the tissues and joints and causes gout. This, I believe, is Haig's theory of the action of uric acid as a pathological factor in gout.

As far as our present knowledge extends, we are, I think, compelied to admit that uric acid is a pathological factor in gout, possibly the great pathological factor, for Garrod has shown us that in an acute attack the blood is loaded with it. Why these metabolic changes? Why these secretory products? Can there be an infection? If an infection, is it directly from the living parasite or from its poisonous secretion, for in diseases either the one or the other may be a cause?

Metabolism begins with assimilation and ends with excretion, and between these boundaries any of these troubles may arise. Then, again, what influences may be at work here for good or for evil? What are the functions of the ductless glands, now being so faithfully studied? What effect has normal cell action, and what may be the effect of abnormal cell action, are questions constantly presenting themselves when we come to study disease with the ever-increasing light of the present day. Accepting uric acid as the prime factor in the causation of gout, what theory of its formation shall we accept? Shall we take Garrod's theory, that it is the result of 
nitrogenous waste, that it represents a lower degree of oxidation than urea, and thus, being more or less insoluble, it is not carried off but accumulates in the system and produces Haig's uricacidæmia? This accumulation in the system is an incomplete waste product, and it is here because it is not urea as it should be; and it is so because of some defect in the liver interfering with its urea-making powers. The fault in the liver is probably its faulty action on the peptones in digestion. Its action on the peptones, if normal, causes the proper formation of urea: if abnormal, it is only uric acid, much lower in oxidation than urea, that is formed. In order to check this formation of uric acid we withhold the nitrogenous foods and thus reduce the amount of peptones for this unfavorable action of the liver.

This is a beautiful theory, and really the theory to-day upon which most of our ablest clinicians base their theory of the treatment of gout. I believe it is about to be pulled down, yet practically the dietetic part of the treatment may not be greatly changed. The prudent gouty man must semi-starve himself still. After all, this is not unnatural, for a life of luxury will always have its penalties, for, as far as man's animal existence is concerned, it is an unnatural life.

Now, as to the other origin of uric acid, brought out by the work of Vaughan and others, which we spoke of at length when treating of rheumatism. Here its origin is given as the result of the oxidlation of the nuclein of the blood-corpuscles. In addition to uric acid, we must also look to the uric acid group of leukomaines as a factor in the causation of gout. Here is a more complex cause, and a better opening still for the workings of pathogenic germs as a near or remote cause too. Here comes in the nervous factor. We must look on this uric acid and these leukomaines, if not normally formed, as victims of a faulty metabolism, or of some faulty secretory functions, or may be of germ origin so far as the leukomaines are concerned, and these faults lie in the nervous system, and here we have gout among the neuroses. What becomes of the methods of treatment of our best clinicians of to-day 
under these circumstances? They must change their rigid and fixed rules as to diet, especially as to the absolute elimination of the nitrogenous foods. Now, if gout may come under any suspicion of the infections, there may still be a good reason for withholding the proteids to a greater or a less degree.

I spoke in the treatment of typhoid fever of the advisability of withlolding animal broths in that disease, as they were available culture media for the pathogenic germ. The same advice may in a measure hold good in gout and many other diseases, and thus we may with propriety withhold in a great degree all foods serving to produce or increase an auto-intoxication, rendered more possible from the presence of such foods in the digestive tract.

In the treatment of gout my experience leads me more than in any other disease, excepting diabetes mellitus, to study well the individual, and to become familiar with his idiosyncrasies, both mental and physical, and this, whether the case be chronic or acute. Above all things, study your patient as to his tolerance of nitrogenous food,-carbohydrates and fats. All persons differ as to their tolerance of these substances, and particularly the gouty so differ. One gouty person may eat roast beef and get a colic, and another may get a colic from starchy food, or from sugar, or from fats. These are most important points to remember in practice, and to disregard them is empiricism. The great factors in treatment are, first, water and plenty of it; second, semi-starvation,--not really semi-starvation, but semi-starvation only as compared with the inordinate eating and drinking labits of the average man; third, salicylic acid and its salts, colchicum and aperients; fourth, exercise and dress, and proper environment, with a life regulated to bring about and keep up the alkalinity of the blood, for we know by experience that our gouty patients only do well under this condition, be the causes what they may.

Now, as to the acute attack. If local. heat applied, even the hot air, is most grateful. Local applications are not usually 
in favor, but logically, I think oil of gaultheria might be painted upon the affected joint. If the disease is general, push the salicylates and colchicum and opium if necessary to stop the suffering as soon as possible. I say opium, although Haig says it increases the arthritis by driving the uric acid from the blood into the joints. The patient should drink water to his utmost capacity, to get rid of the nitrogenous waste through the kidneys; and after the pain subsides, so as to let up on the salicylates and colchicum, salol may be substituted as more of a germicide to the digestive tract, where it breaks up into salicylic acid and carbolic acid.

Whilst it is necessary to watch the patient closely, especially if at all inclined to be feeble, rigid low diet is the rule, and milk is best, and not too rich at that. Watch for retrocessions, for they may come suddenly and bring disaster. The gouty patient is a vulnerable patient, whether his case be acute or chronic. The disease is a protean disease, and I know of no organ of the body, of no function of the body, of no sense of the body, whether special or general, it may not involve.

Allow me to speak of a matter here. Is gout increasing as a disease in the United States? Undoubtedly it is, just as rheumatism appears to be diminishing. The causes undoubtedly are the spread of luxury from the vast increase of wealth accumulated in private hands, the great increase of the use of malt liquors and wines as beverages, and another factor not often taken into account,- the absorption of lead into the system, this coming in the old forms of drinking water through lead pipes and the various other forms unseen and unheard of, as through the enamelled inside bands of our first-quality hats, especially the English hats. The great factors in lead entering the system to-day are the general uses of the metal in water-pipes, in beer-pumps and pipes, in sodawater apparatus, in tinned or canned food products, and in the iree use of lead foils in tobacco products as at present marketed. These ontrages on the health of mankind are preventable, and should be stopped by law without delay. Haig 


\section{FORTY YEARS IN THE MEDICAL PROFESSION}

thinks lead diminishes the alkalinity of the blood and hence causes gout. I believe plumbism is a neurosis, and the presence of lead in the system undoubtedly causes this neurosis, and it so affects tissue metabolism as to produce gout, going back for its cause, if you choose, to the formation of the uric acid and leukomaines from the nuclein of the blood-corpuscles. In gout of the intestines particularly, or supposed gout of the intestines, be very careful to differentiate it from lead colic, and remember that they may and do often coexist. In your differentiation do not fail to bear in mind the various symptoms of appendicitis.

The interesting points in the treatment of gout are, after all, how shall we advise the victims of chronic gout and the victims of the so-called lithæmic condition to live, in order that they may have the most comfort and get the most out of life, not only in its enjoyments, but in its prolongation to a green and happy old age. You may tell your patients at once, there is one way not to do it, and that is " to eat, drink, and be merry," and to endeavor to do away with all untoward consequences by taking the so-called anti-gout remedies, whether they come from their regular medical attendants or come from the long list of proprietary remedies seen in every drug-store. Among men of the world whom gout is pinching, it is common to see them taking Blair's pills, an English preparation of reputation. Colchicum and opium probably are ingredients, and give temporary relief. Laville is another popular remedy, which undoubtedly owes its virtue to colchicum. I do not care what such remedies contain, and how effective they may be, the method does great harm, and invites in the end much suffering and premature death.

Now, as to water. Judiciously used, I believe it to be our greatest weapon in fighting gout, particularly chronic gout. It should be used freely, both per rectum and per orem and in bathing. Intestinal lavage I look upon as of the greatest benefit in the treatment of the lithæmic or gouty condition. The water should be sterilized, and chloride of sodium, one of the best intestinal antiseptics, should be added at the rate 


\section{FORTY YEARS IN THE MEDICAL PROFESSION}

of a heaped teaspoonful to a pint. This may be given on retiring, as much as the large bowel will tolerate, and held as long as possible. If preferable, during an hour before retiring, drink a quart, more or less of water, and with it take thirty grains of sodium bicarbonate should there be a tendency to acid eructations. I particularly recommend sodium here and not the potassium salt, for in gout the kidneys are, we know, very vulnerable, and potassium is more irritating to the kidneys than sodium. If there be no need for the sodium on this account, take from five to ten grains of salol with the water. This breaks up into salicylic acid and phenol in the upper intestinal tract, and is antiseptic and increases nitrogenous elimination. The gouty patient, as a rule, is not a thirsty person, and few drink enough water. They should drink all that it is possible for them to take and be comfortable. It is the great weapon in the fight against the gouty condition. Where it is possible to obtain them, the natural alkaline waters are most useful, and of these the Vichys are the best. Wherever we can get a good alkaline water in our own country, or get to the springs to use them, they will prove useful if taken in large quantities.

The lithium salts have long been recommended by Garrod and others as solvents for uric acid and the urates. In my hands they have never shown any practical effect as lithium. The "lithia" waters on the market are usually good, pure waters, with a suspicion of lithium in them, a mere suspicion, and if lithium was really of any use in the treatment of gout it would take bottles of most of them for a single dose. They come nicely put up, and do good by encouraging patients to drink water; beyond this they amount practically to nothing. Carbonated, they are aiders of digestion and very acceptable. There are many waters of other brands on the market, both plain and carbonated, some of them very pure. Here is their mission: they give good pure water and encourage the drinking of it, and are handy for travellers who become ill by constantly changing the water supply; and they carry off, as do most fluids taken, the excess of nitroge- 
nous waste, which retained becomes a source of pabulum for microbes and a prominent factor in auto-infection and autointoxication. This use of water in gout applies most particularly to women, who are great sufferers from lithæmia, and who very rarely drink water sufficient for their common needs, much less as a remedial measure.

There is another important measure, in addition to this water treatment of gout. Now and again, say once a week or once a fortnight, give a small dose of calomel, sufficient to stimulate the liver, for such it probably does, causing it to throw out an extra amount of bile and thus antisepticize the bowel. There is generally constipation in the gouty, which is best relieved by the aperient waters before the morning meal, and may be taken daily if needed. Any of the saline purgatives may be used if preferred.

Now, as to food. For reasons before given, we must avoid in a great measure foods rich in nitrogen, for if on this score our reasoning is not yet on a firm foundation, experience comes to our aid and tells us much. Do not forget to study your patient. Is he strong and vigorous, or is he weak and failing, and what idiosyncrasies has he as to certain articles of diet? Horatio Wood is one of our best authorities on diet, as he is on many other matters. He says there is no diet for gout; it is diet for the individual. Sydenham first warned the gouty against red meats, and red meats may give one person gout and cure another; that is to say, the latter case may be weak and puny and absolutely in need of the strength only to be derived from nitrogenous food. For the same reasons one may require starch and sugar to a greater or less degree, and one may go to pieces on them as part of the diet. A milk diet may be necessary for some cases for a longer or shorter time, and even reduced milk or skim-milk or other milk preparations, as koumiss and the like. As to meats, there is little difference really in the amount of proteids in the red and white meats. A reference to the article on cliet in a former chapter will show all of this matter in a brief space. Roast chicken is nearly as strong as roast beef, 
and roast turkey is well up to roast chicken, whilst roast goose is very fat and a little lighter in nitrogen than either of the others. The gouty patient must eat less in quantity, and thus cut down his nitrogen. Semi-starvation must be his rule. Overeating is a habit anyhow, and a very bad habit, too. Accustom yourself to leaving the table comparatively hungry a few times, and the inconvenience soon passes away. We all eat too much.

Now as to fish as the lighter flesh diet. It is lighter diet than animal flesh, but it depends on what kind of fish. Salmon is nearly as strong as roast beef. In fact, all fish are comparatively strong in nitrogen. The shellfish are weaker and better food for the gouty. A reference to the article on diet will tell the fish story. As I have said before, whilst fish, or at least many of them, are high in nitrogen, they are lighter food than animal flesh, for they do not overload the blood with waste products as the animal foods do, and the blood sooner clears itself of the waste products from fish than of those from animal food.

Let us go to a clinical study, and by this I think we can show a difference in the effect of animal flesh and fish diet. Intermitting heart, not the more serious irregular heart, is, as we all know, so common among the sufferers from chronic gout and the gouty condition, and is serious, not because it is in itself a serious condition, but only as to the ill effect it may have on the patient. Some never know they have it, whilst others are very unhappy over their condition. Bradycardia and tachycardia come under the same head. Here an excess of nitrogen in the food and the overloading of the blood with waste products are. I think, the prime factors of causation. Fish diet causes much less of this overloading of the blood with waste products, and hence is not nearly so apt to cause arrlyytinnia as the animal flesh diet, for the alkalinity of the blood is not so much lessened by it. Toxines are more apt to develop from such food, and these in the intestines cause such functional heart troubles. They overload the stomach usually; or rather cause the stomach hard, quick 
work to get rid of them, and, the blood-vessels being overloaded, arrhythmia occurs. Excess of blood-pressure is also a factor, and this we usually have in the gouty, hence the gouty man is more apt than the healthy man to suffer from functional heart disturbances after eating and drinking, and particularly after the use of tobacco. These troubles can be classed among the neuroses pure and simple. Again we may ask the question, Is gout a neurosis?

Some teachers have condemned a diet composed chiefly of carbohydrates as of more injury to the gouty than a diet chiefly of nitrongenous food. The reasoning is that too much carbohydrates may take so much oxygen for their oxidation that there will be a deficiency for the changing of the uric acid into urea, and thus leave the uric acid in the blood. Too much fat may do the same thing in the same way. Thus the accumulation of winter fat is apt to give us spring gout, a favorite reason for it.

Now let us take up alcohol and its effect on the gouty. Alcohol, nicotine, and morphine all diminish temperature, the first two by relaxing the blood-vessels and increasing perspiration, and the later by preventing all glandular and molecular activity. Alcohol in any form, ether, chloroform, and the like, all reduce the alkalinity of the blood, and are innately bad in gout. Alcohol also undoubtedly reduces the bactericidal action of the blood, and is bad for that reason in gout. A sober guinea-pig will withstand six times the dose of toxines that a drunken guinea-pig will. Alcohol's affinity for oxygen, of which it robs the blood, causes the loading of the blood with toxines, which result from imperfect oxidation of the tissues, and thus we see hw the drunken guinea-pig succumbed before the sober guinea-pig. An excesss of alcohol is particularly bad for the gouty. It bloats and gives a false look of health. This bloat is an abnormal tissue, an unbalanced tissue, which should have been consumed by the vital processes in health by oxidation, but the alcohol has used up this oxygen and the normal oxidation of the fat did not go on, and hence it is stored up as useless, harmful, unbalanced tissue, and the vic- 
tim is an unhealthy fat person, his ear-marks being plainly risible, for he carries his own sign. He is a bloat.

Alcohol goes to acid in its digestion, and thus reduces the alkalinity of the blood. Sugar with alcohol increases its power of reducing the alkalinity of the blood; so beware! take your whiskey straight, not as a cocktail. The sugar in wines makes them more objectionable, for it starts all sorts of intestinal fermentations and decreases the alkalinity of the blood. The best drink for the gouty is water or milk. Of spirits, a pure California brandy, with no coloring-matter, is best, and next to this is Scotch whiskey, because it is free from sugar. American whiskey is a good drink, except that the sugar coloring-matter is objectionable. Of wines, I should object to all but a good, sound claret, and that well diluted. Sugar in claret is a horror in any form, and those using it not only spoil a good wine, but deserve the horrors of digestive nightmare. If one must have a sparkling wine, use the Moselles rather than the champagnes, unless the latter are inky dry. The malt liquors are poison to the gouty, and should under no consideration be indulged in. Lager beer has only three per cent. of alcohol, but it will not do. In these malt drinks we have alcohol and sugar mixed, and they are highly acid. That is all there is about it. They will not do for the gouty man or woman. Sweet cider and sweet perry (pear cider) are not particularly gouty, but when fermentation has passed to the acid stage they are objectionable. The basis of the cider cure of gout, often used in France, is just this: the juice contains much potash, and this acts by relucing the acid state of the blood, just as the potash in lemon-juice does in the lemon-juice rheunatism treatment.

Shall we aroid the carbohydrates in gout? That depends upon the individual. It is nonsense to lay down absolute rules for numerous patients. One living on carbohydrates to a greater or less extent may have constant acid dyspepsia and auto-intoxication, particularly if sugar be associated with them. If either disagree, avoid them as much as possible. 
For sugar, saccharin or diabetin may be substituted now and again. Saccharin is antiseptic, and may thus interfere with digestion and cause dyspepsia. It renders the urine acid. As a rule, gouty people who have not ruined their digestion can take carbolydrates with impunity, and they agree with them. If they do not agree, they probably interfere with the complete metabolism of the albuminoids, and one or the other must be cut off to a certain extent, or altogether; and so with fats. If they agree, they can be taken in moderation, provided there are no other contraindications. If the kidneys are involved and albuminuria appears, use fats as a rule. They check the waste of the albumin, and so do the carbohydrates, for they are only diluted fats. The kidney troubles in gout are a common and serious complication, and when the patient can endure it for a time, milk diet may be called for, and even skim-milk diet, or buttermilk, a by-product of cream. Remember, one patient may thrive on such diet, another may endure it, whilst a third may sink under it. Milk is a normal alkaline complete food. Fresh breads are microbic food, and usually disagree in gout. Toasted and stale breads are better. Avoid all foods causing fermentative dyspepsia and those that may cause indigestion of any kind, or any that might cause ptomaine poisoning; they each probably have their specific pathogenic germ. Now and then a patient may thrive best on the diet for diabetes mellitus, one of the congeners of gout, but such cases are rare.

Now, an important question comes up: what about the acid vegetables and fruits? I think, as a rule, they may be used, watching the effect on the individual. Strawberries are forbidden in gout by most physicians on account of their acidity. Linnæus, who suffered from gout most of the time, said he was only well in strawberry time, when he ate largely of them. Like the lemon, their acidity may be only apparent, not real, and they may render the blood alkaline, not acid. Their juice is probably germicidal, like that of many other fruits. It is not impossible they may have an effect of producing hippuric and benzoic acids, thus rendering the uric 
acid soluble. We take cabbage, Brussels sprouts, turnips, celery, tomatoes. spinach, asparagus, and such regetables, not forgetting rhubarl, so grateful in the early spring. It is doubtful if rhubarb has any effect on the formation or the elimination of uric acid, although it contains some oxalic acid. Its mineral matter in some way, I loubt not, is useful, and I do not believe it ever caused a serious deposit of oxalates in the urine or tissues. The same may be said of spinach, tomatoes, asparagus, cabbage, and such vegetables; they probably all contain oxalic acid. According to recent investigations the mineral matters of all of these vegetables act chemically and prevent the deposition of gonty matter in the tissues, and are the best remedies to prevent such deposits. I believe this to be true; this is the way in which nature solves such problems, and for such uses they have been given to man.

I know of no vegetable which the gouty person can use freely equal to green corn. The small amount of maizenic acid it contains has a good effect and does not excite metabolic activity of tissues, nor loes the corn as a vegetable to a large degree, and by its bulk it leads to a healthy condition of the bowels where obstinate constipation is so often an umpleasant factor. In soup with milk it may be used every lay in the year, and this makes an ideal dish for the lithæmic sufferer. Do not use much salt with the corn, as the synovial fluids have great affinity for salt, and you thus may check the formation of the soluble sodium biurate. Zea, corn-silk, acts as a dituretic, and $l$ believe is useful in chronic gout, especially in cases where the bladker is irritable. It is a diuretic, increasing arterial pressure, and should be given in large quantities of hot water every few hours.

Cheese is highly nitrogenous and must be used with caution, but I see no reason why a gouty man cannot take a morsel now and again to give zest to a cracker or possibly a mild salad. Eggs are a common and useful article of diet, for, if fresh, they are absolutely sterile food and perfectly safe as far as germ infection goes. They are said to be of 


\section{FORTY YEARS IN THE MEDICAL PROFESSION}

an alkaline tendency and to set the urinary secretion alkaline. If a gouty patient is weak and needs proteid diet, eggs are most useful. If the patient be strong and vigorous, use the yolks freely, and discard the white, as it is too strong, being typical albumin. If you know your gouty patient to be the victim of contracted kidney, interstitial nephritis, be very careful of concentrated nitrogenous food, especially those like red meats, and the white of eggs, which leave more or less waste products, which require much oxygen to eliminate them from the blood.

Uræmic convulsions may be looked for in such cases, and I sometimes think the cause is more the toxines developed from such food than from the other causes usually assigned. Such cases may be infantile convulsions over again. In these renal cases use the amount of urine flowing as the barometer. If you are ordering your patient a large quantity of water, of course it goes off rapidly by the kidneys. If the excess of the normal amount is still too high, check the bloodpressure by nitroglycerin, and possibly save your patient from cerebral hemorrhage or some accident always pending from the impaired condition of the arteries of such patients. Under these conditions asthmatic troubles are apt to show themselves, and may be purely of a neurotic origin connected with the gouty condition, and so may sore throat, generally of an erythematous nature, although this latter trouble I think is common in both acute and chronic gout, as are skin affections generally of an eczematous nature.

Gouty headache is common, and usually alternates with the before-mentioned annoyances. It usually is most annoying on first waking in the morning, and is usually a hot, burning pain through and back of the eyes. Those who have been victims of migraine, or sick headache, up to the age of forty-five usually are the sufferers from gouty headache after that age. High blood-pressure is a factor in gouty headache, and the remedy is plain,-lower it. This headache usually passes off after a cold bath and a rub to the head and shoulders, if the patient is robust and reacts well. A light break- 
fast and a walk in the fresh air complete the cure. Sick headache, as a rule, passes off only with the setting sun. In chronic gout medicinal remedies slould only be used in acute attacks, or subacute attacks, marked with pain. I beliere the best remedy is the salicylates of sodium or strontium, in connection with colchicum; they both do better when used together. The salicylates are antipyretic and possibly antiperiodic and germicidal. They possibly control pain through their influence on the rasomotor system and by causing the elimination of urea and uric acid. If the patient have albuminuria, be careful with the salicylates; better use colchicum alone most of the time or with the iodides. Colchicum may increase the elimination of both urea and uric acid, and may do this probably through its cholagogue effect on the liver and thence through the peptones from the food. Iodide of potassium may be given with colchicum. IVith kidney lesions, strontium is to be preferred with colchicum. This is against Haig's reasoning, if we wish to keep down the arthritis, but in practice it acts well, especially in the feeble, with marked arteriosclerosis in any form. As I have before stated, I usually prefer a capsule containing methyl salicylate and colchicin, and I especially prefer this combination if I have to use salicylic acid when the patient has albuminuria, for if there is any difference in their irritating action on the kidneys, I think the methyl salicylate the least irritating as between it and the synthetic compounds.

Professor James Tyson, one of our best authorities, prefers the salicylates in the treatment of gout. I think a Turkish bath at frequent intervals is one of the best eliminators in the treatment. The best plan, after all has been said, is semistarvation, whether direct, by cutting down the amount of food, or indirect, by active exercise, adding to this semistarvation the free use of water; and the Turkish bath is one of the best ways by which to use the water. By these means we best guard the kidneys from degeneration and save the arteries from the inroads of arteriosclerosis. By such means, with proper clothing, proper environment, and changes 


\section{FORTY YEARS IN THE MEDICAL PROFESSION}

of climate when possible, leading a quiet, sober, and active life, the activity being ganged by the physical condition, the gouty individual may keep his Nemesis at bay and reach a green old age.

Ointments of the salicylates are undoubtedly useful for anointing the joints, and the same may be said of the oil of gaultheria, used as a paint and frequently applied.

As yet there is little favorable to report in regard to the use of piperazine in gout. I am sure of one thing: it is of great use in those cases where there is a tendency to the deposit of the urates in the kidneys, producing frequent attacks of renal colic. I would always give it in these cases for its effect on the diathesis, for its local effect on the stone in the kidney, and after it has reached the bladder. I am satisfied that a five-grain dose three times a day is the best remedy in all forms of muscular rheumatism or gout. It is supposed to act as a solvent to uric acid. Do not give acids in food or medicine whilst the patient is taking piperazine.

Pichi is a shrub found growing in Chile and Peru. It has greenish-blue leaves and a balsamic odor. Its active principle is in its balsamic resin. Dr. Hervey W. Whitaker, of Columbus, Ohio, says it is a strong cholagogue and has a stimulating effect on all mucous membranes. It is a valuable remedy in gall-stones. In the uric acid diathesis, gout, chronic rheumatism, sciatica, muscular rheumatism, and gouty headache it is of great value. Its remedial action far excels that of the salicylates in such troubles. Uric acid formations rapidly disappear from the urine under its use, and the general condition improves. It acts through the liver, being, I suppose, a strong cholagogue. Whittaker thinks its active principle effects some combination in the circulation favorable to the solution, excretion, and elimination of the products of metabolism, which a sluggish liver would otherwise be incapable of transforming. It is the best bitter tonic in chronic alcoholism, and is most useful in the cystitis of enlarged prostate, and in gout of the intestines it is said to be superior to the salicylates. It is useful in jaundice and 


\section{FORTY YEARS IN THE MEDICAL PROFESSION}

cirrhosis of the liver. The fluid extract is the best preparation. It will not mix with water, owing to its resinous properties, except you add a small quantity of an alkali, say, twenty to thirty grains sodium bicarbonate to the ounce. The dose is a half-teaspoonful every four hours, more or less. A good mixture is glycerin one ounce and fluid extract pichi onehalf ounce. A teaspoonful and a half in water is a dose. It may also be given in powder, in a capsule or a tablet.

Thyroid extract and gout and rheumatism, from clinical experience now accumulating, give opportunity for interesting study. Horatio Wood reports four cases in which gout or rhenmatism followed the administration of thyroid extract. He has as yet drawn no conclusions from these cases for publication. Dr. B. K. Rachford, of Cincinnati, Ohio, has also called attention to the action of thyroid extract in producing gout. Rachford sums up as follows:

I. Attacks of arthritic gout are associated with the excretion of an excess of the alloxuric bodies in the urine.

2. Thyroid feeding will increase the excretion of the alloxuric bodies in the urine, and will produce an acute arthritis in a patient suffering from chronic rhemmatic gout.

A third fact he adds: The menstrual period in women often precipitates an attack of gouty inflammation, and may be called menstrual gout. Now, at the menstrual period there is a hyperacidity of the thyroid gland. and thus we may be led to suppose that the thyroid secretion has something to do with the abnormal body chemistry which is coincident with these gouty attacks.

These are valuable and interesting facts, and may in the end give some clue to the true pathology of gout. In giving thyroid we produce a decided loss of weight. due in part to a destruction of the nitrogenous tissues, but chiefly to the wasting of the fats. One-sixth loss is from the former and five-sixths from the latter. The effect here is to interfere with the tissue balance and to lower the fuel values much more than the flesh-formers. Somewhere between these complex processes having to do with tissue-building and fuel 
values must be the cause of gout, and this is where it is now generally located, and is expressed by a faulty metabolism. As age comes over us we grow decrepit, day by day and more and more the victims of disarranged and abnormal metabolism, and so we do in gout, and after all, what is gout but old age, premature if in the young, fully ripened if we have reached the time of the "sere and yellow leaf"? This being the case, the remedy would appear to be, not thyroid extract, which pulls down and destroys, but the extracts probably of those glands which are rather builders up, and the flesh and extracts not of old animals, but of the younger, wherein we might hope to find that of which old age has deprived us, and the taking of which might in some degree or another reinvigorate us. Such was the notion, probably, of the late illustrious Brown-Séquard.

In Europe the good livers, as they reach the age when gout begins to nag them, are accustomed to take the cure, as they designate it, yearly. The cure is nothing more than a rest of the digestive and other organs, with copious washings out of the system with water, to carry off the accumulated nitrogenous wastes of the system. The cure generally consumes a period of six weeks, and is a rational way of letting up, whether the taker is a high roller or merely a good fellow, or a hard worker in professional or business life, or a woman temporarily blasé from the exactions of the social whirl. Carlsbad is the typical resort for the cure. Would we had a Carlsbad in the United States! We should have; we have the making of such at Saratoga or in the Virginia mountains, and many other places where we have the waters. The trouble is, that in this country people look upon all such resorts as a place in which to dissipate, rather than to rest. We are improving in this respect, and soon, I have no doubt, we shall have an American Carlsbad, where the free American citizen will allow himself, under surveillance, at least long enough to wash away his gout along with his other grievous sins. At the same time, the hotel men and boarding-house keepers must be absolutely restricted in their rapacity, for the serving 
of improper food and drink nust be made impossible at the American Carlsbad, as it is at the German Carlsbad. The best we can do to-day is to visit the various sanatoria. There are many well-appointed ones in the country, but, as a rule, they are expensive and are not by any means the Carlsbad we are hoping for and looking for.

Should you go to Carlsbad fairly well and strong, wishing to reduce your weight and get rid of gouty aches and pains, you would visit a local physician of reputation and present your letter from your regular professional adviser. Under the care of the local physician you would probably take a course about as follows: In the morning get up at half-past five o'clock and be at the proper spring at six o'clock. Take one glass of water and move about quietly for fifteen minutes, at the end of which time take another glass and keep in motion. Continue this course until you have taken in all five glasses of water. After the last glass has been taken, continue to walk quietly for one hour. Now go to breakfast, which will probably be composed of three pieces of German zwieback, one portion of boiled ham entirely lean, a cup of tea with milk, but with no sugar. After this the kidneys and bowels will probably act freely. Until eleven o'clock walk briskly over the hills. Hill-climbing will be strongly urged upon you by the doctor; and after this, say, from eleven to twelve o'clock, Swedish gymmastics, and frequently after this a Turkish bath and massage. One o'clock is the mid-day hour for dinner, which is frugal and plain: No soup; boiled fish only, with lemon-juice; your choice of lamb, veal, or chicken, roasted, with little or $n 0$ fat; no potatoes, carrots, or peas are allowed, but you may eat string-beans or lettuce with lemon-juice only, no vinegar nor oil. For dessert a compote without sugar. The only drink allowed is a half-bottle of sound red wine. After dinner, walk until four o'clock P.M., the walking to be done rather quietly and slowly, with little or no hill-climbing. You must keep moving constantly until six o'clock, when tea or supper is ready. The idea is not to sit down and rest at all if you have the strength to continue 


\section{FORTY YEARS IN THE MEDICAL PROFESSION}

moving. Keep in the open air. The supper will consist of either cold lamb, cold mutton, chicken, or ham, with as little of fat as possible. With this you will be served with three pieces of German zwieback and a half-bottle of some of the effervescing waters. Go to bed not later than nine o'clock P.M., having smoked not more than one mild cigar, should you happen to be a smoker. You are constantly enjoined to drink plenty of water. The shortest cure is three weeks at Carlsbad, and the keeping up of the diet and exercise rigidly for three weeks longer, should you leave the Spa. For the gouty, for the high liver, for the gourmand, this is a rational treatment once in a year surely, and doubtless prolongs life and the comfort of living. For six weeks they do penance and eat only to live; for the remainder of the year they enjoy themselves, more rationally, at least, by this abstinence, in the blissful occupation of living to eat.

\section{DIABETES MELLITUS.}

Diabetes mellitus is a condition where there is an excessive secretion and discharge of urine, where there must be at least three parts, and maybe as high as ten parts, in a thousand of saccharine matter in the blood, and secondarily in all the organs, secretions, and excretions of the body, and is due to some derangement of the glycogenic function of the liver; or defect in the assimilative processes may overload the blood with sugar and cause it to appear in the urine. Over-stimulation of the system by eating and drinking and other excesses may cause it temporarily: irritation of the floor of the fourth ventricle and some other parts of the brain and nervous system may cause it, coming probably through a disturbed vasomotor action. Defective assimilation may cause it by failing to properly use the sugar of the system as produced, and thus send it off by the urine. Remember that cane-sugar, called sometines saccharose or sucrose, must be converted into glucose, or grape-sugar, before it can be absorbed or assimilated, and hence glucose is a predigested sugar, a predigested carbohydrate. 


\section{FORTY YEARS IN THE MEDICAL PROFESSION}

Sugars are crystallizable carbohydrates, in which oxygen and hydrogen are present in the proper proportions to form water. As food they have the same use as starches, and starches to be assimilated are first converted into dextrin, which is a gummy mass obtained by heating starch to about $400^{\circ} \mathrm{F}$., or into glucose and some alcohol. Glycogenic matter, called so by its discoverer, the great French physiologist, Claude Bernard, is that substance in the system which is constmed in muscular contraction, and this is its use, or one of its chief uses. The carbohydrates furnish this chiefly, although some may come from the nitrogenous foods. The more the muscles are used the larger they become, a familiar illustration of which are the muscles of the trained athlete, and there must be plenty of nitrogen in the system to feed them, and plenty of glycogen to furnish the fuel, the residue going off as urea. Now, observing diabetics, we see them sometimes going rapidly to a decline, because in such cases the glycogenic matter runs out, runs away by the urine, and they are compelled to get too much of their fuel from their nitrogenous tissues, and are burned up to furnish the fuel to the muscles the glycogen should have furnished. The sorry victim of this condition must soon succumb. He is starving to death. It is in these cases we are accustomed to find in the urine acetone, diacetic acid, beta-oxybutyric acid, and such substances, being formed from the decomposition of the albumin of the body, and not from the albumin taken as food. The invalid is existing by consuming his own nitrogenous tissues, supplying force to his muscles by burning them for fuel.

The lamented and genial William R. Travers was in the last years of his life a diabetic. Near the end he rapidly failed from this consuming of the nitrogenous tissues, and, as he expressed it, he was "burning the candle at both ends, and was devilish near the middle."

The pathogenic germ of tuberculosis is particularly prone to attack diabetics under thirty years of age, and my experience leads me to believe they rapidly consume their nitroge- 


\section{FORTY YEARS IN THE MEDICAL PROFESSION}

nous tissues from a lack of glycogenic matter so necessary to robust health. An interesting point here is, do the tubercle bacilli have any effect, direct or indirect, on the formation or improvident destruction of the glycogenic matter? Another point: the treatment of such cases, whether tuberculous or not, demands the strongest nitrogenous and fatty diet, carefully watching the effect, and the question comes in to vex us, whether or not we must give a liberal amount of carbohydrates too, as they furnish most of the glycogen to the system. We must surely at least test their tolerance of the carbohydrates and alcohol. I have here given the modus operandi of the devastation even unto death produced by this loss of glycogen, which at the temperature of the body is converted into glucose and passes off by the urine, producing nothing more nor less than the disease we call diabetes mellitus. There is probably in the system a glycogenic ferment which causes this change of the glycogen into glucose. What it is we do not know. Pancreatic lesions are found in many cases of diabetes mellitus, but no conclusions have yet been drawn from such lesions. In some cases the nervous element may predominate; in others there are disarrangements of the digestive organs, caused possibly by hepatic or pancreatic lesions; and again, we see cases where we can set our seal on no lesion or important function of any organ.

We have shown the uses of glycogen in the system; it may be well to see how it gets into the system, in order to understand at least something about the disease we are considering. Carl von Noorden has probably given us the best article on Diabetes Mellitus up to this present time, and what I am about to say concerning the causes, physiology, etc., is largely taken from his article, the use of which I beg leave to acknowledge. After all, much of it is mere conjecture, but it looks to me as though in many particulars he was getting near the truth. Glycogen is a polysaccharid, and must be converted into a soluble carbohydrate before it can be absorbed. Diastase is the ferment to cause this conversion, and gives us from starch, amidulin, erythrodextrin, achro- 
odextrin, isomaltose, and maltose. Now, as these pass into the intestinal wall and portal vein, they are almost entirely converted into grape-sugar. Dextrin and maltose are also converted into glucose when taken in food or drink. Canesugar is a disaccharid. In the alimentary canal it is split up by the action of acids, ferments, and bacteria (see the important action of germs here) into grape-sugar and fruit-sugar. If eaten in large quantities, some of it must pass into the blood unconverted into ghtcose or fruit-sugar (levulose). Fruitsugar and milk-sugar enter the blood unchanged. Here is a practical point: diabetics may eat them sparingly, and the same applies to saccharin. Cellulose from wood-pulp, of which cotton is a typical example, is isomeric with starch. If eaten it is never absorbed. In the intestinal canal it is fermented and changed by bacteria into methane, carbonic acid, acetic acid, and butyric acid. From the intestinal wall the carbohydrate stream flows through the portal vein to the liver. Various forms of carbohydrates are in this stream, according to the food taken. There may be glucose, levulose, lactose, saccharose, milk-sugar, with some dextrin and maltose. Whatever the form of the carbohydrate, the liver at once takes hold of it and converts it into glycogen, which is deposited in flakes in the hepatic cells, and probably in loose combination with albumin. The liver closely guards the amount of the sugar in its blood leaving it. The sugar in the blood is grape-sugar. There may be a very little glycogen. The liver always keeps a certain percentage of grapesugar in the blood. It excretes a little glycogen, but first converts it into grape-sugar, and in health the percentage is always about the same. There is some glycogen in the muscles. The muscles get their glycogen from their own store of grape-sugar. The liver collects the carbohydrates from the blood of the portal vein, fixes them as grape-sugar, and gives them up to the general blood when needed. Glycogen is formed from albumin as well as from carbohydrates. This is of practical importance, and tells us why diabetics sometimes consume their own tissues to support life. 


\section{FORTY YEARS IN THE MEDICAL PROFESSION}

The carbohydrates are always present, coming from the carbohydrates and proteids of the food. The muscle-cells are always consuming them, and furnish force and heat from their combustion. So long as grape-sugar is in the blood in physiological quantity, none goes out with the urine. When a muscle is worked, it consumes sugar by oxidation. A muscle can work by consuming albumin, but not long. It will then seize fat as most available. For the muscle to use it, the liver converts it into sugar. The liver only does this when there are no carbohydrates or albumin for it to use for the purpose. Now we see why the diabetic so often loses his fat rapidly: the liver takes it to make sugar for fuel when the normal formation of fuel sugar is running off by the kidneys, possibly.

What happens if the carbohydrates are in excessive supply in the system? Three hundred grammes of glycogen is the normal amount in the system. When this has been made by the carbohydrates, any excess of carbohydrates is deposited as fat. If there be still too much carbohydrates, the individual gets hyperglycæmia,--too much sugar in the blood. If the percentage of sugar in the red blood exceeds 0.2 , alimentary glycosuria results, which is not diabetes mellitus. If a man eat $\mathrm{I} 50$ to 200 grammes of cane-sugar, he will probably, in an hour, have alimentary glycosuria, which will last for three hours. The same thing will happen if he eat I 20 grammes of milk-sugar, 250 grammes of glucose, or 200 grammes of levulose, or fruit-sugar.

A healthy man does not have diabetes, because his glycogen reservoirs can hold all of his sugar. In the diabetic probably these reservoirs overflow and flood the blood with sugar. A temporary glycosuria may be caused by hepatic disturbances, muscular disturbances, nerve disturbances, apoplexy, poisonings, passage of gall-stones, exophthalmic goitre, and some other conditions. The liver, the muscles, and the glands all store up glycogen. We may eat an excess of carbohydrates, and at the same time be suffering from a diseased liver of the most consuming nature. yet not have even a tem- 


\section{FORTY YEARS IN THE MEDICAL PROFESSION}

porary glycosuria. Therefore, we may reason, the cause of diabetes mellitus does not reside in the liver.

There is a temporary diabetes caused by phloridzin poisoning. Phloridzin is a glucoside from the roots of the apple and cherry. It acts on the renal epithelium to cause it to lose its power of holding back the sugar when filtering out the urine. It is a toxic glycosuria, in which under-consumption is joined to over-production. This fact seems to impress von Noorden with the fact that possibly, after all, the kidneys themselves may be a pathological factor in diabetes mellitus. Extirpate the pancreas of a dog, and so long as he lives he is a diabetic. Lepine says the pancreas produces a ferment which enters the circulation and causes a breaking up of the grapesugar molecules within the blood. This is a pretty theory, and may be a true one to explain cases of pancreatic diabetes.

Does the over-production of glucose in the system cause diabetes? Von Noorden does not think so. He does not think there is an incapacity of storage for the glycogen, thus letting out the sugar into the blood. Glycogen is really animal starch, and resembles inulin. Is insufficient consumption of the sugar in the tissues a cause? If the insufficient consumption of the sugar in the cells were a factor, this sugar could still be converted into fat and stop the diabetes, but it is not, for, as a rule, diabetics lose their fat. Von Noorden rather assumes as factors parts of several theories, chiefly insufficiency of glycogen reservoirs and insufficient sugar consumption. The latter may include inadequate distribution of carbohydrates, diminution of the property residing in the tissues of seizing and breaking up the sugar molecule, diminution of the property residing in the tissues of compressing the sugar molecule into a fat molecule. Glycosuria resulting from an over-production of sugar from albumin and fat is not known to occur, he says. Over-production plays no part in diabetes mellitus in man, says von Noorden, but diabetes due to diminished consumption of carbohydrates is an established fact. It is immaterial what may be regarded as the causative factor of this diminished consumption, it stands 


\section{FORTY YEARS IN THE MEDICAL PROFESSION}

in the foreground in experimental pancreatic diabetes, and probably also in the great majority of cases of diabetes mellitus in man.

These are the views of probably our foremost thinker on the subject, and, although an improvement on those of men before him, still lack the precision and requirements of absolute scientific truth founded on absolute scientific fact. All we can do at present is to adhere to the theories advanced, and undoubtedly most cases of diabetes mellitus can be explained quite satisfactorily in one of these ways. In the dietetic form more sugar is taken into the economy than the liver can work up. In the nervous forms there is a vasomotor disturbance which interferes with the blood-supply of the liver, and also with its glycogenic functions. In the pancreatic forms the pancreas may fail to secrete its sugar-destroying ferment, and thus the blood may become surcharged with glucose. The fitid of the pancreas contains at least three enzymic bodies which play important parts in digestion. One of these is diastatic, is capable of converting starch into sugar, and is supposed to be identical with the ptyalin of the saliva. One gramme of the pancreatic juice of a dog containing only .OI4 gramme of organic solids will convert 4.672 grammes of starch into sugar in a half-hour. Impairment of this function surely must have a great effect on the sugar of the econony.

Now we come to another theory as to the origin of diabetes mellitus in man, and although it is a startling one, it is by no means an erratic one. Dr. Abraham Mayer, of New York, advances the theory that it is the result of the pernicious influence of a specific bacterium or its ptomaine in the organism, acting centrally on certain brain-centres, or peripherally on the glycogenic reservoirs. The nervous system controls the normal production of sugar in the body. If from accident, neoplasm, worry or mental strain, poisons, etc., this influence is impaired or abolished, the bacteria and their ptomaines exert their influence for harm. The bacteria invade 
the organism; in health the normal resistance of the economy holds them in check, or perhaps some ferment physiologically produced by metabolic changes in certain organs acts as an antitoxin to them. Granting this, we will cure the diabetes produced by the bacteria by exhibiting a bactericide. Dr. Mayer reports bichloride of mercury as the remedy to do this. His treatment is as follows: A history of the case is obtained, and the patient is weighed. The quantity of urine passed in twenty-four hours is noted, the specific gravity is taken, the quantity of sugar is estimated, and other abnormal characteristics are noted. If the urine fails to react to Gerhardt's test, the patient is put on an antidiabetic diet for two weeks, during which time bichloride is taken, beginning with one-twelfth of a grain three times a day, and in three days increase to one-tenth of a grain. In a week's time onesixth of a grain is given after each meal, well diluted with water. It acts at first on the bowels and does not salivate. In three weeks the sugar has been greatly reduced, and the patient has improved in every way. Now the dose of bichloride is reduced to one-sixteenth of a grain three times a day. The diet is now increased a little, or rather is not so severely restricted. The urine is examined every lay, and the evening urine tested. From time to time the drug is suspended, but, even if the sugar entirely disappears, the bichloride is given in small doses.

These cases he treated were not syphilitic cases. Cases with a history of lues (congenital syphilis, probably meant) showed marked improvement. Dr. Mayer claims the drug as a specific in diabetes, and recommends its general trial by the profession. Dr. G. IV. McCaskey also says it will be well to investigate closely the bacteria of the stomach and intestines in cases of diabetes mellitus, not with the expectation of supplanting dietetic treatment, but with the view of aiding with suitable treatment for possibly existing virulent bacterial protozoa or parasitic growths. These in some way may affect the ferments, checking or increasing the normal sugar 


\section{FORTY YEARS IN THE MEDICAL PROFESSION}

supply of the system, thus acting, whether it be in over-supply or under-supply.

Von Noorden gives some interesting points in regard to obesity and diabetes and the form called by some lipogenous diabetes. In all cases of diabetes the oxidation of carbohydrates is restricted. Glycosuria and hyperglycæmia can only follow when the fat-forming as well as the oxidizing cells have lost their power of arresting the sugar molecule. $\mathrm{He}$ thinks it is possible that both consumption (oxidation) and storage (fat conversion) of the materials are interfered with by a common cause, as, for example, the resistance of the diabetic tissue to glycogen formation. You may conceive a case in which the ability to burn up sugar in the organism is alone interfered with, whilst the carbohydrate conversion to fat continues. Here the cells are bathed in a rich sugar solution, yet they starve, because they cannot seize the sugar molecule. Hence follows a tissue hunger, which by reflex action starts a sharper appetite, and hence more food is taken, and from this more fat is deposited. This person is really diabetic, yet he does not excrete sugar externally, but in the fatty tissues, and in the end almost always becomes a true diabetic. Here is a relationship between obesity and diabetes, and there may be some such relationship between gout and diabetes. Some cases are at first gouty and then become diabetic, and there are cases the reverse. Then there are cases in which the two diseases coexist. The diabetes coming first gives the worst prognosis. The cases in which there is coexistence are usually not severe cases. I have seen such cases in men of middle age who violated every hygienic law applicable to their condition, and yet they did well and appeared to prosper, until suddenly they yielded to some intercurrent attack, like apoplexy or diabetic coma, to which their condition rendered them continually liable.

Von Noorden appears to think diabetes mellitus is not common among the insane. My own experience leads me to believe there is quite a percentage of the insane diabetic, and alimentary diabetes is quite common if they are not well regu- 


\section{FORTY YEARS IN THE MEDICAL PROFESSION}

lated as to their diet. but allowed to give way to their animal instincts. There are no chronic medical cases which I approach with more sense of responsibility than I do those of diabetes mellitus. No man has any right to take them unless he has made himself familiar with the subject, and it is not right to dismiss them with a placeho and tell them to live on nitrogenous diet. Every case requires profound and deep study, and demands ever-watchful and anxious care. In very many cases life may be prolonged indefinitely under proper surveillance, without which the end may come, and in many cases does come, prematurely. Remember, one cannot live on nitrogenous foods indefinitely. Such foods are of easy digestion, and are not prone to putrefaction, but they are deficient in nucleo-albumin, which is essential to the building up of the red blood-corpuscles and for supplying energy to the nervous system. Living a long time on such diet produces anæmia and debility, whether the person be healthy or diabetic.

Let us look at gluten, so much spoken of as diet for the diabetic. It is the nitrogenous element of the food cereals. It has been said that gluten and water constitute all that is necessary for food and drink. Gluten really is not a single food element. There are four substances in it,- -vegetable albumin, vegetable casein, vegetable fibrin, and vegetable gelatin, the latter being considered an albumin-saving food, and there is a possibility of forming fat from the albuminates. If we could get a pure ghten food. and add fat to it by butter and milk and such methods, we could get a more desirable food for those unable to use the carbohydrates. Diabetic patients are often difficult to manage. Early in the case get yourself $c$ rapport with him, get his confidence, and have him consult you as frequently as possible.

Diabetes is doubtless increasing in frequency in this country. Wear and tear is greater every day, over-consumption of the carbohydrates is increasing, and the nature of our foods is causing us to be more and more the subjects of unfavorable bacterial action. Americans are among the great carbohydrate consumers of the world. It is not necessary to say 


\section{FORTY YEARS IN THE MEDICAL PROFESSION}

much of the diagnosis, which is not difficult usually. Keep your eyes open, for there are doubtless intermittent forms. Tuberculosis of some form may mask it, and a word or an action may give us a hint. The first hint may come from the eye, from a tendency to stupor or coma, from a sexual neurosis, from a vaginal pruritis in the female, from a neuritis of the arm or lower extremity, especially a sciatica, the diminution of the tendon reflexes, a loss of flesh, exlaustion, spongy gums, dry skin, great thirst or strong appetite, constipation of the bowels, polyuria, a sticky drop of urine, possibly on the shoe, whitish in color after evaporation, glucose in the urine by test. As to the tests for sugar, the fermentation test with yeast is a sure one, and cne by which we can tell the comparative amount of sugar in the urine. I like Moore's test as an easy one. There must be five per cent. of sugar present to make it available. If you see the specific gravity over 1025 , look ont for sugar. Tyson has seen sugar as low as roro. The low proportion of other ingredients caused this, perhaps, or fermentation. Do not examine your specimens after fermentation and the sugar has gone off. Fehling's solution affords a good test, and by it you can calculate the quantity of sugar present. It may be purchased in tablet form, and is handy. It does not keep long made up, nor does Pavy's. Trommer's test is a fair test, and will show under favorable conditions as low as one per cent. of sugar. You must get an orange-red. After it cools, and the precipitate is only light yellow, you may only have reduced uric acid, creatinin, etc., and thus make a grave mistake. Nylander's test is von Noorden's favorite: Take four grammes of sodium tartrate and dissolve it in one hundred cubic centimetres of a ten per cent. solution of caustic soda, to which two grammes of bismuth subnitrate have been added. Heat this to $122^{\circ} \mathrm{F}$. Cool and filter. Boil ten cubic centimetres of urine in one cubic centimetre of the solution two minutes. If sugar is present, metallic bismuth is thrown down. This is black, and the fluid is dark or even black. If there is no black, there is no sugar. This test will show sugar 


\section{FORTY YEARS IN THE MEDICAL PROFESSION}

if it exists only to the amount of one per cent. It is necessary often to test for acetone, aceto-acetic acid, beta-oxybutyric acid, or oxybutyric acid. The latter is important, for when present, diabetic coma probably soon will follow. For tests for these the reader is referred to text-books.

The pathological and bacteriological laboratories which are, or should be, established in erery community, in which such investigation can be made, are a great advantage and help to practitioners of medicine. and of untold benefit to sufferers from disease. If your patient be pregnant, there may be more thorough investigation needed. Before pregnancy, menstruation is usually very much diminished. In about two-thirds of the cases pregnancy goes on to the end. In about one-third of the cases miscarriage takes place late in the pregnancy. For her own sake and the baby's sake the diabetic mother should not nurse her child.

Pruritus vulve is very common in the pregnant woman, and so are boils and carbuncles, and much sugar goes off by the urine. Some one has said diabetic women are more apt to produce female children, because for the perfect ripening of the ovum oxidation must be perfect; that is to say, no sugar must be left unburnt. When any is left, the ovum becomes less ripe and less well nourished; hence the properties of its protoplasm are less well developed, and by the theory of crossed inheritance it is more than likely to produce a female child. When you commence with your patient you want his family history and his own history from the time he noticed illness. Record his weight and note it from time to time. This is of great importance, as may be well seen. Now you want to find out his condition as to sugar. Put him on his usual diet for sereral days, and measure and take account of the glucose in the urine. For the same length of time let the patient take an absolute diet, say of rare beef and tea without cream or sugar, and then take an account of the sugar, and you will see where you are. From this you will learn mich. Some people bear carbohydrates well, and some do not: so take this into account with a new patient, 
and go on and study his tolerance for carbohydrates. You can soon fix his limit with careful watching. Remember, the diabetic probably does not burn sufficient of his carbohydrates for fuel and strength, he may not store sufficient as glycogen, and he may not convert sufficient into fat. One day he may do worse in these physiological duties than he may the next day. Now, suppose he only eats the rare beef and drinks the tea, and you find considerable sugar, what then? It argues badly. He must be making the sugar from his albumin and letting it gradually into the circulation, and not even consuming this. His glycogen storage must be seriously disabled. The splitting up of the sugar molecule in the tissues and its compression into fat must be seriously disturbed. Here the beef is possibly a dangerous diet, for the patient will get too much sugar even from it. Yet if we do not give it, will he not use too much of his own albuminous tissues to produce it? Your patient is in great danger here. It is your duty to watch him and test him on different diets until you get what suits him best.

In testing the urine in these cases, indeed in all cases, it is best to take specimens from both the morning and evening voidings. If we can get a carbohydrate to go through the kidneys unchanged and yet give heat and force for the system, we will secure a great gain. Alcohol within bounds is a great help in treatment. Spirit is its best form, and California uncolored pure brandy is the best spirit. Next to this comes Scotch whiskey. American whiskeys and French brandies have more sugar from their caramel coloring. Claret is the best wine, and the Rhine wines come next. Champagne, unless absolutely dry, is a poison, and so are the sparkling Moselles. The European physicians allow now and then a glass of dry sherry. To my mind sherry, Madeira, and port should never be offered a diabetic. Gin is too stimulating to the kidneys. Malt liquors of all kinds must be absolutely shunned. Much comfort can be gotten from the effervescing waters. A glass of carbonic acid water with a thimbleful of brandy is as palatable as champagne. 


\section{FORTY YEARS IN THE MEDICAL PROFESSION}

If your patient has a voracions appetite, take this into consideration when testing for sugar. If the stools are large, you may expect the pancreas to be involved. If your patient becomes ill from other causes, of course the sugar is diminished, because there is less formed. This may even happen in advanced cases when tuberculosis coexists. Von Noorden suggests that in bacterial diseases they may give a ferment, and cause the cells then to dispose of more sugar, and thus get rid of it in that way. A friend at my elbow suggests, if they can dispose of it thus easily, why cannot they play some important part in its formation?

I have seen two cases of diabetes mellitus in persons above middle age get well. One was a colored preacher, of good character and habits, and the other was a married white woman. The man was of large frame and muscular, and not inclined to obesity. The woman was short and stout and quite fat, the mother of a large family, and in good circumstances. I have seen both cases recently, and neither shows sugar in the urine, and both are fairly well, except the infirmities of age, both being nearly eighty years old. Some years ago I saw the man a few times, and gave him what I considered good advice. He then disappeared. In a year I saw him again, and he still had a large amount of sugar in - his urine. I asked him what he had been doing for himself. He said he had taken some of the medicine (ten drops of the fluid extract of jambul seeds) for a time, and then stopped and lived on the best diet he could get. Two or three years after this my attention was again called to this man. He looked very well, and like anything but a diabetic. I procured a specimen of his urine, and found it normal in every way. He said he felt well, had been pursuing his calling and working at odd jobs, and had eaten everything that came to hand. The woman I kept under constant surveillance. In about two years, moler the usual treatment applicable to such a case and the exhibition of jambul, I found the sugar to disappear. For several years she has had no sugar, but has now and again attacks of eczema or pruritus. 


\section{FORTY YEARS IN THE MEDICAL PROFESSION}

I am well aware that some cases of diabetes stop when the patient becomes gouty and granular atrophy of the kidneys supervenes, and this is a most interesting condition and one causing us to think of many possibilities as to its pathological factors. The cases I have quoted were not such cases: neither had had gout in the form of arthritis, and neither had interstitial nephritis.

Dr. H. D. Beyea has reported an interesting case, where he removed an ovarian cyst from a diabetic, followed by recovery, wonderful to relate, and, more wonderful still, the diabetic symptoms all disappeared. This case is one worthy of close watching and close study in all of its phases.

A healthy person, for each two and one-fifth pounds of weight, consumes at rest 30 to 35 calories; in motion, 30 to 40 calories; at moderate work, 40 to 50 calories. A calorie, remember, is the amount of heat required to raise one kilogram of water $\mathrm{I}^{\circ} \mathrm{C}$.

Von Noorden takes a diabetic woman doing light work. When well, she needed I925 calories per day; diabetic, she lost 2 IO calories; therefore she consumed 2 IO calories of her own tissue. By calculation she lost 38.9 calories through albumin, and therefore, by the consumption of some of her nitrogenous substance, she lost I7I. I calories. Fat was the only substance available, and this took I 8.4 grammes of fat, each gramme yielding 9.3 calories, making $18.4 \times 9.3=$ I7I.I2 calories lost by fat; therefore she must eat albuminates and fats in excess to keep up with a person in good health. If she eats carbohydrates, they run off as sugar by the urine, and furnish no fuel for steam or power. They only check hunger for a little while, and tissue hunger scarcely at all. The point to watch is when she can begin to tolerate some carbohydrates, for albuminates and fats will not do all the time; she will either become weak and anæmic on them or nervous from loss of nerve-power, or will consume her own tissues to get some, at least, from them. Here is a perfect illustration of how to watch a diabetic and what we are to watch for, and what we may expect under certain con- 


\section{FORTY YEARS IN THE MEDICAL PROFESSION}

ditions, even up to diabetic coma. Diabetics excrete much nitrogen because they eat much. If there is more in the urine than goes in by the food, there is a consumption of the nitrogenous tissues going on, and we must seek to check it. The more nitrogen wasted in this way, the worse the glycosuria, and we must check the exhibition of carbohydrates. A toxamia may arise to affect the protoplasm, and coma may come. Von Noorden gives the nitrogenous substances in diabetic urine as urea, ammonia, creatinin, uric acid, and aibumin. The non-nitrogenous substances as acetone, acetoacetic acid, and beta-oxybutyric acid. Their common source is albumin, body albumin, not albumin of the food.

Diabetic coma is an acid intoxication of some kind. Some think it due to oxybutyric acid, and some to acetone and aceto-acetic acid. Von Noorden does not think the latter the cause. He thinks diabetic coma comes from a paralyzing of the brain and a destruction of protoplasm by a toxæmia. To me it appears the great loss of the salts of potash, soda, etc., by the urine may be a cause, the absence of these rendering more or less inert the protoplasm of the organic cell. Oxybutyric acid in the blood is a sign of its coming. I have never seen pneumaturia or gas in the bladder in diabetes, yet such cases are reported. Germs are probably introduced from without, as by catheterization, and cause it. The skin is usually very dry and harsh, and germs are very active in the diabetic; hence the slightest surgical operation is attended with danger. The books give the operation for phymosis as a very dangerous one, probably from some local infection through the urine. Granulations of wounds are apt to slough, and fractures may be attended by extreme debility and danger, if of the larger bones, bed-sores being a very serious feature if the patient is compelled to rest in bed. Indeed, any accident or intercurrent illness is a cause of the most serions anxiety in diabetics, and sometimes unlooked-for deaths are to be solved by looking for the evidences of sugar in the economy, which had not been suspected by the individual or possibly by his doctor. 


\section{FORTY YEARS IN THE MEDICAL PROFESSION}

Under thirty years of age most diabetics die of tuberculosis within a reasonably short time, and the younger the patient the more rapid the disease, as a rule. I have never recognized it under twelve years of age. The better the circumstances of the patient, the better are his chances. This holds good for two reasons. Every advantage that wealth can give is a help, and these people, as a rule, have the advantages of education, and can conduct their case on their own part more intelligently. It is difficult to restrain in diet or otherwise a rough, ignorant, uncouth man, a silly woman, or an irresponsible child.

Von Noorden says tubercle bacilli are difficult to find at times in the sputa of diabetics with consumption, and that arteriosclerosis is common in some degree or another. Some hypertrophy of the heart is often a help, and a weak heart is serious. Always look to the heart of your patient, and measure his strength by that and other ways, and look to the condition of the arteries, etc. Albuminuria is not a very serious sign, as a rule. If caused by gouty kidney, the sugar may check or disappear. A graver cause may be arteritis. Differentiate by the microscope, observing tube casts, etc. Von Noorden says glycogen clods are found in the kidneys after death. Remember, the lymphatic glands often swell in diabetics; the cause is possibly often tuberculosis. Death from uremia may come in the kidney cases, so be careful to differentiate such from coma cases. Coma may come suddenly or be preceded for a longer or shorter time by severe headache, and the symptoms may even simulate intoxication from alcohol or opium, or any other intoxicant. After some hours cona comes on. The pupils are dilated, the breath is one long and one short, cyanosis increases, the odor of acetone is on the breath, an apple or hay odor probably (convulsions are rare). The urine reacts with chloride of iron, and sugar may be present or absent. Recovery is seldom, and in two or three days the patient sleeps away.

Remedies are of little avail. Alkalies are recommended on general principles. The best reason for giving alkalies 462 


\section{FORTY YEARS IN THE MEDICAL PROFESSION}

is the farorable action they have on the protoplasm of the organic cells. A man cannot live on distilled water as a constant drink. Intravenous injection of the normal salt solution is recommended. Tyson has seen good results from injecting it into the tissues. I slould use it very freely by the rectum. Diabetics bear the slightest operations so badly, I would even be afraid of intravenous or tissue injections. If the patient should get well, sloughing would almost surely follow the latter, and sudden death might come with the former. As a rule, you will not find coma coming on whilst the patient holds his fat. If there are any symptoms of coma, a safe rule is to change the diet, whatever it may be.

The cause of diabetes, whatever it is, causes rapid oxidation of the tissues, and whilst the fat remains it probably exhausts its force in oxidizing it.

As I have no prearranged plan in writing this article, but take matter just as it comes, let us take up thyroid treatment in diabetes mellitus, as we have spoken of fat. The office of the thyroid in the system is probably a secretory one. It furnishes probably some material which enters the blood through the lymphatic system, which is essential to the chemical metabolism and nutrition of the tissues. This material probably checks a tendency to auto-intoxication by destroying poisons resulting from tissue metabolism. Giving of thyroid affects the nervous system, increasing the heart beat, yet lowering arterial tension. The respirations are increased and the temperature is not constant. Headaches and flushings may follow. The intellect usually brightens, the appetite increases, tissue waste increases, showing that the remedy increases nitrogenous waste and the oxidation of the fats. The urine shows no decided changes, as a rule. The secretion of the thyroid is a colloid. Iodine exists in the thyroid at birth, and increases with age. Now, on general principles, thyroid, acting as has been described, surely should not be given in diabetes mellitus, for, among other things, it increases the combustion of fats and causes a loss of both these and muscle tissue, just as diabetes does. 
Hear what Dr. William Murrell says. His patient was a woman, with diabetes of probably neurotic origin, arising from vasomotor paralysis, increasing the blood-supply to the liver, kidneys, etc. In twenty-four hours she passed one hundred and twelve ounces of urine, containing over twelve ounces of sugar, being over fifty-two grains to the ounce, a very large amount. This was the average for fourteen days. Murrell rightly says that what we want is a drug that will get rid of the sugar from the urine, and yet not restrict the supply of carbohydrates to the patient. The pancreas could only be useful in cases of pancreatic diabetes. He gave increasing doses, up to twelve grains, of fresh thyroid every three hours, some inconvenience being noted, until tolerance was established. The appetite was good, and she ate ordinary diet,-—bread and butter, meat, milk, potatoes, tea, gruel, etc. She practically ate what she craved. Under this treatment, from over twelve ounces of sugar daily she came down to a little over six ounces, and in eleven days more to less than three ounces. Now thyroid treatment was stopped and the patient dieted, and she got only fish, beef, tea, milk, and a little toast. The result was, she passed two thousand two hundred and sixty grains more sugar daily on a restricted diet than she did on a full diet plus thyroid treatment.

How did the thyroid act? Thyroid contains colloid matter and a small quantity of nucleo-albumin and extractives. It hastens cell action, it increases oxidation of the tissues, it destroys the circulating proteid, and increases nitrogenous waste; so, in treating obesity with it, the diet should not be restricted. Plenty of nitrogen especially should be taken. If we accept Pavy's theory, that glycogen is converted into fat, we get a clue to the action of thyroid in helping diabetes mellitus. We only know, says Murrell, that in some cases thyroid lessens the amount of urine and the sugar excreted with it, and at the same time reduces the body weight. It will especially suit cases in elderly people in which obesity is a prominent feature. This is encouraging, contradictory as it appears, and will teach us to watch for such cases, and will 464 
further teach us that there is no empirical way to treat diabetes, nor, in fact, other diseases, but that every case must be a study, not more as to its idiosyncrasies than as to its physiological and pathological peculiarities. Remember that in diabetes, probably not only is the oxidation of carbohydrates restricted, but their conversion into fats is equally restricted, and glycosuria can only follow possibly when the fat-forming cells and the oxidizing cells both cease to arrest the sugar molecule.

I have seen quite a number of cases of diabetes mellitus, and the rapid cases, as a rule, have been under thirty years of age, and tuberculosis has been the ending of most of them. I do not remember a case to have ended by pulmonary tuberculosis after thirty years of age. The most chronic and manageable cases were those in men after middle age, and a coexistence of gout appeared to prolong life, yet the conventional diets of gout and diabetes are apparently so opposed. They are not so opposed, for the gouty patient is quite tolerant of carbohydrates. Study his case, and coax him and watch him, and he will usually respond. Serious accidents to diabetics, and surgical operations and shocks of all kinds, are most unfortunate. I have seen no reason to believe it to be contagious, but many instances have been offered to prove such to be the case. That bacterial influences affect it greatly, if they do not cause it altogether, at least in some forms, impresses me gravely. As before stated, I have seen it in the negro. Jews are said to suffer from it in a larger percentage than any other race. They lead active lives mentally, sluggish lives physically, as a rule, and are great eaters of the carbohydrates. My experience leads me to believe diabetes is hereditary in many cases, and members of such families should be warned of the possible bad effects of high living and the excessive use of carbohydrates, and to especially avoid, as far as poor mortals can, over-work and wear and tear, for, remember, it comes in various forms, and the nenrogenous form is a common form. Syphilis may be a factor, particularly through the brain, the blood-vessels, or the pan- 
creas. Take it into account in your differentiation. If you can make out a pancreatic case, above all things use pancreatic preparations, although experience does not yet give you great encouragement in that line.

Von Noorden's suggestions as to diet and general treatment are golden. If your diet is too low, the albumin and the fat both go. The diet of the diabetic man must give him at least thirty-five calories per kilogram of weight per day. The average for a healthy man is two thousand five hundred calories per day. A healthy man takes in his diet forty per cent. of carbohydrates. In a diabetic most of this goes away in the urine, and does him no good. The more carbohydrates he can tolerate, the better for him. Some tolerate more, some less, and the last are the most difficult cases to treat. To find out this tolerance in your patient is one of your first duties. The worse the diabetes, the more proteids, fats, and alcohol we must use. Among the best forms of the carbohydrates are fruit-sugar, milk-sugar, and cane-sugar. Now and again rest the sugar-consuming cells by withholding the carbohydrates. Get the tolerance of the patient to carbohydrates by the amount of sugar in the urine, always taking into consideration the diet being used. Bread and potatoes are more difficult to abstain from than sugar or wines.

I had once a dear friend who died of diabetes. He was an able man, and had held distinguished positions, but dieting was very difficult with his diabetic appetite. I have seen him eat a dinner, indulging in every compound on general principles injurious to one in his condition. After dinner he would, with a good deal of grace of manner, decline sugar in his coffee: "Can't take it; my cloctor forbids it."

So it is with a great many, indeed perhaps with the majority; they knowingly cheat themselves. Study your patient, and calculate the number of calories necessary for his proper existence. He may need two thousand five hundred, and get by his diet and loss through his disease only fifteen hundred. He will get weak and thin, his fat and strength going with his muscles. Now look out for failure at the 


\section{FORTY YEARS IN THE MEDICAL PROFESSION}

heart, coma, and such troubles. Give oceans of fat. Fat is a great factor in the average diabetic. Alcohol will help the fat, it gives fuel. but study the quantity each case may need. Too much may poison the protoplasm of the cells, and thus tissue waste and tissue destruction may go on more rapidly to the disadrantage of the patient.

Remember, though, in serious progressive cases after a while even the fats break up and increase the elimination of sugar. See how complex are these cases, and what tact and watching they require. Exercise short of fatigue consumes sugar, and is therefore to be recommended. Fatigue in any shape or from any cause is bad. Massage is passive exercise, and even approaches active work. Von Noorden's rest plan is the proper plan of treating almost every case of diabetes mellitus. If your case is a moderate one, and you have gotten its carbohydrate tolerance, rest the sugar-consuming cells for three weeks in every three months, at least. If the case is a serious one, rest it absolutely one month in every three months. Every case is a study. Resting these cases makes them much more tolerant of the carbohyllates when they commence them again. A milk diet is near absolute rest. One litre of milk equals fifty grammes of bread. Rest diet must be a diet as free as possible of every form of carbohydrates. Give lots of fat. One hundred grammes of aleuronat bread equal fifty grammes of wheat bread. Ninety grammes of potatoes equal twenty-five grammes of wheat bread. Beware of intestinal catarrhal troubles. They are dangerous. Let up on the solid foods. Take milk, spirits, etc. The prognosis in all cases of diabetes depends on many factors. The physical peculiarities of the patient count much; family history counts much; the mental characteristics of the patient count much; the circumstances of the patient count much, as well as his employment and his environment. The blood-count and colortest of the bloorl tell much. The age of the patient counts much. Sypliilitic cases and obese cases are most amenable to treatment. Tall, spare, weak people are particularly vulnerable. 
After all, the waste of the nitrogenous matters, as indicated by the amount of urea passing off by the urine, is the factor that counts more than any other, and this is the factor which determines the difference between a true diabetes and a mere glycosuria. The one is usually permanent, the other may be only temporary. The physician in the case counts probably more than any one factor. Without intelligent advice, the diabetic, as a rule, goes rapidly to destruction.

As said before, we must learn to distinguish between true glycosuria and trute diabetes. The true diabetic usually has a voracious appetite, and he invariably, under such conditions, eats too much. So much sugar passes off in his urine that he must have starches as the material from which to replace it, and he thus craves carbohydrates, and the trouble in practice is, few can resist this craving. As a result of this overindulgence, fermentation of food takes place after it has been eaten. These patients are always in great danger, for most of them will over-indulge, and an excessive meal of carbohydrates, combined, I think, particularly with shell-fish and such glycogenic foods, is often followed by severe attacks of acute indigestion and sudden death, for these unfortunates have so little vitality, so little ability to resist the attacks of any disease, as to make them particularly vulnerable to even moderate onslaughts. Such patients should be particularly watched and prevailed upon to reduce the excessive quantity of all foods, and especially of carbohydrates and other sugarproducing materials. Such cases usually need lavage of both stomach and bowels, with such antiferments by the mouth as hydrogen dioxide, the salicylates, with antipyrin and bicarbonates of soda and potash if the heart be not too weak. Scotch whiskey or gin, very largely diluted with water and taken regularly, is most useful in such cases; in fact, alcohol is a wonderful remedy here. In case the plan of withdrawing all liquids is tried, a little spirit will make this plan more bearable to the patient. It is in these cases we may look for some premonition of the skin of a bronze hue. This comes from destruction of the hremoglobin. The excess of sugar causes 


\section{FORTY IEARS IN THE MEDICAL PROFESSION}

dilution of the blood. It has been suggested that this sets free some of the hemoglobin, and this is changed and deposited in the tissues and causes the bronze pignentation. Cirrhosis of the liver may occur in these cases.

Now, as to other remedies valuable in the treatment of diabetes mellitus. Arsenic has been used for a long time, on the theory that it has some specific action on the digestive tract, and that it increases the oxidizing power of the red bloodcorpuscles over grape-sugar. My experience with arsenic has led me to abandon it. I doubt if it has any virtue whatever beyond its general tonic properties. Dr. Barney recommends the double bromides of gold and arsenic in five-drop closes after each meal, increasing one drop each day until tolerance ceases. In syphilitic cases the indications are plain. Use mercury and the iodides, being careful of mercury. Opium and its salts have long held a reputation in the treatment of diabetes. They probably act by locking up the secretions, and there must be some specific action in them over the formation or the destruction of the sugar. 1 am afraid of opium in chronic diseases as a general thing, it is so horribly demoralizing. Of the salts, codeine is the least objectionable in most ways. It really appears to control the sugar in some way, but I think I know of better remedies, and hence I rarely if ever use it. It is said to do better given with hydrogen dioxide. The alkalies have been used much. It is claimed that they destroy the sugar in the blood and neutralize volatile acids. They may be useful in conditions approaching coma, which we have already spoken of. In gouty cases the salicylates are useful, and in the neurogenous form they quiet the nerves. Ergot and lactic acid have been much recommended. I see no reason to use them except in special emergencies that may arise. Fats are at times most useful, and especially in those cases where all, or nearly all, of the carbolydrates are converted into glucose and excreted, and the body is encroaching on its own proteids for power, consuming its own tissues. Here give codliver oil and whiskey. Slush the system with it, and let 
FORTY YEARS IN THE MEDICAL PROFESSION

the patient eat fat in all conceivable shapes. Help its assimilation with spirits, and so long as they agree and have a good effect, eat fats and drink spirits.

Upon the theory that brewer's yeast would excite vinous and acetous fermentation in the stomach, and thus convert the excess of sugar there into acetic acid, Dr. George B. Wood years ago recommended yeast. I have used it with little or no benefit, a tablespoonful three times a day. On the theory that the yeast-plant might be antagonistic to certain pathogenic bacteria, I have used it locally and constitutionally in diphtheria, with apparently good results.

Dr. James Gray, of Glasgow, gave rennet, to change the sugar into lactic acid, with repeated good result. Phenacetin and other coal-tar derivatives are said to do good at times. I have had little experience with them. They slow the pulse, and possibly have more or less effect on assimilation and tissue change.

For eczemas and the different forms of pruritus encountered among diabetics, absolute cleanliness and the application of chloral washes are the best remedies. Chloral, ten to twenty grains to the ounce, makes a good wash. A strong solution, sixty grains or more to the ounce, is said by good authority to be almost a specific in rhus toxicodendron poisoning.

There are two remedies from which I have had recently most remarkable results in reducing the sugar in cases of diabetes mellitus. I refer to the fluid extract of the seeds of jambul. Botanically it is Jamboo sy yygium jambolanum, Java plum. It grows in the East Indies generally. The wood yields a brown dye. The berry is olive-shaped to globose, from the size of a pea to that of a pigeon's egg, and black when ripe. It contains one seed enclosed in a thin white shell. Experiment proves that it prevents the conversion of starch into sugar. In ten-drop doses three times a day in all forms of diabetes mellitus except the pancreatic form, in which I have not had an opportunity to use it, it has been very effectual in reducing the sugar. but has never absolutely eradicated 
it from the urine. The other remedy is piperazine, the use of which I have before spoken of in renal calculus and gouty affections. Piperazine has acted with me just as jambul has acted in reducing the amount of sugar in the urine. It is rapidly absorbed and passes rapidly through the kidneys, producing a reddish-brown urine. This is not so marked in diabetes until it has been taken several days and reduced the amount of urine. It checks the saccharifying influence of hamic and other hydrolytic ferments, yet has no destroying influence. It checks diabetes produced by phloridzin.

Here is an interesting point, and points again to the kidney as a possible factor in diabetes mellitus. It is in regard to the combined action of these medicines that I have a word to say. I have in several cases given ten drops of the fluid extract of jambul seed in a tablespoonful of solution of piperazine, containing twenty per cent. of alcohol, in which were five grains of piperazine, the patient being ordered to take it in a half-pint of plain water. I have only to say that so far the results have been wonderful, and give me great encouragement in the treatment of this intractable disease.

During the treatment all diets were used, and a moderate amount of carbohydrates does not appear to seriously affect the gratifying results, and the patient thrives and is kept in good humor. It is scarcely necessary to say that all the rules of hygiene should be observed by the diabetic, and under the surveillance of his medical adviser he should lead the life of a good citizen, clean and clear in mind and body.

Now as to the all-important matter of diet. This has already been gone over pretty thoroughly as to its chemical and physiological attributes, and it only remains to consider the practical points, and show the foods fit for the sufferer from diabetes mellitus, arranged according to their chemical compositions and plysiological action. Here, again, comes in individuality and the specific case you are advising. You cannot lay down a diet for all cases. You can only give certain general rules, and tell the virtues and vices of certain articles in the lists you may see fit to present. The great 
divisions from which you are to choose are the carbohydrates, the albuminoids, and the fats.

Substitutes for Sugar.-It is not difficult, as a rule, for one to give up sugar in coffee and tea, but in diet generally it is difficult to do without it, and we need some substitute for the diabetic to use more or less freely, and yet not affect his condition unfavorably. Saccharin is a crystalline nitrogenous body derived from coal-tar. One-half grain of it will sweeten a cup of coffee. A tablet composed of one-seventh of a grain of saccharin, one-third of a grain of sodium bicarbonate, and eight grains of mannite will sweeten a cupful of any drink. It is not very soluble in cold water, more so in hot water, and quite soluble in glycerin. It is three hundred times sweeter than cane-sugar. Two grains a day may be taken for a long time. It is antiseptic, has the property of rendering the urine acid, and is eliminated unaltered by the kidneys, hence its harmlessness in many cases of diabetes, yet from its antiferment action it may disturb digestion at times. Saccharin present to the amount of one per cent. in pancreatic solutions lessens their activity. It should not be used in pancreatic diabetes, and I am not much in favor of it in diabetes generally. Mannite may be used. It is the active crystalline principle of manna. It does not contain equal parts of hydrogen and oxygen, and is not, therefore, easily converted into grape-sugar or alcohol. Fruit-sugar, levulose, sold under the name of Diabetin, is probably the best sugar for the diabetic if used alone. It is not known to reappear in the urine. It does not disorder digestion. It is sweeter than cane-sugar and is fruity in its taste. Lactose or lactin, or sugar of milk, is more expensive than cane-sugar and not so sweet. It is a form of carbohydrate easy to assimilate, but is not to be recommended in diabetes, yet it does not appear to render milk objectionable in that disease. Glycerin may be used by those who can take it. It often disorders digestion and causes looseness of the bowels. The only cases in which I use it are where the bowels are obstinately constipated, as we often find them when the patient is on absolute diet. 
Drinks. - There is often great thirst, so much of the body fluids going off by the kidneys. Plain water, or water slightly acidulated with a few drops of dilute phosphoric acid or lemon-juice, or with a pinch of bicarbonate of soda or potash, is best. The effervescing waters are grateful to many, perfectly plain. The alkaline spring waters, such as Vichy and the Saratoga waters, are most grateful and useful. Saratoga Vichy, Saratoga Kissingen, and Saratoga Carlsbad are the best. As to spirits, uncolored California brandy and Scotch whiskey are the better. Colored spirits have more or less sugar in the coloring-matter. Claret is the best wine. The Rhine wines come next. Sparkling wines are poison from the sugar they contain. The best sparkling drink is brandy, whiskey, claret, or Rhine wine in soda-water. These are almost as palatable as champagne, and better than some brands. Malt liquors are suicidal to the diabetic. If he must drink them, he will live longest on those long bottled, the sugar having gone to alcohol and carbonic acid.

There are foods which on general principles should not be allowerl to diabetics. Such include syrups, sweet preserves, molasses plain or compounded, all candies and jams. Honey contains dextrose and levulose, but I think the harm of honey is most because it is eaten with bread or other carbohydrate. Breads and pastry must be avoided; as a rule, the latter are injurious to well persons. Tapioca, arrow-root, rice, and sago are very injurions. All articles made of Indian corn are less injurious than those made of wheat, but nevertheless should be forbidden. as well as all hot breads made of buckwheat, barley, and such. Oatmeal is nitrogenous, but has too much carbohydrates. All macaronis in the market are as bad as wheat flour, as we shall see farther on. So are vermicelli and spaghetti. The white potato is proscribed by most physicians. For absolute diet it must be proscribed. Where some carbohydrates are allowable it furnishes the best form for them if well baked. It las only about twenty per cent. of starch. It is a much-abused carbohydrate in the diets for the diabetic and obese, if used well baked and in no other 
way. Of course, much water goes off in baking, but the starch is better broken up. Cauliflower has more carbohydrates than cabbage, the former having six per cent. and the latter four per cent. Cabbage particularly may be allowed raw or boiled in moderation. I speak of this because many diet tables disallow it. Parsnips, carrots, and beets are better to be dropped entirely. All beans except green string-beans should be prohibited. String-beans have only about nine per cent. of carbohydrates; other beans run up as high as seventy per cent. when dried. Lima beans, green only, run twenty-two per cent., the water not having been driven off. Brussels sprouts may be eaten, as they only contain about three per cent. starch. Most diabetic diet tables leave them out. Asparagus is on an equality with Brussels sprouts. Rhubarb is objected to in most diet tables. The truth is, it contains little of anything, and the small amount of oxalic acid in it makes it very grateful in the early spring. I should allow a little, sweetened with saccharin or diabetin. Clams, oysters, and mussels have glycogen in their soft parts, because these soft parts are their livers. I think they should be used very sparingly, and only raw or plainly cooked, with no flour. For the same reason livers of all animals should be shumned.

Most fruits are forbidden in a majority of the diabetic diet tables. This, I believe, is correct as applied to all preserved fruits, as they almost invariably contain cane-sugar. Apples and pears contain only about ten per cent. carbohydrates. Sometimes we have to allow something of the kind to appease cravings and regulate the bowels. Apples and pears, especially the tart apples, do the least harm. A few strawberries unsweetened, or sweetened with saccharin, diabetin, or mannite, may be allowed, or watermelon, ice cold, if craved, as each only has about six per cent. carbohydrates. Raspberries and nectarines are more objectionable. Peaches and blackberries are about in the class with pears, and so are oranges. It is better, as a rule, to avoid them and lemons too. Mind you, these fruits are not urged as diabetic diet, but are only 
given here to let us out of a dilemma sometimes, for the patient may eat things much worse if curbed too much.

Many of the nuts are useful as food, and some of the oily ones especially may be used by diabetics. Chestnuts are away up in carbohydrates, and should never be eaten by the diabetic. Peanuts are also objectionable, but less so than chestnuts. Cocoanut is also objectionable.

As to allowable foods, they are numerous, but even with all these and no bread, life soon becomes a burden, and in many cases confinement to the list is umbearable. All soups made without the addition of carbohydrates, all edible fish, rejecting the livers, lobsters, crabs, and shrimp, and about all of the meats may be used, except livers. In cooking them the use of carbohydrates is to be avoided. Eggs are most useful cooked in various ways. As to fats, you must sound your patient as to tolerance of fats, and where tolerated, as a rule, for reasons before given, use them freely; they save albumin. If the patient crave fats, encourage the taking of them in every conceivable way. Some object to fats on the ground that they form glycerin. There is no good reason given for rejecting them on this score. As to butter, it is among the best of the fats. The little milk-sugar it may contain is no objection whatever.

A list of vegetables allowable is given here for convenience. Nost of the winter and spring greens, as dandelion, cabbage greens, horse-radish, spinach, celery, and plenty of it, okra, lettuce, endives, pickles, kale, cucumbers, cranberries sweetened with saccharin, levulose, or mannite, string-beans, which may be obtained all the year, fresh or canned. The soja beans have very little starch; they are oily and impleasant dried, but I have thought, possibly, we may get a good green vegetable from them by using them half-grown and canning them for winter use. This experiment is worth trying in the interest of diabetics. Asparagus is good all the year round. fresh or cannerl. Of all regetables, asparagus is least affected in flavor or otherwise by canning. Onions are debatable food. The Bermuda onion contains too much sugar, undoubtedly, 
and so do parsnips and carrots. Egg-plant may be used sparingly, if we are put to it for a change. It must not be cooked with carbohydrates, and without these it is like pudding without sauce.

Thompson quotes Fagge as saying, "As a rule, all white parts of vegetables in which chlorophyll has not been developed by exposure to sunlight contain no sugar. Boil all kinds of forbidden vegetables in much water, and if they contain only sugar and not starch, much of their sugar will be lost. and they may be eaten by the diabetic. Beets are in this class, but I am very doubtful as to beets being under any conditions good food for the diabetic."

Mushrooms have a little grape-sugar, but so little that they may be eaten freely by the diabetic. The French morel has a mere trace, and the truffle has none. These are great helps for their flavor, and are often great additions to steaks, pig's feet, tripe, kidneys, sweet-breads, and such.

The diabetic may eat terrapin, a dish for the gods. "Good wine needs no ivy-bush." Terrapin needs no sattce. The only restriction is, be chary of the liver. Butter, pepper, and salt are all that are necessary to bring out the flavor of terrapin, and this is the diabetic's way to eat it. Corn-starch, flour, and Madeira or sherry only take away from its natural gôut. If you must have wine, use a dry Madeira or sherry. Madeira is the gentleman's wine for terrapin, one glass to one count terrapin. Sherry is a good second in the same proportion.

Milk.-Here comes up an important question in the diet for diabetics,-the use of milk. Of course, I refer to cow's milk. In IOOO parts of fresh milk we get water, 873 ; butter, 30; casein, 48.20; sugar of milk, 43.90 ; calcium phosphate, 2.3I ; iron phosphate, .7; potassium chloride, I.44; sodium chloride, .24; magnesium phosphate, .42; compound of sodium and casein, .42. Milk is a complete food and will support life. There is little fecal residue, and it is often necessary to add lime-water, or some alkali, to prevent coagula in the stomach when a patient is living on it alone. The scum of 
boiled or heated milk is from the albuminoids of the milk, and skimming this off renders the milk, of course, weak as a nitrogenous food. There are about one and a quarter ounces of fat in a quart of average whole milk. Casein is the source of albumin in milk, and very mucl resembles animal albumin. The fat of milk, the cream, is olein, palmitin, butyrin, caproin, and caprin. It owes its peculiar odor to the latter. Butyrin is a compound ether, butyric acid and glyceryl. Exposure to the air renders butter rancid by decomposing the butyrate of glyceryl and setting butyric acid free.

The sugar is the important matter in milk to be considered for the diabetic. It is a crystallized sugar obtained from the whey by evaporation. Whole milk contains about five per cent. of sugar of milk. In whole average milk Atwater and Woods give the carbohydrates as only 2.3, and in average skim-milk as 2.2. Of course, these come principally from the milk-sugar. I believe milk to be a most important article of diet in diabetes mellitus. It is rich in nitrogen and fat. These come from the globule chiefly. The corpuscles are fat, surrounded with a delicate albuminoid coating. The fat here makes the butter, the corpuscle being broken by churning, and letting it ont. I believe this is the general idea. Senator thinks the milk-sugar in milk does not increase the glycosuria, as a rule, although some are more tolerant than others of the carbohydrate. Tyson thinks it more difficult to pass into grape-sugar than any other of the carbohydrates. These are matters of clinical experience only, and my own experience conforms to these conclusions.

The time comes in any case of diabetes mellitus when it is proper and even necessary to rest your patient from mixed diet; to rest him from the carbohydrates, even if he tolerates them to a certain extent. Here you have, with which to accomplish this, a resort to whole milk, to skim-milk, and to predigested, peptonized, or pancreatized milk, koumiss, and buttermilk. In koumiss the milk-sugar has been converted into alcohol, and is not there to vex your patient. In buttermilk it has been converted into lactic acid. These two articles 
are in every way a very great help in the diabetic regimen, and should be stand-bys in every case. They are grateful, refreshing, and in every way acceptable.

You may find a patient who cannot take the little carbohydrates in milk even, and so in other forms patients vary as to their capacity. The sugar metabolic limit must be found in these cases by examining the urine. The rest-cure leads to the recuperation of the faculty of the system to absorb sugar, thus checking under-consumption, and yet does not kill the patient by feeding him exclusively on albumin too long a time, and thus rendering his blood too acid, and causing him to consume his own tissues beyond the endurance of life. Never let your patient overstep his carbohydrate tolerance. If the patient needs fat and albumin especially, I see no objection to Devonshire cream. This is taken from heated milk, thus skimming both the cream and albumin.

Tubes for peptonizing or pancreatizing milk may be purchased at the drug-shops with full directions. Horatio Wood's directions are: Dilute a quart of milk with four ounces of water, heat to $\mathrm{I}_{4} \mathrm{O}^{\circ} \mathrm{F}$., adding two teaspoonfuls of Roberts's liquor pancreaticus, with twenty grains of bicarbonate of sodium, digesting in a warm place for an hour to an hour and a half, and raising for a moment to the boilingpoint. Another receipt is to dissolve five grains of pancreatin with twenty grains of bicarbonate of sodium in one ounce of warm water; add this to one pint of new milk, and keep at a temperature of $\mathrm{IIO}^{\circ} \mathrm{F}$. for one hour. It will be less bitter and probably equally effectual if only left a half-hour. In pancreatic diabetes I look upon these preparations as almost indispensable in diet.

I have spoken of the rest-treatment of diabetes, the rest from everything containing carbohydrates for three or four weeks in every three months. Take a case of a man who will not diet, as a rule, one who takes a drinking-bont now and again, eats and drinks everything, and is in the greatest danger of a sudden ending by coma, cerebral hemorrhage, or heart failure from exhaustion. After a bout, particularly, 
these men are quite pious, quite virtuous and docile, and ready to take advice. Milk is the great food with which to commence the treatment, skim-milk, pancreatized milk, or whole milk Pasteurized, aided, if you choose, by koumiss or buttermilk. Gradually increase the diet, and in three or four weeks you see usually wonderful improvement. In your discreet and bidable patients the same course once a quarter will rest them greatly. Alcolool in proper proportions assists the milk wonderfully and adds to the tolerance of the system for carbrhydrates. Upon the theory that uric acid diathesis, oxaluria, and diabetes are different phases of one single morbific entity, Dr. Lupa went on an anti-uric-acid diet, as he termed it, and ate all regetables, excluding all meats and such nitrogenous foods. He claimed great success in his own and other cases of diabetes. Theory is against this method, and yet theory does not always avail to stop a good thing.

"Bread is the staff of life," and the staff of life is the one thing the diabetic needs to satisfy his craving. Unfortunately, all breads, whilst nearly complete foods, have for their chief ingredients carbohydrates, and these, as a rule, are poison, death, and destruction to the diabetic. Palatable substitutes are difficult, almost impossible, to get, unless they transgress in the rule as to carbohydrates. Our main reliance is to be placed! in flours in which more or less of the starch has been washed out, leaving chiefly the gluten, and in flours made from vegetable matter which in nature is comparatively low in starch and sugar. The former are known in the market as "giuten flours," and the latter have special names, according to what they may be made of, or the party manufacturing them.

Let us take up "giuten flour." Through the kindness of Dr. Arthur T. Neale, Director of the Delaware College Agricultural Experiment Station at Newark, Delaware, and Professor C. L. Penny, Professor of Chemistry at the Station, I am enabled to give an analysis of many specimens of gluten flour and special foods purchased in the general market. It is only necessary to go into such work to see how utterly 


\section{FORTY YEARS IN THE MEDICAL PROFESSION}

bereft the American physician is of proper aids in fighting this common disease, how much suffering is entailed upon the unfortunate patients, and what ignorance or rascality, or both, are rife in America in manufacturing dietetic products of such importance and general use. Take a grain of wheat and cut it across. In the centre is a white powder, starch. This is a carbohydrate, carbon, hydrogen, and oxygen. From this we get heat and fat, but no power. The next layer is gluten, a proteid. It is dark-colored, and, in addition to the starch elements, contains nitrogen. Gluten then is a powerproducer. Then we get the phosphates and mineral matters, which help to make the bones of the body, etc. The outside is the bran, which is flinty and indigestible, and makes entire flour a bowel irritant.

Now, white, new-process flour has little gluten and comparatively much starch, because starch is white and gluten is lark; and the market demands white flour. Thus we discard the flesh-formers in our white flours, and keep only the fuel and fat-producers. The best flour for eating should contain from ten to fifteen per cent. of gluten, or more. The patent new-process flours contain much less, and much of the important element of phosphorus is also removed. Gluten flour for diabetics should contain not less than seventy-five per cent. gluten. The books tell us generally that the gluten flour special products of Europe are much lower in starch than those we buy in America. Probably they are, although my examinations do not lead me to get much encouragement in England and Germany, at least. Dr. Frilden gives five examples of English gluten flour. They contained 7.6, I6.7, I $3.26,68.8$, and 11.63 per cent. starch and sugar. This is comparatively a good showing as such flours go. Dr. Kraus, Jr., of Carlsbad, found only five specimens to contain less than thirty per cent. carbohydrates. Four contained between thirty and forty per cent., four between fifty and sixty per cent. This is a bad showing. Wheat flour in the general market contains from sixty to eighty per cent. carbohydrates, 
accordingly as it is white or dark; the greater the amount of carbolydrates, the whiter it is.

To get the starch ont of flour it must be wasled, when the starch runs out through a cloth and leaves the gluten behind. Gluten may thus be obtained starch free. It is very difficult or impossible to get gluten bread absolitely free from starch. Any bread under twenty-five per cent. starch would be very encouraging as things go in America, or even in Europe. I should at present hope more from the French products. Do not turn your patients loose and tell them to buy gluten flour and live on bread made from it. There are no gliten flours that I know of in this country. They are, all of them that I have examined, frauds, delusions, and snares. Each one can make better himself. Wash the starch out as you use the flour by letting a stream of water run on it in a muslin bag until the water coming through ceases to be milky. Gluten is like glue: by drying it becomes brittle. It will probably not make bread withont at least a little starch with it.

I think there is a bright business opening in this country for a firm of honest men to go into the business of manufacturing and selling all possible special dietetic products for invalids. This would cover diabetic foods and drinks, obesity foods and drinks, dyspepsia foods and drinks, tissue-building foods and drinks, fuel-producers, flesh-formers, and all such. I know of no such firm in the world properly organized on a basis at the same time of good morals and honest business principles. Messrs. G. Van Abbott \& Sons, No. 6, Duke Street Mansions, Grosvenor Square, London, W., appear from their advertisements to carry a large stock of special foods. They have kindly sent me their literature, but I have no samples in time for analysis. They make diabetic calf'sfoot jelly, gluten and meat biscuits, carraway, soya, ginger, and gluten biscuits, almond loaves, gluten loaves, soya loaves, bran, gluten, and almond loaves, ghtuten slices, etc. They appear to get up biscuits and cakes of every conceivable composition, suitable apparently for all invalids. They prepare 
diabetic macaroni and vermicelli, gluten flour, almond flour, bran flour, diabetic cocoa and chocolate, etc. This is just such a house as we need in America, honestly and thoroughly conducted.

There is a new flour out for diabetics, called the Chicago sanitary flour. Bread and cake made from it are said to be palatable. It should be used moderately. It is made from edible pine-nuts. It is yellowish in color, and of a bland taste. It contains no starch and seven per cent. of cane-sugar. Make bread from it with yeast, and nearly all of this sugar goes to alcohol, leaving less than one per cent. sugar.

The soja bean is a new product from which to make a diabetic bread. It comes to us from Japan. I have already spolien of it as a vegetable, dry and green. It contains a very little starch, four to six per cent., and much fat. It will prove a desirable make-shift, but it is apt to get rancid from decomposition of its fats. "Every rose has its thorn" in substitutes for our usual bread-stuffs. The flour from the aleuronat-nut is also a late introduction. It is recommended by Tyson, a good authority. I find it very expensive, and will speak of it again.

Let me speak of macaroni, vermicelli, spaghetti, and alphabet noodles. These are usually looked upon rather as gluten foods, and in medical books I have seen them recommended as such. There never was a greater mistake. Every one I have had analyzed has shown that they were made apparently from wheat flour in its purity, and were about as high in carbohydrates as ordinary wheat flour. We ought to have gluten macaroni, vermicelli, spaghetti, and alphabet noodles. They would be very palatable and very useful food. Van Abbott advertises them. I never heard of any in America. The sooner we get them the better, and we must have them. In regard to macaroni and alphabet noodles, I append Dr. Neale's letter. The analyses were made by Professor C. L. Penny. The macaroni was imported Italian macaroni, and the noodles were from the house of Olivier Fils et Cie., Lyon, France. 


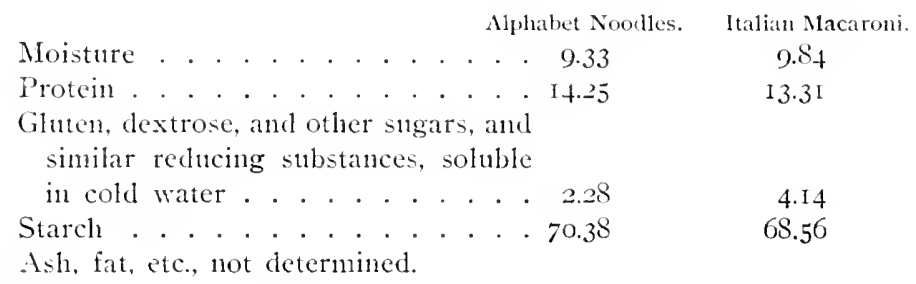

". In Deutz's work on the adulteration of foods a statement to this effect may be found: Genuine macaroni is made from wheat gluten. Imitation macaroni is made from wheat flour. Both of the above analyses, as far as gluten and starch contents are concerned, might easily be mistaken for analyses of a high quality of wheat flour. If Deutz is right, neither of the above samples belongs in the macaroni class.

"Yours truly,

"A. T. Neale,

"Director."

From a great number of samples of macaroni products analyzed from the exhibits of the Chicago Exposition in I 893 by the United States Govermment experts, only one sample showed that it was not made wholly from ordinary wheat flour, and in the exception there was only a little common salt and some oil added. So much for macaroni products, both home-made and imported, as a gluten food. A letter from a high official of the Agricultural Department, Division of Chemistry, at Washington, says, -

"I scarcely think you will be able to find any noodles, spaghetti, or macaroni in our markets which are especially rich in gluten. It is claimed that these products are made from flours rich in gluten, but we do not find the percentage of albuminoids any higher than one would expect from a sample of good wheat flour. In fact, we have reluctantly come to the conclusion that the so-called gluten flours on the market are not by any means to be trusted, and that the only safe way for prescribing gluten flour is to prescribe a known brand which is sold in original packages.'

I may add to this that the original packages do not make better exhibits than that sold in bulk. To tell macaroni rich in gluten, examine it for the following points: When wet it 


\section{FORTY YEARS IN THE MEDICAL PROFESSION}

is thrown over rods to dry. If rich in gluten it will appear flattened where it has rested on the rods. If it is not rich in gluten, it will not carry its own weight, and cannot be dried on rods. Any one who has been in Florence, particularly, can remember how much of it is to be seen hanging out to dry. No place seems too foul in which to hang macaroni to dry. The more gluten there is in macaroni the more direct is its fracture, the larger it swells when cooked, and the better it holds its tubular form. If we are paying the price of firstclass confectionery for a mere mixture of flour and water for macaroni and such products, it is time for tos to know it and to endeavor to turn the attention of honest manufacturers towards the proper utilization of gluten.

Soja-Bean Meal.-This bean comes to us from Japan, and is said to contain little or no starch, generally less than one per cent. It has a peculiar oily taste, but the analysis shows no excess of fat. Professor Penny's analysis is as follows: Moisture, 8.I4; nitrogen, I4.54; equivalent to protein by calculation, 90.97. Starch-like bodies capable of reducing Fehling's solution, trace only. A letter from the Theodore Metcalf Drug Company, of Boston, says, "We find cultivating the bean in this country increases the amount of starch, and we are awaiting a new supply from Japan, which we anticipate will be entirely free from starch." Here is a copy of a letter from Dr. Neale.

"The statement that the percentage of starch in soja beans is dependent on environment interests us very much. A reasonable doubt exists as to the presence of starch, strictly speaking, in this bean. Years ago attention was directed to this plant by a display of seed made by Japan at the Paris Exposition. At that time claims were made in the Halle Laboratory that no starch grains could be detected in soja-bean meal. I held an assistant's position among the chemists of that station when this test was made, and 1ny recollections of the interest aroused then are now reasonably strong. Last month Professor Chester, of this station, attempted to detect starch in a bean taken from the package sent later to you. He reported his inability to obtain a positive result, quantitatively, by the usual microscopic and chemical (iodine) test. By these tests the absence of starch was indicated. The ten per cent. of starch reported by analysis of this bean means starch-like bodies capable of transformation into certain sugars. An as- 
sumption exists that any carbohydrate may be deleterious to a diabetic. The package of beans sent to you represents a crop grown on the college grounds. The seed came to Newark from Kansas. The Kansas supply was brought to this country from Japan by a nember of the Kansas Experiment Station staff. I will follow this matter of environment by comparative analyses of foreign and domestic crops, if $\mathrm{Mr}$. Metcalf will guarantee the origin of his supply. If, however, the slightest question arises as to the source of that supply, a request to the Honorable Secretary of Agriculture will doubtless result in an importation through consular channels of a quantity large enough for this study.

"Yours truly,

"Arthur T. Neale,

"Director."

I find soja-bean meal to make a fair cake, which helps out in diet. The meal must be kept well sealed, or it turns rancid from a transformation of its fat. Eaten dried as a vegetable, it serves a purpose in diet, but patients cannot eat them every day for any considerable time. I have not had the opportunity of testing them as a green vegetable, but, as I have said before, I have great hopes of their use in this direction.

Soja-Meal Muffins (Metcalf).-Take of cream, one cup; eggs, two, entire; baking-powder, one teaspoonful; salt to taste; soja-bean meal, enough to make a batter not too thick. Make into eight cakes.

Soja and Gluten Gems (receipt of a patient).-One cup gluten flour, two eggs. one cup of cream, one teaspoonful baking-powder, enough soja-bean meal to make a stiff batter, half-teaspoonful extract of lemon. This does away with the oily taste of the bean. Bake in gem pans. With a high-grade gluten flour this makes a good bread.

Van Abbott, of London, makes a soja biscuit flavored with carraway, which is palatable now and then. They also make a soja and almond biscuit. These are useful and palatable. Almonds save albumin, and so do the fats in the soja bean. Van Abbott also makes a soja-bean bread. These soja products do not keep for transportation unless hermetically sealed, which is readily done.

Professor John Attfield's analysis of a soja-bean flour in I 890 was as follow's: 
FORTY YEARS IN T'HE MEDICAL PROFESSION

Nitrogenous or flesh-forming material . . . . . 41.24

Fatty or warmth-giving material . . . . . . . . I3.70

Other warmth-giving substances (cellulose, starch, sugar) .. . . . . . . . . . . . . . . . 30.35

Phosphate or bone-forming material . . . . . . 4.8I

Other natural mineral matter . . . . . . . . . .52

Moisture . . . . . . . . . . . . . . . 9.38

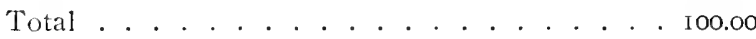

Probably most of the carbohydrates here were in the form of cellulose, which would not affect it as diabetic food to any great extent.

Dr. James Tyson and other authorities recommend the flour made from the aleuronat-nut. I have used it, and find it very expensive and not free from other objections. My supply came from a retail druggist in Philadelphia.

The following analyses have been made by Professor Penny :

Aleuronat flour: Moisture, 6.I; nitrogen, equivalent to protein by calculation, 3r.8I (nitrogen, 5.73); starch-like bodies capable of reducing Fehling's solution, 22.64.

Sample of gluten flour from a factory in New York State, marked "Special Diabetic Flour:" Protein, I5.50; soluble sugars, dextrose, etc., 2.20; starch, 59.87; water, fat, ash, etc., to balance. In round numbers wheat flour may have seventy per cent. of starch-like bodies. Wheat bran in composition closely resembles this sample of gluten flour.

Sample of gluten grits from the same factory. This is put forth as a thoroughly reliable, palatable, and satisfactory breakfast dish and dessert cereal for diabetics and those suffering from obesity, etc.: Protein, I I.56; starch, 73.85; soluble reducing bodies, dextrose (?), .42.

It is a very serious business to be putting such trash as this on the market as a suitable food for invalids in certain diseases. How many are using them with a false iclea of their own security no one knows, and how many physicians are innocently recommending them will never be determined. This showing, I trust, will put all on guard, and end in a 
possibility sooner or later of obtaining a proper fool-supply for these tufortmuate invalicls.

Gluten flour from a Boston firm: Moisture, Io.go; gluten, I 5.69; starch, 6I.58; dextrose, I.53. This is a little worse, if anything, than the New York State sample.

Sample of white wheat gluten from a Health Foorl Company in Philadelphia: Moisture, I I. I 7 : gluten, I6.3 I starch, 59.I7; dextrose, 2.29. This is another specimen tmfitted as diabetic food, althongh it is possibly a little better than the others.

Wheat gluten from a Michigan Sanitaritm Health Food Company: Moisture, 7.54; gltten, I8.28; starch, 67.20; dextrose, I.53. I expected a better showing from this sotrce, but the analysis speaks for itself. Professor Tyson has recommended the gluten flour of this firm as among the best to be fotuld, and stuch a recommendation must have given it a large sale.

Granon flakes from the same company: Moisture, 9.77; gluten, I0.50; starch. 69.52; dextrose. .76.

Gluten biscuit from the same company: Moisture, I I.62; gluten, 25.19; starch, 60.12; dextrose. I.40. The analysis tells the story here.

Nut gluten biscuits from the same company: Protein, 38 ; starch, I5.9: soluble reducing bodies, dextrose. I.I7. This is a creditable showing, and these bisctits are among the best of the bread-foods I have found in the general market for the diabetic or the obese. They are evidently shortened with nut oil and have a taste like rich puff paste. This company makes a forty per cent. gluten biscuit which I did not have analyzed. They are very palatable and taste like the egg biscuits of the grocery shops. Their twenty per cent. gluten wafers were not analyzed. They taste like hardtack.

If you can get a proper gluten flotr. say, with not over ten to fifteen per cent. of carbohyrates, you can make quite palatable bread and cakes, but starch and sugar hunger will assert themselves now and again. If stronger bread must be eaten at intervals, the more it can be toasted up to charring, the 
better it will be for the diabetic eating it. The substitutes for sugar already spoken of may be used, and thus make quite palatable dishes, even porridges. Bran is sometimes added to gluten flour. Do not use too much of this.

To make bread from gluten flour, make a firm paste with warm water. Dissolve one-quarter to one-half of a compressed yeast-cake in a little cold water. Salt to taste. Put the dough in a pan powdered with gluten flour. Place it before the fire, and in two hours it should be raised. Make the dough into small loaves and bake it. To make cake, add four entire eggs and one-quarter pound of butter, and sweeten with glycerin or one of the sugars recommended,--saccharin, mannite, or diabetin. Some flavoring may be added if preferred. A good substitute for milk may be made by a fresh egg beaten up thoroughly and a modicum of sugar of milk added to it with a little water.

Almond flour is much recommended by Pavy as a food for diabetics. In my experience patients do not take well to it. It does well for flavoring porridge and cakes made from gluten flour. A very little bran added to porridge lightens it, acts on the bowels, and does not do serious harm. Gluten does not dissolve until it enters the system, and should be taken in a state of suspension.

It is estimated that the American people alone spend ninety millions of dollars annually on adulterated foods. There are imitations of everything good or useful in dietetics. The better things are, the more they are imitated and the more they are adulterated. You can make bread from ground damaged peas, rice, and soapstone. These ingredients have been found in brands of wheat flour, and the scoundrels making such are still unhanged. Peanut oil and cotton-seed oil are both sold as olive oil. The deception here is really more in the name than in the quality, but the fraud is no less glaring. Potato starch is used to adulterate sago, and glucose, flour, and clay can make a sugar to be sold as canesugar. Potatoes, white and sweet, chicory, peas, beans, and acorns are manipulated and sold as pure coffee, and the 
coffee-bean itself is now imitated, no coffee whatever being used. Butter has been successfully imitated by oleomargarine and sold as butter. Here is the fraud. As oleomargarine, people know what they are getting. Filled cheese is very common, and thus skim-milk and lard, or rather fats. are sold as full cheese. As to spices, no man knows what they contain. Condemned hardtack is a favorite adulterant. Sand, bran, sawdust, cocoanut-shells, corn-meal, olive seeds, and all sorts of earths and clays are used as adulterants. Pure cider vinegar is likely to be dilute sulphuric acid flavored with any sour trash available. Chrome yellow, that horrible sonlconsuming poison, is. I have no doubt, still used to give a golden egg color to the products of some bakers. Candy is subject to all kinds of adulterants, and the only end to it is when the proper ingredients are cheaper than the injurious ones. Honey is imitated by maple sugar and glucose, and the very combs are imitated to hold it. As to preserves, those sold in the shops are mostly horrors. Glucose, gelatin, cochineal, with flavoring extracts from the coal-tar derivatives, compose the most of them, and whatever Providence may vouchsafe to us in the way of fruits, whether the harvest be great or small, these frauds are always obtainable by ignorant. credulous purchasers, the victims of conspiracy most injurious and most foul. So it is in the furnishing of special dietetic foods for the diabetic, fraud keeps pace with rapacity; and as we progress in the evolution of knowledge to eradicate or check these sconrges to mankind, the evolution of greed and deception keeps pace with 11s, and the sorry rictims are sacrificed on the altar of " man's inhumanity to man."

I take great pleasure in introducing here a poem which has come to me merely as a newspaper clipping. I have endeavored to trace its authorship and its history, but have been able to find nothing reliable pertaining to either, more than the few lines of explanation publisher with it. I applied to both Mr. Spofford and Mr. Darid Hutcheson. of the Con- 


\section{FORTY YEARS IN THE MEDICAL PROFESSION}

gressional Library at Washington, but neither could give me any trace of the composition or of its writer. It has so much merit, and exhibits such deep conceptions of human thought and sentiment, that I deem it worthy of much more careful preservation than the mere ephemeral existence this publication may give it.

"More or less interest always attaches to anonymous poetic productions, even when the quality is not very high, but the following lines, found in ISO7 near one of the skeletons in the Royal College of Surgeons, London, aroused unusual curiosity, not only on account of the unique theme, but principally because of the poetic perfection displayed. Great efforts were made to ascertain the identity of the writer, and at one time a reward of one hundred guineas was offered for the discovery of the author, but he has ever remained a mystery.

"Behold this ruin! 'Twas a skull

Once of ethereal spirit full.

This narrow cell was Life's retreat,

This space was Thought's mysterious seat.

What beatiteous visions filled this spot,

What dreams of pleasure, long forgot!

Nor hope, nor love, nor joy, nor fear

Have left one trace of record here.

"Beneath this mouldering canoyy

Once shone the bright and busy eye :

But-start not at the dismal roid-

If socia! love that eye employed ;

If with no lawless fire it gleamed,

But through the lews of kindiness beamed,

That eye shall be forever bright

When stars and suns are sunk in night. 
(3)

"Within this hollow cavern hung The rearly, swift, and tuneful tongue:

If Falsehood's honey it disclained,

And where it could not praise was chained;

If bold in Virtue's cause it spoke,

Yet gentle concord never broke,

This silent tongue shall plead for thee

When time unveils eternity.

\section{(4)}

"Say, did these fingers delve the mine?

Or with its envied rubies shine?

To hew the rock or wear the gem

Can little now avail to them;

But if the page of truth they sought,

Or comfort to the mourner brought,

These hands a richer meed shall claim

Than all that wait on wealth or fame.

"Avails it whether bare or shod

These feet the paths of duty trod?

If from the bowers of ease they fled,

To seek Affliction's humble shed;

If Grandeur's guilty bribe they spurned,

Anil home to Virtue's cot returned, These feet with angel's wings shall vie, And tread the palace of the sky." 



\section{INDEX.}

A.

Abortion and miscarriage, 106.

Acapulco, I4.

Agnew, D. Hayes, M.D., 4 I.

Alcohol, 269.

Alcohol in diabetes mellitus, 458 .

Alcohol, retarding digestion, 300 .

Alcohol, when to give, $30 \mathrm{I}$.

Alcoholic drinks, consumption of, 298.

Aleuronat flour, 486.

Almond flour, 488 .

Almonds, 37 I.

Alphabet noodles, 482 .

American wines, 291 .

Anabolism, 424.

Analyses of diabetic flours, etc., 485487.

Appendicits, I 17.

Apple and Pear, Alligator, 339.

Apples, 3 I9.

Argonauts, 3 I.

Arthritis deformans, 422.

Arthritis deformans multiple, 423 .

Asepsis and Antisepsis, 99.

Atlee, John L., M.D., 57.

Atlee, Walter F., M.D., 57.

Atlee, Washington L., M.D., 57.

Atropia in the eye, I I 3.

Atwater, Professor O. W., 424.

Auscultation and percussion, I3I.

Australia, fruit in, 315 .

Auto-intoxication in disease, $\mathbf{I} 92$.

B.

Bacillus of Eberth, I 50.

Bacillus of tetanus, 168.

Bacillus tuberculosis, 379 .
Banana, 340.

Banting and Ebstein, 223.

Barr, N. W., on the fueble-minded, I77.

Barton, John Rhea, 55.

Bartram, John, 3 I 4 .

Bean, soja, 482 .

Bee, honey, sting of, and immunity, I 69.

Beer, ale, porter, $274,275$.

Betel nut, 373 .

Bicycle, 143.

Blackberry, 353.

Iloat, cause of, 436 .

Blood, etc., I4I.

Brandy, 272.

Brandy, American, 295.

Braun, Karl, $8_{5}$.

Bread for diabetics, 479 .

Breads, 228.

Bromelin, 308 .

Burgundy and clarets, 28.4 .

Burnett, C. H; M.D., $5^{8}$.

Butternilk, 24I.

\section{c.}

Califonia clarets, etc., 293.

California hocks, 293.

California sweet wines, 293.

California, wine product of, 292.

Camac, C. N. B., M.P., 155 .

Camac, Wm., M. D., 60.

Canned foods, 2 I 2.

Cantaloupes, $3+6$.

Carlsbad, I99, 444.

Carson, Josepl, M.I)., $3^{8 .}$

Champagne, $2 S_{7}$.

Champagne, American, 295.

Cherry, $35 \mathrm{I}$. 


\section{INDEX}

Chestnuts, 368 .

Chicago sanitary flour, 482 .

Chilean nut, 373 .

Chocolate, 2 I 5.

Clarets, Virginia and New Jersey, 294.

Climate of San Francisco, 23.

Clinical Thermometer, I24.

Cocoa, 2 I 5.

Cocoa-nut, 339.

Coffee, 214.

Coma, diabetic, $461,4^{6} 3$.

Composition of food, 209.

Consumption, acute, 388 .

Consumption, cure of, 38 r, 395 .

Convulsions, uræmic, 440 .

Cooper, E. S., M.D., 22.

Cottage cheese, 24I.

Country doctor, 90 .

Cramberry, $35 \mathrm{I}$.

Crean, Devonshire, 240.

Cream nuts, 373 .

Currants, 35 I.

D.

Da Costa, I. M., M.D., $5^{8 .}$

Dana, R. H., Jr., I9.

Date plum, 337.

Deaf and dumb, I 83 .

Death struggle, I96.

Defective classes, I 86.

Dewberry, 353 .

Diabetes and Tuberculosis, 447, 465 .

Diabetes mellitus, 446.

Diabetes mellitus, cause of, $45 \mathrm{I}$.

Diabetes mellitus, cure of, 459 .

Diabetes mellitus, diagnosis of, 455 .

Diabetes mellitus, diet in, 473 .

Diabetes mellitus, treatment of, $4^{62}$.

Diabetes mellitus, true, 468 .

Diabetes, thyroid extract in, 463 .

Inabetic foods, manufacture of, $48 \mathrm{I}$.

Diazo reaction, 150.

Diet, 197 .

Ijet and women, 226.

Diet in middle age, 248 .

Diet in old age, 249 .

Diet table, 224.

I)ietary studies, 2 I 6 .
Diets, improper, 226.

Digestion, time required for, etc., 235 .

Digitalis, $12 S$.

Division of foods, 200.

Doyle, A. Conan, 9 I.

Drinks in diabetes, 473 .

Ductless glands, I 37 .

Duels, 22.

Durian, 337 .

E.

Eggs, all about them, 206.

Electricity, I 43 .

English walnut, 375 .

Ether and chloroform, 82.

Ether and chloroform in pelvic operations, $S_{3}$.

Ether and oxygen, 84.

Examination of urine, 145 .

F.

Figs, 339 .

Filberts, 37 I.

Flour, gluten, 479, 486.

Food, adulterations of, 488, 489 .

Food fads, $25 \mathrm{I}$.

Food necessary for a man in twenty-four hours, 220.

Food, uses of, 425 .

Foods, composition of, 203.

Foods, infant, $247,258$.

Fractures and compound fractures, $12 \mathrm{r}$.

Frerichs, 85 .

Fruit-juices, $3 \mathbf{I} 2$.

Fruit, when to eat, 307.

Fruits and nuts as diet, 304 .

Fruits and vegetables, definitions of, 309 .

Fruits, composition of, 307 .

Fruits, decay of, $35^{6}$.

Fruits, dried, $3 \mathbf{I} 2$.

Fruits, uses of, in the animal economy, 3II.

G.

Gerhard, W. W., M.D., 55 .

Germain Sée diet, 226.

Germs, soja and gluten, 485 . 


\section{INDEX}

Gibier, Paul, 1.1), and tulerculosis, 410.

Gin, 273 .

Glaucoma, 113 .

Gluten biscuits, $45_{7}$.

Gluten breal, 488 .

Glycogenic matter, $4+7$.

Glycosuria, temporary, 45 o.

Glycosuria, true, 468 .

Goddard, I'aul lieck, M.I)., 55.

Gonococcus of Neisser, Io\$.

Gooseberries, 350 .

Gout, 423 .

Gout, a neurosis, 429 .

Gout and diabetes mellitus, 454, 460.

Gout, nature and canses of, 426 .

Gout, rheumatic, 422.

Gout, treatment of, $43^{\circ}$.

Grape-fruit, 344.

Grape-juice, 296.

Grapes, 33 I.

Grits, gluten, 486 .

Gross, Samuel David, 49.

Guarana, 374 .

Guava, 339.

Gymxeology, 115.

H.

Hæmoglobin, 142.

Hæmostat, 122.

Haig, Alexander, M.D., 427.

Haw, $35^{\circ}$.

Hay-fever, 4 I4.

Hays, Isaac, M.D., 58.

Headache, gouty, 440 .

Heart, intermitting and irregular, 435.

Heart remedies, $12 S$.

Hemorrhage from genitals in females, 107.

Iernia, irritant injections in, I I 9 .

Hip.joint amputations, 20, $5 \mathbf{I}$.

Hodge, Hugh 1.., N.1)., 33.

Hospital, Lnited States Marine, I4.

llunger, starcl and sugar, 487 .

Hunt, Wm., M.1)., 40.

Hydrophobia, 77 .

Hypnotism, 186.

Ifypodermic Syringe, 124.
I.

Immunity, 93 .

Infants in IBlockley, 224.

Insane and diabetes mellitus, 455.

Intestimal texitnia, 195 .

lntulation, i 19 .

lrom, i 39 .

\section{J.}

Jackson, Samuel, N1.D., 37.

Japanese embassy, the first, 19.

Japanese Tommy, 19.

Jefferson Medical College, $4 \mathrm{~S}$.

Jiggers, 17.

Jordan's tables, 305.

K.

Kalagua, 4 I 2.

Katabolim, 424 .

Kidney, movable, 158 .

Kocl, 77 .

kioch's law, 92, 379.

Kola nut, 374.

Koumis, 205.

L.

Lamballe, Jobert de, 70.

Lane, L. C., M.I)., 22.

Laryngeal paralysis after typhoid fever,

153 .

lawyer, sea, I6.

Learl poisoning, 212.

Leaves, why they turn color, 3 I 7 .

Leguminous plants and nitrogen, $\mathbf{1} 6 \mathbf{1}$.

l.eidy, Joseph, M.L., 39.

Lemonis, $3+5$.

Levis, R. J., M.1)., 34, 63 .

lifuid air, 127.

linter, Lord, 97.

Logan berry, 350 .

Lupus vulgaris, 392.

Lying-in women, 105.

M.

Mc. Mllister family, 250 .

Mctllister, Ward, 250.

Macaroni, $4 \mathrm{Sz}$. 


\section{INDEX}

Maclaren, Ian, $9 \mathbf{I}$.

Madeira and Ward McAllister, 282.

Maderia wine, 282 .

Malt extracts, 275 .

Malthusian theory, 163 .

Nango, 337 .

Mangosteen, 337.

Manzanillo, 14.

Maragliano's serum, $3^{8} 5$.

Maxwell, R. T., M.D., 2 I.

Mayer, I)r., theory of diabetes mellitus, $45^{2}$.

Medical supervision of families, 114 .

Meigs, Charles D., M.D., Sz.

Meigs, John F., M.D., $5^{6}$.

Metabolism, 424.

Milk and infants, 245 .

Milk as food, 236, 259-26r.

Milk, condensed, 240.

Milk, delivery of, etc., 263 .

Milk, evaporated, 240.

Milk, impure, $26_{3}$.

Milk, Pasteurized, 239.

Milk, Pearson's rules, 266.

Milk, sterilized, 238 .

Milk supply and police power, $24 \mathrm{I}$.

Milk, tests of, 264 .

Milk, Walker Gordon, $24 \mathrm{I}$.

Mistakes in Diagnosis, 146.

Mitchell, S. Weir, M.D., 45, 226.

Morels, 363 .

Morton, Thomas G., M.D., 56.

Moselle wines, 286.

Novement cures, 185 .

Muffins, soja, 485 .

Nulberry, 346.

Murphy and tuberculosis, 394 .

Murphy's button, I 16 .

Mushrooms, 357.

Mushrooms, rules for gathering, 365 .

\section{N.}

Napoleon IIr., 7I.

Nash, 43 .

Neale, Dr. A. T., 4ro.

Nélaton, 70.

Newcastle, Delaware, $S_{7}$.

Nitrogen in diet, 203.
Nitrons oxide gas, 137 .

Noodles, alphabet, 482 .

Normal salt solution, 155 .

Normandy, 69.

Nuclein, 420.

Nuts, 367 .

o.

Oakland, 24 .

Obesity and diabetes mellitus, 454 .

Oertels diet, 225.

Olives, 345 .

Operations in malignant disease, 108.

Oranges, 343 .

Origin of life, $9 S$.

P.

Pancoast, Joseph, M.D., 48 .

Papaw, 308, 33 S.

Park, Golden Gate, $2 S$.

Partridge berry, 34 S.

Pasteur, 77.

Port wine, 282.

Peach, Doctor Black, 326.

Peaches, 324 .

Peaches for diabetics, 327 .

Peanuts, $37 \mathrm{I}$.

Pears, 327.

Pecans, 372.

Penny, Professor C. L., 4I 5 .

Penrose, R. A. F., M.D., 44, 63.

Pepper, William, Jr., 36 .

Pepper, William, Sr., 35.

Pessary, Goddard's, 34 .

Pfeifier, bacillus, $3^{87}$.

Pharmacy and chemistry, advances in, I 34.

l'hiladelphia clinics, $5 \mathbf{I}$.

['hiladelphia Hospital, Blockley, 6I.

Phloridzin, 45I.

Pichi, 442.

Pine-apple, 34I.

Piperazin, I 40.

Pistachio nut, 373.

P'lasmodium malarie, 147 .

Plums, 334

Pnemonia, chronic interstitial, 383 .

l'oem, anonymous, 489 . 


\section{INDEX}

l'ske berry, 350 .

l'omegranale, 338 .

l'reserves and canned fruits, $3 \mathbf{I} 3$.

l'reventive medicine, ro4.

l'rinceton College, 33.

l'rofesion in l lelaware, 89 .

Profession in Eugland, 70.

l'rofesion in Cermany, 85 .

l'rofession in Paris, 74.

Prunellos, 336 .

Prunes, 336.

I'tomaines, I 88.

Puff-balls, $36_{3}$.

\section{Q.}

1) ueensland nut, 373 .

Quince, 352 .

Quiz classes in Philadelphia, 42.

R.

Rabies, 78 .

Rabies mephitica, 78 .

Rheumatism, $4 \mathrm{I} S$.

Kheumatism, pathogenic germ of, 4 I 9 .

Rhine wines, 286.

Ricord, 72.

köntgen rays, 123.

Rum, 273.

\section{S.}

Sailors, 16.

San Francisco, 13, 21, 24.

Santerne, 285 .

sichweninger diet, 225.

Scurvy, achult, 17 .

Scurry, infantile, 252.

Serum therapy, $137 \cdot 3^{84}$.

simun treatment in lower animal., I7 I.

Shelllark, 372 .

Sherry wine, 281 .

Shipwrecked, 67 .

simusm, 76. 81 .

Sims, J. Marion, 73.

Storda, 85 .

Smith, Franci, liumey, M.11., 37.

smith. 11. 11.. M.1., $3 x$.

Simari nu, 376 .

special diets, 222.
Stelwagon, 11. 14., M.1), 6o.

Strawberry, 354.

Strawbridge, Cieouge, M.1)., 58.

Sugar, sulmtituten for, 472 .

Sugar, test for, 456 .

Syme, Iames, M.1)., 76, si.

Syphilis, II I.

\section{T.}

Tamarinds. 337 .

Tea, $2 I_{4}$.

Tetanus and treatment of, I66.

Thermotherapy, 120.

Thyroid extract in gout, 443 .

Toart, 230.

Tracheotomy, II 9 .

Travers, William K., 447.

Tronsseau, 73 .

Truffles, 363 .

Tubercle, 378 .

Tuberculin A. $3^{S_{4}}$

Tuberculin $0,3 S_{5}$.

Tulerculin K, 385 .

Tulerculin in diagnosis, 388 .

Tulerculocidin, $3^{S} 3$.

Tulerculonis, 377 .

Tuberculonic and anthrax, 4 Io.

Tuberculosis, climates for, 404.

Tuberculo-is, inhalations in, $4 \mathbf{1}$.

Tuberculosis in lower animals. 390.

Tulerculosi-, prevention of, 389 .

Tulerculosis, pulmonary, 3 So.

Tuberculosis, serums for, 408 .

1 uberculouis, specifics for, tIo.

Tuberculosis, treatment of, 396 .

Tyndall, 76 .

Typhoid fever, 150 .

Typhoid fever, second time in same indivilual, 154.

Typhorid epticitmia, 155 .

Typhu fever, 6.4.

Tyon, proferor James, 441.

\section{U.}

Lniverity of l'emmylvania, 32.

['remia, 193 .

Grea and oxidation, 201.

Lric acid, wurce of, 419. 


\section{INDEX}

V.

Van Abbott \& Sons, 48 I.

Velpean, 69.

Virchow, 385 .

Vivisection, 133 .

Von Grafe, 85 .

Von Langenbeck, 85 .

W.

Wall disease, I60.

Walmut, black, 374.

Walnut, Japan, 375.
Water as a remedy, 201.

Watemelon, 346.

Wharton, H. R., M.W., 59.

Whey, 24I.

Whiskey, 272.

Widal test, I 55

Wineberry, 350.

Wine residues, 297.

Wine taster, 2So.

Wines, 276 .

Wines, adulterated, 296.

Wuod, I'rofensor H. C., 386.

Wood, U. F., M.D., 5 S. 



\section{UNIVERSITY OF CALIFORNIA LIBRARY}

Los Angeles

This book is DUE on the last date stamped below.

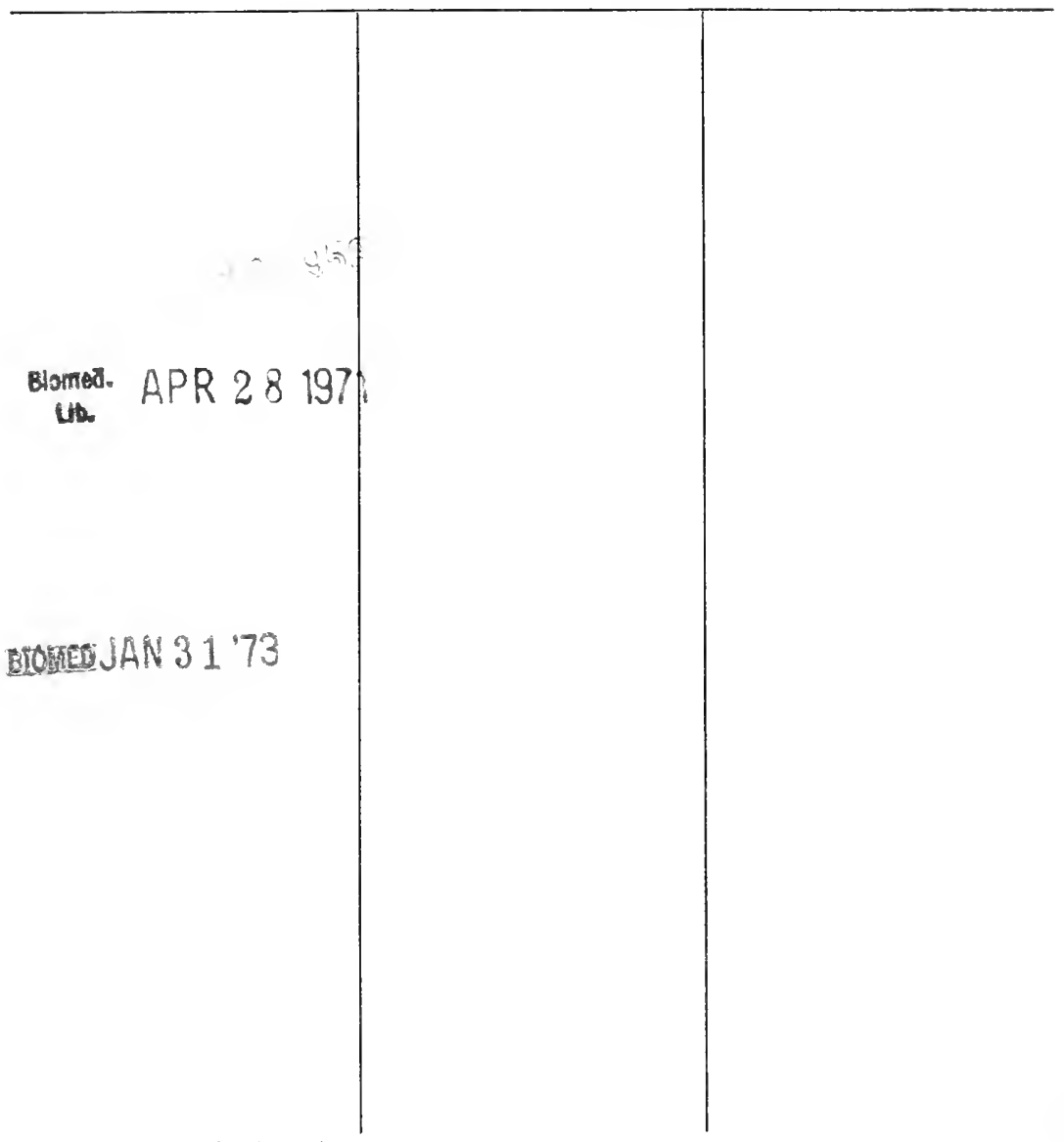

Form L9-25m-8,'46 (9852) 444 


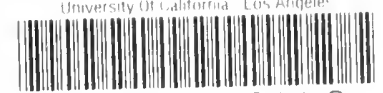

L 0069096113

.154

$250 \div 2$ 


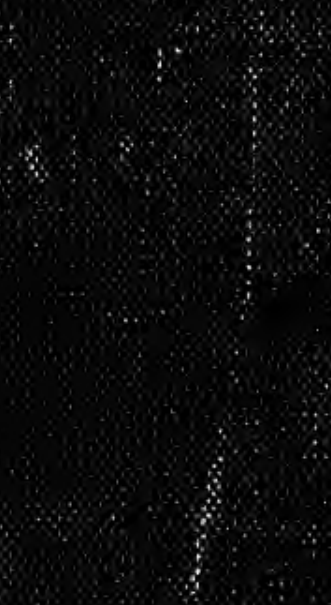

